<smiles>C1CC1</smiles> 



\section{Zoogeography}

A SYMPOSIUM PRESENTED ON AUGUST 26-27, 1957, AT THE STANFORD UNIVERSITY JOINT MEETING OF THE AMERICAN INSTITUTE OF BIOLOGICAL SCIENCES AND THE PACIFIC DIVISION OF THE AMERICAN ASSOCIATION FOR THE ADVANCEMENT OF SCIENCE AND

A SYMPOSIUM PRESENTED ON DECEMBER 28, 1957, AT THE INDIANAPOLIS MEETING OF THE AMERICAN ASSOCIATION FOR THE ADVANCEMENT OF SCIENCE

Edited by

CARL L. HUBBS

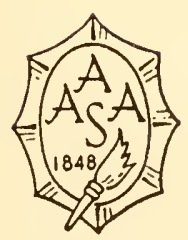

Publication No. 51 of the

AMERICAN ASSOCIATION FOR THE ADVANCEMENT OF SCIENCE WASHINGTON, D. C. 
(C) 1958

The American Association for the Advancement of Science

Library of Congress Catalog

Card Number 59-59993

Printed in the United States of America The Horn-Shafer Company

Baltimore, Maryland 
This volume is dedicated

to the memory of

two great zoogeographers,

CHARLES DARWIN AND

ALFRED RUSSEL WALLACE

Whose observations and reflections on the distribution of animals provided much of the evidence that led them, just one hundred years ago, to propose to the world the epochal concept of Organic Evolution, which unshackled the minds of men and helped inaugurate the Age of Science. 



\section{As science expands and fragments, reviews and} syntheses of broad areas become increasingly useful and necessary. Among the more effective means of review and synthesis are the symposia that are being held in increasing numbers at scientific meetings. Two such symposia, in 1957, encompassed the field of zoogeography, with due attention to the underlying data of geomorphology, paleoclimatology, paleontology, and physiology. The fifteen papers that have become available from these two symposia comprise a notable and rather comprehensive, though somewhat diverse contribution to zoogeography and to its background sciences. The extent of the contribution is greatly enhanced by the publication of these assembled papers as one of the symposium volumes of The American Association for the Advancement of Science.

The first of these two symposia (Part I) was held under the prime auspices of the Pacific Section of The Society of Systematic Zoology, as a feature of the joint meeting of the American Institute of Biological Sciences and the Pacific Division of the American Association for the Advancement of Sciences, at Stanford University, in August, 1957. The symposium, bearing the ample title "The Origins and Affinities of the Land and Freshwater Fauna of Western North America," was abundantly cosponsored by the American Society of Ichthyologists and Herpetologists (Western Division), American Society of Zoologists, California Academy of Sciences, Pacific Coast Entomological Society, Society for the Study of Evolution, and Western Society of Naturalists. The fourteen papers ran through wellattended morning and afternoon sessions on August 26 and 27, plus a final panel discussion that nearly filled a spacious hall on the evening of the second day. The large and attentive audiences demonstrated the liveliness of the subject. Audience contribution was so spirited at the panel discussion that I had difficulty in closing the session at a reasonable hour.

It was my pleasure and privilege to act as general chairman of this symposium. In conducting the sessions I was ably joined by the late Karl P. Schmidt, as one of the last of his many generous acts, and by George F. Edmunds, Jr. Panel members William H. Burt, Alden H. Miller, Robert W. Pennak, Herbert H. Ross, and Dr. Schmidt helped enliven the informal discussion. 
Gratitude is expressed to the fifteen participants, all of whom made notable contributions. Most of the contributors made an extensive and thorough analysis of their chosen subjects, and some treated their topics in exhaustive and carefully documented style.

Credit for the success of this symposium goes to the symposium committee, all of the University of California, Los Angeles: John N. Belkin, chairman, Donald Heyneman, and Marietta Voge. These zoologists were the prime actors in the conception of the idea, in lining up the able speakers, in arranging and managing the sessions, and, as not the least difficult task, in extracting manuscripts from thirteen of the participants. They also helped in processing the manuscripts. I am sure that the officers of the meetings, the speakers, the audiences, and, now, the scientific public, join me in expressing hearty thanks to these tireless and self-effacing workers.

The second symposium (Part II), which is herein represented by three of the six papers, was a feature of the American Association for the Advancement of Science meeting at Indianapolis, and was held on December 28, 1957. It was entitled "Geographic Distribution of Contemporary Organisms," and constituted Part I of the general symposium, "Some Unsolved Problems in Biology, 1957." This was a joint program of AAAS sections F (Zoological Sciences) and G (Botanical Sciences), and was extensively cosponsored, by the Society of Systematic Zoology, Ecological Society of America, Genetics Society of America, American Society of Naturalists, and Botanical Society of America. The program was arranged by Harold H. Plough, of Amherst College, as Secretary of Section F, ably assisted by Ernst Mayr of Harvard University and E. Raymond Hall of the University of Kansas. Dr. Hall presided at the symposium and contributes the introductory remarks.

We of the Pacific Section of the Society of Systematic Zoology welcome the privilege of combining the papers resulting from our symposium with the three submitted from the Indianapolis symposium. As editor of the combined symposia, I want to express the feeling that they very nicely complement the contributions from the first symposium.

Scripps Institution of Oceanography,

Carl L. Hubbs University of California,

La Jolla

October 1958 
George A. Bartholomew, Department of Zoology, University of California, Los Angeles

W. Frank Blair, Department of Zoology, University of Texas, Austin

William H. Burt, Museum of Zoology, University of Michigan, Ann Arbor

E. Raymond Hall, Museum of Natural History, University of Kansas, Lawrence

William Hovanitz, Department of Biology, California Institute of Technology, Pasadena

CarL L. Hubbs, Scripps Institution of Oceanography, University of California, La Jolla

Philip B. KInG, General Geology Branch, United States Geological Survey, Menlo Park, California

E. Gorton Linsley, Department of Entomology and Parasitology, University of California, Berkeley

H. D. MacGinitie, Department of Biology, Humboldt State College, Arcata, California

Paul S. Martin, Geochronology Laboratories, University of Arizona, Tucson

Alden H. Miller, Museum of Vertebrate Zoology, University of California, Berkeley

Robert Rush Miller, Museum of Zoology, University of Michigan, Ann Arbor

Kenneth C. Parkes, Carnegie Museum, Pittsburgh, Pennsylvania

Frank E. Peabody, Department of Zoology, University of California, Los Angeles

Robert W. Pennak, Department of Zoology, University of Colorado, Boulder

James A. G. Rehn, Academy of Natural Sciences of Philadelphia, Pennsylvania 
Herbert H. Ross, Illinois Natural History Survey, Urbana

Donald E. Savage, Museum of Paleontology, University of California, Berkeley

Jay M. Savage, Department of Biology, University of Southern California, Los Angeles

Robert C. Stebbins, Museum of Vertebrate Zoology, University of California, Berkeley 
Part I The Origins and Affinities of the Land and Freshwater Fauna of Western North America

1 Evolution of Modern Surface Features of Western North America

Philip B. King

2 Climate Since the Late Cretaceous

H. D. MacGinitie

3 The Role of Physiology in the Distribution of Terrestrial Vertebrates

George A. Bartholomew

4 Evidence from Fossil Land Mammals on the Origin and Affinities of Western Nearctic Fauna

Donald E. Savage

5 The History and Affinities of the Recent Land Mammals of Western North America

WilliaM H. BurT

6 Origin and Affinities of the Birds of Western North America (Editor's Note)

Alden H. Mitler

7 Origin and Affinities of the Present Western North American Reptile and Amphibian Fauna (Abstract)

Robert C. Stebbins

8 Evolution of a Coast Range Corridor in California and Its Effect on the Origin and Dispersal of Living Amphibians and Reptiles

Frank E. Peabody and Jay M. Savage

9 Origin and Affinities of the Freshwater Fish Fauna of Western North America

Robert Rush Miller

10 Some Problems of Freshwater Invertebrate Distribution in the Western States

Robert IV. PenNak 
11 Affinities and Origins of the Northern and Montane Insects of Western North America

Herbert H. Ross

12 The Origin and Affinities of the Dermaptera and Orthoptera of Vestern North America

$$
\text { James A. G. RehN }
$$

13 Geographical Origins and Phylogenetic Affinities of the Cerambycid Beetle Fauna of IVestern North America E. Gorton Linsley

14 Distribution of Butterflies in the New IVorld

IVilliam Hovanitz

Part II Geographic Distribution of Contemporary Organisms Introduction E. RAYMOND HALL

15 Pleistocene Ecology and Biogeography of North America PAUL S. MARTIN

16 The Palaearctic Element in the New Morld Avifauna Kenneth C. Parkes

17 Distributional Patterns of Vertebrates in the Southern United States in Relation to Past and Present Environments

IV. Frank Blair

General Conclusions

Carl L. Hubbs

Author Index

Index of Scientific Names 


\section{$\mathbb{P} \mathbb{A} \mathbb{R} \mathbb{I}$}

The Origins and Affinities of the Land and Freshwater Fauna of Western North America 



\section{Evolution of Modern Surface Features of Western North America ${ }^{1}$}

Philip B. King

United States Geological Survey, Menlo Park, California

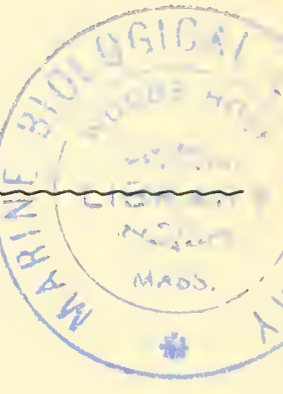

In preparing a summary of the geological background of the origins and affinities of the land and freshwater faunas of western North America, I am faced with several difficulties.

First is the well-known lack of communication between the sciences - a difference in language, in thinking, and in emphasis. Thus, items that may be decisive to a zoologist may receive little attention from a geologist. I welcome this opportunity to bridge a gap between the zoological and geological sciences, to make a contribution to a problem shared by both of us, and to enhance my own education. At the same time, I must admit my present ignorance of facets of the problem which are not geological, so that my analysis in this paper must be mainly geological.

Then, too, even in making a purely geological analysis of the problem one discovers wide gaps in the record, much evidence that is equivocal rather than decisive, and much divergence among geologists as to what the evidence means. Broadly, the subject here treated is the evolution through time of the geological features of western North America, but the aspect of most zoological interest is evolution of the surface forms only. For the record up to the middle Tertiary, the surface forms must be deduced from rocks and structures of various ages, since none of the landscape of that time is now preserved. Some fragments of surface forms as old as middle Tertiary are preserved, and younger ones are preserved in in-

${ }_{1}^{1}$ Publication authorized by the Director, United States Geological Survey. 
creasingly larger entities, but even these surface forms are diversely interpreted.

Finally, in so large a subject as western North America, I cannot hope to do justice to all items and problems in a single paper. The best one can do is to make a sampling and to hope that the samples will be sufficiently representative of the whole. In this paper, the samples will be chosen mainly from the segment in the United States, partly because this is the region I know best, partly because it is the region best known to geologists in general.

\section{PRESENT GEOGRAPHY}

Western North America is the region of the Cordilleran system of mountain ranges, which extend unbroken along the Pacific Coast from Alaska to Central America, and beyond, and inland 400 to 1,000 miles (Fig. 1). In Canada and the western United States they front eastward on the Great Plains of the continental interior, but in Alaska they front northward on a coastal plain at the edge of the Arctic Ocean, and in Mexico they front northeastward on a coastal plain at the edge of the Gulf of Mexico.

Geographically, the Cordillera north of Mexico is commonly divided into two chains of ranges, one along the coast on the west, another fronting the Great Plains on the east, with lower, more broken ranges and plateaus intervening. Highest summits in North America and in the United States are in the chain nearest the coast, Mount McKinley in Alaska at 20,300 feet and Mount Whitney in California at 14,495 feet. The summit of the interior chain, Mount Elbert in Colorado at 14,431 feet, is somewhat lower. Many other peaks in both chains project to heights nearly as great as the absolute summits, and some of these have greater relief relative to their immediate surroundings.

The western mountain chain includes the Alaska Range of Alaska, and the Coast Mountains of British Columbia. In the United States the chain is double, with low Coast Ranges on the west separated by the Puget Trough, Willamette Valley, and Great Valley of California from the higher Cascade Range and Sierra Nevada on the east. A comparable pattern is expressed to the north, in Canada and southeastern Alaska, by the offshore islands and Inland Passage, and to the south, in Mexico, by the peninsula of Baja California and the Gulf of California. 


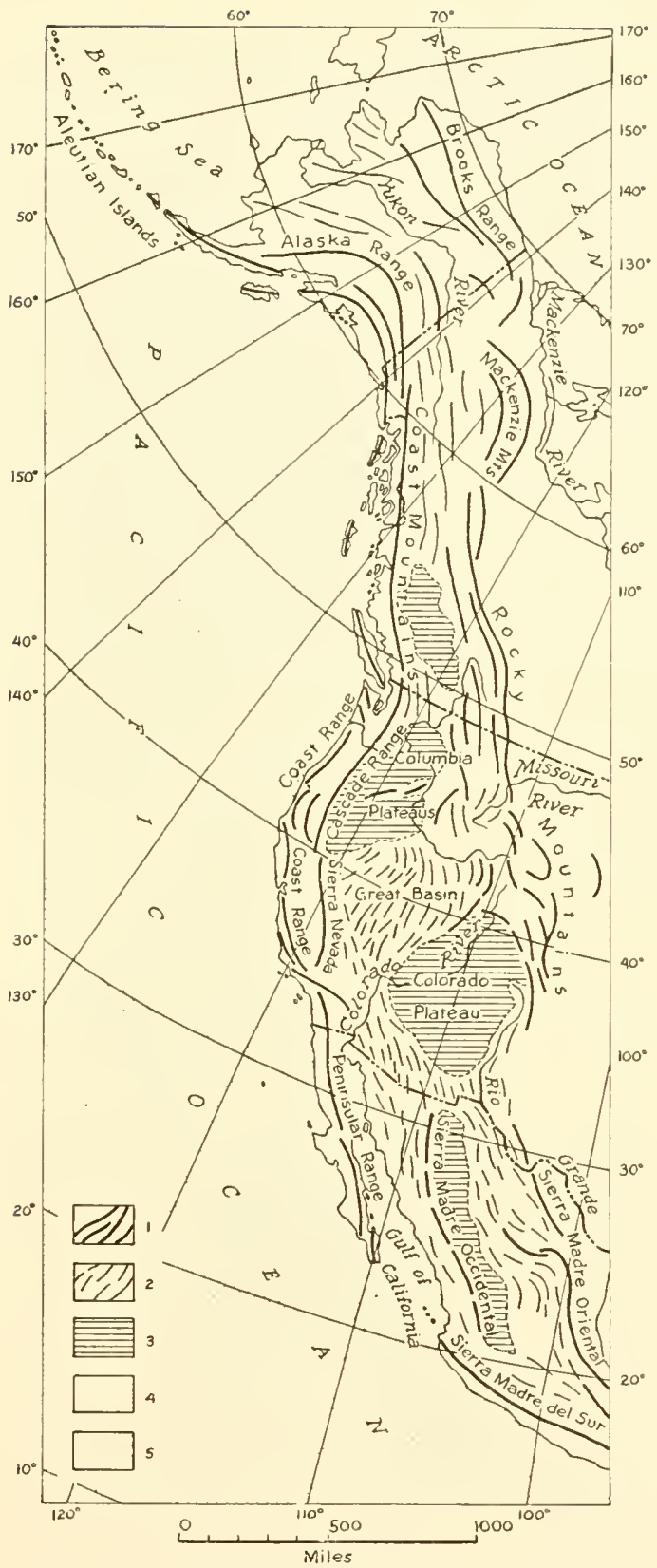

Fig. 1. Generalized map of North American Cordillera, showing present topographic configuration. 1, Principal ranges. 2, Minor ranges. 3 , Plateaus. 4, Lowlands, including plains of continental interior. 5, Submerged areas, mainly ocean basins, but including continental shelves. 
The lower intermontane belt begins on the north with the wide depression along the Yukon River in Alaska, continues southward through various plateaus and ranges in Yukon Territory and British Columbia, and includes the Columbia Plateau, Colorado Plateau, and Basin and Range province in the western United States.

The eastern mountain chain is represented in Alaska by the Brooks Range, and farther south, in Canada and the western United States, by ranges that go under the general title of Rocky Mountains. The Rocky Mountains end as a continuous barrier in northern New Mexico, and for considerable distances southward the eastern ranges are discontinuous and are of Basin and Range type.

In Mexico, the tripartite division of the Cordillera farther north is lost. Here the Cordillera is essentially a high plateau, breaking off in ranges on the east, west, and south, which form the three Sierra Madres of that country-Oriental, Occidental, and del Sur.

These are the gross geographic forms of the Cordillera today, yet to some extent they are accidental, and at most reflect only latest warping of the crust. They have slight utility in an analysis of the evolution of the surface features of the Cordillera, as each consists of diverse geological features that have developed at different times and in different ways. For example, the Sierra Nevada is an uplifted block of crystalline rocks, whereas the Cascade Range, its orographic continuation on the north, was built primarily by volcanic eruptions.

Present surface forms, rocks, and structures of the Cordillera have developed through a long span of geologic time. Mountains arose first in the western part of the region, in the middle of Mesozoic time; others farther east developed in later Mesozoic and early Tertiary times. Subsequently, in Tertiary and Quaternary times, the initial mountains of the whole region were modified in to the forms we now see- by a continuation of crustal mobility, supplemented by volcanism, erosion, and sedimentation. The eastern part of the Cordillera appears to be attaining stability now, so that the modifying processes are becoming less active. On the west they are still at work, as may be seen by the seismic and volcanic unrest near the Pacific Coast, and one may anticipate continuing rearrangements of the geography there. It is my purpose in the pages that follow to elaborate on the sequence of events thus briefly outlined. 


\section{CONTROLLING PRINCIPLES}

\section{Nature of Mountain-Building Processes}

Ultimate cause of mountain building is to be sought, not in such merely superficial processes as erosion, sedimentation, glaciation, or volcanism (however much these may shape the landscape in detail), but in forces within or beneath the crust of the earth, which have deformed the rocks and raised or lowered large areas of the surface. Little is known about these forces themselves, but much has been learned about their effects.

Some of the orogenic phases have been referred to as "revolutions," because they are supposed to have brought about drastic rearrangements of the geography and climate, and so modified the environments as to cause far-reaching changes in distribution and kinds of life. Detailed study shows, however, that the different phases merge into each other, and that the changes they brought about were evolutionary rather than revolutionary. Operation of crustal forces was persistent through time, and although there were certain crescendos, development was orderly and progressive, rather than catastrophic.

\section{Nature of Continental and Oceanic Crusts}

In North America, at least, mountain building was a feature of the edge of the continent-the border zone between the continental platform and the adjacent ocean basins.

Sequentially, the processes may be divided into an initial or geosynclinal phase, followed by an orogenic phase and a postorogenic phase, the nature of which will be examined later. The phases were prolonged. In the Cordilleran region the geosynclinal phase endured for at least 350 million years, from Cambrian to Triassic; the orogenic phase, for about 100 million years, from Jurassic to Paleocene; and the post-orogenic phase, for about 50 million years, from Eocene to present (Table I).

Continental platforms and ocean basins are fundamentally different elements of the crust of the earth (the crust is the relatively thin skin of rocks that overlies the dense material of the interior of the earth). Their surfaces stand today at different levels: the continental averages about half a mile above sea level; the oceanic, 3 miles or more below sea level. The two levels reflect contrasting 
average compositions of the crust beneath the two areas (Ewing and Press, 1955). Crust of the ocean basins is made up of relatively dense rock, called sima, with an average composition about like basalt, and with a thickness beneath the ocean water of about 6 miles. Simatic material like that beneath the oceans also forms the base of the thicker crust of the continental platforms, but most of the thickness of the platforms consists of lighter rock, called sial, of about the composition of granite. Continental crust has a thickness on the order of 20 miles.

TABle I. Subdivisions of Later Geologic Time, and Their Relation to the Phases of the Evolution of the Cordilleran Region

\begin{tabular}{|c|c|c|c|}
\hline Era & System & Series & $\begin{array}{c}\text { Phases in Evolution } \\
\text { of the Cordillera }\end{array}$ \\
\hline \multirow[b]{2}{*}{ Cenozoic } & Quaternary & $\begin{array}{l}\text { Recent } \\
\text { Pleistocene }\end{array}$ & \multirow[b]{2}{*}{ Post-orogenic phase } \\
\hline & Tertiary & $\begin{array}{l}\text { Pliocene } \\
\text { Miocene } \\
\text { Oligocene } \\
\text { Eocene } \\
\text { Paleocene }\end{array}$ & \\
\hline Mesozoic & $\begin{array}{l}\text { Cretaceous } \\
\text { Jurassic } \\
\text { Triassic }\end{array}$ & & Orogenic phase \\
\hline Paleozoic & $\begin{array}{l}\text { Permian } \\
\text { and older }\end{array}$ & & Geosynclinal phase \\
\hline
\end{tabular}

These differences in composition and thickness of the crust underscore a widely held belief in the permanence of continents and ocean basins, and give little comfort to notions of vanished lands within the ocean areas. To create and destroy such lands would involve not merely changes in level, but changes in crustal composition. It is agreed that the Pacific Ocean basin, in particular, was a permanent crustal and topographic feature throughout known geologic time. Even the relatively modest "borderlands" that some geologists have believed once existed along or off the present coasts must each be 
appraised critically on their individual merits. Thus, the supposed borderland of "Cascadia" which has been postulated along the Pacific Coast of North America, if it existed, could hardly have extended beyond the edge of the present continental shelf, the submerged part of the continental crust.

This is not to say that certain modifications of the doctrine of permanence are unworthy of consideration:

Some geologists believe that the plates of continental crust, although permanent, have drifted through time across the subcrust, so that their positions have shifted with respect to other continents, and to the poles. Although there is a great deal of persuasive evidence for such an interpretation, much more evidence, both geological and geophysical, is against it. The possibility of continental drift need not concern us greatly in our present problem; even under such an hypothesis North America has long retained about the same position with respect to Asia, South America, and the Pacific Ocean.

Other geologists believe that, although present oceanic areas are unlikely ever to have been continental, the continental plates may have increased in area through time by processes of accretion-by building of sediments over the edges of the oceanic crust, and their subsequent consolidation into continental crust during mountain building. Western North America may have increased in area, rather than diminished through recorded geologic time, by increments along its Pacific margin, especially during the orogenic period of the latter half of Mesozoic time. The area of the Coast Ranges of California, for example, may have been continental during only the last 100 million years of geologic time; before that, open ocean.

\section{GEOSYNCLINAL PHASE}

\section{General Coneepts}

Growth of a mountain system ordinarily begins with a geosynclinal phase, or time of quiet preparation, when marine sedimentation went on over the site of the future mountain belt. A geosyncline is an area where sedimentation proceeded actively, to the accompaniment of more or less crustal movement (Kay, 1947). Many geologists have believed that the geosynclines of North America were features that developed within the continental platform, between a central nucleus and the "borderlands" along the edge. Now, there is a growing 
suspicion that geosynclines were features marginal to the continental platform, that overlapped its edges, it is true, but that, on the farther side, may have been built outward into the ocean basins (Longwell, 1950, pp. 420-422).

The part of the geosyncline toward the continent, termed the miogeosyncline, was a shelf underlain by continental crust that received various sorts of shallow-water sediments. Mobility of the crust beneath it was greater than that in the continental interior, yet was expressed mainly by subsidence during sedimentation, which permitted gradual accumulation of a thick body of sediments.

The part of the geosyncline toward the ocean, termed the eugeosyncline, was a more mobile area, even during early phases of its history, with deeps, shallows, and strips of land that were shaped by crustal forces, and with volcanic eruptions whose products were mostly spread on the sea floor, but which in places were built up into islands. Later, parts of the geosynclinal phase in this area blended with the succeeding orogenic phase. The extent to which the eugeosyncline formed over a continental or over an oceanic crust is uncertain, as the basement on which the eugeosynclinal deposits were laid has seldom been raised to the surface; at least the outer edge of the eugeosyncline was probably built over an oceanic area.

Our study of western North America can best begin at the start of the Mesozoic era, or late in the geosynclinal phase of development of the Cordillera, and immediately before the orogenic phase.

\section{Eugeosynclinal Area of the Cordillera}

A eugeosynclinal environment persisted for a long period in much of the western part of the Cordilleran region, with an irregular eastern boundary. It extended about to the site of Owens Valley east of the southern Sierra Nevada, east of Winnemucca in north central Nevada, and across Oregon into westernmost Idaho (Fig. 2).

The environment is expressed by a characteristic suite of deposits - volcanics (lavas, tuffs, and breccias) many times repeated and of great thickness, and associated argillites, graywackes, and cherts, nearly all of which must have been laid down beneath the sea (Eardley, 1947, pp. 316-328). The eugeosyncline originated at an early period, for deposits of eugeosynclinal type contain Silurian and Devonian fossils in the Klamath Mountains and Ordovician fossils in north central Nevada and the eastern Sierra Nevada, but 
its record is most extensively preserved in the later Paleozoic, Triassic, and Jurassic rocks. This is not the place to discuss the complexities and variations of these primarily marine deposits, as we are more concerned with the land areas.

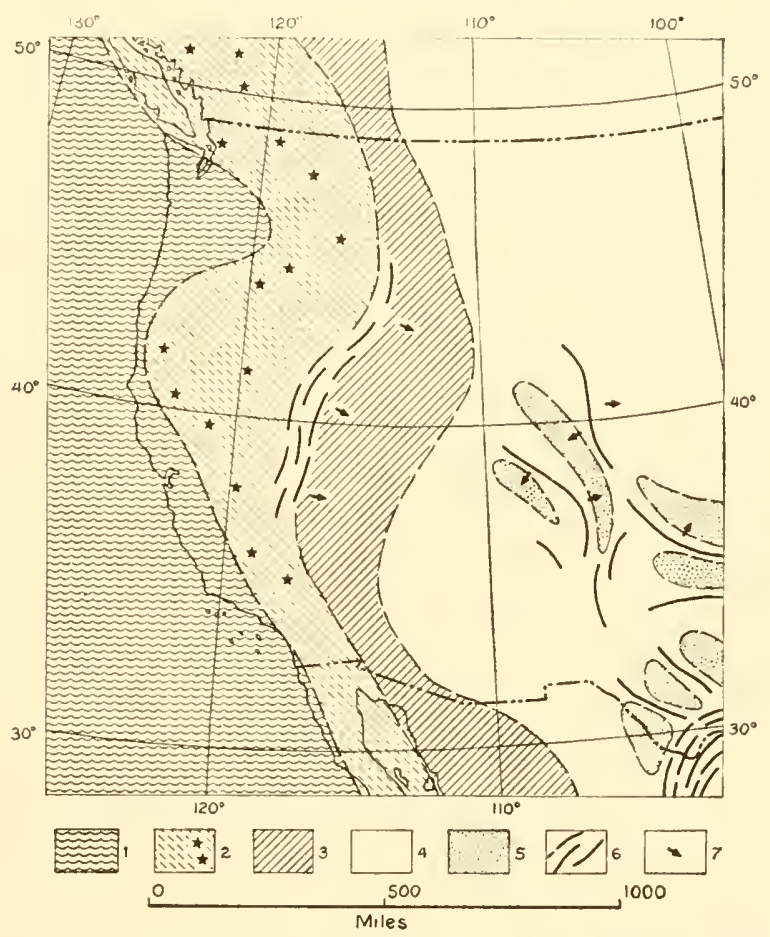

Fig. 2. Map of western United States, showing generalized conditions during middle part of the geosynclinal phase of the development of the North American Cordillera (Pennsylvanian and Permian time). 1, Oceanic area. 2, Eugeosynclinal area; stars indicate approximate positions of volcanic centers. 3, Miogeosynclinal area. 4, Foreland area, or continental interior; partly land, but intermittently covered by ephemeral seas. 5, Deeper sedimentary basins in continental interior. 6, Folds and fold belts. 7, Direction of transport of sediments.

Within the eugeosyncline, indications of any land areas are elusive. Ephemeral islands are suggested by occasional gaps in the sequence (such as absence of any Triassic rocks in parts of the Sierra Nevada) and by local conglomerate layers. Many of the volcanic units change markedly in thickness within short distances, as though 
they were built up irregularly on the sea floor, and perhaps in places to the surface. It has been thought that in some areas sedimentation was interrupted by deformation during Paleozoic time, before the close of the geosynclinal phase (Eardley, 1947, pp. 328-334), so that fold ridges may have emerged as land areas. Indications of such deformation are based on obscure evidence that can be otherwise interpreted, so that any occurrence of fold ridges produced by the deformation remains to be proved.

At the eastern edge of the eugeosynclinal area the record of emergence is more definite. Differences between Triassic and Jurassic deposits east and west of a belt through the center of the Great Basin have long been known, and are sufficiently marked as to suggest that the two sets of deposits were separated by a land barrier (Nolan, 1943, p. 158) (Fig. 3). Geologic work in north central Nevada during the last few decades has indicated something of the antecedents of this barrier (Roberts et al.). Older Paleozoic rocks that had been laid down in the eugeosyncline were deformed and thrust eastward over the miogeosynclinal area, were then eroded, and were overlapped from the east by Pennsylvanian deposits (Fig. 2). Angular unconformities within the higher Pennsylvanian and the Permian attest a continued instability of the area. In the Great Basin region, the Triassic and Jurassic barrier must have been inherited from this belt of Paleozoic deformation. Stratigraphic data indicate, however, that the barrier continued northward from the Great Basin toward Canada, where its origin and prior history are less clearly indicated.

\section{Miogeosynclinal Area of the Cordillera}

A miogeosynclinal environment prevailed over the continentward side of the Cordilleran geosyncline. During Paleozoic time, when the miogeosyncline received thick accumulations of limestone, its eastern edge extended across the site of the Rocky Mountains to the Great Plains near the Canadian border, but farther south in Utah extended no farther east than the boundary between the Great Basin and Colorado Plateau.

Through much of the segment in the western United States, therefore, a wide area of the Cordilleran region lay east of the geosyncline - the present Colorado Plateau and the Rocky Mountains of IVyoming, Colorado, and New Mexico. During Paleozoic time most of 
this area had a history like that of the remainder of the stable continental nucleus, intermittently emergent or receiving the thin deposits of ephemeral seas. In later Paleozoic time, however, part of it began to lose its previous stability. On the site of the Rocky Moun-

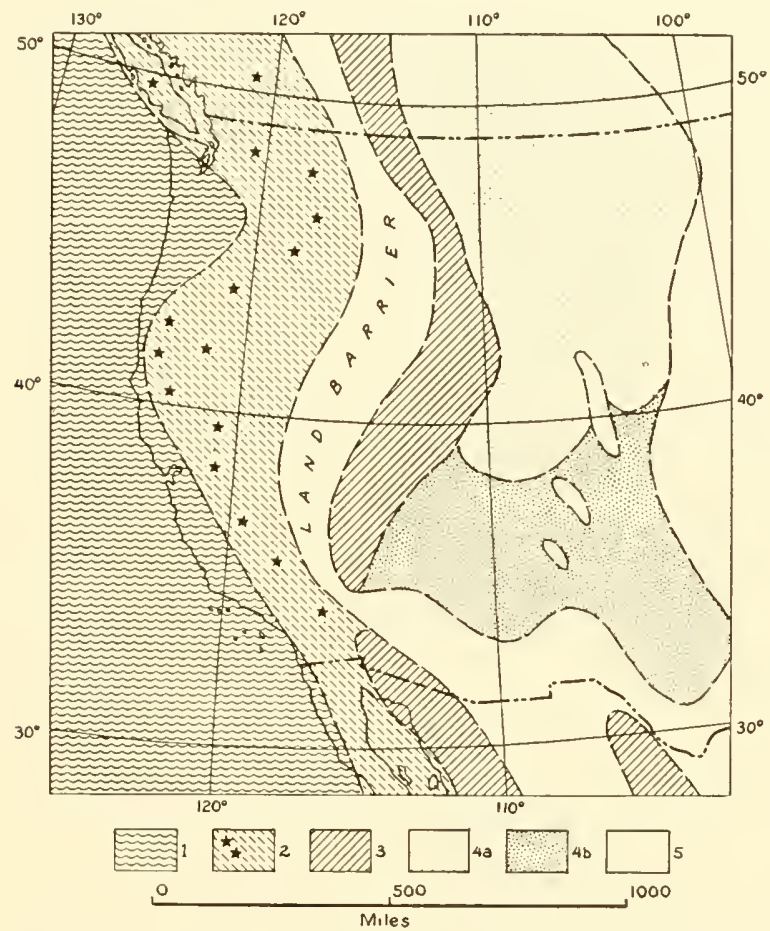

Fig. 3. Map of western United States, showing generalized conditions late in the geosynclinal phase (Triassic and Early Jurassic time). 1, Oceanic area. 2, Eugeosynclinal area; stars indicate approximate positions of volcanic centers. 3, Miogeosynclinal area. 4, Sedimentary wedges that spread from the geosynclinal area across the foreland: (a) dominantly marine, (b) dominantly continental. 5, Land areas that probably did not receive deposits.

tains of Colorado and New Mexico several broad fold ridges were raised; troughs subsided rapidly between them and received thick accumulations of waste eroded from the uplifts (Fig. 2). These "ancestral Rocky Mountains" are the ends of one of the western branches of the mountain belt that formed during Paleozoic time 
along the southeastern side of North America. The zone of weakness that they created in the crust greatly influenced the configuration of the Rocky Mountain structures that developed there later (Burbank and Lovering, 1933, pp. 277-301).

By the first half of Mesozoic time, considerable rearrangements had taken place in the miogeosynclinal area. The land barrier between the miogeosyncline and eugeosyncline, whose development had begun in later Paleozoic time, restricted the extent of Triassic and Jurassic sedimentation on the west; troughs along the eastern side of the barrier received a considerable thickness of marine sediments (Fig. 3). To the east, deposits spread beyond the Paleozoic miogeosyncline, wedging out in the Great Plains area east of the site of the Rocky Mountains. At least in the south, most of these eastern deposits were land-laid, and in the Colorado Plateau include such characteristic units as red stream deposits of the Triassic (Moenkopi and Chinle formations), great sand dune deposits of the Late Triassic and Early Jurassic (Wingate and Navajo sandstones), and varicolored stream deposits of the Late Jurassic (Morrison formation) (Baker et al., 1936, pp. 48-55).

During Cretaceous time, sedimentation continued in much the same region as that covered by the Triassic and Jurassic deposits, but the Cretaceous deposits are so closely related to the orogenic phase of Cordilleran history that it is best to discuss them later.

\section{OROGENIC PHASE}

\section{General Concepts}

Terminology. The word orogeny means mountain building, yet to a degree its use has been perverted by geologists. During early work in mountain regions, geologists observed everywhere the strong disturbance of their rocks and assumed that such disturbances were the cause of the mountains themselves. Now we know that these disturbances, while an essential step in the process, did not produce strong mountainous relief; such relief was only acquired later, in the post-orogenic phase. Use of the term orogeny for the deformative phase of mountain growth has nevertheless persisted for want of a better name; it is convenient to use it here.

The Orogenic Process. The geosynclinal phase of mountain growth blended, as stated, with the succeeding orogenic phase, when 
mobility of the crust reached its climax. Blending was greatest in the eugeosynclinal area, which possessed considerable mobility from the beginning; the orogenic climax was reached earliest here. During this climax the eugeosynclinal sediments and volcanics were strongly compressed and deformed, were more or less metamorphosed, and were invaded by small to large masses of plutonic rocks, ending with masses of granitic composition.

Detritus eroded from the newly deformed belt was in part washed off its oceanward side, where much of its record has been lost, and was in part spread inland as great sheets of clastic rock that tapered across the miogeosynclinal area, which was as yet undeformed. These clastic sedimentary deposits comprise as much as half of many miogeosynclinal sequences.

As crustal compression progressed, the miogeosyncline itself was deformed, sometimes in an orogenic period that appears to be distinct from that in the eugeosynclinal area. Its bedded sedimentary rocks were thrown into folds and broken by thrust faults along which rocks above were moved greater or less distances toward the continental interior. Deformation usually progressed as far as the inland edge of the geosyncline, where the sediments thin out, and the interior region was left undeformed. In places, however, deformation was carried beyond the edge of the geosyncline, as in the southern Rocky Mountains, within the region we are considering.

Effect on Surface Features. The orogenic phase so consolidated and strengthened the rocks of the eugeosynclinal area that they became permanent additions to the continental mass. Also, it ordinarily expelled the seas from the whole geosynclinal area for a long period-or permanently. Nevertheless, there is much question as to how greatly the orogenic phase increased the surface relief. Restoration of folds and fault blocks that are now eroded gives the impression that orogeny might have produced ranges higher than the Himalayas (Fig. 6), but orogeny may have proceeded so slowly that various leveling processes nearly kept pace with it-erosion wearing off the upraised areas and sedimentation filling the depressed areas. If so, creation of truly mountainous relief is largely a post-orogenic event, resulting from processes different from those in operation during the orogenic phase.

Orogenic Land Bridges. Orogenic belts of this sort are thousands of miles long. Some terminate laterally by facling out of effects of 
deformation, but most, in a sense, are endless. Those along the edges of the Atlantic Ocean run out to sea and apparently are broken off at the edges of the continental shelves so that their further extensions are lost. Those around the margins of the Pacific Ocean, however, such as the belt of the North American Cordillera, are continuous or nearly so from one continent to the next, and they appear to be parts of a single great zone of deformation. In the circum-Pacific zone, orogeny created potential conditions for land bridges between the continents, and they came in to being from time to time during the orogenic and post-orogenic phases. Such land bridges were along the present and observable orogenic trends; as already noted, no land bridges could have formed across the ocean basins.

The record suggests that land connections along the circum:Pacific orogenic belt were firmer and more frequent between North America and Asia than between North America and South America. Much of the crust beneath the seas of Middle America, as in the Gulf of Mexico and Caribbean Sea, is more oceanic than land-laid and seems to be in process of transformation into land-laid crust by sedimentation on its surface, and by magmatic transformation within it (Ewing et al., 1957, pp. 909-911). At least a part of the firm land connection between the two continents in the Central American isthmus, especially in Nicaragua and Costa Rica, was built up rather recently by volcanic eruptions: "To be sure it is in fact an isthmian link. But why is it such an outrageous isthmian link?" (Woodring, 1954, p. 730). Before development of the isthmus, the lands along the orogenic belt between North and South America were mainly disconnected islands.

\section{Deformation of Eugeosynclinal Belt of Cordillera}

Cordilleran eugeosynclinal rocks were deformed, metamorphosed, and invaded by granitic rocks in the middle and last half of the Mesozoic era, during a time referred to as the Nevadan orogeny (Fig. 4).

On the west slope of the Sierra Nevada, for which the orogeny is named, Jurassic rocks are steeply upturned, altered, and invaded by plutonic rocks, whereas Cretaceous rocks lie on their deeply eroded edges with little disturbance. From this relation and from more detailed evidence we need not mention here, some geologists have concluded that at least the deformational phase of the orogeny in the 
Sierra Nevada, and perhaps also the plutonic phase, was accomplished during a relatively brief interval near the end of Jurassic time, but before its close (Taliaferro, 1942, pp. 102-105). It has been inferred, as well, that much of the deformation in the eugeosynclinal

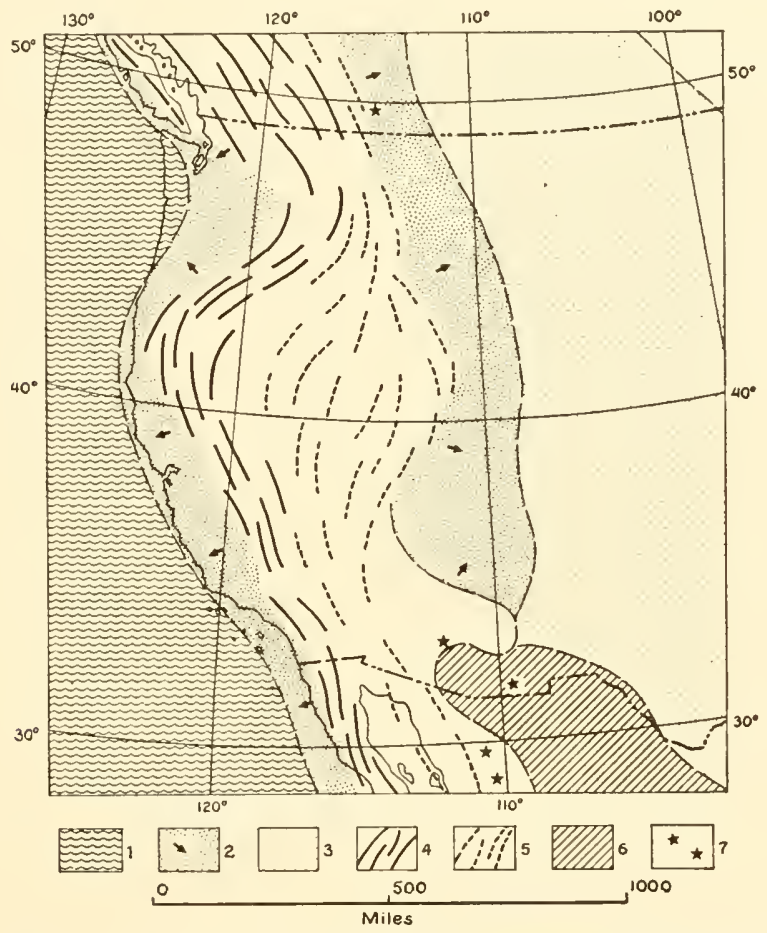

Fig. 4. Map of western United States, showing generalized conditions during early part of orogenic phase (Late Jurassic and Early to Middle Cretaceous time). 1, Oceanic areas. 2, Clastic deposits laid down along edges of orogenic belts; arrows indicate direction of transport of sediments. 3, Marine deposits of foreland area. 4, Folds produced by Nevadan orogeny, late in Jurassic and early in Cretaceous time. 5, Folds produced by orogeny later in Cretaceous time. 6, Miogeosynclinal area. 7, Volcanic centers.

belt to the north and south, where age relations are less clear, took place during the same epoch.

Various considerations suggest that events were more complex and prolonged than thus implied, even in the Sierra Nevada region. The eugeosynclinal rocks were first folded, steeply upturned, and 
regionally metamorphosed, then were invaded by successive masses of granitic rocks - a sequence which began later than deposition of the youngest Jurassic rocks of the Sierra, and must have continued for a long time thereafter. Moreover, radiometric determinations on the granitic rocks indicate that they themselves were injected over a period of more than 60 million years, or between Middle Jurassic and Middle Cretaceous times, with the oldest to the west in the Klamath Mountains and western edge of the Sierra Nevada, and the youngest near the east edge of the Sierra Nevada (Evernden et al., 1957). Elsewhere in the eugeosynclinal belt where evidence is available, the climax of the orogeny varies in age. In the Hawthorne-Tonopah area of southwestern Nevada thrust faulting was in progress during deposition of Lower Jurassic sediments (Ferguson and Muller, 1949, p. 13), whereas in northern Baja California Lower and Middle Cretaceous rocks are involved in the orogeny, and are unconformably overlain by Upper Cretaceous rocks (Woodford and Harriss, 1938, pp. 1328-1330).

Evidence is inconclusive as to the nature of the lands produced by the Nevadan orogeny. Sediments laid down east of the deformed belt suggest that the climate there was arid during Triassic and Early Jurassic times, and became more humid later, but these conditions were influenced by so many unknown factors that they are difficult to relate to local topography. As mentioned earlier, a land barrier existed on the site of the Great Basin during Triassic and Jurassic times, but during initial phases of the Nevadan orogeny the eugeosynclinal belt west of the barrier probably remained low; metamorphism and plutonism of the rocks of the belt indicate that they were deformed at a considerable depth, so that first orogenic movements may have been more downward than upward. Thereafter, during forcible injection of the younger plutonic bodies, the surface of the deformed belt may have risen, and its erosion may have contributed to the large volumes of sediment laid down east and west of it (described under succeeding headings). Such erosion products do not necessarily imply very great relief in the belt; they might as plausibly suggest that leveling by erosion nearly kept pace with uplift.

Be that as it may, it is worth emphasizing that the topographic forms produced by deformation of the eugeosynclinal rocks had little 
similarity to any modern features. The present Sierra Nevada, for example, was produced much later by tilting and faulting of a block within the orogenic belt; other parts were variously raised, broken up, depressed, or buried.

\section{Sedimentation West of Nevadan Belt}

Beyond the strongly deformed and altered rocks of the Nevadan orogenic belt, west of the Sierra Nevada and southwest of the Klamath Mountains, are less altered Upper Jurassic and Lower Cretaceous strata - the Knoxville formation and Shasta series-a sequence of marine shales, sandstones, and minor conglomerates. These are turned up against the Coast Ranges on the west side of the Sacramento Valley, where they are as much as 8 miles thick.

It has been thought that they were not laid down until after the Nevadan orogeny, and that they accumulated in a new trough that developed west of the Nevadan belt and east of the ancestral Coast Ranges along the Pacific Ocean, with most of the sediments derived from the latter (Anderson, 1938, pp. 25-29; Taliaferro, 1942, pp. 103-104). These views require reexamination, as recent paleontologic work indicates that part of the deformed Jurassic rocks of the Sierra Nevada on the east (Monte de Oro formation) are of the same age as the Knoxville, and that a large part of the Franciscan group of the Coast Ranges, once thought to underlie the Knoxville, is as young as early Late Cretaceous (McKee et al., 1956, pp. 3; Irwin, 1957). The dates of orogenic events and distribution of lands and seas during Late Jurassic and Early Cretaceous time must therefore have been quite different from those that have been inferred.

It may be that deformation of the rocks during the Nevadan orogeny diminished westward as well as eastward, so that the sites of the Sacramento Valley and Coast Ranges were little disturbed during the orogeny. The Franciscan, Shasta, and Knoxville strata may have been deposited before, during, and after the climax of the Nevadan orogeny, and have been laid down along the edge of the continent and on the continental slope, in part beneath ocean water of considerable depth. Further critical studies are needed to determine the source of this great body of sediments, but part of them, perhaps the greater part, must have been derived from erosion of rising lands in the orogenic belt to the east and northeast (Fig. 4). 
Existence during this time of lands farther west, along the Pacific border, has been stoutly maintained by various protagonists, but evidence for such lands seems to have little substance.

\section{Sedimentation East of Nevadan Belt}

During Cretaceous time, especially during its latter half, a great seaway extended along the eastern side of the Cordilleran region, from the Gulf of Mexico to the Arctic Ocean (Fig. 4). In mid-latitude in the United States its deposits were spread eastward into the continental interior as far as Kansas and Iowa and westward into the Cordilleran region as far as central Utah.

The eastern deposits were shallow-water shales and chalks of no great thickness, but westward near the front of the Rocky Mountains these pass into a dominantly shaly mass about 2 miles thick. Beyond, wedges of sandstone appear in the shales and thicken westward, with interbedded layers of coal that formed in swamps and floodplains along the edge of the seaway. The westernmost preserved Cretaceous rocks, near the west edge of the present Colorado Plateau, are nearly 4 miles thick and are dominantly of continental origin; they include coarse conglomerates that formed as piedmont deposits adjacent to mountainous lands (Spieker, 1949, pp. 60-68).

The source of these coarse, land-laid beds was clearly to the west in the area of the present Great Basin (Fig. 4). The land barrier that existed there during late Paleozoic and early Mesozoic time was evidently enlarged eastward during Cretaceous time to include the former miogeosynclinal area. This enlargement was the result of folding and faulting, rather than of mere upwarp, and produced a surface of varied relief that was rapidly eroded.

\section{Deformation of Miogeosyncline and Foreland}

During latest Cretaceous and Paleocene times, orogeny progressed into the eastern part of the Cordillera, deforming the rocks of the Colorado Plateau and Rocky Mountains as far as the Great Plains (Fig. 5). This deformation, which completed the orogenic phase of Cordilleran evolution, has been termed the Laramide orogeny. It has commonly been thought of as distinct, both in place and time, from the Nevadan orogeny, but such distinctions are between end members of a continuing sequence of leformation. Deformation began earliest toward the west, then expanded across the miogeosynclinal 
area towarl the continental interior; the Cretaceous rleformation of the Great Basin area occupies an intermediate position in place and time. In any particular part of the eastern Cordillera the observed

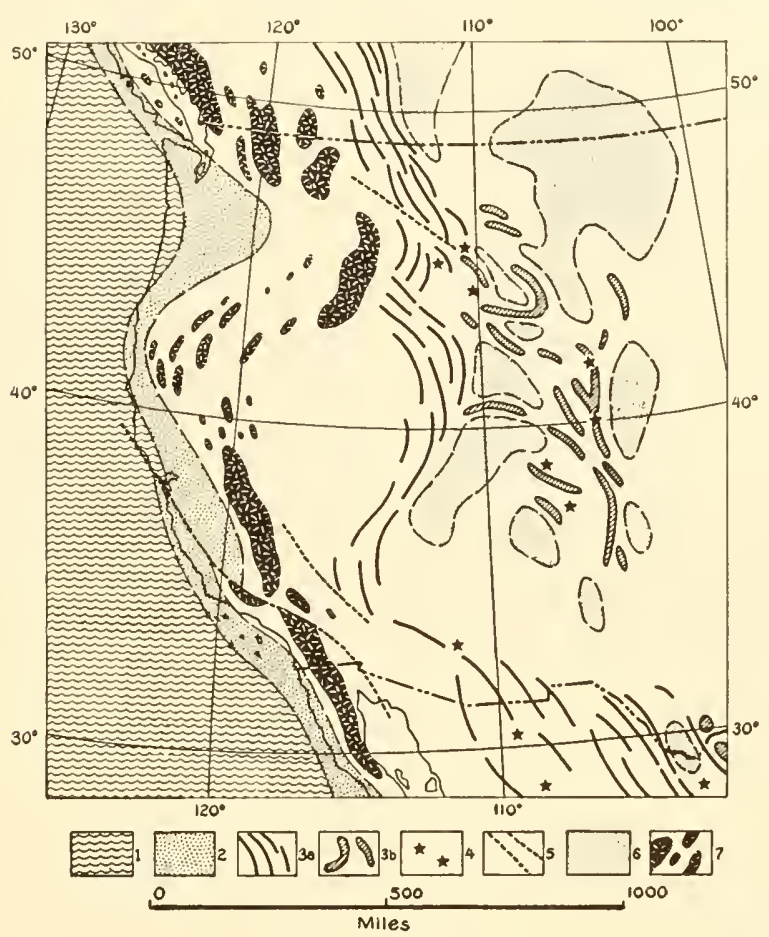

Fig. 5. Map of western United States, showing generalized conditions during late part of orogenic phase (latest Cretaceous and Paleocene time). 1, Oceanic area. 2, Marine sediments along Pacific border. 3, Folds produced by Laramide orogeny: (a) narrow folds and fault blocks in geosynclinal sediments, (b) broad folds in foreland area, involving basement rocks. 4, Volcanic centers. 5, Transverse faults with major components of lateral displacement. 6, Sedimentary basins of nonmarine deposition between folds and along their eastern border. 7, Land areas; shaded areas indicate approximate extent of plutonic rocks of Nevadan age that had been unroofed by erosion.

deformation of the rocks can be placed in this sequence only if stratigraphic evidence is available; as a matter of convenience, all such structures are ascribed to the Laramide orogeny.

Laramide movements compressed the sedimentary rocks of the miogeosyncline into long, closely spaced folds and thrust blocks, 
characteristic examples of which may be seen in the northern Rocky Mountains of western Alberta and northwestern Montana, and in the central Rocky Mountains of western Wyoming and southeastern Idaho. Farther south they have been obscured by later structures of the Basin and Range province.

From central Montana southward, Laramide deformation advanced well beyond the miogeosynclinal belt, disturbing part of what had previously been the foreland, or border of the stable continental

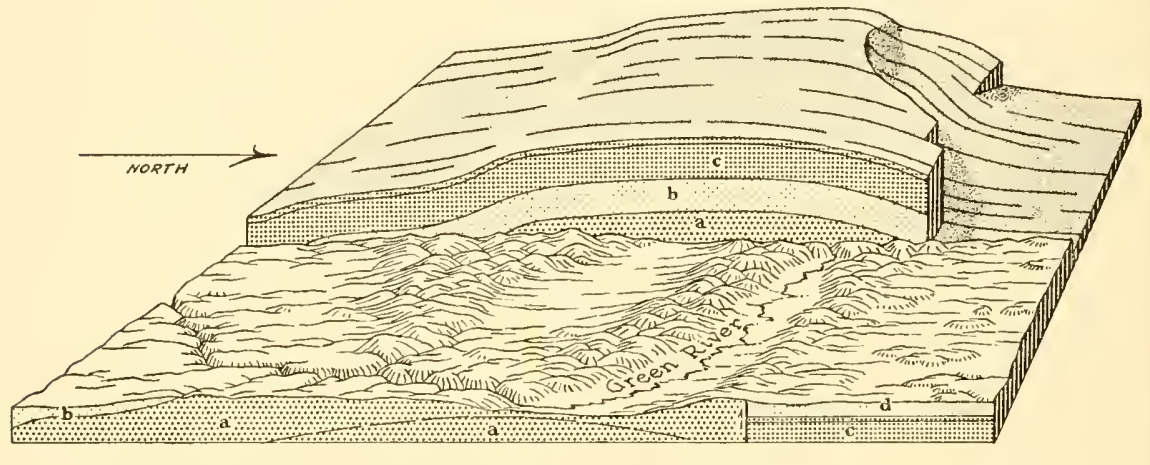

0

5

10

20 Miles

Fig. 6. Diagram of a typical mountain uplift in Southern Rocky Mountains. The example chosen is the Uinta Mountains of northeastern Utah. The block in the background shows the feature without erosion of the uplifted strata; that in the foreground the present topography. (After Powell, 1876.) a, Pre-Cambrian rocks (here, sedimentary strata; in other uplifts of Rocky Mountains, generally plutonic and metamorphic rocks). b, Paleozoic strata. c, Mesozoic strata. d, Tertiary strata.

interior, and raised the central and southern Rocky Mountains of Wyoming, Colorado, and adjacent states. Here, the sedimentary cover was mainly thinner than in the miogeosyncline, and deformation created structures of a different style-broad-backed ranges of diverse trend and spacing, in which Precambrian basement rocks were so uplifted along the cores as to be uncovered by erosion, the ranges being separated by broad basins (Fig. 6).

Many of these structures were newly born during the Laramide orogeny, but in the southern Rocky Mountains of Colorado and New Mexico they were guided by structures of the "ancestral Rocky Mountains" already referred to. Here, some of the Laramide ranges nearly correspond to uplifts that formed in late Paleozoic time, 
whereas others were produced by close folding of sediments which had been deposited in troughs between the earlier uplifts (Burbank and Lovering, 1933, pp. 283-301).

The foreland ranges of the southern Rocky Mountains are separated from the miogeosynclinal structures in the Great Basin on the west by the Colorado Plateau, which remained as a more stable block during Laramide orogeny. Its rocks were broadly upwarped and downwarped in much the same manner as those of the Rocky Mountains, but they attained less structural relief. A typical uplift, in the Kaibab and Coconino Plateaus of the Grand Canyon district, is still sheeted over by sedimentary rocks, except where trenched by the Colorado River, and it is bounded at the sides by steeply sloping monoclinal flexures.

Record of the Laramide orogeny may be read in deposits of latest Cretaceous and Paleocene ages which are preserved to great thickness in basins between the ranges of the Rocky Mountains, such as the Bighorn and Powder River basins of Wyoming-and in the Great Plains east of the mountains, as in the Denver and Williston basins of Colorado and North Dakota (Fig. 7). The deposits are sombercolored land-laid clays and sands with layers of coal, whose upper parts contain increasing quantities of detritus eroded from the cores of the ranges.

Much labor has been expended in a search for immense unconformities that were supposed to be concealed in these deposits, and which would mark the time of upheaval of the intervening ranges, but it is now clear that the deposits are essentially conformable sequences. Very likely the original areas in which the deposits were laid did not greatly differ from the present structural basins, and the deposits were thick, local accumulations derived from erosion of ranges uplifted in the immediate vicinity. The latest Cretaceous and Paleocene deposits are therefore unlike the broad sheet of marine sediments of earlier Cretaceous time, which were derived from erosion of deformed areas far to the west.

Laramide orogeny destroyed the great Cretaceous seaway of the eastern Cordillera (Fig. 5). Except for a brief marine incursion in the northern Great Plains during late Paleocene time, represented by the Cannonball member of the Fort Union formation, seas returned no more to the region, and all succeeding deposits were land-laid. The Upper Cretaceous and Paleocene land-laid deposits evidently 


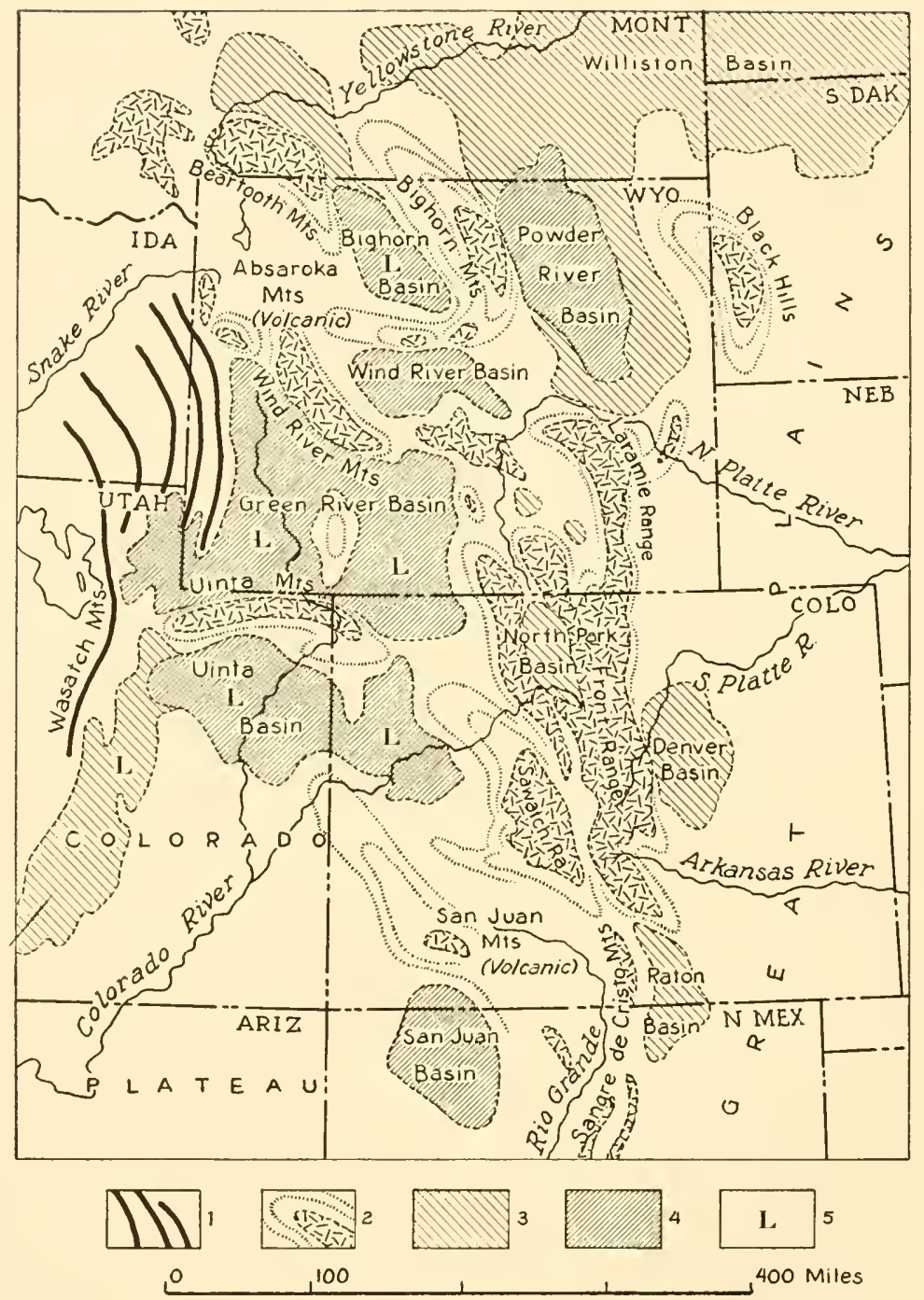

Fig. 7. Map of central and southern Rocky Mountains, showing uplifts and basins of Paleocene and Eocene time. 1, Folds and fault blocks in geosynclinal sediments. 2, Uplifts east of geosynclinal area, with outcrops of pre-Cambrian basement rocks in their higher parts. 3, Basins that received Paleocene sediments. 4, Basins in which Eocene sediments were deposited over Paleocene sediments. 5, Areas of lake deposits, mainly of Eocene age. 
formed in forested floodplains and swamps, in a warm humid climate, probably at an altitude no more than a thousand feet above sea level; Paleocene rocks contain small mammals that were members of an arboreal forest community (Van Houten, 1948, p. 2105).

The ranges that intervened between the areas of deposition were outlined in much their present form during the Laramide orogeny, but could not have projected to their present bold heights, or they would have prevented an ingress of moisture-laden winds from the west and the climate would have been much drier (Mackin, 1937, p. 819). More likely, their summits rose no more than a few thousand feet above the basin floors; their rocks were greatly uplifted by the orogeny, but were worn down nearly as rapidly as they arose.

\section{POST-OROGENIC PHASE}

We pass now to that part of our story which is perhaps of greatest interest to this audience - the shaping of the Cordilleran mountain belt after the orogenic phase, in Tertiary and Quaternary times.

\section{General Concepts}

Crustal unrest continues in a mountain belt long after the orogenic phase. The orogenic phase itself created many modifications in the crust and subcrust, which were stable so long as the region was in the grip of strong compression. Relatively light sialic crust might be thickened as a root beneath the mountain belt, and sialic crust might be added along the oceanward edge where only simatic crust was present before. Although the orogeny generally thickened and strengthened the continental crust, it also produced transverse flaws and zones of weakness, by differential movement between adjoining segments of the belt.

With relaxation of compression, there was a shift to a new equilibrium. Overthickened parts of the crust might have risen buoyantly, or the mountain root might have been dissipated by subcrustal transfer of material. Further movements might have followed the zones of weakness, or such zones provicled routes for the ascent of magmas.

These processes of readjustment are complex, not well understood, and much debated, but their surface manifestations are more evident and can be read in the rocks, their structures, and in the changes in 
the landscape. Such modifications of the Cordilleran region have been perhaps as great as in any other mountain belt, and include:

1. Continued differential movements between mountain uplifts and intervening basins in the epochs immediately succeeding the orogeny, or perhaps in the waning stages of the orogeny. Some, but not all, of the basins in the central and southern Rocky Mountains were thus accentuated during Eocene and Oligocene time.

2. Breakup of extensive areas of the deformed terrain by block faulting to produce a succession of mountains and intervening basins. Such was the fate of the former miogeosynclinal area and the eastern part of the eugeosynclinal area in mid-section in the United States - in the Great Basin-but similar structures extend far to the south and southeast through the more inclusive Basin and Range province.

3. Regional uplift of broad areas without much folding or faulting, especially late in the post-orogenic period. The greatest of these uplifted regions encompassed virtually all the central and southern Rocky Mountains, the Colorado Plateau on the west, and the Great Plains on the east; smaller and more complex areas of regional uplift occur farther west, as in the Sierra Nevada and Cascade Ranges.

4. Volcanic activity and accompanying shallow intrusions. Some volcanism took place locally in the Cordilleran region even during the orogenic phase; in the post-orogenic phase it occurred in varying degree, at one time or another, in almost every part of the region. Volcanism was concentrated more in some areas than others, however, and in some of them was long persistent. By far the most voluminous and persistent volcanism was in the northwestern United States, in the Columbia Plateau and Cascade Range.

5. Development of faults along which movements were not upward and downward, but along which one side moved laterally against the other. The most famous of these is the San Andreas fault of California, but many more occur near it and others elsewhere; some, perhaps, are as yet undetected.

6 . Continued orogeny, marked by local subsidence and sedimentation, uplift, and deformation along the oceanward side of the mountain belt. In the Coast Ranges of California, strata as young as the Pliocene and Pleistocene are strongly folded in places, and the seismic record indicates that the crust is still unstable. 
Eastern Part of Cordillera (Central and Southern Rocky Mountains, Colorado Plateau, and Great Plains)

Eocene Environments. We have arbitrarily chosen the end of Paleocene time as the close of the orogenic, or Laramide, phase in the eastern part of the Cordillera, but environmental changes from Paleocene into Eocene were evolutionary rather than revolutionary. It is true that in some of the intermontane basins initial coarse Eocene deposits overstep the edges of Paleocene and earlier rocks with marked unconformity, and that this has sometimes been thought to have followed immediately on the climax of the Laramide orogeny. We have seen, though, that Laramide structures had been in process of growth long before the end of Paleocene time; the Eocene deposits thus record merely a resumption of sedimentation after the crust had reverted to relative stability.

Within the mountain belt, subsidence of the basins continued through Eocene time; basins which had received Upper Cretaceous and Paleocene deposits also received Eocene deposits (Fig. 7). Significantly, however, basins east of the mountains became quiescent. The Denver, Williston, and other basins in the Great Plains received Upper Cretaceous and Paleocene deposits, but few or no Eocene deposits. Here, the surfaces of the earlier basins are overspread by thin sheets of Upper Tertiary sands and gravels. During Eocene time the regime of the Great Plains changed from one of sedimentation to one of erosion.

Initial Eocene deposits of the intermontane basins (Wasatch formation and equivalents) are red-banded sands and silts of stream origin, which pass marginally into coarse piedmont deposits. The fluviatile deposits contain fossils of large terrestrial mammals which probably lived in savannas and open country; forest-dwelling types, such as those of the preceding Paleocene, are less common. Evidently the passage from Paleocene to Eocene time was marked by a restriction of forests and expansion of grasslands (Van Houten, 1948, p. 2106). Nevertheless, there is no evidence of marked change in climate or general altitude; the environment has been compared with that along the present Gulf Coast of the United States (Bradley, 1948, p. 641).

In some of the basins stream deposition continued through the Eocene (as in the Powder River, Wind River, and San Juan basins), 
but in later Eocene time some of them on the west became the sites of great lakes in which fine-grained, thin-bedded, water-laid sediments accumulated, which were in part calcareous or petroliferous (Bradley, 1948, pp. 640-647). Lacustrine deposition had already begun during Paleocene time in the western part of the Colorado Plateau area, where the Flagstaff limestone was laid down widely, but during the Eocene the center shifted eastward and a great confluent body of water spread north and south of the Uinta Mountains, in which the Green River formation was deposited; a smaller lake also existed in the Bighorn basin, represented by the Tatman formation (Fig. 7).

Ranges between the basins doubtless continued to rise during Eocene time and to shed their detritus in to the basins, but the overlap of the Eocene strata along their edges indicates that uplift was less active than earlier. The ranges could not have projected more than a few thousand feet above their surroundings, else they would have created a rain shadow to modify the prevailing humid climate. Presence of the same species of mammals in more than one basin indicates that the ranges were not barriers to migration.

These conclusions are incompatible with reports of Eocene glacial tills at various places in the Rocky Mountains, especially near Ridgeway, Colorado (Atwood and Atwood, 1938, p. 961). On this basis, some geologists have assumed that the ranges of the Rocky Mountains projected to alpine heights at the time. These far-reaching interpretations have been built on very local, very dubious evidence, which may well be otherwise interpreted (Van Houten, 1957).

The extensive intermontane and lacustrine deposits of Eocene time might suggest that the Rocky Mountains and their environs were then a region of interior drainage-that not only were the seas driven from the region by Laramide orogeny but also, for some time thereafter, no rivers flowed from it to the sea. A little reflection suggests that this is implausible. Although the region was not lofty, its summits must have projected to some height above the lowlands on the east and formed a drainage divide. The probable rainfall was greater than could have been trapped entirely by basins without outlets. The subsiding intermontane basins caught the detritus which was being washed down from the mountains, but during most of the time the streams which entered them probably flowed on to the sea. When subsidence of the basins was excessive, runoff was 
trapped to form lakes, but the nature of their deposits indicates that they possessed outlets through most of their existence.

It is obviously impossible to mark out the courses that were pursued by the Eocene streams. Even the courses of exterior drainage much later in Tertiary time are problematical, and the early history of the modern rivers of the Cordillera has been diversely interpreted, as we shall see.

Cenozoic Volcanic Activity. An additional item of the Eocene and later Tertiary environments in the eastern part of the Cordillera can be discussed appropriately at this point-the widespread and persistent volcanism.

Some trace of volcanic activity can be seen in almost all parts of the region, but with variable manifestations-in places, isolated volcanic cones, patches of lava, and shallow intrusions; in others, extensive volcanic piles that stand as massive plateaus or mountains. Time relations also vary. Some volcanic fields are so ancient that only deeply eroded conduits and dike swarms are preserved; others are recent enough that the forms of the cones, calderas, and flows are still recognizable; still others present a record of intermittent volcanic activity through much of Tertiary time, and even later.

Cause of the localization of the larger Tertiary volcanic fields is not entirely certain. Many of the Tertiary intrusive bodies are clearly aligned along zones of weakness in the country rock, related to the Mesozoic orogenies; such alignments may also exist in the conduits of the volcanic fields but have been hidden by the eruptives that overspread the surface. It is perhaps significant that one of the extensive volcanic fields, in the Absaroka Mountains and Yellowstone Park of northwestern Wyoming, lies at the east end of a transverse zone of volcanic rocks of various ages that extends westward across the Cordillera nearly to the Pacific Coast. Another series of volcanic fields extends around the Colorado Plateau, from the San Juan Mountains on the east through the Mogollon Plateau and San Francisco peaks on the south to the High Plateaus of Utah on the west, as though the plateau block were separated from its neighbors by nearly continuous zones of weakness.

Volcanism began in the eastern part of the Cordillera during the later stages of Laramide orogeny (Fig. 5). Large volumes of andesitic debris occur in the Upper Cretaceous and Paleocene deposits of 
many of the basins. In Colorado, such debris in the Animas formation of the San Juan basin and the Dawson arkose of the Denver basin indicates that the nearby San Juan Mountains and Front Range, during the climax of their uplift, were heavily overspread by eruptives, nearly all trace of which has now been eroded.

In the Absaroka Mountains and Yellowstone Park of northwestern Wyoming, violent and explosive volcanism began in late Eocene time, and built up the "early acid breccias" and "early basic breccias" of that area (Rouse, 1937, pp. 1262-1272); no doubt their edges once extended eastward over the older Eocene deposits of the Bighorn and Wind River basins. Other flows and breccias were piled over these, probably during later Tertiary epochs, and the hot springs and geysers of Yellowstone Park attest that the volcanic heat has not yet cooled.

Climax of the eruptions around the Colorado Plateau appears to have been during Miocene time. In the San Juan Mountains of southwestern Colorado where the sequence has been worked out most completely (Larsen and Cross, 1956, pp. 258-260), the Paleocene andesitic eruptions were followed by quiescence in Eocene and Oligocene times, when relatively thin, non-volcanic deposits were laid down. On these, during the Miocene, a mile or two of lavas, breccias, and tuffs were piled, but with occasional pauses that permitted the cutting of canyons as deep as those today. Lesser eruptions continued through the Pliocene and into the Pleistocene. The volcanic record of other fields on the periphery of the Colorado Plateau resembles that of the San Juan Mountains, although perhaps less complete and on a smaller scale (Hunt, 1956, pp. 39-53).

Volcanism in the eastern part of the Cordillera had a significant, though secondary role in the shaping of the geography. Eruptions in the larger fields much increased the relief, although upbuilding was somewhat compensated by subsidence under the load of eruptives and by transfer of magmas from their subsurface reservoirs to the surface. Volcanism changed the regimen of streams by loading them with detritus, and in places dammed and diverted their courses. In some places these effects may be read plainly; in others, where the eruptives have largely been removed by erosion, the effects are difficult to assess.

Contrast between Eocene and Present Conditions. Compare the 
conditions inferred in the eastern Cordillera in Eocene time with conditions today - in the Eocene, low general altitude, low relief, subdued landscape, and warm, humid climate; today, high general altitude, high relief, rugged mountains and deep canyons, and sharply contrasted climates. How was this change brought about?

Geologists agree on many aspects of the story, and especially that the whole region has been uplifted as a unit many thousands of feet since Eocene time, but they disagree as to the manner in which it was accomplished, and by what stages. One view, perhaps the more customary, is that it came about through a succession of brief upheavals, of which the last great one was during the Pleistocene, separated by more prolonged periods of stillstand (Atwood and Atwood, 1938, p. 978). Another view is that uplift proceeded slowly, with little interruption since the waning of Laramide orogeny; with the upward movement greatest in the first half of the Tertiary and diminishing afterward (Mackin, 1947, pp. 110-111). These divergent views result from differences of interpretation of the middle and late Tertiary deposits and land forms that are preserved in the eastern Cordillera.

Middle and Upper Tertiary Deposits. During middle and late Tertiary time deposits were laid down in the eastern Cordillera as widely as during Paleocene and Eocene time, but in a different pattern. They are preserved now as erosion remnants of original broad sheets of sediment, rather than as downfolds in original depositional and structural basins.

Deposits of the Oligocene White River group are extensive in the northern Great Plains of South Dakota, and are preserved in smaller remnants in the Central Rocky Mountains of Wyoming; they are overlain southward, in Nebraska, by the Miocene Arikaree group. Even more extensive in the Great Plains, however, is the Pliocene Ogallala formation, which spreads southward from Nebraska to Texas, and eastward from the mountain front for nearly 400 miles; its caliche-cemented layers ("mortar beds") form the caprock of the High Plains (Johnson, 1901, pp. 643-647). At about the same time another sheet of deposits, the Bidahochi formation was laid down in the south central Colorado Plateau, and is now preserved as remnants in northeastern Arizona (Repenning and Irwin, 1954). In New Mexico, between the plateau and the plains, the Santa Fe 
formation of late Miocene and Pliocene age occurs in great thickness in fault troughs that extend southward near the present course of the Rio Grande.

These later Tertiary deposits were contemporaneous with eruptions in the volcanic fields of the eastern Cordillera, and near them contain water-borne volcanic gravels and air-borne volcanic ash. The remainder of the deposits were derived from erosion of the rocks of the ranges. Those in the Great Plains contain fragments derived from the Rocky Mountains on the west; those of the Bidahochi formation, fragments from at least as far as the San Juan Mountains on the northeast.

Except in fault troughs, the preserved deposits of middle and upper Tertiary times are relatively thin at any locality - a thousand feet thick or less, rather than much more than a thousand feet as with the Paleocene and Eocene deposits. Their average texture is considerably coarser than the latter, not only cobbly or bouldery near the mountains, but also with lenses and layers of gravel far out in the plains country. Nevertheless, they appear not to have resulted from renewed folding of the region, as they overlap the edges of the ranges without disturbance, and in places nearly bury a rough topography of earlier rocks with complex structure.

Fossil plants and mammals in the middle and upper Tertiary deposits record not only a spread of grasslands at the expense of forests, an accentuation of Eocene tendencies, but also an increasing regional altitude and aridity. By late Miocene time many of the earlier browsing herbivore mammals had disappeared; those that survived, such as the horses, had a dentition adapted to feeding on harsh grasses. Indications of a semi-arid regime appear first in the Oligocene floras and faunas and increase to a climax during late Miocene and Pliocene time when the climate seems to have been much like that in the present Great Plains.

The deposits themselves are compatible with this inferred environment. In the late nineteenth century it was supposed that the Great Plains deposits had been laid down on the floors of a succession of great lakes, hence that they were originally horizontal and later were tilted regionally eastward. Critical study by many later geologists has made clear that they were largely of stream origin, with local ponds at most and with finer deposits perhaps brought in by the wind. The coarse deposits that were formed in the channels of 
withering streams flowing eastward from the mountain are of such a texture that, under semi-arid conditions, they could hardly have moved down a slope much less than that of the present (Johnson, 1901, p. 628).

Erosion Surfaces in the Ranges. So much for middle and late Tertiary conditions in the plains and lowlands around the mountain ranges. What were conditions in the ranges, which were the sources of the streams and of much of the detritus deposited roundabout?

Wide areas in the ranges are beveled by a subsummit surface, marked by accordant crests which extend across the deformed bedrock structures, above which chains and clusters of peaks project on the divides, and below which modern valleys and canyons have been cut to depths of thousands of feet. The surface has been given local names in different ranges, and has been variously dated as Miocene and Pliocene. Precise age does not matter greatly, as the surface may not have been completed simultaneously everywhere; it expresses a general late Tertiary erosional condition, hence deserves the general title of Rocky Mountain peneplain (Atwood and Atwood, 1938, pp. 964-965).

Analysis of this surface on the north slope of the Uinta Mountains, where it is unusually well preserved, indicates that it has a gradient of 400 feet per mile near the high peaks along the mountain axis, flattening to 55 feet per mile toward the plains, where it is largely mantled by the coarse gravels of the Bishop conglomerate (Bradley, 1936, pp. 170-176). This outward flattening of gradient is believed not to have resulted from late differential uplift of the range, but to have been inherent in the nature of the surface itself. The surface must have been cut under conditions of considerable aridity; its graded profile, much steeper and more concave than those of humid regions, was just sufficient in an arid climate for the transport of materials across it.

Regional studies indicate that the Rocky Mountain peneplain in other ranges is like that in the Uinta Mountains, and that it probably formed under similar conditions. They show, as well, that the peneplain in the mountains was originally confluent with depositional surfaces in the Great Plains and other lowlands where, as we have seen, the nature of the deposits suggests deposition on a slope nearly as steep as the present slope of the plains.

Environments of Middle and Later Tertiary times. Between 
Eocene and middle Tertiary times the eastern Cordillera was probably arched upward as a unit by as much as 5,000 feet. During the same period, the climate became more arid, partly because of a world-wide secular change (Axelrod, 1957, pp. 40-41), partly because the crest of the uplift created a rain shadow over the area to the east.

Climax of uplift and aridity was probably also the climax of aggradation in the areas between and east of the mountains. It appears well established (Atwood and Atwood, 1938, pp. 965-968; Mackin, 1937, pp. 821-823) that extensive areas not now covered by later Tertiary deposits, including the earlier Tertiary intermontane basins and the lower mountain ends and spurs, were then buried. Most of the emergent areas were planed to form the Rocky Mountain peneplain, leaving, as projections above the general level, only the unreduced peaks along the axes of the ranges.

Opinions differ as to the relief of the aggraded and planed-off surface of later Tertiary time. The view of many geologists has been that regional relief of the eastern Cordillera was considerably less than that of today, and that modern regional and local relief is the product of renewed uplift during the Pleistocene. Other geologists call attention to the fact that preserved gradients of the Great Plains deposits and of the Rocky Mountain peneplain are about those to which stream regimen would have been adjusted in an arid climate and, by extrapolation, infer that the late Tertiary graded surface had almost the same regional relief as that of the present country. Regional relief had thus increased greatly from that of early Tertiary time, but local relief was about as subdued, and differed much from the present strong local relief.

Quaternary Denudation and Dissection. Transformation of the late Tertiary landscape into that of the present was thus an event of the Quaternary period, mainly of the Pleistocene epoch. Regardless of ultimate causes, it resulted from accelerated stream erosion, which degraded and dissected the whole region.

Such erosion removed large volumes of upper Tertiary deposits from the mountain areas, and excavated the rocks beneath by varying amounts according to their resistance. The basins, formed of weak Cretaceous and lower Tertiary rocks, were etched out, so that the ranges of pre-Cambrian crystalline rocks and Paleozoic stratified rocks projected above them. During the period of aggradation streams had wandered at will down the slopes of the subdued sur- 
faces, but many of them, as they cut downward, were superimposed on hard rocks in the buried mountain ridges beneath, and were there forced to excavate deep canyons (Atwood and Atwood, 1938, pp. 968-976).

The same sort of canyon cutting took place in the less deformed rocks of the Colorado Plateau, southwest of the Rocky Mountains, where uplift and degradation had been in progress since early in Miocene time (Hunt, 1956, p. 77).

Principal cause of the accelerated stream erosion of the eastern part of the Cordillera during Quaternary time must have been renewed regional uplift, but there is uncertainty as to its amount. All graded surfaces of subaerial erosion and deposition possess an original slope toward the sea; if the late Tertiary surfaces were produced in an arid or semi-arid regime, this original slope would have been much steeper than that produced in a more humid regime. How much the slopes of the late Tertiary surfaces and the regional relief of the eastern Cordillera were augmented by uplift is thus difficult to evaluate, but it was probably much less than has been supposed by some authors.

Whatever the magnitude of the uplift, major climatic changes occurred also, as the ice ages of Pleistocene time brought about both refrigeration and increase of rainfall. Under this more humid regime, streams that had become adjusted to steep gradients during the arid times of the later Tertiary were able to readjust themselves to new, lower gradients. Such readjustments were most marked, of course, during the glacial periods, and were less marked during the drier interglacial periods; thus, general downcutting has been punctuated by many pauses expressed in the landscape by a succession of terraces and intervening steps.

Origin of Drainage Courses of Eastern Cordillera. All this is very well as a generalization but what, specifically, has been the history of the individual rivers of the eastern Cordillera? The more specific we become, the more the doubts and confusions multiply.

Streams draining eastward from the Cordillera in to the interior region need trouble us least. Streams of some sort no doubt flowed from the Cordillera in this direction since the Laramide orogeny, although their courses must have shifted with time. The greatest shift in later times was a deflection of streams that formerly flowed into Hudson Bay, southward, around the edges of the Pleistocene 
continental glaciers, to form the Missouri River (Howard, 1958, pp. 585-587).

Greater problems attend the streams that flow southward and southwestward from the Rocky Mountains and find their way through long reaches of mountain, plateau, and desert country, especially the Rio Grande and the Colorado rivers.

The Rio Grande flows southward from its source in the Rocky Mountains for 500 miles through a succession of desert basins before it breaks through the eastern ridges of the Cordillera in the Big Bend country of Texas and enters the slope toward the Gulf Coast. Deposits in the basins of northern New Mexico contain channels of foreign stream-worn gravels that indicate existence there since early Pliocene time of a river or rivers ancestral to the Rio Grande (Bryan, 1938, pp. 205-208), but such gravels are unreported in basin deposits of southern New Mexico and Texas. Perhaps the Rio Grande drained at first into the lake region of northwestern Chihuahua (Lee, 1907, p. 22), and later found its way across the ridges to the east by filling a succession of basins, until it overflowed each in turn at the lowest point on its rim (King, 1935, p. 260).

Very likely the Colorado has drained southwestward from the Rocky Mountains for a long span of Tertiary time, during which it may have persisted in its present position across much of the northeastern half of the plateau. Its lower course across the plateau is more puzzling. It has there cut the Grand Canyon through the south end of the Kaibab Plateau, which is one of the highest uplifts of the region. Noreover, below the lower end of the canyon, the desert basins traversed by the river are filled by the late Tertiary Muddy Creek formation, which is made up of locally derived detritus, without deposits of any large, through-going river (Longwell, 1946, pp. 821-826); the river could not have entered these basins until after Muddy Creek time.

It has been suggested that the river coursed across such uplifts as that of the Kaibab Plateau when they were in an early state of growth, that renewed uplift ponded the drainage on their upstream sides, until the river overflowed through its original valley and cut this to its present depth (Hunt, 1956, pp. 65-67). Such a sequence of events is possible, but field relations suggest otherwise; so far as known the Kaibab uplift was folded entirely by Laramide orogeny.

It has also been suggested that the Colorado River formerly flowed 
southward through the area of the Bidahochi formation, and so to the sea, but was later diverted westward by uplift of the southern rim of the plateau (Repenning et al.). It is believed that filling of the area upstream from the Kaibab Plateau to a depth of about 600 feet would be sufficient to allow the river to drain westward, utilizing the smaller consequent and subsequent stream valleys that had already been established between the Kaibab Plateau and the Grand Wash Cliffs.

Nevertheless, the problem of the course of the Colorado River in its lower segment across the Colorado Plateau remains one of the riddles of the Cordillera, and will no doubt be debated for years to come.

\section{Central Part of Cordillera (Great Basin and Sierra Nevada)}

Basin and Range Topography and Structure. During the postorogenic phase, the Great Basin, or region between the Colorado Plateau and Sierra Nevada, acquired its distinctive Basin and Range topography-a succession of discontinuous, subparallel ranges, separated by desert basins.

The Great Basin itself is a region of interior drainage; streams that flow into its basins have no outlet to the sea. This is in part a product of the structure, for some of the basins, of which Death Valley is an extreme example, have been depressed lower than any possible outlet. To some extent the interior drainage of the Great Basin is a product of its arid climate and its remoteness from the sea; part of its streams could flow out of the region if they had sufficient volume (Hubbs and Miller, 1948, pp. 94-98). Basin and Range topography extends far south and southeast from the Great Basin into Arizona, New Mexico, and Sonora, which are nearer the sea and are drained by the Colorado, Gila, Rio Grande, and other through-flowing rivers.

Some geologists have thought that the distinctive quality of Basin and Range topography is primarily a product of erosion of a complexly deformed bedrock under arid conditions; clearly, the arid regime has done much to shape the details of the landscape. Most geologists believe, however, that the topography of much of the province is related to a distinctive Basin and Range structure, which was superimposed on the earlier orogenic structures, in part so recently that the forms of basins and ranges are a direct result of 
crustal movement. Certain it is that much of the region is still unstable, as attested by many fresh fault scarps along the edges of the mountains and in adjacent alluvial deposits, some of which can be related directly to recorded earthquakes.

Basin and Range structure is thought to be a mosaic of blocks, which have been variously raised, lowered, or tilted along steeply dipping faults (Fig. 8). High-standing blocks produced the mountain ranges, low-standing blocks the basins; detritus eroded from the higher blocks was trapped in the lower ones, and smoothed their surfaces into gently sloping plains. The faulted sides of the most recently upraised mountain blocks still preserve straight base lines

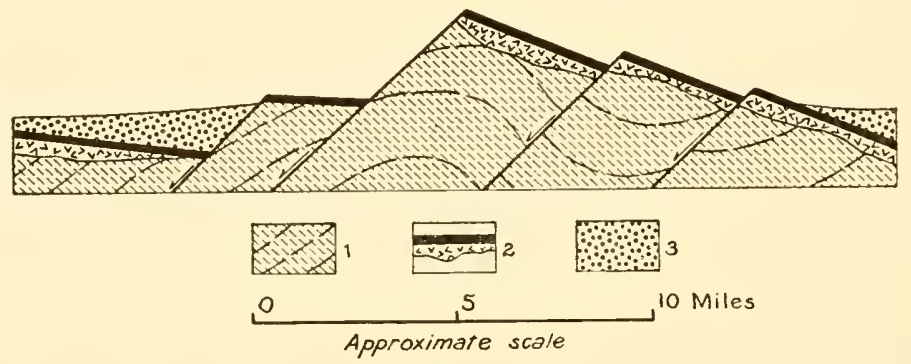

Fig. 8. Generalized section showing Basin and Range structure as commonly interpreted, based on Humboldt Range, western Nevada. (After Louderback, 1904.) 1, Deformed bedrock of Paleozoic and Mesozoic age. 2, Lava and tuff, mainly of early and middle Tertiary age. 3 , Deposits of the intermontane basins, mainly of late Tertiary and Quaternary age.

and steep escarpments; mountain blocks upraised earlier are more frayed and are embayed by erosion (Davis, 1925). Detrital filling in the basins has generally overlapped the edges of the mountains sufficiently to conceal the faults along their borders, but these faults are exposed at some favorable places.

Basin and Range structure is a post-orogenic feature that succeeded the strongly compressed structures of the Cordilleran orogenic phase, but opinions differ as to the forces that caused it (Nolan, 1943, pp. 184-186). An early view is somewhat naive-that it was produced by a breakdown and collapse of the region under tension, after relaxation of orogenic compression. But under pervasive tension the whole region would have subsided from an earlier high-standing position, the ranges less than the basins, whereas the 
region has been uplifted several thousand feet since the early Tertiary, and at least some of the ranges have undergone actual, rather than merely relative, uplift. Structures resulting from crustal tension are no doubt present in the region, but they may have resulted from components of a more pervasive crustal compression. This compression, however, manifested itself in a different guise from that which deformed the eugeosynclinal and miogeosynclinal rocks at an earlier period.

Time Relations of Basin and Range Structure. In the generalized picture sketched above, Basin and Range topography and structure were presented as an accomplished fact, although their development through time was hinted by the varying degrees of erosion observed in different ranges. But the present topography and structure were long in the making, and when one attempts to trace their development through time, the picture at once becomes more complex (Longwell, 1950, p. 427).

For example, it was stated that the low-standing blocks, or desert basins, were largely filled by detritus eroded from the adjoining ranges, but these deposits formed during a considerable span of Tertiary time, in which the geography changed as a result of continuing crustal movements. Earlier basin deposits were derived from ranges in a state of growth different from the present ranges and perhaps even in different positions; in places the deposits were spread over the sites of ranges that developed later. With further movements, the earlier deposits were faulted, tilted, and eroded, and those in which resistant lavas were embedded were raised in places to mountainous heights. Later Tertiary and Quaternary deposits bear a closer relation to modern geography, although even these are more or less deformed and eroded.

Sierra Nevada Topography and Structure. The Sierra Nevada, which lies west of the Great Basin, is a single massive block 400 miles long and 80 miles wide, whose crest attains alpine heights, yet its form and structure differ only in degree from the mountain blocks of the Basin and Range province, and its development was closely related to at least the Great Basin segment of that province. The Sierra Nevada block may have been shaped by the great masses of granitic rocks embedded in its deformed eugeosynclinal strata, as these extend along its eastern side for most of its length.

The Sierra Nevada faces the Great Basin on the east in a series of 
lofty scarps that have been outlined mostly by faults, although the faults are not continuous and are offset en echelon in many places. Minor faults also occur within the range, but most of the range, west of its summit, is a tilted block with remarkably even, westwardsloping crest lines, below which the tributaries of the Sacramento and San Joaquin rivers have cut impressive canyons.

Early Tertiary (Paleocene and Eocene) Environments. By early Tertiary time, the topography that developed on the orogenically deformed miogeosynclinal and eugeosynclinal rocks had become decadent, but the post-orogenic topography of basins and ranges had not yet developed.

At many places in the eastern half of the Great Basin the Mesozoic and older rocks are overlaid by patches of calcareous mudstone, finegrained sandstone, and coarser sands and gravels. These appear to be remnants of originally much more extensive deposits that formed in floodplains, swamps, and lakes, probably in a warm, humid lowland (Van Houten, 1956, p. 2819). Although the deposits have been dated only by meager fossil evidence, they are probably westward extensions of the Paleocene and Eocene deposits of the Colorado Plateau and the central and southern Rocky Mountains, which formed in a similar environment.

The western half of the Great Basin seems to have been part of a low highland which extended westward across the area of deformed eugeosynclinal rocks to the western edge of the Sierra Nevada. Few or no early Tertiary sedimentary units exist in the western Great Basin, although the lower parts of some of its volcanic sequences may be as old as Eocene. At the western edge of the highland the marine Ione formation of middle to late Eocene age overlaps widely on the deformed Mesozoic rocks (Allen, 1929). It is composed of clays of remarkable purity, with interbedded sands, and is traceable up the slope into the older gold-bearing stream gravels of the Sierra Nevada foothills. During Ione time the site of the Sierra must have been worn down to low relief, and was drained by sluggish streams that headed well east of the present mountain crest. The clays were derived from deeply decayed granitic rocks that were widely exposed on this worn-down surface.

Middle Tertiary (Oligocene and Early Miocene) Environments. In Oligocene and early Miocene time lavas, agglomerates, and tuffs of varied composition were spread widely over the western part of the 
Great Basin area, and form the older volcanic sequence of that area, now much disturbed and mineralized. The northwestern corner of the Great Basin was overlapped by basalt flows related to the Miocene Columbia River basalt. Most of the volcanics farther southeast have also been ascribed to the Miocene, but a tuff member in the Alta formation of the Virginia City district contains middle Oligocene plants. At some places in the eastern and southern parts of the Great Basin, ash-rich sand, mud, and gravel were deposited in basins that recently had been outlined by faulting.

Available floras indicate that the western part of the Great Basin stood at an altitude of about 2,000 feet above sea level in middle Tertiary time, with the Sierra Nevada to the west projecting, at most, only a thousand feet higher. Apparently neither the low Sierra Nevada ridge nor the downfaulting of incipient basins interfered materially with drainage westward to the Pacific.

During one or more episodes before late Miocene time, and perhaps mainly in the middle Miocene, the older Tertiary volcanic and sedimentary rocks in many parts of the Great Basin were faulted and tilted, then widely eroded (Van Houten, 1956, p. 2820). These movements, premonitions of which we have seen in the middle Tertiary basin deposits, are the first notable disturbance of the region since the orogenic phase, and mark the beginning of development of Basin and Range structure and topography.

Late Tertiary (Late Miocene and Pliocene) Environments. During late Miocene and early Pliocene time volcanics and sediments were spread widely over the Great Basin and Sierra Nevada, covering an eroded terrain that had been more or less deformed by the preceding disturbances. As these deposits contain mammals and plants at many places, and occasional invertebrates and other fossils, they form not only a useful stratigraphic datum, but also an index of the environments of the time (Van Houten, 1956, p. 2802; Axelrod, 1957, pp. 23-28).

Much of the central and northern parts of the Sierra Nevada were covered by several thousand feet of andesitic lava flows, remnants of which are still preserved on stream divides and mountain tops. Principal centers of eruption were near the modern crest of the mountains, along an axis which continued northward into the Cascade Range, but the flows also spread eastward into the Great Basin. Andesitic debris was transported widely westward and 
eastward, where it became an important component of contemporaneous sedimentary deposits.

Over much of the Great Basin east of the eruptive area a succession of andesitic vitric tuff, reworked ash, bentonitic mudstone, sandstone, limestone, and diatomite was deposited, which has been variously termed the Truckee, Esmeralda, or Humboldt formation, depending on locality. The deposits were laid down in many separate but probably confluent basins, partly in lakes and swamps. They not only covered the earlier Tertiary rocks but overlapped widely onto low intervening highlands of the Mesozoic and Paleozoic rocks. In southern Nevada faulting was more active at the time, and the Muddy Creek formation of that area consists of coarse alluvial fan deposits along the faulted basin margins, and of finer-grained clastics and evaporites in the basin centers.

Comparison of floras in a traverse eastward across the area is instructive as to the late Miocene and early Pliocene environments (Axelrod, 1957, pp. 34-38). Conifer forests like those of the modern Sierra Nevada were not well developed on its western slope probably because of low altitude and warm climate. At Carson Pass on the crest of the range, at a modern altitude of more than 9,000 feet, is a flora of deciduous trees which could not have lived at altitudes higher than 2,500 feet. Farther inland, in the Great Basin, were conifer forests of a type now found at the margins of woodland and chaparral country. Annual rainfall at the western base of the Sierra Nevada must have been about 25 or 30 inches, increasing to 40 or 45 inches on the upper slopes, and thence decreasing to 25 inches over the lowlands of the Great Basin. The summit level of the central and northern Sierra Nevada must have stood at an altitude of less than 3,000 feet, and projected about 1,000 feet above the Great Basin to the east; it created no more than an ineffective rain shadow over that area. Evidence of fossil fishes suggests that the Great Basin at this time stood at altitudes well below 2,000 feet, to allow the ingress of lowland coastal faunas (C. L. Hubbs, personal communication).

The andesitic eruptions along the Sierra crest, although spread over a surface of low altitude and low relief, foreshadowed later uplifts along that axis. By late Pliocene time the floras of the Great Basin changed from a woodland and forest facies to a savanna and grassland facies, adapted to less than 15 inches of rainfall. Evidently 
the Sierra Nevada block was now being uplifted, and was exerting a climatic influence on the region to the east. Uplift continued into early Pleistocene time, until the block had been raised 5,000 to 6,000 feet in the north and 7,500 to 9,000 feet farther south (Axelrod, 1957, p. 42).

At the same time as the Sierra Nevada was being raised, block faulting on an extensive scale disrupted the Great Basin, and was largely responsible for shaping it into its present Basin and Range topography (Van Houten, 1956, pp. 2821-2822). There was also a gradual increase in altitude; basin floors which had stood at well below 2,000 feet above sea level at the beginning of the Pliocene, now stand at 3,000 to 5,000 feet. In part this was a result of sedimentary filling of the basins, but to a much greater extent to regional upwarp.

The reader may note a discrepancy between the record as here set forth for times of uplift in the Rocky Mountain region on the east and the Great Basin and Sierra Nevada on the west. In the Rocky Mountains, some geologists believe that the principal uplift was before the middle of the Tertiary and diminished later, whereas the Great Basin and Sierra Nevada seem to have been low up to middle Tertiary time, and were greatly uplifted afterward. The inferred history of the two areas is based on interpretations of necessarily elusive evidence by various competent observers, but if the contrasts are real, they had a significant influence on the geographic and climatic evolution of the middle Cordillera.

Pleistocene Environments. Events in the Great Basin and Sierra Nevada during the Pleistocene are perhaps sufficiently familiar as not to require detailed recital-the ice fields along the Sierra crest and the valley glaciers below them, the smaller glaciers on higher summits in the Great Basin, and the great lakes, such as Bonneville and Lahontan, which flooded the lower country, in places to depths of more than a thousand feet. Climatic fluctuations are recorded not only by successive glacial moraines in the mountains, but by several epochs of filling and dessication of the lakes. Existence of the lakes indicates a much increased rainfall and implies, as well, that many of the basins temporarily possessed exterior drainage (Hubbs and Miller, 1948, pp. 21-29).

The Great Basin has returned now to conditions of aridity approximately comparable to those at the end of Pliocene time but if, 
as many believe, the present is merely an interglacial rather than a post-glacial period, far-reaching climatic fluctuations in the region may be anticipated in the future.

\section{Northwestern Volcanic Province (Columbia Plateaus and Caseade Range)}

General Setting. The northwestern part of the United States exhibits one of the most drastic later modifications of the orogenic structure and topography in the Cordilleran region. Elsewhere in the Cordillera, volcanism interrupted or modified other post-orogenic processes; here it dominated the scene. The deformed geosynclinal rocks are covered, in places deeply, by great floods and piles of lava, and by associated breccias, tuffs, and sediments. In northern Oregon and southern Mashington no rocks older than these are exposed for 300 miles parallel with the coast, or 400 miles inland; they also extend over an even greater area to the south and southeast where older rocks emerge in places (Fig. 9). The volcanic regime was prolonged and extended, at one place or another, through most of Tertiary and Quaternary times.

The Nevadan belt of deformed eugeosynclinal strata frames the region on the south, east, and north. It is exposed at intervals between the Klamath Mountains of southern Oregon and the Cascade Range of northern Washington, but describes a great arc eastward, which passes through the highlands of northeastern Oregon and western Idaho (Fig. 9). The volcanics are confined by the arc on the north and east, but break across it on the southeast, where they extend into southeastern Oregon and southern Idaho.

This extraordinary localization of volcanic activity provides food for speculation for which there is no certain answer, especially as the substructure upon which the volcanics were built is widely buriedand entirely so within the area enclosed by the Nevadan arc. A question is worth asking, however, whether the area within the arc might not have been an oceanic embayment, floored by simatic crust, until well through the geosynclinal phase (Figs. 2 and 3), and was only added to the continent later, by volcanism and sedimentation. This possibility is suggested by dominance of basalts within the arc, which were seemingly derived without contamination from the underlying simatic layer, and by more varied lavas southeast of the arc, where there was evidently greater mixing of simatic and sialic crustal materials. 

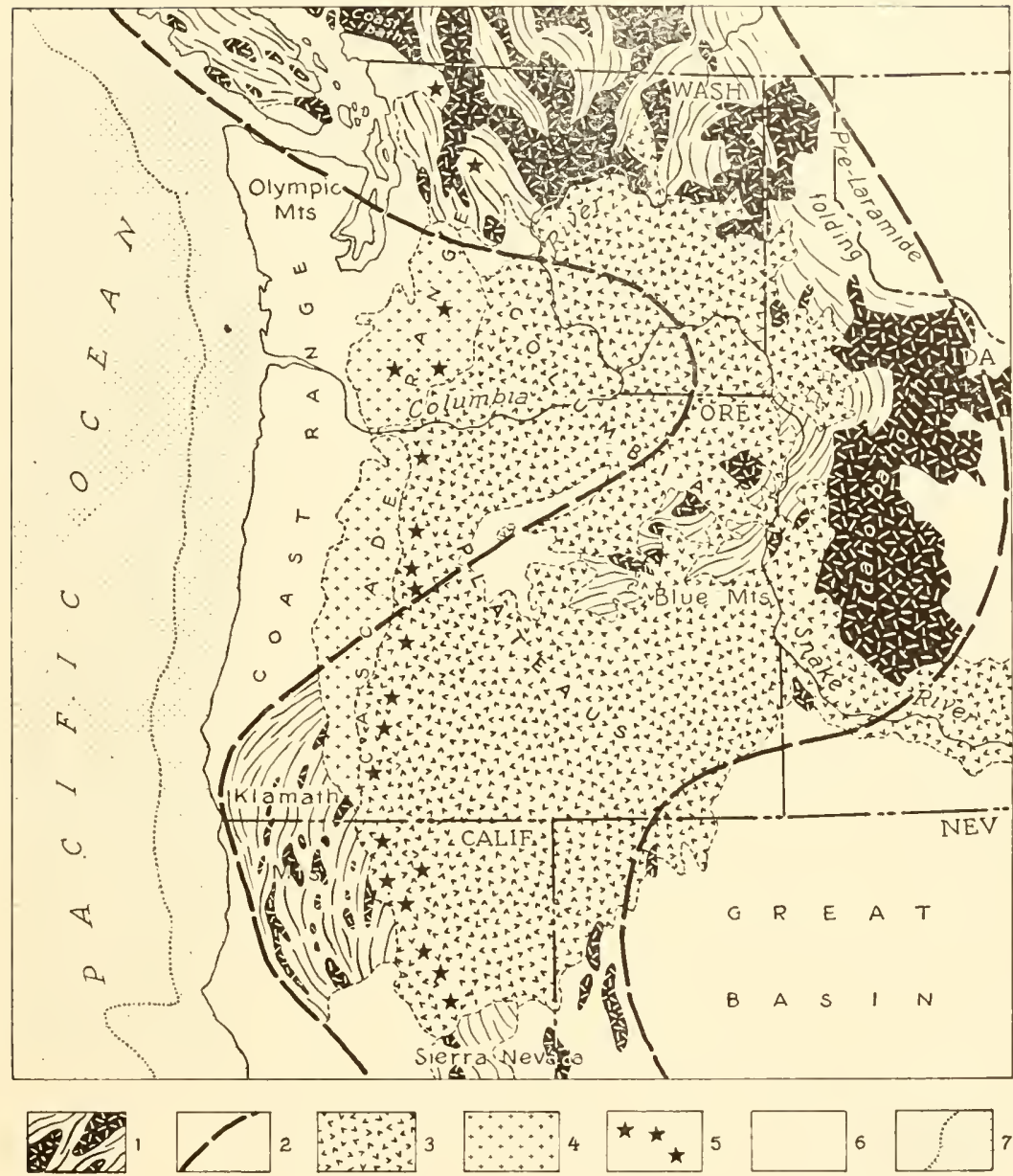

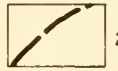

0

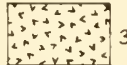

100
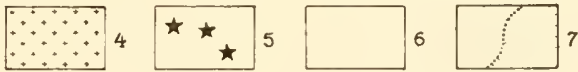

400 Miles

Fig. 9. Map of northwestern volcanic province, in Washington, Oregon, Idaho, and adjacent states. 1, Nevadan basement; metamorphic rocks lined, plutonic rocks in heavy shading. 2, Inferred margins of Nevadan orogenic belt. 3, Plateau basalts of Miocene and later age. 4, Andesitic volcanics of Cascade Range. 5, Volcanic cones of Cascade Range, mainly of Quaternary age. 6, Other rocks; mainly sedimentary rocks of Mesozoic and Tertiary age, but including some older Tertiary volcanics. 7, Edge of continental area.

The volcanic rocks and their associates assume diverse geographic forms: along the Pacific, the low Coast Ranges; east of a longitudinal depression, the high Cascade Range; and farther inland, the 
Columbia Plateaus, partly split in their middle by the emerged Nevadan rocks in the highlands of northeastern Oregon.

Early Tertiary Environments. The record of early Tertiary time may be seen mainly in the Coast Ranges, where marine clastic sedimentary strata several miles thick are turned up in gentle folds. Some of them, such as those of the Olympic Mountains of northwestern Washington, may have been laid down beneath ocean water of considerable depth, and have been derived from turbid flows that moved westward down the continental slope. Interbedded with the Tertiary sedimentary rocks are great lenticular masses of basaltic lava, which were largely erupted beneath the sea, as shown by their pillow structure (Waters, 1955a, pp. 204-707). Inland, where the lower Tertiary rocks are occasionally exposed, the marine beds pass into land-laid deposits, including beds of coal, which formed in floodplains, swamps, and lakes.

During early Tertiary time the northwestern volcanic province probably was a broad coastal plain with an offshore continental shelf and slope, which faced westward on open ocean (Fig. 5). Its environment must have resembled that of the present Gulf Coastal Plain, except for the much greater volcanic activity. No ranges existed near the coast to create a climatic barrier like that today; Eocene floras from both the east and west sides of the present Cascade Range are closely related, and grew in subtropical lowland forests (Chaney, 1938, p. 383).

Middle and Late Tertiary Environments. Miocene time witnessed the great eruptions of Columbia River basalt, which spread over an area of 100,000 square miles, in places to thicknesses of a mile or more (Waters, 1955a, pp. 707-708). The basalt flows cover all the plateau country of southeastern Washington and northeastern Oregon, within the Nevadan arc (Fig. 9), where in many places they still remain nearly horizontal, although in others they have been warped and folded. Along the lower course of the Columbia River the basalt also spreads westward across the site of the Cascade Range. Here its farther edges interfinger with marine deposits.

The Columbia River basalt is a plateau basalt -it was not erupted from volcanoes, but welled out of deep fissures from the simatic layer beneath. Single flows are 100 to 500 feet thick, and must have been very fluid as some of them are traceable for more than a hundred miles. The flows were probably piled thickest near the center of the 
eruptive area, which subsided gradually beneath them, and they spread thence in all directions. Along their edges to the north, east, and south, they overlapped an eroded surface of the Nevadan orogenic belt, damming valleys and ponding their waters.

At about the same time, a different form of volcanism was beginning along the Cascade Range. Eruptions of explosive violence built up piles of andesitic lava, mudflows, breccias, and tuffs, which were probably surmounted by volcanoes. These accumulations formed a chain approximately along the axis of the present range, from northern Washington southward through Oregon into California, where it joined the chain of andesitic eruptions in the Sierra Nevada. The andesitic volcanics had a much more complex origin than the basaltic, and probably formed on a line of weakness that was developing along the Cascade-Sierra Nevada trend (Waters, 1955a, pp. 709-710).

In both the Cascade Range and Sierra Nevada, this line of weakness was first manifested at the surface by eruptions only, but later the rocks along it began to be raised by crustal forces. Unlike the segment in the Sierra Nevada, however, that in the Cascades was neither tilted as a block nor greatly faulted; the faults that occur are minor and local. Moreover, volcanic upbuilding went on hand in hand with crustal uplifts so that basement rocks were not laid bare by erosion, except at the north end. The cross section of the range exposed in the gorge of the Columbia River exhibits both volcanic upbuilding and complex arching (Hodge, 1938, pp. 839-886).

Quaternary Events in Cascade Range. The modern Cascade Range, from northern Washington to northern California, is crowned by a score or more of great volcanic cones (Fig. 9), whose construction apparently began as early as the Pliocene, but whose growth continued until recent times-if, in fact, it has yet ceased. The cones were built upon a deeply eroded surface of the older andesitic volcanic rocks that form the greater bulk of the range, apparently after a time of quiescence of some duration in late Tertiary or early Quaternary time. North of the Columbia River the cones stand singly, but farther south they have built up a massive range of volcanic rocks on the eastern side of the earlier range.

History of Columbia River. The Columbia River, whose sources are in the Rocky Mountains on the east, enters the Pacific in the midst of the volcanic province. Much of its drainage basin is blessed 
with greater rainfall than the country farther south, and its volume far exceeds that of any other stream on the western slope of the Cordillera. Similar greater rainfall probably prevailed in this northern segment of the Cordillera through much of the post-orogenic phase, so one may assume that an ancestor of the Columbia existed there throughout much of the Tertiary and Quaternary.

With onset of the eruptions of Columbia River basalt, the course of the river in the coastal plain downstream from the highlands of the Nevadan orogenic belt was obliterated by the flood of lava. Parts of the river and its tributaries in the highlands to the north and northeast were dammed by the lava, and a series of lakes were formed. Each lake drained around the spur ends of the highlands of older rocks to the next lower lake on the west, thus establishing an exit for the waters along the edge of the volcanic field; with downcutting, there was thus established the new course of the Columbia, part of which it still follows (Fig. 9). Farther downstream in southern Washington, however, the river is deflected eastward in to the lava country, probably as a result of outbuilding of andesitic debris from the Cascade Range on the west (Vaters, 1955b, pp. 681-683).

In southern Washington the river also crosses several anticlinal folds in the basalt, which plunge southeast from the Cascade Range. Each anticlinal fold is expressed topographically as a ridge, and in each ridge the river and several of its tributaries have cut deep gorges. The Columbia and its tributaries were probably antecedent to the anticlines (Waters, 1955b, pp. 679-681) - they had much their present courses before the folding and maintained them by downcutting as the anticlines were raised. Still farther downstream the river cuts a much larger gorge through the complexly upbuilt and upwarped Cascade Range. Many geologists believe that the river is antecedent to the growth of the Cascade Range also, but some would ascribe its course through the mountains to a complex process of superposition (Hodge, 1938, pp. 888-918).

\section{Pacific Border of Cordillera (Coast Ranges of California)}

General Geography and Geology. From the Klamath Mountains southward through California and into Baja California, the westernmost ranges of the Cordillera are the Coast Ranges along the $\mathrm{Pa}$ cific Ocean (Fig. 10). Southward to Point Conception they consist of numerous parallel ridges, each diverging south-southeastward from 

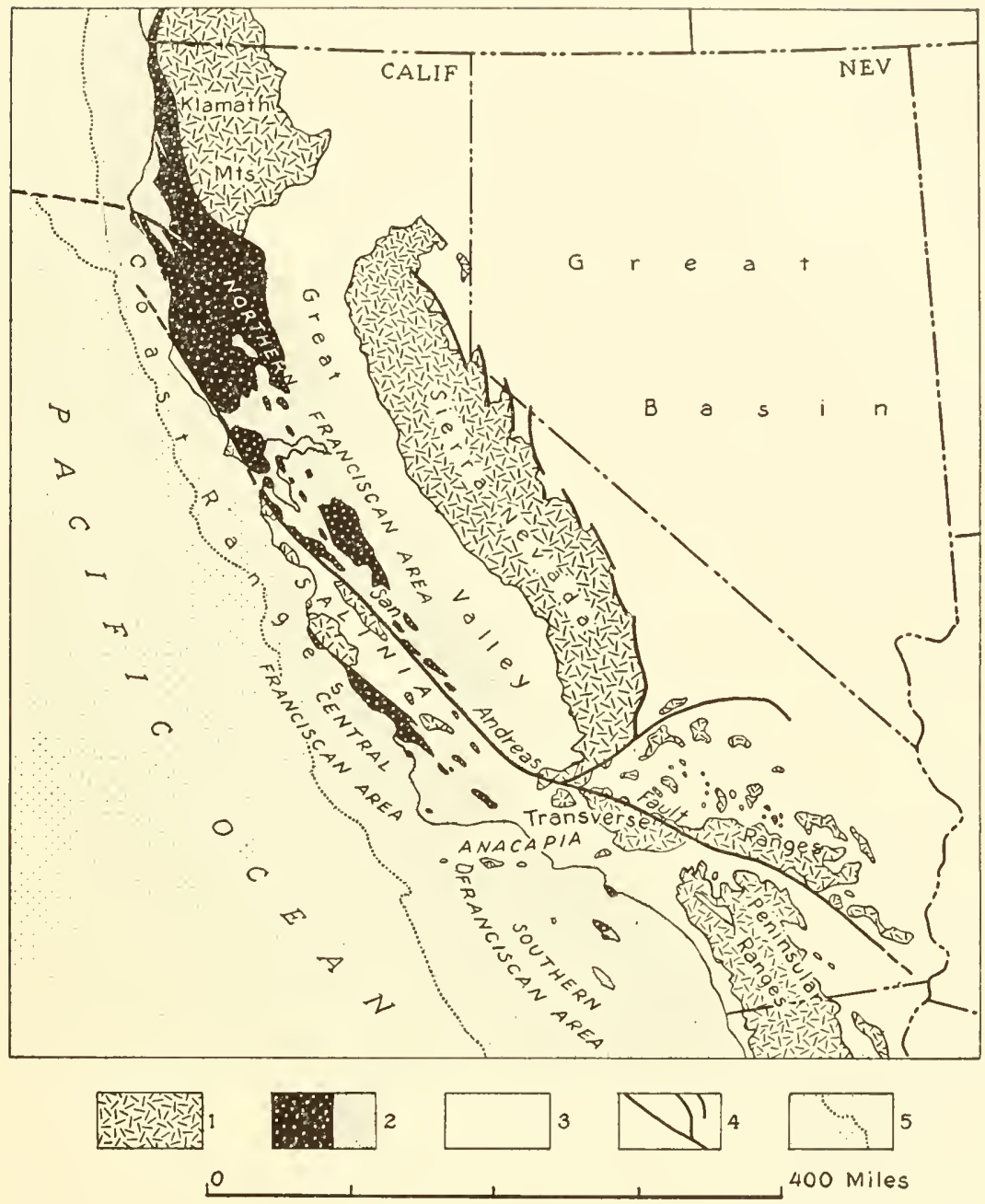

Fig. 10. Map of California, showing the two types of basement in the Coast Ranges and adjacent areas. 1, Nevadan basement of metamorphic and plutonic rocks. 2, Franciscan basement of strongly deformed but little metamorphosed clastic sedimentary rocks; probable extent of Franciscan basement beneath cover of younger sediments indicated by light stipple. 3, Areas covered by younger sedimentary and volcanic rocks. 4, Faults, many of which have large components of lateral displacement. 5, Edge of continental area. 
the coast at a slight angle. At Point Conception, however, the prominent 'Transverse Ranges run nearly eastward, facing the Channel Islands offshore in the longitude of Santa Barbara, and rimming the north side of the Los Angeles lowland farther east. South of the Transverse Ranges and the Los Angeles lowland the Peninsular Ranges resume a trend parallel with the coast, and form a more massive set of blocks, somewhat like the Sierra Nevada.

Dominant surface rocks of the Coast Ranges are mainly of Tertiary age, primarily fine- to coarse-grained clastic sedimentary strata, but with much diatomite and some volcanics. All of them, even the youngest, are folded and faulted, in part heavily so, indicating that the latest phase of the construction of the ranges was late in geologic time.

Basement Rocks. We have suggested earlier that at least the northern part of the Coast Ranges, west of the Sacramento Valley, was a marine realm through Jurassic and much of Cretaceous times - continental shelf, continental slope, and ocean deep-which received great masses of sediments washed off the Nevadan orogenic belt. The Coast Ranges might thus be an element which was built up and added to the continental plate from Mesozoic time onward.

A puzzling feature, incompatible with this concept, is the occurrence in parts of the Coast Ranges of a crystalline basement consisting of granitic rocks, shown by radiometric determinations to be of mid-Mesozoic age like those in the Nevadan orogenic belt, and their host rocks of earlier schists, slates, and marbles. In one area, the San Gabriel Mountains north of Los Angeles, radiometric determinations prove the existence of rocks as early as pre-Cambrian, but these probably do not emerge elsewhere.

Disregarding the cover of Tertiary rocks, the fundamental framework of the Coast Ranges is an alternation of these areas of crystalline Nevadan basement with a basement of much deformed but little metamorphosed Mesozoic rocks, especially the Franciscan group which may have been formed on the western, or oceanic side of the Nevadan belt.

Basement of Franciscan age underlies all the Coast Ranges north of San Francisco Bay and extends thence southward along the west side of the San Joaquin Valley (Fig. 10). Southwest of this northern Franciscan area is a long strip of Nevadan basement, termed Salinia, which extends southward from Point Reyes and the Farallon Is- 
lands near San Francisco, along Salinas Valley (for which it is named) to the Transverse Ranges. Another area of Franciscan basement, the central Franciscan area, lies west of Salinia (Reed and Hollister, 1936, pp. 1547-1550). The Transverse Ranges again are largely floored by Nevadan basement, as are the Peninsular Ranges, but another, the southern, Franciscan area lies to the south and west, mostly beneath the sea, and continues far southward along the Pacific side of Baja California.

'The Nevadan basement has been supposed to be the foundation of the Coast Ranges and to underlie the Franciscan rocks; remarkably enough, however, the base of the Franciscan has never been discovered, and all its contacts with the Nevadan rocks are highangle, through-going faults. For example, the contact between the Nevadan mass of Salinia and the Franciscan rocks on the northeast is the San Andreas and associated faults. There is thus no evidence of the sort of crustal material on which the Franciscan rocks were laid; it might have been quite different from the Nevadan basement.

San Andreas and Other Through-Going Faults. The high-angle, through-going faults thus seem to be a critical feature of Coast Range structure, and many of these faults are remarkable enough of themselves. Instead of their sides merely moving upward or downward, one side shifted laterally past the other, and the faults have a large component of sideward movement. For example, along the San Andreas fault, which has been traced the farthest of any, stream courses and stream valleys are off set-a stream draining northeast across the fault turns along the fault line, then resumes its northeastward course a half a mile or so to the southeast. This faulting has thus altered the geography and surface forms, not merely by raising and lowering blocks of the crust, but by shifting the geographic positions of large sections of the country relative to country on opposite sides; the saying is apt that "San Francisco and Los Angeles are coming closer together," the one city being northeast of and the other southwest of the fault.

Offset of stream valleys is an obvious late feature, but study of the rocks on the two sides of such faults discloses older and much greater anomalies. Gravels in 'Tertiary rocks on one side of a fault may contain material whose only possible source is in some area many miles away on the opposite side, suggesting that the source area has moved away from the gravels in the time since they were 
deposited. Such stratigraphic evidence indicates a sideward shift on the San Andreas and some of the other faults of 30 miles or more since the mid-Tertiary (Crowell, 1952, pp. 2030-2035; Noble, 1954, pp. 44-47). Even greater shifts are suggested when comparisons are made between basement rocks on the opposite sicles, but they are as yet difficult to prove and require further detailed research (Fig. 11).

There is thus a suggestion that the San Andreas fault has been moving progressively for a long period-at least since the close of the

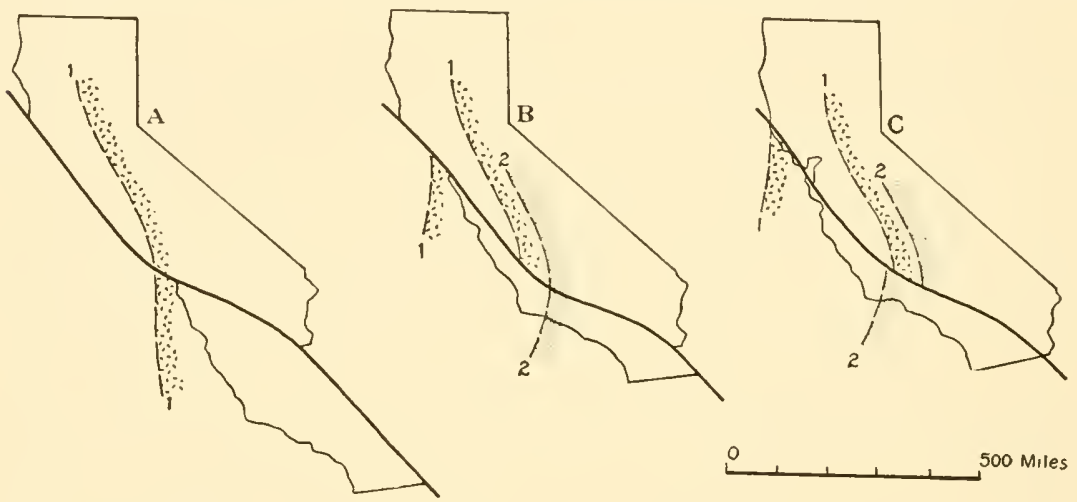

Fig. 11. Maps of California during successive periods to illustrate an hypothesis of extensive lateral displacement on the San Andreas and related faults. A, In late Mesozoic time. B, In late Miocene time. C, Present time. (Modified from M. L. Hill, 1954.) 1, Boundary between Nevadan basement (to east) and Franciscan basement (to west). 2, Boundary between Miocene continental sediments (to east) and marine sediments (to west).

Nevadan orogeny - so that rocks of each older age have been shifted by greater amounts (Hill and Dibblee, 1953, pp. 445-451). This picture, if valid, is greatly complicated by the fact that the San Andreas, or master fault, is only one of many in the same region with similar habit; attempts at reconstruction of the geography at successive periods thus involve, not a single break, but many breaks with diverse movements.

Be that as it may, the possibility has thus suggested itself that the anomalous strips of Nevadan basement are slivers that were faulted off the orogenic belt on the east, and have been transported scores or hundreds of miles northwestward, into an environment foreign to them (Fig. 11). Such movements are strongly indicated in 
southern California, where shifts of as much as 30 miles on the San Andreas fault since the micl-Tertiary have been proved, and where even greater shifts are suggested in the earlier rocks. Farther north, however, total movements of less than a mile on the San Andreas fault have been claimed (Taliaferro, 1943, pp. 159-161). Such claims seem to be based merely on the latest of a series of breaks, and fail to consider total offset in a broader San Andreas fault zone (Wallace, 1949 , p. 803). Nevertheless, it is puzzling in this northern area that there is so little offset of the coast where the San Andreas fault goes out to sea south of San Francisco, and no detectable offset of the edge of the continental shelf farther offshore to the northwest. An offset of the continental shelf of more than 50 miles occurs west of Cape Mendocino, but along an east-west fracture system, aligned differently from the San Andreas trend (Menard and Dietz, 1952, p. 273) (Fig. 10).

Although we now appear to have acquired the rudiments of an explanation for the anomalies of the Coast Ranges, this explanation is still obscured by negations and contrary evidence. At this stage, almost any explanation for a set of anomalies in the Coast Ranges creates other, unexplainable anomalies.

Tertiary Environments. Regardless of the anomalies in the basement rocks and the possible shifts of large segments of the area along through-going faults, the different types of basement have exerted a profound influence on the structures of the Tertiary rocks. Areas underlaid by Nevadan and Franciscan basement have been land or sea at different times and, when compressive forces were exerted, the areas underlaid by the weaker Franciscan basement have been much more deformed than those underlaid by the stronger Nevadan basement.

Such compression was exerted at many different times during the Tertiary. Some areas show a record of almost continuous deformation through long spans of Tertiary time, and the sedimentary sequences frequently contain so many unconformities that it is difficult to generalize any orogenic climaxes (Gilluly, 1949, pp. 567569). Nevertheless, two principal climaxes seem to have occurred, one near the middle of the Miocene, the other early in the Pleistocene (Reed and Hollister, 1936, pp. 1551-1597). It is interesting to note that these climaxes of deformation are of about the same age as those which have been inferred in the Great Basin area. Effects of 
the early Pleistocene orogenic climax are especially striking in the Ventura and Los Angeles basins of southern California, where thick masses of Pliocene and lower Pleistocene marine and land-laid strata are steeply upended, and are overlaid by nearly undisturbed later Pleistocene deposits. This has been termed the Pasadenan orogeny (Stille, 1936, pp. 867-870).

The influence on the surface features of the varied faulting and folding during different times since the beginning of the Tertiary have been portrayed in many sets of paleogeographic maps prepared by different geologists. The earlier, or mid-Miocene, deformation shaped the ridges and troughs of the Coast Ranges into about their present configuration, but left wide tracts of lower country still submerged; the later, or early Pleistocene, deformation produced widespread emergence. During times of greatest submergence, the Coast Range area probably resembled the present offshore region of southern California, with shallow shelves, interspersed with much deeper troughs, and linear islands that resembled the present Channel Islands. During times of greatest emergence, the Coast Range area probably resembled the present topography around San Francisco Bay, with mountain ridges and intervening troughs or valleys, in which land-laid sediments were being deposited, and whose lowest parts, like the present bay, were covered by shallow, ramifying seas.

\section{SUMMARY}

Western North America is the region of the Cordilleran system of mountain ranges, which extend inland from the Pacific Coast 400 to 1,000 miles to the Great Plains of the continental interior. The landscape of the region has been shaped by surface processes of erosion, sedimentation, and volcanism, but ultimate cause of the features is deeper in the crust, in processes that have deformed the rocks, brought about emplacement of magmas, and raised or lowered large sections of the surface. These processes, though spasmodic, are persistent through history. In considering the growth of a mountain system such as the Cordillera, they may be generalized in to a geosynclinal phase, an orogenic phase, and a post-orogenic phase.

The geosynclinal phase was a time of sedimentation and rather mild crustal activity. In the Cordilleran region it persisted through Paleozoic time and through the first half of Mesozoic time.

The orogenic phase began earliest in the western part of the 
Corlillera, broadly in mid-Mesozoic time-in places in the Jurassic, elsewhere somewhat later. Rocks formed in this part of the geosyncline were deformed, metamorphosed, and invaded by large bodies of magma. The deformed rocks were raised into a land surface, from which detritus was shed westward in to the Pacific Ocean basin, and eastward as a broad sheet into the interior of the continent, across the remainder of the geosyncline.

During Cretaceous time, deformation progressed eastward from the initial disturbed belt, folding and faulting the rocks of the Great Basin area, more lightly affecting those on the site of the Colorado Plateau, and more heavily affecting those in the Rocky Mountains beyond. In the southern part of the Rocky Mountains, zones of weakness had already been created by mountain-making during Paleozoic time. By the close of the orogenic phase, in Late Cretaceous and Paleocene times, deformation had reached the edge of the present Great Plains, but it progressed no farther inland.

The folding and faulting of the orogenic phase did not produce the modern topography. While the surface was raised and lowered by it, leveling processes of erosion and sedimentation were active and prevented development of strong relief; moreover, regional altitudes remained low.

Modern surface features evolved by a multitude of crustal processes during the post-orogenic phase, in Tertiary and Quarternary times. Intermontane basins subsided (as in IVyoming and Colorado), large areas were broken up by block faulting (as in the Great Basin), other large areas were overspread by lava (as in the Columbia Plateau), and mountains were formed by the building of chains of volcanoes (as in the Cascade Range). Besides, extensive regions were uplifted relative to their surroundings, with little internal deformation. The largest uplifted region centered in the Rocky Mountains and extended into the Great Plains and Colorado Plateau; it was raised mainly before later Tertiary time, but with diminishing uplifts into the Pleistocene. Smaller, more complex uplifts took place somewhat later in the Sierra Nevada and Cascade Range; in the Sierra Nevada, uplift was accompanied by marked faulting along the eastern side.

The post-orogenic (Tertiary and Quaternary) movements raised the Cordilleran region to its present generally high altitude. Streams, quickened by the uplift and by increased rainfall during the Pleisto- 
cene, etched out the mountains and canyons; mountain barriers prevented free circulation of moisture-laden winds from the Pacific and heightened the climatic contrasts. Since mid-Tertiary time, regional relief, local relief, and climatic contrasts have been greater in the Cordillera than at any earlier period.

Throughout geologic time, the Cordilleran system has been bordered on the west by the deep Pacific Ocean basin, floored by crustal material different from that of the continent. It is unlikely that any additional lands ever existed offshore that have since foundered to oceanic depths. More likely, continental area has been added at the expense of ocean basin by various accretionary processes. On the other hand, land connections persisted intermittently along the strike of the Cordilleran system, between North America, Asia, and South America, as the coastal areas of all three are part of a circum-Pacific belt of mountain structures whose origin, like the North American Cordillera, extends far back into the geologic past.

\section{Acknowledgments}

This paper was compiled largely from existing publications, but its context has been shaped to a considerable degree by the climate of thought and opinion of the writer's many geological friends and colleagues, in California and elsewhere in the west. Their observations and ideas, too numerous to recall and mention separately, have given the writer many insights in to the interpretation of the printed record.

In particular, one or more of the versions of the paper have been read by C. R. Longwell and G. D. Robinson of the U. S. Geological Survey, J. H. Mackin of the University of Washington, and A. O. Woodford of Pomona College. Also, C. A. Repenning of the U. S. Geological Survey has furnished helpful information on the history of the Colorado River from his unpublished work. Their generous help and their thoughtful criticisms are gratefully acknowledged, and have been carefully considered in preparing final revisions.

Nevertheless, decisions as to the context of the paper are those of the writer, and he assumes all responsibility for the views herein expressed, whether right or wrong. As one critic remarked, no two geologists would summarize this complex and diverse subject in the same manner, either in the subjects selected for coverage or in the interpretations which are made of them. The perfect story of the evolution of the surface features of western North America is yet to be written. The present paper is an interim report which it is hoped will stimulate further thought, especially in that fascinating no-man's land which lies between the geological and the biological sciences. 


\section{REFERENCES}

A complete list of references for a general review of this kind woulc1 include nearly all the publications on western geology. Some sort of selection is thus obviously necessary. Although I have not been entirely consistent, I have, for the most part, restricted my documentation to papers published in the last decade or two, and especially to papers presenting novel or controversial matters. Well-known or long-established facts of western geology are for the most part not documented. For these, the reader can profitably consult various general works and compilations, including those listed.

\section{General References}

Dunbar, C. O. 1949. Historical Geology. John Wiley and Sons, New York. Eardley, A. J. 1951. Structural Geology of North America. Harper and Brothers, New York.

Fenneman, N. M. 1931. Physiography of Western United States. McGrawHill Book Co., New York.

\section{Special References}

Allen, V. T. 1929. The Ione formation of California: Calif. Univ. Dept. Geol. Sci. Bull., 18: 347-448.

Anderson, F. M. 1938. Lower Cretaceous deposits in California and Oregon. Geol. Soc. Am. Special Paper 16.

Atwood, W. W., and W. IV. Atwood, Jr. 1938. Working hypothesis for the physiographic history of the Rocky Mountain region: Bull. Geol. Soc. Am. 49: 957-980.

Axelrod, D. I. 1957. Late Tertiary floras and the Sierra Nevada uplift. Bull. Geol. Soc. Am., 6s: 19-45.

Baker, A. A., C. H. Dane, and J. B. Reeside, Jr. 1936. Correlation of the Jurassic formations of parts of Utah, Arizona, New Mexico, and Colorado. U. S. Geol. Survey Prof. Paper 183.

Bradley, W. H. 1936. Geomorphology of the north flank of the Uinta Mountains. U. S. Geol. Survey Prof. Paper 185-I, pp. 163-204.

- . 1948. Limnology and the Eocene lakes of the Rocky Mountain region. Bull. Geol. Soc. Am., 59: 635-648.

Bryan, Kirk. 1938. Geology and ground-water conditions of the Rio Grande depression in Colorado and New Mexico. Natl. Res. Comm., Regional Plan., Pt. 6, Upper Rio Grande, pp. 197-225.

Burbank, W. S., and T. S. Lovering. 1933. Relation of stratigraphy, structure, and igneous activity to ore deposition of Colorado and southern Wyoming, in Ore Deposits of Western States (Lindgren volume). Am. Inst. Min. Metall. Eng., pp. 272-316.

Chaney, R. W. 1938. Paleoecological interpretations of Cenozoic plants in western North America. Bot. Rev., 9: pp. 371-396. 
Crowell, J. C. 1952. Probable large lateral displacement on San Gabriel Fault, southern California. Bull. Am. Assoc. Petrol. Geologists, 36: 2026-2035.

Davis, W. M. 1925. The Basin Range problem. Proc. Natl. Acad. Sci., 11: 387-392.

Eardley, A. J. 1947. Paleozoic Cordilleran geosyncline and related orogeny. J. Geol., 55: 309-342.

Evernden, J. F., G. C. Curtis, and J. I. Lipson. 1957. Potassium-argon dating of igneous rocks. Bull. Am. Assoc. Petrol. Geologists, 41: 2120-2127.

Ewing, J. L., C. B. Officer, H. R. Johnson, and R. S. Edwards. 1957. Geophysical investigations in the eastern Caribbean; Trinidad shelf, Tobago trench, Barbados ridge, Atlantic Ocean. Bull. Geol. Soc. Am., 65: 719-732.

Ewing, Maurice, and Frank Press. 1955. Geophysical contrasts between continents and ocean basins. Geol. Soc. Am. Special Paper 62, pp. 1-6.

Ferguson, H. G., and S. W. Muller. 1949. Structural geology of the Hawthorne and Tonopah quadrangles, Nevada. U. S. Geol. Survey Prof. Paper 216.

Gilluly, James. 1949. Distribution of mountain building in geologic time. Bull. Geol. Soc. Am., 60: 561-590.

Hill, M. L. 1954. Tectonics of faulting in southern California, in Geology of Southern California, California Div. Mines Bull. 170, Chap. 4, pp. 5-13.

Hill, M. L., and T. W. Dibblee, Jr. 1953. San Andreas, Garlock, and Big Pine faults, California. Bull. Geol. Soc. Am., 64: 443-458.

Hodge, E. T. 1938. Geology of the lower Columbia River. Bull. Geol. Soc. Am., 49: 831-930. (Review by J. H. Mackin, J. Geomorphology, 3: 70-35.)

Howard, A. D. 1958. Drainage evolution in northeastern Montana and northwestern North Dakota. Bull. Geol. Soc. Am., 69: 575-588.

Hubbs, C. L., and R. R. Miller. 1948. The Great Basin, with emphasis on glacial and post-glacial times. II. The zoological evidence: correlation between fish distribution and hydrographic history in the desert basins of western United States. Utah Univ. Bull., 38: 17-166.

Hunt, C. B. 1956. Cenozoic geology of the Colorado Plateau. U. S. Geol. Survey Prof. Paper 279.

Irwin, P. L. 1957. The Franciscan group in the Coast Ranges and its equivalents in the Sacramento Valley of California. Bull. Am. Assoc. Petrol. Geologists., 41: 2284-2297.

Johnson, W. D. 1901. The High Plains and their utilization. U. S. Geol. Survey 21st Ann. Rept., Pt. 4, pp. 601-741.

Kay, Marshall. 1947. Geosynclinal nomenclature and the craton. Bull. Am. Assoc. Petrol. Geologists, 31: 1289-1293.

King, P. B. 1935. Outline of structural development of trans-Pecos Texas. Bull. Am. Assoc. Petrol. Geologists, 19: 221-261. 
Larsen, E. S., Jr., and Whitman Cross. 1956. Geology and petrology of the San Juan region, southwestern Colorado. U. S. Geol. Survey Prof. Paper 258. 303 pp.

Lee, W. T. 1907. Water resources of the Rio Grande Valley in New Mexico. U. S. Geol. Survey Water-Supply Paper 188.

Longwell, C. R. 1946. How old is the Colorado River? Am. J. Sci, 244: $817-835$.

1950. Tectonic theory viewed from the Basin Ranges. Bull. Geol. Soc. Am., 61: 413-434.

Louderback, G. D. 1904. Basin range structure of the Humboldt region. Bull. Geol. Soc. Am. 15: 289-346.

Mackin, J. H. 1937. Erosional history of the Bighorn basin, Wyoming. Bull. Geol. Soc. Am., 48: p. 813-894.

- 1947. Altitude and local relief of the Bighorn area during the Cenozoic, in Field Conference in Bighorn Basin, Guidebook. Wyoming Univ., Wyoming Geol. Assoc., and Yellowstone-Bighorn Research Assoc., pp. 103-120.

McKee, E. D., S. S. Oriel, V. IV. Swanson, M. E. MacLachlan, J. C. MacLachlan, K. B. Ketner, J. W. Goldsmith, R. Y. Bell, and D. J. Jameson. 1956. Paleotectonic maps of Jurassic system. U. S. Geol. Survey Misc. Geol. Inv., map I-175.

Menard, H. W., and R.S. Dietz. 1952. Mendocino submarine escarpment. J. Geol., 60: 266-278.

Noble, L. F. 1954. The San Andreas fault zone from Soledad Pass to Cajon Pass, California, in Geology of Southern California, Chap. 4 (Structural features). California Div. Mines Bull. 170, pp. 37-48.

Nolan, T. B. 1943. The Basin and Range province in Utah, Nevada, and California. U. S. Geol. Survey Prof. Paper 197-D, pp. 141-196.

Powell, J. W. 1876. Report on the geology of the eastern portion of the Uinta Mountains and a region of country adjacent thereto. U. S. Geol. Geog. Survey of the Territories. 218 pp.

Reed, R. D., and J. S. Hollister. 1936. Structural evolution of southern California. Bull. Am. Assoc. Petrol. Geologists, 20: 1533-1704.

Repenning, C. A., and J. H. Irwin. 1954. Bidahochi formation of Arizona and New Mexico. Bull. Am. Assoc. Petrol. Geologists, 38: 1821-1826.

Repenning, C. A., J. F. Lance, and C. R. Longwell. A history of the Colorado River. Bull. Geol. Soc. Am., in press.

Roberts, R. J., P. E. Hotz, James Gilluly, and H. G. Ferguson. Paleozoic rocks of north-central Nevada. Bull. Am. Assoc. Petrol. Geologists, in press.

Rouse, J. T. 1937. Genesis and structural relationships of the Absaroka volcanic rocks, Wyoming. Bull. Geol. Soc. Am., 48: 1257-1296.

Spieker, E. M. 1949. Sedimentary facies and associated diastrophism in the Upper Cretaceous of central and eastern Utah, in Sedimentary Facies in Geologic History. Geol. Soc. Am. Mem. 39, pp. 55-82.

Stille, Hans. 1936. Present tectonic state of the earth. Bull. Am. Assoc. Petrol. Geologists, 20: 849-880. 
Taliaferro, N. L. 1942. Geologic history and correlation of the Jurassic of southwestern Oregon and California: Bull. Geol. Soc. Am., 53: 71-112.

1943. Geologic history and structure of the central Coast Ranges in California, in Geologic Formations and Economic Development of the Oil and Gas Fields of California. California Div. Mines Bull. 118: 119-163.

Van Houten, F. B. 1948. Origin of red-banded early Cenozoic deposits in Rocky Mountain region. Bull. Am. Assoc. Petrol. Geologists, 32: 2083-2126.

- 1956. Reconnaissance of Cenozoic sedimentary rocks of Nevada. Bull. Am. Assoc. Petrol. Geologists, 40: 2801-2825.

—. 1957. Appraisal of Ridgeway and Gunnison "tillites," southwestern Colorado. Bull. Geol. Soc. Am., 68: 383-388.

Wallace, R. E. 1949. Structure of a portion of the San Andreas rift in southern California. Bull. Geol. Soc. Am., 60: 781-806.

Waters, A. C., 1955a. Volcanic rocks and the tectonic cycle. Geol. Soc. America Special Paper 62, pp. 703-722. - 1955b. Geomorphology of south-central Washington, illustrated by the Yakima East quadrangle. Bull. Geol. Soc. America, 66: 663684.

Woodford, A. O., and T. F. Harriss. 1938. Geological reconnaissance across Sierra San Pedro Martir, Baja California. Bull. Geol. Soc. Am., 49: $1297-1336$.

Woodring, W. P. 1954. Caribbean land and sea through the ages. Bull. Geol. Soc. Am., 65: 719-732. 


\section{Climate Since the}

\section{Late Cretaceous}

H. D. MacGinitie

Iumboldt State College, Arcata, California

$\mathrm{P}_{\text {ast climates and their changes comprise one }}$ of the most fascinating subjects in science, since climates have so profoundly affected the evolution and distribution of life on the surface of the earth. Of one conclusion we can be sure: as we turn back the pages into the past, we see that world climates were greatly different from those of today. In order to appreciate just how different, we have to clear the cobwebs of the present entirely out of our minds. Some time ago when I was discussing with a wellknown western botanist the fossils of Metasequoia and its associates found in the far north-the McKenzie basin, Greenland, the Arctic Islands, and Alaska-I was astonished at his remark, "Why, how could they grow there in all that ice and snow?" His thinking was tied to present conditions. Another conclusion we can be sure of, in thinking about past climates, is that the conditions of the Recent and Pleistocene have been most unusual in the history of the world. Our present combination of widely emergent and elevated continents, lofty mountain ranges, and polar glaciation has probably existed (with recurrences in the past) for less than one-fiftieth of geologic time.

As an illustration of the misconceptions that can result from picturing the past too closely in terms of the present, here is a brief quotation from a discussion of fossil arctic floras in a paper on the evolution of plant associations (Mason, 1947, p. 206):

An earth, tilted on its axis relative to the plane of its orbit, will inevitably be characterized by a darkened polar area that will alternate seasonally with a lighted condition. The duration of the darkness will vary to some extent with position but will range from a few days of total darkness to almost six months of total darkness. By total darkness I mean the 
absence of insolation capable of being converted into heat energy and of light of sufficient value for use in photosynthesis. The area so involved will be a disc approximately 3,000 miles in diameter. Receiving no insolation, such an area would soon dissipate any residual heat in its soil and rock surfaces. There would result extended and bitter arctic cold throughout the darkened area that would affect winter temperatures for considerable distances into subarctic areas.

If we assume now that the poles have been stationary as most astronomers insist that they have, and if we assume that the continents and ocean basins have been perpetuated in their present places through geological time as many geologists insist that they have, we must conclude that no tropical, warm temperate, or even temperate forest flora could possibly live and develop in high arctic latitudes. It would be too cold on the one hand and too dark on the other hand.

Such statements neglect entirely changes in world climates, the effects of past oceanic temperatures, and the effects of oceanic and atmospheric circulation.

In order to arrive at a background for understanding later climatic changes, we may turn now briefly to the world climate of the late Cretaceous and early Tertiary. In the Upper Cretaceous the continents appear to have been smaller and more occupied by epicontinental seas than at any time since the Ordovician (Zeuner, 1945 , p. 164). The continents were comparatively featureless and rather uniformly of low elevation. North America was divided into two subcontinents by a great inland sea extending from the Gulf of Mexico to the McKenzie Delta, with an east-west breadth of about $12^{\circ}$ of longitude. If we could transport ourselves back to the world of the Upper Cretaceous, it would be like taking a flight to another planet, so different would conditions seem. Just how different we may never be able fully to know or appreciate. Tropical to subtropical floras occupied most of the southern two-thirds of the United States. When we investigate the late Cretaceous floras of the far north we find an astonishing circumstance in terms of present conditions. All around the North Pole, north of latitude $55^{\circ}$, we find fossil floras dominated by temperate deciduous trees. Some of the more significant localities of such floras are in western Greenland at about $75^{\circ} \mathrm{N}$. Lat., in Spitzbergen at about $78^{\circ} \mathrm{N}$., and in the area of the present Yukon Valley in Alaska at about $65^{\circ} \mathrm{N}$. It has been shown that these northern Cretaceous floras were zoned about the North Pole just as floras are today farther south. In his work on the late Cretaceous floras of the Rocky Mountain region, Dorf 
(1942, pp. 100-103) has shown a definite change from subtropical to warm-temperate floras between southern Colorado and Montana. It appears clearly established that the area between the temperate northern forests and the tropical forests at the southern border of the United States was occupied by an ecotone characterized by a gradual transition from the one type to the other. In considering the "problem" of the northern floras (which is really no problem at all) we have to remind ourselves again of conditions in the past. All the evidence points to the fact that the seas were much warmer than at present. As an example of this kind of evidence the attention of the reader is called to a paper on Cenozoic marine climates of the Pacific Coast by Durham (1950), who based his conclusions on an intensive study of fossil reef-building corals and the associated invertebrate faunas. His fundamental postulate was that living reef corals cannot endure a minimum temperature much below $18^{\circ} \mathrm{C}$. for any length of time. Thus, he took the figure of $18^{\circ} \mathrm{C}$ for the coldest month (February) as the limiting isotherm beyond which reefbuilding corals cannot exist. According to the fossil corals of the IVest Coast, the February isotherm of $18^{\circ} \mathrm{C}$ must have been located at about $53^{\circ} \mathrm{N}$. Lat. in the late Cretaceous. That is approximately 1,500 miles north of its present location on the coast of Lower California. It is difficult to appreciate the full significance of such a difference in ocean temperatures from that of the present.

Today a large proportion of the ocean is close to the freezing temperature. Polar waters are denser than equatorial owing to the low temperatures; cold water settles in the polar regions and slowly creeps along the sea floor to rise to tropical and equatorial regions where it is warmed. Warm water from within the tropics moves north at the surface to complete the thermal circulation. The layer of warm water is comparatively shallow on account of the slow upwelling of cold water from below. Thus, "the temperature of abyssal waters in the open ocean basins is conditioned by the temperature of surface waters in the polar regions" (Emiliani, 1954, p. 854). Even in equatorial regions the abyssal waters are close to the polar waters in temperature. All the evidence that we now possess indicates that this type of circulation existed throughout the Tertiary. Emiliani (1958, pp. 57-58), from his tudy of a deep-sea core, has indicated that the abyssal temperatures in the equatorial Pacific in the Middle Oligocene were about $10^{\circ} \mathrm{C}$, which implies a 
similar mean temperature for the polar seas. Brooks $(1951$, p. 1005) independently arrived at the same figure for polar oceanic temperatures in the Middle Tertiary.

When warm surface water extends far to the north, atmospheric and oceanic circulation must profoundly modify polar climates. Any permanent ice caps would be impossible under such conditions, although winter snows north of the Arctic Circle would be probable. "Extended and bitter arctic cold" around the poles would not be possible with the indicated ocean temperatures of the Upper Cretaceous and Lower Tertiary. The polar forests of those times were deciduous, and it is a reasonable assumption that the deciduous habit, at least in part, arose in response to photoperiodicity, as an adaptation to the long period of winter darkness in polar regions, rather than as an adaptation to thermoperiodicity.

If we turn to the Lower Tertiary, there is again abundant evidence for the existence of a temperate deciduous forest occupying a zone around the Pole. Several well-known localities are well within the Arctic Circle. According to the best evidence available, these ArctoTertiary Geo-floras, as they have been called (Chaney, 1947, pp. 144-146), range in age from Paleocene to Middle Eocene. Some notable localities (Seward, 1933, pp. 408, 478-479) are in eastern Greenland $\left(70^{\circ}-75^{\circ} \mathrm{N}\right.$. Lat.), Spitzbergen $\left(78^{\circ} \mathrm{N}.\right)$, Elsmereland and Grinnell Land (to $83^{\circ} \mathrm{N}$.), the McKenzie River Delta $\left(64^{\circ} \mathrm{N}\right.$.), and the New Siberian Islands $\left(75^{\circ} \mathrm{N}\right.$.). Farther south, to latitude $55^{\circ}$ $\mathrm{N}$. in the central part of the continents, are many more fossil localities of this northern, summer-green forest. Among the characteristic trees are the dawn redwood, ginkgo, sycamore, alder, oak, chestnut, poplar, hazelnut, and many close relatives of trees now growing in the deciduous forests of the Appalachians and eastern China. It was, in no sense, a cold-temperate flora. The species would find a congenial habitat at present in the mountains of western North Carolina at moderate elevations.

In the early Tertiary as well as in the Cretaceous there was a zonal distribution of forests around the Pole that points clearly to the fact that the Pole was in the same place as it is today (Chaney, 1940). There was a gradual transition from the tropical floras of the Gulf states to the warm-temperate floras of Yellowstone Park and southern Canada and thence to the temperate deciduous floras of the far north. We can now amend the quotation given at the begin- 
ning, and say that no tropical, warm-temperate, or even cooltemperate, forest flora could possibly live and develop in high arctic latitudes under present conditions. However, the conditions of the early Tertiary at high latitudes were vastly different from those of today. Durham (1950, pp. 1253-1254) concluded that during the Eocene, the $18^{\circ} \mathrm{C}$ isotherm was at latitude $53^{\circ}$ to $55^{\circ} \mathrm{N}$., even farther north than it was in the late Cretaceous. The fossil floras also indicate that the temperatures of the Lower Tertiary may have been higher than those in the late Cretaceous, since we have subtropical floras, such as that at Raton, New Mexico (Knowlton, 1917, pp. 239-240), growing at moderate elevations, and this in spite of a generally emergent continent and mountain building in the Cordilleran region. The great inland seaway of the Upper Cretaceous was drained at the close of that period. Intermittent mountain building occurred throughout the area of the western Cordillera. The western mountains of the carly Tertiary, with a few possible exceptions, were of moderate elevation and did not seem to pose an insurmountable barrier to plant and animal dispersals, and the general elevation of the continent was still comparatively low during the Lower Tertiary. There seems to have been none of those great continental upwarps that characterize the present Cordilleran region.

By the beginning of the Middle Eocene there were at least three botanical provinces in western North America (MacGinitie, 1941, pp. 92-95). In the far-western states a subtropical forest extended along the coast as far north as latitude $55^{\circ} \mathrm{N}$., and, with some modifications, inland at least as far as the present area of northwestern IVyoming. The Eocene flora of Kupreanoff Island in southeastern Alaska, at Chalk Bluffs on the west slope of the Sierra, and at Yellowstone Park have many characteristic plants in common. The low-lying shores of the Mississippi embayment were occupied by a warmer, practically tropical flora of quite different composition. Far to the north were the summer-green Arcto-Tertiary forests.

Two Eocene floras are particularly significant with respect to climatic trends: (1) the flora of the London Clay at latitude $52^{\circ} \mathrm{N}$. is of Lower Eocene age and is a tropical strand flora - not warmtemperate, but tropical (Reid and Chandler, 1933, pp. 47-74); (2) the Green River flora of Middle Eocene age, found at many localities in northwestern Colorado and southern Wyoming, shows the 
beginnings of climatic trends that were later accelerated. The flora represented by the fossil leaves and fruits was a streamside and lakeside flora of warm-temperate or subtropical aspect. The abundance of small and coriaceous leaves and leaflets shows that the vegetation on the open divides and higher ground around the lake basins was somewhat like our modern subtropical scrub (Chaney, 1944). The pollen flora of the Green River gives us a picture of temperate forests, with oaks and conifers, occupying the surrounding uplands. Subhumid or even arid local conditions are indicated by pollen of the desert shrub Ephedra. IVe also find in the Green River flora a few representatives of the Arcto-Tertiary flora, the vanguard of a dispersal, down the moderate elevations of the Rocky Mountain axis, that was later to result in a complete replacement of the Lower Tertiary forests. The negative evidence of the Green River flora is significant. There is no pollen of grasses or other herbs except that of a few primitive aquatic forms. There is no pollen of the sunflower family or sagebrush or greasewood and the like. The modern herbaceous vegetation or desert shrub vegetation evidently did not exist in that area during the Middle Eocene (Wodehouse, 1933, pp. 518-522).

A general view of the Eocene forests of the United States shows us essentially tropical floras along the Gulf Coast, slowly merging into warm-temperate floras at the north. There appears to have been a slow shift to the north of these warmer floras, culminating in the late Eocene (Chaney, 1947, p. 143). The most tropical Tertiary flora of the IVest Coast is at Goshen, Oregon. All the Upper Eocene floras at Comstock, Oregon, at Steel's Crossing, Washington, and at LaPorte, California, have a definitely tropical aspect.

When the time boundary between the latest Eocene and the Lower Oligocene is crossed, we find a marked climatic change, and we can look down the vista of cooling and drying climates that finally culminated in the glaciation of the Pleistocene. There was an irregular, but, in the long run, a continuous change over the whole world toward cooler and also, in general, drier climates. This trend is clearly shown by the many fossil floras of the Upper Tertiary that are scattered over the western states, from the high plains to the Pacific Coast, and by the fossil floras of Europe and Asia. In a recent study of fossil pollen from localities in southwestern Russia, Bogelepov (1955, p. 988) has shown the same sequence of forest 
types and climates from Oligocene to Pleistocene as we can trace in the western states. This slow but inexorable climatic change (MacDonald, 1953) profoundly affected the evolution of vegetation types and their associated faunas. The Middle and Upper Oligocene mark the influx from the north of Arcto-Tertiary species over the western states. The trend toward cooler climates brought about the southward dispersal of a host of temperate-forest trees and the beginnings of the modern vertebrate faunas. By the Upper Oligocene we find much of the earlier tropical or subtropical elements of the floras displaced by northern forms whose ancestors were members of the Eocene Arcto-Tertiary forests. A striking aspect of the Upper Oligocene floras of the western states is the large number of species related to those now living in the forests of eastern Asia. This Asiatic aspect is one of the characteristic features of the western Oligocene floras and is due, of course, to the fact that the ArctoTertiary complex, as it dispersed southward, came down in to both eastern Asia and the western part of North America. Dozens of common species in the western fossil floras have their living counterparts in the forests of eastern China (Chaney, 1947, p. 145). Among the common genera are Acer, Ailanthus, Castanopsis, Celastrus, Dipteronia, Exbucklandia, Glyptostrobus, IIolmskioldia, Metasequoia, Koelreuteria, Paliurus, Pterocarya, Quercus (Asiatic types), and Zelkova. The widespread Bridge Creek flora of late Oligocene age occupied a large area from northern California into British Columbia and eastward to Montana and Colorado. It is characterized by an abundance of Metasequoia and Asiatic oaks. The Florissant flora of Lower Oligocene age, in central Colorado, is extraordinarily rich in warm-temperate species. It comprises many forms derived from the earlier Green River flora, together with representatives of the flora moving down from the north.

It is a curious fact that practically none of the western Oligocene species having living relatives in eastern Asia was able to get into Mexico or into the Appalachian region. A climatic barrier that prevented migration either southward or eastward arose in the Eocene and was well established in the Oligocene. The evidence seems clear that this barrier was one of reduced rainfall. There is good evidence, obtained from a study of the Green River and Florissant floras (MacGinitie, 1953, pp. 52, 58), that an area of subhumid scrub extended across northern Mexico and northward 
across the United States in the region of the present high plains and the prairies. While the relationship of the Oligocene floras is markedly Asiatic, the early Eocene floras of the W'est Coast contained many species that are related to plants now living in the upland floras of Mexico and Central America. This indicates a rather free interchange of floristic elements north and south at that time.

The later Tertiary was characterized by repeated flurries of mountain growth, in the Cordilleran region and westward, which finally culminated in the great uplifts of the late Pliocene and the Pleistocene. This orogeny resulted in an increasing complexity of climatic barriers and in the local differentiation of faunas and floras. According to the coral faunas studied by Durham, the $18^{\circ}$ isotherm, by lower Miocene time, had moved down the West Coast to approximately the latitude of northern California. The climate of the western states in the Lower Miocene, though more genial than at present, shows none of the subtropical aspects of the earlier Tertiary (except along the coast at the south). The flora in Oregon and Washington and over the northern Great Basin was essentially a mixed deciduous-conifer forest of warm-temperate aspect, with many species of deciduous trees having modern counterparts in the Appalachian region and in eastern China. There is evidence of abundant summer rainfall over the area which at present has little or no summer rainfall. The climatic barrier to the south and in the plains area that was initiated in the Eocene effectively prevented the migration of forest species east-west and also north-south until well into the Miocene. There appears to have been little or no admixture of forest species between the Appalachians and the Rocky Mountains in the interval between the Lower Eocene and the Lower Miocene. The Upper Miocene floras of the Columbia Plateau area contain many species of oaks, elms, beeches, maples, and the like, that are closely related to living species in the eastern states, indicating a dispersal path between the two areas, probably through southern Canada. As the climate cooled in the Upper Tertiary, the vegetation of the region between the Mississippi and the Rocky Mountains, which was at first a subtropical scrub, was slowly replaced by the modern herbaceous prairie vegetation.

Evolution of the herbs was comparatively rapid after the close of the Oligocene. Pollen of the sunflower family (Compositae) first becomes noticeable in the deposits of the Middle Miocene and such 
pollen has not surely been found earlier than the Lower Miocene. It is probable that the components of the existing prairies had their beginnings about the Middle Miocene, although the prairies as such do not seem to have developed until well into the Pliocene (Elias, 1942; MacGinitie, 1953, p. 59). The climatic change (Chaney and Elias, 1936, pp. 25-34) that stimulated the growth of herbaceous vegetation had a profound, indirect effect on the evolution of the mammals, since abundant new supplies of nutritious food became available for herbivores. The fossil localities of the later Miocene and Pliocene offer striking evidence of the astonishing abundance of mammalian life on the Great Plains and westward.

By making comparisons between the present deciduous forest floras of eastern Asia and North America we can gain some idea of the herbs that came southward with the dispersal of the ArctoTertiary flora. Here we find closely similar or identical species of herbs on the two continents, and these are almost entirely broadleafed, perennial forms with heavy rootstocks. Hui-Lin Li (1952, pp. 385-405) has presented this evidence in his excellent paper on the related floras of Asia and America.

The numerous Upper Miocene and Lower Pliocene floras of the West have been studied by Axelrod $(1956,1957)$ and their climatic significance has been well set forth. He has recognized about a halfdozen climatic provinces-beginnings of the sharply demarked climatic provinces now found in the area, but by no means as clearly defined. He has also shown that the average temperatures were not much higher than those of today, but that the summer maximum temperatures were reduced and the winter minima considerably raised; in other words, there was a much more equable climate. The frost-free season in west-central Nevada was probably three or four months longer than at present. Axelrod has also emphasized the strong evidence for a shift in the pattern of seasonal distribution and kind of precipitation, from summer showers and winter rain to the present regime of dry summers and winter snows.

The late Miocene and early Pliocene floras from Nebraska to California still indicate comparatively mild conditions, with, on the whole, moderate rainfall. The presence of such trees as Cedrela (cedro) and Persea (avocado) in the latest Miocene suggests the absence of severe winters, but the majority of the species are essentially modern in aspect and are not greatly displaced north of 
their present habitats. The northern oceans were still warmer than at present. On the West Coast the $18^{\circ}$ isotherm had moved to latitude $35^{\circ} \mathrm{N}$, $5^{\circ}$ to $6^{\circ}$ north of the existing location. There is no clear evidence of permanent polar icecaps at this time. The composition of the fossil flora that the writer has been collecting near Valentine, Nebraska, at latitude $43^{\circ} \mathrm{N}$., the richest late Miocene (or lowest Pliocene) flora yet found in that area, indicates that the minimum temperatures were higher than at present and that the severe outbreaks of polar continental air that characterize the present winter climate had not yet reached their later intensity. It is surprising to find abundant Cedrela and Meliosma in a flora of Barstovian (late Miocene) age in northern Nebraska, surprising, because these genera are now confined to the tropics, although Meliosma grows at elevations of 6,000 feet in the mountains of southern Mexico. A majority of the species, however, would find a congenial habitat in southeastern Oklahoma, some $8^{\circ}$ or $9^{\circ}$ to the south.

Frye and Leonard (1957) have been able to reconstruct the sequence of late Tertiary climatic changes on the high plains by studying the lithologic characters of the beds and the types of fossil land snails found in them. The picture is one of steadily deteriorating climates with decreasing rainfall, increased seasonal temperature fluctuations, and lowered minimum temperatures. Conditions essentially the same as those of the present were reached by the Upper Pliocene. All except the hardiest and most drouth-resistant trees of the once rich western montane floras had become extinct. The seasonal distribution of rainfall, with the cooling of the bordering Pacific Ocean, had changed over the area west of the Rockies from adequate rainfall at all seasons to the present Mediterranean type with dry summers. Along the West Coast of the United States, and especially in California, only those plants capable of withstanding summer drouth were able to survive. Pollen studies show that the prairies had become well established by the Middle Pliocene.

One of the climatic consequences of low-lying continents and warm oceans are truly equable climates, with comparatively small seasonal temperature changes. In the modern world such climates are found at moderate elevations in the tropical mountains, such as the Tierra Templada of southern Mexico and Central America. The earlier floras show conclusively that the modern severe winters with their cold waves were nonexistent as late as the Upper Miocene. 
The cooling continued until, in the late Miocene or Lower Pliocene, winter snows may have occurred along the northern boundary of the United States, but the outbreaks of polar air so characteristic of the present winters appear to be a development of the late Pliocene. The world climatic changes of the late Tertiary were intensified and aggravated by the mountain building that reached its peak at the close of the period. One of the effects of the climatic changes that finally culminated in the Glacial period was an enlargement of the area of polar climates and a compression or shrinkage of the area occupied by temperate and tropical climates (Brooks, 1949, pp. 55-62). In the earlier Tertiary the area of warm-temperate and tropical climates was enlarged at the expense of the area occupied by polar climates, but this situation was gradually reversed in the later Tertiary (Craig and Willett, 1951, pp. 381-382). The zone of polar-front weather, marked by the succession of moving high- and low-pressure areas, was greatly intensified, and moved southward. In contrast, the polar front in pre-Miocene time must have been nonexistent during the summer and of weak development, far to the north, in the winter. During the Glacial stages the zone of maximum cyclonic activity was even farther south than at present. The southward movement of the polar front and the increased temperature gradients caused the Glacial periods to be rainy or pluvial periods in the zone just south of the glaciated area. The large inland lakes of the Great Basin waxed and waned in response to Glacial and Interglacial conditions. At the times of Glacial advances the temperature gradient across the temperate zone, between the Gulf and the northern states, must have reached a maximum. Manley (1955) has indicated that this temperature gradient could have had at least twice its present value and has estimated that at the time of maximum cooling the minimum annual temperature, on the Fahrenheit scale, was lowered about $13^{\circ}$ near the Gulf, $16^{\circ}$ at latitude $35^{\circ}$ N., $20^{\circ}$ in the Ohio Valley, and $27^{\circ}$ at New York.

Glaciers form wherever snowfall exceeds summer melting, and the maximum development of Pleistocene glaciers was in just those regions where at present there is maximum winter snowfall and cool, cloudy summers. A comparatively slight lowering of summer temperatures from that of the present would suffice to reinitiate glaciation in those areas. 
One of the distinguishing features of the Glacial ages seems to have been the cyclic or periodic character of the climate-the alternation of Glacial and non-Glacial stages. A new approach to the problem of "fossil" temperatures has been developed by Urey and his students (Urey, 1948; Emiliani, 1955, pp. 538-546). The relative proportion of the oxygen isotope of mass 18 in carbonates, for example, is inversely proportional to the temperature at which the carbonate was formed. The ratio of the two isotopes (mass 18 and 16) can be determined accurately by spectrographic means. Although many difficulties are still to be worked out, this method of investigating past temperatures holds much promise and some interesting results have already been achieved by Urey and by Emiliani. Investigation of sea-bottom cores from the equatorial and subtropical Atlantic Ocean has shown that there were no periodic or cyclic temperature fluctuations during the Miocene or Oligocene and that the "cause responsible for Pleistocene climatic variations was not effective during Tertiary times" (Emiliani, 1956, pp. 285-287).

The distribution of living plants, and animals in the present temperate regions can be explained only on the basis of the violent climatic fluctuations of the Pleistocene. The extent of these climatic fluctuations can hardly be overemphasized. For instance, the climate on the Michigan Peninsula varied from that of the frigid continental icecap to climates warmer than at present. Along the front of the glaciers there were changes from tundra through steppe to broadleafed forests, and back again. Studies have indicated that the snowline in all the high mountains of the world descended during times of glaciation. It has been estimated (Leopold, 1951; Anters, 1954; Flint, 1957, p. 304) that the snowline on the mountains of New Mexico, for example, descended approximately 4,000 feet below that of the present. There is evidence from deep-sea cores that the surface of the ocean also underwent refrigeration, even in the tropics. Through the study of fossil pollen from scattered bogs, it has been indicated that a cool-temperate climate extended from western Florida to near Austin, 'Texas (Brown, 1938; Davis, 1946, pp. 193-196; Potzger and Tharp, 1947, 1954). The lower levels of these bogs contain pollen of spruce and fir species now characteristic of forests around the Great Lakes. The distribution of the bogs indicates that these cool-temperate forests could hardly have been small 
isolated islands of such forest types. A few small fossil floras show that the climate of southern California was cooler and moister than at present. Such examples could be increased almost indefinitely (see, for example, Murray, 1957). On the other hand, studies of fossil pollen give evidence of the existence of oak-hickory forests during Interglacial periods in areas around the Great Lakes that were occupied by ice during the Glacial stages.

The succession of Glacial and Interglacial stages was no doubt the impetus for plant and animal dispersals north-south and up and down in the mountainous areas. The distributional, ecological, and speciational changes may be inferred, as follows. As the climate ameliorated in an Interglacial interval, southern forms expanded their habitat areas to the north and upward, while withdrawing at the south. This northward extension continued until the climatic trend was reversed. Isolated, relict areas of occupancy were left scattered in favorable, or at least tolerated, locations south (and possibly west) of the main occupied area. These relict areas, for species dispersing northward, were on the higher elevations and on cool north slopes, and may have offered especially favorable conditions for the beginning of further speciation. Uninhabited areas, newly exposed by the retreating ice, may have presented somewhat different environments and changing competition to the vanguard of the northward dispersal. With a turn toward advance of the ice sheets, areas of occupancy tended to be driven southward, posing new competitors and, perhaps, putting a premium on adaptability to unaccustomed foods. There were many changes in local physiographic barriers, ice sheets, rivers, and lakes.

Pollen studies indicate that vegetational changes in middle latitudes were marked. There is evidence that the prairies moved northward and, in response to warmer and drier conditions, also eastward during Interglacials. During pluvial Glacial stages prairies invaded the eastern areas of our south-western deserts. During such times of cyclic climatic changes the stimuli to admixture, hybridization, and natural selection must have been intensified. The effects on life were naturally greatest along the southern extension of the glacial fronts, but these effects are found far to the south (in the mountains of Mexico, for instance). Apparently the most favored areas climatically were along the Pacific Coast and the southern Atlantic seaboard. It is probable that there were dispersals back and 
forth along the Gulf Coast from the Appalachians to the mountains of eastern Mexico (Sharp, 1950, pp. 316-318).

The world climate has undergone striking fluctuations since the retreat of the last continental glacier, without physiographic changes of any consequence. A gradual warming culminated in the "climatic optimum" (about 6,000 years ago), followed by a return to cooler conditions. Now a warming trend seems to have been renewed. Prehistoric sites of human habitation in the western states show clear evidence of great climatic instability since the retreat of the glaciers (Malin, 1957). Occupance layers are separated by thick layers of wind-blown dust that indicate intervals when the sites were uninhabited and when the vegetational cover was at a minimum. There are historical accounts of severe dust storms in the Plains states long before modern settlement and the "plowing of the plains." One of the latest effects of climatic changes is the spread of the tropical deserts from western India across the Mediterranean and northern Africa, and in our own Southwest (Vadia, 1955).

Attention is called to two stimulating papers dealing with the present apparently erratic distribution of certain vertebrate animals. In dealing with the biogeographical problems concerning some American genera of salamanders, Lowe (1950) has plausibly explained the puzzling distribution of these animals by a consideration of late Tertiary and Pleistocene changes. Smith (1957) has treated some unusual problems concerning the distribution of mammals in the north-central states. Almost any type of erratic distribution and almost any inconsistency of distribution appear possible when the effects of climatic changes in the later Tertiary and Pleistocene are considered.

The world climate has been comparatively stable throughout the ages, but subject, at times, to the most amazing variations. In emphasizing certain aspects of past climates the writer has hoped to furnish some hints concerning the remarkable effects of climatic changes on the evolution and distribution of living plants and animals.

Space does not permit a critical presentation of all the different theories and ideas as to the causes of world climatic changes (Flint, 1957; Willett, 1953). However, in considering these causes it is always necessary to go back to the two fundamental controls of world 
climate: (1) composition of the atmosphere and (2) amount and kind of solar radiation. Without doubt there have been changes in both of the fundamental controls during geologic time. In addition, it is important to note that changes in solar radiation can also affect the composition of the atmosphere by changing the amount of both water vapor and carbon dioxide. Thus the two controls are not independent. As far as we know now the two constituents of the atmosphere most concerned with world climate are carbon dioxide and water, although the concentration of oxygen and ozone aloft may also play a part. Carbon dioxide and water both act to absorb earth radiation while they are comparatively transparent to short-wave solar radiation. Thus the surface of the earth is blanketed by these gases and, as a consequence, is much warmer than it would be without them, and daily fluctuations are much reduced. Recent studies of the absorption bands of carbon dioxide indicate that it can have a rather large effect independently of the presence of water vapor. Plass (1956) brought up to date the climatic effects of changes in the concentration of carbon dioxide. However, he did not explain convincingly the role of this gas in initiating world wide climatic changes, such as the beginning or ending of the Glacial periods. It is only necessary to recall again the climatic changes between the spring of 1956 and of 1957 to realize that circulation patterns can vary remarkably from one year to another without changes in the composition of the atmosphere. We still have much to learn concerning the true causes of these year-to-year fluctuations, let alone those of longer periods. The problem of the function of carbon dioxide as an atmospheric climatic control is most complex, and several important questions remain unanswered. Removal of carbon dioxide from the atmosphere by natural causes might lower world temperatures. Removal is accomplished by lime-secreting organisms, by the weathering of the rocks, and by the deposition of oil, coal, and the like. When we consider the huge limestone deposits of the Paleozoic and the Cretaceous, together with the accompanying coal deposits, we wonder if the concentration of carbon dioxide in the atmosphere has not been tremendously reduced since pre-Cambrian days. If the role of carbon dioxide in the atmosphere is of climatic importance, there must be some natural means of replenishing the atmospheric supply. The glaciation of the late Paleozoic might be a natural consequence of the removal of the gas in the formation of 
the Paleozoic limestone beds, but what brought the return of the mild climates in the Mesozoic? As far as we know now, the only source of carbon dioxide in any quantity is volcanism. Yet intense and long-continued volcanism seems to precede rather than follow Glacial ages.

Carbon dioxide is more soluble in cold water than in warm. The present cold oceans are a storehouse for incredible amounts of $\mathrm{CO}_{2}$. If the climate should become warmer, large amounts of the gas would be released to the atmosphere. But here we see that an increase of carbon dioxide is an effect of, rather than the cause of, warmer climate. Warmer climates also mean an increase in the total amount of water vapor in the atmosphere. There is little question that changes in the concentrations of these gases tend to emphasize climatic fluctuations. The role of continentality in initiating or terminating Glacial ages has been greatly overemphasized. No known distribution of land and water and no known variations in topography are adequate to account for the changes in climate since the Upper Cretaceous. Anyone who is familiar with the climatic change in the central United States between the spring of 1956 and the spring of 1957 must be aware that some other effect than size, shape, and topographic relief of the continents must be the cause of major changes in circulation patterns. 'Terrestrial factors are capable of increasing climatic contrasts and channeling currents of air and water, but they cannot, on the basis of our present knowledge, affect the climate of the earth as a whole (Willett, 1953, pp. 58-59). The solution of the problem of changing climates is not to be found in the theories of wandering poles and drifting continents. Any forms of these theories yet developed directly contradict the known facts concerning the distribution of fossil floras. In addition to the negative biologic evidence there is also direct physical evidence against the idea of wandering poles. From his study of the orientation of magnetic grains in sediments, Hospers (1955) has "concluded that the large amount of polar wandering suggested by Kreichgauer, Koppen and IVegner, and Milankovitch cannot be reconciled with the new data. If ... at all . . it has not exceeded $5^{\circ}-10^{\circ}$ since Eocene times."

The evidence of a recent warming of world climate is clear. If the present trend toward warming and drying continues, our southwestern deserts will eventually expand into Oklahoma, Texas, and 
Kansas, and the prairies will move eastward and northeastward. Is this warming and drying trend due to the enormous amounts of carbon dioxide being returned to the atmosphere through the burning of fossil fuels, as Plass believes, or is it due to some secular change in solar radiation? In this connection, accumulating evidence indicates that short-wave and corpuscular radiations from the sun appear to fluctuate rather markedly, and that the amounts of such radiation absorbed by the outer atmosphere may produce rather large effects in modifying atmospheric circulation patterns (Craig and Willett, 1951; Willett, 1953, pp. 62-69).

In his study of past climates the writer has become convinced that the fundamental cause of world climatic changes has its origin in small fluctuations in the amount and kind of solar radiation (see also Willett, 1953, pp. 57, 61; Flint, 1957, pp. 481-509). Öpik (1958) has developed what is perhaps the first plausible mechanism for long-term changes in solar radiation. These solar changes are considerably modified by the resulting changes in ocean temperatures, concentrations of $\mathrm{H}_{2} \mathrm{O}$ and $\mathrm{CO}_{2}$, and, on a more local scale, by topographic changes. The problem is a complex one, but the writer, on the basis of present evidence, always returns to the conclusion that the primary cause lies outside the earth itself. Brooks' solar-topographic hypothesis (Brooks, 1951, pp. 1016-1017) offers an adequate and satisfying explanation of the observed facts.

\section{REFERENCES}

Antevs, E. 1954. Climate of New Mexico during the last Glacio-pluvial J. Geol., 62: 182-191.

Axelrod, D. I. 1956. Mio-Pliocene floras from west central Nevada. Univ. Calif. Publs. Geol. Sciences, 33: 1-322.

. 1957. Late Tertiary floras and the Sierra Nevada uplift. Bull. Geol. Soc. Am., 68: 19-46.

Bogolepov, K. V. 1955. Stages in the development of the Tertiary vegetation in the Angara region of the Enisei ridge. Doklady Akad. Nauk SSSR, 100: 985-988.

Brooks, C. E. P. 1949. Climate through the Ages. McGraw-Hill, New York. - 1951. Geological and historical aspects of climatic change. Compendium Meteorol., pp. 1004-1023.

Brown, C. A. 1938. The flora of Pleistocene deposits in the western Florida parishes; West Feliciana Parish, East Baton Rouge Parish, Louisiana. Louisiana Geol. Survey, Geol. Bull., 12: 59-96. 
Chaney, R. W. 1940. Tertiary forests and continental history. Geol. Soc. Am. Bull., 51: 469-488.

. 1944. A fossil cactus from the Eocene of Utah. Am. J. Botany, 31: 507-528.

- 1947. Tertiary centers and migration routes. Ecol. Monographs, 17: 139-148.

Chaney, R. W., and M. K. Elias. 1936. Late Tertiary floras from the high plains. Carnegie Inst. Wash. Publ. No. 476: 1-72.

Craig, R. A., and H. C. Willett. 1951. Solar energy variations as a possible cause of anomalous weather variations. Compendium Meteorol., pp. $378-390$.

Davis, J. H., Jr. 1946. The peat deposits of Florida, their occurrence, development and uses. Florida Geol. Survey, Geol. Bull. 30.

Dorf, E. 1942. Upper Cretaceous floras of the Rocky Mountain region. Carnegie Inst. Wash. Publ. No. 508: 1-168.

Durham, J. IV. 1950. Cenozoic marine climates of the Pacific coast. Bull. Geol. Soc. Am., 61: 1243-1264.

Elias, M. K. 1942. Tertiary prairie grasses and other herbs from the High Plains. Geol. Soc. Am. Special Paper 41.

Emiliani, Cesare. 1954. Temperatures of Pacific bottom waters and polar superficial waters during the Tertiary, Science, 119: 853-855.

—_. 1955. Pleistocene temperatures. J. Geol., 63: 538-573.

- 1956. Oligocene and Miocene temperatures of the equatorial and subtropical Atlantic Ocean. J. Geol., 64: 281-288.

- 1958. Ancient temperatures. Sci. American, 198: 54-63.

Flint, R. F. 1957. Glacial and Pleistocene Geology. John Wiley \& Sons, New York.

Frye, J. C., and A. B. Leonard. 1957. Ecological interpretations of Pliocene and Pleistocene stratigraphy in the Great Plains region. Am. J. Sci., 255: 1-11.

Hospers, J. 1955. Rock magnetism and polar wandering. J. Geol., 63: $59-74$.

Knowlton, F. H. 1917. Fossil floras of the Vermejo and Raton formations of Colorado and New Mexico. U. S. Geol. Survey Prof. Paper 101: $223-455$.

Leopold, L. B. 1951. Pleistocene climate in New Mexico. Am. J. Sci., 249: $152-168$.

Li, Hui-Lin. 1952. Floristic relationships between eastern Asia and eastern North America. Trans. Am. Phil. Soc., N. S., 42, Pt. 2 : 371405 .

Lowe, C. H., Jr. 1950. The systematic status of the salamander Plethodon hardii, with a discussion of biogeographical problems in Aneides. Copeia (2) : 92-99.

MacDonald, J. R. 1953. Climate of western South Dakota during the Oligocene epoch. Program Geol. Soc. Am., Cordilleran Sect., p. 17. 
MacGinitie, H. D. 1941. A Middle Eocene flora from the central Sierra Nevada. Carnegie Inst. Wash. Publ. No. 534: 70-78.

- 1953. Fossil plants of the Florissant beds, Colorado. Carnegie Inst. Wash. Publ. No. 599.

Malin, J. C. 1957. Review of "The North American grassland in historical perspective," by J. E. Weaver and F. W. Albertson, Ecology, 38: 362-363.

Manley, G. 1955. A climatological survey of the retreat of the Laurentide ice sheet. Am. J. Sci., 253: 256-273.

Mason, H. L. 1947. Evolution of certain floristic associations of western North America. Ecol. Monographs, 17: 202-210.

Murray, K. F. 1957. Pleistocene climate and the fauna of Burnet's Cave, New Mexico. Ecology, 38: 129-132.

Opik, Ernst J. 1958. Climate and the changing sun. Sci. American, 198: 85-92.

Plass, G. N. 1956. Carbon dioxide and the climate. Am. Scientist, 44: $302-316$.

Potzger, J. E., and B. C. Tharp. 1947. Pollen profile from a Texas bog. Ecology, 28: 274-280.

- 1954. Pollen study of two bogs in Texas. Ecology, 35: 462-466.

Reid, E. M., and M. E. J. Chandler. 1933. The flora of the London Clay. British Museum, London.

Seward, A. C. 1933. Plant life through the ages. Cambridge University Press, Cambridge, England.

Sharp, A. J. 1950. Characteristics of the vegetation in certain temperate regions of eastern Mexico. Ecology, 31: 313-333.

- 1953. Notes on the flora of Mexico. J. Ecology, 41: 377-378.

Smith, P. IV. 1957. An analysis of post-Wisconsin biogeography of the Prairie Peninsula region based on distributional phenomena anong terrestrial vertebrate populations. Ecology, 38: 205-218.

Urey, H. C. 1948. Oxygen isotopes in nature and the laboratory. Science, 10: 489-496.

Wadia, D. N. 1955. Deserts of Asia-their origin and development in late Pleistocene time. Second Seward Mem. Lect. Birbal Sahni Institute of Paleobotany, Lucknow.

Willett, H. C. 1953. Atmospheric and oceanic circulation as factors in glacial-interglacial changes of climate. In H. Shapley, Climatic Change, pp. 51-71. Harvard University Press, Cambridge, Mass.

Wodehouse, R. P. 1933. Tertiary pollen. II. The oil shales of the Green River formation. Bull. Torrey Botan. Club, 60: 479-524.

Zeuner, Frederick E. 1945. The Pleistocene Period. Ray Society, London. . 1952. Dating the Past, 3rd edition. Methuen, London. 



\title{
The Role of Physiology
}

\author{
in the Distribution of
}

\section{Terrestrial Vertebrates}

George A. Bartholomew

Department of Zoology, University of California, Los Angeles

The inclusion of this paper in a symposium on the origins and affinities of the land and freshwater fauna of western North America may be taken as an expression of the tacit assumption of most biologists that physiology plays a determining role in the complex problems of animal distribution. I have accepted this assumption, but in attempting to formulate conclusions available from present knowledge, I find that the relation of physiology to distribution in terrestrial vertebrates is neither direct, simple, nor obvious. All that a brief essay such as this can do is offer a point of view with regard to certain groups. To attempt a taxonomically extended treatment of a topic so broad would be presumptuous, and I shall concentrate on the animals that I know best-the amniotes. The literature cited is not exhaustive, but most of the papers are quite recent, and all include extensive bibliographies that offer convenient access to the literature relevant to the role of physiology in the distribution of terrestrial vertebrates.

Biology is a continuum, but we biologists, because of our limitations, divide ourselves into categories, and then we pretend that these categories exist in the living systems that we study. From the functional point of view, of course, an animal is indivisible, and physiology is not in any sense an isolatable component of an organism. If physiology is defined as the study of vital functions, it becomes inseparable from morphology and behavior. When one defines physiology as broadly as this and then undertakes to discuss its role in distribution, one attempts the impossible-nothing less than an 
interpretation of all the ways in which the dynamic capacities of an organism influence its distribution. In the present paper therefore, we shall restrict our discussion to the kinds of data that comparative physiologists and physiological ecologists gather. In this way we can confine our topic to reasonable limits and also insure that we have at least some data on which to base our conjectures.

Once an organism has been identified, two of the most obvious questions to ask are first, "How many are there?" and second, "Where do they live?" Simple as these questions are, they are usually extremely difficult to answer. But let us assume that, by years of unremitting effort, we have succeeded in obtaining approximate answers to these obvious questions. Since abunclance and distribution may be considered as different aspects of the same problem (Andrewartha and Birch, 1954, p. 5), two additional and inextricably interlocked questions inevitably present themselves: first, "Why are there as many as there are?" and second, "Why do they live where they do?" Ne may start our inquiry concerning the role of physiology in distribution by asking the straightforward question, "What information do physiologists supply that relates more or less directly to the above questions, particularly to the last one, which is a major concern of most students of distribution?" Unfortunately it is useless to pretend that answers to these questions can supply us with much that is specifically and immediately relevant; first, because of the complexity of both physiology and distribution, and second, because physiologists have only infrequently considered these questions.

It is obvious that an organism's distribution is a complex integration of all facets of its present biology, together with a past history in which chance has played an indeterminable but not necessarily an unimportant role. Moreover, the occurrence of an organism is dependent not only on a complex summation of its present and past activities plus chance; it is often profoundly influenced by the occurrence or non-occurrence of other organisms, and these organisms may be of quite a different nature and have different physiological tolerances, requirements, and reactions from the one whose distribution is being studied.

Viewed in this context it is obvious that most present knowledge of the physiology of terrestrial vertebrates is likely to have either no apparent distributional importance or to have a contribution so 
broad that it is of little assistance in the analysis of any specific distribution. The aspects of physiology that are directly pertinent to distribution - and these are the only ones with which it is ordinarily possible to deal - are not those concerned with internal integration, but are those that either involve the animal's exchanges with the environment or control and regulate these exchanges, and those that affect reproductive performance. The exchanges referred to involve food, water, heat, radiation, and metabolic wastes, and are usually studied in terms of rates and limits. The factors controlling reproductive performance under natural conditions are at present only in the first stages of analysis (Lack, 1954) and offer a challenging series of problems related to distribution.

Since an organism is inseparable from its environment, any person who attempts to understand an organism's distribution must keep constantly in mind that the item being studied is neither a stuffed skin, a pickled specimen, nor a dot on a map. It is not even the live organism held in the hand, caged in the laboratory, or seen in the field. It is a complex interaction between a self-sustaining physicochemical system and the environment. An obvious corollary is that to know the organism it is necessary to know its environment. If this view is valid, and if the distributionally relevant data of physiology relate to the dynamics of the complex interaction between organism and environment, then to evaluate the contribution of physiological data to knowledge of distribution, one must first examine the environment critically, analytically, and in detail. Obviously a searching examination of the environment cannot be made in a general discussion addressed to only the broad aspects of the problem, but for purposes of comparison we may consider the sea. From the point of view of this discussion, the most conspicuous feature of the open sea is that it offers few places for an animal to go to avoid unfavorable conditions that may develop locally. If one excludes shore and estuarine areas, the number of aquatic microhabitats that offer significant possibilities of escape from unfavorable conditions is negligible. We can therefore expect that marine organisms will often be limited in distribution by physical conditions, particularly temperature. In contrast, the terrestrial environment and to a lesser degree the freshwater habitat offer many microhabitats that make available an enormous range of temperature, moisture, and radiation. 
On land an almost infinite series of physical situations is available. Plants, generally speaking, meet the impact of the terrestrial environment head on, although of course they in turn modify the physical environment by adventitious group activity. The individual plant cannot select its habitat; its location is largely determined by the vagaries of the dispersal of seeds or spores and is thus profoundly affected by chance. Because of their mobility and their capacity for acceptance or rejection terrestrial animals, in contrast, can and do actively seek out and utilize the facets of the environment that allow their physiological capacities to function adequately. This means that an animal by its behavior can fit the environment to its physiology by selecting situations in which its physiological capacities can cope with physical conditions. If one accepts this idea, it follows that there is no such thing as The Environment, for there exist as many different terrestrial environments as there are species of animals.

We can now take a somewhat closer look at the relation of physiology to distribution. First of all, we must consider what questions the student of ecological animal physiology is trying to answer. (A more realistic approach might be to ask to what questions can conveniently obtained physiological data be applied.) It usually develops that after much laborious and frustrating effort the investigator of environmental physiology succeeds in proving that the animal in question can actually exist where it lives. It is always somewhat discouraging for an investigator to realize that his efforts can be made to appear so trite, but this statement does not belittle the ecological physiologist. If his data assist the understanding of the ways in which an animal manages to live where it does, he makes an important contribution to the study of distribution, for the present is necessarily a key to the past.

The contributions of physiological knowledge to an understanding of distribution are necessarily inferential. Distribution is a historical phenomenon, and the data ordinarily obtained by students of physiology are essentially instantaneous. However, every organism has a line of ancestors which extends back to the beginning of life on earth and which, during this immensity of time, has invariably been able to avoid, to adapt to, or to compensate for environmental changes. By examining in retrospect this prolonged exercise in the art of survival and at the same time bearing in mind the physio- 
logical capacities of living forms, it is possible to adduce some obvious, familiar, and general statements about the broad relations of physiology to the distribution of terrestrial vertebrates. Such an effort is greatly facilitated by application of Liebig's law of the minimum (Hesse, Allee, and Schmidt, 1951, p. 26), one of the most useful of generalizations to which an ecological physiologist can turn. In the context of the present essay this generalization may be stated thus: the distribution of a species will be controlled by that environmental factor for which it has the narrowest range of adaptability or control. The limiting factors will of course be different at different stages in the life cycle and will vary from group to group and from time to time.

The evolution of terrestrial vertebrates has been characterized first, by increasingly effective homeostatic mechanisms and second, by increasingly variable and flexible behavior. Together these two trends mean that the evolutionary history of vertebrates has resulted in increasing physiological competence and, at the same time, increasing capacity to select from the environment the special physical situations that are appropriate to an animal's physiological capacity. This increase in ecological versatility allows some forms to occupy a remarkably diverse array of habitats and makes the determination of distributionally limiting factors an intriguingly subtle problem. If we examine the major groups of terrestrial vertebrates with regard to the aspects of their physiology that are likely to be limiting, we can make several obvious general observations. Amphibians. Amphibia show poor osmoregulation (see Sawyer, 1956, for a recent review), poor control of water loss (Cohen, 1952; Thorson, 1956), and complete lack of physiological thermoregulation other than the passive cooling incidental to dehydration.

Reptiles. Of the major homeostatic capacities reptiles lack only effective physiological thermoregulation, and they compensate for this with surprisingly effective behavioral thermoregulation (Cowles and Bogert, 1944; Bogert, 1949; Norris, 1953). A dramatic example of behavioral thermoregulation is shown by the Andean lizard Liolaemus multiformis, which under some circumstances can achieve body temperatures as much as $30^{\circ} \mathrm{C}$ above air temperature (Pearson, 1954a).

Birds. Birds have reached a level of homeostatic control comparable to that of mammals. Considering their small size, they have 
remarkable powers of thermoregulation. Their capacity to tolerate severe hyperthcrmia allows them to operate effectively at remarkably high environmental temperatures (Bartholomew and Dawson, 1958), and their high rate of heat production, effective insulation, and peripheral vasomotor control allow them to operate at extremely low environmental temperatures (Scholander et al., 1950a; Wallgren, 1954; Irving et al., 1955). With regard to water, however, birds have less independence of the environment than do many mammals.

In the birds that have been measured, evaporative water loss exceeds metabolic water production even under resting conditions. (Bartholomew and Dawson, 1953). This unfavorable relationship necessitates a high intake of water either through drinking or the eating of succulent foods, which places birds, particularly small ones, at a disadvantage with regard to the occupancy of arid regions (Bartholomew and Cade, 1956).

Documented records of both daily and seasonal torpidity are now available for adult birds in four different orders (see Bartholomew, et al., 1957, for a summary). Although the advantages of torpidity with regard to energy conservation are obvious for birds of extremely high metabolism, such as humming birds (Pearson, 1954b), or for birds dependent on periodically unavailable food (swifts, poor-wills, and nighthawks), the limited number of species and the fragmentary nature of the available data do not warrant rigorous distributional inferences.

Mammals. One of the most impressive attributes of mammals is the excellence of the physiological homeostasis that they have attained; one form or another is able to meet head on the most severe naturally occurring environmental conditions of heat, cold, or aridity. Hence, any taxonomically extensive generalizations concerning physiologically determined distributional limits are apt to be particularly unsatisfactory in this group. Large arctic mammals by the excellence of their insulation and vasomotor control can maintain a difference of as much as $70^{\circ} \mathrm{C}$ between air and deep body temperatures without increasing metabolism above basal level or decreasing the deep body temperature (Scholander et al., 1950b; Scholander, 1955).

Most medium to small-sized mammals living in areas of very high environmental temperatures avoid heat stress by being fossorial, 
nocturnal, or both. Such patterns of behavior are often impossible for large mammals, but if they can sweat and if drinking water is available, they are able to cope with any high air temperatures that occur naturally. In at least one large mammal, the dromedary camel (Camelus dromedarius), tolerance of hyperthermia contributes significantly to effectiveness of adaptation to high ambient temperatures by allowing heat storage rather than by requiring heat dissipation through evaporation of water (Schmidt-Nielsen et al., 1957).

The availability of surface water is of no importance in the distribution of many desert rodents. Several species in the family Heteromyidae lose so little water through evaporation, excretion, and defecation, that as long as they are not forced to resort to evaporative cooling, they are able to produce all the water they need through their own metabolism even while subsisting on a dry diet (see Schmidt-Nielsen and Schmidt-Nielsen, 1952, for an extensive review). It has yet to be demonstrated, however, that large herbivorous mammals can produce enough metabolic water while on a dry diet to compensate for water losses. Unlike a rodent, the larger mammals cannot escape the heat of the day by burrowing and must therefore depend in part on evaporative cooling to prevent harmful hyperthermia. Nevertheless, the capacity of some large herbivores to go without water is impressive. A dromedary camel exposed to the full heat load of radiation from sun and ground during the summer at a Saharan oasis survived a 17-day period on a dry diet without water (Schmidt-Nielsen et al., 1956). Its performance is attributed to its capacity to tolerate a loss in body water equivalent to 30 per cent of its body weight. (Most mammals cannot tolerate more than 12 per cent dehydration.)

One may summarize by saying that by a combination of behavior and physiology mammals can successfully occupy all but the most extreme environments on earth without anything more than quantitative shifts in the basic physiological pattern common to all. With regard to dietary limits their performance is almost as impressive. For example, ruminant artiodactyls can subsist largely on cellulose because of the synthetic capacity of the bacterial flora of the rumen (see Blaxter, 1954, for a discussion). (The existence of a fauna of ruminant ungulates of course is an essential feature for the survival of populations of many of the larger mammalian carnivores.) How- 
ever, a deficiency in critical trace elements in the soil apparently represents an unbeatable physiological problem even to ruminants (see Underwood, 1956, for a comprehensive review).

In several groups of mammals there is an additional capacity in the repertory of environmentally relevant physiology, namely hibernation, which allows smaller mammals to avoid for weeks or even months climatic conditions too severe for them to cope with otherwise (see Lyman and Chatfield, 1955, and Kayser, 1955, for recent reviews). Prolonged periods of dormancy may occur at any season, and the limited data presently available indicate that there is no clear-cut difference between hibernation and estivation except the environmental temperatures at which they occur (Bartholomew and Cade, 1957). Daily periods of torpor are known among mammals only in bats (Hock, 1951). Since hibernating mammals can arouse spontaneously from their torpor, this capacity significantly extends the range of environmental conditions which they can occupy, by allowing them to confine their activity to the periods of the day or the year when environmental conditions are favorable.

In addition to the capacities summarized above, many animals including members of all classes of vertebrates have the capacity to acclimate to environmental changes. This process of acclimation allows the organism to accommodate its own range of control to a wide range of physical conditions (see Bullock, 1955, for a review of temperature compensation in poikilotherms).

Now that some of the relevant physiological capacities of vertebrates have been surveyed very briefly, we may consider some ideas concerning the relation of physiological tolerance to distribution. An environmental factor that exceeds the limits of an animal's physiological tolerance will control its distribution, but only at irregular intervals in time and only on that perimeter of its range where the factor is becoming extreme. On most of the boundaries of the animal's range, the distributional limits are set by factors other than simple physiological tolerance to the given environmental factor. Familiar examples demonstrating that physiological incapacity to meet environmental extremes is a factor in distributional control only at isolated points in time and space are offered by the distribution of many species of vertebrates the ranges of which impinge on the deserts of southwestern United States and northern Mexico. The heat and aridity of the desert may actually limit the occurrence of 
these species, but the desert comprises only part of the perimeter of their ranges. On other parts of the perimeters, different factors must be limiting.

Locally the distribution of many amphibians and reptiles is often determined by aridity and temperature, but even these animals, which are relatively dependent on climate, are able by their diurnal and seasonal patterns of activity to select from apparently unfavorable physical circumstances the environmental conditions that do not exceed their particular physiological tolerances. A result is that while it is possible to reason from physiological data to the conditions necessary for survival, it is not possible to reason from distributional data to physiological capacities in the absence of detailed ecological knowledge. Two examples may be cited. Thorson (1955) found that the spade-footed toad, Scaphiopus hammondii, which occupies arid regions, actually takes up water more slowly than do frogs from more moist environments. In western Australia, frogs of the genus Neobatrachus frequent clay soils in which they cannot dig deep burrows, whereas all species of the genus Heleioporus occupy friable soil in which they can dig deep burrows. In the various species of Neobatrachus, rate of water uptake increases with increasing aridity of habitat, whereas in IIeleioporus no such correlation can be demonstrated. Presumably because of the microhabitat occupied during estivation, rapidity of water uptake by Neobatrachus is of selective importance, whereas for IIeleioporus it is not selectively important because the latter can dig deep enough to remain in damp soil where rapid recovery from seasonal dessication is not critical (Bentley, Lee, and Main, 1958).

The behavioral and physiological virtuosity of bircls and mammals makes the assignment of distributional control to environmental extremes particularly difficult even after detailed studies of ecology and local distribution, although some documented instances are available in the literature. Opossums (Didelphis marsupialis) on the northern limits of the species' distribution frequently suffer frostbite of ears and tail and it may be that low temperatures per se are limiting the northward spread of this species (see Hamilton, 1958, for a (liscussion). At the opposite extreme, Alaska fur seals (Callorhinus ursinus) become overheated at air temperatures only a few degrees above $0^{\circ} \mathrm{C}$, and death from heat prostration is frecuent during the commercial seal drives in the Pribilof Islands (Bartholomew and 
Wilke, 1956). The inability of these fur seals to prevent hyperthermia even at low air temperatures and low levels of solar radiation may restrict the location of their breeding grounds to the Bering Sea area. In contrast to such situations, wherein environmental temperatures may be limiting, several species with very different capacities for thermoregulation may successfully occupy the same demanding environment. Brown Pelicans (Pelecanus occidentalis), Great Blue Herons (Ardea herodias), and Western Gulls (Larus occidentalis), although having comparable thermoregulatory abilities as adults, differ markedly in this respect while young. The first two species are altricial; the third is precocial. Nevertheless all three species nest successfully in unsheltered rookeries on the desert islands of the Gulf of California, where they are subjected to high air temperature, intense solar radiation, and extreme aridity. They are able to breed despite these unfavorable physical conditions and despite the profound differences in the capacity for temperature regulation of the young, because the parents in the two precocial species are extremely attentive and shade the nestlings during the hours of intense heat, thus behaviorally compensating for the physiological limitations of the young (Bartholomew and Dawson, 1954).

There can be no doubt that in areas such as the deserts, polar regions, and high mountains where the environment is so demanding that life is extremely difficult or impossible, physiological capacities and tolerances limit the distribution of all groups of vertebrates. But if one considers the continental areas as a whole and amphibia and amniotes only, it becomes surprisingly difficult to find distributional limits that are set by physiological tolerance to physical factors in the environment, except for those species that occupy one of the unusually demanding environments such as mentioned above. Ordinarily one species replaces another geographically. Such replacement may of course on occasion be caused by physiological differences between the forms in question. The problems of sympatry and competition are so complex, however, that in the absence of detailed ecological and physiological knowledge, it seems unwise to assume that in an area of contact or overlap each of a pair of geographically complementary species is distributionally limited by its physiological capacities. (See Dumas, 1956, for a carefully analyzed study of the ecological and physiological responses to temperature and humidity in two sympatric salamanders.) Although the topic has been one of 
great interest and enormous theoretical importance since the time of Darwin, a satisfactory evaluation of the role of competition in the determination of distribution in general is obviously impossible at the present time. As Hutchinson (1957, p. 419), has pointed out:

The only conclusion that one can draw at the present from the observations is that although animal communities appear qualitatively to be constructed as if competition were regulating their structure, even in the best studied cases there are nearly always difficulties and unexplored possibilities. These difficulties suggest that if competition is determinative it either acts intermittently ... or it is a more subtle process than has been supposed.

My obvious reluctance to accept the direct role of physiology in the determination of distribution of species probably needs defense from the students of geographic variation in western North America, where so many subspecies and species have been shown to have limits that can be readily correlated with vegetation types and hence indirectly with conditions of the physical environment. Since such correlations are striking, it is often assumed that the distributional limits are physiologically determined and that closely related species or even subspecies are characterized by physiological differences. There is little a priori reason to presume that animals are any less variable in physiology than in morphology. Aside from coloration, however, the minute morphological differences separating subspecies or closely related species are not necessarily adaptive; similarly, small physiological differences between closely related forms need not be adaptive. If physiological differences are not adaptive, they have little significance in determining the distribution of the forms that possess them. Moreover, when one deals with the smallest taxonomic categories - subspecies and obscurely delimited speciesand finds adaptive physiological differences, it is impossible to state categorically whether or not these differences allow or follow changes in distribution.

In view of the difficulty of demonstrating physiologically determined distributional limits and physiologically determined competitive success in terrestrial vertebrates, it is reasonable to turn to habitat selection and ecological tolerance for help in understanding distribution. The correlation of habitat with both local and general distribution is familiar to all field zoologists. It is a well-documented fact that discontinuities of populations of terrestrial vertebrates 
coincide with changes in plant formations and soil types. These discontinuities in distribution are related to active selection of habitat by the animals involved. The ability to recognize and react to factors in the environment, in such a manner that a given species characteristically occupies a certain type of situation, is of course referred to as habitat selection. As Miller (1956, p. 269) has pointed out, "It does not imply selection of a habitat coincident with the limits of environmental tolerance of the species but usually reaction to some feature of the habitat far within those limits . .." In areas of great altitudinal relief such as western North America, many clear-cut examples of the roles of habitat selection are available (Miller, 1942). A spectacular instance is offered in the mountains of northern Nicaragua where tropical rain forests interdigitate with montane pine forests and each vegetational complex supports its own characteristic avifauna, so that boreal species such as the Red Crossbill (Loxia curvirostra) and tropical species such as the Jacamar (Galbula ruficauda) may live only meters apart (T. R. Howell, personal communication). Equally spectacular examples can be cited for other groups. An unusually clear-cut example of the role of the substratum in determining distribution is afforded by the fringetoed lizards of the iguanid genus Uma of the deserts of southwestern America. Members of this genus occur only on aeolian sand, and the changes in distribution of present day forms are cletermined by the movements of the sand dunes that they occupy. Despite the total dependence of this genus on a specific and limited physical habitat, it occupies a broad altitudinal zone extending from 244 feet below sea level to 3,700 feet above sea level (Norris, 1958).

\section{SUMMARY AND CONCLUSIONS}

It is the thesis of this paper that although the distribution of many marine and aquatic organisms and many terrestrial invertebrates may be explicable in terms of physiological tolerances, no such general statement can at present be made for terrestrial vertebrates. The relationship between physiology and distribution becomes progressively more obscure as one ascends the phylogenetic series of vertebrates. The homeostatic mechanisms of terrestrial vertebrates and the exceedingly complex relations which their behavior allows them to maintain with the physical environment make any assignment of causality between physiology and distribu- 
tion extremely difficult. In the light of present knowledge it appears more reasonable to look for the determinants of distribution of the higher vertebrates in behavioral and ecological factors rather than in terms of physiological tolerances. Available knowledge of physiology helps to explain how a vertebrate can live where it does, but rarely reveals why it does not occur beyond the observed limits of its distribution. Physiological tolerances are permissive in that they set the environmental parameters within which a species can occur. By habitat choice, seasonal and daily patterns of activity, selection of appropriate microhabitats, and acclimation, however, a species with sufficient ecological tolerance can assemble the environmental conditions necessary for survival and reproduction out of remarkably unlikely arrays of environmental factors. Consequently, assignments of distributional limits on the basis of assumptions about the physiology of an animal are unrealistic. An animal's distribution represents an integration of all the factors-behavioral, ecological, competitive, reproductive, or other-that limit its existence as a population. It is, therefore, unrewarding to attempt to explain distribution solely in terms of the data presently available from physiological studies, which because of the orientation of most physiologists, have been neither sufficiently varied taxonomically, sufficiently intensive from the standpoint of species and populations, nor of ten enough oriented toward ecology to yield dlata adequate for the analysis of problems as subtle as those involved in distribution.

\section{REFERENCES}

Andrewartha, H B., and L. C. Birch. 1954. The Distribution and Abundance of Animals. University of Chicago Press, Chicago, Ill.

Bartholomew, G. A., and T. J. Cade. 1956. Water consumption of house finches, Condor, 58: 406-412.

-1957. Temperature regulation, hibernation, and aestivation in the little pocket mouse, Perognathus longimembris. J. Mammal., 38:60-72.

Bartholomew, G. A., and IV. R. Dawson. 1953. Respiratory water loss in some birds of southwestern United States. Physiol. Zoöl., 26: 162-166.

- 1954. Temperature regulation in young pelicans, herons, and gulls. Ecology, 35: 466-472.

- 1958. Body temperatures in California and Gambel's quail. Auk, 75: 150-156.

Bartholomew, G. A., T. R. Howell, and T. J. Cade. 1957. Torpidity in the white-throated swift, anna hummingbird, and poor-will. Condor, 59: 145-155. 
Bartholomew, G. A., and F. Wilke. 1956. Body temperature in the northern fur seal, Callorhinus ursinus. J. Mammal., 37: 327-337.

Bentley, P. J., A. K. Lee, and A. R. Main. 1958. Comparison of dehydration and hydration of two genera of frogs (Heleioporus and Neobatrachus) that live in areas of varying aridity. J. Exptl. Biol., 35: $677-684$.

Blaxter, K. L. 1954. Ruminant nutrition. In Progress in the Physiology of Farm Animals, Vol. 1, J. Hammond, Editor. Butterworths Scientific Publications, London.

Bogert, C. M. 1949. Thermoregulation in reptiles, a factor in evolution. Evolution, 3: 195-211.

Bullock, T. H. 1955. Compensation for temperature in the metabolism and activity of poikilotherms. Biol. Revs., 30: 311-342.

Cohen, N. W. 1952. Comparative rates of dehydration and hydration in some California salamanders. Ecology, 33: 462-479.

Cowles, R. B., and C. M. Bogert. 1944. A preliminary study of thermal requirements of desert reptiles. Bull. Am. Museum Nat. Hist., 83: 261-296.

Dumas, P. C. 1956. The ecological relations of sympatry in Plethodon dunni and Plethodon vehiculum. Ecology, 37: 484-495.

Hamilton, W. J. 1958. Life history and economic relations of the opossum (Didelphis marsupialis virginiana) in New York State. Cornell Univ. Agr. Expt. Sta., Memoir 354, pp. 3-48.

Hesse, R., W. C. Allee, and K. P. Schmidt. 1951. Ecological Animal Geography. John Wiley \& Sons, New York.

Hock, R. J. 1951. The metabolic rates and body temperatures of bats. Biol. Bull., 101: 289-299.

Hutchinson, G. E. 1957. Concluding remarks. Cold Spring Harbor Symposia Quant. Biol. 22: 4.15-427.

Irving, L., H. Krog, and M. Monson. 195.5. The metabolism of some Alaskan animals in winter and summer. Physiol. Zoöl., 28: 173-185. Kayser, C. 1955. Hibernation et hibernation artificielle. Revue de Pathologie Générale et Comparée, No. 668, pp. 704-728.

Lack, D. 1954. The Natural Regulation of Animal Numbers. Oxford University Press, London.

Lyman, C. P., and P. O. Chatfield. 1955. Physiology of hibernation in mammals. Physiol. Revs., 35: 403-425.

Miller, A. H. 1942. Habitat selection among higher vertebrates and its relation to intraspecific variation. Am. Naturalist, 76: 25-35.

. 1956. Ecologic factors that accelerate formation of races and species of terrestrial vertebrates. Evolution, 10: 262-277.

Norris, K. S. 1953. The ecology of the desert iguana Dipsosaurus dorsalis. Ecology, 34: 265-287.

1958. The evolution and systematics of the iguanid genus Uma and its relation to the evolution of other North American desert reptiles. Bull. Am. Museum Nat. Hist., 114: 247-326. 
Pearson, O. P. 195ta. Habits of the lizard Lioluemus multiformis multiformis at high altitudes in southern Peru. Copeia (2): 111-116.

. 1954b. The daily energy requirements of a Wild Anna Hummingbird. Condor, 56: 317-322.

Sawyer, W. H. 1956. The hormonal control of water and salt-electrolyte metabolism with special reference to the Amphibia. Memoirs of the Society for Endocrinology, No. 5., Part II, pp. 44-59.

Schmidt-Nielsen, K., and B. Schmidt-Nielsen. 1952. Water metabolism of desert mammals. Physiol. Revs. 32: 135-166.

Schmidt-Nielsen, K., B. Schmidt-Nielsen, T. R. Houpt, and S. A. Jarnum. 1956. Water balance of the camel. Am. J. Physiol., 185: 185-194.

Schmidt-Nielsen, K., B. Schmidt-Nielsen, S. A. Jarnum, and T. R. Houpt. 1957. Body temperature of the camel and its relation to water economy. Am. J. Physiol., 188: 103-112.

Scholander, P. F. 1955. Evolution of climatic adaptation in homeotherms. Eiolution, 9: 15-26.

Scholander, P. F., R. Hock, V. Walters, and L. Irving. 1950a. Adaptation to cold in arctic and tropical mammals and birds in relation to body temperature, insulation, and basal metabolic rate. Biol. Bull., 99: $259-271$.

Scholander, P. F., R. Hock, V. Walters, F. Johnson, and L. Irving. $1950 \mathrm{~b}$. Heat regulation in some arctic and tropical mammals and birds. Biol. Bull., 99: 237-258.

Thorson, T. B. 1955. The relationship of water economy to terrestrialism in amphibians. Ecology, 36: 100-116.

- 1956. Adjustment of water loss in response to dessication in amphibians. Copeia (4): 230-237.

Underwood, E. J. 1956. Trace Elements in Human and Animal Nutrition. Academic Press, New York.

Wallgren, H. 1954. Energy metabolism of two species of the genus Emberiza as correlated with distribution and migration. Acta Zool. Fennica, 84: 1-110. 



\section{Evidence from Fossil Land Mammals on the Origin and Affinities of the} Western Nearctic Fauna

Donald E. Savage

Museum of Paleontology, University of California, Berkeley

The living nonmarine mammal fauna of Nearctica is divided into 9 orders. These orders are subdivided into about 28 families, about 100 genera, and a minimum of about 175 species. Approximately $75 \%$ of its orders, $60 \%$ of its families, $30 \%$ of its genera, and $1-6 \%$ of its species are also found in the parts of eastern Asia not occupied by tropical rain-forest. $100 \%$ of its orders, about $65 \%$ of its families, $15 \%$ of its genera, and $3 \%$ of its species occur in the parts of South America not occupied by tropical rain forest. But these imposing numbers and their graphic demonstration in Fig. 1 do not afford a satisfactory basis for concluding whether the mammals of North America have closer affinity with those of eastern Asia or with those of South America. The number of taxonomic units in the living ensemble and the taxonomic percentage comparisons are figures that serve only as a crude index of the total characteristics and affinities. Living mammals are but a small part of the total land mammal fauna of this continent, for many more lived here in the past, and the exterminated forms must also be studied if our knowledge of origins and affinities is to be complete. Beginning in force with Sclater, Darwin, Wallace, and Lydekker, with tremendous propulsion from Osborn (1910) and Matthew (1915), and with recent thorough refinement by Simpson (1947, 1953), we see the development of our present knowledge of mammalian biogeography, involving millions of years of history. Biogeography "must reckon with time as well as with space" (Hesse, Allee, and Schmidt, 1937, 1951, p. 121). The attributes of a living 
fauna are to a large degree, then, reflections of the paleodynamics of the fauna.

Our symposium theme, Origin and Affinity, involves certain reasoning and inferences, probably elementary to most zoogeographers,

TAXONOMIC COMPARISON OF LIVING LAND-MAMMAL FAUNAS

EAST

ASIA

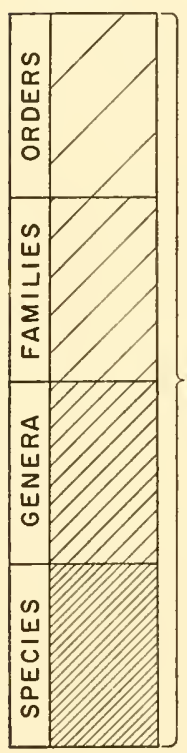

NORTH

AMERICA

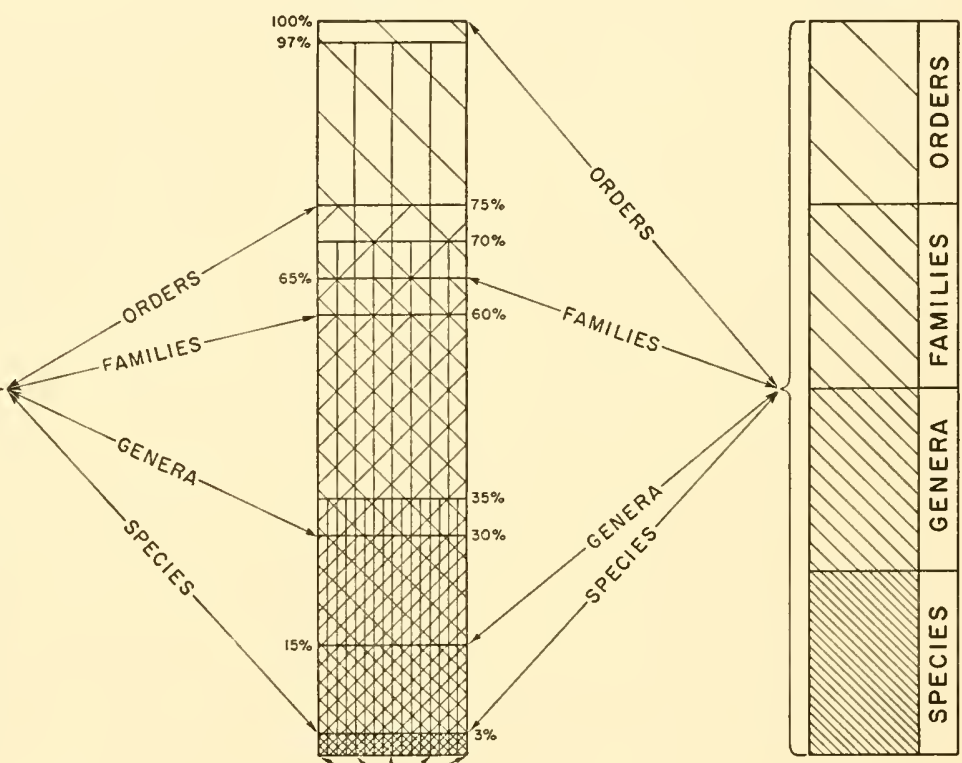

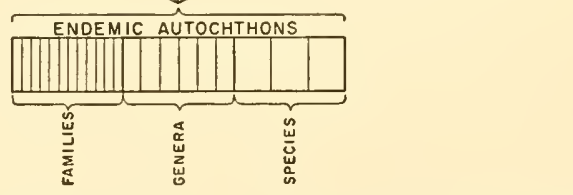

Fig. 1. A graphic demonstration of the approximate percentage of living nonmarine mammalian taxonomic units of North America that are also found in East Asia and in South America respectively.

certainly basic to paleozoogeographers, that can appropriately be acknowledged and reviewed; for they form a philosophic background to our interpretations. It is fitting that a paleontologist make the initial review of this background for he is particularly concerned with the secularly developed phases in the evolution 
and dispersal of organisms and with the ideas that pertain thereto. Certain criteria for determination of origin, as listed below, apply particularly to the expanded field of paleozoogeography - a field extending through millions of years.

\section{Criteria for Determination of Origin}

1. The earliest record of the group in the proposed area of origin. In the absence of strong contradictory data, the district in which there is the oldest, that is, earliest, occurrence of a group may be taken as the area of origin. This procedure is elementary but essential, just as Steno's rule of superposition is an essential in the science of stratigraphy (Steno's rule states that in an undisturbed succession of sedimentary rocks, the oldest formation is at the bottom, the youngest on top.) For example, on this criterion, we may claim that Africa, perhaps the restricted area in North Africa that was the southern coastal plain of the old Tethyan Seaway, was the area of origination of the Proboscidea and that the armadillos originated in South America. These statements are based primarily on the earliest records. In the case of the proboscideans such claims should be employed only as exploratory models of interpretation because of the paucity of the fossil record of early forms. Proboscideans may have originated in central Asia, as some workers suggest, rather than in North Africa; but if the record of late Eocene warm-temperate, savanna, gallery-forest habitats in Asia becomes better known, yet does not produce remains of proboscideans or pre-proboscideans, the probability becomes greater that Africa was inrleed the homeland. Already the relatively complete Focene records in Europe and in the United States make it probable that these territories were not centers of proboscidean origin. In the case of the armadillos, contenporary and comparable environments are relatively well represented in North America, and we believe that armadillos would have been found if they had lived here as early as in South America.

2. An earlier record of progenitors in the proposed area of origination. From the standpoint of paleontology, this, along with the first criterion, is the ultimate basis for definition of center of origin and dispersal. These criteria rlenonstrate that final statements as to the origin of any taxonomic unit of animals whose classification is supported by morphology of geologically preservable parts must be based on the complete stratigraphic record of the unit.

3. A group probably originated in the area wherein it has greatest taxonomic differcntiation (see, also, Emerson's conclusion 13 (1952, p. 224). Taxonomic differentiation is here taken as the best available index of general evolutionary differentiation.

This criterion is based on the reasoning that with given equality of opportunity to diversify, the group has had more time to adapt to the various niches, hence has greater antiquity in the area of greatest diversi- 
fication. Mayr (1946) uses this criterion extensively; his example (p. 13) of the lark family is illustrative: "The larks are a family of more than 70 species and are represented in all parts of the Old World. Only certain subspecies of a single species occur in the New World. There can be no shadow of doubt concerning the family's Old World origin" [italics are mine]. Perhaps not in Mayr's example but in many similar statements, such an approach may be very tenuous and of ten misleading unless biostratigraphic, sedimentologic, mineralogic, and geochemical studies indicate that the proposed center of origin was comparable in ecologic diversity with the inferred non-origination areas.

The interpreted center of dispersal, as evidenced by the distribution and case history of living forms, may be altogether different from the center of origin, particularly in the bradytelic phyla. The environment of origin for many groups of organisms has shifted across great distances since their inception. See, for example, Chaney (1936, 1940), Axelrod (1952 and eariier papers), and Stebbins (1950, Chap. XIV).

A complication may arise also in the consideration of animal groups that become less diversified in the later episodes of their phyletic history for reasons that may not be apparent in the sedimentary record. The living Didelphoidea (opossums) are most diversified and include possibly the most advanced members in the Neotropical region, but all living didelphoids show less morphological variation than the late Cretaceous Nearctic forms that are presently considered members of the group ${ }^{1}$. Thus we conclude that the Neotropics are an asylum of diversified didelphoids and that these Neotropical forms had their ecologic counterparts in late Cretaceous Nearctica. Moreover, we must look for the origin of the didelphoids in sediments that are lower in the stratigraphic column than the presently known fossil sites.

Finally, the third criterion is the more revealing for the smaller taxa. Later diversification within an order, for example, may have little geographic relationship to the origin of the first and most primitive species of the order.

4. Phyletic age of the group is important. Phyletically ancient forms; groups that have changed relatively little (in hard parts, of course) through a long interval of time, are frequently known from restricted or from scattered, relict type occurrences. Pertinent examples may be found in many living amphibians, reptiles, and invertebrates, and even in some mammals. Living lemurids in Madagascar have close relatives in the early Cenozoic deposits of North America and Europe. The South American, Asiatic and African distribution of living hystricomorph rodents may represent an unrecorded Paleocene transworld dispersal of a primitive stock, as suggested by Landry (1957). There are many records

\footnotetext{
1 Only jaws and dentitions are known for the late Cretaceous forms, but greater size range and greater diversity of tooth structure are clearly indicated. Paleomammalogists infer, therefore, more diversified gross morphologies, diets, and habits in these early types.
} 
in the Cretaceous and early Cenozoic in the northern hemisphere of the pleurodire turtles, which now live in the southern hemisphere. Gavials now live in Asia, but are known from the Oligocene of South America according to Langston (1953). Cryptobranchid amphibians live in eastern North America and in eastern Asia, but they are represented by the renowned Andrias scheuchzeri ("Iomo diluvii lestis") in the Miocene of Switzerland (Schmidt, 1946, p. 149; Romer, 1945, p. 592). These littlechanging types are in various degrees characterized by fragmented or by recessed representation of a once greater geographic range that was established during an expanding phase of their dispersal history.

5. Vagility of the group must be considered. This factor adds immeasurable complexity and uncertainty to the interpretation of the fossil record. Migratory birds may, theoretically, become a part of the fossil record at any resting point on their flyway. Rapidly dispersing land mammals might be first trapped in the sediments at great clistance from their district of origin. These uncertainties tend to be overcome by an increasing probability that correlates with an increasing paleontologic sample. Several concordant examples lend an inference greater credence.

Darlington (1948) and Stebbins (1950, Chap. XIV) have discussed other approaches to interpretation of the origin and dispersal of organisms: numbers of animals and of taxonomic units; size and continuity of geographic range; distribution of related, competing, or associated groups. Size and continuity of geographic range appear to comprise an especially useful neontologic criterion for interpreting origin of the smaller taxa. A large and continuous range tokens the origin area.

Thus to confirm an interpretation of origin for a group of animals, we must first explore the diverse palcobiotopes for earliest occurrence. This documentation is fundamental to the historical zoogeography of the phyla and is then enriched by the succeeding criteria. If, then, an area contains the earliest record, shows a biostratigraphic sequence from progenitors to the group concerned, contains most differentiated subgroups, and exemplifies a large and continuous group geographic range, it is probably the center of origin and dispersal.

Natthew (1915) claimed that the more advanced and progressive members of a group should be nearer the center of origin because evolution was more progressive at this point. He also conclucled that the less advanced members tend to disperse radially and will be peripheral. Because of the known climatic changes through time in Holarctica, and because of the concentration of primitive animal 
forms in the equatorial and southern hemisphere land areas, Matthew decided that the Holarctic region has been the principal center of evolution and dispersal of land vertebrates - that the southern and tropical areas are refuges for primitive species. This thesis, along with Matthew's erudition, had an overwhelming effect on North America zoogeographers, as Myers (1938) pointed out. In so far as non-mammalian vertebrates and land invertebrates are concerned, Matthew's thesis has been strongly opposed by many neontologic disciplines. Myers (1938, p. 351) believed that there is no evidence for the North American origin of any of the South American freshwater fishes. Schaeffer (1952, p. 231), however, asserted that centers of origin for the true freshwater fishes are unknown but that some elements were present in South America by the late Cretaceous. He concluded that Mesozoic freshwater fishes suggest a dispersal relationship between South and North America on the one hand, and between Africa and Eurasia on the other. Darlington (1948, p. 110) concluded that the main center of evolution of dominant groups of freshwater fishes, amphibians, and reptiles has been the tropical part of the Old World. Mayr (1946) reemphasized that the classic zoogeographic terms such as Holarctic and Nearctic cannot be applied usefully to the historical zoogeoggraphy of birds. He believes that such terms add nothing, in the geographic sense, to the meaning of standard geographic names for the areas involved. And he proposes Pantropical, Panboreal, Old IVorld, North American, Pan-American and South American centers for avian origin and dispersal. Conclusions opposing Matthew's generalizations are equally numerous in the literature of nonmarine invertebrates, but Emerson (1952) believed that termite history is in essential accord. Much of the opposing viewpoint stemmed from Matthew's rationalization that the more progressive species develop in an area of secularly changing climate-that the warm, humid swamp and forest environments promote a "relatively slugish life." Some of the contradictory statements have been weakened by too great a dependence on the natural and organic phenomena of the presently arranged and restricted climatic belts. Much of Darlington's contention that the Old IVorld Tropics were the main center of evolution for cold-blooded vertebrates, for example, is based on the knowledge "that the tropical part of the Old World $i s$ the largest favorable area for existence of cold-blooded life. . ..' 
[italics are mine], and on the misconception that north temperate to tropical climatic zones have not shifted much during the Cenozoic. It has been effectively demonstrated that there was a tremendously greater latitudinal expanse of tropical, subtropical, and warntemperate climates during the late Mesozoic and early Cenozoic interval when many of the now surviving orders and families and some of the genera of animals were actually beginning; even though the orientation of climatic belts was similar to the present.

Holarctica, although defined originally by the fauna living in the present temperate and frigid climates, means much more than the extant north temperate frigid region. When visualized through the span of its geochronologic age, most of Holarctica was tropical and subtropical throughout the first two-thirds of mammalian history. Perhaps the inception date for Holaretica should be specified as the time when oceanic and continental segments of the earth's crust were first arranged roughly as at present, whenever that might have been. I can see no utility for the term prior to the time of abundant land life, however, and probably not before the "Age" of endotherms. To the paleomammalogist, Holarctic is a shorthand term to signify: (1) the fauna of the northern world continent; (2) the northern world continent, characterized by its fauna through the geochronologic age of the fauna; or just (3) the world continent of North Africa, Eurasia, and North America through a geochronologic interval. The term is therefore, a generalization, involving geography, organisms, and time duration, with varying emphasis on these respective constituents. Holarctica, like fama, flora, stratigraphic zone, species, and many other terms in our technical dictionaries is entrenched by usage and is not vitiated because it has been used with differing connotations or because certain organisms do not have a dispersal history that can be described most effectively by using Holarctic and sister terms.

Many groups of mammals may have originated in tropical, subtropical, or warm-temperate biotopes, whether in northern latitudes or in the present "tropies." Entire orders of mammals may be autochthonous and endemic to the warmer and more humid areas, probably for varied reasons. As examples we may take the Primates, the Dermoptera, and the Chiroptera (with most exceptions). I suggest to the other contributors in this symposium that, if a "tropical" origin is proposed for a group of animals, they carefully specify 
whether "tropical" means past or present, for the geographic connotation is much different.

\section{CHARACTER OF THE FOSSIL LAND MAMMAL RECORD}

Mayr, Linsley, and Usinger (1953, pp. 14-15) have reemphasized that the study of many living groups of animals has hardly begun. If the knowledge of living groups is in its infancy, the knowledge of fossil groups is embryonic; for we yet lack complete study series in the fossil sample. Darwin (1859, end of Chap. $\mathrm{X}$ ), remarking on the poorness of the paleontological record, said: ". . I look at the geological record as a history of the world imperfectly kept, and written in a changing dialect; of this history we possess the last volume alone, relating only to two or three countries. Of this volume, only here and there a short chapter has been preserved; and of each page, only here and there a few lines. Each word of the slowly-changing language, more or less different in the successive chapters, may represent the forms of life, which are entombed in our consecutive formations, and which falsely appear to have been abruptly introduced." Matthew (1915, 1939 edition, pp. 13-14) noted: "We know more about fossil mammals in proportion to their modern numbers than about any other of the larger groups of land animals, yet the number of species of which we have any adequate knowledge is but a minute fraction of the number which must have lived since the class first came into existence." Even in a thoroughly studied district such as Crazy Mountain Field of Montana, Simpson (1937, p. 69) found that $25 \%$ of the species in the sample were known from only one specimen each. And new animals are yet being discovered in the frequently prospected Chadron formation of Nebraska (Cook, 1954). At the present time, and undoubtedly for a long time to come, we can claim little more than did Darwin or Matthew. The total taxonomic diversity may be usefully represented for some stratigraphic intervals, but only a few fossil assemblages adequately portray the populations that they represent.

Locations of the pre-Pleistocene land mammal localities of Nearctica are shown on Fig. 2. The record of earliest mammals is from two upper Jurassic localities, one in Wyoming and one in Colorado. (Late Triassic representatives of the class are found in Europe.) Fortunately the Wyoming site produced a splendid as- 


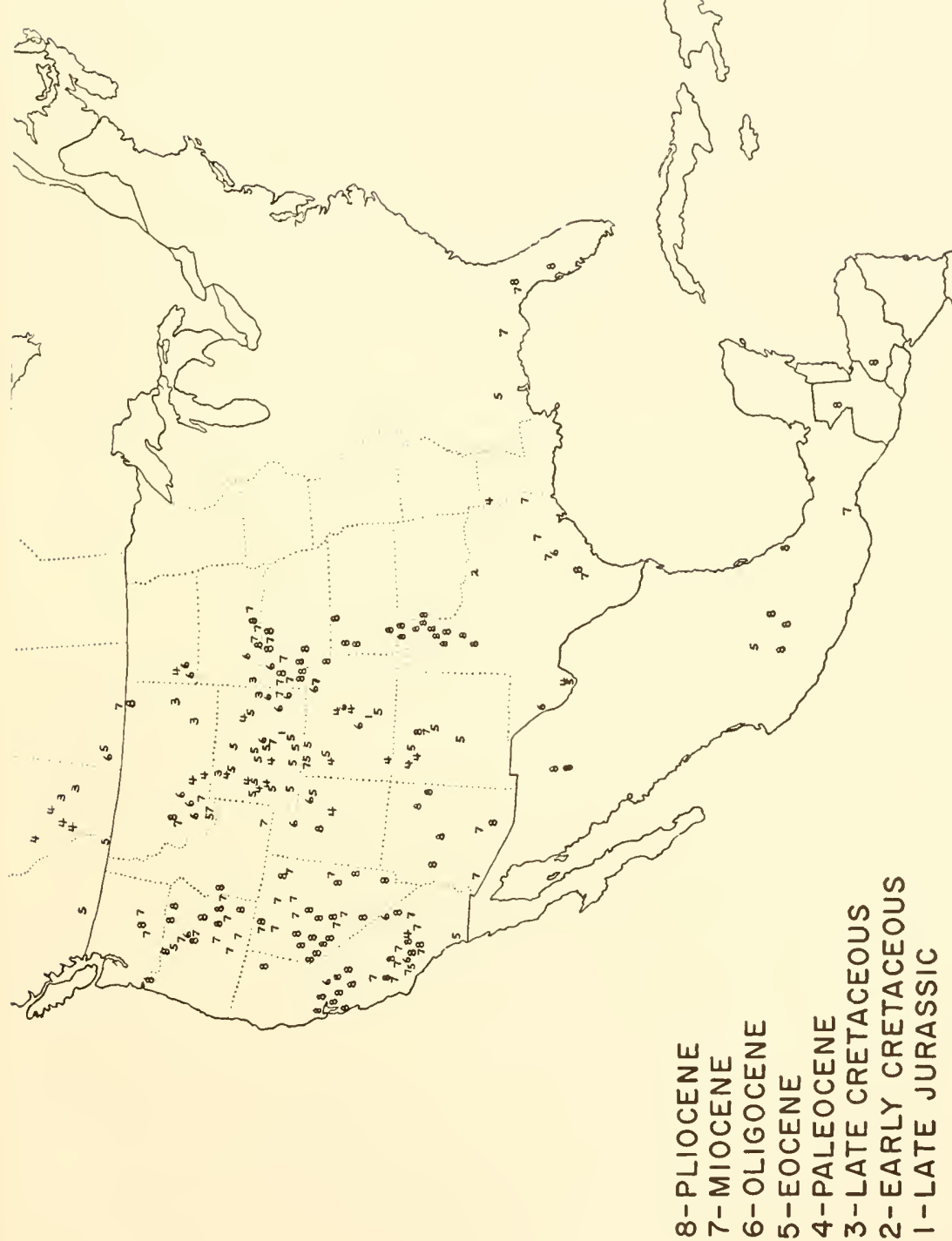


sortment of jaws and teeth and is one of the best of the Mesozoic mammalian assemblages (Simpson, 1929). The early Cretaceous record, at the threshold of dichotomy between eutherian (placental) and metatherian (marsupial) mammals, is limited to a few tantalizing scraps of bone, isolated teeth and jaw fragments from a site in north Texas (Patterson, 1956). The later Cretaceous land mammal localities-principally in Wyoming, Montana, and Alberta-indicate at present a curiously undiversified aggregate of multituberculates, didelphoids, and generalized eutherians.

The Cenozoic mammals of North America inherited an array of nonmarine environments that extended across the entire continent; for our emergent land mass has suffered only marginal inunclation through the last 70 million years. In the freshwater deposits of the middle and southern latitudes, mammalian aggregates have been uncovered that are delightfully complete and varied when compared with earlicr records, but they are woefully small as compared with the obtainable living sample of the same area. With the exception of the interesting Miocene and Pliocene faunas in Florida, the fossil mammal sample of western North America must represent all the Nearctic region. Very few pre-Pleistocene fossil mammal specimens have yet been found east of the Mississippi River.

Paleocene forms, tokened by skulls, dentitions, and some complete skeletons, have been collected in the present Rocky Mountain province. A few materials have been discovered in California (McKenna, 1955), and one jaw came from a deep well in Louisiana (Simpson, 1932). The better and more varied Paleocene assemblages are in New Mexico, Utah, Wyoming, and Montana.

Eocene mammalian local faunas extend from the West Coast into the Rocky Mountain area and from British Columbia (Russell, 1954) to southwest Texas (Wilson et al., 1952), and possibly to central Mexico (Fries, Hibbard, and Dunkle, 1955). A few fragments are known from New Jersey (Wood et al., 1941, p. 31; Gazin, 1953 , pp. 8, 34). The better and more diversified Eocene assemblages are in the Rocky Mountain states and in California.

Oligocene mammals are known from sites in the central part of western North America: from the northern Great Plains to California, from southwestern Saskatchewan (Russell, 1940) to southwestern Texas (Stovall, 1948). Best Oligocene assemblages are from 
Texas, from the world-famous White River group of the northern Great Plains, from Montana, and from Saskatchewan.

Late Cenozoic assemblages are widely scattered through the middle latitudes of western North America. Every western state claims several local faunas representing the last 30 million years of land mammal history on this continent. Pliocene Nearctic mammalian assemblages have been discovered as far south as Honduras (Olson and McGrew, 1941). Pleistocene localities would make a dense, stippled pattern for many areas on the map of Fig. 2 and have consequently been omitted. Some of the more important Pleistocene localities in the West include stream and lake deposits of the Great Plains and Texas, cave and shelter accumulations in the Southwest and Mexico, "mucks" and gravels in Alaska, and breas in California. This suite of samples forms the biostratigraphic basis for conclusions as to the origin and affinities of land mammals in western Nearctica.

\section{SIGNIFICANCE OF FOSSIL LAND MAMMAL SAMPLES}

Since at least the day of Madison Grant's (1904) essay on the origin and relationships of the large mammals of North America, such statements as the following have appeared in the literature: $\ldots$ the poverty of animal life which lived in $Y$ area ..., or ... in the $X$ beds of corresponding age, a similar but more limited fauna is found. These statements, usually based on little more than preliminary surface collecting in newly discovered fossiliferous areas, should have been carefully qualified as pioneer generalizations, but were not. The authors made no evaluation of the factors of accumulation, preservation, discovery, and collection; and the printed conclusions, in light of present knowledge, are no more than facile verbiage. It is no secret that paleontologists yet lack raw data as to the density and relative numbers of individuals, population size, species associations and the like in the once living biocenoses. Surprisingly, the more common a given fossil is in an area, the more likely that there is a poor census for the animal represented. Through the years, the common forms have been kicked aside in the quest for the "remarkably new" exhibition specimens or the perfect study skeleton. Some collectors have been disproportionately intrigued with the remains of giants (alas, the lust for the mighty 
dinosaur!); others spurn the labor-consuming giants for microsized remains; others collect only complete skulls or skeletons and discard individuals represented by only fragmentary specimens.

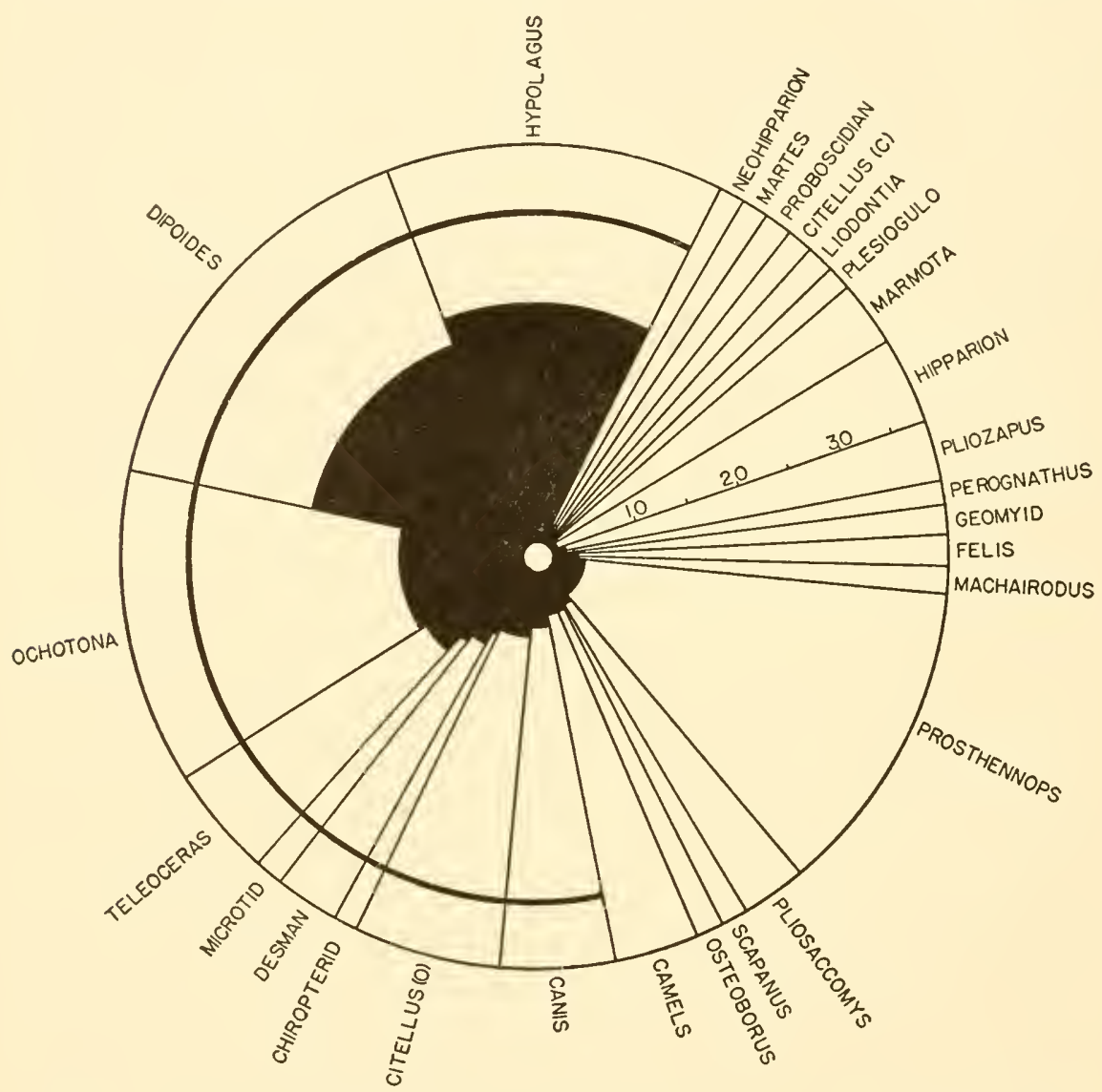

Fig. 3. Faunal analysis diagram of the quarry sample from McKay Reservoir, Oregon. The divisions of the circle graph represent relative abundance of the mammals indicated. The radial bar graph represents the number of specimens per individual. The heavy concentric line includes genera assigned to the proximal community. Reproduced from Shotwell (1955, p. 333).

Shotwell (1955) demonstrated, as in Fig. 3, that useful census and ecological interpretations may be derived from a meticulously collecter fossil sample. Such a sample will be composed of all the obtainable bones and bits of bones from a given site. Shotwell pro- 
vided an objective basis for the evaluation of the numbers of individuals of each species in the sample and from this census inferred the species whose ranges were more proximal or more distal to the accumulation site. No doubt other interpretations of the data will differ from Shotwell's, for, as Shotwell notes, many variables and assumptions are involved, but a new method of inquiry has been pioneered. And this approach to the significance of relative numbers of fossil remains at a given locality will make the formerly indifferent collector think twice before destroying or leaving behind the identifiable fragments.

The taxonomic composition of quarry samples may differ significantly from samples made up of specimens picked up only on the surface of a fossil-bearing stratum. Simpson (1937) noted the differences between two such samples in the Paleocene of Montana and concluded that the apparent differences probably represented two facies of the fauna. In a footnote (p. 52) he remarked:"Correlations of faunal types and collecting methods are real but indirect. Flood-plain deposition and facies would not normally result in concentration of fossils sufficient to permit profitable quarrying." Van Houten (1945) concluded that in the continental sediments of late Paleocene and early Eocene ages in the Rocky Mountain region there is a definite relationship between mamalian faunal facies and the lithofacies. He found (p. 444) that the arboreal forest faunal facies [micro-mammals] are concentrated in local pockets of the drab grayish sediments, whereas the large ungulates and creodont carnivores, representing savanna floodplain habitats, are sparsely scattered throughout the red-banded varicolored sediments. Here the micro-mammal facies were obtained from quarries and the mega-mammal facies from surface collecting. A comparison of a quarry sample with the surface discoveries from one formation shows taxonomic and census differences comparable to those in the lithofacies studied by Simpson and by Van Houten. Simpson (1935, p. 4) showed the abundance of different species in the Tiffany fauna, late Paleocene, from the San Jose formation of southwestern Colorado. In his chart, here slightly modified (Fig. 4) following later work by Simpson, the numbers of micro-mammals from the Mason Pocket faunule, contained in less than a cubic yard of marrix, are compared with the known surface discoveries on the upper Paleocene part of the San Jose formation. In this comparison only one species, 
Plesiadapis gidleyi, among the eight known from the San Jose surface and among the eleven from the pocket, is common to the two assemblages. The larger animals such as Phenacodus and Periptychus are known only from surface finds; so that one's concept of faunal composition would be completely different if only the surface ma-

\section{MASON POCKET ELSEWHERE}

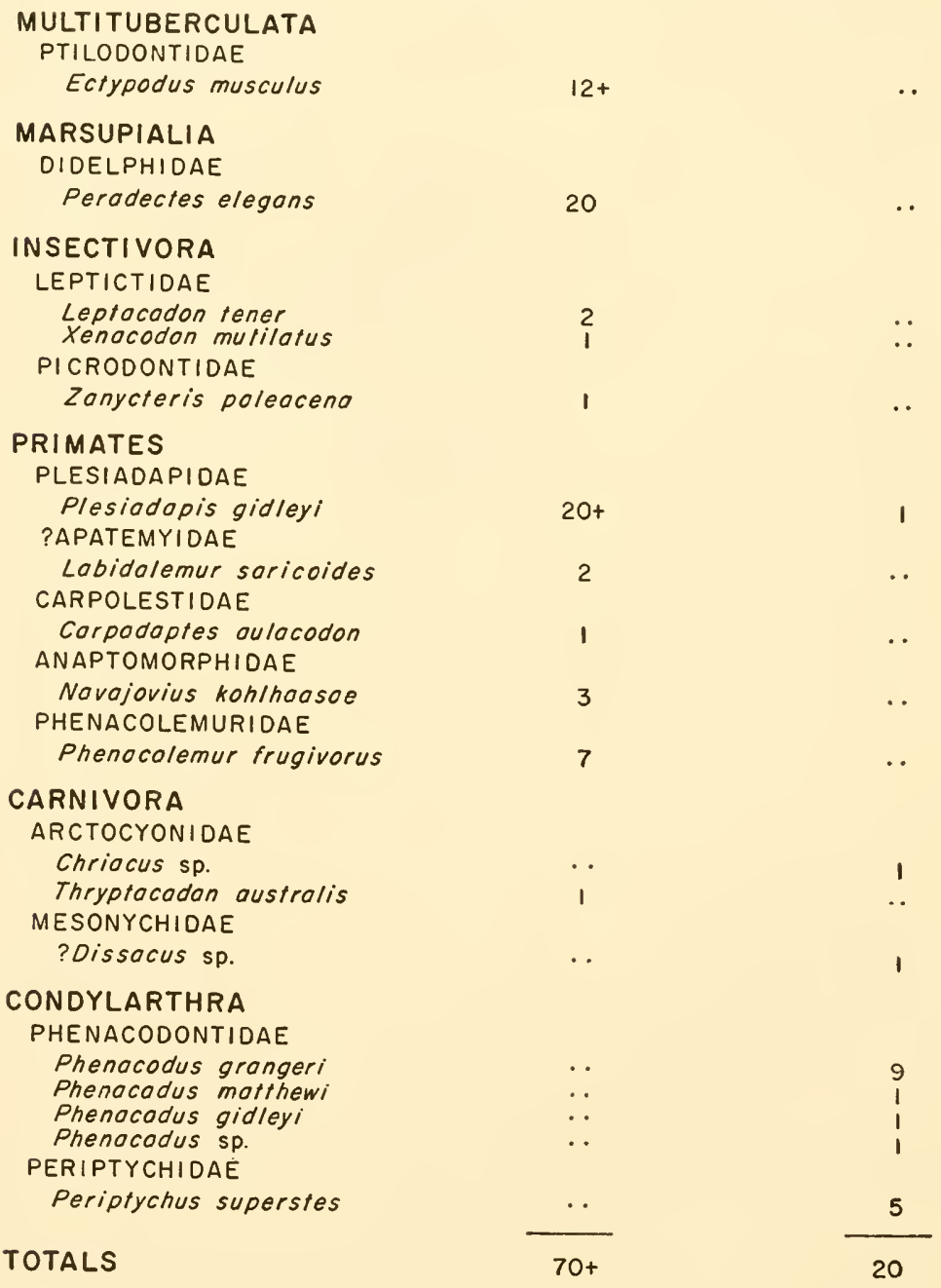

Fig. 4. Census of individuals of various land mammal species from the Mason Pocket and from elsewhere in the San Jose formation, late Paleocene, Colorado. Modified from Simpson (1935, p. 4). 
terial had been collected. Taxonomic and relative abundance differences may be the result of incomplete quarrying at the site of surface discoveries (one jaw on the surface may indicate fifty at six feet down!), or lithofacies differences may indicate a complete biofacies change, as suggested by Simpson and by Van Houten. The final confirmation of one or more of the various possibilities rests on the completion of exhaustive quarrying with improved collecting techniques in the areas where the variegated, red-banded formations are exposed and where the sample is essentially surface pickup at present.

During the last fifteen years several institutions in the midwestern and western United States have been employing a screen-washing technique for the recovery of small fossils. This technique calls for the handling of tons of fossiliferous sediment. The sediment is washed through screen boxes. Available bodies of water are used, whatever they may be: streams, lakes, stock tanks, or the ocean. Fossiliferous matrix, frequently appearing quite barren on its surface exposure, is quarried and shoveled into burlap bags for transport to the washing site. Experience has shown that the transport distance may be 20 miles or more before the method can be considered unprofitable in terms of collecting expense. At the water, the matrix is screen-washed, dried, and picked; and the number of specimens recovered is often astounding when compared to standard quarrying methods. During three summer seasons in the lower Eocene of northwestern Colorado and adjacent Wyoming, M. C. McKenna and colleagues of the University of California obtained about 20,000 individual specimens of teeth, jaws, and bones of ultra-small fossil vertebrates. And these were taken from terrain that had been passed over and considered unworthy for collecting by earlier workers. Through a work period of five months, we have washed slightly more than 30 tons of sandstone and have recovered 2,500 museum specimens of fossil mammals from the late Cretaceous of Wyoming. This is about one mammalian study specimen for each 24 pounds of matrix. And these mammals are especially significant to the understanding of basic diversification (now largely conjectural) within the Class Mammalia. Even greater numbers of specimens representing a combined assemblage of lizards, frogs, snakes, fishes, dinosaurs, turtles, crocodiles, and birds were obtained from the depositional association with the Cretaceous mammals. In both the Eocene and 
the Cretaceous, the first and principal sign of the richly fossiliferous matrix was an accumulation on an ant hill of tiny teeth, gar scales, reptile teeth, and the like.

These are admittedly the words of an enthusiast. Screen washing is not the solution for all collecting problems, and it is efficient only as a mass production technique. Some matrices and some fossils are not susceptible to this type of treatment. But the method is useful in many areas, and it may be especially useful for census and ecology studies in the varicolored flood-plain formations that have been proclaimed barren by previous workers.

The possible contrast in abundance of adaptive types between samples from the drab gray quarry pockets and the varicolored flood-plain deposits is also interesting. In the continental late Paleocene of the Rocky Mountains, Simpson $(1935,1937)$ and Van Houten (1945) found that the small herbivores abound in the quarry samples and that the large herbivores, carnivores, and carnivore-omnivores are relatively abundant in the scattered surface finds. Combined floral, faunal, and sedimentological clata show that these late Paleocene environments were in intermontane lowlands and were subject to humid warm-temperate or subtropical climate (Knowlton, 1917, 1924; Berry, 1935; Bell, 1949). By contrast, work in the late Miocene deposits in the Cuyama Badlands of southwestern California shows quite different proportions of adaptive types. Figure 5 gives the stratigraphic correlation between red-bed and gray-bed occurrences of land mammals within the Caliente formation in this area. Present mapping and studies of the physical stratigraphy of the district indicate that the red-bed and gray-bed mammal locations, here assigned to the Barstovian (late Miocene) Mammalian Age, are geochronologically contemporaneous. Figure 6, a preliminary census of the Caliente formation mammals, is based on both surface collecting and incomplete quarrying in both lithofacies. In this comparison it may be noted that the small insectivores and herbivores (including rodents and rabbits) are relatively abundant in the red beds, whereas large herbivores, such as camels, horses, and oreodonts, are the dominant element in the gray-bed faunule. The Cuyama example, therefore, suggests a quite different relationship between lithofacies and mammalian adaptive types. Combined paleontological and geological evidence shows that the Cuyama paleobiotope was in coastal intermontane valleys and was subject 


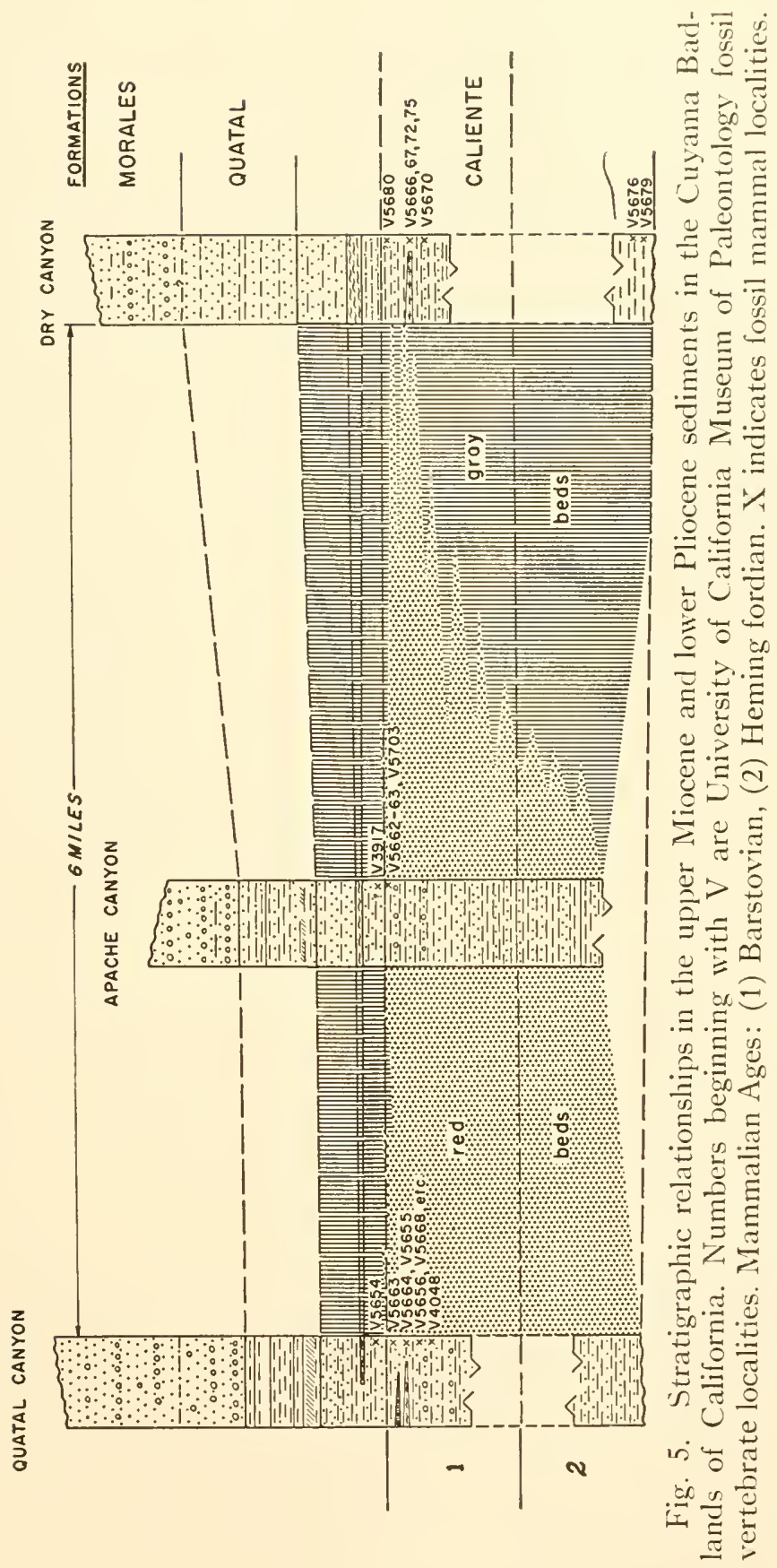




\section{BARSTOVIAN MAMMALS IN THE CALIENTE FORMATION}

RED BEDS

GRAY BEDS

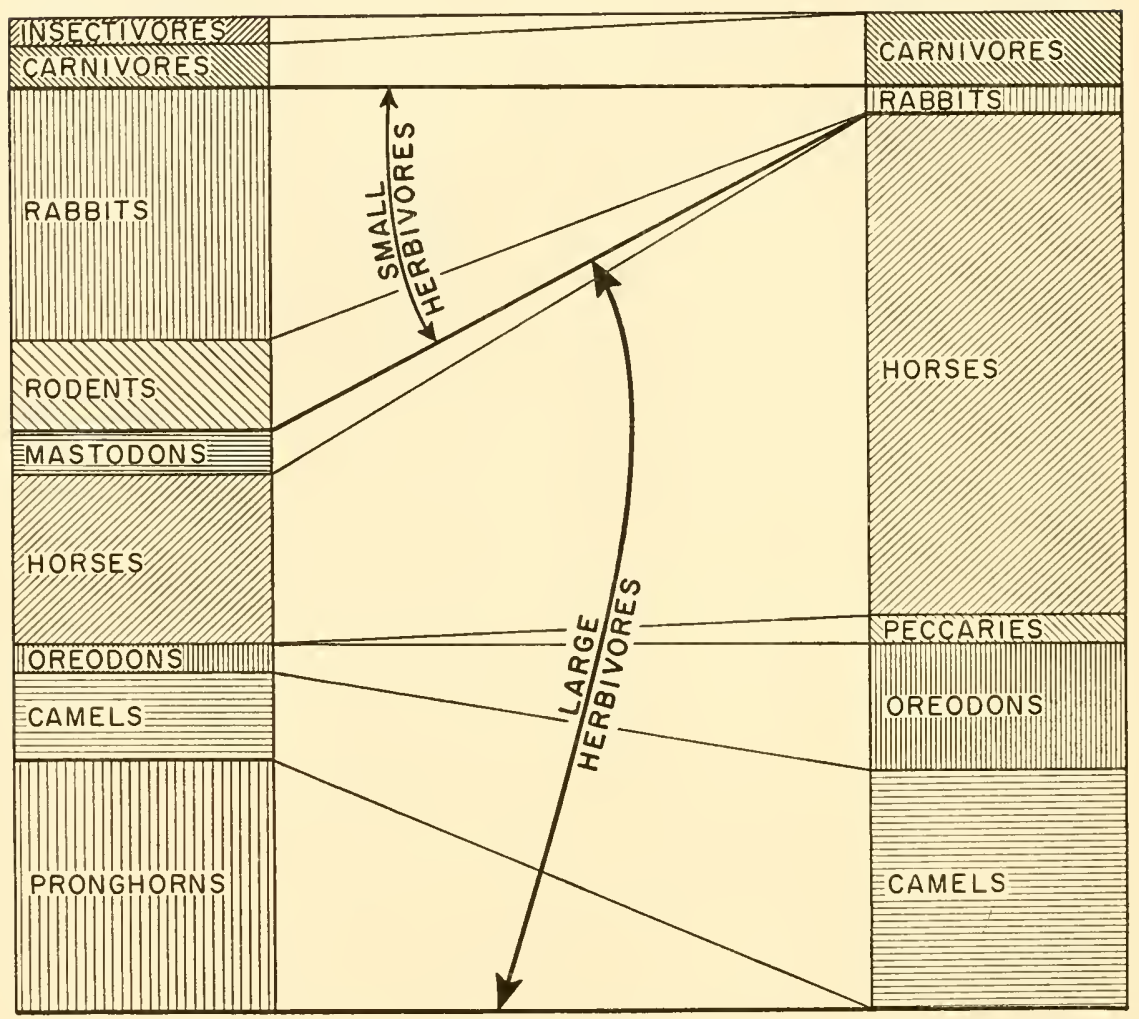

Fig. 6. Census of land mammal adaptive types in the late Miocene Caliente formation of southwestern California, showing approximate abundance of each type on a percentage bar graph for the red-bed facies and the gray-bed facies respectively.

to probable temperate-mesic to xeric climatic conditions, depending upon local topography (Axelrod, 1940, 1950; Dibblee, 1952; Durham, 1950; Schwade, 1954). But this comparison between the paleobiocenoses across western North America provides only tentative conclusions because:

1. The compared faunas are dissimilar taxonomically.

2. There was a profound climatic and vegetative difference between the two areas. 
3. Approximately 45 million years, a sufficient interval for great evolution of morphologies and change of ecological-physiological tolerances, elapsed between early Eocene and late Miocene.

4. There are possible subtle differences between the similar lithofacies of the two areas. Similar lithofacies were not necessarily formed under the same environmental conditions. The color differences in the Caliente formation may mean little more than differing sediment-source, and both the red and the gray facies may have been deposited in the same physical environment.

Detailed sedimentological studies have not yet been accomplished, and much work lies ahead. Nevertheless, the example from Cuyama suggests that conclusions as to relative abundance of taxonomic units and adaptive types in certain lithologies are premature and may be completely misleading, especially when based on samples collected by techniques of disparate refinement.

\section{HISTORY AND AFFINITIES OF THE ORDERS OF NEARCTIC LAND MAMMALS}

Earliest records of the class Mammalia are from the late Triassic of England, but generalized reptilian progenitor stocks are known from South Africa as well as in various Holarctic districts. Therefore, on the basis of the stratigraphic record, the possibility of either Holarctic or Paleotropic origin for the class Mammalia must be conceded.

Pre-Paleocene land mammal faunas are so poorly known on most continents that little can be determined as to intercontinental dispersal and affinities. From late Paleocene to the present, however, the fauna of North America is clearly dominated by groups common to many parts of Holarctica, especially such forms as shrews and moles, rabbits and pikas, sciuromorph and myomorph rodents, creodont and fissiped carnivores, condylarths, uintatheres proboscideans, perissodactyls, and artiodactyls. All zoogeographers know that the Nearctic Cenozoic mammalian fauna differs markedly from the prototherian-metatherian fauna of Australasia and is only slightly less distinct from the pre-Pleistocene metathere-edentatearchaic ungulate assemblage of South America.

Nearctica is dominant in the recorded range and clispersal of the 33 recognized orders of land mammals (Fig. 7), but only 9 orders (with 27 families) are represented here by living forms: Marsupialia 
(1 family); Insectivora (2 families); Primates (1 family); Chiroptera (3 families); Edentata (1 family); Carnivora (5 families); Lagomorpha (2 families); Rodentia (8 families); Artiodactyla (4 families). However, 14 additional orders were here during various intervals of the Mesozoic and Cenozoic, but are now either extinct or survive on other continents: Multituberculata (extinct); Triconodonta (extinct); Docodonta (extinct); Pantotheria (extinct); Symmetrodonta (extinct); Dermoptera (now in the Paleotropics); Tillodontia (extinct); Taeniodonta (extinct); Condylarthra (extinct); Notoungulata (extinct); Pantodonta (extinct); Dinocerata (extinct); Proboscidea (now in the Paleotropics); Perissodactyla (now in the Paleotropics, Palearctica, and Neogaea). Of the 23 orclers of land mammals recorded in Nearctica, 9 have earliest record here, and 6 have earliest record here and elsewhere. First let us consider the possibility that Nearctica was the origin and dispersal center for these 15 orders, following the criteria proposed in the first part of this paper; then we may consider the possible Nearctic origin for other orders. Center of origin or origin area, as here used, of course means place where earliest and most primitive members appeared.

\section{Orders with Earliest Record in North America}

1. Multituberculata (extinct)

a. Earliest record in upper Jurassic of England and United States

b. A group of uncertain phylogenetic affinities

c. Possibly originated somewhere in Holarctica

2. Marsupialia

a. Earliest record in upper Cretaceous

b. Comparisons on the basis of jaws and characters of dentition leacl to conclusion that this group was derived ultimately from the Jurassic mammalian radicle, the Pantotheria; but forms with annectant morphologies are unknown

c. Possibly originated in North America, but comparable Cretaceous biocenoses are poorly known in Asia and are not yet known on the other continents

3. Dermoptera ("flying lemurs")

a. Earliest record in upper Paleocene

b. Probably distinct since middle or early Paleocene derivation from generalized unguiculate eutherian; intra-ordinal relationships are uncertain

c. Possibly originated in North America, but poorly known in the North American fossil record and unknown as fossils elsewhere 


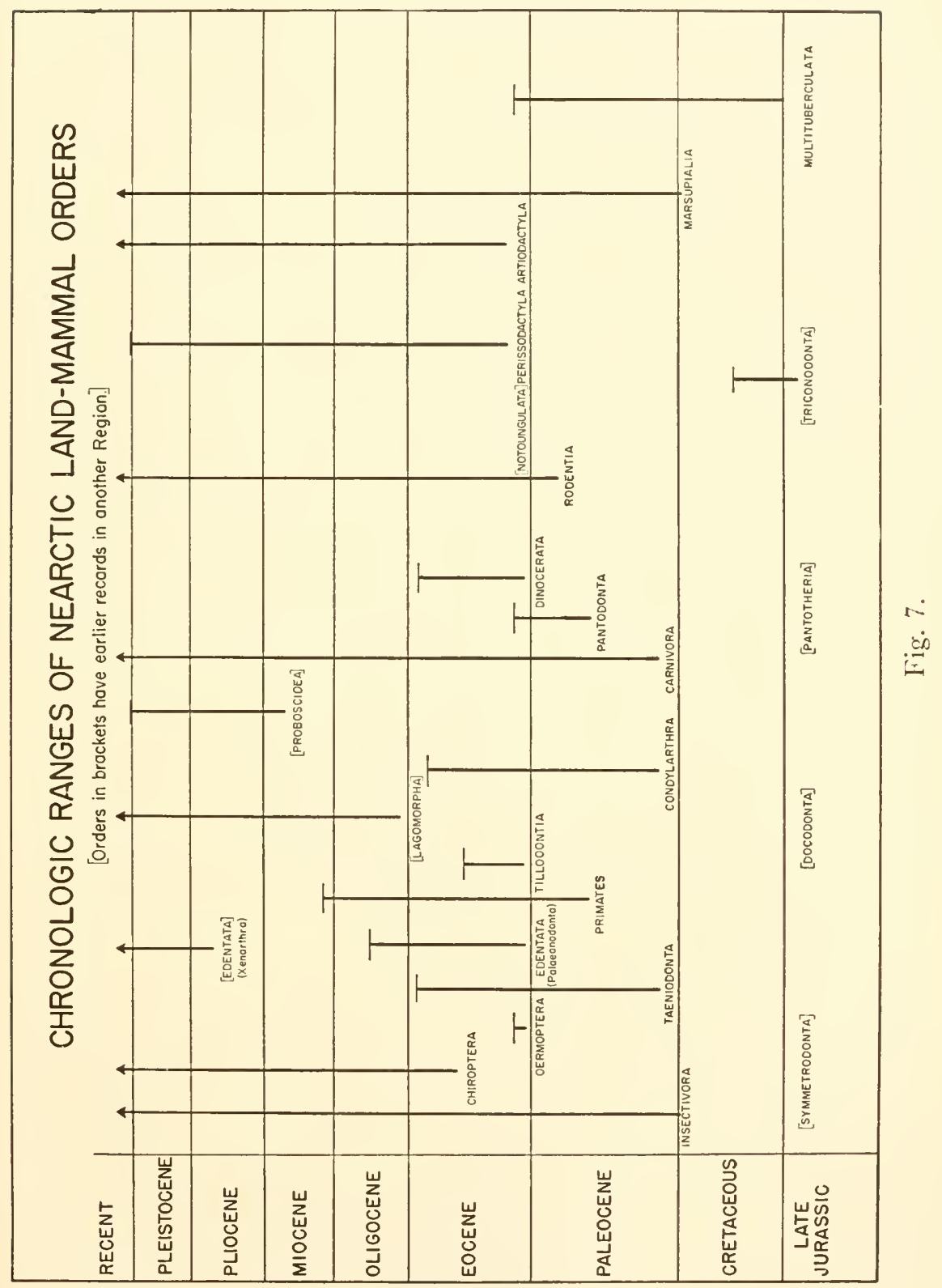


4. Chiroptera (bats)

a. Earliest record in Eocene of North America and Europe

b. Probable latest Mesozoic or Paleocene derivation from a eutherian stock (Insectivora?)

c. Bat-like forms are reported from the late Paleocene of North America, but the group is too poorly known to conjecture as to center of origin

5. Primates

a. Earliest record in middle Paleocene

b. An early Paleocene or latest Cretaceous differentiation in the radicle Eutheria

c. Possibly originated in North America, but mammal-bearing deposits as old as the early North American records are not known on the other continents

6. Tillodontia (extinct)

a. Earliest record in upper Paleocene

b. An early to middle Paleocene differentiation from unguiculate (?) stock

c. Possibly originated in North America, but evidence inconclusive

7. Taeniodonta (extinct)

a. Earliest record in lower Paleocene

b. A probable late Cretaceous differentiation within the Eutheria

c. Entire record of this group is in Nearctica

8. Edentata

a. Earliest record in upper Paleocene

b. An early to middle Paleocene differentiation from unguiculate stock

c. Probable Nearctic origination because the earliest forms known lack dermal armor and have a less specialized skeleton; but early and middle Paleocene records of mammals are lacking in Neogaea, the center of mid-Cenozoic evolutionary radiation of the Edentata

9. Rodentia

a. Earliest record in upper Paleocene

b. Presumed origin from early or middle Paleocene unguiculate stock, but annectents are completely unknown

c. Possibly originated in Nearctica, probably in Holarctica, but evidence is inconclusive

10. Carnivora

a. Earliest record in lower Paleocene

b. Probably derived from a late Cretaceous eutherian group that has been referred to the Insectivora or is not yet recorded; possibly became a discrete group before the end of the Mesozoic

c. Probably of Holarctic origin, possibly in Palearctica

11. Condylarthra (extinct)

a. Earliest record in lower Paleocene 
b. A horizontally classified group in which subdivisions are presumably derived from a ferungulate stock; some of the families are a probable late Cretaceous differentiation

c. Most of the families (Hyopsodontidae, Phenacodontidae, and Periptychidae) may have originated in North America, although some paleomammalogists would propose origin elsewhere because of the "sudden" appearance of differentiated groups in the lower Paleocene here. Didolodontidae, as presently recognized, appear to have a South American history, but are only slightly divergent from phenacodonts (McKenna, 1956). Meniscotheriidae might have originated in Palearctica

12. Pantodonta (extinct)

a. Earliest record in middle Paleocene

b. An early unique differentiation within the Eutheria, possibly a derivative of the ferungulate radicle but annectants with earlier eutherians unknown

c. Probably of Holarctic origin

13. Dinocerata (uintatheres, extinct)

a. Earliest record in upper Paleocene of North America and Asia

b. Unique giants of uncertain phyletic origin within the Eutheria, possibly derived from a ferungulate stock

c. Probably of Holarctic origin

14. Perissodactyla (horses, tapirs, rhinos)

a. Earliest record in lower Eocene of North America and Europe

b. Probably derived from advanced phenacodontid condylarths of the type seen in the middle and late Paleocene of North America

c. Possibly originated in North America but the pre-perissodactyl record is poorly known in Eurasia

15. Artiodactyla (pigs, deer, bovids)

a. Earliest record in lower Eocene of North America and Europe.

b. Probably derived from a generalized eutherian group of Paleocene

c. Probably of Holarctic origin, possibly of Paleotropic origin

Eight orders of mammals known in North America have earlier records elsewhere: Triconodonta, Docodonta, Symmetrodonta, Pantotheria, Insectivora, Lagomorpha, Proboscidea, and Notoungulata. On the basis of prospecting and collecting data for North America these orders may be divided into two groups: those that may have a yet unknown earlier record in North America and those that more probably do not have an earlier record in North America. The lagomorph, proboscidean, and notoungulate beds of this continent are underlain by relatively well-explored mammal-bearing strata; hence, these orders fall into the second group. The other orders, all with earliest record in the Mesozoic, may be included in 
the first group, and it is pointless to guess as to an origin area, even an area of continental size.

The remaining orders, not presently recognized in the Nearctic record, can be discussed briefly.

1. Monotremata, as Patterson (1956, p. 100) has suggested, may be related to forms that are being uncovered in the late Triassic of England. This Mesozoic group (Docodonta Kretzoi, fide Patterson) has representatives in the late Jurassic of North America.

2. Pholidota, Embrithopoda, Hyracoidea, and Tubulidentata have no presently recognizable North American affinities. The relationships between hyracoids and the Holarctic, early Cenozoic meniscothere condylarths are yet to be studied thoroughly. The affinity of Tubulodon Jepsen from the early Eocene of North America with the Tubulidentata is disputed (Jepsen, 1932; Colbert, 1941). More fossil material referable to Tubulodon is badly needed.

In summary, the evidence appears strongest for Nearctic origin of the marsupials, edentates, tillodonts, taeniodonts, perissodactyls, dermopterans, primates, and rodents. For none of these groups, however, is the evidence compulsory. Figure 7 also demonstrates that late Paleocene through Eocene was the time when most of the modern orders of mammals arose.

\section{HISTORY AND AFFINITIES OF THE MINOR TAXONOMIC GROUPS}

Simpson (1947) so meticulously covered the evidence for origin and dispersal direction of families and certain lesser taxa of North American mammals that it would be superfluous to do more than summarize his conclusions. Figure $S$, showing possible origins, is presented with the belief that most of the participants in this symposium will be interested primarily in the families that are now living. It is to be remembered that an individual subfamily, genus, or species does not necessarily correspond with the origin and dispersion of its family; for example:

1. Castor (beaver; Castoridae) evidently dispersed from Palearctica to Nearctica; Miocene and middle Pliocene members of the family dispersed in the opposite direction.

2. Didelphis (opossum; Didelphidae) and Tayassu (peccary; Tayassuidae) appear to be Neotropical autochthons and Nearctica is recently marginal to their expanded or expanding range. 


\section{ORIGIN AND DISPERSAL OF LIVING NEARCTIC MAMMALIAN FAMILIES'

$R E G I O N S$
PALEARCTIC NEARCTIC NEOTROPIC

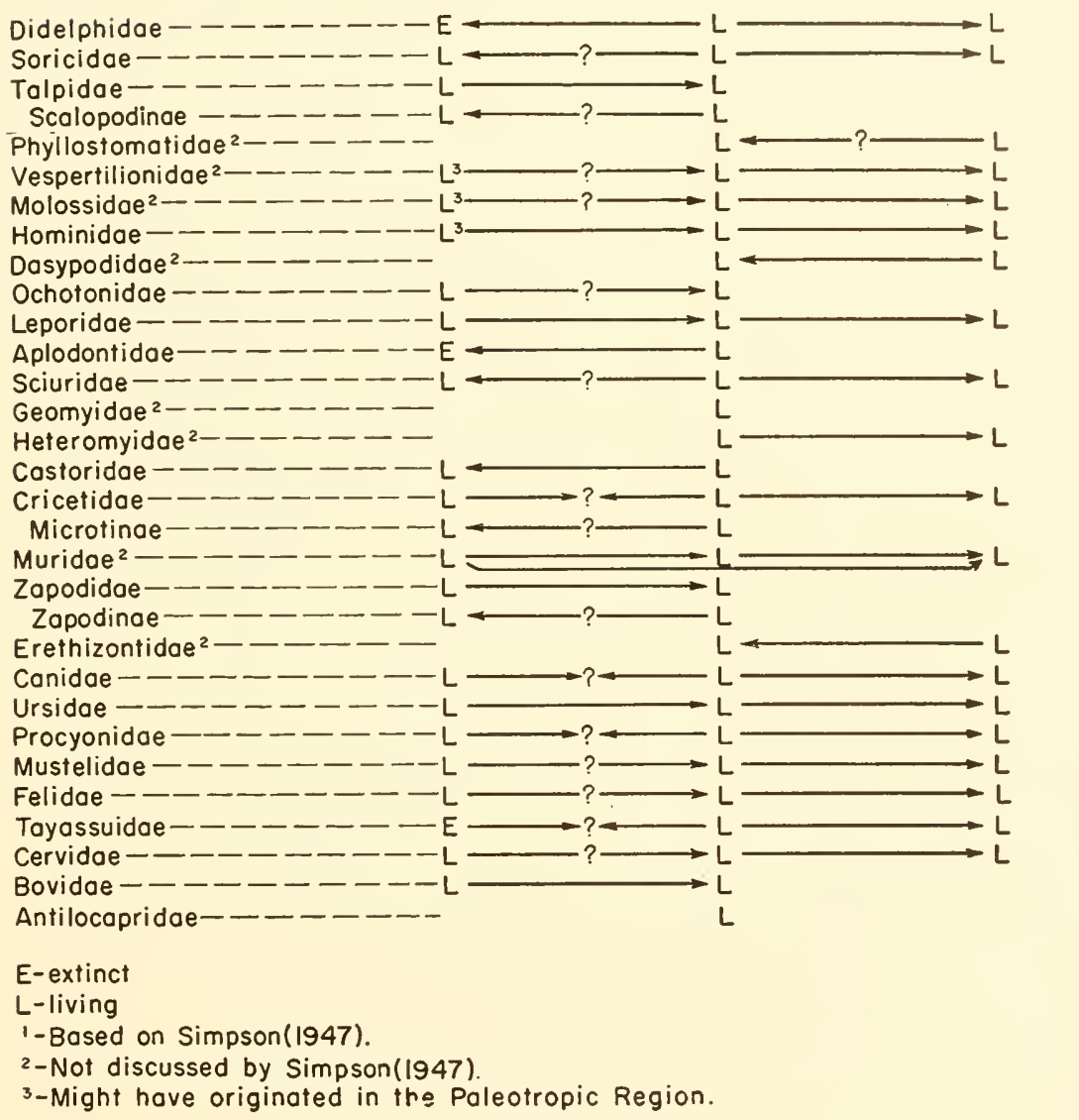

Fig. 8.

A consideration of the time of origin of the 28 living Nearctic families (Fig. 9), supports the generalization that the Oligocene or possibly late Eocene-Oligocene, was the interval of inception of modern families of mammals. ${ }^{2}$

The living genera of Neàrctica are either autochthonous or have immigrated from Palearctica or from the Neotropics. Interpretation

${ }^{2}$ Old World and South American families have a comparable geochronologic history. 
of the origin of these genera is shown in Table I. We may say that the interval from Miocene into Pleistocene was the time when most modern genera of land mammals arose.

Most species in the living Nearctic land mammal fauna are evidently autochthonous. Probable exceptions are the transboreal

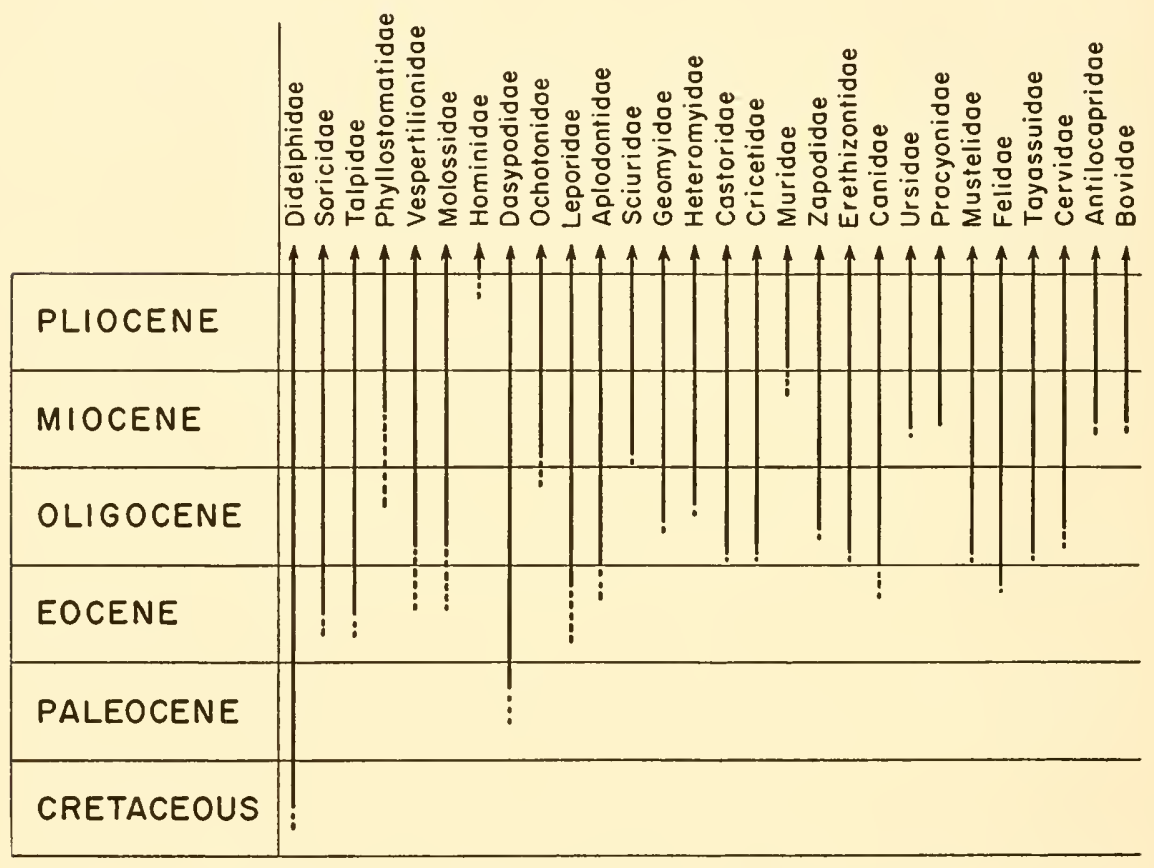

\section{TIME OF ORIGIN OF LIVING NEARCTIC MAMMALIAN FAMILIES}

Fig. 9.

forms, such as the moose, muskox, caribou, and polar bear; certain "pan-American" forms, such as Eptesicus fuscus (big brown bat), Lasiurus borealis (red bat), Tadarida macrotis (big freetail bat), and Eumops perotis (Western mastiff bat); and probable Neotropical autochthons - Dasypus novemcinctus (armadillo) and Tayassu angulatus (peccary). A species list of land mammals from the Pleistocene [including the Holocene of some workers] is given by Hibbard (1956; in Flint, 1957, pp. 458-467). No taxonomist will recognize exactly the same number of species as appear on the compilation by 
Hibbard; but it is beyond the intent of this paper to consider the taxonomic problems of Pleistocene mammals or the effects of "splitting" or of "lumping" on the species lists of fossils. Hibbard's list indicates the general stocks that were available for evolutionary modification and zoogeographic change through the last few thousand years. Many of the late Pleistocene animals are very similar in hard part structures to the living species and have been so identified. Very few of the middle or early Pleistocene forms have been referred to living species.

Intercontinental faunal comparisons show probable trans-Holarctic mammalian dispersal waves during most of the subepochs from late Jurassic through late Pleistocene. Strongest evidence for such dispersal is found in the late Jurassic, late Paleocene, early Eocene, early Oligocene, middle to late Miocene, and middle Pliocene through late Pleistocene. Sharp peaks in the intercontinental faunal resemblance curve indicate, as shown by Simpson (1947), that these dispersals were discontinuous pulsations.

\section{SUMMARY}

1. A given area may be considered the most probable center of origin of a group of animals if : (a) it contains the earliest record of the group; $(b)$ it contains the record of suitable progenitors; $(c)$ it contains greatest taxonomic differentiation within the group; $(d)$ it contains a large and continuous geographic range of the group.

2. The extant climatic belts and districts are poor geographic indices for late Mesozoic-early Cenozoic arrangements. Therefore, to propose the Holarctic or Paleotropic or other regions as centers of origin and dispersal for a given group of animals we must first evaluate the climate and ecology of these regions at the time of origin.

3. The fossil sample may now give a good picture of the taxonomic diversity of once living mammals for some districts, but the study of paleobiocenoses, based upon significant numbers of individuals, is in its infancy.

4. The biostratigraphic record is not yet adequate to reveal precisely the districts of origin and directions of dispersal for many groups of land mammals.

5. Useful census and ecological interpretations may be derived from a meticulously collected fossil sample made up of all identi- 


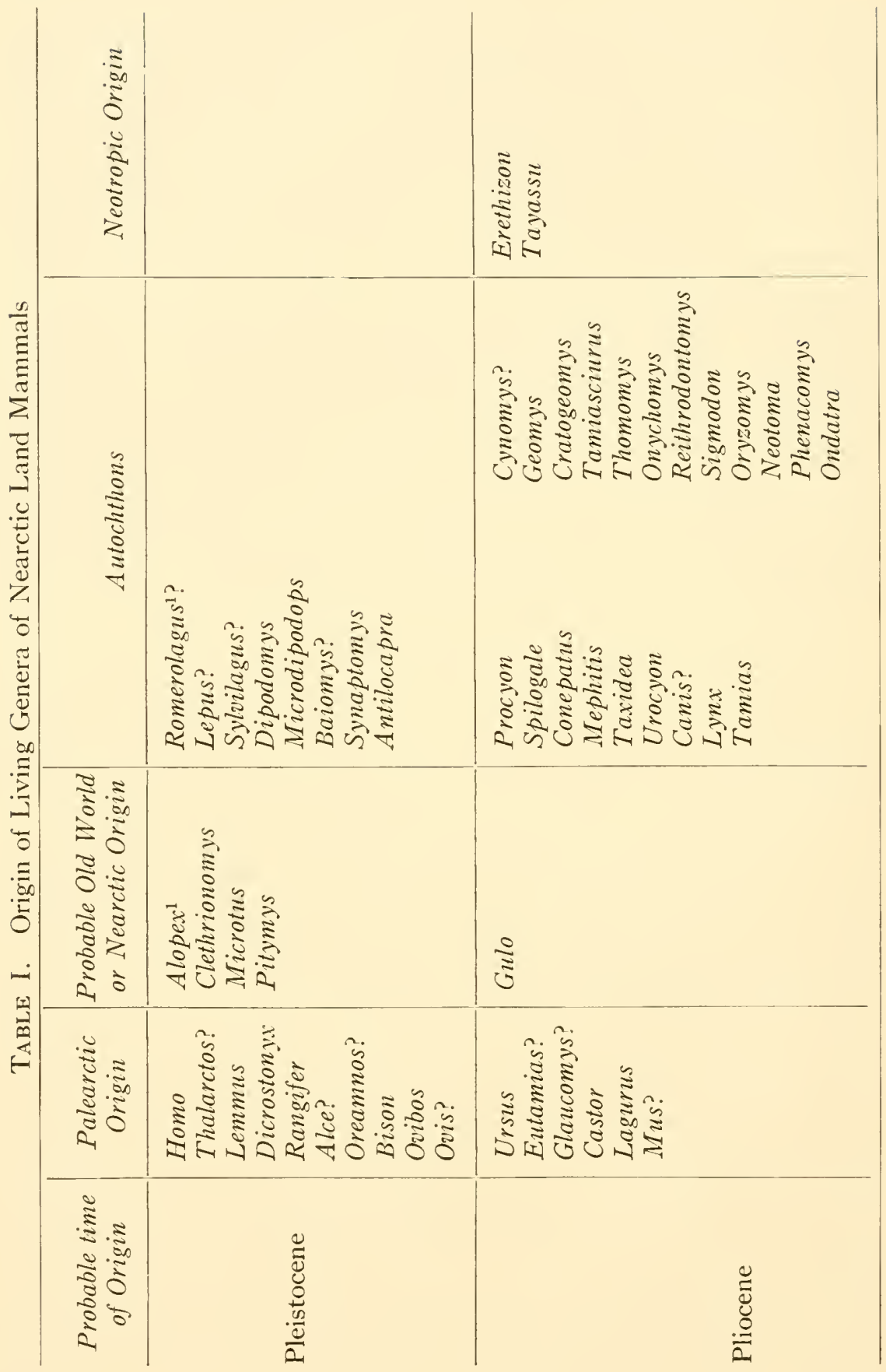




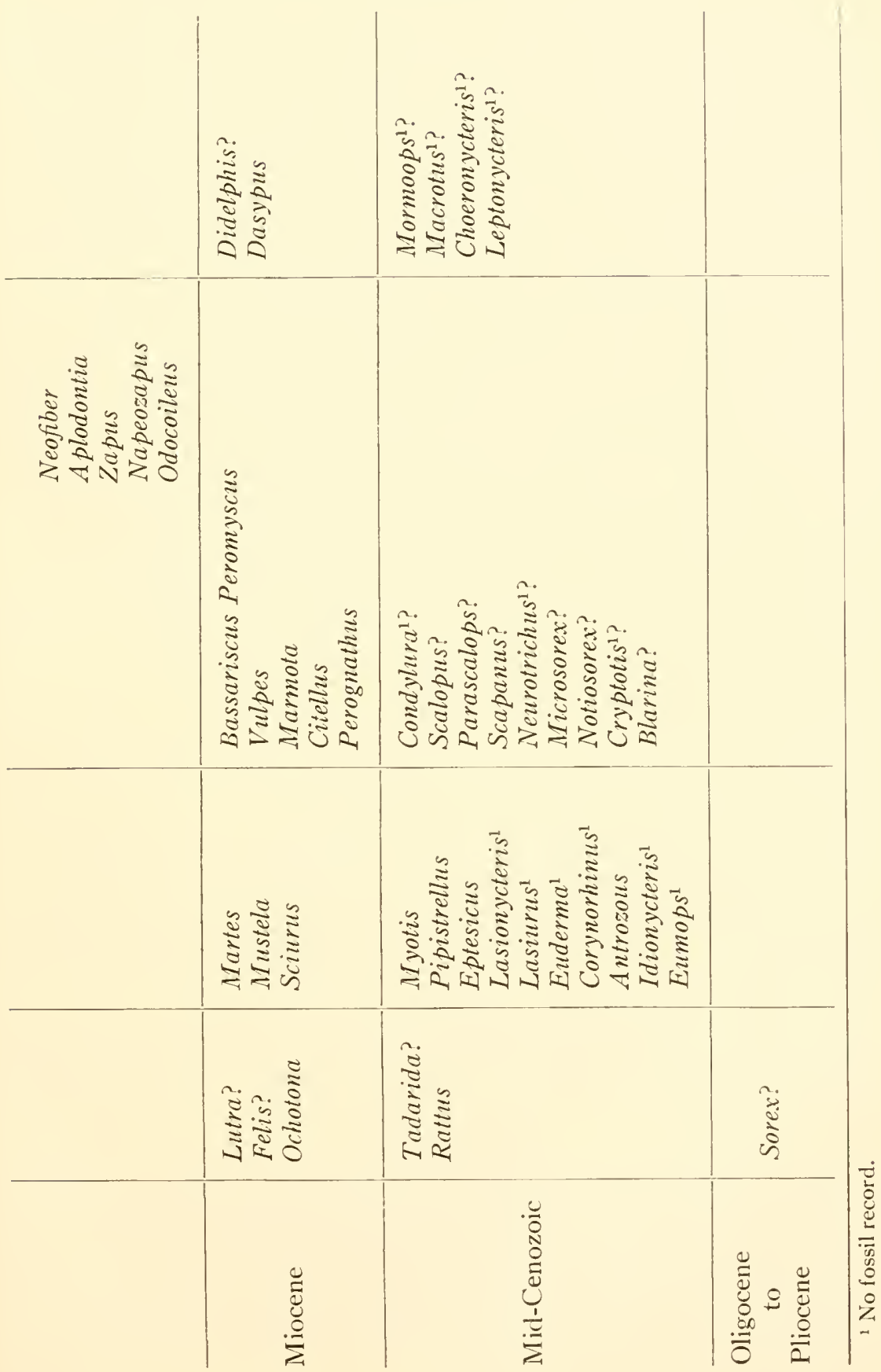


fiable bones and bone fragments. This statement is trite unless considered in the light of the actual case history of fossil vertebrate collecting.

6. It is possible that there may be a fixed relationship between mammalian faunal facies and the containing lithofacies, but previous generalizations as to this possibility were premature and will have to be confirmed by exhaustive quarrying and by improved collecting methods.

7. Screen washing is being applied to formations that earlier workers believed to be unprofitable for recovery of fossils. The abundance of small vertebrates in these formations indicates that we may obtain large samples from seemingly barren, red, redbanded, or varicolored flood-plain deposits.

8. Evidence is strongest for the Nearctic origin of Marsupialia, Edentata, Tillodontia, Taeniodonta, Perissodactyla, Dermoptera, Primates, and Rodentia, but the evidence is not conclusive. These orders evidently differentiated within the Infraclass Eutheria in the interval extending through late Cretaceous and Paleocene, roughly 85 to 65 million years ago.

9. About $35 \%$ of the living land mammal families of Nearctica are autochthonous, about $7 \%$ endemic; most of the families originated in the interval late Eocene-Oligocene, approximately 50 to 35 million years ago.

10. About $70 \%$ of the modern Nearctic land mammal genera are probably autochthonous; and as many as $15 \%$ were living as early as late Miocene, $30 \%$ by middle Pliocene. All together, the genera originated from about 15 million to possibly several thousand years ago.

11. About $97 \%$ of the modern Nearctic land mammal species are probable autochthons that originated in the interval, later Pleistocene into Recent, possibly two or three hundred thousand years ago to present.

\section{REFERENCES}

Axeirod, D. I. 1940. The Mint Canyon flora of southern California: a preliminary statement. Am. J. Sci., 238: 577-585.

- 1950. Evolution of desert vegetation in western North America. Carnegie Inst. Wash. Publ., 590: 215-306.

- 1952. Variables affecting the probabilities of dispersal in geologic. time. Bull. Am. Museum Nat. Hist., 99: 177-188. 
Bell, W. A. 1949. Uppermost Cretaceous and Paleocene floras of western Alberta. Bull. Geol. Surv. Canada, 13.

Berry, E. IV. 1935. A preliminary contribution to the floras of the Whitemud and Ravenscrag formations. Mem. Geol. Surv. Canada, 182.

Chaney, R. W. 1936. Plant distribution as a guide to age determination. J. Wash. Acad. Sci., 26: 313-324.

1940. Tertiary forests and continental history. Bull. Geol. Soc. Am., 51: 469-488.

Colbert, E. H. 1941. A study of Orycteropus gaudryi from the Island of Samos. Bull. Am. Museum Nat. IIist., 78: 305-351.

Cook, H. J. 1954. A remarkable new mammal from the Lower Chadron of Nebraska. Am. Midland Naturalist, 52: 388-391.

Darlington, P. J., Jr. 1948. The geographical distribution of cold-blooded vertebrates. Quart. Rev. Biol., 23: 1-26, 105-123.

Darwin, C. 1859. On the Origin of Species. John Murray, London.

Dibblee, T. W., Jr. 1952. Cuyama Valley and vicinity. Guidebook, Calif. Oilfields. American Association Petroleum Geologists, Tulsa, Okla., pp. 82-84.

Durham, J. IV. 1950. Cenozoic marine climates of the Pacific Coast. Bull. Geol. Soc. Am., 61: 1243-1264.

Emerson, A. E. 1952. The biogeography of termites. Bull. Am. Museum Nat. Hist., 99: 217-225.

Flint, R. F. 1957. Glacial and Pleistocene Geology. Wiley, New York.

Fries, C., C. W. Hibbard, and D. H. Dunkle. 1955. Early Cenozoic vertebrates in the red conglomerate at Guanajuato, Mexico. Smithsonian Inst. Misc. Collections, 123: 1-25.

Gazin, C. L. 1953. The Tillodontia: an early Tertiary order of mammals. Smithsonian Misc. Collections, 121: 1-110.

Grant, M. 1904. The origin and relationship of the large mammals of North America. Rept. New York Zool. Soc., 8: 182-207.

Hesse, R., W. C. Allee, and K. P. Schmidt. 1937. Ecological Animal Geography. Wiley, New York; 2nd edition, 1951.

Jepsen, G. L. 1932. Tubulodon taylori, a Wind River Eocene tubulidentate from Wyoming. Proc. Am. Philos. Soc., 71:255-274.

Knowlton, F. H. 1917. Fossil floras of the Vermejo and Raton fornutions of Colorado and New Mexico. U. S. Geol. Surv. Prof. Paper, 101: 223-435.

- 1924. Flora of the Animas formation. U. S. Geol. Survey Prof. Paper, 134: 71-98.

Landry, S. O., Jr. 1957. The interrelationships of the New and Old World hystricomorph rodents. Univ. Calif. Publ. Zool., 56: 1-118.

Langston, IV., Jr. 1953. Longirostrine crocodilians from the Tertiary of South America. Bull. Geol. Soc. Am., 64: 1520 [Abstr.].

Matthew, W. D. 1915. Climate and Evolution. Special Publ. New York Academy Science, 1939 edition. 
Mayr, E. 1946. History of North American bird fauna. Wilson Bull., 58 : $3-41$.

Mayr, E., E. G. Linsley, and R. L. Usinger. 1953. Methods and Principles of Systematic Zoology. McGraw-Hill, New York.

McKenna, M. C. 1955. Paleocene mammal, Goler formation, Mojave Desert, California. Bull. Am. Assoc. Petrol. Geologists, 39: 512-515. - 1956. Survival of primitive notoungulates and condylarths into the Miocene of Colombia. Am. J. Sci., 254: 736-743.

Myers, G. S. 1938. Fresh-water fishes and West Indian zoögeography. Smithsonian Inst. Ann. Rept., 1937: 339-364.

Olson, E. C., and P. O. McGrew. 1941. Mammalian fauna from the Pliocene of Honduras. Bull. Geol. Soc. Am., 52: 1219-1244.

Osborn, H. F. 1910. The Age of Mammals in Europe, Asia and North America. Macmillan, New York.

Patterson, B. 1956. Early Cretaceous mammals and the evolution of mammalian molar teeth. Fieldiana: Geology, 13: 1-101.

Romer, A. S. 1945. Vertebrate Paleontology, 2nd edition, University Chicago Press, Chicago, Ill.

Russell, L. S. 1940. Titanotheres from the lower Oligocene Cypress Hills formation of Saskatchewan. Trans. Roy. Soc. Canada, 34: 89-100.

-. 1954. Mammalian fauna of the Kishenehn formation, southeastern British Columbia. Ann. Rept. Natl. Museum Canada, 132: 92-111.

Schaeffer, B. 1952. The evidence of the fresh-water fishes. Bull. Am. Museum Nat. Hist., 99: 227-254.

Schmidt, K. P. 1946. On the zoögeography of the Holarctic Region. Copeia, 1946, no. 3: 144-152.

Schwade, I. T. 1954. Geology of Cuyama Valley and adjacent ranges, San Luis Obispo, Santa Barbara, Kern, and Ventura Counties. Calif. Div. Mines Bull., 170: Map Sheet 1.

Shotwell, J. A. 1955. An approach to the paleoecology of mammals. Ecology, 36: 327-337.

Simpson, G. G. 1929. American Mesozoic Mammalia. Mem. Peabody Mus., 3 .

- 1932. A new Paleocene mammal from a deep well in Louisiana. Proc. U. S. Natl. Musuem, 82:1-4.

- 1935. The Tiffany fauna, upper Paleocene. I. Multituberculata, Insectivora, and ?Chiroptera. Am. Museum Noritates, 795: 1-19.

_- 1937. The Fort Union of the Crazy Mountain Field, Montana and its mammalian faunas. Bull. U. S. Natl. Museum, 169: 1-279.

1947. Holarctic mammalian faunas and continental relationships during the Cenozoic. Bull. Geol. Soc. Am., 58: 613-688.

. 1953. Evolution and Geography. Condon Lectures, Oregon State System Higher Education.

Stebbins, G. L., Jr. 1950. Variation and Evolution in Plants. Columbia University Press, New York. 
Stovall, J. IV. 1948. Chadron vertebrate fossils from below the Rim Rock of Presidio County, Texas. Am. J. Sci., 246: 78-95.

Van Houten, F. B. 1945. Review of latest Paleocene and early Eocene mammalian faunas. J. Paleontol., 19: 421-461.

Wilson, J. A., R. A. Maxwell, J. T. Lonsdale, and J. H. Quinn. 1952. New Paleocene and lower Eocene vertebrate localities, Big Bend National Park, Texas. Rept. Invest. Bur. Econ. Geol. Texas, 14: 9.

Wood, H. E., R. W. Chaney, J. Clark, E. H. Colbert, G. L. Jepsen, J. B. Reeside, Jr., and C. Stock. 1941. Nomenclature and correlation of the North American continental Tertiary. Bull. Geol. Soc. Am., 52: $1-48$. 



\section{The History and Affinities \\ of the Recent Land Mammals \\ of Western North America}

Villiam H. Burt

Museum of Zoology, University of Michigan, Ann Arbor

When we speak of the origin of a fauna or of some component of a fauna we imply that a more or less definite place and time is involved. If our present concept of evolutionary process is correct, faunas or parts thereof do not arise de novo. Instead, they constitute a continuum. How, then, without being strictly arbitrary, can we reasonably designate a place and time as a starting point in this continuum - a place and time for the originwhen the fauna or taxon is merely changing from one complex to another. Can we really talk about the origin of a fauna or a taxon without going all the way back to the origin of life itself, which may also have been a continuum? Would it not be more nearly accurate to speak of a phase in the history of a fauna or a taxon? In mammals, for example, we might speak of the reptilian-mammalian phase, which must have persisted for some millions of years, then the mammalian phase, which has continued to the present. Geologically speaking, we might designate a pre-Tertiary phase and a Tertiary phase in mammalian history. In this way we would indicate a gradual change, not an abrupt one. Part of our thinking, perhaps, has been influenced by the great discontinuities in the geologic record. These break the continuum in the fossil record and give to the uninitiated the impression of great steps in evolution. They make for easy categorizing, but the animals and plants were living and evolving during these great intervals of time when, in the history of land mammals, no terrestrial deposits were being formed, and no record was left. We are apt to pass over these unknown intervals of time and say, for example, that the mammals 
appeared in abundance at the beginning of the Tertiary. What we actually mean is that their fossil remains show up in abundance first at the beginning of the Tertiary period. But, they must have been abundant and diversified long before the first grain of sand was deposited in what we now call Tertiary beds. The paleontologist knows all this, but I fear that he sometimes inadvertently conveys the wrong impression by the language he uses and the charts he draws, stacking one representation of a geologic age, referring to the deposits containing fossils, on top of another and not indicating lapses of time between them.

Although the title of the present symposium contains the word "origin" I have not used it in this paper for the reasons just given. I believe it is more in keeping with the subject of the symposium to call it "The history and affinities of the Recent land mammals of western North America." There is precedence for this in W. B. Scott's monumental work A IIistory of Land Mammals in the Western IIemisphere, published in 1913. But, whether we speak of origins or histories, it is necessary first to establish space and time limits, otherwise the discussion is somewhat meaningless. The area about which I shall be concerned in North America is that segment of the continent lying principally west of meridian $100^{\circ}$ West and north of parallel $30^{\circ}$ North. In Asia, it is that area principally east of meridian $100^{\circ}$ East and north of parallel $30^{\circ}$ North. In South America, I consider the entire continent. These areas admittedly are unequal, but each contains diversified ecological conditions, and each is sufficiently large to give a good sample of the total mammalian fauna. The time interval is from the beginning of the Tertiary through the Recent. Bats and marine mammals are not included in the following analysis. I shall be little concerned with the fossil record since that was discussed in the preceding paper. I should like, however, to point up a few criteria used by students of Recent faunas in attempts to determine the so-called place of origin of a group of animals. I would prefer to call this the area of differentiation-where the group passed from one evolutionary phase to another.

1. The Present Geographic Distribution of the Group Indicates Its Origin. (a) Some have thought that the central part of the area now occupied may represent the area of "origin" (differenti- 
ation) of the group. This may or may not be so. Here, it is important to know what time interval is being considered and, also, the taxonomic level of the group-species, genus, family, etc. We know that faunas have shifted geographically in the past, and, unless we have the fossil evidence we cannot prove that the faunal element involved did not move in from some other locality. A good example in the mammals, in the area under consideration, where we do have a fossil record from the same general area now occupied by the group, is the assemblage of pocket gophers, pocket mice, and kangaroo rats, involving two closely related families as now recognized by specialists, the Geomyidae and Heteromyidae. These mammals are, and have been, primarily western North American in their distribution, as indicated by the fossil record and knowledge of Recent kinds (Fig. 4). This is true also of the pronghorn, Family Antilocapridae. If we base our interpretation solely on Recent kinds and their present geographic distribution and use the criterion just set forth, we would be correct in saying that the area of differentiation was in western North America. But, if we were to use the same criterion for the camels, Family Camelidae, we would be far wrong. None of the latter are now found in North America where they had their great development in Tertiary times and continued into the Quaternary.

(b) The periphery of the present range has been considered by some as being the most likely place for differentiation of a group. This might hold for some of the lesser categories, such as species, but for the higher categories, camels, for example, we find the same objections as we did in the preceding discussion. As a matter of fact, any segment of a population of a species might have the potential of evolving in a different direction from the parent stock if a barrier is established to isolate it. This barrier need but stop or sufficiently dilute the genetic interchange between populations. Even in a continuous population over a relatively large area, the segments at the extremes may be sufficiently isolated by distance that they will evolve in different directions (Peromyscus maniculatus is an example).

2. The Area of Present Greatest Abundance Is Likely the Place Where Group Evolved. This theory assumes that the area where optimum conditions prevail today was always so. It ignores the 
possibility of climatic change and the accompanying changes in flora. These changes, if they occurred, would have influenced not only distribution patterns but also population densities.

3. The Area of Greatest Diversification (at present) of the Group Is Likely the Place Where It Evolved into Its Present Phase. Some authors have thought that the area now supporting the greatest number of species (of a genus) must be the area where the group reached its present evolutionary phase; that far from the place where they evolved, individuals of a species are less plastic and less able to adapt to diversified conditions. However, this does not necessarily follow. It is usual to find diversity in a group (a genus, for example) in an area that supports many kinds of habitats, where ecological conditions are diverse. If these diverse ecological conditions have persisted over a long period of time in the same area, it is conceivable that many of the lower categories and, given enough time, the higher categories might have developed there. But, especially for the larger categories, this is problematical. They might or might not have evolved in the area.

4. The Area Where Individuals Show the Highest Development, Are Least Primitive, Is Probably the Place of Differentiation of the Group. This is in keeping with Matthew's hypothesis. It is more likely to hold for the higher categories (families and orders) than for the lower ones. Without the fossil record, the same objections apply to this as to other hypotheses.

5. Ecological Tolerance. Some authors have held that if a species can adapt to several kinds of habitat, if it is not confined to narrow ecological conditions, it still maintains a certain plasticity and some of its initial potential for adaptation. Therefore, this area, where the species is adaptable, is likely to be at or near the place where it evolved from its ancestral stock. This, of course, need not be true.

These are some of the ideas that have been expressed by students of Recent biota. (For others, and a critique of them, see Cain, 1944; Darlington, 1957, pp. 29-35). They are all indirect lines of evidence, but they may be used to advantage where other evidence is not available. If any one of the above criteria is used, it should be applied with extreme caution, because it may or may not lead to a true interpretation of the facts. Darlington (1957, p. 580) goes so far as to state: "I doubt whether any existing animals tell 
anything about more ancient times." But he does use present situations to explain past events. It is my opinion that the only indisputable evidence comes from the fossil record, but we can get leads from present distributions and relationships. However, I shall not dwell further on this subject here, but shall go directly to my principal topic, that of the present affinities of our Recent mammalian fauna.

When one attempts to evaluate, or designate, affinities of two or more faunas, he must first indicate the criteria to be followed. It might seem simplest to count the species or genera, or whatever category is to be employed, apply a formula, and come up with a measure indicating degree of taxonomic resemblance between two or more faunas. This will give a quantitative measure and make it possible for us to conmunicate our results to our fellow workers without elaborate descriptive material. But, the source data are subject to errors, as I shall point out later, and the errors, if they exist, will influence the result. As in dealing with so many biological problems, a certain amount of subjectivity must enter the picture, and to reduce everything to numerical terms may be misleadingor downright wrong. Many non-taxonomists, and some taxonomists, I am sorry to report, think of species and subspecies of mammals as discrete entities. When they look at a check list, or faunal list, they assume that each name represents a distinct unit, and that all names in the same category represent units of equal value. Nothing could be farther from the truth. All the categories of mammals are to some extent subjective. In addition, they have changed with time. What was once a species may now be a genus or a family, either through evolution of the animals, if enough time is involved, or through changes in man's concepts. Let me give a couple of examples that I cited in a previous paper (1954). These have nothing to do with the evolution of mammals, but they do show the evolution of man's ideas. In 1909, when Osgood revised the genus Peromyscus, some twenty-eight named species in the literature ended up as one (maniculatus), when he had finished his study. More recently, in 1951, Hall reduced what were listed as twenty-five species of weasels in the literature to three. I think it is apparent that if one were using numbers of species per se, in comparing faunas, the results would be quite different if data were taken from the 1908 literature or that of 1956 . Yet, many biologists continue 
to count names in a list and take them at their face value. They then formulate hypotheses on what they innocently, but erroneously, think are substantial data.

These and other problems have confronted me in the preparation of this paper, and I have found no good solution to them. I have tried various formulas for taxonomic resemblance, and will discuss some of these presently. However, no formula will give a correct answer unless the basic data are accurate. If we must use a formula, and this method has great popularity in biology today, I prefer one that takes into account the entire faunas, not just the smaller of two. The latter may be best for fossil faunas, as Simpson (1947) seems to think, but for our purposes I believe there are better ones. After counting the species and genera listed in the literature, primarily in Miller and Kellogg (1955) for North America, Ellerman and Morrison-Scott (1951) for Asia, and Cabrera and Yepes (1940) for South America, I decided to use the genus as my category for the application of the various formulas. I have also prepared a chart in an attempt to show graphically the relationships of these three faunas. Other authorities were also consulted, and when there was disagreement on a generic name, I arbitrarily included or excluded the name as I thought best. The numbers used, therefore, should be considered approximate. I then employed "taxonomic intuition." With this system, I came up with similar, but somewhat different results. Neither system is accurate, but they show the same general trends which fit the concepts of every competent mammalogist today. My objective here is to test different methods of indicating taxonomic resemblance - to discover, if possible, how nearly accurate they are and where they might be misleading. I shall attempt to analyze some of these, but first I should like to indicate some of the perplexing problems that confront one in this kind of effort.

To begin with, our knowledge of the three faunas under consideration is not equal, so our basic data are not equivalent, and this in itself makes comparisons difficult. Our knowledge is best for North America, but even here we have many names in the literature that no doubt will be omitted from the books in another twenty-five years or so. As a matter of fact, our total knowledge of any one kind of mammal is inadequate to evaluate it properly in the whole scheme of things. 
Secondly, we have conservatives and liberals, or lumpers and splitters, among students of Recent mammals. Ellerman and Morrison-Scott (1951) tend to be conservative for genera and species while Cabrera and Yepes (1940) are quite liberal with the number of genera that they recognize. Miller and Kellogg (1955) include the findings in the latest revision of each group, with no critical analysis of their own, so their list is a mixture of conservatism and liberalism. In some groups, such as the Grizzly Bears, the last authors, following Merrian's 1918 revision, list no fewer than 69 species for North America. They also give the black bear different generic rank (Euarctos) from the grizzly (Ursus). In 1953, two years before the list by Miller and Kellogg appeared, Erdbrink included all the Recent bears in the one genus Ursus, and all the North American species of the grizzly, along with those from Asia and Europe, in the one species arctos. These two works represent extremes in the evaluation of names. It must be frustrating to the nontaxonomist to see two such treatments within two years by two different authorities. It is also frustrating to the taxonomist who is attempting to apply a formula for taxonomic resemblance between North America and Asia.

Thirdly, and somewhat related to the two previous difficulties, is the fact that some kinds are considered in the literature to be conspecific or congeneric while others, probably just as closely related, are not. Some examples of species that are now considered by some, at least, to be conspecific for North America and Asia are: a shrew (Sorex pacificus), the gray wolf (Canis lupus), Arctic fox (Alopex lagopus), wolverine (Gulo gulo), two weasels (Mustela erminea and $M$. nivalis), moose (Alces alces), a ground squirrel (Citellus undulatus), and two voles (Microtus oeconomus and Clethrionomys rutilus). Such kinds as the red fox (Vulpes), marten (Martes), river otter (Lutra), lynx (Lynx), lemmings (Dicrostonyx and Lemmus), chipmunk (Eutamias), and several voles and shrews are considered to be distinct species, at least in the literature. In a case like this, the counting of names without some evaluation may give a false impression.

A fourth problem, but not a difficult one, is what category to use. If we simply count the species listed for western North America and for northeastern Asia, we come up with about 229 and 160, respectively. On the basis of species names, North America would 
appear to have a larger fauna, 229 to 160 , but if we consider genera, it would have the smaller fauna, 68 to 93. South America, with 114 generic names, tops them all. But this is not as bad as it might seem at first glance. Obviously, if we are comparing faunas which are relatively close geographically, and there are no great barriers, most of the genera will be common, so we should use a smaller

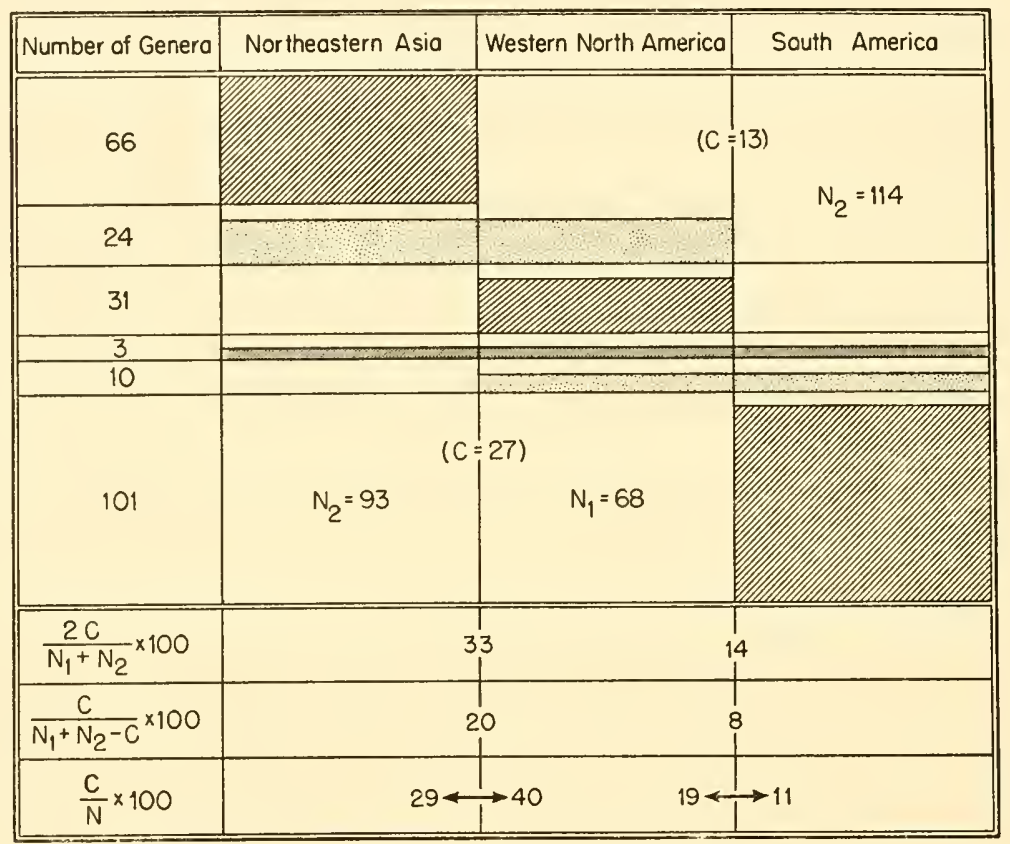

Fig. 1. Chart showing relationships of non-flying land mammals on three continents. Number of genera is approximate. Shaded areas represent parts of total faunas. Formulas at bottom are for taxonomic resemblance.

category such as the species. If we are comparing remote faunas where few, if any, of the species are common, we must use a higher category, the genus or family.

These are some of the items that one must consider when comparing faunas for resemblance. Now let us look at Fig. 1 and the measures we get by using different formulas. Numbers of genera listed in the literature are given in the left column and are plotted to scale in the others. My intuition tells me that South America has too many genera in the indigenous block, relative to North 
America and Asia. However, I am of the opinion that the number of common genera is near reality. The great variables, then, will be found in $N-C$ for each fauna, in any of the formulas used here. But, regardless of the formula used, the trend is the same for these three faunas, and all seem to be indicative of the relationships. In Simpson's formula, $\left(C / N_{1}\right) \times 100$, if we compare western North America with Asia and South America, $N_{2}$ could vary from 69 to infinity and the measure would be the same, 40 for western North America and Asia; 11 for western North America and South America. What his formula actually gives is the percentage of common kinds in the smaller of the two faunas, regardless of the size of the larger one. This formula is usable as far as it goes, but it is my opinion that it should be applied in both directions to give the true picture. This gives two measures and makes it more cumbersome to use than a formula that takes into account the total of the faunas to be compared and gives but one measure. Such a formula is the middle one in Fig. 1, $\left[C /\left(N_{1}+N_{2}-C\right)\right] \times 100$. In this formula, $C$ appears in both numerator and denominator, and the measure obtained is the percentage of common kinds in the total of two faunas. This formula works best if the two faunas being compared are equal, or nearly so, in size. If they are very unequal in size, and the smaller fauna is mostly common to the larger one, the result obtained may be misleading.

The top formula, $\left[2 C /\left(N_{1}+N_{2}\right)\right] \times 100$, where $C$ appears only in the numerator, gives a measure, different from the others, but shows the same trend in the faunas here compared.

In the figure, you will note that twenty-seven genera are common to North America and Asia $(C=27)$. Several genera have close relatives on the two continents, but, because of a different name in the lists, they will appear in that part of the fauna which is considered indigenous. Some of these for western North America are: Scapanus (mole), Taxidea (badger), Tamiasciurus (red squirrel), Glaucomys (flying squirrel), Phenacomys (vole), Sylvilagus (cottontail), and Odocoileus (deer). These genera are given the same value, on the indigenous side for North America, as Dipodomys (kangaroo rat), Perognathus (pocket mouse), Thomomys (pocket gopher), and Antilocapra (pronghorn). But, they are related, and fairly closely, to their Asiatic counterparts, whereas kangaroo rats, pocket mice, pocket gophers, and pronghorns are not. If we use 
a formula based strictly on names in the literature, these relationships are obscured and given negative instead of positive weight. In my subjective system, which presupposes a knowledge of the group, these seven kinds would be added to $C$, to give it a value of 34 , instead of 27 . Other adjustments would be made in various groups, either combining or separating them. With this system, I ended up with over half of the mammal fauna of western North America showing affinities with that of Asia, about 57 per cent. I believe this is nearer reality than anything the formulas would indicate. However, the results are not in a form that is easily communicable to other workers. By using this arbitrary system further, about 30 per cent, instead of 45 per cent, of the western North American mammals are considered as indigenous. In comparing North and South America, I arrived at 13 per cent, instead of 19 per cent, of the western North American mammals showing affinities with those from South America. This is fairly close.

\section{MOVEMENTS OF MAMMALS BETWEEN EURASIA AND NORTH AMERICA}

Faunal relationships of the nature just discussed, where two land masses are now separated by water, indicate a movement of animals from one land mass to the other in past times. That there was a nearly continuous land connection from the beginning of the Tertiary to Pleistocene time between what are now the North American and Asiatic continents is well established. There is still doubt concerning the directions of movements of many kinds of mammals. This would be important to know, but it is not essential to the present discussion (see Simpson, 1947, for a summary on these connections and movements). But, a land connection is in itself not sufficient for the transfer of non-flying terrestrial mammals, unless it be a very short one which an animal might cross in a single journey. The distance from Cape Prince of Wales to East Cape, across what is now the Bering Strait, some 75 miles, might conceivably have been crossed by some of the larger mammals such as caribou, moose, elk, and bear, even though no vegetation were present. For the smaller mammals, some of which are restricted within fairly narrow limits to specific ecological conditions, I think it most unlikely that they would, or could, make the crossing 
without food and shelter. This principle was pointed out several years ago by Scott (1913, p. 143) in the following statement.

In the case of lands newly raised above the sea and connecting formerly separated areas, it is necessary that they should first be taken possession of by vegetation, before they can become passable by animals, for the migration of mammals from continent to continent is an entirely distinct phenomenon from the annual migration of birds.

Not only the land bridge, but the abutments to it must possess ecological conditions suitable for those kinds that are likely to make the crossing (Simpson, 1947). Simpson (ibid., p. 685), no doubt influenced by earlier workers such as Merriam (1894) and Scott (1913), stressed the climate as being "Not the only, but probably the most important, selective factor..." in the faunal interchanges between Eurasia and North America. Further, he stated that "the migrants generally are those groups tolerant of relatively cold climates," and thereby gave importance to the temperature at the time of crossing. But, he did not rule out other ecological factors. I am of the opinion that climatic conditions, as regards movements of mammals over long periods of time, are important in an indirect way, as they affect vegetation and soils, rather than in a direct one. It is fairly well established that through Tertiary times the climate was more moderate than at present (Emiliani, 1958). Even in the Pleistocene, the interglacial stages had fairly moderate climates (Deevey, 1949). Temperature tolerance in mammals is primarily physiological, and most of them can withstand great changes if supplied with food. It is true that those mammals that live in cold-temperate climates, especially the large mammals that live above the snow, are tolerant of greater fluctuations in air temperature than are many of the tropical kinds. Yet, there are several kinds that range through the tropics to the colder regions today (mountain lion, Felis; river otter, Lutra; weasel, Mustela; and others). Recent studies, on the bioclimate of small mammals that live beneath the snow in winter in an Alaskan taiga, show that the temperature at ground surface, where many of the small mammals live, ranged through no more than $27^{\circ} \mathrm{F}$ from summer to winter, whereas the air above the snow ranged through $152^{\circ} \mathrm{F}$. The temperature where many of these small mammals live rarely goes below $+20^{\circ} \mathrm{F}$ even in the most severe winter 
(Pruitt, 1957). It is misleading to consider air temperatures in relation to these forms. The microclimate in which they live is the important factor.

The northern porcupine must have evolved a different physiology from that of its tropical ancestors to endure the low temperatures in parts of its present range, and this since Pliocene times when the Panama land connection was made between North and South America. Although the porcupine can den in a sheltered place, it must expose itself to the elements when it is feeding. I suspect that physiological evolution may proceed more rapidly than morphological change, although I have no direct proof of this. However, I think it not too far-fetched to postulate that physiological adjustment to climate might have kept pace with changing temperatures and that temperature per se was no direct selective mechanism in the interchange of mammal kinds between Eurasia and North America. In some kinds of burrowing mammals, type and depth of soil might be the important selective agent (Hardy, 1945). An analysis of the Recent mammalian fauna of western North America, with these considerations in mind, should throw some light on the general problem of what were or were not selective agents. Also, we should get some idea of the relative times of the last crossings made by each group. Not all mammals have evolved at the same rate, but close relationships should indicate recent crossings and distant relationships earlier crossings. We must first make one assumption, and it seems a reasonable one, i.e., that the habits of mammals have not changed markedly since the times when their ancestors had the opportunity to cross the land bridge. If this assumption is not valid, then we have no way of interpreting many of the phenomena of the past. Also, to have had an interchange of the kinds that are related and now living on the two continents we demand a corridor with the following specifications: There must have been soil and vegetation with a fairly continuous forest and areas of open savanna country. The two types of vegetative cover might or might not have been coexistent. These demands are in conformity with modern interpretations of past climate and vegetation in the area of the approaches as well as of the land bridge itself (see Darlington, 1957, for a summary of studies in this area). In the following discussion of the various groups of mammals I 
have used the excellent summary of fossil evidence by Simpson (1947).

\section{LAND MAMMALS FOR WHICH LAND BRIDGE SERVED AS A CORRIDOR}

Moles (Family Talpidae). These animals must have required a soil cover of the proper kind. This means also a vegetative cover and soil organisms for food. Our western moles today range no farther north than southern British Columbia. However, the eastern representatives go well into Labrador. The present distribution,

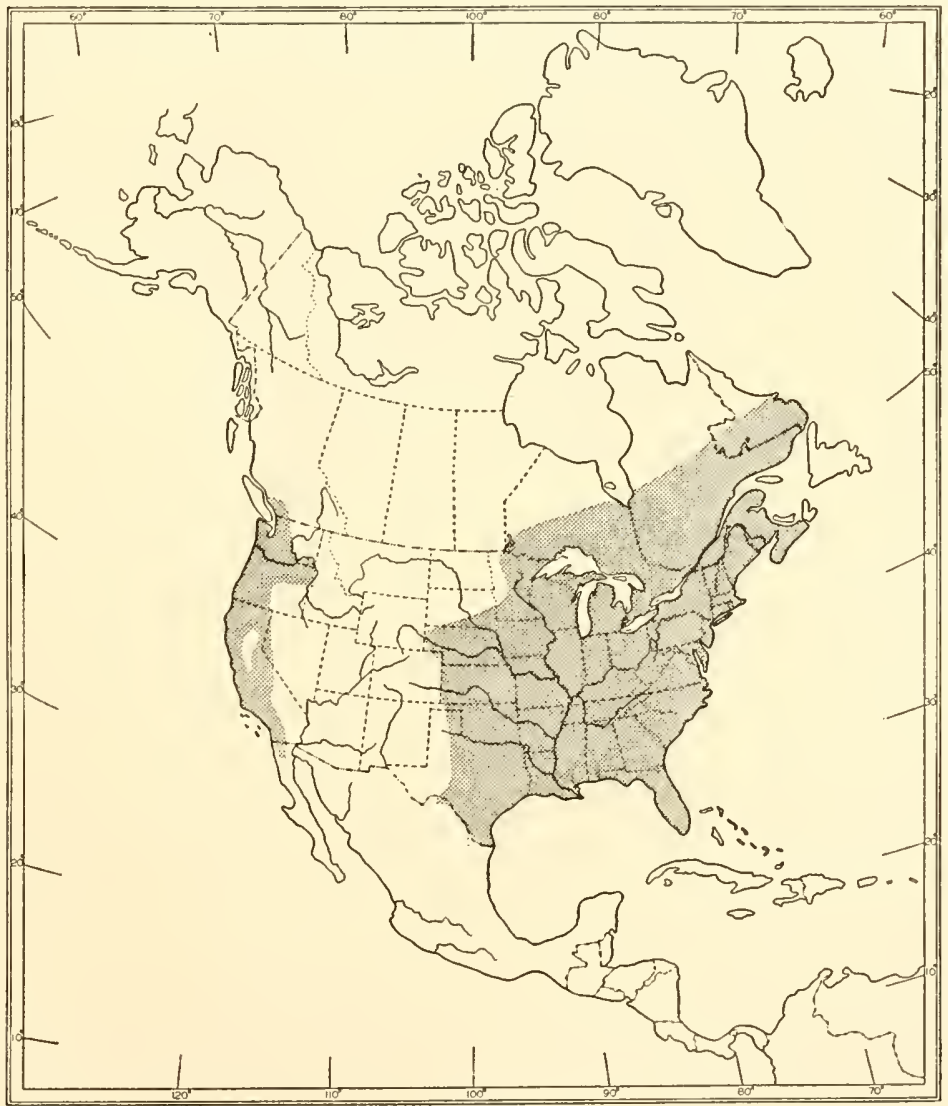

Fig. 2. General distribution of the moles, Family Talpidae, of North America. Late crossings of the Bering land bridge are not indicated. 
relationships, and the fossil record would indicate an early Tertiary crossing. Late crossings are not indicated. This group has been on the North American continent long enough to evolve into two genera on the West Coast and three genera in eastern North America.

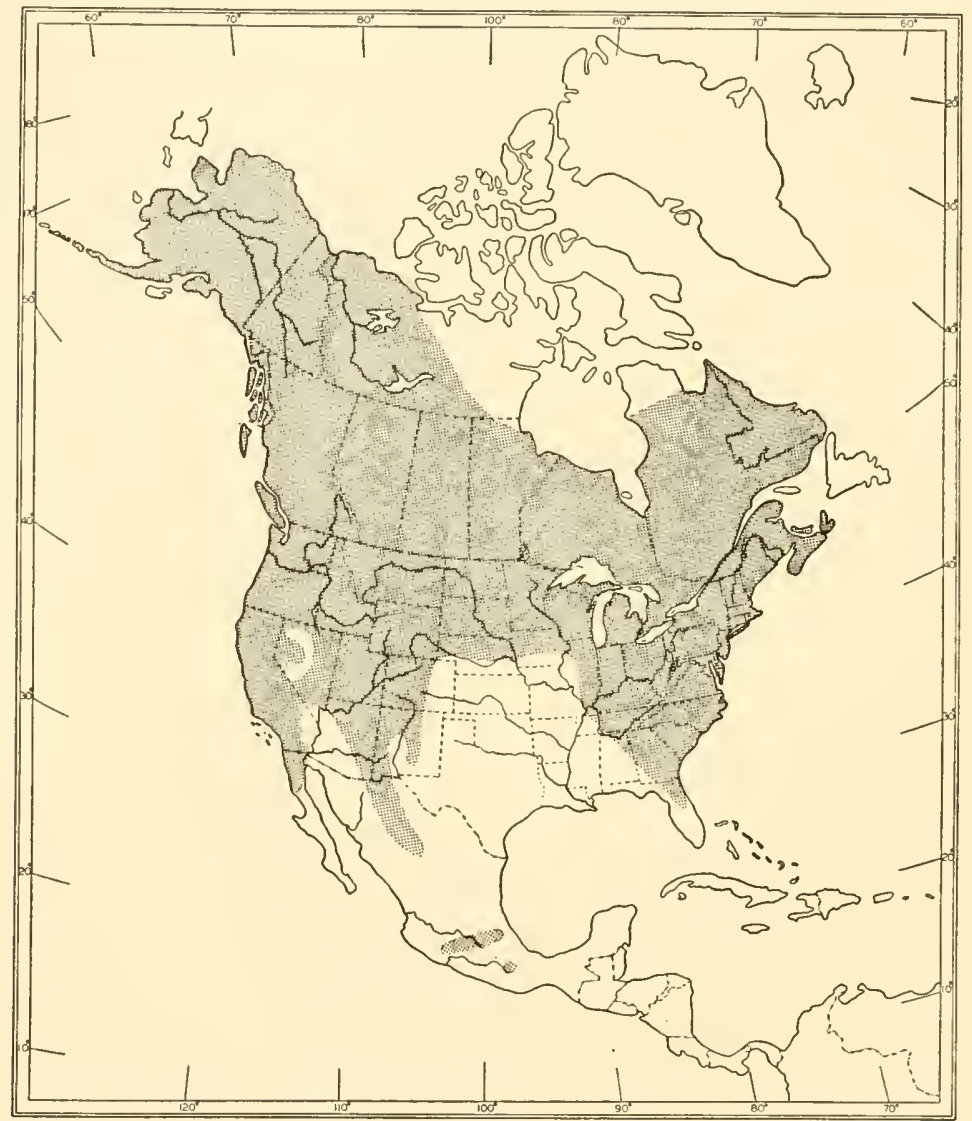

Fig. 3. General distribution of shrews of the genus Sorex in North America. Late crossings of the Bering land bridge are indicated. The genus occurs also in Eurasia (Table I).

A large area now separates the western and eastern kinds (Fig. 2). In like manner the Eurasian moles have evolved into several genera, all distinct from those of North America. Temperature probably would not have been a factor in dispersal of moles, but soil type would. Moles are able to survive in rather heavy soils as well as 
lighter, friable types, but arid conclitions, with accompanying light soils and a paucity of soil organisms are not suitable for them.

Shrews (Family Soricidae). Present day shrews live in various types of habitats and in various climatic zones (Fig. 3). With a vegetative cover of any kind they would find easy passage. Both early Tertiary and late passages are indicated by the fossil record and present relationships.

Man (Family Hominidae). There is no problem here, even without a land bridge man could have made the crossing.

Bears (Family Ursidae). There is no problem in getting bears from one continent to the other. Polar bears, which are not strictly terrestrial, are circumpolar in distribution today, and the other bears on the two continents are closely related (the grizzlies are considered to be of the same species by Erdbrink, 1953). Exchanges probably continued through the period of the last connection.

Weasel-like mammals (Family Mustelidae). Fossil records indicate an early Tertiary passage and Recent relationships and distributions indicate late passages, particularly of the fisher, marten, otter, wolverine, mink, and weasels. The fisher and marten would indicate a forested bridge, the others might pass over open or forested country. Temperature would not be a factor with these animals. However, for some of the skunks (Mephitinae), particularly those of the genus Conepatus, climatic zoning could have served as a selective agent in late Tertiary and Pleistocene times. Mephitis and Spilogale now live under temperature conditions that are probably more severe than they were during much of the time that the two continents were connected.

Dogs (Family Canidae). Because of the diversity of habitats occupied by this group, we need not look for special conditions to effect an interchange. Fossil records and present distributions and relationships indicate exchanges from early Tertiary to the last land connection.

Cats (Family Felidae). Members of this family are nearly worldwide in distribution and occupy various habitats. Indications are that they passed from one continent to another many times from early Tertiary to Recent. Although some kinds are now confined to the tropics and some to cold areas, others, including Felis concolor, range through the different climatic zones. 
Squirrels (Family Sciuridae). 'This is a diversified group with many closely related kinds on the two land masses today. Particularly close, in the two areas, are the marmots (Marmota), ground squirrels (Citellus), chipmunks (Eutamias), tree squirrels (Sciurus), and flying squirrels (Glaucomys in North America and Pteromys in Eurasia). For the passage of the marmots and ground squirrels, open savanna is required, but for the tree squirrels and flying squirrels, there must have been a fairly continuous forest. Climate and soil would have been influencing factors only as they affected the vegetation. There must have been several crossings up to and including the last land connections.

One group in this family of rodents, the prairie dogs (Cynomys), apparently had their entire evolutionary history in North America. They are inhabitants of short-grass areas and require deep soil for their burrows. These conditions apparently did not prevail to the northward and they never reached the land bridge.

Beaver (Family Castoridae). A forest, or cover of shrubs, and fresh water would seem to be required here. Fossil evidence would indicate an early Tertiary crossing. Present day relationships and distributions indicate a late crossing also. It is possible that there were several interchanges. Temperature would not have been a factor.

New World mice and voles (Family Cricetidae). This group is so diversified that any type of vegetative cover would have sufficed. The subfamily Cricetinae, long-tailed representatives, probably had a fairly early ancestral crossing. Evidence of this is found in their present distant relationships and in the fossil record. A Pleistocene crossing is not indicated. However, the subfamily Microtinae now has close relatives on the two continents (in some genera the same species) so crossings must have persisted to the end of the last land bridge. Climatic conditions would not affect this group directly. The vegetative cover postulated would suffice, be it forest or savanna. Why the North American cricetids or the Old World murids did not make the crossing is difficult to explain. Some would argue that because they are ecological homologues, competition would keep the two groups separated. I am not convinced that this is the answer. It is possible that each group had its evolutionary history far to the south, fairly late, and that time was not sufficient for them to reach the bridge before separation of the continents. However, there is no good evidence of this.

Mountain beaver (Family Aplodontidae). The little information 
we have on this group indicates a late Tertiary crossing from North America to Asia. A rather heavy vegetative cover is required. Jumping mice (Family Zapodidae). Conditions suitable for the Microtinae would be suitable for this group. Late crossings are indicated.

Pikas (Family Ochotonidae). The fossil record would indicate a middle Tertiary crossing for this group, and present relationships indicate late crossings also. The pika now lives in talus slopes near timberline. For the first ancestral crossings, when climates were more moderate, a change in the habits of these little lagomorphs is called for. In the Pleistocene, environmental conditions suitable to present day pikas would have been more likely.

Rabbits and hares (Family Leporidae). Either forest or savanna would have been suitable for the crossing of these mammals. Climate would not, in itself, have been a factor. Fossil evidence and present relationships indicate early and late crossings.

Peccary (Family Tayassuidae). Indications are of an early Tertiary crossing. The peccary was then restricted to the North American (and later South American) continent from about middle Tertiary on. Open or wooded areas would have been suitable for the crossing.

Deer (Family Cervidae). From about middle Tertiary on, members of this family probably crossed over the land bridge several times. The elk, moose, and caribou now have close relatives on the two land masses, an indication of late crossing. Most any vegetative cover would have been suitable for the crossing over.

Bovines (Family Bovidae). The bison and big horn sheep both have close relatives on the two continents, an indication of late interchange. There is less certainty about the mountain goat (Oreamnos). From present relationships with Old World antelopes, the indication is that no late passages occurred.

It will be noted that the groups in this section required only soil (moles) and a vegetative cover of savanna and forest (others) for a suitable corridor. Temperatures were at no time (except possibly during the glacial stages in the Pleistocene) prohibitively low.

\section{LAND MAMMALS FOR WHICI LAND BRIDGE APPARENTLY DID NOT SERVE AS A CORRIDOR}

Raccoons (Family Procyonidae). There is no indication of intercontinental exchange since the evolutionary phase in which 
TABLE I. Genera of Strictly Terrestrial, Non-Flying Mammals of Temperate North America, ${ }^{a} 30$ of Which Also Occur in Eurasia

\begin{tabular}{|c|c|c|c|c|}
\hline & Genus & Eurasia & $\begin{array}{c}\text { Western } \\
\text { North } \\
\text { America }\end{array}$ & $\begin{array}{c}\text { Eastern } \\
\text { North } \\
\text { America }\end{array}$ \\
\hline Didelphis & & & & $\mathrm{x}$ \\
\hline Condylura & & & & $\mathrm{x}$ \\
\hline Scalopus & & & & $\mathrm{x}$ \\
\hline Parascalops & & & & $\mathrm{x}$ \\
\hline Scapanus & & & $\mathrm{x}$ & \\
\hline Në̈rotrichus & & & $\mathrm{x}$ & \\
\hline Sorex & & $\mathrm{x}$ & $\mathrm{x}$ & $\mathrm{x}$ \\
\hline Microsorex & & & $\mathrm{x}$ & $\mathrm{x}$ \\
\hline Notiosorex & & & $\mathrm{x}$ & \\
\hline Cryptotis & & & & $\mathrm{x}$ \\
\hline Blarina & & & & $\mathrm{x}$ \\
\hline Ursus & & $\mathrm{x}$ & $\mathrm{x}$ & $\mathrm{x}$ \\
\hline Procyon & & & $\mathrm{x}$ & $\mathrm{x}$ \\
\hline Nasıa & & & $\mathrm{x}$ & \\
\hline Bassariscus & & & $\mathrm{x}$ & \\
\hline Martes & & $\mathrm{x}$ & $\mathrm{x}$ & $\mathrm{x}$ \\
\hline Mustela & & $\mathrm{x}$ & $\mathrm{x}$ & $\mathrm{x}$ \\
\hline Gulo & & $\mathrm{x}$ & $\mathrm{x}$ & $\mathrm{x}$ \\
\hline Lutra & & $\mathrm{x}$ & $\mathrm{x}$ & $\mathrm{x}$ \\
\hline Spilogale & & & $\mathrm{x}$ & $\mathrm{x}$ \\
\hline Mephitis & & & $\mathrm{x}$ & $\mathrm{x}$ \\
\hline Conepatus & & & $\mathrm{x}$ & \\
\hline Taxidea & & & $\mathrm{x}$ & \\
\hline Vulpes & & $\mathrm{x}$ & $\mathrm{x}$ & $\mathrm{x}$ \\
\hline Urocyon & & & $\mathrm{x}$ & $\mathrm{x}$ \\
\hline Alopex & & $\mathrm{x}$ & $\mathrm{x}$ & $\mathrm{x}$ \\
\hline Canis & & $\mathrm{x}$ & $\mathrm{x}$ & $\mathrm{x}$ \\
\hline Felis & & $\mathrm{x}$ & $\mathrm{x}$ & $\mathrm{x}$ \\
\hline $\operatorname{Lynx}$ & & $\mathrm{x}$ & $x$ & $\mathrm{x}$ \\
\hline Marmota & & $\mathrm{x}$ & $\mathrm{x}$ & $\mathrm{x}$ \\
\hline Citellus & & $\mathrm{x}$ & $\mathrm{x}$ & \\
\hline Cynomys & & & $\mathrm{x}$ & \\
\hline Tamias & & & & $\mathrm{x}$ \\
\hline Eutamias & & $\mathrm{x}$ & $\mathrm{x}$ & \\
\hline Tamiasciurus & & & $\mathrm{x}$ & $\mathrm{x}$ \\
\hline Sciurus & & $\mathrm{x}$ & $\mathrm{x}$ & $\mathrm{x}$ \\
\hline Glaucomys & & & $\mathrm{x}$ & $\mathrm{x}$ \\
\hline
\end{tabular}

${ }^{a}$ Designation to eastern or western North America is arbitrary in many instances. One species of the genus Eutamias (minimus), for instance, occurs as far east as Ontario, yet it is designated western because that is where all the other species are found. 
TABLE I.-(Continued)

\begin{tabular}{|c|c|c|c|}
\hline Genus & Eurasia & $\begin{array}{l}\text { Western } \\
\text { North } \\
\text { America }\end{array}$ & $\begin{array}{c}\text { Eastern } \\
\text { North } \\
\text { America }\end{array}$ \\
\hline Thomomys & & $\mathrm{x}$ & \\
\hline Geomys & & & $\mathrm{x}$ \\
\hline Cratogeomys & & $\mathrm{x}$ & \\
\hline Liomys & & $\mathrm{x}$ & \\
\hline Perognathus & & $\mathrm{x}$ & \\
\hline Dipodomys & & $\mathrm{x}$ & \\
\hline Microdipodops & & $\mathrm{x}$ & \\
\hline Castor & $\mathrm{x}$ & $\mathrm{x}$ & $\mathrm{x}$ \\
\hline Onychomys & & $\mathrm{x}$ & \\
\hline Reithrodontomys & & $\mathrm{x}$ & $\mathrm{x}$ \\
\hline Baiomys & & $\mathrm{x}$ & \\
\hline Peromyscus & & $\mathrm{x}$ & $\mathrm{x}$ \\
\hline Oryzomys & & $\mathrm{x}$ & $\mathrm{x}$ \\
\hline Sigmodon & & $\mathrm{x}$ & $\mathrm{x}$ \\
\hline Neotoma & & $\mathrm{x}$ & $\mathrm{x}$ \\
\hline Synaptomys & & $\mathrm{x}$ & $\mathrm{x}$ \\
\hline Lemmus & $\mathrm{x}$ & $\mathrm{x}$ & $\mathrm{x}$ \\
\hline Dicrostonyx & $\mathrm{x}$ & $\mathrm{x}$ & $\mathrm{x}$ \\
\hline Phenacomys & & $\mathrm{x}$ & $\mathrm{x}$ \\
\hline Clethrionomys & $\mathrm{x}$ & $\mathrm{x}$ & $\mathrm{x}$ \\
\hline Microtus & $\mathrm{x}$ & $\mathrm{x}$ & $\mathrm{x}$ \\
\hline Lagurus & $\mathrm{x}$ & $\mathrm{x}$ & \\
\hline Pitymys & $\mathrm{x}$ & & $\mathrm{x}$ \\
\hline Neofiber & & & $\mathrm{x}$ \\
\hline Ondatra & & $\mathrm{x}$ & $\mathrm{x}$ \\
\hline A plodontia & & $\mathrm{x}$ & \\
\hline Zapus & & $\mathrm{x}$ & $\mathrm{x}$ \\
\hline Napaeozapus & & & $\mathrm{x}$ \\
\hline Erethizon & & $\mathrm{x}$ & $\mathrm{x}$ \\
\hline Ochotona & $\mathrm{x}$ & $\mathrm{x}$ & \\
\hline Lepus & $\mathrm{x}$ & $\mathrm{x}$ & $\mathrm{x}$ \\
\hline Sylvilagus & & $\mathrm{x}$ & $\mathrm{x}$ \\
\hline Pecari & & $\mathrm{x}$ & \\
\hline Cervus & $\mathrm{x}$ & $\mathrm{x}$ & $\mathrm{x}$ \\
\hline Odocoileus & & $\mathrm{x}$ & $\mathrm{x}$ \\
\hline Alces & $\mathrm{x}$ & $\mathrm{x}$ & $\mathrm{x}$ \\
\hline Rangifer & $\mathrm{x}$ & $\mathrm{x}$ & $\mathrm{x}$ \\
\hline Antilocapra & & $\mathrm{x}$ & \\
\hline Bison & $\mathrm{x}$ & $\mathrm{x}$ & $\mathrm{x}$ \\
\hline Ovibos & $\mathrm{x}$ & $\mathrm{x}$ & $\mathrm{x}$ \\
\hline Ovis & $\mathrm{x}$ & $\mathrm{x}$ & \\
\hline Oreamnos & & $\mathrm{x}$ & \\
\hline
\end{tabular}


ancestral forms can first be recognized as raccoons (subfamily Procyoninae). Raccoons proper probably had their early evolution in tropical America. Climatic zoning might have been a selective factor with these animals. However, they do range into southern Canada today and it is difficult to see why they did not reach Asia in late Tertiary or Pleistocene times. From fossil evidence we may assume that the early ancestors passed over in Early Tertiary times. The coati (Nasua) is a southern form that likely never did get very far north. Climatic factors could have been important in limiting the dispersal of this mammal.

Ringtails (Family Bassariscidae). The ringtail occupies the same kind of situation as the coati (Nasua) discussed above.

Prairie dog (Family Sciuridae). The prairie dog was mentioned earlier, but should be included in this section. It is an inhabitant of short-grass areas, and ecological factors probably prevented it from making the crossing. Although it now inhabits areas where winter temperatures are low, it avoids the extreme cold by going into hibernation.

Pocket gophers (Family Geomyidae). The present and what we know of the past distribution of pocket gophers is primarily western North American. A segment inhabits southeastern United States. Their latitudinal range is from southern Canada to tropical America. They are excellent diggers and can occupy the regions of heavy soils as well as sandy loams. They apparently require soil moisture sufficient to grow a good cover of vegetation. Normally, nonforested areas are preferred. I suspect that a continuous, dense forest would be a barrier to their dispersal-shallow, rocky soils might serve the same purpose. Temperature probably would not have prevented them from reaching the land bridge - there must have been a barrier of forests or soil types, or both.

Kangaroo rats and pocket mice (Family Heteromyidae). Here again, the fossil record indicates a strictly North American evolutionary sequence. Soil type is probably the most important limiting factor in the distribution of these rodents. Although partially fossorial, they are weak diggers and, therefore, they require friable soil. This kind of soil is to be found primarily in the arid and semiarid western part of North America (Fig. 4). Some of these animals, particularly along the eastern border of their ranges, penetrate areas of fairly heavy clay soils, but they prefer the lighter types. 
They tolerate temperatures from those found in Death Valley in summer (about $120^{\circ} \mathrm{F}$ ) to those of the northern Great Plains in winter (about $-40^{\circ} \mathrm{F}$ ). I cannot see that temperature played a

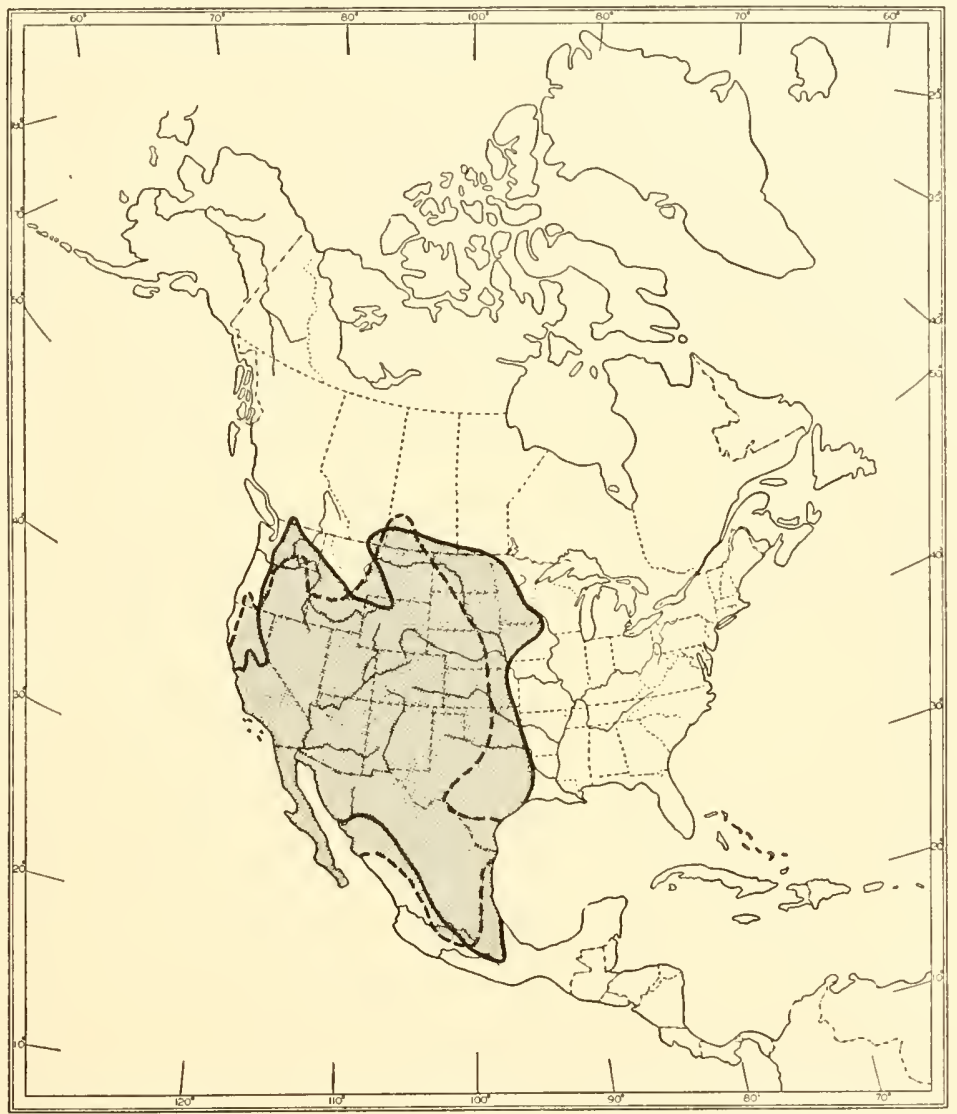

Fig. 4. General distribution of the genera Dipodomys (broken line boundary) and Perognathus (solid line boundary). All evidence indicates that these mammals had their evolutionary history approximately within their present range. There is no indication that they ever approached the Bering land bridge.

major role in keeping these mammals on the North American continent. I suspect it was soil type with the accompanying vegetation that prevented these rodents from approaching the land connection.

Porcupine (Family Erethizontidae). The porcupine did not 
find its way to North America until after the Panama land connection with South America was established. It has now penetrated to the far northern forests and no doubt would have made the crossing had it not arrived too late. Time, I suspect, was the important factor for the porcupine.

Pronghorn (Family Antilocapridae). As far as known, this is strictly a North American product. Any intercontinental exchange must have been by pre-pronghorn ancestors. Why did not this animal reach Asia when other artiodactyls did? I suspect that the answer is to be found in the ecology of the pronghorn. It is an inhabitant of short-grass, semi-arid country. It is tolerant of low as well as high temperatures. If the ancestors of pronghorns had similar habitat preferences, we may assume that these short-grass semi-arid conditions did not form a pathway on the approaches or on the bridge itself. In this case, ecological conditions would serve as a selective agent to prevent movement of the pronghorn.

Except for the coati and ringtail, these groups that apparently did not cross the land bridge now inhabit areas of lower winter temperatures than those that prevailed when the continents were connected. General ecological conditions, soil and vegetation, I suspect, were more important in restricting their northward movements than was temperature. For the porcupine it was probably the time element. The coati and ringtail conceivably could have been restricted by low temperatures.

\section{SUMMARY AND CONCLUSIONS}

It is suggested that the term "origin" as applied generally to faunas or taxa be replaced by the term "evolutionary phase." Origin implies a fairly definite time and place for the beginning of a fauna or taxon. But the evolutionary process is a continuum, and a phase may represent a transition in time and space.

The difficulties in evaluating mammalian faunas in order to designate affinities are pointed out. After a somewhat subjective analysis, it is concluded that over one-half ( 57 per cent) of the mammalian fauna of western North America shows affinities with the fauna of Asia, about 13 per cent with that of South America, and the remainder ( 30 per cent) may be considered as indigenous.

Present relationships indicate an exchange of faunas in the past. Further, they indicate suitable habitats on land connections for 
those kinds that made the crossing from one continent to the other. The various groups of mammals of western North America are analyzed for habitat selection, and general ecological conditions are postulated for those that apparently made the crossing on the Bering land bridge. Ecological conditions, soil and vegetation, are considered to have been more important than climate, especially temperature, in preventing certain kinds from making the crossing.

From the analysis of the mammalian fauna it is evident that generalizations are dangerous. Each kind must be judged by itself. What is applicable to one may not be to another. Still more hazardous would be the application of rules derived from the study of mammals to other classes of vertebrates or to invertebrates without first understanding those groups.

\section{REFERENCES}

Burt, William H. 1954. The subspecies category in mammals. Syst. Zool., 3 (3): 99-104, 3 figs.

Cabrera, Angel, and Jose Yepes. 1940. Historia Natural Ediar.-Mamíferos Sud-Americanos. Buenos Aires.

Cain, Stanley A. 1944. Foundations of Plant Geography. Harper and Brothers, New York.

Darlington, Philip J. 1957. Zoogeography. John Wiley and Sons, New York.

Deevey, Edward S., Jr. 1949. Biogeography of the Pleistocene. Bull. Geol. Soc. Am., 60: 1315-1416.

Ellerman, J. R., and T. C. S. Morrison-Scott. 1951. Checklist of Palaearctic and Indian mammals, 1758 to 1946. British Museum (Natural History). London.

Emiliani, Cesare. 1958. Ancient temperatures. Sci. American, 198: 54-63. Erdbrink, D. P. 1953. A Review of Fossil and Recent Bears of the Old World, Pt. 2, pp. 321-597. Deventer-Drukkerij Jan de Lange.

Hall, E. Raymond. 1951. American Weasels. Univ. Kansas Publs., Mus. Nat. Hist., Vol. 4, pp. 1-466.

Hardy, Ross. 1945. The influence of types of soil upon the local distribution of some mammals in southwestern Utah. Ecol. Monographs 15: 71-108.

Merriam, C. Hart. 1894. Laws of temperature control of the geographic distribution of terrestrial animals and plants. Natl. Geogr. Mag., 6: 229-238.

- 1918. Review of the grizzly and big brown bears of North America. North Am. Fauna No. 41.

Miller, Gerrit S., Jr., and Remington Kellogg. 1955. List of North American Recent mammals. U. S. Natl. Museum Bull. No. 205. 
Osgood, W. H. 1909. Revision of the mice of the American genus Peromyscus. North Am. Fauna No. 28.

Pruitt, William O., Jr. 1957. Observations on the bioclimate of some taiga mammals. Arctic, 10: 131-138.

Scott, William B. 1913. A History of Land Mammals in the Western Hemisphere. The Macmillan Company, New York.

Simpson, George Gaylord. 1947. Holarctic mammalian faunas and continental relationships during the Cenozoic. Bull. Geol. Soc., 58: 613-688. 


\section{Origin and Affinities of the \\ Birds of Western North America}

\section{Alden H. Miller \\ Museum of Vertebrate Zoology, University of Califormia, Berkeley}

In a well-illustrated talk, Dr. Miller presented a critical and characteristically lucid analysis of the origin and affinities of the birds of western North America, with special reference to those of Asiatic and South American origin. He compared the eastern and western bird faunas of North America. One of the points he stressed is the high incidence of endemism in the California fauna, conditioned in large part by the isolation of this fauna, by the arid lands of the Great Basin and the Colorado Desert. Pressure of other duties forestalled the preparation of his paper for publication.-Editor. 



\title{
Origin and Affinities of the Present Western North American Reptile and Amphibian Fauna
}

\author{
Robert C. Stebirns \\ Museum of Vertebrate Zoology, \\ University of California, Berkeley
}

\section{ABSTRACT}

The present distribution of amphibians and reptiles in western North America suggests a comparatively recent (geologically speaking) trend toward widespread increasing aridity. This trend has been especially potent in affecting the course of evolution and distribution in the more sedentary, moisture-dependent species. Examples are presented from among the major groups of amphibians and reptiles.

The origin and affinities of the present salamander fauna of the West are discussed. 



\section{Evolution of a Coast Range Corridor in California and Its Effect on the Origin and Dispersal of Living Amphibians and Reptiles}

Frank E. Peabody ${ }^{1}$ and Jay M. Savage

Department of Zoology, University of California, Los Angeles and Department of Biology, University of Southern California, Los Angeles

\section{Thirty years ago, A. B. Howell wrote (1927,} p. 18) that "the fauna of the Pacific Coast of the United States is of unusual interest, and presents many fascinating problems." After three decades of intensive study, Howell's statement is no less true, and many fascinating problems remain for the solving. However, in three decades there has accumulated a great mass of information on the terrestrial fauna and flora of far western North America. Numerous investigators approaching the region from the varied point of view of the zoologist, botanist, paleontologist, and geologist have worked to a large degree independently. Perhaps the time is right for significant syntheses culled from the data of biological and physical disciplines.

Obviously, any synthesis must draw on the data of geology and paleontology as well as on that from the modern biota. A most important contribution of geology is that our western region is in the throes of violent physical revolution in marked contrast with long antecedent epochs of quiescence. Our modern biota exists in what we and many others regard as an interglacial stage of the Pleistocene epoch. A most important contribution of paleontology is the clear evidence of marked southerly shifts of isotherms on a continental scale culminating in the Pleistocene and integrated with profound topographic changes affecting vast inland areas. While it may be charged that the biologist has not sufficiently heeded these

' Deceased June 27, 1958. 
major contributions outside his immediate field, it is probably true that the paleontologist and even the geologist may profit from a closer look at biological data. It is the general purpose of the present paper to demonstrate the advantages of a many-sided approach to the problems of origin and dispersal of the biota of far western North America. Attention is focused on the late Cenozoic era because the historical events of that time are most completely documented and because these events produced the major patterns of origin and distribution of modern species.

Distribution diagrams are based on the treatise by Stebbins (1954), with some emendations by the junior author. The distribution patterns are selected to illustrate best the relationship to the coastal corridor. It is believed that the pattern of present distribution of species provides a general indication of the point of origin with respect to the geologically recent corridor. Obviously, fluctuations must have taken place in the past as at present, as witness the northward advance of southern species and northward retreat of boreal species which are presently being documented across North America.

\section{THE FOSSIL RECORD}

Fossil remains of amphibians and reptiles are rare in North America west of the Mississippi and extremely rare in the far west. Some indication of the fact is afforded by the paucity of citations from bibliographic sources. For the 41-year period from 1913 to 1954, the journal Copeia, of the American Society of Ichthyologists and Herpetologists, contains only four papers describing Pleistocene reptiles, and only three papers on Pliocene reptiles (Reed, 1956). The more complete coverage in the Camp bibliographies of vertebrate paleontology over the 20-year period 1928-1948 includes approximately eleven papers on amphibians, none concerning far western North America, and approximately sixteen papers on reptiles, none concerning the far west (Camp et al., 1940-1953). More current literature includes a few but important contributions, for example, the description of the salamander, Paleotaricha, from the Oligocene of Oregon (Van Frank, 1955), and contributions by Bayard H. Brattstrom (particularly 1954, 1955) and Richard G. Zweifel $(1955,1956)$ on the herpetofauna of the Tertiary and Pleistocene. In general the described fossils older than the late Pleistocene 
are rare, isolated fragments. Cave and asphaltic deposits of the late Pleistocene produce more remains, but nearly all are disarticulated and easy to overlook in the quest for larger and more durable remains of mammals and birds.

Current interests of paleontologists in the washing and sifting of sediments for microfossils are greatly increasing the recovery of herpetological remains. For example, students of the University of California, Berkeley, have made large collections of small lizard remains from Eocene and Cretaceous strata of Colorado and Wyoming (Malcolm McKenna and Robert Estes, personal communication). However, a fossil amphibian, particularly a fossil urodele, will continue to be a rare find for the paleontologist because of the ancient trend toward deossification in their skeleton and because bone is a prime prerequisite for preservation. Fortunately, the fossil record of amphibians is enhanced significantly by the discovery of numerous, clear, and distinctive trackways of urodeles in MioPliocene sediments of the Sierra Nevada Mountains in California (Peabody, 1940, 1954).

A general conclusion from a survey of the paleontology of the far western herpetofauna is that considerable progress is to be expected in the future as a result of new techniques and of heightened interest in paleoherpetology. However, we cannot ever expect to approach the relative completeness of the mammalian record, and discoveries in the far west will continue to be infrequent. Also a necessary adjunct to paleontological studies will continue to be more detailed osteological studies of living species.

The fossil record of the herpetofauna, admittedly deficient, is complete enough to establish firmly some general considerations of historical importance. Fossils from the Cenozoic of Europe and North America clearly indicate great antiquity for most living genera of salamanders. By the dawn of the Cenozoic the three families of terrestrial salamanders, Salamandridae, Ambystomidae, Plethodontidae, were evolved, and by the Miocene epoch living genera of all urodeles were probably in existence. The most dramatic and unusual evidence of modern families and genera comes from the Mio-Pliocene trackways of the Sierra Nevada (Peabody, 1940) where the genera Taricha, Batrachoseps, and a Dicamptodon-like form coexisted in association with a fossil flora described by Condit (1944). These trackways and the Oligocene skeleton of Paleotaricha 
from Oregon (Van Frank, 1955) clearly indicate an additional, important conclusion. Before the end of the Miocene epoch the far west possessed a salamander fauna distinct from those of eastern North America and Asia. The fossil record suggests that the antiquity of anuran development at the familial and generic levels was similar to that of the urodeles. However, the anuran fauna of western North America has not become as clearly differentiated from the eastern fauna.

On a worldwide basis the antiquity of families and genera of modern reptiles does not correspond to that of the amphibians, that is, the rate of evolution has been faster. A general impression is that whereas most modern families, for example, the Iguanidae and Varanidae, were evolved before the beginning of the Cenozoic, the majority of modern genera in all families originated in middle to late Cenozoic. In any event, the fossil record has little to offer on the origin of modern genera and families of reptiles in far western North America.

The fossil record makes little contribution to the origin of modern species of the herpetofauna generally. Our knowledge of specific characteristics of modern skeletons, of representative herpetofaunas, and of stratigraphic controls within the Quaternary epoch is much too deficient. Historical insight of the paleontologist would suggest, however, that in our far western area, physical events culminating in the Pleistocene epoch provided abnormally strong stimuli to the rate of evolution at the level of species and subspecies.

\section{THE CALIFORNIA COAST RANGE CORRIDOR}

Obviously the above account of purely paleontological contributions to the stated theme of the symposium are disappointing and inadequate. With this fact all too apparent, the writers groped for a more significant contribution in the form of a multi-directional approach-essentially a new look at old data from geology, paleontology, and herpetology. The senior author has long been fascinated by the classic rassenkreis of subspecies of Ensatina as ably described by Stebbins (1949). Reflection on possible historic controls of the sympatric association of Ensatina subspecies in southern California suggested that somehow the physical history of California may reveal the vital causative factor - a possibility not entertained by 
Stebbins. Interest was stimulated by the discovery that southern California is an area of relatively high incidence of sympatry between closely related forms in the modern herpetofauna. While searching for the explanation for this phenomenon of distribution, the writers evolved the concept of a Pacific Coast Range corridor culminating in the Pleistocene epoch, accompanied by collateral physical changes and affecting directly the origin and distribution of the modern herpetofauna. The concept is hopefully presented as a useful adjunct to understanding of the problems of origin and dispersal of faunas of far western North America.

Evolution of a Coast Range corridor essentially involves the Central Coast Ranges, consisting of western and eastern segments and extending from San Francisco south to Santa Maria, and the Southern Coast Ranges extending from the Santa Barbara region through the Transverse Ranges. The corridor has important connections on the south with the Sierra block and with the Peninsular Ranges, both of which are genetically related to the Basin and Range

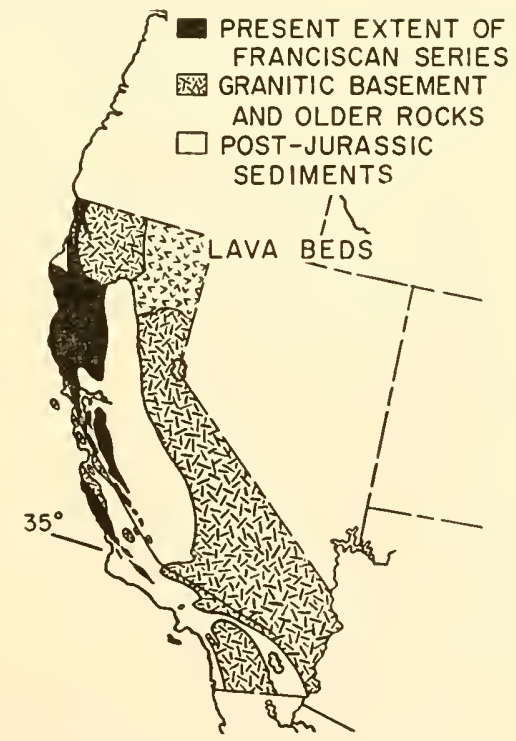

Fig. 1. Lithologic provinces of California. The present Great Valley and Central and Southern Coast Ranges are the site of extensive marine deposition (to $50,000 \mathrm{ft}$. thick) from Cretaceous into early Pleistocene time. (After Camp.) 
Province of Nevada. The corridor is bordered on the west by the ocean and on the east by a great structural depression, only recently reclaimed from the sea by continental uplift.

The data of geology (Taliaferro, 1943; Eardley, 1951) supply antecedent chapters in the formation of the corridor. Geomorphologic provinces of California (Fig. 1) show that the site of the present corridor was dominated by a large geosyncline receiving mainly marine deposits in the approximate position of the Great Valley of California during most of the Cenozoic. Adjacent structural basins of marine deposition to the south contributed to the limiting of the stable edge of the continent to a line running lengthwise through the middle of modern California. The area of the corridor was an archipelago at best during most of the Cenozoic.

During the Miocene epoch the area of the future corridor was essentially "wiped clean" of terrestrial organisms by maximum flooding of marine waters (Fig. 2). Flooding was followed by acceleration of orogeny in the Coast Range belt. The orogeny surged to one peak in late Pliocene, affecting mainly the western part of the Central Coast Ranges, and to a second peak in the Mid-Pleisto-

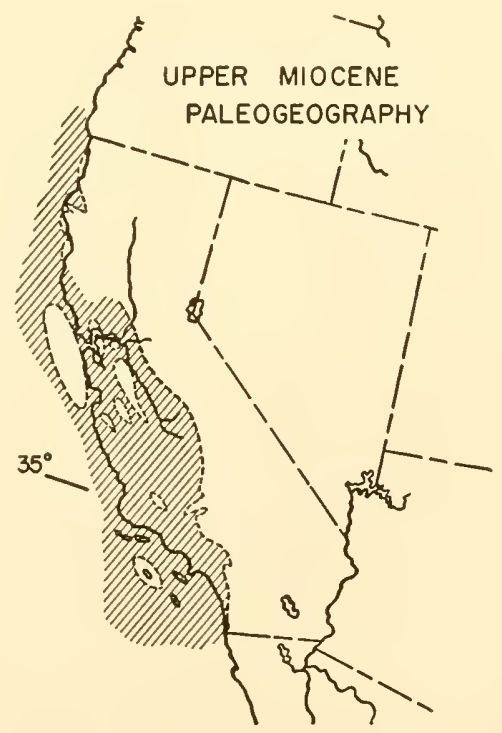

Fig. 2. Late Miocene paleogeography of California, showing extensive marine flooding in position of present Central and Southern Coast Ranges. (After Camp.) 
cene, affecting the eastern part of the Central Coast Ranges and the Southern Coast Ranges generally. The last surge is still in its climactic phase as the present is a time of active orogeny. The midPleistocene orogeny is associated with the final disappearance of Tertiary troughs of deposition and the foundering of considerable segments of the Coast Ranges into the Pacific Ocean. Also, and of particular importance to the corridor concept, a marked uplift of

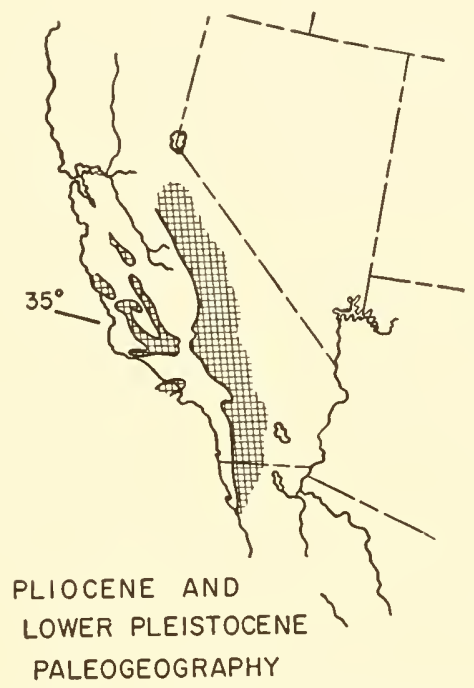

Fig. 3. Pliocene and early Pleistocene paleogeography, showing archipelagic nature of Coast Range region, and presence of strait connecting Pacific with San Joaquin embayment. (After Eardley.)

epeirogenic proportions affected the continent generally and the area of the corridor in particular following the peak of mid-Pleistocene orogeny. (At present, dissected erosion surfaces exist at levels of several thousand feet elevation in the San Gabriel Mountains.) Volcanism appears to have occurred sparingly in the area of the corridor and has contributed little to its crust.

Paleogeography of the Pliocene and early Pleistocene (Fig. 3) suggests that the Central and Southern Coast Ranges constituted a reasonably continuous land mass probably extending far northward but separated at the southern end from the continent proper by a wide strait. Distribution of terrestrial plant and mammalian localities (Fig. 4) of Pliocene and early Pleistocene age suggests that the 
strait at the southern end of the future corridor opened directly westward from the southern San Joaquin embayment. In view of the many complexities of Coast Range geology it is difficult to follow in detail the rapid geomorphic changes attending Coast Range orogeny. However, the distribution of the modern herpetofauna in California suggests strongly that there was an important marine barrier in the position of the present Southern Coast Ranges, in fact

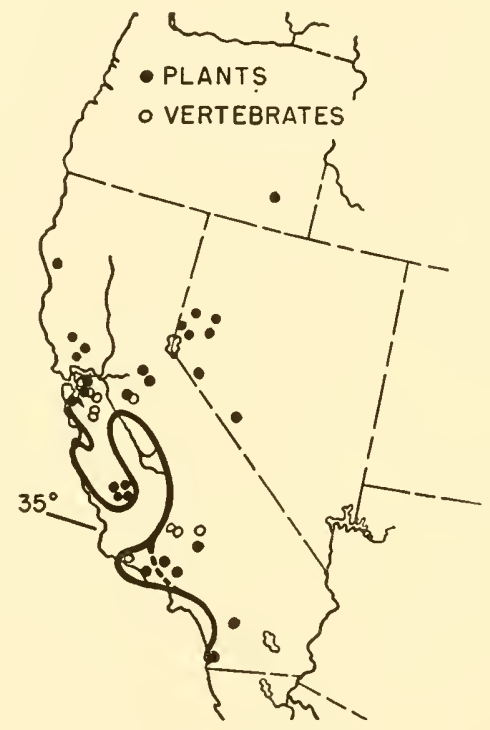

Fig. 4. Distribution of terrestrial Pliocene and early Pleistocene localities for plants and mammals suggestive of southern strait connecting Pacific with San Joaquin embayment.

precisely coincident with the strait shown in Fig. 3. Also a continuity northwestward from the strait is indicated. The continuity need not have been geographic but was almost certainly zoogeographic, allowing free access to northern species of the herpetofauna but not to southern species. Paleobotanical data (Axelrod, 1957) indicate that the marine strait was not a barrier to northward extensions of tropical and subtropical floras (Fig. 5). In terms of the herpetofauna, it seems reasonable to conceive of a long peninsula or a series of closely adjacent islands forming a zoogeographic unit extending southward from the San Francisco region and including the Santa Lucia basement rocks as a relatively stable component. 

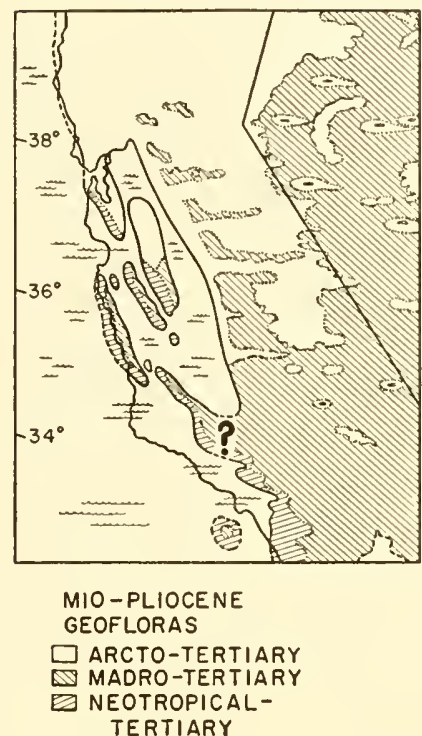

Fig. 5. Distribution of geoflora during Mio-Pliocene time. (After Axelrod (reconstructed).)

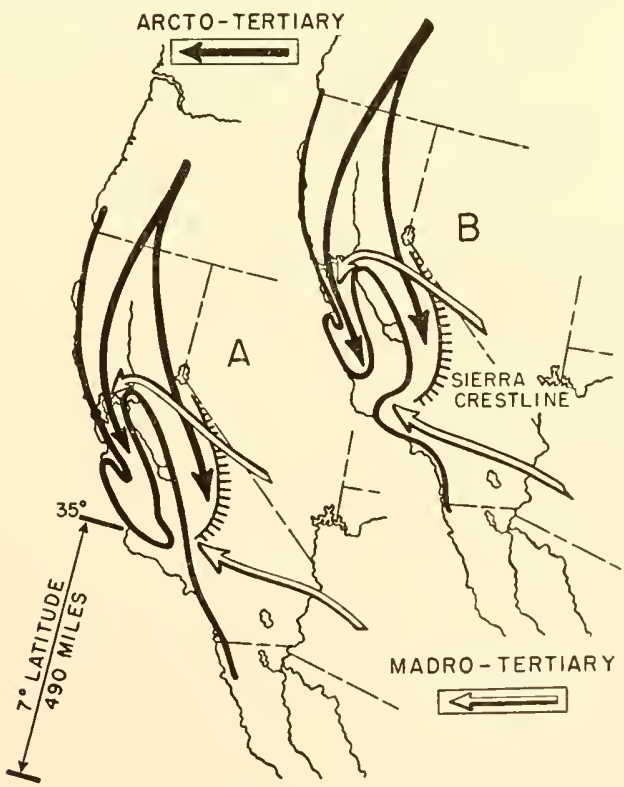

Fig. 6. Alternative interpretations of zoogeographic peninsula existing in California during Pliocene and early Pleistocene time. 
Alternate maps may be presented (Fig. 6) depending on the presumed position of the marine strait, but in both cases demonstrating the barrier at the southern tip of the peninsula. The peninsula persisted until the second peak of Coast Range orogeny in midPleistocene time and the following uplift brought the Clast Range corridor into being.

Physical changes associated with Coast Range orogeny were not in themselves sufficient to convert the Coast Ranges into a zoogeographic corridor. Entirely coincidental and independent climatic changes were in progress. The work of Chaney (1940) in paleobotany and of Durham in invertebrate paleontology (1950) has mutually documented a continent-wide shift of isotherms southward throughout the Cenozoic, reaching a maximum (with fluctuations) in the Pleistocene epoch. According to Durham, the $18^{\circ} \mathrm{C}$ marine isotherm was at latitude $35^{\circ} \mathrm{N}$, coincident with the Southern Coast Ranges, in the late Pliocene, and shifted $7^{\circ}$ southward (over 400 miles) at the peak of Pleistocene glaciation. Here is the climatic stimulus needed to force faunal elements southward into the peninsula, perhaps causing "jamming" or peninsular effects. Future study of fossil mammals in the presumed peninsular area may show such effects to be present. Certainly the marine faunas of the area are extremely provincial in character. However, this is commonly attributed to the many local, shifting basins of deposition attending the Coast Range orogeny.

Coincidental with the Coast Range orogeny, the vast Sierra Nevada block began to tilt westward, so as to form a high crest running southward from a point near the present Lake Tahoe and curving westward to a junction with the Southern Coast Ranges. Axelrod's masterly use of paleobotanical data (1957) graphically portrays the rise of the Sierra Crest from an average of 3,000 feet in the Miocene to 8,500 feet in the Pleistocene, and the accompanying, drastic, climatic effect on vast inland areas of the continent. Undoubtedly the formation of the Coast Ranges also contributed to the drying of the interior. The combination of geological and climatic changes in the far west resulted in a southward movement of the Arcto-Tertiary geoflora, especially along the coast, and a northward and northwestward movement of the Madro-Tertiary geoflora from a Mexican center of origin. A Neotropical-Tertiary geoflora retreated southward along the coast. 
In summary: Geological data conclusively demonstrate that the Central and Southern Coast Ranges were formed largely from submarine portions of the continental shelf. The Coast Ranges then constituted a land bridge between northern and southern California, because a San Joaquin embayment to the east persisted as a marine barrier well into the Pleistocene. Later withdrawal of the sea from the embayment reduced the barrier potential between the Coast Ranges and the Sierra Nevada, but the low, wide, dry valley remains an effective barrier to many terrestrial organisms.

There is no doubt that the Central and Southern Coast Ranges eventually formed a connecting bridge around the seaward side of a great structural depression, but the connection remained incomplete near the southern end until Mid-Pleistocene time. The area of the bridge is cut lengthwise by one of the world's major faults, the San Andreas. However, the movement along the fault is largely horizontal, and although there may have been horizontal displacement of several hundred miles in the Plio-Pleistocene, it is thought that the zoogeographic effect of the fault movement was negligible. Only after the second peak of Coast Range orogeny, accompanied by continental uplift, did the land connection become a continuous bridge or corridor available to the herpetofauna.

The original point of view here presented is that the land connection existed prior to the mid-Pleistocene as a large peninsula broadly connected northward to the continent, as a continuous zoogeographic (if not geographic) unit, and with an effective marine barrier in the form of a wide strait at the southern tip. The barrier remained until mid-Pleistocene time. At this time the Central and Southern Coast Ranges became an effective corridor for the dispersal of many terrestrial organisms.

During late Miocene and early Pliocene the peninsula was largely occupied by Neotropical and Madro-Tertiary geofloras. The ArctoTertiary geoflora was excluded and along with it the associated herpetofauna, on the basis of purely climatic control. At the same time, herpetofauna of Mexican origin and associated with the Madro-Tertiary geoflora may have been unable to reach the evolving peninsula because of the marine barrier at the southern tip. The barrier, however, was not effective in limiting the northward extention of the Neotropical and Madro-Tertiary geofloras. The above hypothesis is strengthened by the fact that no endemic species of 
the present herpetofauna exist in the stable Santa Lucia positive area of the peninsula. Geological and climatic events of the late Cenozoic preclude such endemism. Finally, the profound and complex influences brought to bear on the biota of the California region are shown to be the result of an entirely fortuitous combination of interacting geological and climatic changes having peak effect during Pliocene and Pleistocene time: evolution of the Coast Ranges; southward shift of marine and continental isotherms on a worldwide basis; rise of the Sierra Nevada crestline with concomitant drying of the interior; continental uplift.

\section{CORRIDOR EFFECTS}

\section{Areto-Tertiary Speeies}

Major migrations of western geofloras described by Axelrod (1957) are important to an understanding of distribution changes in the contemporaneous herpetofaunas. The writers believe that the late Cenozoic herpetofauna of the west may be correlated broadly with the Arcto-Tertiary and Madro-Tertiary geofloras. Salamanders are fundamentally boreal and Arcto-Tertiary, the lizards and snakes are fundamentally Sonoran and Madro-Tertiary in historical relationship. The frogs and toads are transitional in that some forms appear to be Arcto-Tertiary elements while others are of MadroTertiary relationships. Bufo boreas and Rana aurora are examples of the former; Bufo microscaphus, Rana boylii, and Rana muscosa of the latter. As a result of the combination of geological and climatic events described above, the Arcto-Tertiary salamanders and frogs tended to move southward and split around east and west sides of the Great Valley depression. However, the western route down the corridor was not complete until the mid-Pleistocene. Thus until the last half of the Pleistocene a "dam" was in force which would allow accumulation of genetic differences between east (Sierran) and west (Coast Range) arms of Arcto-Tertiary dispersals. Unless the "dam" was in force until relatively late in the Pleistocene, the flow of genetic material down the corridor should have merged compatibly with the flow down the mainland to eastward. Apparently this was not the case. Once the corridor was in operation it was possible for an Arcto-Tertiary species to disperse southward, subject to fluctuations, in a pattern like that of Rana aurora (Fig. 7). Development of clines along the route would be expected, and do occur. Few of the 
Arcto-Tertiary species range around the southern end of the Great Valley at present, but many range around the northern end.

Trans-valley "leaks" have occurred across the valley harrier but only from west to east at the position of the San Joaquin delta. Apparently the "leaks" became possible during relatively recent

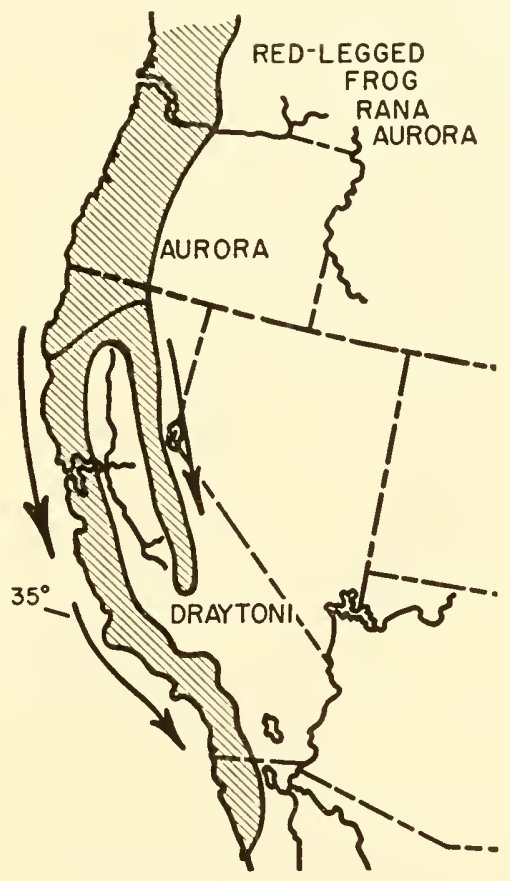

Fig. 7. Distribution of red-legged frog, Rana aurora. Pattern is typical of Arcto-Tertiary forms that have moved southward through Sierra Nevada and coastal corridor. Arrows in Figs. 7-18 indicate probable movements from points of origin. (Figures 7-18 based on Stebbins, with some modifications.)

fluctuation of humidity in the delta region. The subspecies xanthoptica of Ensatina eschscholtzii has established a population in the Sierras and is currently showing some interbreeding with the established Sierran subspecies platensis (Fig. 15). Similarly, the coastal Aneides lugubris has established a population in about the same area as the subspecies of Ensatina (Fig. 8). In a valuable study of this phenomenon, Rosenthal (1957) points out that no biological or physical factor, other than time itself, limits the Sierran range of the 
trans-valley leak, hence the Sierran population must be a recent introduction across the valley. The only other trans-valley leak noted seems to have occurred in the distribution of the limbless lizard, Amiella pulchra, which is a Madro-Tertiary species. Again, the leak has been from west to east, near the position of the delta. It is not known if moisture has been the critical factor here as it surely has been for the salamanders, or whether the leak is indeed

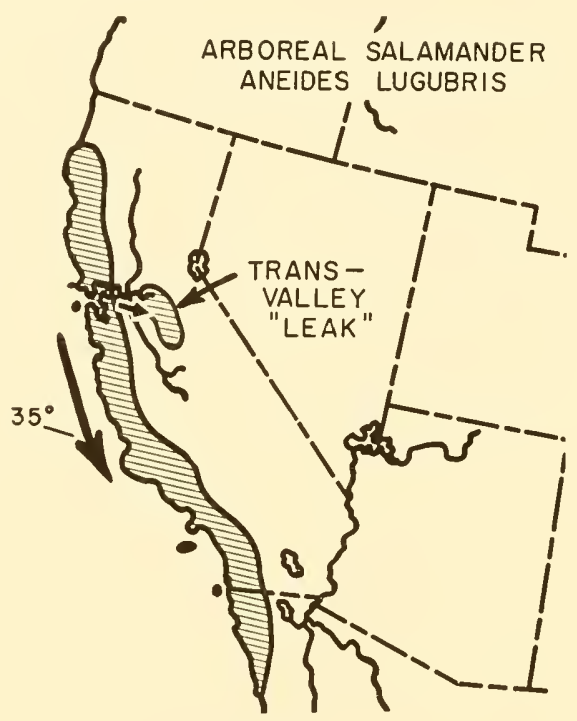

Fig. 8. Distribution of arboreal salamander, Aneides lugubris. Note trans-valley leak, which probably occurred in pluvial times and established species in Sierra foothills.

genuine (the supposed leak may represent an inarlequately known distribution of the lizard northward along the entire eastern side of the Great Valley). The few occurrences of trans-valley leaks emphasize the overall efficiency of the Great Valley as a barrier to transverse dispersal between the corridor and the Sierras except at the north and south ends. Finally, no Arcto-Tertiary species appears to have moved down the corridor and back up the Sierras, or vice versa. Dispersals southward along the corridor and along the Sierras have remained largely separated in southern California in coastal lowland and interior highland, or have achieved only limited sympatry there. 


\section{Madro-Tertiary Species}

Species of lizards and an anuran illustrate best the relationship of the corridor to Madro-Tertiary elements moving in from Mexican centers of origin. Southern mesic elements of the Madro-Tertiary complex invaded the corridor from the south end, but in a variable manner. The western spadefoot, Scaphiopus hammondii, appears to have "flooded" the corridor (Fig. 9) and the adjacent valley to its northern end, meanwhile developing a wide disjunction in the lower Colorado Valley. A related, northern species in the Great Basin appears to be in the process of invading the San Joaquin Valley via Valker Pass. Patterns somewhat similar to that of S. hammondii occur in Bufo microscaphus and Iyla arenicolor, without the presence of a related Great Basin species. This suggests that species ap-

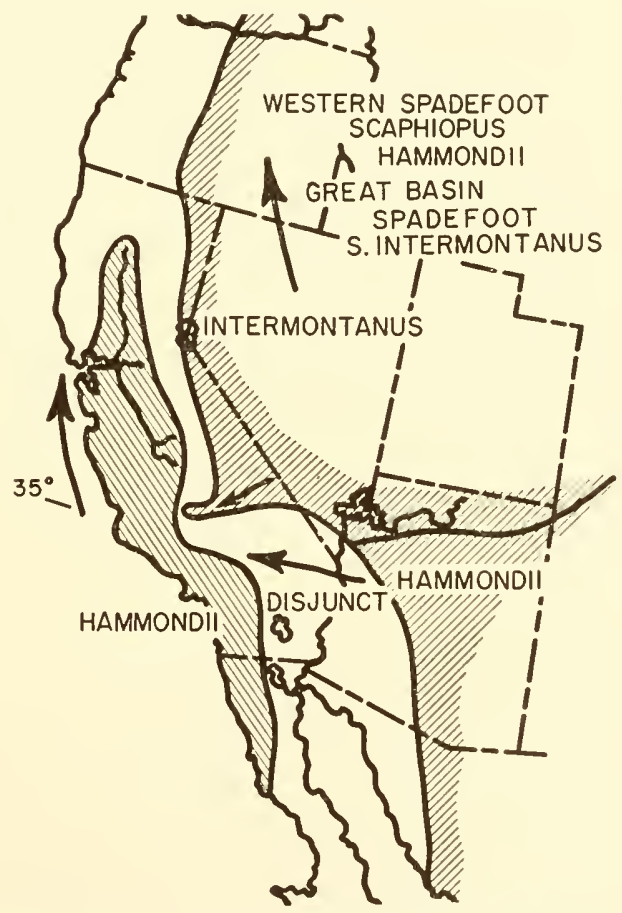

Fig. 9. Distribution of western spadefoot, Scaphiopus hammondii, and Great Basin spadefoot, Scaphiopus intermontanus. Former now has disjunct distribution in Californias and areas to east. Apparently $S$. intermontanus has recently invaded western Sierran foothills through mountain passes. 
proaching the southern end of the corridor from the interior encounter a barrier at the southern Sierra crest and at the Transverse Ranges. Warming and drying trends may enable desert species to spread northward into the San Joaquin Valley via Walker, Tehachapi, and Tejon passes. Distribution of the desert night lizard, Xantusia vigilis (Fig. 10), indicates a relatively recent invasion via Tehachapi and up the Sierra foothills, and an invasion via Tejon

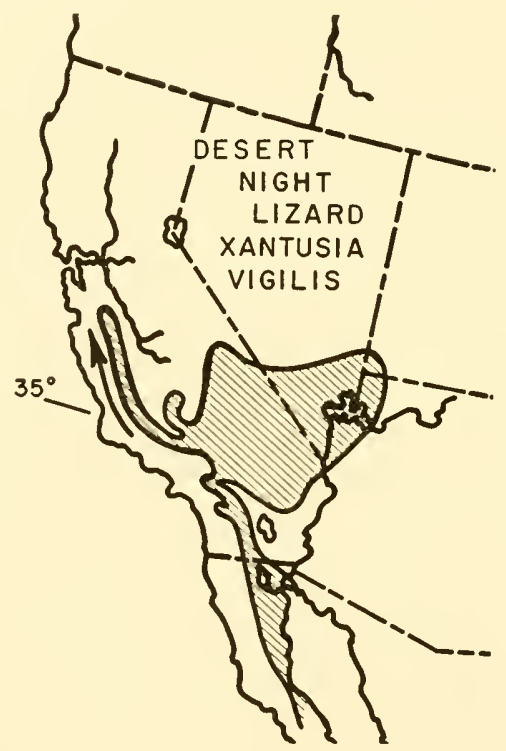

Fig. 10. Distribution of desert night lizard, Xantusia vigilis. Invasion of foothills on both east and west sides of Great Valley is apparently progressing actively at present.

and up the dry inner Coast Ranges. A somewhat older invasion through the passes into the San Joaquin Valley is suggested by the distribution pattern of the leopard lizard, Crotaphylus wislizenii (Fig. 11). The San Joaquin subspecies, silus, represents a stock differentiated from the parent subspecies of the Great Basin, and certainly reached the San Joaquin Valley from the south, across mountain passes, during a climatic fluctuation.

Northern elements of the Madro-Tertiary complex have tended to invade the corridior from the north, following the path of ArctoTertiary species. The sagebrush lizard, Sceloporus graciosus (Fig. 12), has differentiated a Californian subspecies, graciosus, which has, 
so to speak, made an "end run" around the north end of the Great Valley and down the corridor. However, disjunct populations of this and the southern subspecies, vandenburghianus, suggest a postPleistocene fragmentation and retreat northward. Somewhat similar distribution patterns are found in the ringneck snake, Diadophis amabilis, and the mountain kingsnake, Lampropeltis zonata.

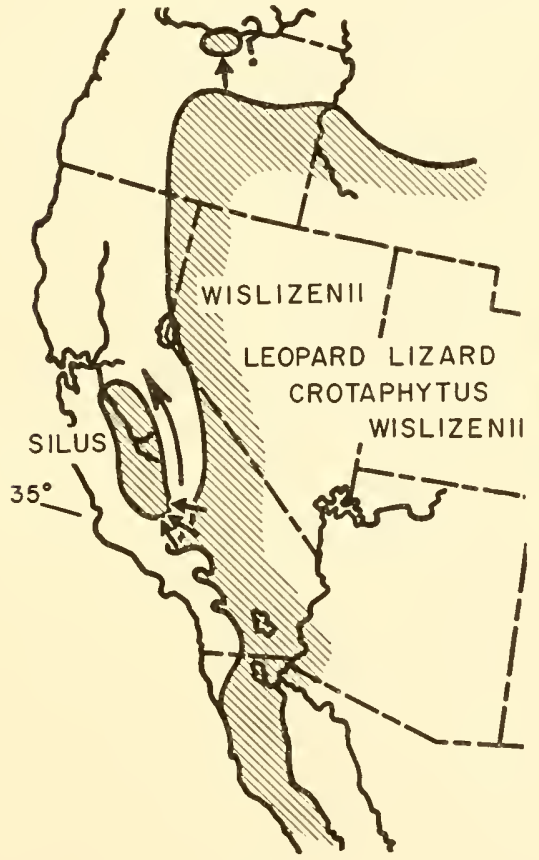

Fig. 11

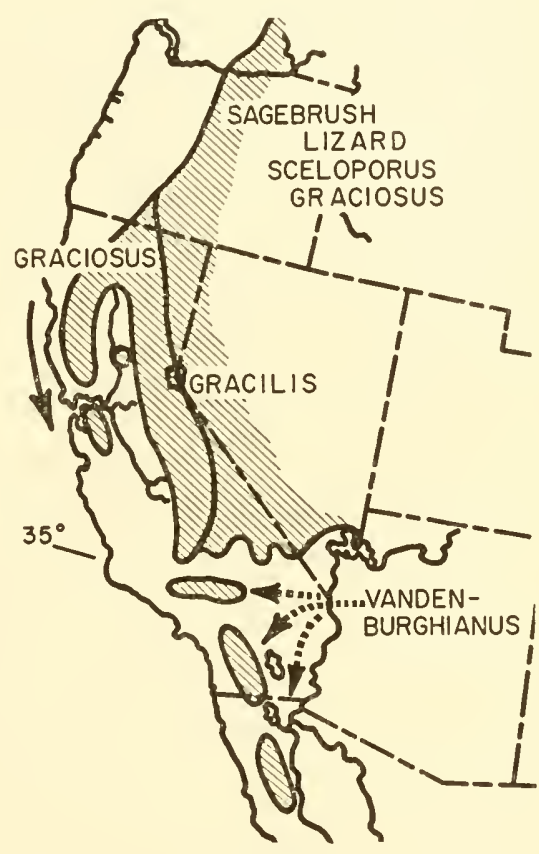

Fig. 12

Fig. 11. Distribution of leopard lizard, Crotaphytus vislizenii. Race silus, is isolated in arid southern portion of Great Valley.

Fig. 12. Distribution of Sceloporus graciosus, sagebrush lizard. Effect of coastal corridor on this mesic species and fragmentation of its range are noteworthy.

The northern alligator lizard, Gerrhonotus coeruleus (Fig .13), and the foothill alligator lizard, G. multicarinatus (Fig. 14), probably differentiated from an ancestral Mexican species. The derived species present a curious contrast in distribution. The northern alligator lizard appears to have made an "end run" around the Great Valley and invaded the corridor part way. The coastal arm is sub- 
specifically distinct. Generally the distribution pattern is like that of Sceloporus graciosus (Fig. 12). The foothill alligator lizard, preferring warmer, drier habitat than the northern alligator lizard, ranges completely around the Great Valley and broadly up and down the California Coast. However, there is subspecific differentiation, which

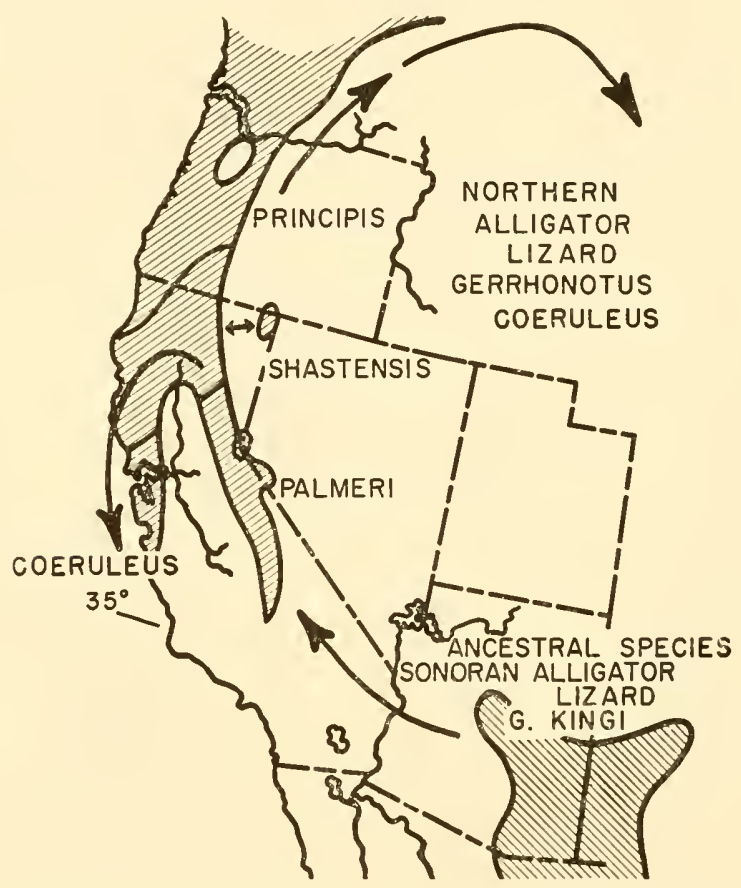

Fig. 13. Patterns of distribution for northern alligator lizard, Gerrhonotus coeruleus, and related Sonoran alligator lizard, Gerrhonotus kingi. Filter effect of coastal corridor is clearly apparent.

has highly interesting boundaries. Gerrhonotus multicarinatus webbii ranges the southern California Coast and up the Sierra Nevada, but is differentiated from the northern California subspecies precisely in the position of the marine barrier postulated earlier. This coincidence would be unimportant were it not for the fact that insular representatives of the two subspecies (Fig. 14) are also separatedmulticarinatus occurring on four islands north of the mainland boundary, webbii on three islands south of the boundary. There is 
the possibility that the subspecies in the corridor came in from the North in the Pleistocene at a time when the marine barrier existed at the south end of the present corridor. In any case the coincident insular and mainland distribution suggests a certain antiquity of subspecific differentiation. It would be interesting to know the rela-

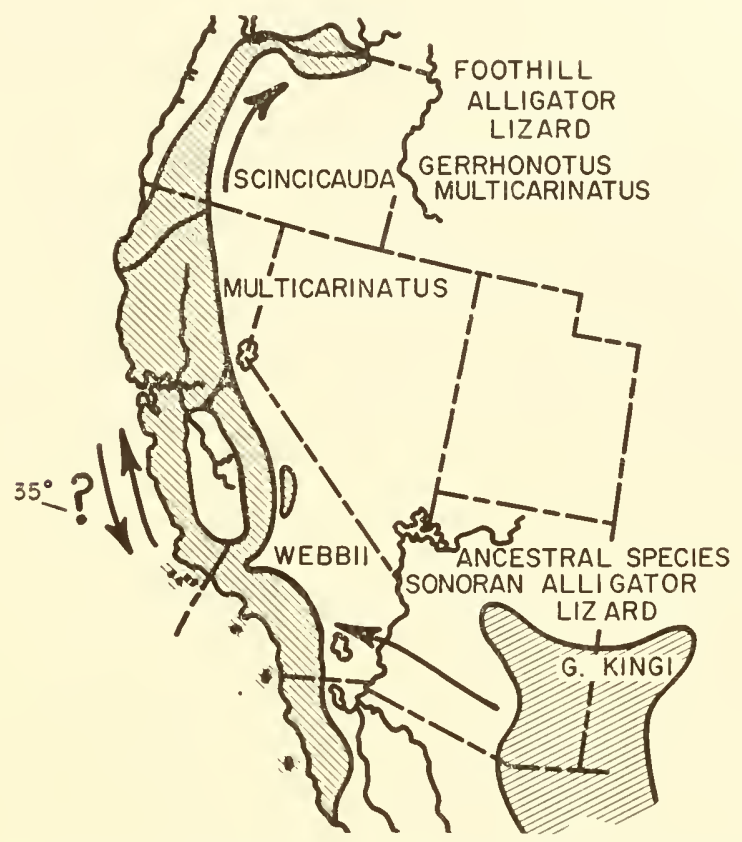

Fig. 14. Distribution of foothill alligator lizard, Gerrhonotus multicarinatus, and its relationship to range of Gerrhonotus kingi, Sonoran alligator lizard. Eastern species is more closely allied to G. multicarinatus than to $G$. coeruleus, and the last two forms occur sympatrically in many regions.

tive degree of differentiation between webbii and multicarinatus on the south and north ends of the San Joaquin Valley.

In summary: Relations of Madro-Tertiary species to the corridor and adjacent land features appear more varied than for ArctoTertiary species. Northern elements of the Madro-Tertiary moved around the north end of the Great Valley and down the corridor; southern elements moved up the corridor, or if xeric in habitat preference, met an effective barrier at the Transverse Ranges and 
the southern Sierra Nevada. Warm, dry trends of elimate allowed xeric elements to move north through mountain passes and into the San Joaquin Valley and bordering foothills.

\section{Sympatry in Southern California}

Four cases of sympatry between closely allied forms occur in southern California. Two of the four cases involve amphibians of Arcto-Tertiary affinities; one of amphibians and one of reptiles are of northern Madro-Tertiary affinities. The sympatry is not of the same degree in each case, but it is sufficiently clear-cut to draw attention to its localized occurrence in southern California. The high incidence of sympatry here strongly suggests a controlling, historical factor. It is believed that this factor is primarily the evolution of a Coast Range corridor as outlined earlier.

1. A classic rassenkreis of subspecies is represented by the distribution pattern of Ensatina eschscholtzii in California (Stebbins,

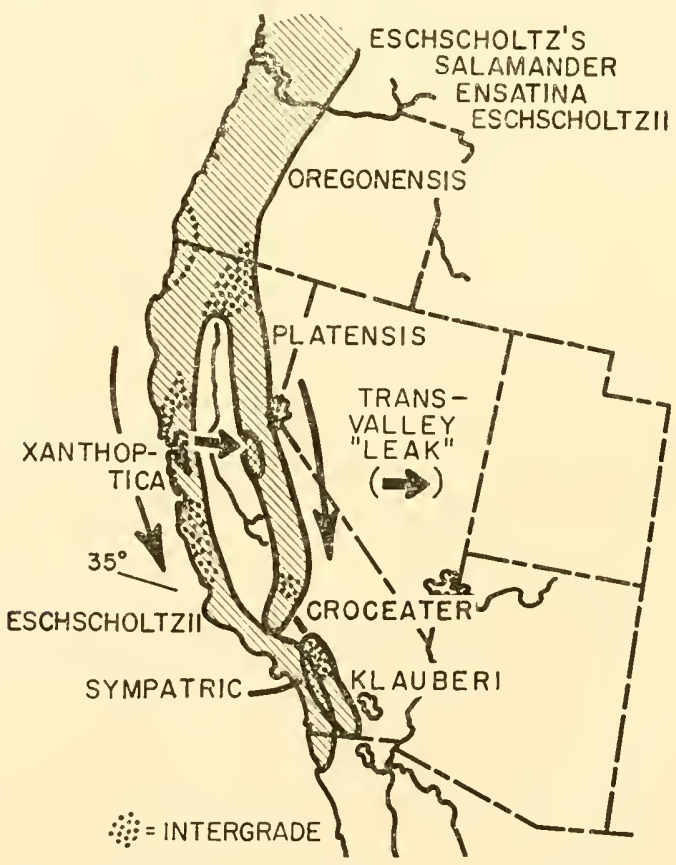

Fig. 15. Distribution of painted salamander, Ensatina eschscholtzii. Subspecies E. e. eschscholtzii and E. e. klauberi occur together in upper San Gorgonio River system, San Bernardino Mountains. 
1954, 1957). The pattern results from a southward movement of a boreal species that split around the Great Valley barrier (Fig. 15). The coastal arm is characterized by a solid color pattern, the Sierran arm by a spotted color pattern. Aside from a trans-valley leak noted earlier, the two arms maintain their identity at separate elevations in southern California, but are found in true (if limited) sympatric association at moderate elevations in the Peninsular Ranges. The Sierran arm has undergone more differentiation and more fragmentation, thus suggesting that it is older than the coastal arm.

2. Two closely related species of the slender salamander, Batrachoseps attenuatus and B. pacificus, are associated in extensive sympatry (Fig. 16) in southern California, along the coast (Stebbins and Lowe, 1949; Savage and Brame, 1957). The species may live together under the same rock or piece of wood. B. pacificus appears to be an older species in southern California, if judged from the degree of subspecific variation and particularly because of its oc-

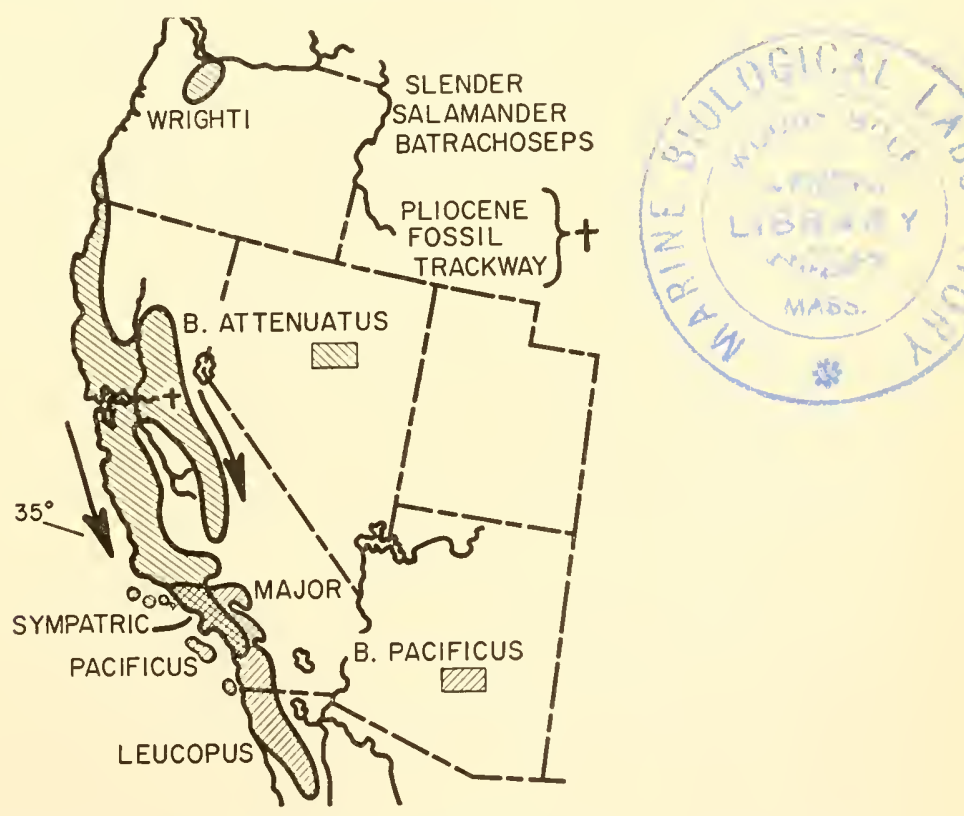

Fig. 16. Distribution of slender salamanders, genus Batrachoseps. Slender salamander, B. attenuatus, is found in sympatry with worm salamander, B. pacificus, in numerous localities in Los Angeles and Orange counties of California, and on Santa Cruz Island. 
currence on six offshore islands, while the other species has managed only one insular invasion. Fossil trackways of Mio-Pliocene age, near Sonora in the Sierra Nevadas (Peabody, 1940) suggest that $B$. pacificus was derived from the north in pre-Pleistocene time. $B$. attenuatus represents the appearance of a younger species in southern California, more advanced in a trend toward attenuation, and one that shows the forked distribution pattern of a boreal species with respect to the Great Valley barrier.

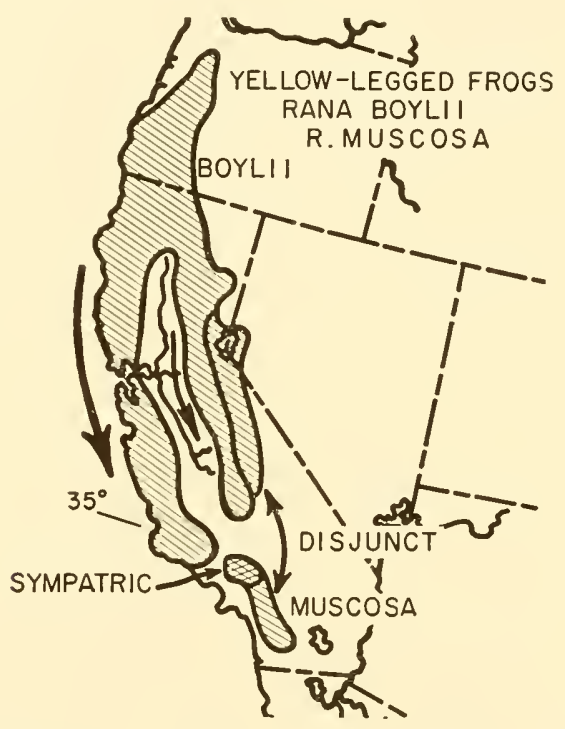

Fig. 17. Distribution of yellow-legged frogs, Rana boylii and $R$. muscosa. The latter is found at high elevations in Sierra Nevada and in montane situations in southern California. Sympatry with $R$. boylii occurs at one locality in San Gabriel Mountains.

3. The distribution pattern of the two species of the yellowlegged frogs, Rana boylii and Rana muscosa (Fig. 17), displays a situation resembling that of Ensatina (Zweifel, 1955). The younger of the two species, boylii, ranges around the Great Valley barrier in the familiar forked pattern. The range is more or less continuous except for a small, disjunct population at the southern end, in the San Gabriel Mountains. Here there is a limited sympatry with the older species, muscosa. The older species ranges at high elevations in the Sierra Nevada and has undergone post-Pleistocene fragmenta- 
tion into populations on several mountain ranges of southern California-San Gabriel, San Bernardino, San Jacinto, and Palomar.

4. Two closely related species of skinks (Fig. 18) show a limited sympatry in the Southern Peninsular Ranges of southern California. The sympatric relationship is not so well established as for Ensatina

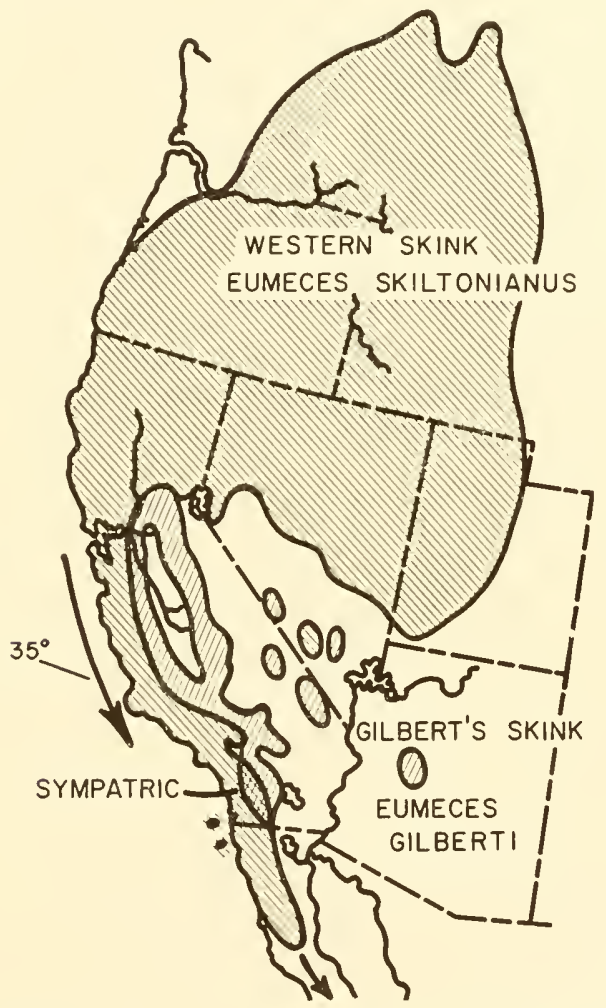

Fig. 18. Distribution of western skink, Eumeces skiltonianus, and giant western skink, Eumeces gilberti.

and Batrachoseps, but appears to be valid. Also, it is more difficult to explain reasonably the location of the sympatry. However, the sympatry of the skinks is of particular interest for the reason that it is unique for closely related species of reptiles in the far west, and involves a northern Madro-Tertiary component that has made an end run around the northern end of the Coast Range corridor. The northern species, Eumeces skiltonianus, appears to have moved down the corridor along with boreal species. A few insular popula- 
tions, a derived endemic species (E. lagunensis) at the tip of Baja California, and a disjunct population in southern Nevada suggest that the species was an early migrant down the corridor. Eumeces gilberti maintains strict separation of range along its western limits except for the sympatry in southern California. There may be a limited sympatry also at the northern end of the range. The species has several disjunct populations in the Great Basin and one in Arizona, all suggesting considerable post-Pleistocene fragmentation.

The relatively high incidence of sympatry between closely related forms in southern California suggests a set of well-timed physical conditions which must first maintain genetic isolation and then allow the isolation to break down. If the Coast Range corridor, Great Valley, and Sierra block had possessed their present form and relationship from Late Pliocene to Recent, it is doubtful that genetic isolation would have been maintained by west and east arms of species dispersing southward around the Great Valley barrier, whether or not gross climatic changes acted as stimulants. Something must have blocked one of the dispersal routes. The evolution of a Coast Range corridor, as outlined earlier, exactly fulfills the conditions of time, place, and climate necessary to produce the observed sympatric conditions. Under the conditions that prevailed, sympatry anywhere else in the far west was unlikely. Also, it was unlikely under prevailing conditions that sympatry would develop in Madro-Tertiary species unless a northern element were to make an end run from the northern Great Basin to the west and down the corridor in company with purely boreal species. That this could happen is indicated by the somewhat special sympatry of the skinks (of example 4, above). Under the prevailing conditions MadroTertiary species of more xeric preference could not disperse up the corridor, and in fact, were barred from it until relatively recent times when dispersal over mountain passes has been possible. Finally, it should be emphasized that the areas of sympatric association are precisely where they should be in relation to the presumed barrier to dispersal down the corridor in Pre-Middle Pleistocene time and to the junction of corridor and Sierran dispersals. (See Fig. 19 for summation.)

The time when sympatry in southern California became possible must not be earlier than mid-Pleistocene time, if our concept of the evolution of the Coast Range Corridor is correct. Thus one is more 
alle to judge the relative age of west and east arms of clispersals reaching southern (alifornia via the corridor and the Sierran or inland route. At least in the four examples of sympatry cited, it is fairly certain that the dispersals clown the corridor are the "newcomers" to southern California. The evidence of corridor evolution, together with relative development of insular populations and

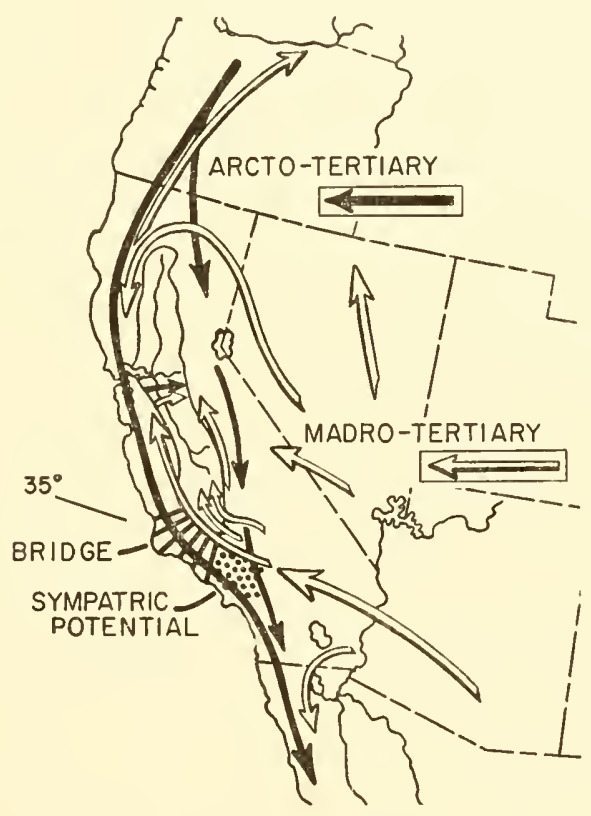

Fig. 19. Nap showing probable migration paths taken by modern amphibians and reptiles with respect to the Coast Range corridor and associated geographic features.

development of post-Pleistocene fragmentation of patterns of distribution are keys to relative age determination.

\section{Coastal Islands and "Waif" Faunas}

Distribution of the far western herpetofauna on offshore islands of southern California (Stebbins, 1954) suggests that it may be profitable to reexamine the established theory that the offshore islands have been connected with the mainland at one time or another during the late Pleistocene. Among the amphibians, only Batrachoseps, Aneides lugubris, and IIyla regilla have reached offshore islands. 
These amphibia are well suited for "waif" dispersal and the mainland opposite the islands has numerous stream channels that frequently sweep enormous amounts of sediment and floating debris into the ocean. In the case of Batrachoseps, the older species (pacificus) on the mainland has populated the largest number (5) of the offshore islands. The younger species (attenuatus) has reached but one island (Fig. 16).

The reptilian insular fauna appears erratic in distribution, and significantly there are no chelonians. Certainly the distribution of insular herpetofauna does not support the theory of "tied" islands, and the relationship of mainland herpetofauna to the Coast Range corridor suggests a generally high degree of sensitivity to land routes.

\section{CONCLUSIONS}

The fossil record at present contributes little to a detailed study of origins and dispersals of the modern herpetofauna of western North America. However, a synthesis of the data from geology, paleontology, and herpetology indicates that the far west, particularly California, was the locus of physical events during the late Cenozoic era that shaped the destiny of the modern herpetofauna. The synthesis reveals an especially intriguing example of the physical factors inherent in biological evolution - the coincidence of time, place, and climate contributing to the randomness and opportunism of evolution. The synthesis suggests that such fortuitous interactions of time, place, and climate might be considered a major factor in biologic evolution, along with genetic variability, selective pressure, and geographic isolation. Perhaps this might be considered a fourth major factor in biologic evolution along with genetic variability, selective pressure, and geographic isolation. Perhaps this factor could be included in the term "geodynamics."

A major result of the synthesis is the concept of a Pacific Coast Range corridor which took shape in Pliocene and early Pleistocene time as a zoogeographic peninsula connected to the mainland on the north, and separated by a marine barrier strait from mainland to the south. After mid-Pleistocene time the peninsula became a continuous corridor allowing dispersal in both directions, but causing a high incidence of sympatry in the herpetofauna of southern California. The study of origins and dispersals relative to the evolution 
of the Coast Range corridor would appear to represent a fruitful field of investigation, not only in herpetology but also other branches of natural history. Evolution of the Coast Range corridor provides a unique opportunity to study the influence of a small but effective land bridge on its associated biota. Unlike large, classic land bridges, such as the Panamanian Isthmus, the Coast Range corridor is a phenomenon of small scale lending itself to intensive investigation from many directions by biologists and geologists alike. We may confidently reaffirm and echo A. B. Howell's assertion of thirty years ago that the fauna of the Pacific Coast is of unusual interest and presents many fascinating problems. Californians have a land bridge laboratory in their own back yard!

\section{ACKNowledgMent}

Grateful acknowledgment is given to Miss Madeline Peabody for her most valuable aid in drafting the illustrations and assisting with the manuscript.

\section{REFERENCES}

Axelrod, D. 1957. Late Tertiary floras and the Sierra Nevadan uplift. Bull. Geol. Soc. Am., 68: 19-46.

Brattstrom, Bayard H. 1954. Records of Pleistocene reptiles from California. Copeia, 3: 174-179.

- 1955. New snakes and lizards from the Eocene of California.

J. Paleontol., 29: 145-149.

Camp, C. L. 1952. Earth Song. University California Press, Berkeley, Calif.

Camp, C. L., et al. 1940-1953. Bibliography of fossil vertebrates. Geol. Soc. Am.: Spec. Papers 27, 42; Memoirs 37, 57.

Chaney, Ralph W. 1940. Tertiary forests and continental history. Bull. Geol. Soc. Am., 51: 469-488.

Condit, Carlton. 1944. Pliocene floras of California and Oregon, Chap. 3, The Table Mountain flora. Carnegie Inst. Wash. Publ., 553, pp. $57-90$.

Durham, Wyatt. 1950. Cenozoic marine climates of the Pacific Coast. Bull. Geol. Soc. Am., 61, 1243-1264.

Eardley, A. J. 1951. Structural Geology of North America. Harper, New York.

Howell, A. B. 1927. On the faunal position of the Pacific Coast of the United States. Ecology, 8: 18-26.

Peabody, F. E. 1940. Trackways of Pliocene and recent salamandroids of the Pacific Coast of North America. M. A. thesis in Library of the University of California, Berkeley. 
1954. Trackways of an ambystomid salamander from the Paleocene of Montana. J. Paleontol., 28: 79-83.

Reed, C. F. 1956. Index to Copeia 1913-1954. Scierce Press, Lancaster, Pa. Rosenthal, Gerson M. 1957. The role of moisture and temperature in the local distribution of the plethodontid salamander, Aneides lugubris. Univ. Calif. Publ. Zool., 54: 371-420.

Savage, J. M., and A. H. Brame. 1957. The Southern California slender salamanders: A solution of the Batrachoseps problem. (1957 meeting, Soc. Evolution, Stanford Univ.) (manuscript).

Stebbins, R. C. 1949. Speciation in salamanders of the plethodontid genus Ensatina. Univ. Calif. Publ. Zool., 48: 377-526.

- 1954. Amphibians and Reptiles of Western North America. McGraw-Hill, New York.

1957. Intraspecific sympatry in the lungless salamander Ensatina eschscholtzi. Evolution, 11: 265-270.

Stebbins, R. C., and C. H. Lowe, Jr. 1949. The systematic status of Plethopsis with a discussion of speciation in the genus Batrachoseps. Copeia, 1949: 116-129.

Taliaferro, N. L. 1943. Geologic history and structure of the Central Coast Ranges of California. Calif. State Div. Mines, Dept. Nat. Resources, No. 118, pp. 119-162.

Van Frank, Richard. 1955. Palaeotaricha oligocenica, new genus and species, an Oligocene salamander from Oregon. Breviora, Museum Comp. Zool., Cambridge, No. 45, pp. 1-12.

Zweifel, Richard G. 1955. Ecology, distribution, and systematics of frogs of the Rana boylei group. Univ. Calif. Publ. Zoöl., 54: 207-292.

. 1956. Two Pelobatid frogs from the Tertiary of North America and their relationships to fossil and recent forms. Am. Museum Novitates, 1762: 1-45. 


\section{Origin and Affinities of the Freshwater Fish Fauna of Western North America}

Robert Rushi Miller

Museum of Zoology, University of Michigan, Ann Arbor

The area covered by this paper is primarily North America west of the Continental Divide, northward to the Stikine River, British Columbia, and southward to the Rio Yaqui, northwestern Mexico. The Yaqui is included because it contains certain faunal elements derived from the Colorado River, and British Columbia is treated since its coastal streams include a number of Columbia River types (Lindsey, 1957). Excluded from consideration, except in passing, are the Arctic and Bering Sea drainages, and only mentioned is the interdigitation of Nearctic and Neotropical fishes in Middle America.

Thirty families comprising nearly 200 species have been recorded from fresh water within this area (Table I). These groups form a diverse assemblage. Twelve of the families include species in the Western fauna that are predominantly marine, although some inhabit brackish water or invade fresh water to a limited extent, especially toward the tropics, e.g., herrings, flatfishes, silversides, mullets, sticklebacks, and gobies. Representatives of four families regularly pass only part of their life cycle in the sea or in fresh water (lampreys, sturgeons, some smelts, and most trouts). Species representing four families were derived from marine ancestors but they are now virtually restricted to fresh water (a gizzard shad, Dorosoma ; a codfish, Lota; a viviparous perch, IIysterocarpus; and the freshwater sculpins, Cottus). Two families, the whitefishes (Coregonidae) and graylings (Thymallidae), are intimately related to the salmons and trouts (Salmonidae), which occur in either the sea or fresh water.

In interpreting origins and dispersal patterns it is essential to distinguish the true freshwater fishes from these groups. Although I 


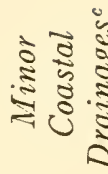

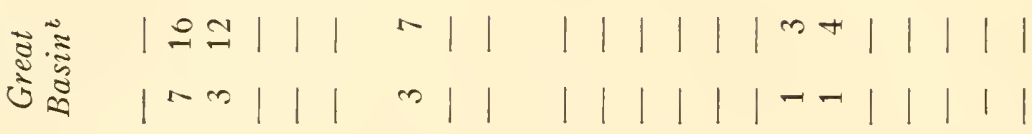

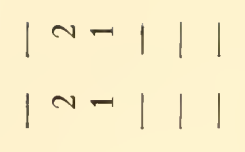

N

$-1|-1| \infty|1| 1 \mid-$ $-1$

$-1 \mid-$

10

$1 \mid 1-$

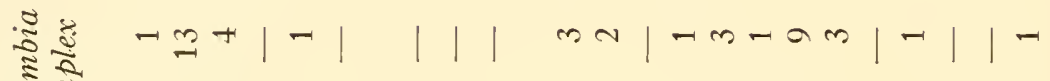

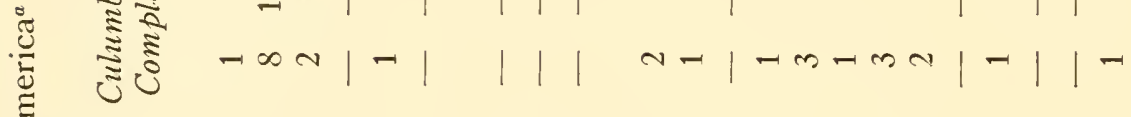

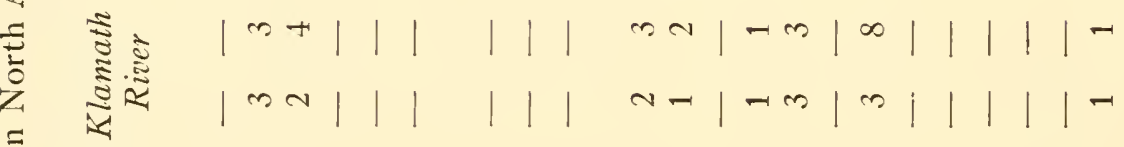

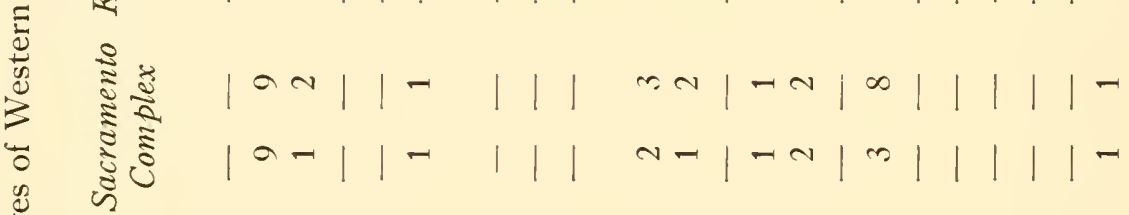

范

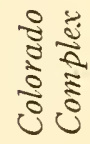

$|\Xi a||| N-1$

$|-1||N-|||||$

$\operatorname{lon}|| N-1$

$|1-1| 1-1|1| 1$

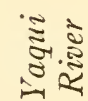

$|\infty m-1|-n-$

$\left.|-N|\right|^{-1}|-| N-1$

$\ln n-1 \mid \rightarrow-7$

$|-\infty| 1-1-1-\rightarrow \mid$

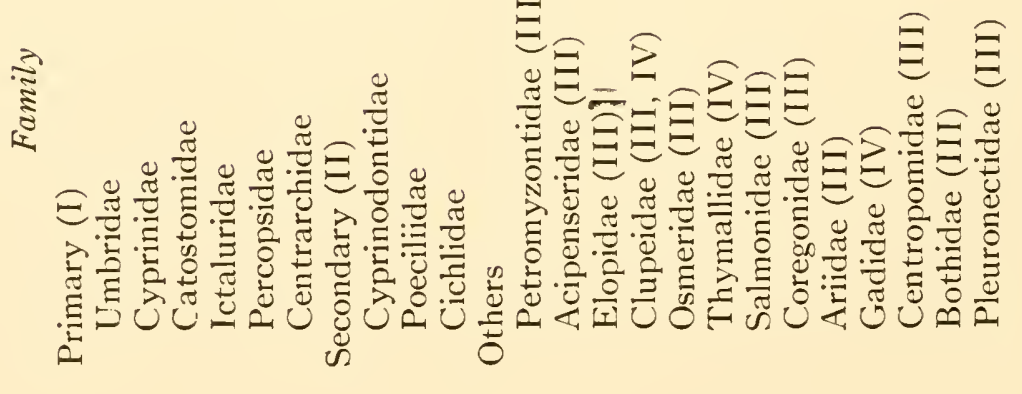

自 


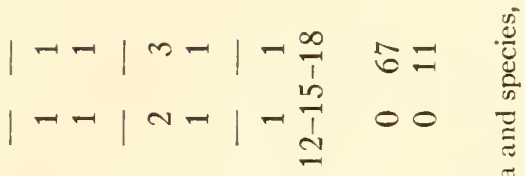

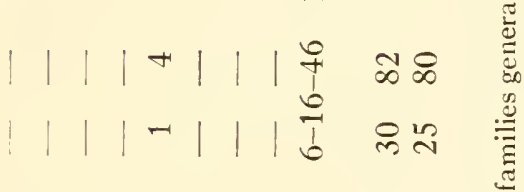

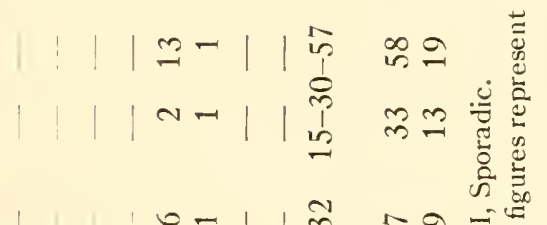

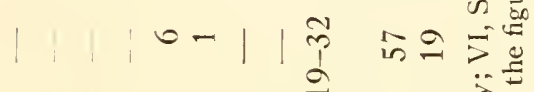

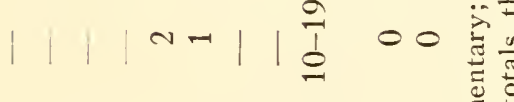

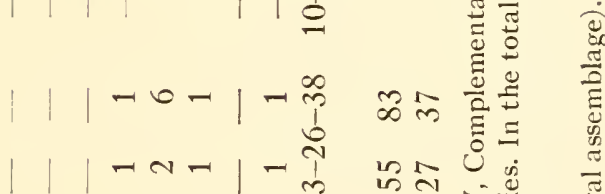

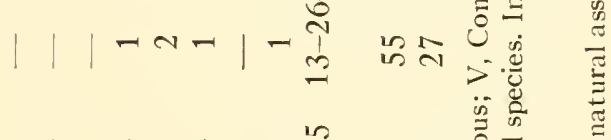

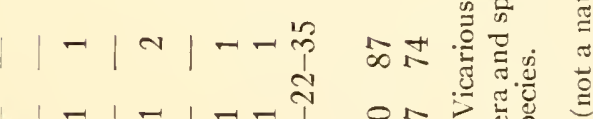

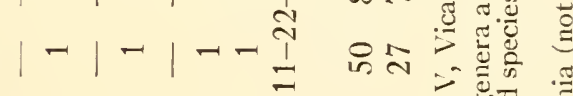

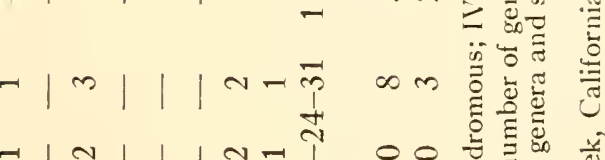

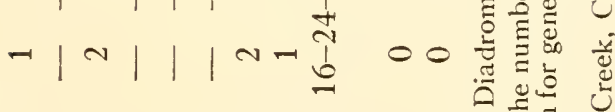

$$
\begin{aligned}
& \text { ق. } \\
& \text { 三. } \\
& \therefore=-\frac{n}{0} \cdot \frac{0}{0}
\end{aligned}
$$

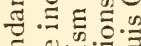

$$
\begin{aligned}
& \text { 造造: }
\end{aligned}
$$

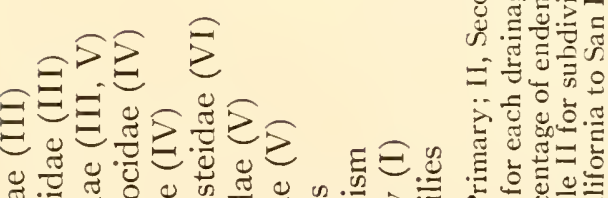

$$
\begin{aligned}
& \text { త } \\
& \text { 골. }
\end{aligned}
$$

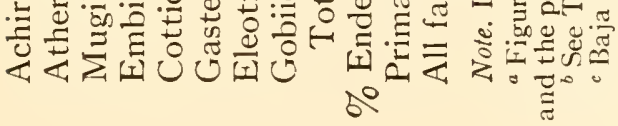


consider affinities of the freshwater fauna as a whole, emphasis is placed on groups designated as primary (I) - made up of those fishes that throughout their known history have, with rare exceptions, heen restricted to fresh water (Fig. 1). These comprise the great continental faunas dominant on all land masses save Australia (Darlington, 1957, Fig. 11); they fall principally into a single order

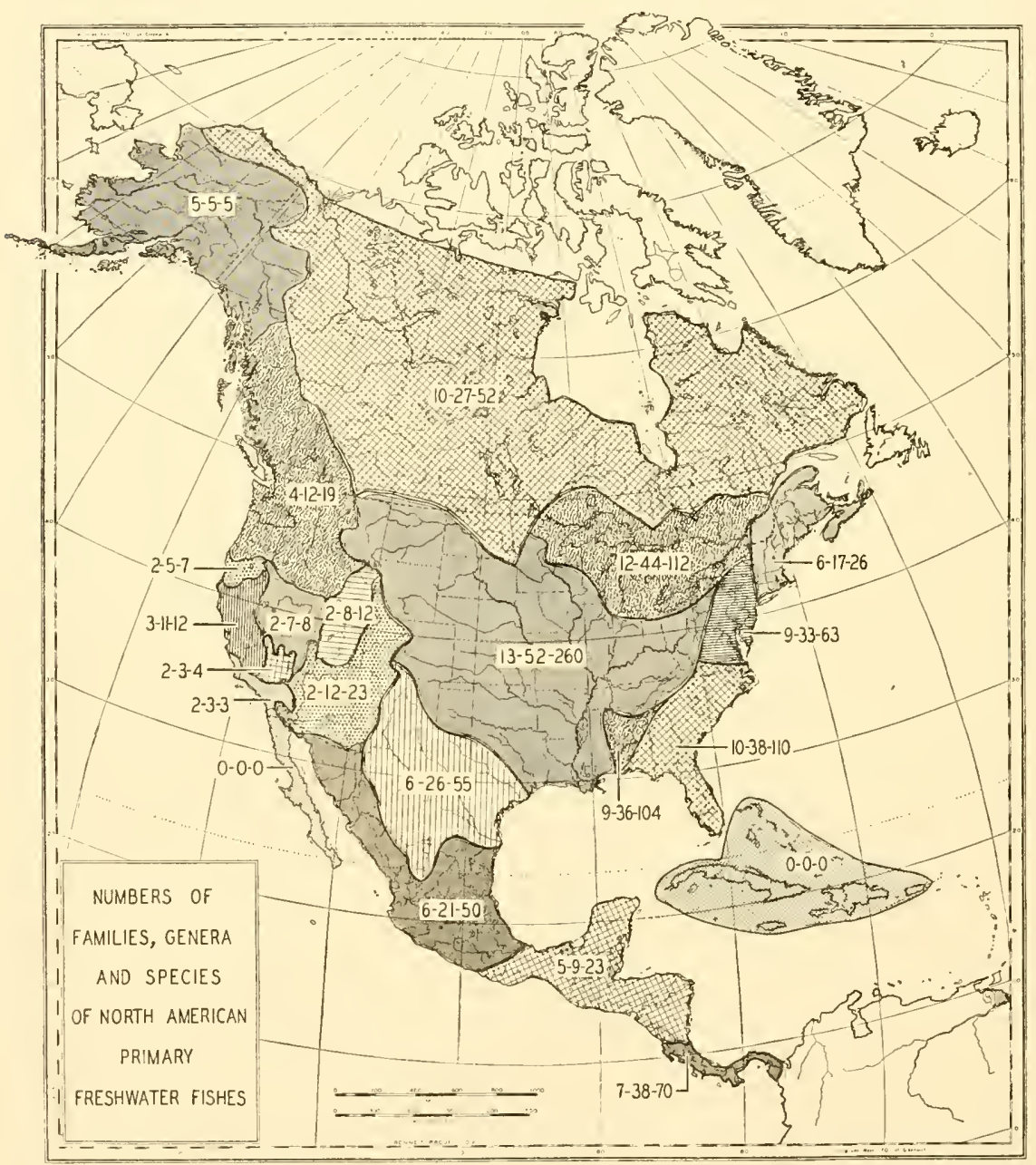

Fig. 1. Primary freshwater fishes of North America. For simplification, the Lahontan Basin (labeled 2-7-8) is mapped too extensively, including areas treated separately under Isolated Basin Drainages. See text for discussion. See also Tables I-II. 
(Ostariophysi $=$ Cypriniformes) containing about 5,000 species. Also of value are the seconlary (II) freshwater fishes representing groups largely restricted to fresh water but salt-tolerant and capable of occasionally crossing narrow sea barriers. The remaining fishes known from fresh water may be divided as follows (Myers, 1938, 1951): Diadromous (III), those that regularly migrate between fresh and salt water during a definite period of the life cycle. Vicarious $(\mathrm{IV})$, essentially or presumably non-diadromous freshwater representatives of partly or primarily marine groups. Complementary $(\mathrm{V})$, species that are often or usually diadromous and belong to marine groups that become dominant in fresh waters only in the scarcity or absence of primary and secondary fishes. Sporadic (VI), fishes living and breeding more or less indifferently in salt or fresh water or entering fresh water only sporadically. The 30 families recorded from fresh water within the area comprise 6 primary groups with nearly 100 species and 3 secondary families with only 15 species. Thus the primary (I) and secondary (II) fishes constitute somewhat more than half the total number of species that occur in western fresh waters.

The absence of a large and diverse drainage system, such as the Mississippi, and the general scarcity and instability of the aquatic environment help to explain why the freshwater fish fauna of the West lacks many of the families and genera, especially lowland types, that live east of the Rockies (Fig. 1). The depauperate western fauna comprises only half as many families and one-fourth as many species of primary and secondary fishes as the eastern fauna. It is made up of relicts, an abundance of monotypic genera, and a complex of endemic faunas with few widespread species in common. Many of the species are of restricted (listribution (Fig. 2).

Our knowledge of the systematics of this fish fauna is behind that of the other vertebrates. This is especially true of the published record. Although the few taxonomists who have worked with western fishes in the past quarter century have restricted most of their publication to the description of new taxa, I estimate that about 10 per cent of the species have yet to be clescribed. Rather considerable recent field work, begun in 1934, has built up a wealth of preserved material and observations that await critical evaluation. No up-todate generic revisions have appeared, and the inadequate fossil record provides few hints for speculation on the interrelationships of 


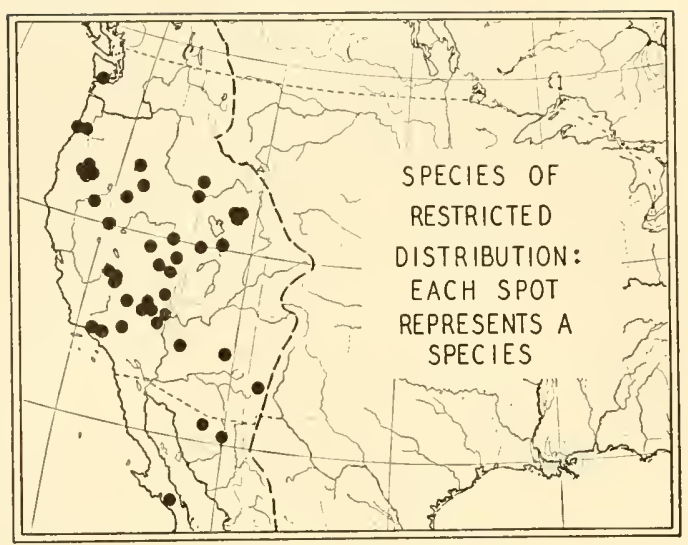

Fig. 2. Approximate location of species of closely restricted distribution in western North America. Note the concentration of localized forms in the Great Basin and in disrupted waters (in southern Nevada) of the Colorado River drainage. Only 14 of the 43 species occur outside of those areas.

the modern forms, particularly at the generic level. It is not surprising, therefore, that the affinities of many of the genera are unknown.

\section{FOSSIL RECORD}

The paleontological record of Tertiary and Quaternary fishes in western North America is meager. What little material is available has not received critical comparative study. For the most part, the available skeletal remains, particularly of the Pliocene and Pleistocene fossils, are hardly adequate for identification below the generic level or, occasionally, not even below the family. The only reasonably well-known formation is that of the Green River Eocene, which involves a fauna too early in fish evolution to give much help in interpreting the modern forms. Tertiary fishes have been treated chiefly by Cope, and since his death in 1897, only scattered papers have appeared with little attempt at evaluation or reappraisal. Vigorous, organized search for and comprehensive study of late Cenozoic fish fossils by students thoroughly familiar with the Recent fauna is one of the urgent needs for advancing knowledge of the origin, dispersal, and evolution of the present fauna.

Fossils representing nine families have been recorded from freshwater deposits of Miocene to Pleistocene age in western North 
America (Cyprinidae, Catostomidae, Ictaluridae, Aphredoderidae, Centrarchidae, Salmonidae, Cyprinodontidae, Cottidae, and Gasterosteidae). The first five are primary division freshwater fishes; the remainder are of diverse origin (boreal, secondary tropical, marine types or derivatives). Certain Miocene fossils from the Great Basin, e.g., from the Humboldt Formation, Nevada, indicate that at this time there were kinds of fishes (a sucker, $A$ myzon, and a pirate perch, Trichophanes) quite unlike those that now inhabit the West; Miocene and Pliocene sunfishes (Centrarchidae) of extinct genera from Oregon, Nevada, and Utah demonstrate that this family, now largely restricted to eastern North America, was then more widespread. A minnow from British Columbia, Leuciscus rosei (Hussakof, 1916), thought to be of Miocene age, probably represents the living genus Richardsonius, and a Miocene minnow from Nevada is of essentially modern facies (Hubbs and Miller, 1948, p. 26). From these sketchy data it may be inferred that during the long Miocene epoch and extending into the Pliocene, one family (Aphredoderidae) and a number of genera (Amyzon, sunfishes, Trichophanes) became extinct in the West, though relatives have persisted in eastern North America, and that, although the Miocene fauna as a whole is quite different from the existing fishes, at least one modern freshwater type (Richardsonius) probably became established during this epoch.

Two early Pliocene fossils from beds within the Lahontan system of Nevada, a killifish (Fundulus nevadensis) and a stickleback (Gasterosteus doryssus), belong to genera of coastal and lowland distribution living today in western North America only along the Pacific slope. Their entrance into Nevada, perhaps in late Miocene or early Pliocene times, may have been from the southwest by way of what is now the Death Valley region, since fossil killifishes of the same genus occur there (Miller, 1945b) and sticklebacks are found as far south today as northern Baja California.

Middle Pliocene fossils from the Bidahochi formation in the Colorado system of northern Arizona represent species of Gila and Ptychocheilus similar to the living forms that are adapted to a swiftwater habitat. This suggests that the Colorado was then a swift river, and such an ecological picture is supported by recent studies of geologists on the evolution of the Colorado (Repenning et al., manuscript). A Pliocene minnow from the Esmeralda formation of 
Nevada, Leuciscus turneri (Lucas, 1900), is likely identical with a modern genus (Gila); the age of this formation, first thought to be Miocene, was discussed by Stirton $(1936,1939)$.

A late Pliocene to early Pleistocene fauna from southern Idaho and eastern Oregon contains representatives of 6 families, including a catfish of the genus Ictalurus and a sunfish likely of the genus Lepomis; the latter genus is now restricted to eastern North America and Ictalurus is not native on the Pacific slope north of the Yaqui basin (Figs. 5 and 9). Both genera represent invaders from the East whose extinction in the Snake River basin in early Pleistocene times is probably correlated with lowering of water temperatures below the minimum spawning requirements of these fishes. Most of the fossils representing this fauna were discussed by Cope (1983, pp. 153-165).

This brief summary of the sketchy fossil record indicates the urgent need for research on the paleoichthyology of the later Cenozoic, particularly for comparisons of the fossils with their living relatives. Much of the material is not identifiable because of our inadequate knowledge of the osteology of modern fishes.

\section{PRIMARY AND SECONDARY GROUPS}

The primary freshwater fish fauna of North America (Fig. 1) comprises 21 families with approximately 600 species. Although these are mapped by areas that generally follow major watersheds, it is not intended that these areas portray zoogeographic regions. The numbers, representing families, genera, and species, become less accurate south of the United States border. The richness of the Mississippi Valley fauna is noteworthy, as is the absence of primary fishes in the West Indies. In general, there is a trend toward more species to the south, perhaps correlated with more equable water temperatures and a greater diversity of habitats. The apparent richness of the Arctic fauna is largely the result of invasion of the Red River by Mississippi fishes during late Pleistocene times. Similarly, as a result of Glacial and Postglacial connections, the fauna of the Great Lakes basin is strikingly similar to, though smaller than, that of the Mississippi Valley.

The Plateau Region of northern Mexico has provided a broad highway over which many Nearctic types have traveled southward. Although the bulk of these fishes are stopped by the east-west chain 
of volcanoes lying at about $19^{\circ} \mathrm{N}$. Lat., a sucker (Ictiobus meridionalis) and a catfish (Ictalurus meridionalis) have managed to reach the basin of the Río Usumacinta, Guatemala. The Mexican coastal regions, particularly the Atlantic coastal plain, have similarly allowed the northward penetration of Neotropical groups. A single representative each of the characins (Astyanax fasciatus) and cichlids (Cichlasoma cyanoguttatum) has invaded the United States in extreme southwestern Texas, and the characin has moved into New Mexico (these two are the only primary families shared by the United States and South America).

The southern end of the Middle American peninsula has been invaded by a number of South American groups, most of which drop out beyond western Panama, although the eel-like Gymnotidae are represented as far north as Guatemala. The fish fauna inhabiting the peninsular-like region between the Isthmus of Tehuantepec and Panama is dominated by secondary freshwater fishes, notably the Poeciliidae and the Cichlidae. The viviparous poeciliids presumably arose within this area, diversified greatly, and spread northward and southward; the cichlids and pimelodids, on the other hand, probably originated in South America and speciated in the unsaturated environment of Middle America. These two groups, with additions from the Characidae and Atherinidae, constitute the more tropical portion of Middle American fauna. Intervening between this portion of the Middle American fauna and the Nearctic fauna of northern Mexico are several transitional faunas and the highly distinctive Lerma fauna, which includes a limited representation of both middle American and North American genera, and is dominated by the endemic cyprinodont family Goodeidae and the endemic and diverse atherinid genus Chirostoma. The Lerma fauna may be regarded as a distinct element in the Middle American complex.

The relatively impoverished primary fauna of western United States is indicated for the 8 drainage areas shown on the map (Fig. 1). Within the entire area there are only 6 primary families ('Table I): the mudminnows (Umbridae), minnows (Cyprinidae), suckers (Catostomidae), catfishes (Ictaluridae), trout-perches (Percopsidae), and sunfishes (Centrarchidae). The first three are regarded as of Eurasian origin, and the last three as North American.

The mudminnows (Fig. 3) are represented by two genera, Nov- 


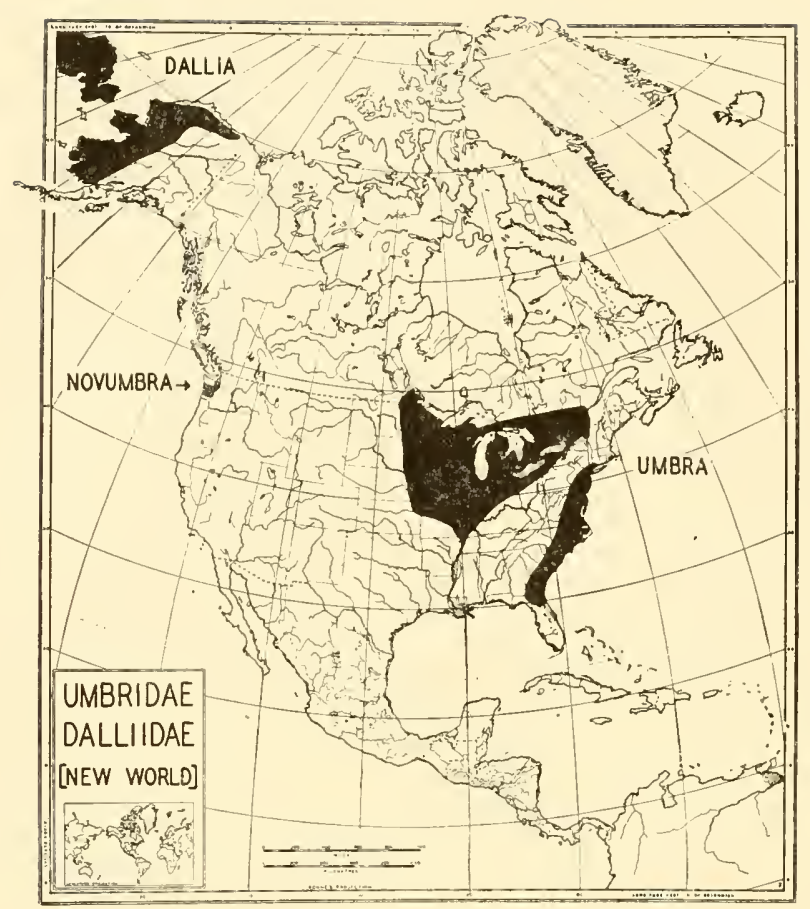

Fig. 3. New World distribution of the mudminnows (Umbra and Novumbra) and the blackfish (Dallia). The only other mudminnow, Umbra krameri, lives in eastern Europe. Dr. Norman J. Wilimovsky provided the northeastern limit of the range of Dallia.

umbra (Fig. 4), a monotypic relict from the Olympic Peninsula of IVashington (Schultz, 1936), and Umbra, with two species in eastern United States and one in Europe. The suborder (Haplomi = Esocoidei) to which these fishes belong contains also the pikes, which are circumboreal but most speciose in North America, and the

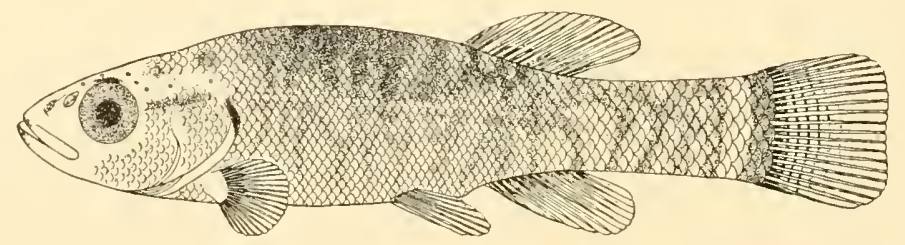

Fig. 4. The western mudminnow, Norumbra hubbsi, a relict species of the Chehalis and Deschutes rivers, Washington. (From original drawing by Dorothea B. Schultz; see Schultz, 1936, Fig. 38.) 


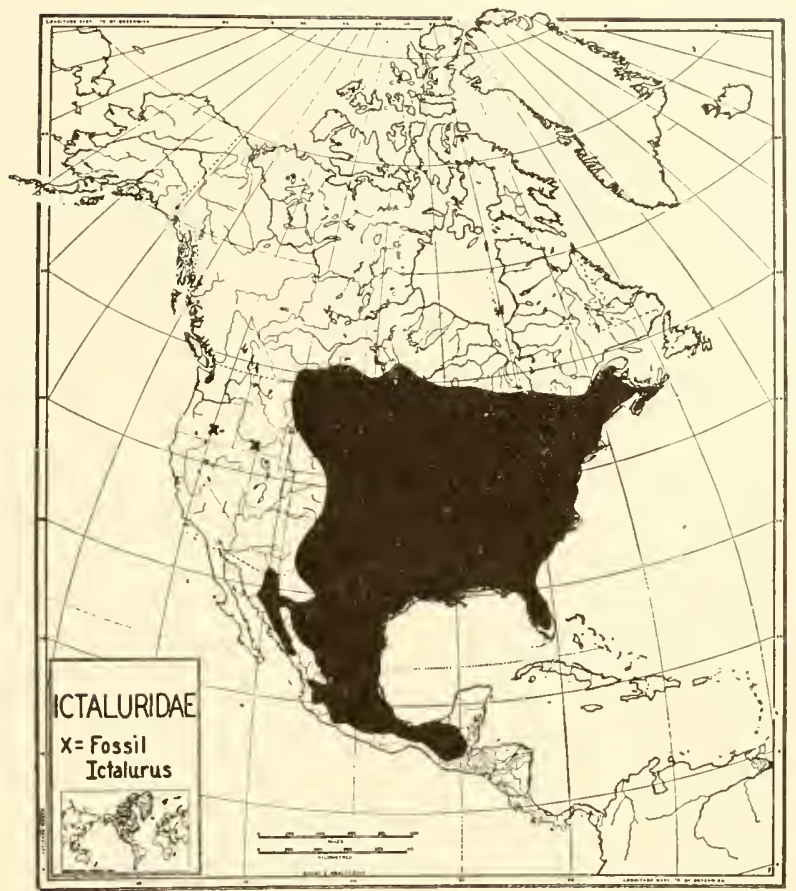

Fig. 5. Distribution of the North American freshwater catfishes, family Ictaluridae. Fossil occurrences of Ictalurus are shown for western North America only. (Modified from Rostlund, 1952, maps 18-20; Mexican portion original.)

blackfish (Dallia), which lives in Alaska and Siberia. Although the present distribution suggests a North American origin, all known fossils, including the primitive genus Palaeoesox (Berg, 1936), are from the Eocene to Miocene of Europe.

The North American catfishes, comprising about 6 genera and 35 species, barely enter the western fauna with a single species in the Yaqui River. That these fishes formerly occurred much farther north in the West has already been pointed out. All known fossils are North American, as is the present distribution (Fig. 5).

Trout-perches constitute a singular group represented by two monotypic genera, Columbia (Fig. 6) restricted to the basin of that name in the West, and Percopsis, of much wider distribution in the East. With the closely related monotypic pirate perches (Aphredo- 


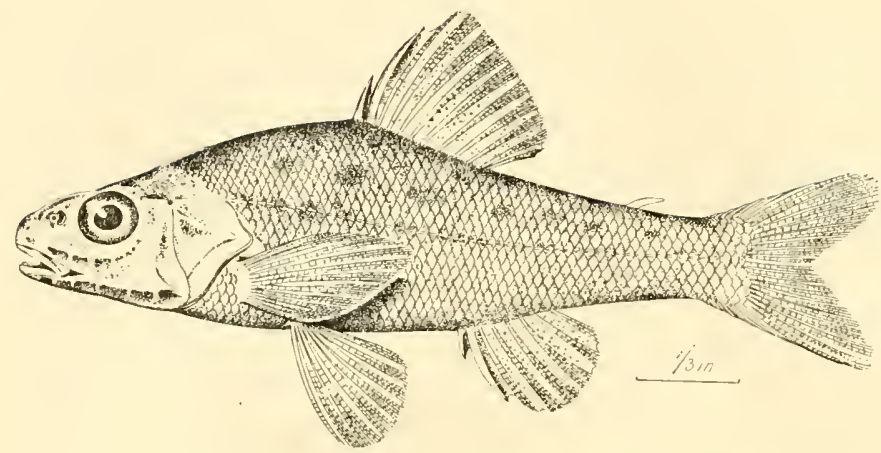

Fig. 6. The Columbia River trout-perch, Columbia transmontana. (From original drawing by A. H. Baldwin; see Jordan and Evermann, 1900, Fig. 330).

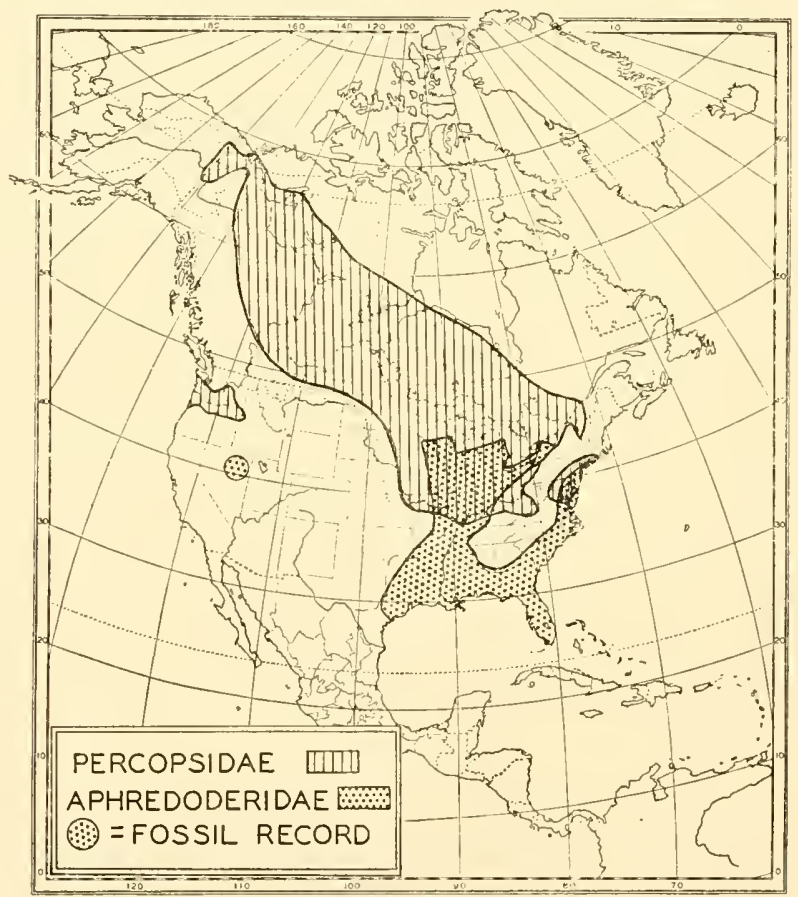

Fig. 7. Distribution of the North American trout-perches and pirate perches. The fossil pirate perch, Trichophanes, is known only from northeastern Nevada. (Percopsidae greatly modified from Rostlund, 1952, map 32, using Walters (1955), Lindsey (1956), and original data. Range of Aphredoderidae from unpublished map by Reeve M. Bailey.) 
deridae), they form a North American group known from Eocene to Recent (Fig. 7).

The centrarchids, or sunfishes, comprise a compact family of about 11 genera and 30 species, which, except for the relict genus Archoplites of California (Fig. 8), are confined to eastern North America (Fig. 9). The present center of distribution is in the middle and lower Mississippi Valley. Relatively numerous fossils are recorded from Oligocene to Pleistocene deposits of North America; whether or not the Green River Eocene genus Priscacara is a sunfish has not been conclusively shown, although Regan (1915, p. 106) unquestionably referred it to the Centrarchidae. This freshwater group dates from the early Cenozoic and is closely related to the sea basses (Serranidae). Since as a whole sunfishes are characteristic of lowland waters, the sole survivor in the West presumably attained its present distribution prior to the formation of the Rocky Mountains and Sierra Nevada Ranges.

The two remaining families, the minnows and suckers, account for 95 of the 99 species of primary freshwater fishes in western North America. The suckers, a compact group of 14 living genera ${ }^{1}$ and about 80 species, are known fossil and Recent from eastern Asia and Alaska, as well as from eastern and western North America. In the New World (Fig. 10) they range southward on the Atlantic slope to northern Guatemala (Ictiobus, Río Usumacinta) and on the Pacific versant to western Mexico (Moxostoma, Río Armería, Jalisco). In the Old World there are but two representatives, an ancient, monotypic genus in China (Myxocyprinus) and Catostomus catostomuts, in eastern Siberia, representing a recent invasion of a species widespread in northern North America (Darlington, 1957, p. 31, Fig. 9). In the most recent treatment (Nelson, 1948, 1949), division of the family into three subfamilies (Fig. 11) has been made largely on the basis of the morphology of the four highly modified anterior vertebrae (the IVeberian apparatus) that connects the gas bladder with the middle ear. The Cycleptinae, with a primitive genus in each continent, might justifiably be segregated as two subfamilies with Cycelptus as the North American and Myxocyprinus as the Asian representative. The Ictiobinae includes but 2 genera and 9 species in eastern North America and appears to

\footnotetext{
I The following are regarded as synonyms: Deltistes = Catostomus; Megapharynx and Placopharynx $=$ Moxostoma; Megastomatobus $=$ Ictiobus.
} 


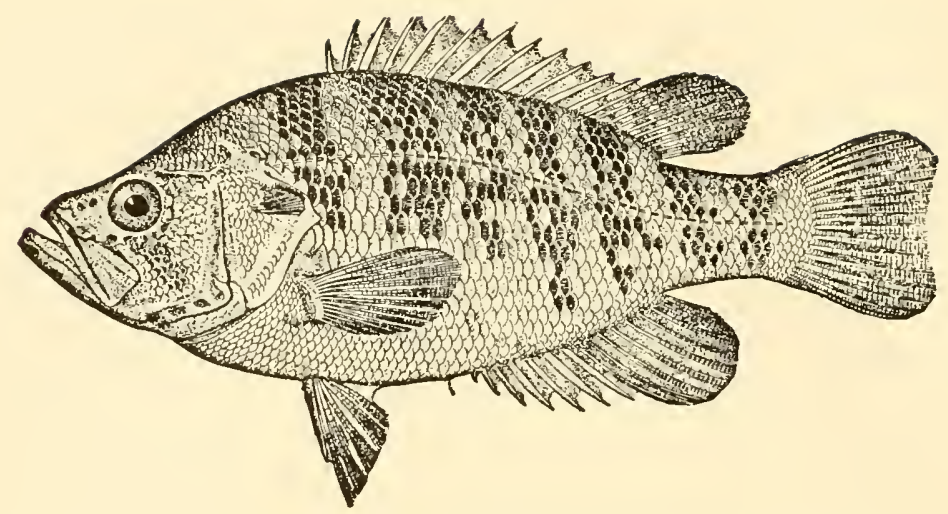

Fig. 8. Sacramento perch, Archoplites interruptus, the only native sunfish west of the Rocky Mountains. (From Jordan and Evermann, 1902, p. 341).

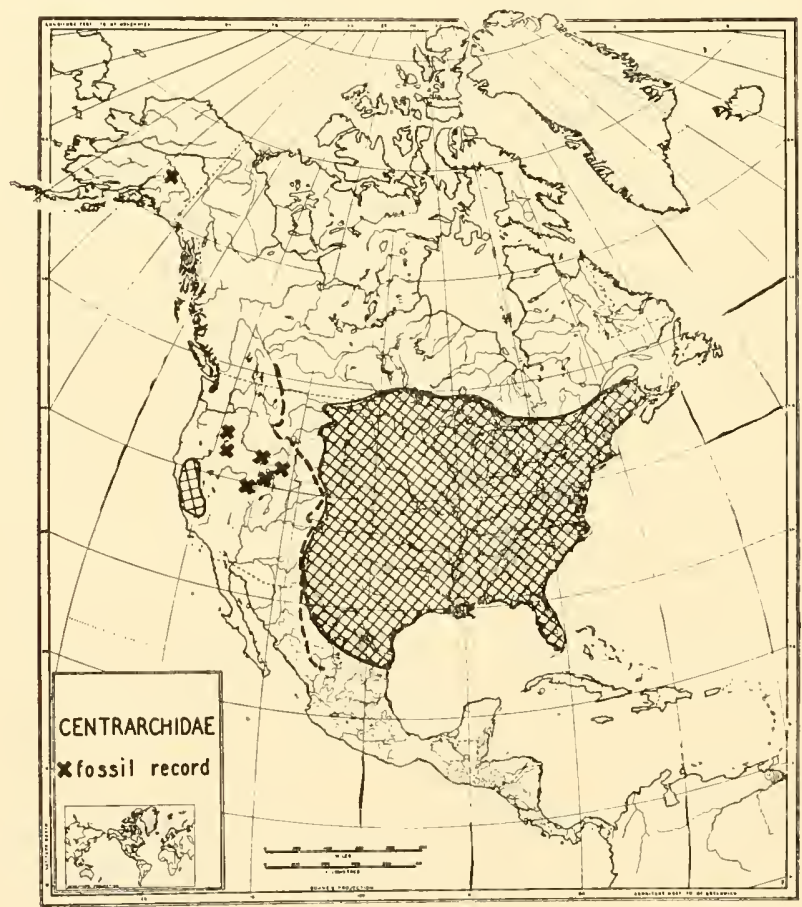

Fig. 9. Distribution of the Nearctic family Centrarchidae. Fossil records are indicated only for areas outside of the present natural range of the sunfishes. 
be a conservative group characteristic of lowland waters. The remaining 10 genera belong to the Catostominae; 2 of its 3 tribes, the Moxostomatini and Catostomini, contain over 80 per cent of the known species of suckers. Five of the 14 genera are monotypic: 3 in eastern United States (Cycleptus, Lagochila, and Minytrema), 1 in western United States (Xyrauchen, Fig. 12), and 1 in China

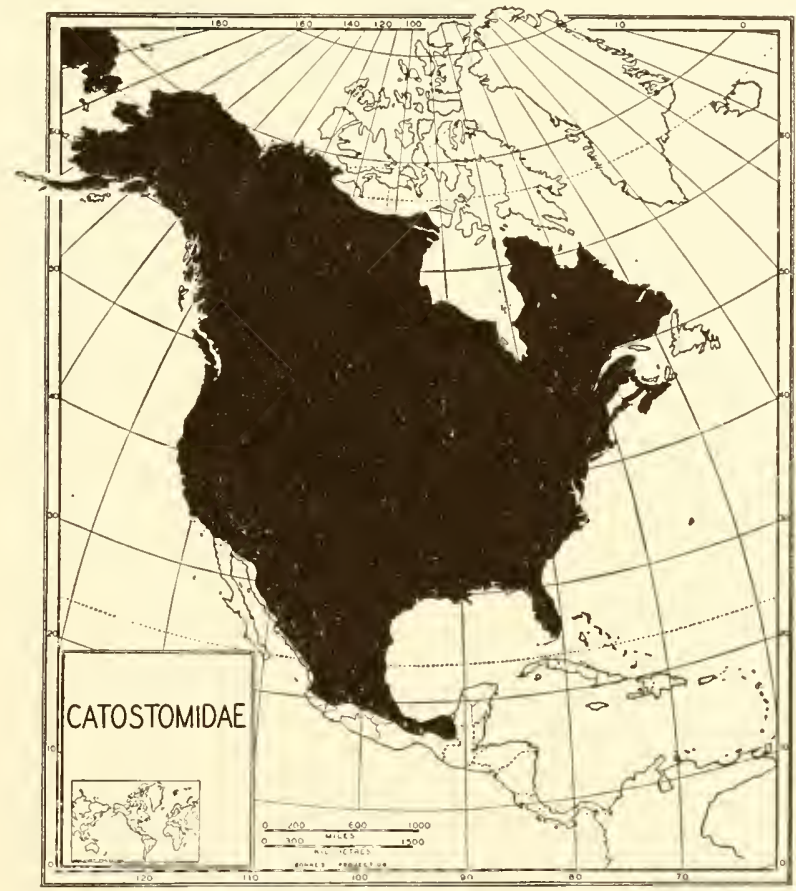

Fig. 10. Distribution of the sucker family, Catostomidae, in North America and adjacent Siberia; one genus is endemic to China. Northern limit between western side of Hudson Bay and Coppermine River from IYynne-Edwards (1952, p. 18).

(Myxocyprinus). One genus in the East, Moxostoma, and 2 with most of their species restricted to the IVest (Catostomus and Pantosteus), account for 65 per cent of the modern species.

The earliest possible fossil sucker remains (Hussakof, 1932, pp. 16-17) are from Eocene deposits of Central Asia and are probably closest to the Chinese genus Myxocyprimus (Nelson, 1949, p. 566). The earliest reliably dated remains of the family in North America 


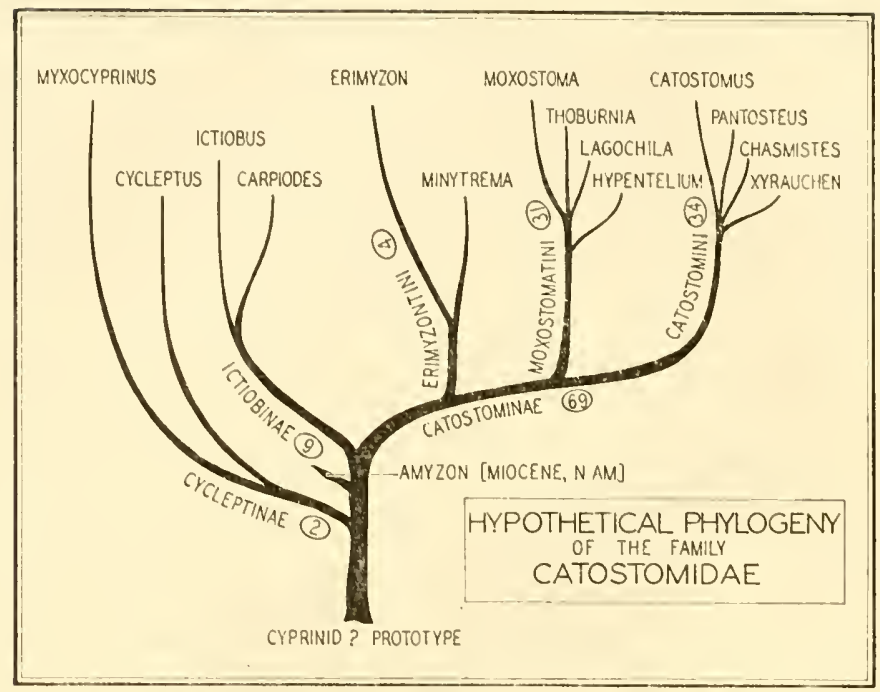

Fig. 11. Hypothetical phylogeny of the Catostomidae. The approximate number of species in each subfamily and tribe is shown in the circles.

are from Miocene deposits in British Columbia, Nevada, and Colorado, and are placed in an extinct genus Amyzon. Superficially, at least, this sucker bears a close resemblance to the living genus Ictiobus, but a careful comparison with Myocyprinus may show Amyon to be closer to that Old IVorld representative. Although the fossil evillence is inconclusive, it seems probable that the Catostomidae arose in southeastern Asia and soon crossed a Bering land bridge to America, leaving a relict in China, and that in late Pleisto-

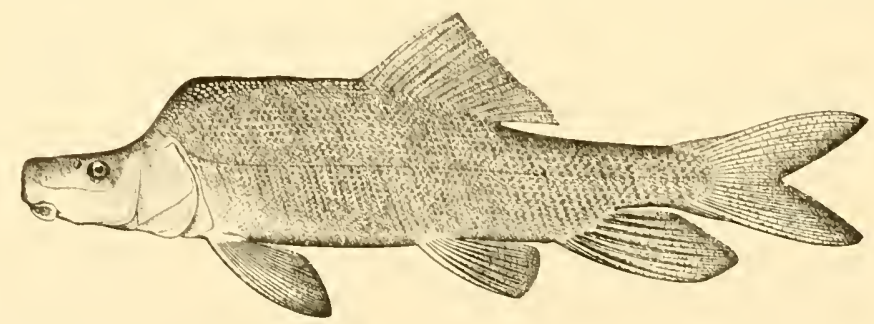

Fig. 12. Humpback sucker, Jyrauchen texanus, an endemic genus of the Colorado River system. (From original drawing by S. F. Denton (nuchal hump retouched); see Jordan and Evermann, 1900, Fig. 88.) 
cene time the North American species Catostomus catostomus recrossed to eastern Siberia. The recency of that crossing is inclicated by the common occurrence, in Siberia and western Arctic America, of the same subspecies (WValters, 1955, pp. 295-296).

It is rather generally held that the suckers are ancestral to (or at least more primitive than) the minnows, family Cyprinidae, but a comparative study of the upper jaw mechanism in the bony fishes led Eaton (1935, p. 168) to conclude that suckers undoubtedly descended from minnows. And, after studying skeletal features of two groups of Asiatic minnows and comparing them to those of certain catostomids, Ramaswami (1955a, pp. 152-153; 1955b, p. 236 ; 1957) found certain catostomid skeletal features in members of the gudgeons, a subfamily of minnows inhabiting China, and concluded: ". . . it is not likely that the Catostomidae could have given rise to the Cyprinidae." The weight of present evidence thus indicates (Fig. 11) a cyprinid prototype as probably ancestral to this family.

The carps and minnows comprise the largest of all freshwater fish families, the Cyprinidae, with an estimated 250 genera and upwards of 2,000 species, inhabiting all the continents except South America and Australia. The group attains its greatest number of species and diversity of form in southeastern Asia, where the most generalized types also are found. Relatively, the family is not very richly represented nor is it particularly diverse in the New World, where there are only about 40 genera and 250 species, and the paleontological evidence indicates that minnows arrived here in comparatively recent times, not prior to the Miocene epoch. Whereas a number of distinct subfamilies are recognized in the Old World, for example in China (Chu, 1935), it is probable that all of the New World cyprinicls belong to a single subfamily, the Leuciscinae (Notemigonus is possibly a member of the Abramidinae, but its relationships to that Old World group are in need of critical study). Not only lack of basic morphological diversity but also the readiness with which most American minnows hybridize (Hubbs, 1955) supports the evidence that the group has not been here long enough to develop strongly divergent lines.

About 27 genera and 58 species of cyprinids live in western North America. Of the genera 15 (or 56 per cent) are monotypic. Twenty 
are strictly western in distribution; another, $G i l a,{ }^{2}$ has only 4 of its approximately 13 species living east of the Continental Divide (Miller and Uyeno, manuscript); 5 (Hybopsis, Iybognathus, Notropis, Campostoma, and Pimephales) are clearly recent invaders from the East; and one (Rhinichthys) is well represented in both areas, although two-thirds of its species live in the West. The 21

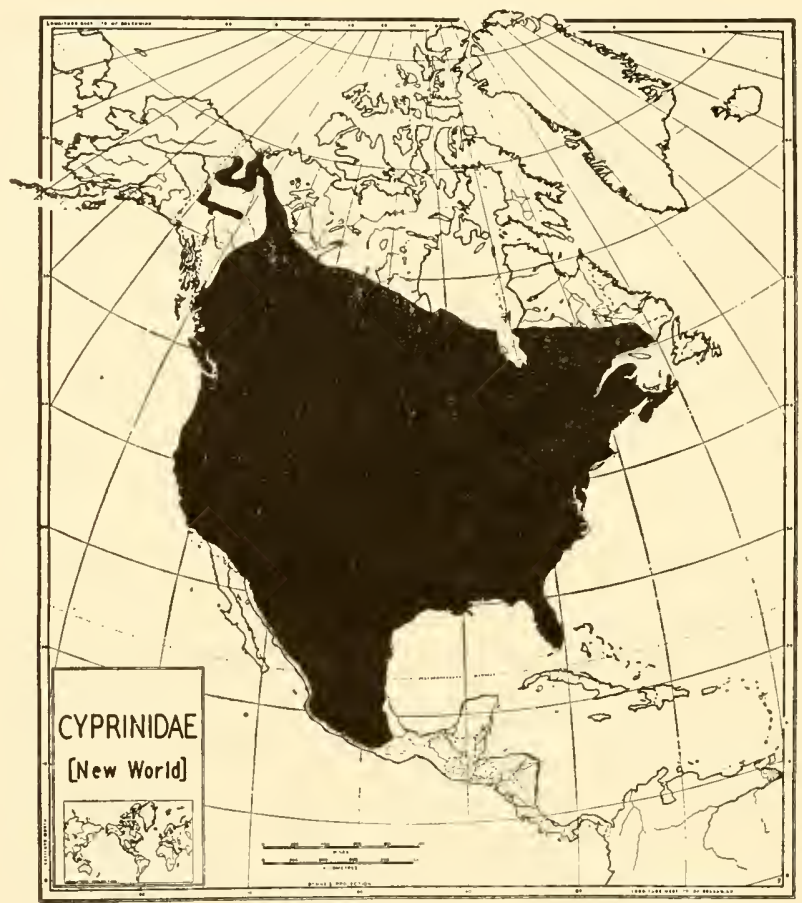

Fig. 13. New World distribution of the minnow family, Cyprinidae. The extreme northwestern portion of the range is taken from WynneEdwards (1952, pp. 18-19).

genera that are strictly or virtually western may well be autochthonous, but it is clear that the family originated in southeastern Asia around the close of the Cretaceous. It has been suggested that there are close relationships between certain western genera and ones that occur in China and Japan-for example, between Mylo-

${ }^{2}$ Because of inadequate information about the affinities of this genus, I recognize Gila, Richardsonius (Fig. 14), and Clinostomus as distinct genera, pending further study (see Bailey, 1956, p. 331). 
pharodon (California), Mylocyprinus and Mylocheilus (fossil, Idaho; Recent, Columbia River), and Mylopharyngodon (China). The indicated similarities in this series pertain to the common possession of crushing type (molariform) pharyngeal teeth, an obvious feeding adaptation subject to independent and repeated evolution throughout the family. More likely candidates are the western genus Gila and Tribolodon of the Japanese fauna. None of the affinities postulated above has been thoroughly investigated. At the present time, only one American genus, Gila, is regarded by some as congeneric with an Old World genus, Phoxinus (see Berg, 1949, p. 571), but I

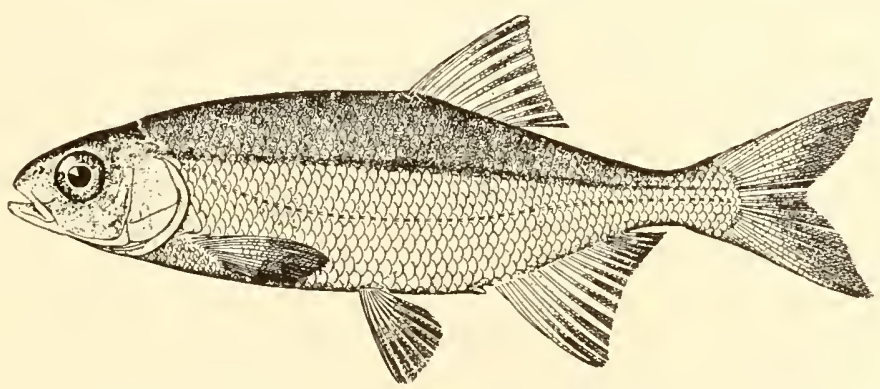

Fig. 14. Redside shiner, Richardsonius balteatus, of the Columbia River basin. Fish of this type represent the earliest known fossils of the Cyprinidae in North America. (From Jordan and Evermann, 1900, Fig. 105).

do not accept this allocation for reasons already given. The New World distribution of the Cyprinidae (Fig. 13) indicates that this family is less tolerant of low maximum temperatures than are the Catostomidae.

The three secondary families have barely been able to invade the western fauna from the south and southeast. One species of mojarra (Cichlasoma beani), of the tropical family Cichlidae, has managed to reach the Yaqui River; the genus to which it belongs is most speciose in Middle America, but was derived from a South American ancestor (Regan, 1906-08, p. xiii). The viviparous topminnows of the family Poeciliidae, exclusively American and essentially tropical, have moved a little farther north to the lower Colorado River system, where they are represented by a single species of Poeciliopsis in southern Arizona (two species occur in the Yaqui). The egg-laying killifishes of the family Cyprinodontidae, largely tropical but push- 
ing well into the temperate region of North America (Fig. 15), have penetrated Nevada and southeastern and coastal California, where they are represented by 4 genera and 11 species. This group is

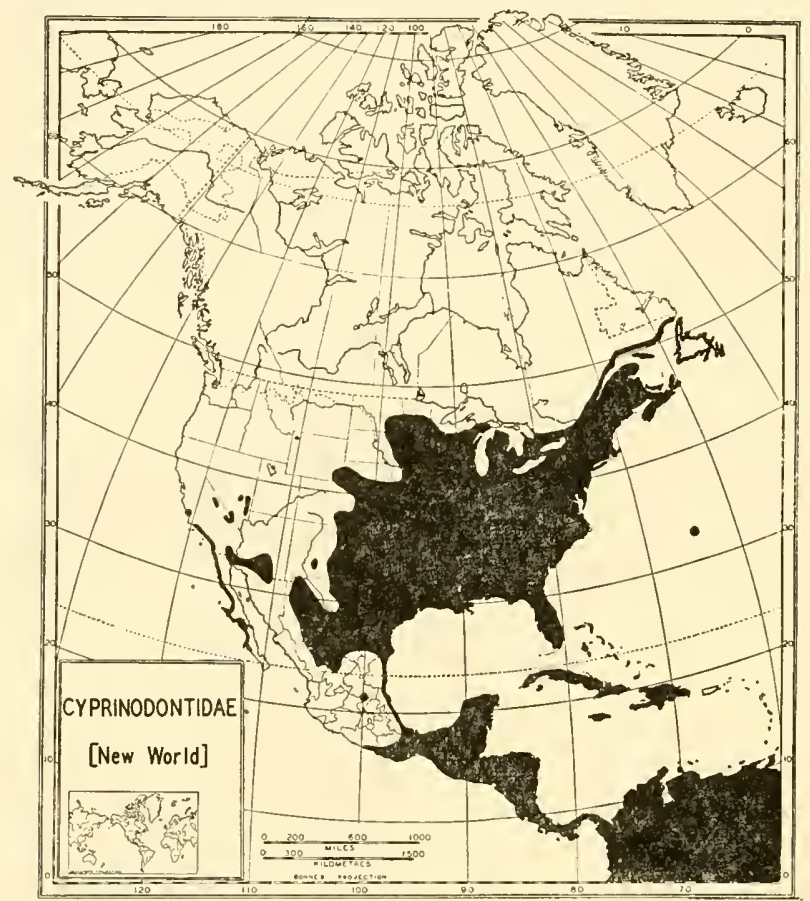

Fig. 15. New World distribution of the killifishes, family Cyprinodontidae, a secondary freshwater group.
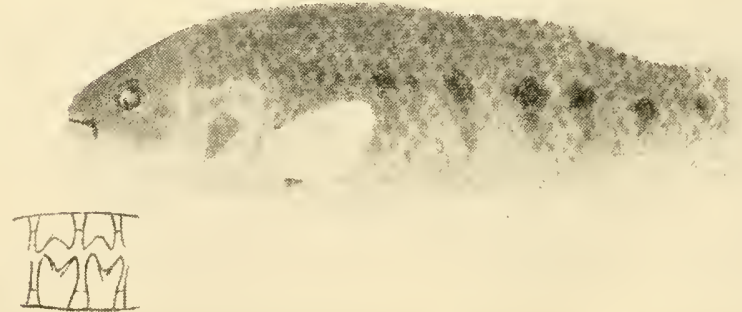

Fig. 16. Railroad Valley springfish, Crenichthys nevadae, a relict confined to warm springs of the enclosed valley (Fig. 15, south central Nevada). Another species lives in a former tributary of the Colorado River and a related genus, Empetrichthys, inhabits the Death Valley system. (From original drawing by Grace Eager; see Hubbs, 1932.) 
dominant in the saline, alkaline, and frequently warm waters of the Death Valley system (Miller, 1948). Two of the four genera are well isolated relicts, Crenichthys, Fig. 16 (Hubbs, 1932), and Empetrichthys, each with two species, and the two remaining genera (Fundulus and Cyprinodon) have their closest relatives in southern United States and northern Mexico. The importance of this secondary family in indicating past connections of such disrupted drainages as the Death Valley system has been substantiated by geological evidence.

\section{CENTERS OF ENDEMISM}

In correlation with the physiographic disruption of the West during late Tertiary and Quaternary times, the fish fauna has differentiated within a group of isolated basins each with a more or less high incidence of endemism and generally having few strictly freshwater species in common (Hubbs and Miller, 1948). Seven main centers of endemism may be recognized constituting the following drainage systems: (1) Colorado, (2) Sacramento, Klamath, (4) Columbia, (5) Bonneville, (6) Lahontan, and (7) Death Valley (Tables I-II; Fig. 1). Not all the fishes inhabiting the West are included in these 7 systems since there are certain independent basins (for example, between the Lahontan and Columbia, Lahontan and Bonneville, and Lahontan and Colorado systems) that harbor a few primary species (about 13 in all) unknown elsewhere. The faunas of these extralimital systems are discussed later.

Most species that occur in more than one of the seven isolated drainages belong either to the semi-marine groups (e.g., lampreys, sturgeons, smelts, most salmonids, and sticklebacks) or are mountain-creck types (such as mountain whitefish, cutthroat trout, and certain suckers and minnows, particularly the ubiquitous speckled dace, Rhinichthys osculus). The montane types probably attained their widespread distribution by means of stream captures, headwater distributary connections (like Two-Ocean Pass, Wyoming; Evermann, 1892, pp. 24-28, Pl. II), or through stream shifting across low divides. The distribution of the genera of primary fishes that are common to a number of the basins (such as the suckers, Catostomus and Pantosteus, and the minnows, Gila, Ptychocheilus, Rhinichthys, and Siphateles) probably took place largely in Pliocene or early Pleistocene times. 


\section{Colorado River Complex}

The primary fish fauna of this basin, including that of the late Pleistocene tributary White River of eastern Nevada (Hubbs and Miller, 1948, pp. 95-98), is the richest and has the highest percentage of species endemism ( 87 per cent) of the seven major drainages. Two factors contribute to this: (1) the basin developed as isolated segments for a long period prior to its formation as the continuous river we see today; and (2) it has fewer competing groups of marine derivation than the three other coastal drainages (Sacramento, Klamath, and Columbia) and about half of these (Elops, Mugil, Eleotris, Gillichthys) are restricted to the terminal portion of the river and the others (Prosopium, Salmo, Cottus) mostly to the higher headwaters.

The affinities of the fishes vary in different parts of the Colorado. Cutthroat trout (Salmo clarki), mountain whitefish (Prosopium williamsoni, Fig. 17) and sculpins (Cottus bairdi and C. annae), all confined to the upper portion, have their closest relatives in the

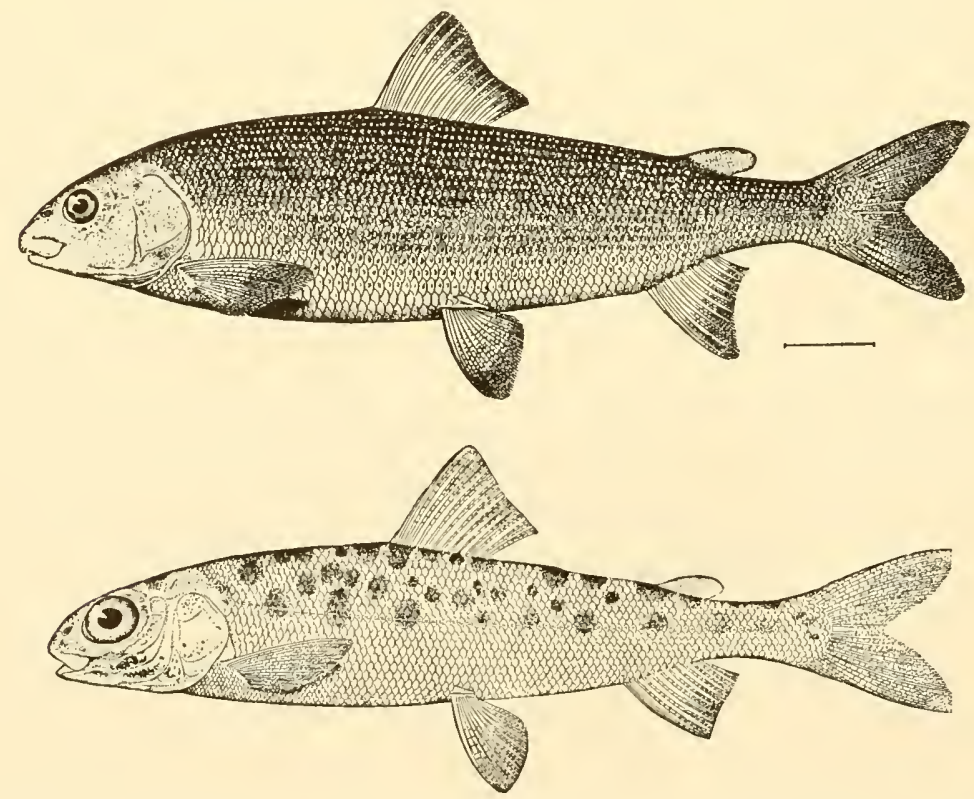

Fig. 17. Breeding male and juvenile of the mountain whitefish, Prosopium williamsoni, a species of cold, clear mountain streams that has probably dispersed by stream capture. (From Jordan and Evermann, 1900, Figs. 200, 200a.) 
Bonneville and upper Snake (Columbia) drainages. The middle section, in the vicinity of and including the Little Colorado River and the ancient White River, holds in common the species of the endemic cyprinid genus Lepidomeda (Miller and Hubbs, in press). The Gila River division has $S$ endemic species, most of which are likely autochthonous but at least 2 (Cyprinodon and Poeciliopsis) of which were derived from the east and south, respectively. Except for headwater types, which are identical with or representative of headwater species of adjacent basins, 71 per cent of its total of 35 species are confined to the Colorado. This bespeaks a long isolation from surrounding faunas. Only limited faunal exchange has taken place with the Río Yaqui (1 sucker and 2 minnows have moved south from the Colorado and Poeciliopsis has moved northward from the Yaqui).

\section{Sacramento Complex}

The Sacramento-San Joaquin, streams entering Monterey Bay and San Francisco Bay, and the Russian River and other coastal streams north to the Mad River are included in this complex. Nine of the 13 families occurring here contain semi-marine species, and one (Iysterocarpus traski of the Embiotocidae, Fig. 18) is the only freshwater representative of an otherwise wide-ranging marine family. The only native centrarchid west of the Rocky Mountains survives in the lowland waters but has been greatly reduced from its

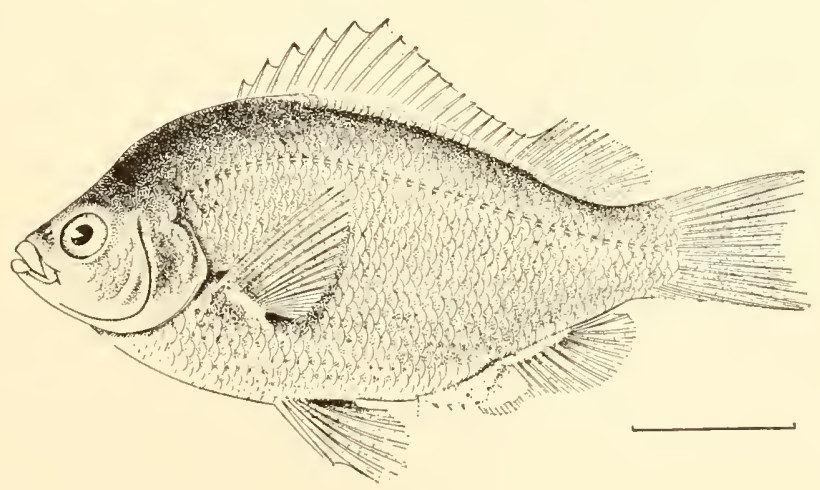

Fig. 18. Tule perch, Hysterocarpus traski, the only freshwater member of its marine family (Embiotocidae). (From original drawing by W. S. Atkinson; see Jordan and Evermann, 1900, Fig. 577.) 
one-time abundance, presumably through competition with introduced fishes. Sculpins are common (5 species of Cottus and 1 of Leptocottus), but suckers are not numerous; minnows have developed 5 enclemic genera (in part, perhaps relicts). The fish fauna shows affinities with each of the surrounding basins, the Columbia (Ptychocheilus, Siphateles), the Great Basin (Gila, Siphateles), the Klamath (Cottus), and the Colorado (Ptyclocheilus). High cndemism (75 per cent) at the species level indicates rather long and effective isolation for much of the basin. The likely mode of penetration of Great Basin types was indicated by Robins and Miller (1957, pp. 229-230).

\section{Klamath River}

Studies of the geology and ichthyology of this drainage indicate that the part above Klamath Falls has only recently established an outflow to the Pacific by the headward erosion of Klamath River; certain elements of the fauna largely or entirely restricted to the lakes and streams above the Falls strongly suggest former connections with the Great Basin (Hubbs and Miller, 1948, pp. 67-68; Robins and Miller, loc. cit.). Nine genera and 13 species occur above the Falls, and of these, 8 species (Entosphenus tridentatus, Salmo clarki, S. gairdneri, Catostomus snyderi, Gila bicolor, Rhinichthys osculus, and Siphateles bicolor) have also been reported from below (Snyder, 1908). Catostomus snyderi and Gila bicolor are known from single records only but Siphateles bicolor was taken at 3 localities by Snyder (1908, p. 159, as Rutilus bicolor). On distributional grounds it is clear that these three species were originally present only in the upper part of the Klamath basin and gained access to the remainder of the river by being carried downstream over the Falls. It is likely

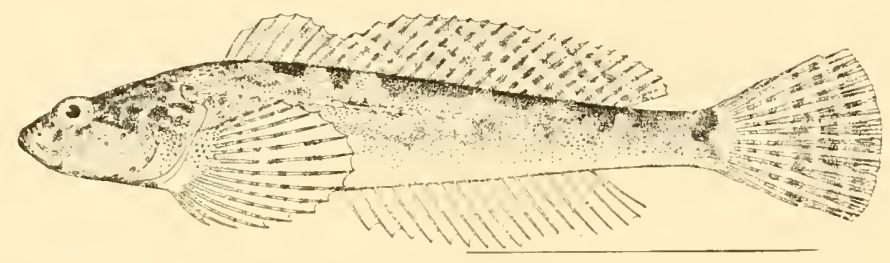

Fig. 19. Klamath Lake sculpin, Cottus princeps, a vicarious freshwater fish restricted to Upper Klamath Lake, Oregon. (From original drawing by Anna L. Brown; see Gilbert, 1898, p. 12.) 
that Rhinichthys osculus (Agosia mubila and A. klamathensis of Snyder) moved in the same direction, since the species does not otherwise occur south of the Coquille River, Oregon, or north of the Sacramento River system. Ten genera and 19 species have been stopped by the Falls; only one of these, Catostomus rimiculus, is a primary fish (known elsewhere only from Rogue River, Oregon). Two species of Cottus (C. princeps, Fig. 19, and C.tenuis) are confined to the Upper Klamath basin. The percentage of endemism at the species level is lowest in this system.

\section{Columbia Complex}

This system, as here expanded to include not only the Columbia River but also the Umpqua, Malheur, Fraser, Skeena, and Stikine rivers, is the largest of the centers of endemism (Fig. 1). The Snake River above American Falls is not included in the complex, as this part is faunally allied to the Bonneville Basin and received the outle of Lake Bonneville. In correlation with its size, the Columbia has the richest fauna-15 families, 29 genera, and 57 species. However, its primary fishes, though including four families, are not as numerous as in the smaller Colorado complex (Table I). The accessibility of the Columbia to the wealth of marine and semi-marine types accounts for its large total fauna but also is correlated with a relatively weak primary fauna with specific endemism at about the same level as that of the Klamath River. A noteworthy element of the fauna is the richness of the genus Cottus, the Columbia River system alone containing about 12 species ( 6 endemic). Salmonoids also are numerous, constituting 6 genera and 13 species, including Thymallus arcticus from the Stikine River only and Coregonus clupeaformis from the Skeena and Fraser rivers (Lindsey, 1956, p. 763).

The primary fauna shows relationships with that of eastern United States: 4 species occur on both slopes of the Continental Divide (Catostomus catostomus, Hybopsis plumbea, Hybognathus hankinsoni, and Rhinichthys cataractae). Two, Siphateles bicolor and Pantosteus platyrhynchus, are invaders from the Great Basin. Novumbra hubbsi and Columbia transmontana are ancient (Miocene?) relicts.

\section{Bonneville System}

This is the largest of the Great Basin (lrainages with ahout 21 species, 67 per cent of which are endemic (Table II). Included is the 
Snake River above American Falls, into which Lake Bonneville overflowed in late Pleistocene times. Excluded from consideration in the Bonneville fauna, however, are two suckers (Catostomus catostomus and C. columbianus) known from the upper Snake (and elsewhere in the Columbia complex) but absent from the Bonneville system. These two species are believed to represent part of the original Snake River fauna that survived a volcanic deluge which presumably destroyed the other species during or after the formation of American Falls but prior to the overflow of Lake Bonneville (Hubbs and Miller, 1948, p. 30).

TABLE II. Fishes of the Great Basin

$\begin{array}{ccccc} & \text { Bonneville } & \text { Lahontan } & \text { Other } & \text { Death } \\ \text { Family } & \text { System } & \text { System } & \text { Drainages }^{a} & \text { Valley }\end{array}$

Primary (I)

Cyprinidae

Catostomidae

$\begin{array}{llllllll}5 & 7 & 4 & 5 & 2 & 5 & 2 & 3 \\ 3 & 5 & 3 & 3 & 2 & 3 & 1 & 1\end{array}$

Secondary (II)

Cyprinodontidae

Others

Coregonidae (III)

Salmonidae (III)

Cottidae (IV)

Totals

$\%$ Endemism

Primary (I)

All families

Bonneville Lahontan

\begin{tabular}{rrrr} 
& & & \\
\cline { 3 - 4 } & & & \\
1 & 4 & 1 & 1 \\
1 & 1 & 1 & 3 \\
1 & 4 & 1 & 1 \\
$5-11-21$ & $5-10-13$
\end{tabular}

$1 \quad 1$

26

a These include basins between Pluvial Lake Lahontan and the Columbia, Bonneville, and Colorado systems (see Hubbs and Miller, 1948, pp. 43-67).

The affinities of the upper Snake and the Bonneville Basin proper indicate that 5 species (Prosopium williamsoni, Salmo clarki, Catostomus ardens, Rhinichthys cataractae, and Cottus bairdi) entered Lake Bonneville from the Snake River; 4 species (Pantosteus platyrhynchus, $P$. virescens, Gila atraria, and Snyderichthys copei) moved northward into the Snake; and 3 species (Rhinichthys osculus, Richardsonius balteatus, and Cottus beldingi) may have moved either or both ways. Two primary genera (Richardsonius and Chasmistes) are shared with the Lahontan system and 4 montane species (Prosopium williamsoni, Salmo clarki, Rhinichthys osculus, and Cottus belding $i$ ) are common to these two drainages. The Lahontan relationships indicate a former connection, perhaps of Pliocene or early 
Pleistocene age, between the Bonneville and Lahontan basins. Three of the 4 species (mountain whitefish, cutthroat trout, and Cottus bairdi) shared with the Colorado River are headwater types and indicate headwater transfers from the Bonneville into the Colorado (the fourth species, R. osculus, is too poorly analyzed and too widespread to be of much zoogeographic value).

\section{Lahontan System}

This isolated basin is second in size of the interior drainages and second also in the number and variety of its fishes, with 78 per cent of the primary species endemic (Table II). It has very little of significance in common with the Colorado River (for example, that basin lacks Chasmistes, Siphateles, and Richardsomius, and Gila is absent from the Lahontan basin), but shows affinities with the Klamath, Columbia, Bonneville, and Death Valley systems. Unlike Lake Bonneville, Lake Lahontan had no outlet in late Pleistocene time and the connections with the surrounding basins were either of comparatively recent headwater exchanges across existing divides (whitefish, trout, and Cottus) or more ancient low-elevation transfers, e.g., of Chasmistes (Hubbs and Miller, 1948, p. 40). Blackwelder (1948, p. 12) felt that a mid-Pleistocene outlet of the Lahon$\tan$ basin to the sea via Pit River into the Sacramento or in to the Klamath, or northward in to the Columbia, is a plausible speculation.

\section{Death Valley System}

This much disrupted drainage is noteworthy for the lack of salmonoids and Cottus, the strength of secondary types (6 out of 10 species), and the weakness of the primary fauna (Table II). The highly saline, often warm, and alkaline waters of a large part of the system are particularly suited to the family Cyprinodontidae, of which all the species and 1 of the 2 genera are endemic (Miller, 1948). That this family has been in the system for a long time is attested not only by the high degree of endemism but also by the fossil record (Miller, 1945b) of Cyprinodon and Fundulus from Tertiary deposits in Death Valley. The endemic genus Empetrichthys was probably derived from Fundulus.

The faunal relationships point to a former connection to the southeast, probably in Pliocene time, with what we now know as the Colorado River, and from the north, with the precursor of Lake 
Lahontan. Evidently the invasions were not simultaneous since the movement southward of Siphateles was timed so that this genus did not become established in the Colorado complex. The hypothesis that Siphateles (as well as Catostomus and Rhinichthys) entered the Owens River portion of the Death Valley system from the Lahontan basin via the Mono Lake basin (Hubbs and Miller, 1948, p. 79) fails to explain why Prosopium, Salmo, and Cottus, common associates of Catostomus and Rhinichthys (if not of Siphateles), are absent from the Death Valley system. The common occurrence of Siphateles points to an earlier, low-elevation connection such as may have permitted the entrance into the Lahontan basin of Fundulus and Gasterosteus.

\section{O'THER DRAINAGES}

The fauna of the Río Yaqui, of coastal streams from Baja California to central California, and of certain isolated waters not included in the seven centers of endemism are briefly discussed here.

\section{Yaqui River}

The fauna of the Yaqui River of northwestern Mexico is distinguished from that of the drainages already discussed by the presence of a native freshwater catfish (Ictalurus pricei), a cichlid (Cichlasoma beani), and a host of tropical fishes of marine derivation (Dorosoma, Lile, Galeichthys, Centropomus, Dormitator, Trinectes, etc.). It has the largest number of families, 16, and is second to the Columbia and Sacramento in number of genera. Only 12 of its 31 species are primary freshwater fishes (Table I). Not included in the tabulation are Gila ditaenia (Miller, 1945a), of the Río de la Concepción, and Catostomus wigginsi (Herre and Brock, in Herre, 1936), of the Río Sonora, both independent tributaries of the Gulf of California lying between the Yaqui and Colorado drainages. The relationships of the minnow are with Gila purpurea of the Yaqui and $G$. orcutti of southern California; those of the sucker have not been determined.

Seven of the 12 primary species are Rio Grande types, which, it is plausibly postulated, have entered the Yaqui by stream capture across the Sierra Madre Occidental (Meek, 1904, p. xxvii). These are Pantosteus plebeius, Campostoma ornatum, Gila" nigrescens," Notropis mearnsi, N. ornatus, Pimephales promelas, and Ictalurus pricei. Pre- 
cisely when and where they or their inmediate ancestors arriverl has not been stated. Study of the physiographic map of Mexico prepared by Hoy (1943) and of World Aeronautical Charts 470 (Santiago Mountains, 1950, rev. ed.) and 520 (Lake Santiaguillo, 1951, rev. ed.), shows that capture of a tributary of the Río Conchos by the Río Papigochic (of the Yaqui system) could readily have taken place about 28 airline miles south of Miñaca, Chihuahua. Also, instead of taking the abrupt horseshoe turn that the Papigochic now follows northwest of Miñaca, this segment of the stream may formerly have flowed northward to form the headwaters of Río Casas Crandes, a stream of interior drainage in Chihuahua. In either event, Rio Grande types would have been transferred to the Yaqui fauna.

Three species, Catostomus bernardini, Agosia sp. (near chrysogaster), and Gila minacae ( $=$ G. robusta; Miller and Uyeno, manuscript), are the same as or most closely allied to Colorado River species, and thus indicate entry into the Yaqui from the north. The 2 remaining primary fishes are a sucker (Catostomus) and a minnow (Gila purpurea). The former, of uncertain relationships, occurs in the headwaters of both the Yaqui and the Casas Grandes, whereas the latter, related to $G$. orcutti and $G$. ditaenia, inhabits the Yaqui and Río Sonora. No genera are endemic and but one species, Notropis mearnsi, scarcely distinct from $N$. formosus of the Río Casas Grandes, is regarded as indigenous.

\section{Minor Coastal Drainages}

Streams and interior springs from central Baja California northward to San Luis Obispo Creek, California, harbor limited fish faunas (arbitrarily combined in Table 1). Although 12 families are represented, these comprise only 18 species, of which but 3 are primary freshwater fishes. One of these, Rhinichthys osculus, is of little zoogeographic help. Gila orcutti, with its closest relatives in northern Sonora $(G$.ditaenia) and in the Yaqui $(G$. purpurea), evidently came into southern California from the direction of the Colorado River. The third freshwater fish, Pantosteus santaanae, is most closely related to species now inhabiting the Creat Basin, whence it presumably came, perhaps in Pliocene time.

The two secondary fishes, Fundulus parvipinnis and $F$. lima, are the only Pacific representatives of a genus that has its center of 
abundance in southeastern United States (Miller, 1955), but which was once more numerous west of the Continental Divide, whence 5 fossil species have been described (Miller, 1945b).

\section{Isolated Basin Drainages}

Certain isolated basins lying between the Lahontan, Bonneville, and Colorado systems harbor a small but interesting remnant fish fauna (Hubbs and Miller, 1948, pp. 51-67, 73-75).

A group of valleys in northeastern Nevada share a peculiar Rhinichthys-like dace, the only native fish in 4 of the 5 basins (Hubbs and Miller, 1948, Map 1, Nos. 24-28, 30). The southernmost basin (No. 30), Spring Valley, also harbors a species of Pantosteus, which is related to species in all surrounding major watersheds; the common ancestor of this sucker probably originated in the Great Basin.

Lying north of the Lahontan basin are the Madeline Plains, site of Pluvial Lake Madeline (Hubbs and Miller, 1948, Map 1, No. 33). This region contains but a single fish, Rhinichthys osculus. The remnant populations show remarkable uniformity and are apparently indistinguishable from the Pit River form, suggesting that Madeline Plains received its stock from that source (Hubbs and Miller, 1948, p. 59). A very distinctive chub of the genus Siphateles occurs in Alvord Valley, mostly in Oregon, and another species of the same genus is known from Catlow and Guano valleys. Surprise Valley, in northwestern Nevada, has an endemic sucker as well as the noncommittal Rhinichthys, and the nearby Warner Valley, mostly in Oregon, harbors Catostomus warnerensis (endemic), Rhinichthys osculus, Siphateles bicolor, and was probably inhabited by Salmo clarki (a Sacramento genus, Hesperoleucus, has likely been introduced). Too little is known about the affinities of these species to enable one to draw reliable conclusions as to their origin.

A number of isolated basins in south central Oregon, lying in the desert region between the headwaters of Deschutes River and Malheur Lake, were once united into Pluvial Fort Rock Lake (Hubbs and Miller, 1948, p. 73). The Recent fauna includes Salmo clarki, Rhinichthys osculus, and Siphateles bicolor, each of which has relatives in adjacent watersheds. The fossil occurrence of Pacific salmon (Oncorhynchus) establishes that the waters of this lake were once directly connected to the ocean and the physiographic data indicate that the connection was via Deschutes River. Study of the 
fossil minnows and suckers, along with careful comparison of the living fishes, should help to determine whether the fauna entered this region by more than one route.

One other well-isolated basin shows a curious faunal mixture. Railroad Valley, in eastern Nevada, was the site of a large Pluvial lake (Hubbs and Miller, 1948, p. 90, Map 1, No. 60). The surviving waters contain chubs referable to Siphateles bicolor and an endemic cyprinodontid, Crenichthys nevadae (Fig. 16). The only other species of Crenichthys, $C$. baileyi, is known from the remnants of the adjacent Pluvial White River, once a permanent tributary of the Colorado River. Structural troughs lead from Railroad Valley in a southeasterly direction toward the Colorado River suggesting, along with the mutual occurrence of Crenichthys, that Railroad Valley once drained in that direction, perhaps in early Pleistocene time. Siphateles is particularly characteristic of the Lahontan basin and presumably entered Railroad Valley from the north after the connection between that valley and the Colorado system was severed.

\section{SPECIES CROSSOVERS BETWEEN EASTERN AND WESTERN NOR'TH AMERICA}

A study of the extralimital ranges of western and eastern fishes shows that 29 species have taken part in recent crossings of the Continental Divide. Possibly some of these transgressions are the result of human intervention (Lindsey, 1956, pp. 780, 782). These fishes comprise 23 genera in 9 families, 3 of which are primary. About twice as many species have moved from east to west as from west to east; where the crossing was effected by stream capture, this suggests that the western rivers have been the more active in the piracy. A total of 19 eastern species has entered the Columbia complex of streams and the Yaqui drainage, whereas only 10 western species have invaded eastern waters at points from British Columbia to Wyoming.

Stream capture by the Yaqui River of a drainage that once was connected with the Rio Grande has given the Yaqui $S$ eastern species (7 primary, 1 secondary); except for a Gila and Ictalurus pricei, none of these is recorded elsewhere on the Pacific slope. The eastern element makes up 26 per cent of the total fauna and 58 per cent of the primary fishes inhabiting the Yaqui. A well-established route of two-way faunal exchange has taken place between the Snake River 
(of the Columbia complex) and the upper Missouri River. Mountain whitefish (Prosopium villiamsoni), cutthroat trout (Salmo clarki), and the mountain sucker (Pantosteus) have moved eastward; and the longnose sucker (Catostomus catostomus), longnose dace (Rhinichthys cataractae), and mottled sculpin (Cottus bairdi) have moved westward. Farther north, the Continental Divide has been crossed at several points, notably between the upper Fraser or Skeena basins and the MacKenzie Valley in British Columbia (Lindsey, 1956), where at least $S$ and likely 10 species have crossed from east to west and 7 species have moved from west to east.

Multiple crossings of the Continental Divide are evident from the distribution patterns of such western species as Prosopium williamsoni, Salmo clarki, and Salvelinus malma, and of the eastern Catostomus catostomus and possibly Rhinichthys cataractae. Most species have not spread far after entering eastern or western waters but the cutthroat trout, mountain whitefish, and mottled sculpin (Cottus bairdi), all of which ascend tributaries, have extended their ranges into isolated basins probably via stream captures, at least in part. Two northern species are not included in the above discussion since they are unknown from Pacific streams in the area covered by this report. Round whitefish, Prosopium cylindraceum, and northern pike, Esox lucius, have invaded the Alsek River, a Pacific tributary in extreme northwestern British Columbia, which also contains Arctic grayling (Lindsey, 1956, p. 789); Esox and Thymallus also inhabit the Taku River, next to the south. Headwater transfer from the MacKenzie drainage furnishes a plausible explanation of their limited occurrence on the Pacific slope. Most of these crossings of the Continental Divide probably took place in Postglacial times, at least in the northern Rockies, and no crossing is thought to be earlier than the latter part of the Pleistocene. The identity of most or all of the now separated species on each side of the Divide supports the view that the transfers were recent.

\section{CONCLUSION}

Of the 21 families of primary freshwater fishes inhabiting North America (Fig. 1), about 30 per cent of the species are judged to be of North American origin, 55 per cent of Eurasian ancestry, and 15 per cent of South American affinities. Two relict families, the Polyodonticlae and the Amiidae, with a single species each in eastern 
Inited States, are clearly of northern origin, but whether Eurasian or American is problematical. Hence they are not included in the above estimates. Darters (Etheostomatinae) are considered North American, but the three other large percids are tentatively assigned a Eurasian origin.

In western North America there are an equal number of families of North American and Eurasian origin but the three Eurasian groups (Umbridae, Cyprinidae, and Catostomidae) account for 97 per cent of the primary fauna. The rather sharp differences between the western and eastern American fish faunas are of relatively recent origin, probably post-Miocene except for the three old lowland relicts, Novumbra, Columbia, and Archoplites. Excluding the very recent, Postglacial eastern invaders, there is an overlap of only about 5 per cent in the total number of species between the two regions.

\section{Acknowledgments}

During the approximately 20 -year period that I have been studying western fishes, Dr. Carl L. Hubbs has provided guidance and repeated stimulation both by encouragement of my work and through our joint studies. He has also criticized this manuscript. Although I accept full responsibility for the conclusions here expressed, my indebtedness to him is considerable. My colleague, Dr. Reeve M. Bailey, has also made valued suggestions for improving the manuscript and has generously allowed me to use the map (Fig. 1) which he compiled and which appears here with only minor modifications. Dr. Leonard P. Schultz kindly arranged for the use of photographic copies of certain original drawings (Figs. 4, 7, 13, 18-19). Research grants from the Horace H. Rackham School of Graduate Studies, University of Michigan, made possible much of the field work that provided the raw data for this report. The maps and charts were drafted by Mrs. Betty Anthony.

\section{REFERENCES}

Bailey, Reeve M. 1956. A revised list of the fishes of Iowa, with keys for identification, in James R. Harlan and Everett B. Speaker, Iorea Fish and Fishing. Iowa State Conserv. Comm., 3rd edition, Pp. 327377.

Berg, Leo S. 1936. The suborder Esocoidei (Pisces). Bull. inst. recherches biol. Perm, 10: 385-391 (in Russian and English).

-1949. The freshwater fishes of the USSR and neighboring regions. Acad. Nank Moscow, 2: 469-924, Figs. 288-674 (in Russian).

Blackwelder, Eliot. 1948. The geological background, in The Great Basin, with emphasis on Glacial and Postglacial times. Bull. Univ. Utah, 38 (20): 3-16. 
Chu, Yuanting T. 1935. Comparative studies on the scales and on the pharyngeals and their teeth in Chinese cyprinids, with particular reference to taxonomy and evolution. Biol. Bull. St. John's Univ., No. 2.

Cope, E. D. 1883. On the fishes of the Recent and Pliocene lakes of the western part of the Great Basin, and of the Idaho Pliocene lake. Proc. Acad. Nat. Sci. Phila., 1883: 134-166.

Darlington, Philip J., Jr. 1957. Zoogeography: The Geographical Distribution of Animals. John Wiley and Sons, New York.

Eastman, Charles R. 1917. Fossil fishes in the collection of the United States National Museum. Proc. U. S. Natl. Museum, 52: 235-304.

Eaton, Theodore H., Jr. 1935. Evolution of the upper jaw mechanism in teleost fishes. J. Morphol., 58 (1): 157-172.

Evermann, Barton Warren. 1892. A reconnaissance of the streams and lakes of western Montana and northwestern Wyoming. Bull. U.S. Fish Comm., 11 (1891): 3-60.

Gilbert, Charles H. 1898. The fishes of the Klamath River basin. Bull. U. S. Fish Comm., 17 (1897): 1-13.

Herre, Albert IV. C. T. 1936. Notes on fishes in the zoological museum of Stanford University. IV. A new catostomid from Mexico and a new callionymid from Celebes and the Philippines. Proc. Biol. Soc. Wash., 49: 11-14.

Hoy, Harry E. 1943. A new map of the surface configuration of Mexico. Papers Mich. Acad. Sci., 28 (1942): 441-443.

Hubbs, Carl L. 1932. Studies of the fishes of the order Cyprinodontes. XII. A new genus related to Empetrichthys. Occ. Papers Museum Zool.

Univ. Mich., No. 252, pp. 1-5.
. 1955. Hybridization between fish species in nature. Syst. Zool., $4(1): 1-20$.

Hubbs, Carl L., and Robert R. Miller. 1948. Correlation between fish distribution and hydrographic history in the desert basins of Western United States, in The Great Basin, with Emphasis on Glacial and Postglacial Times. Bull. Univ. Utah, 38 (20): 17-166.

Hussakof, L. 1916. A new cyprinid fish, Leuciscus rosei, from the Miocene of British Columbia. Am. J. Sci., 42: 18-20.

1932. The fossil fishes collected by the central Asiatic expeditions. Am. Museum Novitates No. 553, pp. 1-19.

Jordan, David Starr, and Barton Warren Evermann. 1900. The fishes of North and Middle America. IV. U. S. Natl. Museum, Bull. 47.

- 1902. American Food and Game Fishes. Doubleday, Page and Co., New York.

Lindsey, C. C. 1956. Distribution and taxonomy of fishes in the MacKenzie drainage of British Columbia. J. Fisheries Research Board Can. 13 (6): 759-789.

- 1957. Possible effects of water diversions on fish distribution in British Columbia. J. Fisheries Research Board Can., 14 (4): 651-668. 
Lucas, Frederic A. 1900. A new fossil cyprinoid, Lenciscus turneri, from the Miocene of Nevada. Proc. U. S. Natl. Museum, 23: 333-334.

Meek, Seth Eugene. 1904. The fresh-water fishes of Mexico north of the Isthmus of Tehuantepec. Field Col. Museum Publ. 93 (Zool. Ser., Vol. 5).

Miller, Robert Rush. 1945a. A new cyprinid fish from southern Arizona, and Sonora, Mexico, with the description of a new subgenus of Gila and a review of related species. Copeia No. 2, pp. 104-110.

- 1945b. Four new species of fossil cyprinodont fishes from eastern California. J. Wash. Acad. Sci., 35: (10), 315-321.

- 1948. The cyprinodont fishes of the Death Valley system of eastern California and southwestern Nevada. Misc. Publ. Museum Univ. Mich. No. 68, pp. 1-155.

. 1955. An annotated list of the American cyprinodontid fishes of the genus Fundulus with the description of Fundulus persimilis from Yucatan. Occ. Papers Museum Zool. Univ. Mich. No. 568, pp. $1-25$.

Miller, Robert Rush, and Carl L. Hubbs. In press. The spiny-rayed cyprinia fishes (Plagopterini) of the Colorado River system. Occ. Papers Museum Zool. Univ. Mich.

Miller, Robert Rush, and Teruya Uyeno. Classification of the cyprinid fishes of the genus Gila in Mexico and New Mexico (manuscript).

Myers, George S. 1938. Fresh-water fishes and West Indian zoogeography. Ann. Rept. Smithsonian Inst., 1937, pp. 339-364.

- 1951. Fresh-water fishes and East Indian zoögeography. Stanford Ichth. Bull., 4 (1): 11-21.

Nelson, Edward M. 1948. The comparative morphology of the Weberian apparatus of the Catostomidae and its significance in systematics. J. Morphol., 83 (2): 225-251.

. 1949. The opercular series of the Catostomidae. J. Morphol., 85 (3) : 559-567.

Ramaswami, L. S. 1955a. Skeleton of cyprinoid fishes in relation to phylogenetic studies. VI. The skull and Weberian apparatus in the subfamily Gobioninae (Cyprinidae). Acta Zool., 36: 127-158.

- $1955 \mathrm{~b}$. Skeleton of cyprinoid fishes in relation to phylogenetic studies. VII. The skull and Weberian apparatus of Cyprininae (Cyprinidae). Acta Zool., 36: 199-242.

-1957. Skeleton of cyprinoid fishes in relation to phylogenetic studies. VIII. The skull and Weberian ossicles of Catostomidae. Proc. Zool. Soc. (Calcutta), Mookerjee Mem. Vol., pp. 293-303.

Regan, Charles Tate. 1906-08. Pisces, in Biologia Centrali-Americana, Vol. 8.

- 1915. Reptilia, Batrachia, and Pisces, in Biologia CentraliAmericana, Introd. Vol., pp. 105-117.

Repenning, Charles A., John F. Lance, and Chester R. Longwell. A history of the Colorado River (manuscript). 
Robins, C. Richard, and Robert Rush Miller. 1957. Classification, variation, and distribution of the sculpins, genus Cottus, inhabiting Pacific slope waters in California and southern Oregon, with a key to the species. Calif. Fish and Game, 43 (3): 213-233.

Rostlund, Erhard. 1952. Freshwater fish and fishing in native North America. Univ. Calif. Publ. Geog., 9.

Schultz, Leonard P. 1936. Keys to the fishes of Washington, Oregon and closely adjoining regions. Univ. Wash. Publ. Biol., 2: 103-228.

Snyder, John Otterbein. 1908. The fishes of the coastal streams of Oregon and northern California. Bull. U. S. Bur. Fisheries, 27 (1907): 153-189.

Stirton, R. A. 1936. Succession of North American continental Pliocene mammalian faunas. Am. J. Sci., 32: 161-206.

1939. The Nevada Miocene and Pliocene mammalian faunas as faunal units. Proc. Sixth Pacific Sci. Congr., 1939, pp. 627-640.

Walters, Vladimir. 1955. Fishes of western Arctic America and eastern Arctic Siberia. Taxonomy and zoogeography. Bull. Am. Museum Nat. Hist., 106: 255-368.

Wynne-Edwards, V. C. 1952. Freshwater vertebrates of the Arctic and subarctic. Fisheries Research Board Can., Bull. 94, pp. 1-28. 


\title{
Some Problems of Freshwater
}

\section{Invertebrate Distribution in the}

Western States ${ }^{1}$

\author{
Robert W. Pennak \\ University of Colorado, Boulder
}

Any brief discussion of the distribution of free-living freshwater invertebrates of the West (even excluding insects) is a rather large and difficult matter, chiefly because of the great taxonomic and ecological diversity of the many taxa involved and because of scanty definitive data. For this reason, I shall deal primarily with a few of the basic problems, and I shall limit myself largely to generalizations. My remarks are restricted to the Recent distribution of freshwater invertebrates, other than insects, of the eleven western states. There are six major points which I should like to make.

1. The freshwater invertebrate fauna of the West is not well known. Aquatic biologists are relatively far more numerous in the eastern half of the United States, where for many years collecting, identification, and zoogeographical studies have been actively pursued. To an even more striking degree, our familiarity with the western freshwater fauna is still farther behind the situation in Europe, where such studies have produced a remarkably thorough knowledge of freshwater invertebrates.

Our first point, therefore, is a plea for more field, laboratory, and zoogeographical work in our West, especially published work. We hope that, as time goes on, more and more students can be encouraged to enter these fields of research. Incidentally, we suspect that a good deal of unpublished information is already hidden away in field notes, master's theses, and unpublished doctoral dissertations.

\footnotetext{
${ }^{1}$ Contribution No. 32, Limnology Laboratory, University of Colorado.
} 
2. From a purely environmental standpoint, the freshwater fauna of the West does not have the advantages of stable flowages and many associated large lakes. Western topography is violent and broken, the climates are highly demanding because of wide annual variations, and barriers are abundant and rigorous. Many of our rivers are laden with silt during much of the year, the gradients are steep, and the water levels sometimes vary from trickles (or dry beds) in late autumn and winter to rushing torrents cluring the spring runoff. Droughts in the West are often extreme and extensive; undoubtedly they are effective in inhibiting or exterminating local populations. Except in mountainous regions, the West has relatively few natural lakes, and many of these are small, ephemeral, and pondlike.

3. We assume that many species of freshwater invertebrates in the eastern half of the United States could become well established in western areas, but for several important reasons these eastern species in certain taxa are apparently prevented from naturally spreading westward. The following barriers, for example, are undoubtedly effective: prevailing westerly winds, the topography and headwater drainages of the Continental Divide area, steep stream gradients, intermittent rivers, streams, and ponds, and extensive deserts and semi-arid regions.

4. Nevertheless, when examined closely, the western states appear to present a set of conditions that should encourage isolation and speciation, especially in certain taxa containing macroscopic forms, and the West should theoretically have a unique population of freshwater invertebrates. Some of these conditions may be enumerated briefly, as follows: (a) the abundance of barriers to gene flow (mountains, deserts, closed drainage systems, variety of climates, etc.); (b) the abundance of natural and artificial lakes and springs with peculiar chemistry (alkali lakes, saline lakes, saline springs, etc.); $(c)$ thermal springs; $(d)$ the generally wide variety of lakes and streams. Indeed, there is already evidence to show that the western aquatic invertebrate fauna is much richer and more varied than is indicated in the literature. Our personal experience with alkali lakes, thermal springs, and high-altitude lakes and ponds convince us of this.

Some of the most striking examples of western endemism are to be found in the arid and semi-arid Great Basin and adjacent regions, 
notably among the stream snails (Pleuroceridae). Freshwater shrimps in the Family Atyidae, restricted to a few California coastal streams, present a further example.

Perhaps it should be pointed out that the IVest appears to be lacking in extensive limestone caves and associated underground stream systems of the sort found in Kentucky, Tennessce, Indiana, Illinois, Missouri, and Florida. Such habitats are often marked by unusual endemic aquatic invertebrates. Interesting counterparts, however, are the occasional western lava-tube caves where a few unusual forms have been found, e.g., Kenkia (turbellarian) and some species of Stygobromus (amphipods). On the other hand, it should be noted that the West, so far as we know, is lacking in truly archaic species, such as amphipods, isopods, Bathynella, Troglochaetus, and Marifugia, that are so typical of southeastern Europe.

5. Unlike the situation for certain vertebrates and for invertebrate terrestrial groups, it is quite clear that the western freshwater invertebrate fauna involves a zoogeographic situation that is confusing, poorly known, and greatly diverse. Omitting insects and a few of the minor taxa, however, an assessment or appraisal of this fauna would seem to indicate five zoogeographic categories, as follows.

Six taxa are characterized in the West by numerous cosmopolitan species, most of which produce resting eggs, cysts, and other resistant and dispersal devices that are remarkably effective in surmounting barriers. Protozoa and Rotatoria are typical of this category and are fairly well known in the IVest. Four other groups (Oligochaeta, Tardigrada, Gastrotricha, and Nematoda) are poorly known, but judging from studies in other parts of the world, we assume that many common species are widely distributed throughout the West.

A second category includes five taxa that are not necessarily cosmopolitan but whose speciation and abundance in the West are largely unknown. There are a few records of triclad Turbellaria from the West, but little is known about the rhabdocoels, and we are greatly in need of studies on pond, alpine, and springbrook species in this order. Little is known about the Hirudinea of the Vest; a good many eastern species, however, have highly restricted distributions, and a comparable situation may exist in the West. Of the thirty species of freshwater Porifera in the United States, 
only about seven have been reported from the western states; presumably many of the turbid low-altitude lakes and streams discourage the establishment of sponges, but very little work has been done in mountain ponds and lakes that are sometimes fruitful places for sponge collecting. Only about four species of hydras have been reported from the IVest; more intensive collecting should undoubtly reveal a fauna perhaps even richer than that of the eastern states. The same situation applies to the Bryozoa; they are easily transported from one place to another by virtue of their hibernacula and statoblasts, yet the western species are poorly known.

A third category includes four taxa that are known to be well represented in the West; they are also groups in which the lists of western species will undoubtedly eventually be longer than those for the eastern portion of the United States. The Cladocera, for example, are represented by many cosmopolitan species, perhaps largely owing to the viability and ease of transport of the ephippial eggs; in addition, a good many species are restricted to certain habitats in the western states, especially species of Moina, Camptocercus, and Pleuroxus in alkali ponds and lakes. Cosmopolitan species of cyclopoid and harpacticoid copepods are likewise abundant in the IVest; the diaptomicls, however, are more interesting because of their proliferating speciation in western lakes and ponds (the list of known species is growing markedly); furthermore, even a few Asiatic and Alaskan species are now being reported from certain cold-water habitats of the West. Although Ostracoda have been subjected to relatively little collecting in the West, each new study turns up numerous cosmopolitan and endemic species; further systematic collecting should reveal a remarkably large fauna. The same is true for the Hydracarina, especially in view of the experience of European specialists; the little collecting already done in the western states is ample evidence that it is an area rich not only in cosmopolitan but also in endemic species, as one might assume in view of the wide variety of isolated aquatic habitats.

A fourth category includes five large taxa that are poorly represented in the West. It is, for example, remarkable that this region contains relatively few gastropods, especially as compared with the very rich fauna of the Mississippi clrainage area. To be sure we have an interesting assemblage of isolated genera and species in such 
areas as the Great Basin, including Parapholyx, Carinifex, and Fluminicola, but these do not constitute a large fauna. The Pelecypoda (exclusive of the Sphaeriiclae) are very poorly represented west of the Continental Divide; for example, only about six species of unionids are native to California. One of these, Margaritifera margaritifera, is widely distributed in the western states but also occurs in the North Atlantic states. But presumably the great unionid population of the Mississippi Valley has never been successful in overcoming the difficulties of the Divide, sandy and silty rivers, and the intermittent nature of many western streams. Undoubtedly a further problem in the West is the lack of proper fish hosts for the glochidia stages of unionids. Isopoda and Amphipoda are apparently poorly represented in the West, although most of the few species found there are endemic; the relative abundance of species in the eastern states is probably a reflection of speciation in springs and subterranean waters. Freshwater crayfishes were originally represented by only five species of Astacinae west of the Continental Divide, and this same subfamily is represented elsewhere only in northern Europe and eastern Asia, by about ten species. The Cambarinae, however, which are so abundant east of the Continental Divide, have, in Recent times, apparently never been successful in spreading westward from their centers of dispersal and speciation in Mexico and the south-central and south-eastern parts of the United States. It is, of course, entirely possible that the Cambarinae inhabited the western states area in pre-Pleistocene times.

A fifth and last category inclucles three small groups that are especially characteristic of the West and that are also abundant in comparable geographic and climatic areas elsewhere in the world. These are the Anostraca (fairy shrimps), Conchostraca (clam shrimps), and Notostraca (tadpole shrimps). All are far better represented in the West than in the eastern half of the country. Two peculiarities of these groups are perhaps primarily responsible for their occurrence here. First, they produce an abundance of highly resistant, thick-shelled eggs that are able to withstand extremely unfavorable conditions for long periods. Second, many species are adapted to living in unusually saline, alkaline, and silty bodies of water. Permanent and vernal ponds and pools throughout the West thus afford ideal conditions for these phyllo- 
pods, and although they are usually considered more typical of the Great Plains, they are just as characteristic of suitable mountain and desert habitats west of the Divide.

TABlE I. Systematic and Zoogeographic Status of Certain Groups of Freshwater Invertebrates in the Western Portion of the United States

\begin{tabular}{|c|c|c|c|c|}
\hline & & $\begin{array}{l}\text { Groups } \\
\text { containing } \\
\text { preponder- } \\
\text { ance of } \\
\text { species wide- } \\
\text { spread in the } \\
\text { United } \\
\text { States }\end{array}$ & $\begin{array}{l}\text { With } \\
\text { high } \\
\text { percentage } \\
\text { of endemic } \\
\text { species } \\
\text { in West }\end{array}$ & $\begin{array}{l}\text { Western } \\
\text { status } \\
\text { largely } \\
\text { unknown }\end{array}$ \\
\hline $\begin{array}{l}\text { Protozoa } \\
\text { Rotatoria } \\
\text { Oligochaeta } \\
\text { Gastrotricha } \\
\text { Tardigrada } \\
\text { Nematoda }\end{array}$ & $\begin{array}{l}\text { West relatively } \\
\text { rich in species }\end{array}$ & $\begin{array}{l}\mathrm{x} \\
\mathrm{x} \\
? \\
? \\
\mathrm{x} \\
?\end{array}$ & & \\
\hline $\begin{array}{l}\text { Eubranchiopoda } \\
\text { Hydracarina } \\
\text { Ostracoda } \\
\text { Copepoda } \\
\text { Cladocera }\end{array}$ & & $\begin{array}{l}\text { ? } \\
\text { ? }\end{array}$ & $\begin{array}{l}\mathrm{x} \\
\mathrm{x} \\
\mathrm{x} \\
? \\
?\end{array}$ & \\
\hline $\begin{array}{l}\text { Turbellaria } \\
\text { Hirudinea } \\
\text { Gastropoda } \\
\text { Bryozoa } \\
\text { Porifera } \\
\text { Coelenterata }\end{array}$ & & & $\mathrm{x}$ & $\begin{array}{l}\mathrm{x} \\
\mathrm{x} \\
\mathrm{x} \\
\mathrm{x} \\
\mathrm{x}\end{array}$ \\
\hline $\begin{array}{l}\text { Amphipoda } \\
\text { Isopoda } \\
\text { Decapoda } \\
\text { Pelecypoda }\end{array}$ & $\begin{array}{c}\downarrow \\
\text { West relatively } \\
\text { poor in species }\end{array}$ & & $\begin{array}{l}x \\
x \\
x \\
x\end{array}$ & \\
\hline
\end{tabular}

Certain of the generalizations thus far discussed are summarized in an alternate fashion in Table I. The twenty-one taxa in the first column are listed in order of their decreasing relative species abundance in the West (particularly as compared with the situation in the eastern half of the United States). The first five taxa comprise a group characterized by a preponderance of cosmopolitan species, 
even though definitive data are lacking for the Oligochaeta, Gastrotricha, and Nematoda, and their inclusion here is based on information gathered primarily from European sources. The next five taxa of crustaceans form a natural group featured by a high percentage of endemic species in the West (with the possible exceptions of the Copepoda and Cladocera). The following six taxa are a heterogeneous group which, with the exception of the Gastropoda, are poorly known in the West, chiefly because of the lack of intensive and systematic collecting. The last four taxa listed in the first column are all relatively poor in species in the West, but nevertheless most of the species found there are endemic.

6. The last point I should like to make is concerned with the increasingly important role being played by man in the distribution of freshwater invertebrates in the West. Residents of California, for example, are well aware of the nuisance and economic importance of cambarine crayfishes that were intentionally introduced here many years ago. In Colorado we are seeing the same process, although the end results will probably not be so serious; cambarine crayfishes have been introduced into certain Colorado mountain lakes, and in some such habitats they have become abundant and a welcome addition to the trout diet. In addition, however, they have been introduced into the Western Slope drainages, and in a few irrigation ditches they are occasionally a nuisance because of their burrowing habits.

Aquarium enthusiasts are often responsible for setting up new centers of distribution for both bivalve and univalve mollusks. Many species native to the eastern states are well adapted to home aquarium use, and, of course, these are commonly shipped west as a part of the thriving aquarium business. Frequently, however, when the hobbyist is tired of his aquarium, he empties it into the nearest pond or lake, and we may thus have a new mollusk population established under natural conditions.

Fishermen are consciously accomplishing the same ends. We have seen fishing parties from Nebraska, for example, bringing milk cans full of vegetation and the associated invertebrates to Colorado. These they commonly empty into mountain lakes on both sides of the Continental Divide. Furthermore, state fish and game departmants frequently do exactly the same thing when they transport large quantities of invertebrates and vegetation from 
one "rich" lake to another "poor" lake. Over a period of time these activities will undoubtedly assume considerable importance in spreading various invertebrates over wider areas of the West.

A further and unintentional means by which aquatic invertebrates are greatly increasing their ranges and abundance is through the extensive system of thousands of farm ponds and stock tanks which have been constructed in the West, especially during the past twenty-five years. In areas formerly characterized by great stretches of unbroken arid or semi-arid land, we now have an extremely effective system of "stepping stones" by which invertebrates may disperse much more effectively than was the case many years ago. This is no exaggeration. Anyone who will take the trouble to examine the invertebrate population of a stock tank or ranch pond in the middle of a large semi-arid tract is bound to be impressed with the abundance of species occurring there. (Incidentally, this facet of aquatic biology seems to have been completely neglected.)

During the past seventy years the IVest has become densely criss-crossed with an extensive system of irrigation ditches, many of them carrying water at all times of the year. Such ditches connect with a host of artificial irrigation reservoirs. In our estimation, these waterways also provide an enormous transportation and dispersal system by which our aquatic invertebrates are becoming much more generally distributed. 


\section{Affinities and Origins of the Northern and Montane Insects of Western North America}

Herbert H. Ross

Illinois Natural History Survey, Urbana

$T_{\text {he subjects of this paper are the insects }}$ belonging to the cool-adapted biota and occupying an ecological band comprising essentially the cool-temperate and arctic regions. The arctic region comprises both the tundra of the Arctic and the alpine tundra found above timberline in subarctic areas. The cool temperate region comprises the taiga and its equivalents - the northern coniferous spruce and pine forests and various higherelevation forests toward the south. In North America today this double band - cool temperate and arctic-extends in a wide swath across roughly the northern third of the continent and extends southward as islands at higher and higher elevations, through the mountain chains of eastern and western America. In the West these cool-temperate islands are larger and occur much farther south than in the eastern part of the continent.

A large number of insect species are abundant in both taiga and tundra, and are almost entirely restricted to these two major ecological formations. These insects represent many orders and families, including such well-known types as caddisflies, sawflies, and mosquitoes. Although today these many species of various families form what appears to be a closely knit ecological aggregation, they must have arrived in this general area of the continent by diverse paths and at different geologic times.

Concerning this cool-adapted biota of western North America, we can deduce that some elements arrived from Asia, that other elements spread westward from the eastern parts of North America, and that still others spread northward from the more tropical areas to the south. Present information gives evidence of dispersals of living genera dating from Cretaceous time to practi- 
cally the present. Undoubtedly dispersals between the same areas occurred many times, each time involving different ecological conditions in the bridging area and resulting in the spread of different lines of insects having corresponding ecological adaptations.

We know far too little concerning this historic process, however, to be able to detail the spread of all the insect species in these northern communities, or even that of the plants and other animals.

Because fossils of northern insects are rarities, we must rely chiefly on the biogeographic analysis of living species in delving into the past history. Two sets of facts constitute the backbone of such an analysis, first, the morphological characters of the species
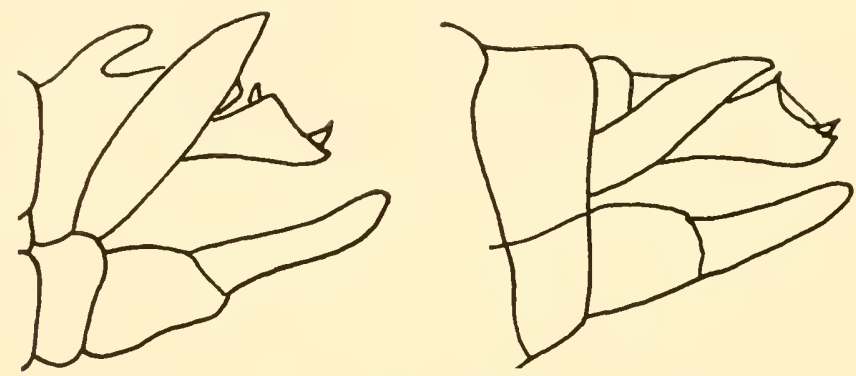

Fig. 1. A Baltic Amber caddisfly: right, Lype sericea and left, one of its living counterparts, the European Lype phaeopa. (From Ulmer, 1912, and Mosely, 1939.)

on which phylogeny is based, and then the known geographic distribution of the species from which the dispersal pattern may be deduced. When present, fossil evidence is a welcome and valuable adjunct to these data.

One fact of inestimable importance in attempts at phylogenetic reconstruction is deduced from the fossil record, namely that in some insect lines evolutionary change may be very slow. The caddisfly genus Lype is represented in both the Baltic Amber (probably deposited no later than upper Eocene) and present day biotas. One of the Baltic Amber species is almost identical in diagnostic characters of the male genitalia with a species existing today (Fig. 1), and only slight differences can be detected between these populations some $\mathbf{5 0}$ million years apart in time. In this slow rate of evolutionary change found in some of their phyletic lines, the insects resemble the freshwater Pelecypoda and certain other 
invertebrates and contrast sharply with the rapid evolutionary rates described as characteristic for many groups of Mammalia.

\section{PREIISTORIC FAUNAL ELEMENTS}

Fossil records show that many insect genera occurred previously in western North America but are now absent from the area. Examples from the cool-adapted biota include the fern-boring

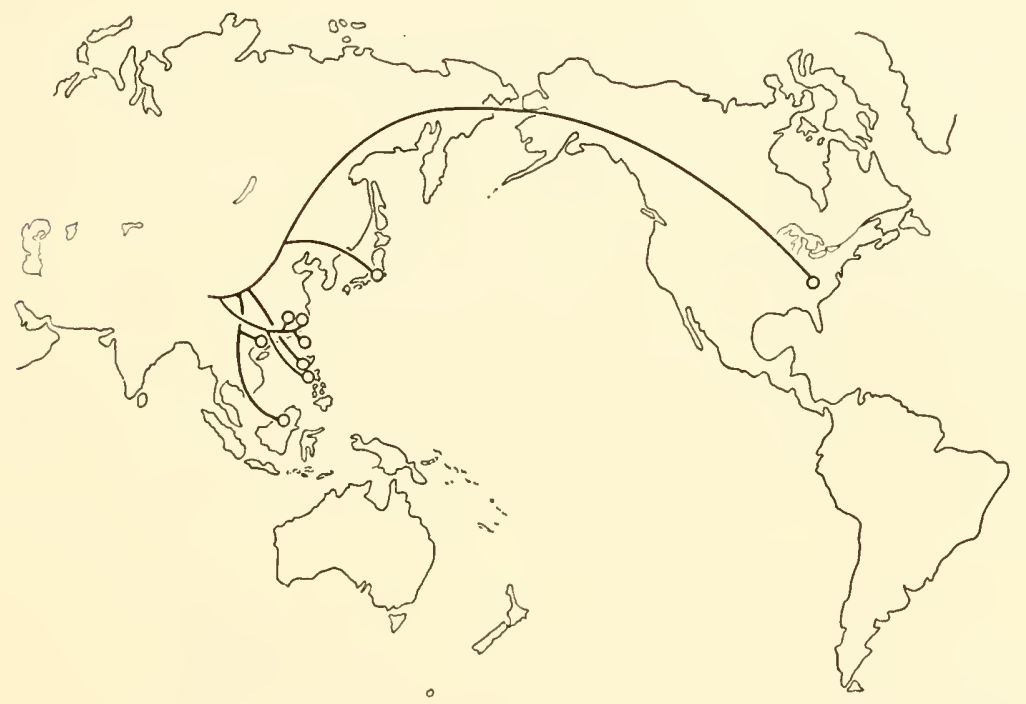

Fig. 2. The phylogenetic tree of the caddisfly genus Wormaldia subgenus Doloclanes superimposed on the known distribution of the species. This subgenus may be most closely related to more primitive Baltic Amber species.

sawfly Blasticotoma, known only from fossil remains in the Florissant shales of Colorado and from living representatives in Europe (Benson, 1942); and the snakefly genus Raphidia, known also from the Florissant shales but not now occurring in North America (Carpenter, 1953). Since representatives of the caddisfly genus Phylocentropus are now known only from Baltic Amber fossils and from living species restricted to eastern North America, intervening areas must have been populated by this genus at some past time. Because considerable evidence indicates that the intercontinental connection was between northwestern North America and north- 


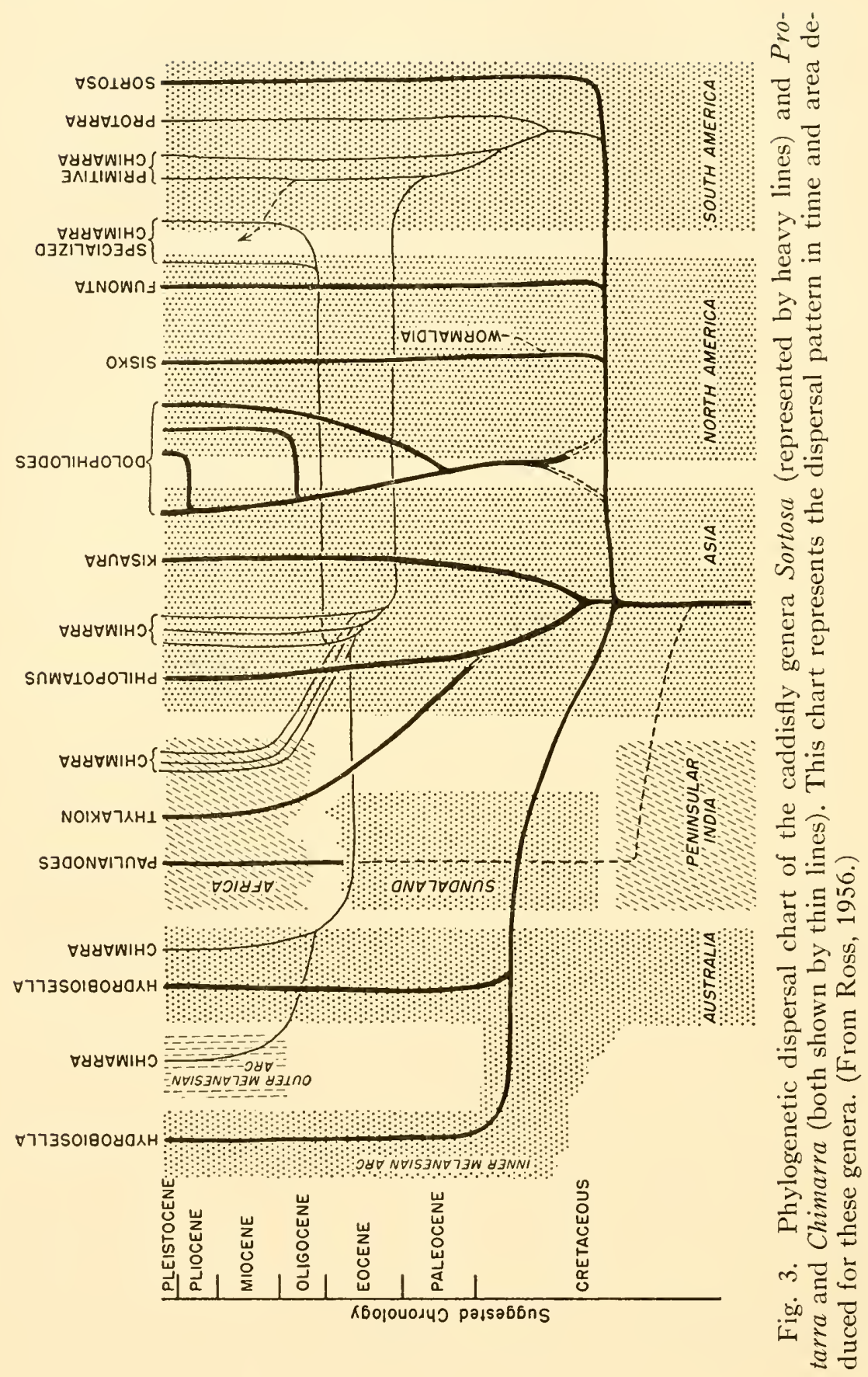


eastern Asia, it is plausible to assume that this genus and others of similar range characteristics were former denizens of the American Northwest.

A few cases drawn entirely from the distribution of living forms give practically conclusive proof of the same phenomenon. An example is the subgenus Doloclanes of the caddisfly genus Wormaldia (Ross, 1956). The main group of species involved in this subgenus evolved in and is now restricted to the eastern part of Asia (Fig. 2 ), but one species (most closely allied to one in Japan) occurs in the Great Smoky Mountains of eastern North America. The only logical explanation for this set of circumstances is that a northeastern Asiatic species spread across North America and ultimately became established in the Smoky Mountains. During this dispersal, we must assume that a species of Doloclanes lived in northwestern North America, although we have no definite records for this subgenus there.

Some insect fossils from western localities represent highly specialized genera not known from living species and undoubtedly have become extinct. The existence of such extinct "side branches" of phylogenetic trees cannot be deduced from the study of living forms, hence how many of them existed in the past we do not know.

\section{PRESENT INHABITANTS OF THE WEST}

The oldest dispersals of northern insects involved in the origin of the present western North American fauna for which we have evidence seem to have been in middle Cretaceous. It may be inferred that the caddisfly genus Sortosa dispersed at that time to almost every continental land mass and that after this great spread, many populations of Sortosa became isolated in and persisted in various parts of the world. In western North America five species, comprising the subgenera Sisko and Fumonta, represent this old movement (Fig. 3). It is highly likely that several archaic western genera of limnephilid caddisflies, including Dicosmoecus, Ecclisomyia, Farula, and Pedomoecus, also are surviving lines dating back to this same mid-Cretaceous dispersal (Schmid, 1955). All five of these caddisfly genera frequent streams in the extreme north or at higher elevations in mountains.

Judged from their known present distributions, most of these northwestern genera or subgenera have either remained isolated in moun- 


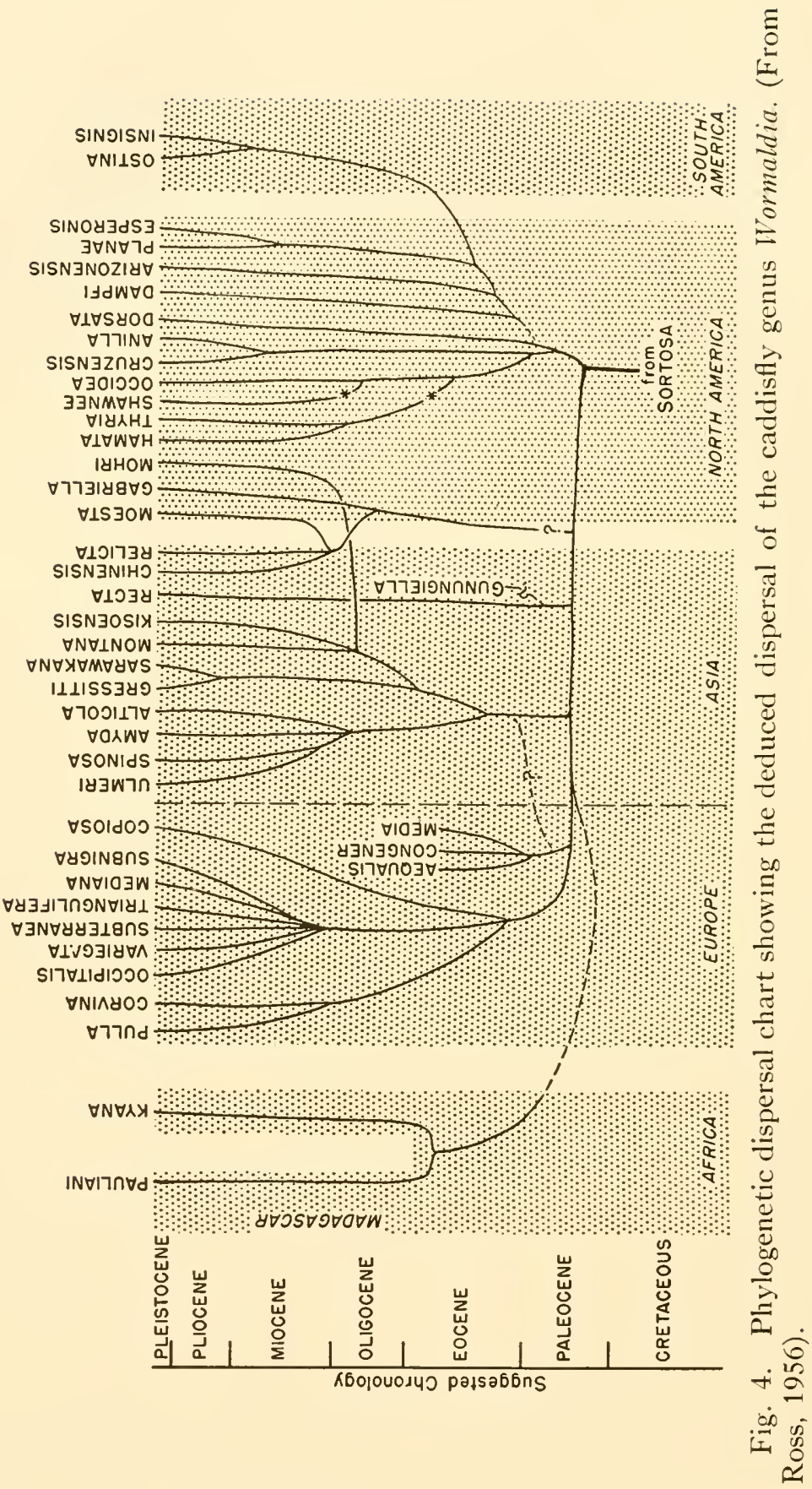


tain regions of western North America since the time of this supposed mid-Cretaceous dispersal, or if they did spread to other areas have become established in no other region. This situation suggests that for survival these insects must have streams which are not only cold but rapid, and that in the past greater continuity of mountainous terrain was a major factor in permitting their dispersal.

Evidence is highly suggestive that during the height of the Laramide orogeny, that is, the very end of Cretaceous and the earliest part of Cenozoic, many members of the cool-adapted biota spread between western North America and Asia. The mountaininhabiting caddisflies offer evidence for this dispersal also. The genus Wormaldia, which could very well have evolved from a Cretaceous subgenus of Sortosa isolated in western North America, probably spread in Paleocene into Asia and across to Europe. Whichever way the dispersal occurred, it antedated the Baltic Amber (in which Wormaldia occurs) and is documented by clusters of Wormaldia species in many continental areas (Fig. 4). One cluster of nine species occurs in western North America. It may be postulated that members of two other caddisfly families dispersed in similar fashion at this same time. The genus Rhyacophila, belonging to the family Rhyacophilidae, is one of the largest and commonest mountain caddisfly genera of the West. Of its 44 species groups, 19 occur in the IVest but 7 are known also from other areas. It is almost certain that the ancestors of the other 12 groups either reached the West no later than Paleocene or evolved in the mountains of western North America from older parental forms. The same may be true also of certain of those seven groups that now occur in two or more major areas.

In the family Glossosomatidae (the caddisflies whose larvae construct saddle-like cases) both the archaic genus Anagapetus and the subgenus Ripaeglossa of Glossosoma appear to have had similar early histories. It is impossible to be sure whether the ancestral forms of these groups arose in Asia or North America, but wherever they did originate, they dispersed between the two continents at some early date. In western North America a remnant of each line appears to have evolved in, and to have been restricted ever since to, the higher elevations of this area (Fig. 5).

The next dispersals of cool-adapted insects for which we have 


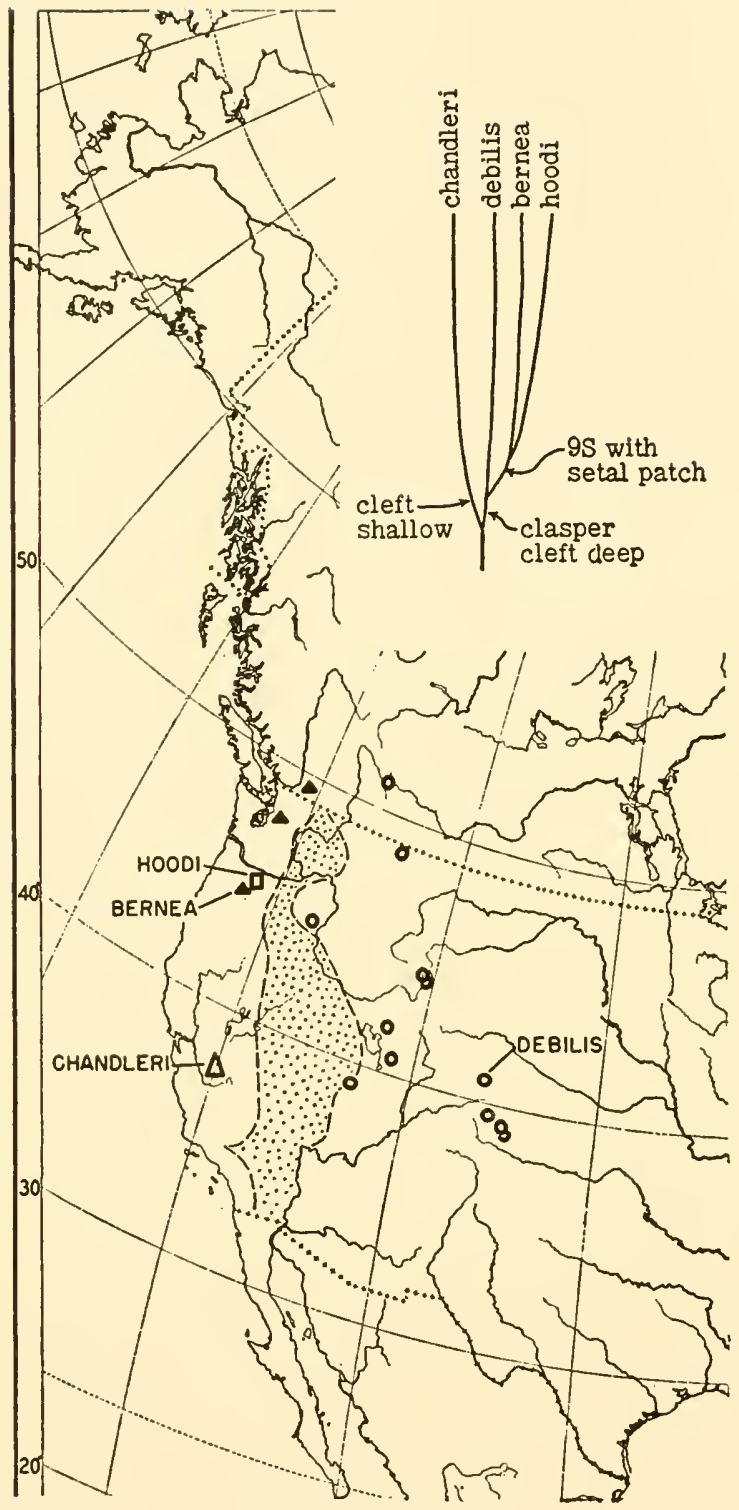

Fig. 5. Family tree and distribution of Anagapetus, an archaic genus of small caddisflies restricted to western North America. (From Ross, 1956.) 
plausible evidence occurred in mid-Cenozoic and involved chiefly species which may be considered ecologically as forming the warmer fringe of the cool-temperate biota. The best evidence involves treefeeding leafhoppers of the genus Erythroneura and caddisflies of the genera Pycnopsyche, Agapetus, and the more warm-arlapted species of Rhyacophila, which presumably became widespread across North America and Eurasia along with the temperate deciduous forests of that era. Most of these insect examples had a greater eventual effect on the fauna of eastern North America than on that of the West, and established nuclei for groups that became important elements of the eastern temperate decichous forest.

Certain of these mid-Cenozoic dispersals did apparently result in colonizations that evolved in to species flocks in the West comparable with those that evolved in the East. The best examples with which I am acquainted are the sawfly genus Neodiprion and the caddisfly genus Agapetus. We do not know where the ancestral form of Neodiprion (Fig. 6) arose, but it seems obvious that an eastern and a western population became established, that each evolved into a distinctive species flock, that each now constitutes an important element in the conifer-inhabiting insect fauna, and that the eastern and western branches of the genus have remained separate geographically until almost the present time (Ross, 1955).

A comparable situation may be postulated for the American species of the caddisfly genus $A$ gapetus. The larvae of these species construct saddle-like cases and inhabit clear, cool, spring-fed streams in hilly and mountainous country throughout the Allegheny system in the East and much of the western montane region south of Canada. Available evidence, based on characters of venation and abdomen, indicates that the North American species arose from an Asiatic ancestor which spread into North America at the time of the Holarctic temperate deciduous forest. The present day North American species of Agapetus appear to constitute two primary phyletic branches, one in the East and one in the West. Each branch has evolved into a moderate cluster of species, many of which exhibit striking changes compared with more primitive forms. This combination of phylogeny and distribution suggests that when the American transcontinental temperate deciduous forest broke up in mid-Cenozoic into widely separated segments, one segregate of Agapetus persisted in the East and one in the West. There is no 


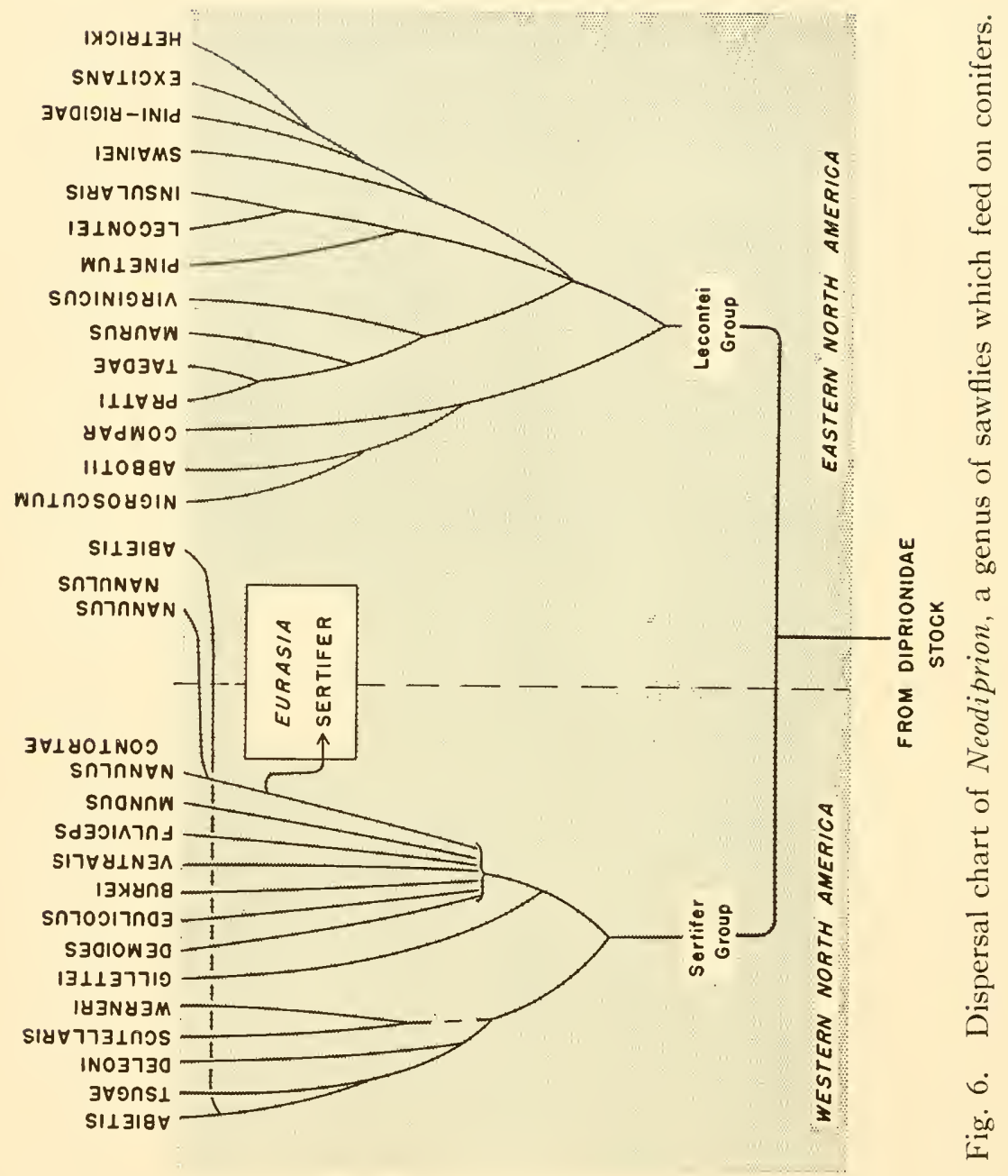


evidence that the two resulting phylogenetic lines ever again mingled geographically.

In addition to these mid-Cenozoic events which can be linked ecologically with temperate forest dispersals, we have evidence of other intercontinental dispersals of cool-adlapted insects that are difficult to date. An example (Ross, 1956) is the deduced dispersal of the caddisflies belonging to the Rhyacophila sibirica group (Fig.

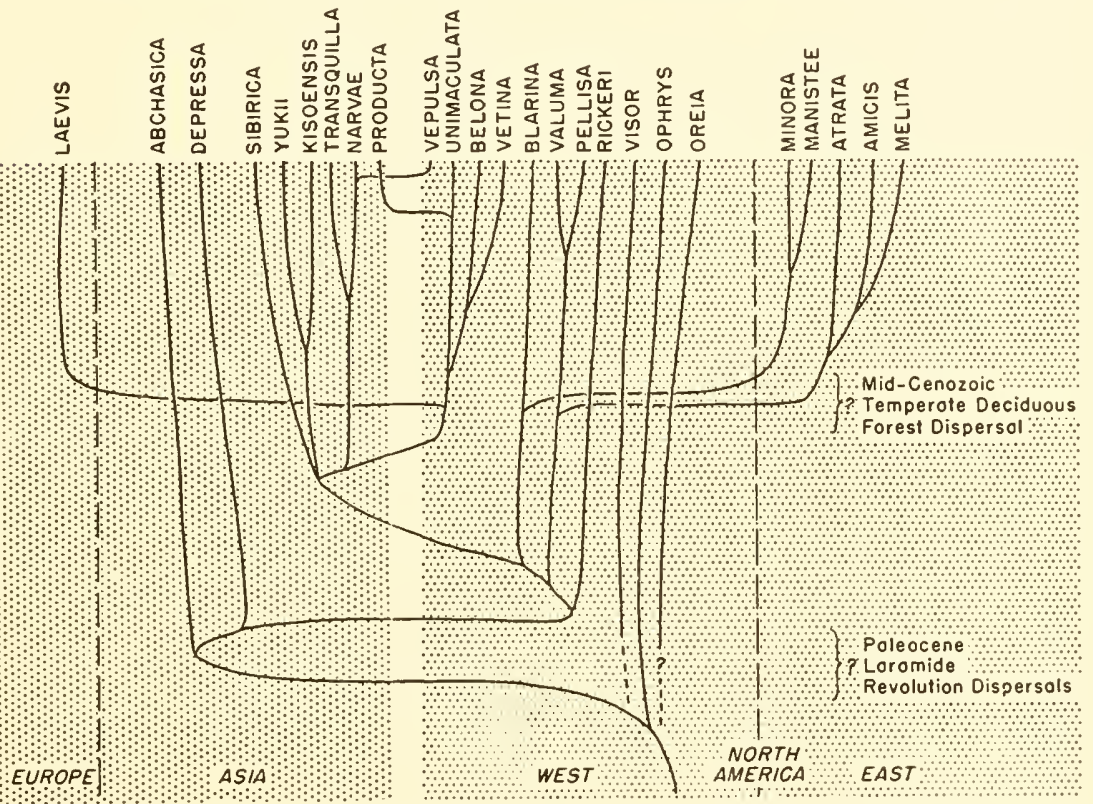

Fig. 7. Phylogenetic dispersal chart of the Rhyacophila sibirica group, comprising caddisflies restricted to rapid, cold streams. (From Ross, 1956.)

7). Its main evolutionary lines seem to have oscillated between northwestern America and northeastern Asia, with many surviving species in both areas. The distribution of these chiefly northern montane species indicates the possibility of some interchanges in the northern elements of our western cool-adapted biota at moderately frequent intervals cluring the Cenozoic. For other groups of montane caddisflies of indicated Asiatic origin, a single line seems to have spread to and to have become established in western North America. Examples are Himalopsyche phryganea (Fig. 8), Glossosoma penitum, and the entire Rhyacophila acropedes complex. Beacuse each line 
offers eviclence of only one intercontinental clispersal, it is impossible to approximate the late of arrival of these lines in North America.

We should not forget that during this Cenozoic period many lines were almost certainly already present and evolving in the cooler habitats of western North America. In the montane caddlisflies some of these lines apparently remained in the area (e.g., the

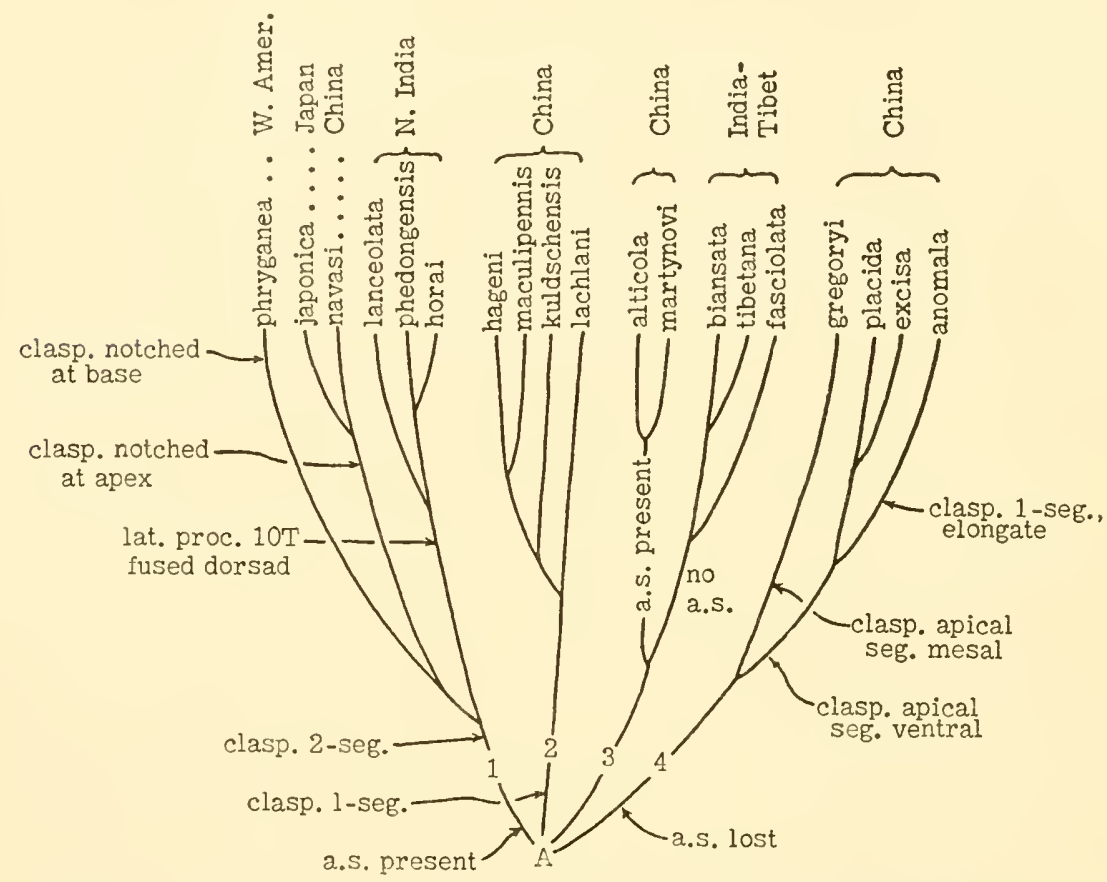

Fig. 8. Phylogenetic diagram of the caddisfly genus Himalopsyche. Note that all the species occur in Asia except the one shown at the extreme left, phryganea, which represents the only known dispersal of the genus into North America. (From Ross, 1956.)

Rhyacophila verrula and vagrita groups), whereas others (Fig. 9) seemingly gave rise to species that spread into eastern North America, e.g., the Rhyacophila invaria and carolina groups, or into Eurasia, e.g., the Rhyacophila glareosa and pepingensis branches.

The climatic and geologic changes in late Pliocene and the Pleistocene are associated with what appears to have been a wholesale redispersal of many cool-adapted insects throughout the Holarctic region. This phenomenon is especially well illustrated in the 
sawflies. The predominantly northern genera Dolerus, Nematus, Amauronematus, Rhadinoceraea, and many others have entire complexes within which all western North American species either are Holarctic or have a sister species in Eurasia. It is obvious in these cases that probably during the immediate past either an existing species or its immediate ancestor became widespread

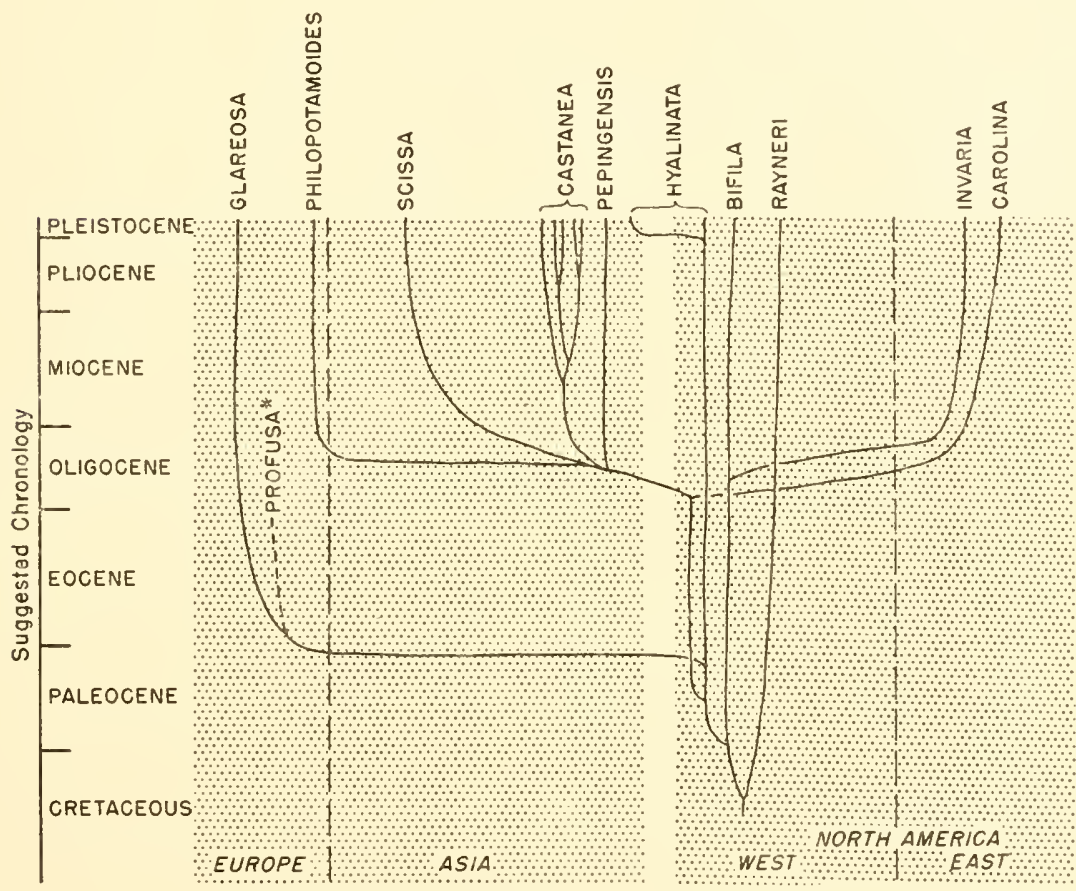

Fig. 9. Phylogenetic dispersal chart of several species groups from one of the distinctive branches of Rhyacophila, comprising caddisflies which inhabit cold, rapid rivers and streams. (From Ross, 1956.)

across the Holarctic region. The same situation is shown graphically by evidence from the herb-feeding leafhopper genus Macrosteles (Moore and Ross, 1957). The present distribution of known species of this genus can plausibly be explained only by the intercontinental dispersal of at least sixteen phyletic lines (indicated by black dots on Fig. 10). These sixteen movements were of course not all contemporaneous, but judged by the uniform morphological similarity of many pairs of sister species, at least the upper thirteen dispersals 


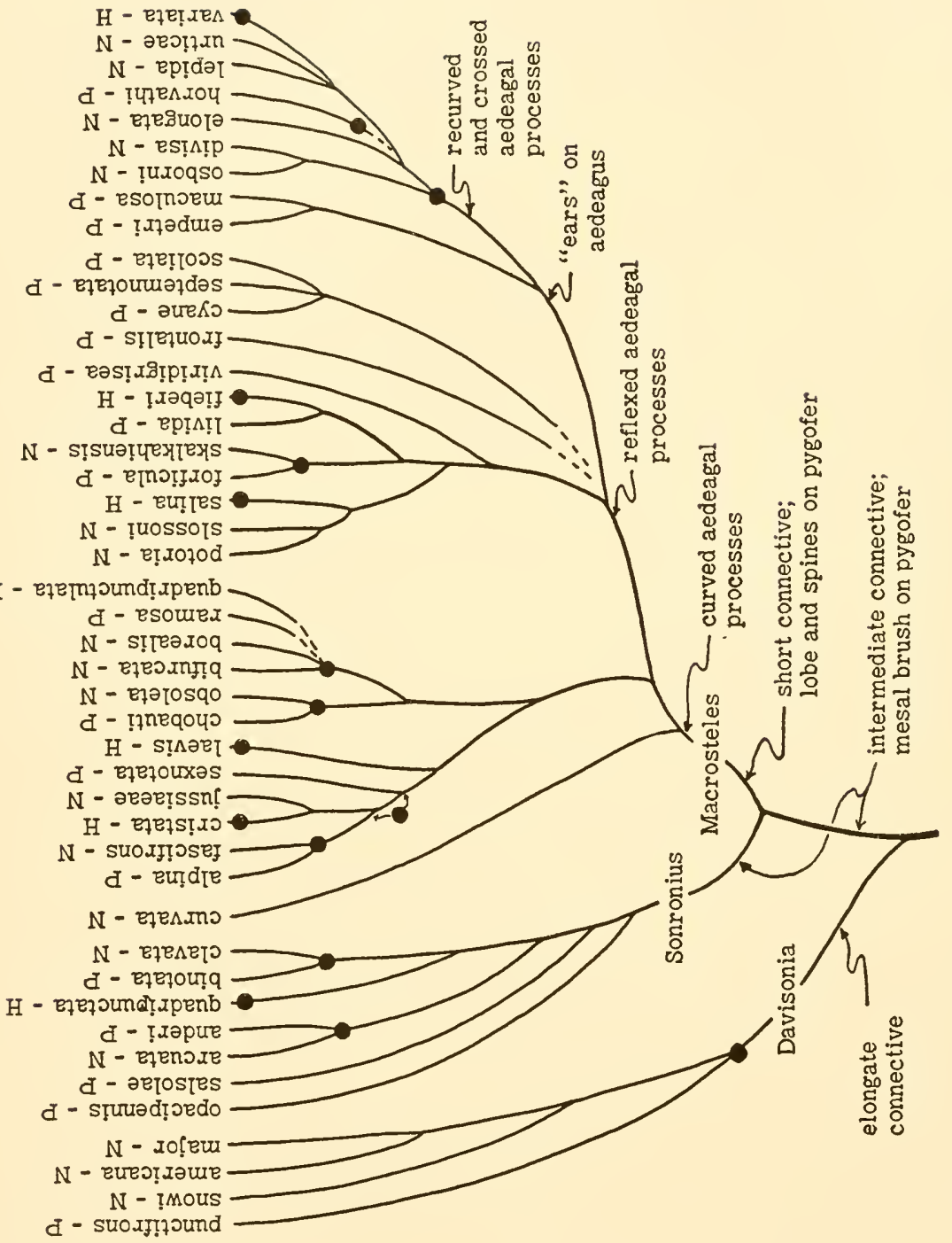


indicated in Fig. 10 were relatively recent and without much doubt within the late Pliocene-Pleistocene period. Similar circumstances prevail in many genera of northern grass-feeding leafhoppers and also, I am sure, in a large number of other insects abundant in the North and Northwest. In Culicoides, an extremely widespread genus of biting flies, Khalaf (1954) found evidence of even wider and relatively recent dispersals, some indicating a total spread including central and northwestern North America, Asia, Europe, and Africa. Two Alaskan species, Culicoides obsoletus (Meigen) and C. tristriatulus Hoff, belong to such widely ranging complexes.

In addition to these intercontinental movements, dispersals from the eastern to the western areas of the continent are illustrated by insects. Although there is abundant evidence that members from many western species flocks spread to and colonized the East at various times in the Cenozoic, present information indicates that dispersals to the West from eastern species flocks were much rarer and occurred chiefly in the Pleistocene. Of the seven older eastern species flocks in the caddisfly genus Rhyacophila, none has apparently spread to the West. Some other caddisflies do indicate such a dispersal. In the genus Triaenodes nineteen species form a fairly old, distinctive, polyphyletic complex which appears to have evolved in the eastern deciduous forest area as a series of species flocks (Fig. 11). Seventeen of these nineteen species are still restricted to the East and Northeast (Fig. 12), but two, baris and tarda, extend westward into the Rocky Mountain region.

Because no morphological differences have been detected between eastern and western populations of the two species just mentioned, the most logical interpretation is that they evolved originally in the East and spread to the West along ecological corridors brought into existence by Pleistocene events. An alternative logical possibility is that the progenitors of tarda and baris spread from the East to the West, that the western populations of each became isolated and evolved into distinctive species, and that these two species in turn spread eastward during Pleistocene. The restricted western distribution and extensive eastern range of $T$. tarda, however, strongly suggests that it was of eastern origin.

Several species of the related genus Athripsodes, notably cancellatus and tarsipunctatus, exhibit parallel phenomena and may also represent recent dispersals from the East to the West. It is quite 


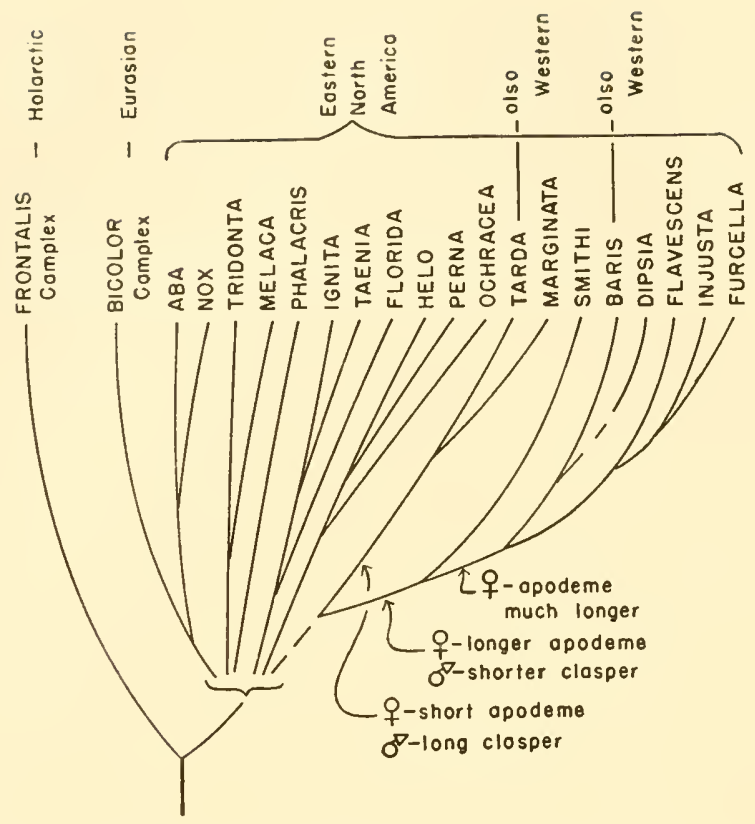

Fig. 11. Phylogenetic diagram of the North America components of the case-making caddisflies belonging to the genus Triaenodes.

possible that comparable information on other insect groups will add greatly to these examples.

The sum of the Holarctic and trans-American dispersal patterns points to a truly extensive faunal interchange associated with the colder climates of the Pleistocene.

The American species of the caddisfly genus Helicopsyche illustrate another type of range extension into the cool-temperate world. The larvae of Helicopsyche live in small clear streams and make strong cases shaped like snail shells. All fourteen described species occur in the tropical and/or subtropical regions and three of them extend northward into the temperate region (Fig. 13). For two species, these extensions are slight or small: H. mexicana has outpost populations in central Arizona, northern New Mexico, and Arkansas, and $H$. vergelana has an outpost in western Louisiana. The species borealis, however, extends northward into the cooltemperate zone, reaching Washington in the West and Quebec in the East. Thus $I I$. borealis has in some manner acquired an ecological tolerance much wider than that of other members of the genus, and 


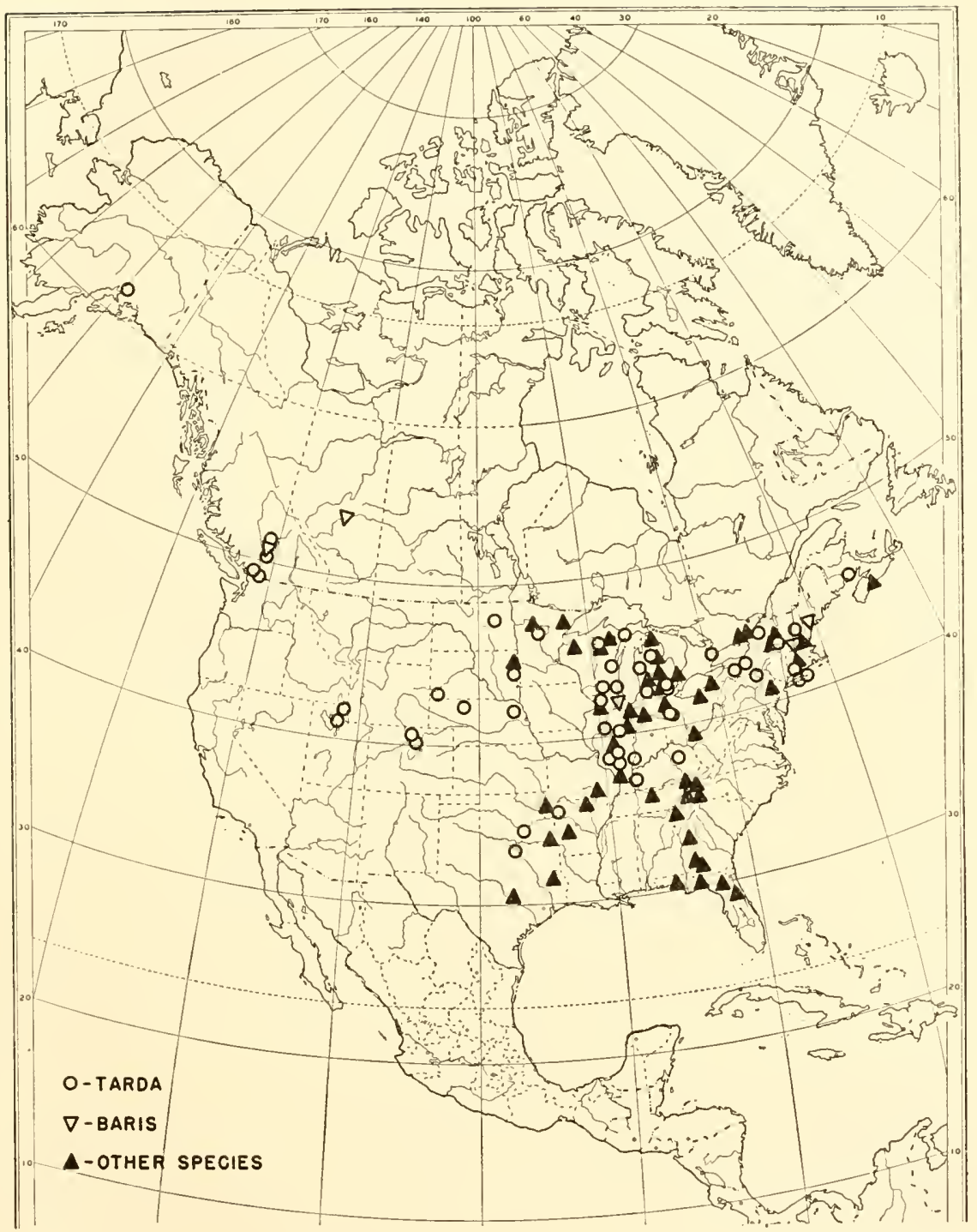

Fig. 12. Known distribution of certain North American species of the caddisfly genus Triaenodes. The category "other species" includes all those except tarda and baris listed between tridonta and furcella in Fig. 11. 


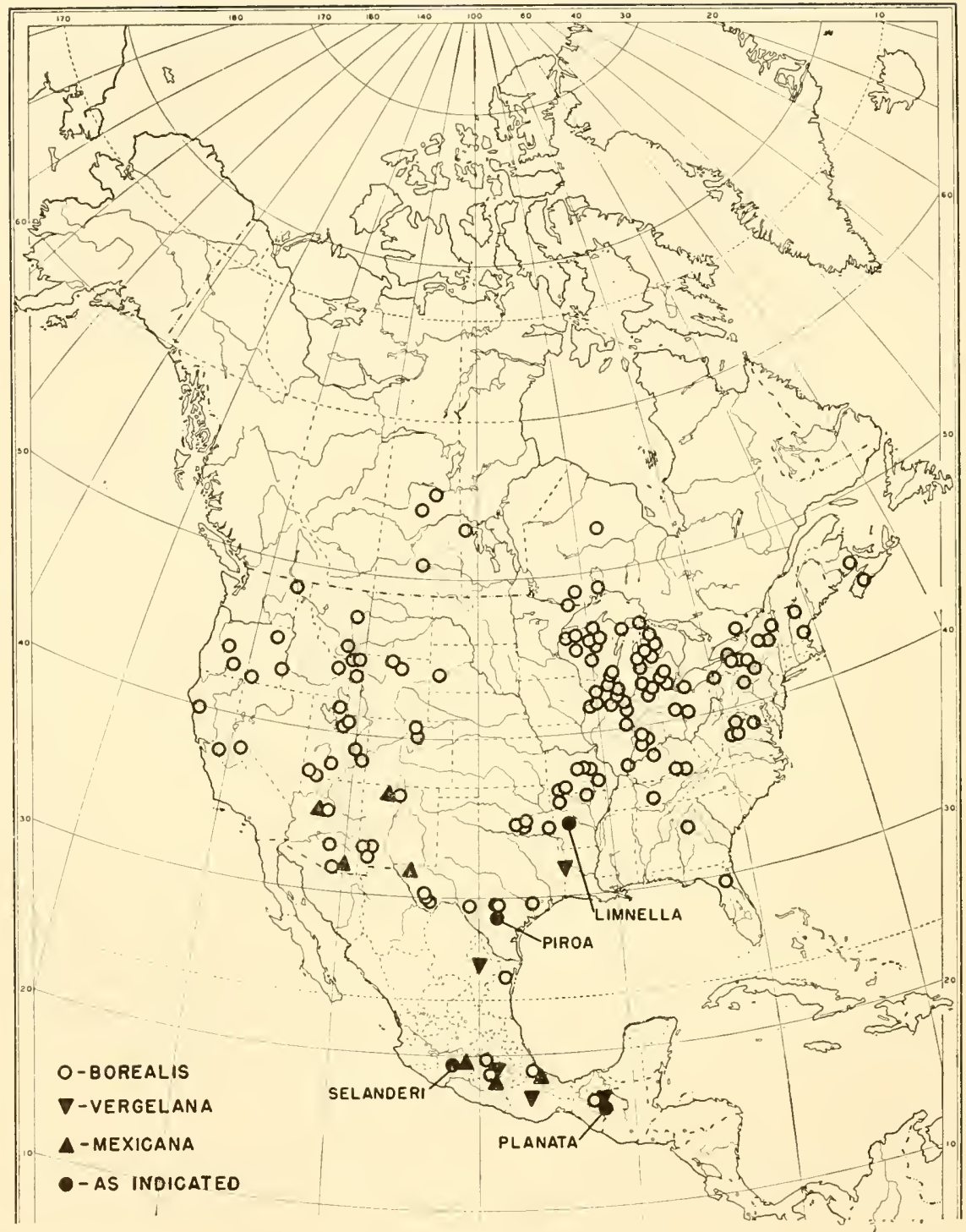

Fig. 13. Distribution of Helicopsyche borealis and the six other species belonging to the same phylogenetic branch. The species limnella, known only from Arkansas, is so close to mexicana morphologically that it is here considered as merely an outpost colony of mexicana. 
thereby has effected an intrusion of a predominantly subtropical group in to the cool temperate belt. There is in these data no suggestion as to when this extension of range developed, but the lack of formation of distinctive northern species in the group suggests that it occurred relatively recently.

Adding together the known data concerning cool-adapted insects, one gets the definite impression that at three points in geologic

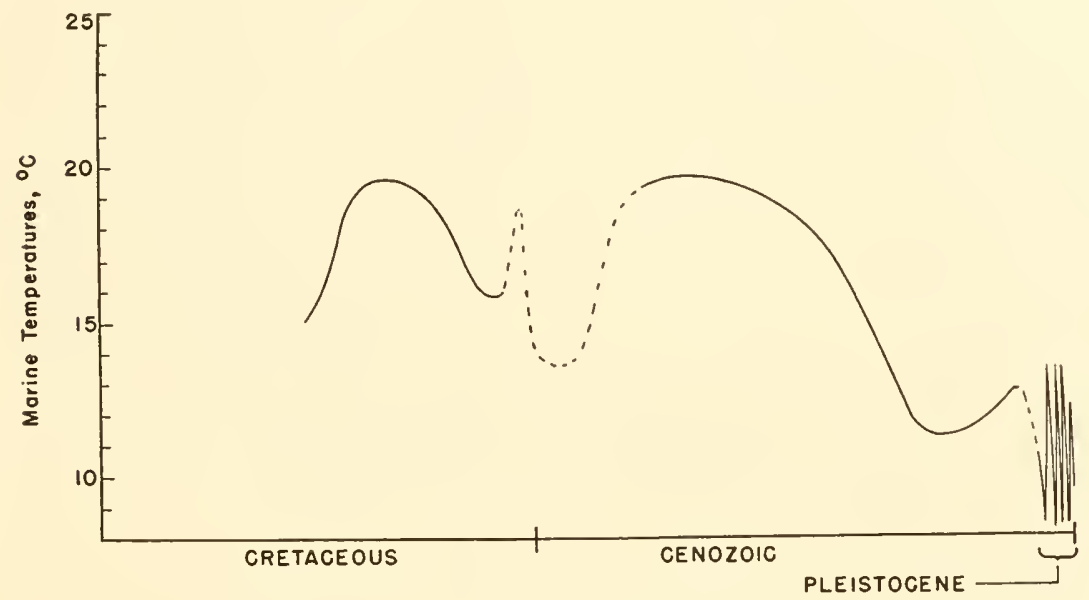

Fig. 14. Suggested temperature trends during the latter part of Cretaceous and Cenozoic time, combining data for the Cretaceous from Lowenstam and Epstein (1954), the Cenozoic from Durham (1950), and the Pleistocene from Emiliani (1955). These authors stress that the values represent trends and should not be construed as indicating absolute climatic measurements.

time-middle Cretaceous, Paleocene, and Pleistocene-conditions were such that extensive dispersal of cool-temperate forms took place. Various estimates of temperature trends during Mesozoic and Cenozoic agree closely (Fig. 14), but they indicate that periods of widespread cool conditions were of relatively short duration. During the long intervening periods when warmer climates prevailed over the lowlands, we must presume that the cool-temperate biota existed in higher elevations in the montane regions. Two sets of data from the western region of North America fit well into such a hypothesis.

1. The relatively flat portions of the present day northern tundra 
and coniferous forests are sufficiently extensive to have an air of permanence. If, however, they were stable features of the landscape, geologically speaking, one would expect some distinctive taxonomic units to have evolved, and remained, therein. Among the insect groups of my acquaintance, the species of the flat north country are either the same as those in the western or eastern mountains, or were obviously derived relatively recently from montane species. It appeared at one stage in our studies that case-making caddisflies belonging to the Limnephilus subhunatus complex might be a species flock which had evolved in the flat northland. Most of the earlier records for many species in this group were from northern Saskatchewan, the Mackenzie River Delta, and Great Slave Lake. More recent collections from Yukon and Alaska emphasize the possibility that the Limnephilus sublunatus complex may be associated historically with the northern ranges of the Rocky Mountains rather than with the flatter country.

2. The two main areas of caddisfly distribution in the mountains south of Canada, the Cascade-Sierra Nevada area to the west and the main Rocky Mountain area to the east, are separated by an irregular strip of arid, less mountainous country, including the Great Basin. This pattern is illustrated by the distribution of those caddisflies of the genus Glossosoma that comprise the subgenus Ripaeglossa, which abounds in large, fast, clear streams in both areas. The sixteen species of Ripaeglossa form two major phyletic branches. The branch comprising the alascense and traviatum species groups apparently evolved primarily in the western ranges and the one comprising the parvulum species group evolved in the eastern ranges. At the present time the northern six of the sixteen species of Ripaeglossa extend around the northern end of the arid zone separating the two mountain areas, but no phyletic line appears to have divided into sister species in the area to which it spread (Fig. 15). From these data it is possible to reconstruct a plausible series of events. When the progenitor of all existing forms of Ripaeglossa lived, clear mountain rivers of the West formed a sufficiently well-connected system to allow this caddisfly to spread throughout the West. Increased aridity of the Interior Basin area broke this river network and split the ancestral Ripaeglossa species into wellseparated eastern and western populations. This same condition presumably prevailed during the entire subsequent evolution of 
these two populations. Only in comparatively recent times have shifts in climates or topography produced conditions under which northeastern species of Ripaeglossa spread westward and northwestern species eastward. This and other similar examples of caddisfly distribution indicate that in these mountain areas Pleisto-

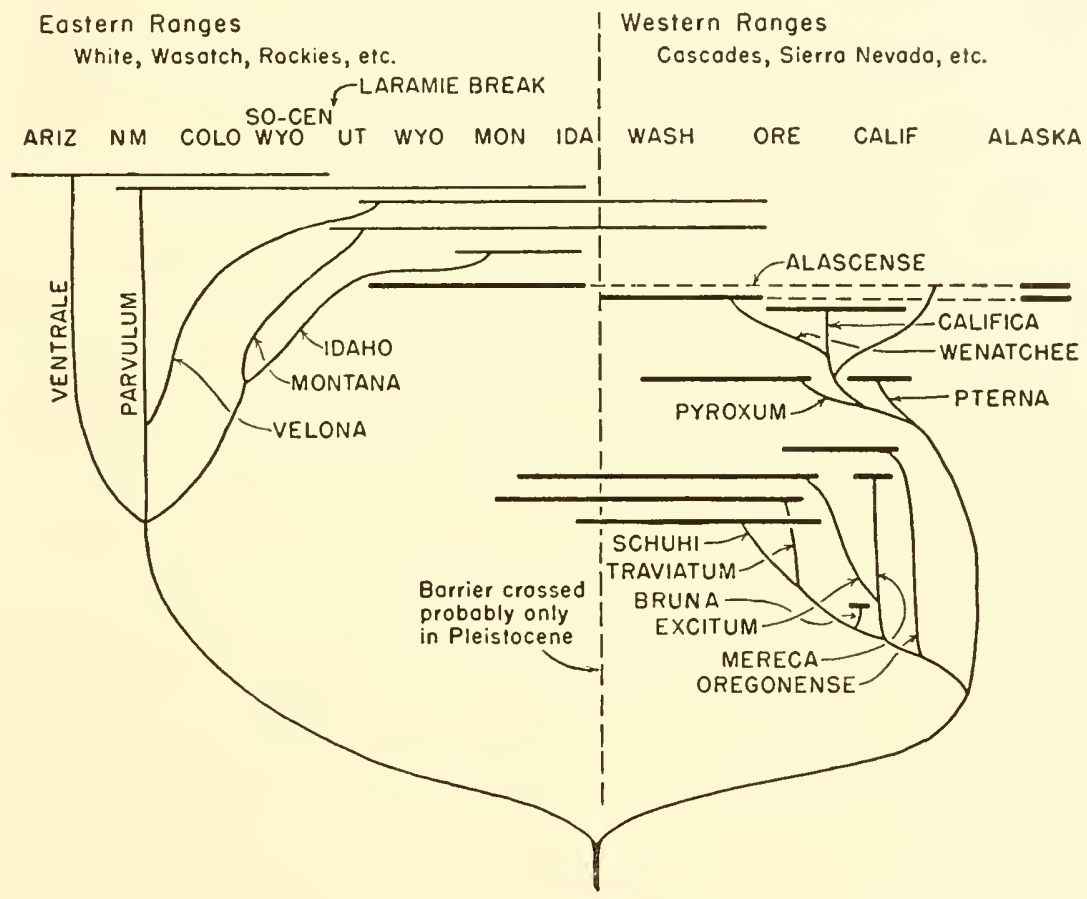

Fig. 15. Phylogenetic dispersal chart of Glossosoma subgenus Ripaeglossa, a group of caddisflies inhabiting cold, rapid rivers and confined to the mountainous area of western North America. (From Ross, 1956.)

cene events effected a mixing of phyletic lines previously separated from each other for long periods.

In exploring the origin of the cool-adapted western insect fauna we have surveyed data from only a small fraction of the insects that occur in the cooler parts of the West. It is noticeable, however, how most of the data fits readily into the concept of an almost cyclic alternation of brief dispersals and long separations. The many small but different types of evidence pointing in the same direction give us reason to visualize an extensive dispersal and intermingling 
of cool-adapted phyletic lines during mid-Cretaceous, a similar series of events occurring again during Paleocene, and a third extensive set taking place in the Pleistocene. At each time the details of the dispersals were different. Finding out more about these cletails is proving a challenge to our investigations. Each dispersal, however, crossed or crisscrossed the West and had a tremendous effect on its cool-adapted fauna. In their total action these three cool-dispersal periods, with long intervening periods of chiefly local movement, were the most important events determining the composition of the present northwestern fauna.

\section{REFERENCES}

Benson, Robert B. 1942. Blasticotomidae in the Miocene of Florissant, Colorado (Hymenoptera: Symphyta). Psyche 49: 47-48.

Carpenter, F. M. 1953. The geological history and evolution of insects. Am. Scientist 41: 256-270.

Durham, J. Wyatt. 1950. Cenozoic marine climates of the Pacific Coast. Bull. Geol. Soc. Am. 61: 1243-1264.

Emiliani, Cesare. 1955. Pleistocene temperatures. J. Geol. 63: 538-578. Khalaf, Kamel. 1954. The speciation of the genus Culicoides (Diptera, Heleidae). Ann. Entomol. Soc. Am. 47: 34-51.

Lowenstam, H. A., and S. Epstein. 1954. Paleotemperatures of the PostAptian Cretaceous as determined by the oxygen isotope method. J. Geol. 62: 207-248.

Moore, T. E., and H. H. Ross. 1957. The Illinois species of Macrosteles, with an evolutionary outline of the genus (Hemiptera, Cicadellidae). Ann. Entomol. Soc. Am. 50: 109-118.

Mosely, Martin E. 1939. The British Caddis Flies (Trichoptera). George Routledge \& Sons, Ltd., London.

Ross, H. H. 1955. The taxonomy and evolution of the sawfly genus Neodiprion. Forest Sci. 1: 196-209.

- 1956. Evolution and Classification of the Mountain Caddisflies. University of Illinois Press, Urbana, Ill.

Schmid, F. 1955. Contribution a l'etude des Limnophilidae (Trichoptera). Mitt. schweiz. entomol. Ges. 28: 1-245.

Ulmer, Georg. 1912. Die Trichopteren des baltischen Bernsteins. Beiträge zur Naturkunde Preussens, Königsberg 10. 


\section{The Origin and Affinities of}

the Dermaptera and Orthoptera of

Western North America

James A. G. RehN

Academy of Natural Sciences of Philadelphia,

Pennsylvania

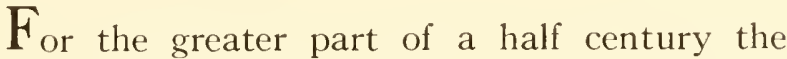
assembly of data and evidence bearing on the fields of this symposium, as relating to the Dermaptera and Orthoptera of North America as a whole, has been a major objective of a group of colleagues now or formerly associated with my institution. The evidence here summarized has been drawn largely-and particularly for the United States-from field investigations personally carried on over a period of fifty-five years.

Much of the past literature, and considerable past collecting, is not at all helpful. However, very definite and clear-cut conclusions are now emerging, as extensive collections, representing many seasons of fully documented field work, are being critically studied as part of a long-range project assisted by a National Science Foundation grant. The general results, systematic, zoogeographic, and binomic, are now being made known in a series of papers preliminary to a more condensed monograph. In view of these circumstances citations to the literature have been omitted in this paper.

In the present analysis of the subject I am assuming a full understanding of the terminologies that have long been in general use for life areas, particularly by the vertebrate school, which in North America produced some of the zoological pioneers in biogeography; also that the descriptive terms, based on physiographic areas, such as Cordilleran (for the Rockies alone), Sierran, and Campestran, are equally familiar and precise. 


\section{ORDER DERMAPTERA}

Fossil evidence indicates that the two oldest known members of the Dermaptera were present in the Jurassic of Kazakstan, from which they were reported in 1925 by Martynov. One of these, Protodiplatys, was separated by him as a distinct fossil suborder, the Archidermaptera, which has blattoid suggestions. The other, Semenoviola has since been regarded as a member of the restricted suborder Dermaptera. From the early Caenozoic we know true forficulids from the middle Eocene of Italy, the Lower Oligocene of Belgium, the Upper Miocene of Germany, and the Florissant Miocene of Colorado, as well as from the Baltic Amber. However, from the Permian of Kansas Tillyard described a representative of what he regarded as a new order, the Protoelytroptera, which he regarded as a link between the Paleozoic blattids and the Recent Dermaptera. It is therefore within the realm of possibility that North America may at one time have been as much a center of development of the Dermaptera as the Old World.

Of the ten genera Dermaptera in North America six (Labidura, Anisolabis, Euborellia, Labia, Chelisoches, and Forficula) are clearly introduced adventives, and several of these are almost entirely riparian types, possibly dating back to "ballast" days, while the genus Prolabia is represented in our fauna by two lines, one clearly an Old World adventive (now known from southern Texas), the other an intrusive Neotropical line of the genus found only in our southeastern states west to Texas.

The three remaining genera are clearly of Neotropical origin as far as their presence in our limits is concerned. Two occur outside our territory in Central and South America. One, Spongovostox, is a pantropical assemblage with probably half the species Ethiopian or Malagasian in distribution. The second of these genera, Vostox, is clearly of Neotropical origin. Its single North American species ranges broadly northward through the eastern United States to Pennsylvania, yet does not extend any considerable distance westward in Texas.

The third and last genus Doru is also of Neotropical origin, and is of very broad distribution in tropical America. In our territory it is widely spread in the eastern and southwestern United States. In Texas and in the extreme southwest only the widely distributed, basically Neotropical, D. lineare, occurs, whereas in the eastern 
United States there are two distinctive endemic members of the genus. It is possible that Doru reached North America in two separate invasions, the earlier of which established the line that developed the endemic southeastern species D. aculeatum and davisi, and the later of which brought in the widely spread $D$. lineare, which is now known from within our territory only from areas of Texas, southern New Mexico and Arizona, and California. A single species undoubtedly referable to Doru was described from New South Wales in 1891. With an intimate knowledge of the hiding places that Doru selects, I suggest that a restudy of the unique type will probably show it is inseparable from the widely spread Neotropical $D$. lineare, and also that it was introduced from Rio de Janeiro, when in 1789 various specimens of Opuntia, the nest-egg of the Australian "prickly pear" scourge, were brought in to supply food for the similarly introduced cochineal insect.

One of the really puzzling anomalies in the relationship and distribution of the Dermaptera found in America north of Panama is the occurrence in areas of south-central Mexico of one species (vara) of the genus Anechurella, the sole representative known from the New Morld of the otherwise widely distributed subfamily Anechurinae, members of which elsewhere occur from western Europe and the Madeira Islands to India, China, Japan, Formosa, and Borneo, but not from continental Africa.

No genera of the Dermaptera are peculiar to North America. The areal distribution of the genera of Dermaptera shows clearly that the largest number of generally recognized generic entities occurs exclusively in the Oriental Region, this closely followed in numbers by the similarly restricted Neotropical, with the Indo-Malayan and Ethiopian (with its Malagasy subregion) following. The exclusively Palearctic genera (12) are equaled in number by those which are pantropical, with the Australian, Melanesian, and Pacific, broadly paleotropical, and cosmopolitan following in regularly reducing representations.

No member of the North American dermapterous fauna, except those of cosmopolitan distribution, and these usually limited to such special environments as sea beaches or river banks, appears to have been derived from the Palearctic Rezion. All other elements have clearly come from the Neotropical Region. Several genera of this source have apparently been established sufficiently long in the east- 
ern and southeastern United States to develop distinct specific entities. All non-adventive forms found west of central Texas and Kansas clearly have entered our limits within geologically recent times.

\section{ORDER OR'THOP'TERA : SUBORDER CAELIFERA}

\section{Superfamily Acridoidea}

Family Tetrigidae. The Tetrigidae, or "grouse locusts," are cosmopolitan, except for the true arctic and antarctic regions and New Zealand; they are even represented on some of the Pacific island groups by distinctive genera. Although terrestrial in habits, they almost invariably show close association with moist areas, and many species are fully capable of sustaining themselves on the surface of water, or of swimming beneath the surface. Their known paleontological picture is represented by a fossil genus in the Baltic Amber, material referred to a Nearctic and Neotropical genus from the Upper Miocene of Bavaria, and an unplaced species of the family from African copal gum.

Very narrowly within our limits, in coastal south Texas, there enters the genus Neotettix, an endemic eastern and southeastern North American assemblage, possibly developed relatively early, either from a primitive Tetrix-like ancestor, or more probably from the Neotropical genus Liotettix, to which it has some affinity. A similar history is probably that of the Mexican and Central American Ochetotettix, which is related to Neotettix and also to Liotettix, but Ochetotettix does not enter our territory. Indications point to Neotettix being one of the number of orthopterous genera apparently derived from a relatively early, certainly pre-Pleistocene, invasion from the Neotropics; most of these genera are now isolated in the eastern or southeastern United States.

The genus Tetrix, which is represented in western North America by five distinct lines, is clearly of Palearctic origin, but it is warranted to believe that our North American lines of the genus represent a number of distinct incursions from the Palearctic, certainly one or two much earlier than the last. From the earlier one or ones three of our stocks have probably developed: T. arenosa, presumably the earliest, is now confined to the eastern, central, and southeastern United States and extreme southeastern Canada; T. ornata is much more broadly distributed; $T$. sierrana, clearly related to Old World 
species, was recently described from Madera County, California, in the Sierras at an elevation of 4,300-5,000 feet. The components of the Tetrix ornata line, which is confined to North America, are of particular interest, as they clearly show reactions to the varying aspects of Postglacial climate, as well as the probable results of Glacial control. Two subspecies, dominant in eastern and middle North America, namely Tetrix ornata ornata and T. o. hancocki, are clearly differentiated in certain areas, and are less sharply, probably environmentally, segregated in others. The more predominantly eastern of the two, T. o. ornata, is far less frequent in large series that represent many localities in the western United States and Canada, whereas the other, $T$. o. hancocki, which seems to be more partial to steppe country or coniferous forest lands and also is more frequent at higher elevations, is the prevailing form in the broad sweep of the Great Plains and the Cordilleran region. The Postglacial ebb and flow of prairie land and coniferous and deciduous forests appears to account for the mosaic pattern of distribution presented by these two elements of this species over a large part of its range. However, an isolated subspecies, T. o. insolens, is known only from the western slopes of the Sierras in California, and is broadly isolated from the other localities where the species occurs. Another subspecies, T. o. occidua, is limited to the Snake River and Columbia River region of Idaho and Washington, reaching northward to Lake Okanagan in southern British Columbia, in the general vicinity of which it intergrades with $T$. o. hancocki of the higher levels about the Okanagan area. It is probable that the Columbia-Snake River subspecies represents survival in an area of relative aridity of a species once more uniformly distributed, and which normally requires a greater degree of humidity.

The last incursion of the genus Tetrix may have been Interglacial or even Postglacial, as New World and Old World individuals of the one species involved, $T$. subulata, are inseparable. In the New World it is broadly distributed north to the northern border of the Subarctic, reaching southward in western America to the southern Sierras of California, to relatively high mountain areas in southern Arizona and New Mexico, and even to the Sierra Madre region of northern Chihuahua, Mexico. In eastern North America it does not range south of eastern Pennsylvania and southern New Jersey. Another line of the genus developed in North America a 
species, $T$. brunneri, which is found in Hudsonian and Boreal conditions extending from Alaska to New Brunswick and Quebec, north to the northern limits of the Subarctic and south in western North America in mountain areas as far as the Cascades of central Oregon and the Rockies of south-central Utah and central Colorado; in the eastern United States it is known to occur only in the upper Great Lakes region and the Adirondacks; a closely related, or possibly inseparable, analog is now known from extreme eastern Siberia. It would appear that the brunneri line of Tetrix may owe the base pattern of its distribution to the same activating causes as the members of the acridoid genus Zubovskya and the blattid Cryptocercus, discussed beyond.

Paratettix is the most widely distributed genus of the Tetrigidae, occurring in both hemispheres but not reaching as far northward as Tetrix. All representatives of the genus in North America are now regarded as developments of lines that have reached us from the Neotropical Region. Whether the four chief lines of the genus in western North America moved from a developmental point in southern Mexico and Central America northward into the truly Sonoran areas of more northern Mexico and the western United States, or whether they evolved in the latter, at present relatively more arid district, and then spread southward, can hardly be determined from present knowledge. The more pluvial conditions which prevailed over much of that country during the late Pleistocene and/or early Recent clearly were more favorable for tetrigids than the severe restrictions of suitable environment there today. One North American member of Paratettix, P. cucullatus, has a very broad distribution, reaching from southwestern Ontario and the northeastern United States to north-central peninsular Florida and westward broadly to the lower Rio Grande in Texas and the eastern border of the Great Plains to the northward. However, it apparently spread, Postglacially in a period of greater precipitation, from the Platte drainage across the non-mountainous Wyoming Basin in to the drainages of the Green and Colorado rivers and certain of their tributaries, and also to the Bear and Snake rivers, and eventually to the Columbia in northern Oregon and southern Washington. In these immediate areas $P$. cucullatus and the quite distinct $P$. aztecus are the sole members of the genus. The species aztecus has clearly reached the northwestern United States from its 
broad sweep in the southwestern United States and Mexico by an extension of its range covering much of the state of California.

The tetrigid subfamily Batrachideinae is one that has, fundamentally, a "Gondwanaland" type of distribution and perhaps of origin. The genera are limited to the Americas, particularly the Neotropical section, and to the Ethiopian, Oriental, Melanesian, and Australian regions. Their greatest development is in South and Central America, where eleven of its sixteen genera occur. One genus is Melanesian and Australian, one is Oriental, and two are Ethiopian, while a single one, Paxilla, is a Nearctic endemic, found only in the southeastern United States. The genus Tettigidea is clearly of Neotropical origin, as it has many species limited to South and Central America, but it became established in our continent, and particularly in eastern North America, relatively early in the invasion of our continent by Neotropical types. There are four wellmarked lines of the genus in the eastern United States, with clearly marked, related species in Mexico and Central America, the range of none of which, however, is contiguous to those of its relatives in the southeastern and central United States. One of these lines, $T$. lateralis, is much more broadly distributed than the others over the eastern and central portion of North America, occurring westward to parts of the Cordilleran region and to certain areas on the Mexican boundary.

Family Eumastacidae. This is, for the Orthoptera, an old assemblage, on the basis of present knowledge probably older than the true grasshoppers or Acrididae. The oldest fossil definitely referred to the Eumastacidae is Promastax of Handlirsch, from the Oligocene of British Columbia. From the Miocene of Florissant, Colorado, three species of the genus Taphacris have been described, and these have been considered eumastacoid by Cockerell, Tillyard, and Zeuner. A species described from the Oligocene of Baden, Germany, by Théobald, has also been referred to this family by Zeuner, who is probably the most capable student of fossil Saltatoria in recent years. Therefore, the Eumastacidae seem to have appeared in both hemispheres, relatively early in the Caenozoic, at a time of probably greater warmth than today.

The greatest development of the Eumastacidae at present is in the tropics of both hemispheres, with the maximum generic differentiation in the Indo-Malayan and Oriental Regions, followed by the 
Ethiopian and Malagasian and the Neotropical. One of the most aberrant subfamilies, limited to Australia and Tasmania, in a number of respects approaches the exceedingly distinctive and endemic Neotropical family Proscopiidae. No member of the Eumastacidae extends into the Palearctic Region except in elevated areas of Central Asia and in Japan, and the family is absent from the Pacific Islands east of New Guinea and from New Zealand, as well as from Chile and southern Argentina. Three genera are known from two of the greater Antilles (Cuba and Hispaniola), but the family has not been taken in any of the others.

The southwestern United States is the only part of North America in which members of the family now occur. They represent five genera of two very different subfamilies, both of which, as far as present knowledge indicates, are endemic within the area. One of these subfamilies, the Tanaocerinae, comprising the genera Tanaocerus and Mohavacris, is localized in certain semi-arid and arid mountains and adjacent desert areas of southern California and southern Nevada, except for one species of Tanaocerus that is also found in northern Baja California. This subfamily in many respects is one of the most distinctive assemblages in the superfamily Acridoidea, the antennae being the longest in any members of that extensive and varied aggregation known as the "short-horned" grasshoppers. The Tanaocerinae, which has been regarded by some as of family rank, and even considered by one student to represent two families, is clearly a Nearctic autochthon, which because of its combination of unusual characters certainly may be inferred to have developed a considerable time in the past. It is in a number of respects probably the most strikingly isolated section of the whole family, and it apparently developed from one of its ancestral lines. The other Nearctic subfamily, the Morseinae, comprising the three genera Morsea, Eumorsea, and Psychomastax, is a cohesive assemblage known only from Arizona, extreme southwestern Utah, southern Nevada, and areas of southern and coastal California north to Mt. Tamalpais. Morsea, the most widely distributed of the three, occurs in its preferred habitat over the greater part of the full range of the subfamily, although it is not known from southern Arizona. Psychomastax is peculiar to mountain areas of southern California and southern Nevada, reaching northward along the eastern slope of the Sierra Nevadas, occurring also in the White Mountain section of the 
Inyo Range, and in the Charleston Mountains of southern Nevada as high as 11,500 feet. Both genera are chiefly thamnicolous; Morsea occurs largely on chamise (Adenostoma) and manzanita (Arctostaphylos). The genus Eumorsea is known only from a few areas in the mountains of what Mearns sixty or so years ago called the "Central Elevated Tract," in extreme southern Arizona, where it has been found on the foliage of conifers. Most certainly Eumorsea also occurs to the southward in the Sierra Madre of Mexico, and the same is doubtless true of Morsea and Psychomastax in at least some of the mountains of Baja California, although neither has been so reported to date. The nearest relatives of the members of the subfamily Morseinae are probably those of the central and eastern Asian subfamily Gomphomastacinae, of which the five or so known genera, range altitudinally upwards to high areas in the Karakoram section of the Himalayan uplift (to at least 14,500 feet), and in northern Afghanistan (where exact elevations are largely unrecorded). Whether the Morseinae and the Gomphomastacinae have had a reasonably recent common ancestry remains to be determined but this possibility is now under investigation. However, the Morseinae clearly comprise a cohesive natural assemblage, occurring in a relatively limited Nearctic region, which also shows numerous similar parallels in the distribution of other elements of the Orthoptera.

A third subfamily of the Eumastacidae, the Teicophryinae, consisting of two Mexican genera, is known from the Cape Region of Baja California, but has not been taken north of that limited area, although the same genus (Teicophrys) occurs in certain areas of south-central and southern Mexico. The other genus, Cadomastax, is known only from a section of western Mexico. The Teicophryinae do not occur south of the Isthmus of Tehuantepec, where several other subfamilies of the Eumastacidae of more austral Neotropical relationship are present. Presumably the Teicophryinae have developed in Mexico.

Family Acrididae. (1) Subfamily Romaleinae. The Romaleinae is a well-marked subfamily of the Acrididae, or true grasshoppers, with more than two score genera from South and Central America and certain areas of the United States. Several Old World genera have quite recently been referred to this assemblage, but I question this association, which is now under careful study. Within this 
subfamily is found a wide range of structural modifications and developments, and adaptations to conditions ranging from those of the densest of lowland rain-forest undergrowth to the most arid desert environments. In my opinion the subfamily is clearly one of Neotropical development. Its members occur over the Americas from the Dakotas to central Argentina and Chile, with a single endemic genus on one island (Cuba) of the West Indies.

Within the territory we are covering five genera of the subfamily occur, one of which, Brachystola, sweeps north broadly from Mexico over the Great Plains to South Dakota, and also is locally abundant in central and southern Arizona; another, Taeniopoda, is narrowly intrusive from Mexico and Central America, where the genus is broadly developed, in border areas of the United States from western Texas to central-southern Arizona; a third, Phrynotettix, is an inhabitant of Sonoran deserts, brushland, hills, and mountains, from western Texas to south-central Arizona, and also extends southward in non-tropical Mexico; a fourth genus Tytthotyle, is reported from the hottest and most arid Lower Sonoran deserts of southwestern Arizona, southern Nevada, extreme southwestern Utah, and southern California, although it doubtless occurs in suitable sections of Sonora and perhaps Baja California; while the fifth genus, Dracotettix, is known only from the coastal ranges, the San Gabriel and San Bernardino Mountains, the lower and drier eastern slopes of the southern Sierras, the Panamint Range, and other desert mountains of southern California, as well as extreme northern Baja California, where the most generalized member of the genus has been found.

The broad center of origin of our Romaleinae has clearly been the Neotropical Region, but the genera in western North America have doubtless developed as generic entities in our territory and in Mexico (particularly in northern Mexico); only one of the genera, Taeniopoda, extends as far south as Panama and none is represented in South America. Romalea, the sixth genus of this subfamily, in North America, is limited to the southeastern United States, ranging only as far west as central Texas and not entering semi-arid country. It would appear that the North American genera of the subfamily indicate a number of incursions from the south, of which the first is now represented by Romalea. The ancestral line of Romalea probably entered the area at least as early as the Pliocene. Dracotettix, con- 
ceivably just as old in California and Baja California, has no present day relatives in Mexico proper (its nearest relative is the rare and little known Litoscirtus of Baja California, which for a number of reasons I feel represents the ancestral line of Dracotettix). The genus Brachystola probably entered North America in the grass-dominant Pliocene, as it is more frequently encountered in dry or desert grass conditions than the other genera. The ancestral stock of Phrynotettix, which is more truly an arid land genus, may have reached our territory about the same time, as it has developed within our limits two well-distinct specific lines. The genus Tytthotyle has no very close relatives, and may have evolved within our territory and northern Mexico from an old ancestral line, possibly dating back of any of the others. It has a very circumscribed distribution, prefers areas of creosote bush (Covillea tridentata), and altitudinally does not occur above 2,500 feet, yet is at home under the extremely rigorous conditions on the floor of Death Valley in August. The genus Taeniopoda, represented within our territory by the northern border of the distribution of a widely ranging Mexican species, appears to be a post-Pleistocene intrusive from Mexico.

(2) Subfamily Cyrtacanthacridinae. The great group of the "spine-breasted" grasshoppers and locusts, which includes many of the world's most important migratory and destructive locusts, is represented in western North America by at least four well marked tribes, the Leptysmini, the Cyrtacanthacridini, the Vilernini, and the Melanoplini. Of these, the Leptysmini and the Vilernini are entirely Neogaeic; the Cyrtacanthacridini, or "bird locusts," are almost entirely Paleogaeic, and chiefly Paleotropical, with but a single genus entering the Western Hemisphere; and the Melanoplini, while predominatingly Neogaeic, also share the Palearctic Region and, more narrowly, the Oriental.

Of the Leptysmini the single genus Leptysma occurs within the limits of our symposium scope, and is found very locally in suitable areas of tall grass and other vegetation growing generally in standing water (a preferred habitat for members of the tribe, all of which possess definite ability to dive into and swim for short distances in water, usually to rest longitudinally on the stems of grasses or rushes). In the Neotropical Region, particularly in its South American section, are numerous species of Leptysma and certain related genera. Within our territory Leptysma is clearly of Neo- 
tropical origin, and it has broadly established itself, with a related genus of similar Neotropical relationship, in suitable environments, across parts of the southern United States. However, Leptysma occurs across the entire southern border of the western United States, and into Mexico, while the other genus (Opshomala) is found within North America only in the southeastern United States. It would appear probable that the presence of Leptysma in localized areas in the southwestern United States is a reminder of a broader dispersal, probably in Pleistocene times of a greater degree of precipitation.

Of the Cyrtacanthacridini, to which tribe belongs the striking and often exceedingly destructive "bird locusts," but a single genus, Schistocerca, lives in the Western Hemisphere, and while it has developed there a considerable number of endemic species, a single member of the genus is limited to the Old World, and is there one of their most serious plague forms (the desert locust, Schistocerca gregaria). While this species is known to reach as far across the Atlantic Ocean from the West African coast as the island of Ascension, and has also been captured landing on a ship midway between Africa and South America, there is no certainty that the numerous New World species of Schistocerca, representing at least ten diverse lines of the genus, have entered the New World by flying the South Atlantic, as a number of our species are not addicted to extensive flights, and also some are definitely localized in their distribution and ecological preferences. The optimum differentiation of the Cyrtacanthacridini clearly took place in the Old World, and our stock was certainly derived from progenitors there. It is possible that Schistocerca, from a basic ancestral stock of the tribe, developed its various lines in the New World, and that the one to which gregaria belongs, which is well represented in the Americas, North, Central and South, later reentered the Old World, giving it its troublesome $S$. gregaria. If the latter were a local or restricted type we could conclude that the genus was Old World in origin and is there dying out, but with gregaria in an entirely different category, and the genus greatly diversified in the Americas, it is plausible to conclude that its ramifications had their base in the New World.

Of Schistocerca five lines occur within western North America, and they are restricted to the same general area except that certain 
of them reach into Mexico, with, however, the greater part of the known range of three north of the Mexican boundary. One, $S$. mexicana, is but narrowly intrusive in our territory from Mexico. Also in the eastern, central, and southeastern United States are four other lines of the genus, two there limited, one largely restricted to that area, and the fourth also found rather broadly and passing into Mexico, but almost limited westward by the eastern border of the Great Plains. Clearly certain of these distinctive lines of Schistocerca have been established in our territory for a considerable time. Their history is tied to our area because, where found in Mexico, most of them are Sonoran only. One of the lines in the eastern and central United States, but hardly encroaching on our territory, is broadly developed in Central and South America, there having spawned one of the most destructive locusts of the New World, the Paraná locust (Schistocerca paranensis) of Argentina and many other areas of South and Central America.

The Vilernini are a most distinctive Neotropical assemblage of a score or more genera, ranging from Argentina northward to briefly north of the Mexican boundary, and are found in a variety of habitats. Clematodes, the single genus in our region, is an apterous thamophilous grasshopper, known only from the border regions of western Texas, southern New Mexico, and Arizona, extending into Mexico in several areas. It clearly has entered our territory from the southward, and with us is probably more widely distributed in the Lower Sonoran Life Zone than the records indicate (the secretive habits of this grasshopper, which, among other situations, likes the main stems of the intrusion-resisting cat-claw (Acacia), are largely responsible for our limited knowledge of it).

European students have broadly assumed that the great assemblage of the Melanoplini is basically a Eurasian group, with an Angara background, and that its presence in the New World is attributable to a relatively recent extension from the Old. Recently this assumption has been challenged, on the basis of a relatively critical analysis of the whole picture for the tribe. Little help can be drawn from the fossil picture, as the total of such evidence to date indicates the presence of two existing species of two genera in the Pleistocene of Starunia in the Polish Carpathians. What we do know is that in the New World members of the Melanoplini occur at localities reaching from the Arctic Circle to at least south-central 
Argentina and Chile, thus well over one hundred degrees of latitude, and occupy stations ranging from extremely arid ones below sealevel to others as high as Arctic-Alpine in North America and the Paramo in South America. Three major centers of evolution of the Melanoplini in the Americas have clearly been indicated: (1) North America south to the Isthmus of 'Tehuantepec; (2) the Venezuelan Andes and adjacent, chiefly montane, areas in northern and eastern Columbia; and (3) South America from approximately $15^{\circ}$ south latitude southward. Few genera of the tribe occur over the intervening areas. In the Old World the tribe is much more circumscribed, for it is absent from the Ethiopian region, from most of the Oriental region and from all the Australasian region. In Eurasia twenty-seven genera occur, three of which are also in the Nearctic. In the Nearctic and Neotropical combined, we find 59 genera, including the three occurring also in Eurasia. In the New World forty genera are known north of the Isthmus of Tehuantepec, the majority only north of the Mexican boundary.

Within the northern United States we find one line of the Melanoplini, the genus Podisma, which clearly is of Old World relationship, for it has numerous species in Eurasia and only one in North America, $P$. hesperus, in the Cascades of Oregon, the nearest relative of which appears to be a species of northern Japan, P. sapporensis. It is probable that the ancestral stock of this species reached our continent in the Pleistocene, perhaps Interglacially, or even earlier. Another line in North America, comprising the genera Dendrotettix and Appalachia, also represents an older invasion of the same stock. (This line is not now present in western North America; its two generic members occur, so far known discontinuously, in the eastern and central parts of the United States.) These two genera clearly developed within our territory. A third line, including the single flightless genus Zuborskya, which occurs discontinuously in eastern forested areas of North America and in the Cascades of Oregon, is also represented in a limited section of eastern Asia by several distinct species. Whether Zubovskya is an Asiatic genus that has traveled to North America and spread broadly there, or is of North American origin and has narrowly entered the Old World, remains to be determined. Clearly, however, it has been present in North America since before the Glacial period, as there can be little question but that the present dis- 
continuous distribution of the genus in our continent reveals the part the ice-sheets had in separating the eastern form of this forest land genus from that now occurring in the Oregon Cascades. A largely parallel case of discontinuous distribution of this type, with apparently the same origin, is that of the flightless woodboring cockroach Cryptocercus.

It seems that all the other numerous lines of the Melanoplini in western North America have developed within our territory, and that a single species of the genus Melanophus has crossed into the Old World. The genus Melanoplus developed a considerable number of specific lines in North America, with a very marked center of speciation in the southern Appalachians and the adjacent lowlands, while other lines, clearly representing evolutionary phyla, have centered in the grasslands of the Great Plains, the Transition and Canadian areas of the Rockies, the Great Basin region and its various mountain areas, the Lower Sonoran Deserts of the southwestern United States and northern Mexico, the Sierra Nevadas, and the coastal ranges of California and Oregon. In each of these areas one or more definite lines of development of the genus will be found. Some lines reach as high in their distribution as Hudsonian or even Arctic-Alpine conditions, of ten with some species quite localized. To the southward the genus Melanoplus enters Mexico, where there is a considerable number of more broadly ranging and endemic species, but the genus does not extend south of that country. The Melanoplini of Mexico are rich in species and work now under way will shortly give us a clearer picture of the richness of that fauna, which with the western part of North America has been a major site in the evolution of the Melanoplini.

Of the other genera of the Melanoplini in western North America, the Campestran Great Plains apparently produced at least four, Campylacantha, Argiacris, Phoetaliotes, and Hypochlora. Phoetaliotes is more widely distributed in grassland areas (formerly of greater extent, perhaps in the Pliocene, a grassland optimum), and relict populations remain in sections of southern Arizona and certain other areas. The genus Dactylotum, now widely distributed in Sonoran situations in western North America, is doubtless of Mexican origin, as there the genus has developed a broader specific diversity than it has north of the Mexican line, although in the latter territory its range is much more extensive. The same is prob- 
ably true of the array of distinctive genera found broadly over areas of central and western Texas (Phaedrotettix, Phaulotettix, Paraidemona, Chloroplus, and Agroecotettix). The genus Aeoloplides is of broad distribution in the Great Plains, the Sonoran deserts of the southwestern United States, the Great Basin, and areas of California, and is probably a relatively old line, very adaptable to the distinctly thamnicolous habitat it prefers. The genus Aidemona is narrowly present in our territory as an intrusive from Mexico and Central America (it ranges southward to Colombia).

In the Sonoran desert mountains and on the benches of the southwestern United States we find a group of genera that probably originated there, or in adjacent northern Mexico, where they also do or may occur. These are Conalcaea, Barytettix, Poecilotettix, and Aztecacris. Another clearly Sonoran type is the genus Hesperotettix, which is of wide distribution over most of the lower level land areas of the western United States and Canada, where its favorite cover of yellow-flowered composites of several genera ("rabbit weed") occurs. Two lines of the genus undoubtedly entered the southeastern United States from more western territory a considerable period in the past and there developed a subsidiary evolutionary center of the genus, while another line of campestran relationship spread in ecologically suitable areas over much of the eastern states. In many areas of California and of the Great Basin, as well as the Columbia River and Snake River plains, the genus Oedaleonotus has developed a marked radiative speciation. It apparently is an autochthon which has no very close relatives.

In mountain areas of the western United States and southwestern Canada there have developed a number of apterous, and of course flightless, endemic genera, of which three, Bradynotes, Prumnacris and Buckellacris, are of Canadian and Hudsonian Zone distribution. The most highly specialized is probably Bradynotes, which occurs in isolated areas of the more northern Rockies in the United States and adjacent Canada, the Cascades, the pumice plains east of the Cascades in Oregon, and in the more northern Sierras. The genus also reaches southward to the Kaibab Plateau of northern Arizona, although in the main Rockies it is not known from south of South Pass, Wyoming. It is possible future work may show that Prumnacris and Buckellacris, as well as the strange Nisquallia of the Olympic Mountains of Washington, are more nearly related to 
Old World genera than has yet been determined. Prumnacris and Buckellacris are both distinctly northern montane types: Prumnacris occurs chiefly in the northern Cascades, and Buckellacris extends from the same range northward to the Chilcotin area of British Columbia, and eastward over the northern Rockies to southeastern Idaho. In the Rockies of the northern United States and southern Canada, and in adjacent parts of Washington and the northern Sierras of California, the distinctive genus Asemoplus is localized, and in the southern Sierras only at or near timberline do we find Mebardacris, which has nearest affinity to Bradynotes. All these montane genera are clearly of relative antiquity, and probably survived Glacial conditions by retreating moderate distances before the advancing sheets or the encircling spread of mountain glaciers. Some of them seem to have reoccupied only limited sections of suitable terrain which was heavily glaciated.

(3) Subfamily Oedipodinae. The Oedipodinae comprise a large number of chiefly ground-dwelling grasshoppers, some of which have become of economic importance. The subfamily is poorly represented in the Southern Hemisphere, and is best developed in Eurasia and North America. In South America its members are limited to a few genera, one of which, Trimerotropis, is markedly developed in North America, while another, IIeliastus, narrowly enters our territory. The maximum diversity of the subfamily is in semi-arid grasslands, although it is also well represented in true deserts and semideserts, and a number of types occur in more humid grasslands and bush country; a very few are more partial to wooded areas. Some of the species live in the most arid environments to be found in this continent and in similar areas in Asia and North Africa. Some are governed in their occurrence by the presence of favorite food plants, but on this point our information is less conclusive than for some other grasshoppers. Apparently most, if not all, of the North American genera have developed in our territory or in northern Mexico, although the possible relationship of a few of the genera to those of Central Asia remains to be more accurately determined. Broadly speaking, however, the oedipodine fauna of North America is autochthonous. A number of the genera probably originated in the Sonoran region of our southern Great Plains, the southwestern United States, and northern Mexico. Certain of these genera have extended their ranges into the more eastern United States and 
adjacent Canada, and some have developed well-marked subsidiary evolutionary centers there. Trimerotropis, an entity with a considerable number of North American species, is probably a relatively old type, which has extended locally into boreal conditions, has formed certain localized species in the eastern United States, and has further intruded itself southward, so that today the genus is also present in semi-arid and Andean areas of western South America. Its range there is now cut off from the southern limits of its mass distribution at the southern edge of the Mexican tableland. This discontinuous distribution probably exemplifies a far broader and drier Pliocene grassland distribution, and reflects the increased Pleistocene development of forest areas in the intervening territory, which doubtless eliminated Trimerotropis from Central America and parts of northwestern South America. A similar postulate would explain the present discontinuous distribution of the grassland mantid Brunnerin and the acridine grasshopper genus Dichromorpha.

The genus Chortophaga is probably of southeastern origin, there showing two types of the genus, one species of which, present over much of the eastern and central United States, is also found in the more temperate parts of Mexico and Central America as far south as Costa Rica. The endemic Californian genus Chimarocephala is rather an anomaly, although its ancestral stock may have had a common origin with Chortophaga. The genus Cammula probably developed from the same stock as Hippiscus or Encoptolophus, possibly in the Cordilleran region, but it now has an unusual type of distribution; it is essentially Boreal in the eastern and central United States and Canada, broadly present in the Cordilleran region, and much more localized westward (in southern California it even descends to virtual sea level in coastal Lower Sonoran conditions). The broadly spread but often localized genus Xanthippus, a close relative of Hippiscus, apparently developed in the Sonoran region of our Great Plains, the southwestern United States, and northern Mexico, with numerous localized and seasonally limited montane forms, but it has not spread eastward, while the related Cratypedes is much more definitely an inhabitant of the Cordilleran and Great Basin areas. The genera Sticthippus and Agymnastus are Californian endemics, clearly derived originally from the same basic stock as Hippiscus, Pardalophora, and Xanthippus. The genera Leprus and Derotmema are certainly of Sonoran origin, and both 
have spread northward over the Great Plains and entered the Great Basin, in which area Derotmema has developed a very distinctive type (D. piute). Hadrotettix, Tropidolophus, and Platylactista are also Sonoran. The first two extend to varying degrees northward over the Great Plains. Hadrotettix is also known from relict grassland areas in northern Arizona.

The more dominantly eastern genus Spharagemon probably had its origin in the eastern United States, where it now has three distinct lines. Two of these lines extend westward, but the extent of the genus in that direction is virtually limited by the Rockies. Spharagemon has four well-marked lines in the Great Plains and in Texas, of which two also occur in the eastern United States. The genus Dissosteira is widely spread over the United States, narrowly entering Canada. One of its species is almost ubiquitous in the eastern United States, but west of the Rockies it chiefly occurs in the Transition zone. A second species is basically a Great Plains form, a third is largely Californian and Great Basin, and a fourth occurs locally only in California. The genus is apparently of Sonoran origin, and the same may be true of the related Scirtetica, which has one locally distributed stock in coastal areas of the eastern and southeastern United States and in the Great Lakes sections of the United States and southeastern Canada, while another stock is isolated in the mountains of southern Arizona, with no representatives known from the intervening sections of the territory the present symposium is covering, or as yet from Mexico. The strange little genus Microtes is an autochthon of the Californian coastal mountains and adjacent valleys, with no very close relatives, and is probably an old type. Lactista and Tomonotus are clearly Mexican Sonoran entities rather narrowly intrusive in our border states.

The genera Trepidulus, Shotwellia, and Cibolacris are relatively arid land Sonoran types. The last is also coastal in southern California. All three probably range into northern Mexico, and doubtless all had their origin in that great area on both sides of the international boundary which, even in its diversity of surface features, has to a considerable degree had a similar faunistic history. The genera Mestobregma and Metator are clearly of Sonoran origin; each extends northward over the Great Plains and the Great Basin, with distinctive lines in each of these areas, indicating a considerable period of time for divergence and development of differentiating 
stocks. Trachyrhachis, which clearly has had a similar history, has also extended the range of one of its species eastward, probably Postglacially, to parts of the Appalachian uplift in the eastern United States. The genus Rehnita is an additional Sonoran type, probably derived from the same basic stock as Mestobregma.

The genus Conozoa has more affinity to Trimerotropis, which has already been mentioned, than to any other member of the subfamily, and it may represent an offshoot from the same stock. If so, its divergence was not recent. The genus occurs entirely within the area of our coverage, only rarely east of the Continental Divide. The chiefly Boreal and generally montane genus Circotettix may also originally have been derived from the basic Trimerotropis stock. Its distribution is often discontinuous, extending eastward across southern Canada and the northern United States into Boreal areas in eastern North America. Its species are among the few grasshoppers that perform aerial stridulating dances. Another genus with the same proclivities, that may be related in some degree to the Eurasian genus Bryodema, is Aerochorentes, which occurs in Upper Austral and even Transition areas of the northern Great Plains, northern Great Basin, and the Columbia-Snake River semi-arid hills.

The extremely arid sections of the Lower Sonoran life zone are the home of the genus Anconia, which also occurs some distance southward into northern Mexico. It would appear to be endemic in the territory where it now occurs. Its only known relative is Spaniacris, which lives in limited, and intensely arid, sections of the same area in southern California and extreme western Arizona. These two genera clearly are old desert types, with no close relatives, markedly specialized in a number of respects, and with distinctive habitat preferences. The genera Xeracris and Coniana, smaller desert types known only from the most arid sections of the Colorado, Yuma, and Mohave Deserts, are similar to Spaniacris in distribution, but are of different affinities. They are clearly authochthons without any very close relatives, although further study on this matter is required.

The genus Heliastus is a Mexican and Central American type, which reaches even to northern South America, but in our territory is found only narrowly and locally in southern Arizona and coastal Texas. This is clearly a Sonoran genus which has spread southwarda less frequent pattern. A Sonoran type of higher levels, largely 
Upper Sonoran, is the genus IIeliaula, which extends northward over the Great Plains as far as eastern Colorado, but does not go far west of the Continental Divide.

(4) Subfamily Acridinae. The Acridinae, or slant-faced grasshoppers, which in our section of the world are in considerable part grassland forms, are very well represented in our fauna, and the greater part of the forty or more genera reviewed clearly have developed within North America west of the Mississippi. Two genera, Chorthippus and Stethophyma, are certainly relatively recent Palearctic intrusives in North America, the former so recent that the single species we have is also widely distributed in Eurasia. Chorthippus has a large number of Old World species, and it is possible we received $C$. longicornis in an Interglacial period. Our three species of Stethophyma are endemic, two with preferences for Boreal or sub-boreal conditions, the other of infrequent and very local occurrence over a broad section of eastern North America. The species of sub-boreal preferences occurs in widely separated parts of western North America, but has been taken at only a few localities. Presumably Stethophyma reached North America from Eurasia prior to the advent of Chorthippus, as its species are well differentiated from Old World forms.

One set of three genera, representing the group Chrysochraontes, has presumably also been derived from Eurasia, probably through a succession of waves. The earliest invasion was probably that of an ancestral stock of the genus Chloealtis, which today is chiefly an inhabitant of the more northern parts of eastern North America, although it narrowly reaches our included territory in eastern Colorado. Apparently a second intrusive line of the same group is represented by Chrysochraon, which occurs broadly in the Palearctic, and of which we have a single endemic species in Cordilleran montane localities. A third line of the same group comprises the equally endemic genus Napaia of Coastal Range mountains of southern Oregon and California, as well as the San Cabriel Range in the latter state. The members of the Chrysochraontes are peculiar in that they usually oviposit in dead wood, an unusual situation for acridids. Another genus of Palearctic relationship is Aeropedellus a Cordilleran and high Great Plains genus, which clearly has been derived from the same stock as a number of Palearctic genera related to, and including, Gomphocerus and Aeropus. A distant 
relative of Aeropedellus, but without Old World relatives, is Bruneria, which is a northern type, usually found under Boreal, or even Hudsonian, conditions, from southern Canada sporadically and very locally south in the Cascade-Sierran uplift to northern California and in the Cordilleran massif at least as far as southern Utah. It appears to have developed in the territory where it now occurs, with greater diversity in the Cordilleran section than elsewhere.

Three of our acridine genera, Amblytropidia, Orphulella, and Rhanmatocerus, are clearly of Neotropical origin. All have a far greater specific development and areal extent southward than in our area, extending to southern Brazil and Argentina. Amblytropidia is only narrowly represented along our Mexican border by one of a number of Mexican species, although a distinct endemic species occurs rather broadly over the southeastern United States. Rhammatocerus is similarly represented along the Mexican border, but not elsewhere in North America. Both of these genera apparently are more recent intrusives than Orphulella, which is broadly present in North America from Atlantic to Pacific. Because of its habitat preferences Orphulella is of much more localized occurrence in the western part of its range than in the East. A considerable number of the genera of the subfamily in North America, including Paropomala, Acrolophitus, Amphitornus, Opeia, Cordillacris, Phlibostroma, Boopedon, Ageneotettix, Drepanopterna, and Aulocara, I would regard as autochthonous in our Great Plains, the adjoining Texas Sonoran area, or the Sonoran areas to the westward. Other genera, including Achurım, Eremiacris, and Morseiella may, with reasonable assurance, be regarded as having developed in Mexico, and species there found, or closely related ones since evolved, occur on our side of the border. Another genus that should be placed in this category is Syrbula, although it apparently entered our territory quite some time in the past, as one of its species, which also is distributed over much of Texas, is broadly established in our more southern and southeastern states. The genus Mermiria is represented in the West by four of the well-differentiated lines that it has evolved in the United States. In all probability this genus developed in the Sonoran region, spread broadly over the Campestran, and then extended its range into the southeastern and central states, where three of its lines occur. One of its most distinctive species, M. texana, is present on both sides of the Mexican 
border, on arid rocky hills and in brush land, while another, definitely a Campestran (Great Plains) type, narrowly extends in to Mexico. Pseudopomala, a near relative of Mermiria, is widely distributed over the more northern section of the United States, occurring sparingly in restricted environments. At least some of its present spotty distribution probably can be explained as a subsequent readjustment to Glacial displacement, but on this point more study is needed.

The highly specialized genus Radinotatum is largely limited to the southeastern United States, but includes a quite distinct species in southern Texas. Its nearest relative is apparently Achurum, which is Mexican in origin, although found within our limits in southern Arizona. The genus Prorocorypha is of localized occurrence in certain mountains of extreme southern Arizona. Its nearest relative is the rather broadly distributed and highly specialized, equally graminicolous Sonoran genus Paropomala. The genera Acantherus and Horesidotes are apparently endemic generic types of the Sonoran Mexican border country in Texas, New Mexico, Arizona, and California. The same is true of the strictly thamnophilous genera Ligurotettix and Goniatron, the former of which does not occur east of the Continental Divide and extends northward as far as westcentral Nevada, while Goniatron lives almost entirely east of the Continental Divide in the Chihuahuan Desert area and is much more limited in its north and south distribution, but with its range definitely known to extend a considerable distance into northern Mexico. In habitat Goniatron is restricted to "black brush" (Flourensia), while Ligurotettix is found on more than one species of shrub, but often on creosote bush (Covillea).

The genus Pedioscirtetes comprises two lines of development, one of which occurs in the Mexican border territory from western Texas to southern Arizona, as well as some distance southward into Mexico; the other is known only from very limited, distinctly more elevated areas in northern Arizona, Nevada, Utah, and southern Idaho. It appears to me that the genus originally developed in our older plateau areas adjacent to the Cordilleran mass, and that one element moved southward, perhaps in Pleistocene times, while the other remained, survived lower temperatures, and has even extended its range northward. The genus Bootettix is always associated with the Lower Sonoran creosote bush (Covillea), and is almost never 
found off of it. It clearly developed in the area of our Mexican border. One species occurs on the Pacific side of the more elevated Continental Divide, the other on the Atlantic side; both are known to extend southward, with their host plant, into Mexico.

The genera Esselenia and Eupnigodes are Californian endemics. The former is found only in the central section of the Coast Range region, and has no known close relatives. On the other hand Eupnigodes, which is more broadly distributed over the San Joaquin Valley and the lower western slopes of the Sierra Nevada, is relatively close to Ageneotettix, which is a quite widely dispersed Sonoran genus, and clearly the stock from which Eupnigodes developed in relatively recent times. Another apparent development from the Ageneotettix line is Zapata, of which a few species are quite locally distributed in southern Arizona, western Texas, and northern Mexico. A genus almost exclusively Texan Sonoran is Mesochloa, which is clearly derived from Eritettix. The latter, probably also of Sonoran origin, is broadly distributed northward over the Great Plains and westward along sections of the Mexican borderland. One species of Eritettix has deeply penetrated into the central and eastern United States, where it occurs from New England and Nebraska southward. A related, and apparently derived, endemic genus, Macneillia, is restricted to peninsular Florida.

The genus Dichromorpha is probably of Sonoran origin, but ranges northward over most of the central and eastern United States, with several species in Mexico, while to the southward, after a gap of some thousands of miles, it reappears in areas of Paraguay and northern Argentina. It is a grassland type and its distribution, like that of the mantid Brunneria, probably reflects the much broader extent of grasslands in the Pliocene, and their later restriction by the moister and colder Pleistocene, with its greater development of forests.

A dominant genus of largely arid or semi-arid sections of the whole Sonoran region, also occasionally entering the Transition Life Zone, is Psoloessa, one line of which extends as far northward in the Upper Sonoran as the Okanagan Lake country of extreme southern British Columbia, and also to sections of the Great Plains of southern Alberta, Saskatchewan, and Manitoba. Southward one line of Psoloessa reaches as far as the Mexican states of San Luis Potosi, Guadalajara, and Mexico. Psoloessa is probably one of the 
types that developed in areas of our Southwest, or it may have been intrusive in our area from Mexico, though I am more inclined to place its origin as north of the Mexican line, since one of the three main elements of the genus does not, as far as we know, reach Mexico, and it is, with us, always an Upper Sonoran or Transition species. A second of these main elements is restricted to the western section of the southern half of California and several areas of Baja California, while the third is broadly distributed from east-central Texas west to west-central Arizona and northward over the Campestran region to South Dakota.

\section{ORDER ORTHOPTERA: SUBORDER ENSIFERA}

\section{Superfamily Tettigonoidea}

Family Tettigoniidae. Passing now to the great assemblage of what we Americans call the "katydids," but which are elsewhere, in the English-speaking world, referred to as "long-horned grasshoppers," or technically the Tettigoniidae, we have first the virtually cosmopolitan subfamily of the Phaneropterinae. This is represented in western North America by eight endemic genera, none of which is Holarctic, and by one, Microcentrum, the "angular-winged katydid," that is clearly Neotropical in origin and is much more variedly developed in that region. This genus reaches on one hand to California, and on the other is broadly spread over the interior and eastern United States, but does not reach high altitudes in the Cordilleran section. One genus, Platylyra, is endemic in the California coastal mountains, and probably represents a relatively early development, perhaps from fundamentally Neotropical ancestors. The genus Insara was certainly Neotropical in origin, but it clearly has been in and has undergone a considerable part of its evolution in the broad Sonoran region, developing there at least four lines, one of which lives only on the creosote bush (Covillea). Other species of Insara range from Mexico to Panama, while related genera are known from Panama and northern Argentina. The genus Brachyinsara, which as clearly has had a common ancestry with Insara, is known only from extreme southern California and Baja California.

The genus Arethaea, composed of spectral, ghostlike species, is clearly a development of the Sonoran center. Certain of its species are found in northern Mexico, but the majority occur within the limits of the United States, ranging northward in the Great Plains 
to the Dakotas and western Iowa. A single very distinctive species is isolated in the extreme southeastern United States. The greatest specific diversity of Arethaea is in southwestern Texas and adjacent Mexico, and only one species reaches westward to southern California and southern Nevada. Another genus with a similar, and clearly Sonoran, pattern of development and distribution is Dichopetala, a thamnophilous flightless genus of nearly a score of species, which range from Oklahoma, Texas, New Mexico, southern Arizona, and southern California southward to the Rio Balsas Valley and northern Vera Cruz, Mexico, with several species similarly referred generically from Peru and Ecuador. However, its greatest specific development is in southern Texas and the north and central parts of the Mexican tableland and its bordering eastern Cordillera. It is possible that the South American species may require generic separation or that they represent a southward extension of the genus across the "Panama fault," rather than the more usually postulated one of a reverse movement. However, the maximum diversity of Dichopetala is clearly in the Sonoran region, very largely east of the Continental Divide.

The genus Scudderia, which apparently developed from a Neotropical center, includes a certain number of species limited to Central America, and others intrusive into the western United States from Mexico. However, a secondary evolutionary center most certainly developed in the southeastern United States. From that area, apparently some of the most distinctive members of the genus extended. Several broadened their range into the western United States, reaching the Pacific Coast, and also into southern Canada. The genus Amblycorypha, which probably came from a Neotropical ancestral stock, developed an evolutionary center in the eastern and southeastern United States. Four of its five lines center there, whereas only one is definitely Sonoran. The Sonoran line extends narrowly along the Mexican border area from western Texas and Coahuila to southern Arizona. The broad north to south range of Amblycorypha in western North America reaches from southern Manitoba and Wyoming to Zacatecas, Mexico.

The subfamily Pseudophyllinae, which is a greatly diversified and remarkably developed, almost entirely pantropical, assemblage is represented in North America by a single tribe, the Pterophyllini, which may be called the "true katydids." This tribe is a Neogaeic 
group that has three peculiar genera in North America, two in the West Indies and one in South America. The center of development of the North American elements of the subfamily seems to have been eastern and midland North America, where two (Pterophylla and $L e a$ ) of the three genera are most diversely developed, while the third (Paracyrtophyllus) is essentially Campestran and Sonoran. No member of the tribe is found west of the Continental Divide.

The Copiphorinae is a subfamily of broad distribution, more strongly developed in the Neotropical Region than elsewhere. While a number of its genera occur in Mexico, Central America, and the Viest Indies, but a single genus, the predominatingly Neotropical Neoconocephalus, enters western North America. It occurs but sparingly in the Campestran area. West of the Continental Divide a single species has been taken in southern Arizona and southern California. It may be intrusive from Mexico, where the same species is broadly distributed. Any such intrusion seems to be largely or wholly unrelated to the marked secondary developmental center for Neoconocephalus in the southeastern United States, that is clearly indicated by the varied lines of the genus there present and in part there limited.

The subfamily Conocephalinae includes the small species of katydids often referred to in economic works as "meadow grasshoppers." One of its two genera found within western North America, Orchelimum, is strongly developed in the eastern and central United States, and reaches into the Sonoran in Texas and eastern Mexico. A single sub-boreal species extends from eastern Canada across the northern United States to Montana, Washington, and northern California. Orchelimum, while known only from America north of Tehuantepec, is closely related to the very widely spread genus Conocephalus, and probably represents a line that has developed in our territory from the Conocephalus stock. Like Neoconocephalus, Orchelimum prefers grassy and usually quite moist meadows, and unless the continuity of such conditions has been assured, as in the eastern and southeastern United States, Orchelimum is usually not present, and hence we do not find in western North America the varied representation of Orchelimum that is present to the eastward. The nearly cosmopolitan genus Conocephalus has habits rather similar to those of Neoconocephalus and Orchelimum, and but four of the eighteen species known from 
North America occur west of the Continental Divide. Two of the three subgenera of Conocephalus known from North America are almost entirely confined to the eastern and central parts of the continent. We doubtless received the ancestral stock of these lines from the Neotropical Region well before the Pleistocene, and they probably evolved almost entirely in the southeastern United States between their advent there and the present. It is also quite probable that the two forms of the genus peculiar to the western United States have evolved from eastern species, while the other two there present are relatively localized western extensions of broadly dominant eastern species.

Until very recently the subfamily Listroscelinae was not considered to be present in North America or even in Mexico. Recent work has shown that the genus Rehnia, which occurs from Kansas to the Rio Grande and southward into northern Mexico, and there westward to Sinaloa, is a member of the Listroscelinae, a subfamily chiefly of pantropical distribution, with a number of most distinctive genera in South America. Apparently Rehnia is a bush- and tree-loving Sonoran development from a line of the subfamily, the entry of which into our general region from a Neotropical stem probably dates back a considerable time. Another genus of the same subfamily Neobarrettia is an inhabitant of the very hot Rio Balsas Valley of Guerrero, Mexico, while the remainder of the Neogaeic genera of the subfamily occur almost exclusively in South America and more southern Central America.

The subfamily Decticinae is made up of a very extensive array of genera occurring almost entirely in the Nearctic and Palearctic regions. A very few narrowly extend southward and several isolated genera are known from South America. A large percentage of the members of the subfamily are bush- or thicket-loving species, but some are grassland types, and others live entirely on the ground in forested areas; a very few, such as the Mormon cricket (Anabrus) and the coulee cricket (Peranabrus) are often economic problems, and these latter, although flightless, have well-developed migratory instincts when in search of food. In North America only one genus (Atlanticus) is limited to its eastern part, while twenty-one genera are known from, and all but one are peculiar to, the western part of our continent. One interesting peculiarity is that the one eastern genus, Atlanticus, is the only one having its greatest diversity in 
our continent that is also found outside of North America (in the last few decades a fair number of species of the genus have been made known from eastern Asia). This distribution is paralleled in part by the acridid genus $Z u b o v s k y a$, the blattid genus Cryptocercus and also by numerous genera of trees and shrubs which have similar patterns of discontinuous distribution and are now un represented in western North America.

Of the various genera of the Decticinae in western North America, a single genus (Metrioptera, s. 1.) is shared with the Palearctic region. This genus with us is a truly boreal type, not occurring south of Alberta. Its nearest relative is considered by some European authorities to be M. ussuriana of the Soviet Far East. Of truly Sonoran development we would regard the genera Eremopedes and Pediodectes. Genera limited to, and probably developed in, the very arid western section of the Sonoran are Anoplodusa and Ateloplus. The genus Aglaothorax is limited to the Mohave Desert and the Great Basin, and to the latter the exceedingly rare and local $\mathrm{Za}$ cycloptera is also restricted. Plagiostira, although chiefly a Great Basin genus, extends southward over parts of the Arizona Plateau and eastward into sections of New Mexico, and Capnobotes, which is chiefly a western Sonoran type, also extends northward in mountainous portions of the Great Basin.

Probably originally of Sonoran origin, but now extending its distribution widely over the Great Basin and the Columbia Plains, and even to very considerable elevations in the Rocky Mountains, is the genus Anabrus, the dreaded Mormon cricket. In the northwestern United States are two endemic decticid genera, Peranabrus the economically important coulee cricket, and Apote, which is chiefly localized in the Columbia Plains, but reaches southern British Columbia and is apparently restricted in its occurrence. It is possible that further study may show that both Anabrus and Peranabrus have Palearctic relationships, and the same also may be true of Apote. Material for such study is now available and will be used in the near future.

In the broadly Pacific area from British Columbia to southern California are a number of clearly endemic genera of Decticinae, such as Neduba, which often is taken on the ground in heavy coniferous forests from British Columbia to the mountains of southern California, and Idiostatus, from more arid regions of the same 
general territory east to Montana, while the little-known Oreopedes and Crytophyllicus are Sierran endemics, occurring respectively on the eastern and western slopes. Only at high elevations in the Sierras, generally above timberline, occurs the flightless Acrodectes, which is known from the summit and vicinity of Mount Whitney, and which also may be found to have Palearctic affinities. Californian endemic decticid genera of lower levels are Idionotus, Decticita, and Clinopleura. The last-named genus apparently developed from the same basic line as the genus Steiroxys, which is chiefly a Cordilleran and Great Basin type, with, however, a few records from east of the Rockies (its distribution as a whole is at present poorly understood). It is possible that Clinopleura and Steiroxys may be found to have Palearctic affinities.

It is possible, and even probable, that a comprehensive study, now outlined, may show that the very complex and greatly differentiated decticid fauna of western North America represents several lines of infiltration of Palearctic elements, and that they have come into our territory long since the sole eastern representative of the subfamily, Atlanticus, either moved into our territory from eastern Asia, or conversely traveled to the latter area from eastern North America, where today it has a number of distinct specific lines. Clearly, however, a number of our genera of western North American Decticinae, such as Aglaothorax, Neduba, Zacycloptera, Capnobotes, and Plagiostira, have no approximate counterparts in the Palearctic region, while others, such as Eremopedes, Pediodectes, Ateloplus, Idiostatus, and Idionotus, exhibit almost as well-marked differences and represent distinct lines from the many Old IVorld genera of the subfamily. Certainly a very considerable period of time, isolation, and evolutionary pressure and opportunity has been required to make evident what we see in our western American Decticinae.

Family Gryllacrididae. The Gryllacrididae, for which the most generally used vernacular name is "camel crickets," are an extremely complex and difficult group systematically. Their ancestral stock, according to Zeuner, who is probably our most able scholar in this respect, diverged from the Protorthoptera probably in the Mesozoic. What he regards as ancestral stocks have been found in the Upper Jurassic of Solenhafen, although typical Gryllacrididae are not known from earlier than the Tertiary. Several genera from 
the Florissant Miocene have been referred to the family. The majority of fossil forms, which can in a general way be associated with this family, or superfamily as some regard it, belong to the family Prophalangopsiclae, or the subfamily Prophalangopsinae, depending on the rank accorded it, and occur in deposits as old as certain Mesozoic formations of Turkestan. Two living genera have been referred to this assemblage, one Prophalangopsis of India (known only from the unique type taken nearly ninety years ago), and Cyphoderris of the northwestern United States and adjacent Canada. Cyphoderris, however, has by some authors been referred to the gryllacridine subfamily Henicinae, in which nearly two score existing genera have been placed (the majority of these genera occur only in the Southern Hemisphere, from which several reach northward in the Neotropical Region to Central America and the Greater Antilles). The Henicinae are also regarded as having a single representative within our territory in Cnemotettix, an endemic genus of San Clemente, one of the Californian coastal islands. Except for the two Nearctic genera which have been placed in it, the members of the Henicinae occur in areas which could be associated as parts of the often postulated "Gondwanaland." There can be no question but that Cyphoderris is a relict genus, and of a line that definitely has long passed its optimum development. It also should be noted that the area where Cyphoderris occurs is also the chief center in the New World of Grylloblatta, which is probably the most aberrant and primitive orthopteron still existing.

The subfamily Stenopelmatinae, which has fossil representatives as far back as the Lower Miocene of Croatia, is well represented in western North America, but only by the typical genus Stenopelmatus, which apparently developed from a Sonoran center, thence spreading southward at least as far as Costa Rica, and northward over the campestran Great Plains to the Dakotas and Montana, over the Great Basin to southern Idaho, and along the Pacific Coast area to British Columbia, whereas eastward it does not extend beyond the Great Plains. It is a highly specialized apterous burrowing genus, whose existing relatives are of South African and Indian distribution. Its pattern of relationship would indicate the fragmentation, well in the past, of a once widely spread assemblage adapted to subterranean life. The presence of Stenopelmatus in the New World clearly is not a matter of very recent times. As a 
genus, it evidently has evolved in our hemisphere, probably within the broad limits of the semi-arid and arid Sonoran life center.

In the subfamily Rhaphidophorinae one definitely placeable genus, Prorhaphidophora, is known from as far back as the Lower Oligocene amber of East Prussia. Existing members of the subfamily are wingless, usually nocturnal, and many are cavern-dwelling. More than a score of genera are represented in Europe, Asia, North America, Australia, and New Zealand. Only one of the thirteen genera in North America occurs outside of this continent, and this genus, Tachycines, is a rather recent accidental introduction from eastern Asia, now well established under protected conditions in the eastern and central United States as far west as the Dakotas and Colorado. The remaining twelve North American genera are all endemic. They are related to two genera occurring to the southward, Phoberopus in the mountains of Central America and Argytes on the Pacific side of the Mexican Plateau. It is clearly evident that this assemblage of more than one hundred species, which Hubbell, who has done detailed work on it, regards as the tribe Ceuthophilini, has as a whole developed in North America, and to a lesser degree in adjacent Mexico and northern Central America.

Three of the genera of the Ceuthophilini are western North American endemics: Tropidischia, which ranges northward in Pacific territory to British Columbia; Rhachocnemis, which is known only from the unique type from "California"; and Gammarotettix, which occurs in various non-desert parts of California, with one species also occurring about the headwaters of the Gila River in eastern Arizona. The genus Pristoceuthophilus occurs solely in western North America from British Columbia to north-central Mexico, often in montane localities. Styracosceles is limited to areas of the southwestern United States east to Colorado. The very unusual recently described genus Salishella is known only from the mountains of north-central Idaho and the Olympics of Washington. It is a type of marked specialization, that probably developed in a northwestern center, as it has no close relatives in any surrounding territory. The genera Daihiniodes and Daihiniella are definitely Sonoran in their distribution. Ammobaenetes has a similar pattern, in sand areas. The genus Udeopsylla is truly Campestran. Daihinia has a similar range, but reaches into adjacent Cordilleran territory. The widely spread genus Ceuthophilus is represented by some scores 
of species in North America south only to northern Mexico, and they are considered to have had as their main centers of differentiation $(a)$ the Eastern Deciduous Forest, (b) the Sonoran region, and (c) the northern Great Basin. In the more arid regions of western North America specific lines of Ceuthophilus appear limited to mountain areas, probably as hot lower levels are less favorable for their existence. It is very probably that the tribe had a broader and less localized range in western North America in the moister and cooler Pleistocene, and that present distributional patterns, as for many other groups, reflect an average greater aridity in Recent times.

\section{Superfamily Gryllodea}

The second superfamily of the existing suborder Ensifera, the Gryllodea, has, in a conservative evaluation of its component major groups, three families in our fauna, the Gryllotalpidae, or mole crickets, the Tridactylidae, or pygmy crickets, and the Gryllidae, to which belong the true crickets.

The oldest fossil of an undoubted mole cricket, from the Upper Miocene of Germany, is considered to represent an existing genus, Gryllotalpa, and to be closely related to the existing European G. gryllotalpa. Zeuner believes that both the Gryllotalpidae and the Gryllidae have developed independently from the Liassic Protogryllinae, and that the Gryllotalpidae have not evolved through the medium of the Gryllidae. In western North America we find but one genus of the Gryllotalpidae, which is variously referred to as generically identical with Gryllotalpa of the Old World, or representative of a New World genus Neocurtilla. It is clearly evident, however, that the two distinct species of this genus in North America are of Neotropical derivation, as one, found broadly over the United States west to the Rockies, is also widely spread over eastern South America, and the other, the sole species occurring very locally and infrequently from Texas to California, is closely related.

The position of the Tridactylidae, or pygmy locusts, which were long considered gryllids, is now regarded broadly as with the acridids. I mention the group here, as this is the position given in most past literature. Their ancestral stock is now known from the Tertiary, but the single genus found broadly in North America 
is the almost cosmopolitan Tridactylus, one of the very few genera of these strangely specialized orthopterons.

Passing to the true Gryllidae, of which a number of subfamilies are generally recognized, the Myrmecophilinae, composed of ant inquilines, is represented in our fauna by the single widely spread genus Myrmecophila. While members of the genus occur in certain tropical countries, most of our knowledge of the group has been drawn from representatives found in more temperate regions. At least four species occur in western North America. No fossil forms are known and any postulate as to centers of origin seems at present unwarranted.

The subfamily Mogoplistinae, of which also no fossil forms are known, is represented in western North America by two genera, one of which, Cycloptilum, is distributed broadly over the southeastern United States, narrowly enters the Campestran region, extends from Texas to coastal southern California, and is intrusive in the Colorado-Virgin rivers area to southeastern Utah. Cycloptilum is broadly distributed in tropical regions, even occurring in Polynesian islands, but it apparently developed certain centers of evolution or radiation, where a number of distinct species occur, one in the southeastern United States, and another in its southwestern section, Baja California and apparently extreme northern Mexico. The second genus, Hoplosphyrum, is peculiar to the Sonoran region of North America, Baja California, and mainland Mexico, with one species in each of these areas, but it does not, as far as we know, extend greatly to the southward.

The single genus of the subfamily Nemobiinae in western North America is virtually cosmopolitan in distribution. The subfamily is known fossil only from the Oligocene, in Prussian amber and Isle of Wight deposits. The dominant and widely distributed genus Nemobius clearly developed an evolutionary center in the eastern and central United States, where a number of endemic species occur. Six species and subspecies of the genus occur in western North America which the genus appears to have entered by this group from both Mexico and the eastern United States. Several species are but narrowly present in the southwestern United States. Another is a Campestran subspecies of an eastern species and reaches the foot of the Rockies in eastern Colorado. Of two subspecies of a dominant and widely spread eastern species, $N$. fasciatus, one reaches 
westward as far as Salt Lake City, Utah (possibly an accidental introduction) and eastern New Mexico, and northward to southern Manitoba, Saskatchewan, and Alberta, and the other, a more southern race, extends west to central Texas.

The subfamily Gryllinae is represented in western North America by three genera, each with a very limited representation of species. A single species, $A$. assimilis, of the virtually cosmopolitan genus Acheta ranges over the greater part of the Neogaeic from Canada to southern South America. It is now regarded by some as comprising a group of probably physiological subspecies, as morphologically these subsidiary elements intermingle to an inextricable degree, and also they have no clearly defined gegraphic allocations. Members of the genus Gryllulus are known from the Tertiary of both Europe and Argentina, and it is probable that in the New IVorld Gryllulus has had a very ancient history, but fossil evidence is very limited.

The genus Miogryllus, which is represented in western North America by two species, is clearly of Neotropical origin. Members of the genus, including one of those found in North America, ran ge southward to central Argentina, while others are more closely lim ited in the Neotropical Region. One of the North American species is known in our territory only from a portion of the southwestern United States, reaching from southern California to portions of Texas and eastern Colorado. The second species, which is that also of wide Neotropical distribution, occurs rather broadly over the southeastern and central United States westward to Nebraska, Kansas, Oklahoma, and central Texas.

The genus Gryllita is also Neotropical. The one species known in the southwestern United States, has been found only in the Baboquivari Mountains of Arizona, only a few miles from the Mexican border, south of which undoubtedly the species also occurs. Other members of the genus Gryllita are known from more southern Mexico, Central America, and the Greater (Cuba) and Lesser (St. Vincent) Antilles, and its occurrence within our territory has clearly been due to extension from a more austral center.

The subfamily Oecanthinae is a cosmopolitan assemblage, including the so-called tree crickets, because many of them frequent the foliage of trees or bushes. The little we know about them as fossil forms is that specifically unidentifiable remains have been found 
in the Lower Oligocene and Upper Miocene of Germany and France. In the present world fauna members of the subfamily are to be found wherever their chosen environment exists in virtually all parts of the temperate and tropical regions. They are represented in the Nearctic fauna by two genera, one of which Neoxabea occurs in Nearctica only in the eastern part of North America, but other members of that genus are well distributed over the Neotropical Region south of Mexico, as far as northern Argentina. The other genus, Oecanthus, is cosmopolitan over the temperate and tropical parts of the world, but its greatest concentration of species is in North America. A definite area of marked specific differentiation is in eastern North America, and three of the four specific lines of the genus represented in western North America, are there at the extreme western limits of distribution of more widely spread and dominant eastern species of the genus. The status of at least one of the endemic species reported from the western United States is at present uncertain, but another one, O. califormicus, is clearly autochthonous and doubtless will be found to extend into northern Mexico.

The subfamily Pentacentrinae is an aberrant group of small crickets broadly distributed within the tropics. A single genus, Trigonidomimus, enters our territory in central Texas, while to the southward it ranges across Mexico and Central America to Panama. The other genera of the subfamily are known from Brazil, Cuba, Madagascar, West Africa, Ceylon, and Formosa. Clearly Trigonidomimus entered our territory from the Neotropical Region. No fossil members of the subfamily are known.

A single genus, Anaxipha, of the subfamily Trigonidiinae is represented within western North America by one species which is largely eastern in its distribution, reaching to central Texas and to the eastern parts of Nebraska and Kansas. The subfamily is found in virtually all the warmer parts of the earth, on foliage or in low plant cover, and is also represented in Pleistocene or post-Pleistocene African copal. The genus Anaxipha is entirely New World in its distribution, with many tropical American species. A secondary evolutionary center for the subfamily and also for the genus Anaxipha apparently developed in the southeastern United States, where several other distinctive genera of the subfamily occur, one of which is entirely restricted to that area. 


\section{Superfamily Grylloblattoidea}

Family Grylloblattidae. The exceedingly strange orthopteron Grylloblatta, which was first made known by my old friend, Dr. E. M. Walker, in 1914, from material taken near Banff, Alberta, has probably provoked more discussion as to its relationship and its phylogenetic position than any other living insect discovered in the last half century. Its original describer fully realized the unique character of the insect and modestly created the family Grylloblattidae for it. Crampton in 1915 erected the order Notoptera to include it, and while some have followed this ordinal arrangement, another school inclines toward the belief that in Grylloblatta we have a connecting link between the saltatorial Orthoptera (the true Orthoptera of some present day scholars) and the Oothecaria (or Dictyoptera) and the Phasmatoidea (or Cheleutoptera). Zeuner recently succinctly stated, "Since it has a number of features which are more characteristic of the true Orthoptera, it might rightly be called a living, though specialized representative of the ancient Protorthoptera."

Our knowledge of the family Grylloblattidae has grown considerably since Grylloblatta was described. It is now known to be made up of Grylloblatta, which is entirely Nearctic, Grylloblattina, of the southern Maritime Provinces of Siberia, and Galloisiana, of Japan. The genus Grylloblatta contains six species, all from montane localities in southwestern Canada and the western United States. They are known from localities in southern British Columbia, montane Alberta, similar areas in Washington, Montana, Yellowstone National Park, the Cascade region of Oregon, and the Sierran section of California as far south as Mammoth Crest. Almost all the species seem to have very special humidity and temperature requirements, occasionally are found in contact with snow or ice, grow with exceeding slowness, and exhibit numerous attributes that clearly indicate their overall primitive character. It is clearly evident that today the Grylloblattidae is a Holarctic assemblage. Its segregation into three distinctive generic units was probably accomplished well in the past, as the genera are well defined and regionally limited. The species of Grylloblatta also show in their distribution, that the relatively numerous forms of the genus (five) now known from California, Oregon, and Washington (the last also reaching northward into British Columbia) apparently differenti- 
ated at different periods from the line represented by G. campodeiformis (the genotype), which ranges in the Cordilleran region from as far north as Jasper Park, Alberta, to the Yellowstone National Park. The fact that the Cascarlan and Sierran species are more divergent from campodeiformis, would inclicate to me that these more southern representatives have been established as divergent entities for a longer time. The greatest known specific differentiation in the family has taken place in North America, and it is fair to assume that the family had its beginnings in western North America, and that ancestral lines probably traveled eastward over a Bering Sea land bridge well in the past. We have parallel cases in the Orthoptera, such as the decticid genus Atlanticus and the acridid Zubovskya.

\section{Superfamily Phasmatoidea}

\section{(Cheleutoptera of some authors)}

The Phasmatoidea, or "walking-stick insects," are a very distinctive assemblage, much more diversely developed in the number of genera and species in certain tropical areas than in more temperate ones. The areas of optimum differentiation are the Neotropical, the Indo-Malayan, and the Australian. Africa has in proportion a relatively smaller representation, even its great forested area having a much less marked diversity than similar regions in the Neotropical and Indo-Malayan regions.

In North America we find representations of four entities of higher rank (variously regarded as families or subfamilies), one of which, elsewhere entirely Neotropical, occurs in the southeastern and central United States but does not enter more western territory. One very distinctive line, which is almost universally regarded as a family, the Timemidae, with the single genus Timema, is as far as known restricted to certain areas of the western United States. Timema possesses a number of unusual, possibly primitive, characters, and its six species are known from well-separated areas in the mountainous areas of California and of extreme southeastern Arizona. The species are, as far as known, tree or bush dwelling. The family is clearly an autochthon of the general area where it is now found, and it shows a pattern of distribution essentially parallel to that of the three genera composing the Morseinac of the Eumastacidae. Perhaps as our knowledge becomes more compre- 
hensive we may find that this, and similar correlations, indicate parallel spreads of widely distinct entities, but of similar faunistic histories. While it is purely a postulate, it is my belief that the distributional evidence here reflects Pleistocene conditions, and heavier precipitation and lower temperatures then over extensive areas now largely desert or semi-desert, and that the genesis of the Timemidae probably took place in California very much before the Pleistocene.

The subfamily Pachymorphinae, a group widely spread over the world is represented in much of the western half of North America by the genus Parabacillus. Its range extends northward over the Great Plains to the Dakotas and elsewhere into New Mexico, Arizona, southern Nevada, and southern California. While it also extends a considerable distance into Mexico, its greatest distribution is northward over the Great Plains, and I would regard it as Campestran in origin, with closest relationship probably to certain rather poorly known Asiatic genera.

The subfamily Heteronemiinae is entirely one of Neogaea, with representatives distributed from Canada to at least Paraguay. Five genera have been reported from western North America, and all but one of these I would regard as of Sonoran development. The exception is Sermyle, which is clearly a Mexican and Central American Neotropical type, with a single species found in southern Texas. Of the other four genera, Megaphasma is an endemic usually infrequent in forest, generally bottom, land of eastern Texas, Oklahoma, Louisiana, and other Mississippi valley areas, but narrowly entering the territory we are considering. Two of the three remaining genera, Rhabdoceratiles and Pseudosermyle, are limited to western North America, except for narrowly reaching into Sonoran sections of Mexico. They doubtless have developed in the great Sonoran area, where Pseudosermyle in particular is a dominant type. The remaining genus, Diapheromera, is probably also a Sonoran derivative, for several of its species are limited to that area. One species of the genus, however, has spread more broadly eastward over most of eastern North America, and there also has developed a very distinctive species in the southern Appalachians. The southeastern and central United States apparently have served as a secondary developmental center for the Heteronemiinae, not only for Diapheromera, but also in producing there an endemic genus 
(Manomera) which is not found to the westward. However, I would regard the basic developmental center for Diapheromera as Sonoran on account of the specific diversity in the genus there.

\section{ORDER ORTHOPTERA: SUBORDER OOTHECARIA}

(Dictyoptera of some authors)

\section{Superfamily Mantodea}

The Mantodea are represented in western North America by members of five subfamilies or families (the exact rank of the higher entities is debatable). Two of these subfamilies are known only from the New IVorld, while the others are found in both hemispheres. One of the latter is the Amelinae, which has two genera in North America, both found only within its western part and in northern Mexico. These are curious, almost entirely terrestrial mantids, one of which, Yersiniops, has considerable saltatorial powers. The genus Litaneutria occurs rather broadly over western North America and northern Mexico, reaching northward to North Dakota, Montana, Washington, and extreme southern British Columbia. Yersiniops has a more limited distribution, extending from western Texas westward to central southern Arizona and northward to parts of Colorado. A related genus, Yersinia, occurs in northern Mexico. All three genera clearly developed in a Sonoran faunal center.

The widely distributed subfamily Manteinae is represented in our territory by a single genus, Stagmomantis, which is clearly of Neotropical origin. Species of this genus range southward to Amazonia. The greatest diversity of Stagmomantis is in Central America, where a number of lines of the genus not present elsewhere are developed. It later, probably, spread both to the north and to the south. In western North America there are four species of Stagmomantis. S. carolina, a dominant eastern species, which is also widely spread southward over Central America and northern South America, reaches as far westward as the Great Plains in the panhandle of Texas, eastern New Mexico, and the Arkansas Valley of eastern Colorado. S. gracilipes, a very distinctive type, is known only from several mountain areas in southern Arizona. S. californica occurs rather broadly in desert conditions from western Texas to southern California, southern Nevada, Utah, and western Colorado. S. limbata is broadly intrusive from Mexico, where it is widely 
distributed. In our limits it occurs from central Texas and eastern and northern New Mexico to Needles and Calexico, California.

Within our territory the subfamily Oligonicinae is represented only by the genus Oligonicella, which, like the subfamily, is clearly of Neotropical derivation. The two species of the genus within our limits are known there only from Texas and southern Arizona. One, which elsewhere has a broad distribution in the southeastern United States, extends across Texas to its trans-Pecos section. The other, an intrusive from Mexico, is known only from extreme southern Texas and southern Arizona.

The subfamily Vatinae, a Neotropical assemblage, includes two genera that narrowly enter our territory from northern Mexico. Both also range broadly over Central and South America. One of these genera, Phyllovates, has a single species of much broader distribution occurring with us only in extreme southern Texas, and the other, Vates, is represented by one endemic species in certain mountain areas of extreme southern Arizona.

The subfamily Photininae, all the other members of which are entirely Neotropical, is represented in our territory by one species of the striking genus Brunneria, which ranges from the grass prairie country of east-central Texas to central North Carolina. The North American species of Brunneria, B. borealis, is parthenogenetic - no male has ever been taken, although hundreds of females have been secured at a considerable number of localities. The genus has a discontinuous distribution; no member other than $B$. borealis is known from north of central Brazil, Paraguay, and northern Argentina, where other species occur with the male sex as frequent as the female. All members of the genus are strictly grassland forms, and the postulate that what we see is a reflection of the far greater extent and former broader prevalence of grasslands in the Pliocene, with their marked restriction in the more humid Pleistocene, with the correlated augmentation of lowland forests in that period in the tropics, seems to be the logical explanation. A theory of drift across the Caribbean has been advanced to explain the situation, but the genus does not occur in northern South America as far as known, in fact at no place between Texas and territory much south of the Amazon. Somewhat parallel conditions exist in other genera of the Orthoptera which are grassland forms, and for which the same postulate seems applicable. 


\section{Superfamily Blattodea}

The superfamily Blattodea or cockroaches is represented in North America by twenty-seven genera, of which eleven are regarded as adventives. Some of these were probably introduced several centuries ago in the early historic periods of the Atlantic states and provinces. Others were brought in during the early years of the present century, particularly from the IVest Indies. The original home of a number of these adventives was Africa, and the early transport was by cargo or slave ships. Of these eleven adventives, six are now known to be present in western North America, namely Supella, Blattella, Neostylopyga, Blatta, Periplaneta, and Pycnoscelus. Of these Periplaneta was doubtless brought in by the slave trade, as the genus, while now almost cosmopolitan in the warmer regions, is clearly a native of Africa, where feral species of the genus also occur. Supella probably had a similar history in reaching the West Indies, as it was not known from the United States until the early years of this century, although its dominant species, S. supellectilium, the only one that has reached America, had long been established in the West Indies. The genera Blatta and Blattella reached America in much the same way as the black rat (Rattus rattus) and the Norway rat (Rattus norvegicus), and their spread westward across Europe coincided very much in sequence and time with the spread of the two species of domiciliary rats. Both of these cockroach genera are probably natives of northeastern Africa, where a number of feral species of each genera occur. Pycnoscelus is of Oriental origin, and wild species of the genus are known from Farther India. Today the domiciliary species, $P$. surinamensis, is frequent in subtropical, as well as tropical, America. It presents another case of usual parthenogenesis.

The Oriental genus Neostylopyga, very readily recognized by its form and coloration, is common in the Philippines and also over much of Indo-Malayia, and west to Madagascar and the eastern coast of Africa. The first report of its one domiciliary species, $N$. rhombifolia, in America was made in 1865 . It was reported from Acapulco, Mexico, and from Venezuela and Argentina. From Acapulco it has spread to the Cape Region of Baja California, northward over Sinaloa, and even to the railroad entry port of Nogales, southern Arizona. Acapulco was the port at which in colonial days the Spanish galleons from Manila landed their cargoes 
for land transfer across Mexico for shipment to Spain. In coming years Neostylopyga probably will gradually become established in parts of the southwestern United States, as well as in much of the warmer parts of Mexico.

Seven of the blattid genera that are endemic in western North America can definitely be called Neotropical in origin. The majority belong to the subfamily Pseudomopinae, which is a cosmopolitan assemblage that is highly developed in the Neotropical Region. Of these the genus Euthlastoblatta is known in our territory only from extreme southern Texas, although other members of the genus occur southward to Panama. Latiblattella, another basically Neotropical genus, has a single species in western North America, restricted to certain mountain areas of southern Arizona. A number of other species of Latiblattella occur in Mexico and Central America, and one is endemic in peninsular Florida. The genus Ischnoptera is another very diverse and basically Neotropical genus, of which two species reach North America: the endemic I. deropeltiformis, which is widely distributed in eastern North America and reaches westward as far as central Texas, and I. rufa occidentalis, a race of a widely spread Neotropical species, which has a broad range in Mexico and Central America, entering our territory only on the Gulf Coast of Texas.

The flower-haunting harlequin-patterned cockroach Pseudomops is another very widely spread Neotropical genus, of which a single species enters our territory, and is found in Texas north to the central part of the state. The remaining genus of the Pseudomopinae in our territory is Parcoblatta, which, unlike all the other genera of the subfamily, is strictly limited to North America. Of the twelve species of this genus four eastern ones narrowly impinge on our territory in eastern Texas; bolliana is found westward to central and southern Texas, and north to Nebraska; desertae is distributed from eastern New Mexico to central Texas and Oklahoma; fulvescens ranges westward to central and southern Texas, north to the Red River, but not west of Texas; pensylvanica extends west to central and southern Texas, north to Nebraska; americana is a Pacific species distributed from Oregon to western Arizona and Nevada; and notha is an endemic species of certain mountain areas of central and southern Arizona. Apparently Parcoblatta has developed from a relatively early Neotropical ancestor, and the 
center of differentiation, on the basis of present diversity, presumably was in the eastern and central United States.

Another subfamily of the Blattodea, the Panchlorinae, aside from the already mentioned Pycnoscelus, is represented in our territory by a single species of Panchlora, which may be autochthonous with us in a circumscribed area. The genus is greatly diversified in tropical America, and also has a few endemic species in forested West Africa. The single species we have within our boundaries, $P$. cubensis, is broadly distributed to the southward, but reaches its northern natural limit in the Brownsville area of southern Texas. This insect is often brought in accidentally in bananas, but cannot survive our usual winter conditions. The subfamily Chorisoneurinae is a Neotropical assemblage made up of a large number of species, although but a single genus and species, Chorisoneura texensis, reaches our territory, where it ranges rather broadly over the southeastern United States from North Carolina to eastern and southern Texas in the Brownsville area. The genus, with us, is clearly intrusive from the south, for our representative is the most northern member, and the number of species represented regularly increases as one goes southward in Mexico and Central America.

The subfamily Attaphilinae, the members of which are ant inquilines, is represented in our territory by the single genus Attaphila, of which the genotypic species is known only from central Texas. This genus is represented by a number of other species in South America, and a number of allied genera are found in the Neotropical Region. It is evident that Attaphila, along with its host Atta, has been derived from that great center.

The subfamily Corydinae is represented in North America by a single genus, Compsodes, the sole species of which in our territory is known from the mountains of southern Arizona and from localities in south and central Texas and Baja California. The genus, as well as a number of related ones, is clearly Neotropical in origin. A number of genera of this subfamily are inquilines with various Hymenoptera, as well as with Isoptera.

The morphologically very distinct subfamily Polyphaginae is made up of genera that are largely desert forms, and that show marked antigeny between their sexes. The greater number of the genera, and the bulk of the species, are Palearctic, with others arid Ethiopian. In Neogaea we have representatives of the sub- 
family in North America and in Mexico. The North American species represent two quite distinct genera, one of which, Arenivaga, is now considered by Russian colleagues also to include certain Central Asian species. Of Arenivaga seven species are now recognized in North America, all but one of which are found within the territory covered by this symposium. Several also occur in northern Mexico. The one exception is known only from Florida, but it clearly has been derived from the Sonoran area where the other species have developed. The forms of Arenivaga in our territory range from east-central Texas west to southern California, and north as far as Monterey, California, St. George, Utah, and Oklahoma. The other genus Eremoblatta, is more exclusively a desert type. Its distribution extends from eastern New Mexico and extreme western Texas to the Mohave and Colorado deserts of California, north to Kern County, California, and to Las Vegas. Nevada.

The last genus of the Blattodea to be considered is in some respects one of the most interesting of our North American blattids. This one, Cryptocercus, is the sole member of the subfamily Panesthiinae in the New World. Like many of the other species of the subfamily it lives in dead wood, can digest cellulose, bores channels in dead logs, preferably of fir or chestnut, and is also wingless. In North America the genus, and its single American species, is discontinuously distributed. It is found in the eastern Appalachians and the Appalachian Plateau from New York to Kentucky and Georgia, and again is present in western Washington, the Cascades of Oregon, and possibly the Sierras of California. It is absent from virtually all the Middle West, the Great Plains, the Rockies, and the intervening basins, even where these are heavily timbered. Apparently the separation of the two distinct areas of the distribution of the species has been due to the southward advance of the lobes of the various Glacial ice sheets, which severed previously connected areas and isolated the two elements of the species, in the same way the two segments of the acridoid genus Zubovskya were developed (but in that case specific entities were established). The particularly interesting feature in connection with Cryptocercus is that it, with several distinct species, also occurs in eastern Asia. Clearly we have here a case basically parallel to those of the acridid Zuborskya and the decticid Atlanticus, although the explanations for each may not be identical, but in their patterns they 
are clearly expressive of the roles of Bering Sea connections and of Glacial ice in past biogeographic movements or controls.

\section{CONCLUSIONS}

In the absence of adequate fossil evidence which would integrate with living elements we must draw our relevant evidence from the known centers of existing genera and their allies. Of the 229 genera of Dermaptera and Orthoptera that occur west of the eastern edge of the Great Plains, exclusive of purely Mexican ones, 35\% ( 82 genera) are clearly Sonoran types, using this term in its broad sense or, when limited, to that area of the same east of the Continental Divide. This great evolutionary center has been the outstanding North American center of generic differentiation for Orthoptera. In descending importance $14.8 \%$ (36 genera) clearly were derived from the Neotropical Region; $7.3 \%$ (17 genera) represent a distinctive and endemic coastal and non-Sierran montane California fauna; $6.5 \%$ (15 genera) are endemic there and probably developed in Lower Sonoran Zone deserts; $5.6 \%$ (13 genera) are introduced adventives; $4.8 \%$ (11 genera) are at present Sierran endemics and most probably autochthons, and $5.2 \%$ (12 genera) holds for a group of genera also of Palearctic occurrence or relationship; while $3.9 \%$ (9 genera) similarly are Cordilleran in their present distribution and probable origin. A number of the genera here regarded as developed in the Sonoran center also moved eastward, and subsequently established specific evolutionary centers in the eastern and southeastern United States. I regard 8 genera $(3.5 \%)$ as derived from purely eastern centers of development. The remaining $4 \%$ (13) represents basically Sonoran types that developed subsidiary radiative centers in eastern North America, Mohavan and Great Basin endemic types, cosmopolitan genera, and others considered purely Nearctic Boreal and restricted Campestran. The occurrence of certain genera in both western North America and eastern Asia leaves unanswered the natural query as to whether their original center was in the one or the other, with much of the weight of evidence in some of the genera in favor of a North American, and also definitely pre-Glacial, origin. 


\section{Geographical Origins and Phylogenetic Affinities of the Cerambycid Beetle Fauna of Western North America}

E. Gorton Linsley

University of California, Berkeley

The two previous papers deal with distributional patterns, respectively, of groups of cool-adapted animals, including northern and montane insects, particularly caddisflies and sawflies, and of certain free-living terrestrial forms (Orthoptera and Dermaptera). The Cerambycidae, or long-horned beetles, as larvae, are mostly internal feeders in living, dead, or dying woody plants, a fact that has greatly influenced the distributional and evolutionary history of the family. Nearly 900 species are now known from America north of the Mexican boundary. The adults of a few groups are flightless, but most are relatively strong but somewhat inefficient fliers. They seek the appropriate host plant before or after mating and subsequently oviposit in cracks or crevices in the bark or in notches cut by the female. The degree of host specificity varies. The forms that attack living trees and assemble on the host plant for mating usually exhibit the greatest specificity, and those that attack dead or decomposing wood, the least. The fact that many of the latter group congregate on flowers for mating precludes or weakens selection for host specificity. Thus the close association of Cerambycidae with woody plants and the varying degrees of intimacy in relation to particular trees and shrubs must be considered in any analysis of the origins and affinities of the North American elements of the family.

Based on analyses of contemporary distributions, on phylogenetic and ecological relationships, and on the limited fossil record, the North American cerambycid fauna appears to be a complex of diverse distributional elements or subfaunas, of which five are rather readily identified: a Holarctic element (largely boreal), 
a Neotropical element (largely austral), an Alleghenian element (centering mainly in the Appalachian and Ozark plateaus), a Vancouveran element (centering along the Pacific Coast), and a Sonoran element (centering in southwestern United States and northern Mexico).

The modern Holarctic and Neotropical constituents are of relatively recent derivation and endemism is expressed largely at the species level (Table I). The Alleghenian, Vancouveran, and Sonoran elements are of more ancient origin, although the first two were apparently derived largely from an early Holarctic fauna, and the last originated almost entirely from the early Neotropical. Much of the endemism in these subfaunas is at the generic level (Tables I and II).

TABle I. Primary Geographical Ranges of Contemporary Species of North American Cerambycidae

Number

Holarctic

Nearctic

Alleghenian

Vancouveran

Rocky Mountain

Great Basin

Californian

Sonoran

Austro-Riparian

Neotropical

Totals

$\begin{array}{cc}\text { Number } & \text { Per cent } \\ 9 & 1.03 \\ 14 & 1.60 \\ 264 & 30.28 \\ 147 & 16.86 \\ 39 & 4.47 \\ 27 & 3.09 \\ 45 & 5.16 \\ 194 & 22.25 \\ 46 & 5.28 \\ 87 & 9.98 \\ 872 & 100\end{array}$

TABle II. Contemporary Occurrence of Genera of Cerambycidae Now Represented in North America

IVorld-wide

Holarctic

Number

Per cent

Nearctic

4

1.70

Alleghenian

Vancouveran

10

4.26

Rocky Mountain

30

12.76

16

6.81

Californian

0.85

Sonoran

7.66

Eastern Austral

18.72

Neotropical

2
18

4.26

10

28.51

Totals 


\section{EVIDENCE FROM THE PALEONTOLOGICAL RECORD}

In North America, fossil Cerambycidae have been found only in the Florissant beds of Colorado. The lacustrine deposits at this site contain abundant plant remains and the richest modern-type insect fauna yet discovered on this continent. MacGinitie (1953) made a critical taxonomic and ecological study of the flora, which he regards as of Lower Oligocene age but, based upon vertebrate evidence, R. A. Stirton (in litt.) treats the beds as micldle Oligocene. In any event, by comparing the fossil plant community with living plant communities and considering the chemical and physical aspects of the sediments, MacGinitie has reconstructed the environment as follows:

The Oligocene forest occupied streamside and lakeside habitats in a piedmont of low relief and moderate elevation which bordered the Rocky Mountain uplift on the east. The drainage was disorganized and partly ponded by successive volcanic outbursts which covered the area with dust, pumice, and mudflows.

The fossil fauna and flora were deposited in the resulting shallow and ephemeral lakes. The climate was subhumid and warm temperate, not unlike the present climate of Monterrey, in the state of Nuevo Leon, Mexico. Warm winters and hot summers prevailed, and abundant sunshine is indicated. The vegetation on the high ground, away from the stream and lake borders, was characterized by pines and evergreen oaks and was most probably of an open, scrub-forest type, with grass and microphyll shrubs in the drier areas.

MacGinitie has provided a useful table of the fossil gymnosperms and angiosperms together with the modern occurrence of the most similar living species. Of these last, 57.1 per cent are found in habitats encompassed by a circle of radius 400 miles, centered in southwestern Coahuila, Mexico, especially in the southern Rockies of San Luis Postosi and Texas and northeastern Mexico. The west Mexican and southern Arizona area now contains only three or four additional species. The Ozark-southern Appalachian area and the Asiatic area have nearly equal representation and together comprise 57.1 per cent of the list. These living forms are very largely mesic, streamside types of warm-temperature aspect, and many of their fossil equivalents were found by MacGinitie to be relatively abundant forms. However, nineteen of the Ozark species are also found elsewhere; only six are unique to the region. The species now living in California he regards as having no particular 
ecological significance as a group, being either wide-ranging forms or species with restricted distribution isolated by events of the late Tertiary and Pleistocene.

Less than thirty species of Cerambycidae have been named from these beds (Linsley, 1942). Among the species that are well enough preserved to permit interpretation (Table III), about two-thirds are northern types and some of these are very close to, if not identical with, living forms. About half of these belong to genera that are

TABLE III. Modern Occurrence of Some Genera of Cerambycidae Represented in the Oligocene Beds of Florissant, Colorado ${ }^{a}$

Genus

Gaurotes

Anoplodera

Grammoptera

Leptura

Callimoxys

Semanotus

Phymatodes

Pidonia

Saperda

Dryobius

Leptostylus

Psapharochus

Megacyllene

Stenosphenus

$\begin{array}{cccccc}\text { Fossil Recent } & \text { Recent } & \text { Recent } & \text { Recent } & \text { Recent } \\ \text { Floris- } & \text { East } & \text { Alle- } & \text { Mexican Van- } & \text { Euro- } \\ \text { sant Asiatic ghenian } & \text { Plateau couveran pean }\end{array}$

$\begin{array}{lcrrrr}1^{b} & 3 & 2 & 3 & 1 & 1 \\ 2+ & 12 \pm & 12 & 2 & 23 & 20 \pm \\ 1 & 2 \pm & 3 & - & 4 & 9 \pm \\ 2 & 10 \pm & 5 & - & 5 & 20 \pm \\ 1 & - & 1 & - & 1 & 1 \\ 1 & 1 & 1 & - & 3 & 4 \\ 2 & 6 \pm & 5 & - & 10 & 15 \pm \\ 2 & - & 4 & - & 1 & 2 \pm \\ 2 & 8 \pm & 15 \pm & - & 1 & 9 \pm \\ 1 & - & 1 & - & - & - \\ 1 & - & 6 \pm & 15 \pm & 1 & - \\ 1 & - & 1 & 8 \pm & - & - \\ 1 & - & 3 & 8 \pm & - & - \\ 1 & - & 1 & 12 \pm & - & -\end{array}$

${ }^{a}$ Modified from Linsley (1939, 1942).

${ }^{b}$ Numerals indicate approximate number of known endemic species (widely distributed species excluded).

now more or less equally represented in the present day Vancouveran and Alleghenian subfaunas. Grammoptera, Anoplodera, Leptura, and Gaurotes are flower-visiting forms of low host specificity associated with dead and decomposing conifers and hardwoods; Callimoxys attacks Ceanothus and certain other shrubby plants (the fossil form suggests the modern Alleghenian subspecies); Semanotus is now associated largely with Taxodiaceae and Cupressaceae; and Phymatodes includes some species that attack conifers and some that attack hardwoods (the fossil species resemble the latter). Six species belong to genera better represented today in the Alleghenian sub- 
fauna than in the Vancouveran (Pidonia, Leptostylus, and Saperda, now associated with broad-leaved deciduous trees) and four belong to genera found in the present Alleghenian but not in the Vancouveran (Dryobius, Stenosphenus, Psapharochus, and Megacyllene, which are also associated with hardwoods, the last with Carya and Robinia, which were represented in the Florissant flora). Among the fossil genera with recognizable affinities, Protospondylis is apparently related to the living genera Spondylis (with one species in the Palearctic Region, one in the Vancouveran subfauna, another on the Mexican Plateau, but none in the Alleghenian) and Scaphimus (one living species in the Alleghenian). All known members of this group are associated with conifers (Pinaceae). Protipochus and Parolamia appear to be related to forms now living in the Mediterranean region. The affinities and/or interpretations of the remaining fossil genera are obscure.

In Europe among the oldest records for species that might belong to modern cerambycid genera are fragments from the Middle Eocene of the Geisel Valley near Halle (Pongracz, 1935). Baltic Amber contains many fine examples, but these have not been adequately studied, although modern Holarctic genera are well represented (Klebs, 1910). From Early and Middle Tertiary, Handlirsch (1908) listed 70 species, but most need to be reexamined in the light of current classifications. However, Statz (1938) reported on a small sample of cerambycids from the Middle Oligocene sediments at Rott am Siebenbirge, all of which could be placed in modern genera (about half are now Holarctic in distribution, the remainder Palaearctic). He emphasized that the varied and rich growth of deciduous trees and shrubs of the Rott environment provided an abundance of living and decaying wood for larval development and numerous composites, umbellifers, and flowering shrubs for pollen-feeding adults, yet cerambycids represent only 0.6 per cent of the known beetle fauna in contrast to the 9 per cent of the living forms. Although, in part this may reflect lower population levels in the family, Statz considers that their over-all representation in the Tertiary record as from 3 to 4 per cent of the beetle fauna reflects a less highly developed group, at least in the Early and Middle periods, than at present.

Although no later fossil Cerambycidae are known from North America, Axelrod (1956) has characterized several Mio-Pliocene 
floral provinces in the Far West. These represent the beginnings of our modern floral and climatic provinces and undoubtedly had a profound influence on the distribution and evolution of the present fauna of cerambycid beetles. In his words:

... a North-coastal province, extending along the coast from Washington to central California, supported a relict warm-temperature facies of the Arcto-Tertiary Geoflora. At the north it graded inland in to the Columbia Plateau province which was characterized by a typical temperate ArctoTertiary Geoflora, and which gave way at higher levels and eastward to a cool-temperate conifer facies. Near its southern margin the North-coast province merged eastward into a floodplain facies of the Arcto-Tertiary Geoflora which occupied central California, extending to the foothills of the ancestral Sierra Nevada. On these better-drained slopes the floodplain forest was replaced by vegetation representing an ecotone between the Arcto-Tertiary and Madro-Tertiary Geofloras; owing to its near-coastal position this ecotone included more humid types than that in westcentral Nevada. At higher levels in the Sierra, Madro-Tertiary species were supplanted by the more mesic, temperate Arcto-Tertiary plants. A South-coastal province, extending from coast-central into southern California, was characterized by arid subtropical climate in which a relict Neotropical-Tertiary Geoflora was in ecotone with the subhumid Madro-Tertiary Geoflora. To the eastward, in the drier interior Mojave province, the Madro-Tertiary Geoflora was dominant, grading northward rapidly into an ecotone with the Arcto-Tertiary Geoflora in west-central Nevada.

MacGinitie has contributed to this symposium a vivid account of the Tertiary climates of western North America. These have profoundly influenced the distributional and phylogenetic histories of the modern floras of western North America, including the redwood forest, the black oak-madrone forest, the North Coast Douglas fir forest, the upland conifer forest of the Sierra Nevada, and the Rocky Mountain forest (Mason, 1947), which support large segments of the endemic cerambycid fauna.

According to Axelrod (1948), most of the important trees and shrubs now characterizing the Redwood, Sierra-Cascade, Rocky Mountain, and North-coast conifer forests have close equivalents in the West American Element of Miocene floras from the Columbia Plateau and adjacent areas. These species are in such genera as Abies, Acer, Alnus, Amelanchier, Betula, Castanopsis, Chamaecyparis, Cornus, Fraxinus, Gaultheria, Libocedrus, Lithocarpus, Mahonia, Rhododendron, Rosa, Salix, Sequoia, Sorbus, Thuja, Tsuga, 
and Vaccinium and their modern counterparts are largely hosts of Vancouveran Cerambycidae with northern affinities. Regularly associated with these plants are fossil species that find their nearest relatives in the temperate, summer-wet eastern portions of North America and Asia. In the East American Element are fossil species in genera no longer indigenous to the region west of the Rocky Mountains, such as Carya, Carpinus, Castanea, Fagus, Liquidambar, Nyssa, Taxodium, and Ulmus, whose closest counterparts are now found in eastern North America and serve as hosts for Alleghenian Cerambycidae. Also included in this element are fossil species of genera such as Acer, Betula, Crataegus, Fraximus, Populus, Prumus, Smilax, Quercus, and Vaccinium which have their nearest relatives in eastern North America. Members of the East Asian Element are distributed in Ailanthus, Cercidiphyllum, Ginkgo, Keteleeria, Metasequoia, and Pterocarya, genera no longer indigenous to North America; in species of Carya, IIamamelis, Iydrangea, Ostrya, Lindera, Sassafras, and other genera that are represented also in eastern North America; and in certain fossil species of Acer, Abies, Picea, Populus, Quercus, and Prunus, which have their nearest homologues in the temperate forests of eastern Asia.

Another important modern ecological type, the Woodland formation, with dominant live oaks and such associated conifers as pinyon pine, juniper, and digger pine, according to Axelrod, makes up a prominent part of the Madro-Tertiary Flora, which ranged widely over southwestern North America in middle and later Tertiary times. Members of the Sierra Madrean Element have their nearest equivalent species in summer-wet areas extending from the Cape region of Baja California across the Sierra Madre of eastern and western Mexico and into the southwestern United States. This element includes plants that are no longer represented generically in California, Nevada, or Colorado, such as Bumelia, Clethra, Eysenhardtia, Ilex, Pistacia, Robinia, Sapindus, Ungnadia, and Zanthoxylum, as well as certain species of Arbutus, Cupressus, Forestiera, Fraxinus, Populus, Quercus, and Rhus that now have their closest homologues in areas with summer rains and mild winters. The California Woodland Element, with species in such genera as Celtis, Juglans, Lyonothamnus, Platanus, Pinus, Populus, Prumus, Quercus, and Umbellularia, finds its nearest relatives making up living California woodland associations. Cerambycidae 
attached to these woodland associations exhibit both northern and southern affinities.

Chaparral, according to Axelrod (1948) in such genera as Arctostaphylos, Ceanothus, Cercocarpus, Dendromecon, Fremontia, Garrya, Photinia, Quercus (scrub oak), and Rhus, has a large representation in the Madro-Tertiary Flora. Close relationship is apparent with the sclerophyllous associations now in California, Arizona, and Coahuila. The Cerambycidae now associated with this formation include several forms with southern affinities discussed below as "Californian" as well as overflow species classed as Vancouveran.

\section{EVIDENCE FROM PRESEN'T DISTRIBUTIONAL PATTERNS OF PIYLOGENETIC RELA'TIONSIIIPS OF CONTEMPORARY GENERA AND SPECIES}

The modern Holarctic elements of the cerambycid fauna appear to be more or less equally represented in the northern forests and mountainous regions of Europe, Asia, and eastern and western North America. Their distribution reflects Postglacial dispersal and their hosts are largely spruces and other northern and high-elevation Pinaceae or northern-type deciduous trees as Salix and Populus (Salicaceae). In western North America these are the dominant Cerambycidae of the Canadian and Hudsonian life zones, but occur also in dilute form in the coniferous phases of the Transition and Upper Austral life zones, and a few species are represented in the high-altitude coniferous forests at least as far south as Guatemala. Representative genera of this Holarctic fauna include: Asemum, Arhopalus, and Tetropium of the Aseminae; Callidium, Semanotus, Xylotrechus, and Clytus of the Cerambycinae; Toxotus, Pidonia, Grammoptera, Leptura, and Anoplodera of the Lepturinae; and Monochamus, Acanthocinus, and Pogonocherus of the Lamiinae. In addition to genera, there are a number of species with a similar circumpolar or Holarctic distribution. Among these are Tragosoma depsarium (Linnaeus), Asemum striatum (Linnaeus), Arhopalus rusticus (Linnaeus), Stenocorus inquisitor (Linnaeus), Acmaeops pratensis (Laicharting), Pachyta lamed (Linnaeus), Judolia sexmaculata (Linnaeus), and Saperda populnea (Linnaeus). The last of these is associated with poplar, the remainder with conifers.

The recent neotropical elements, derived from areas of high temperatures and humidity and attached largely to southern-type 
hardwoods and Leguminosae, have penetrated northward very unequally. They are largely restricted to the Austro-Riparian belt bordering the Gulf of Mexico, the Atlantic coastal plain, and a few warm river valleys as those of the Mississippi, the lower Rio Grande, and the lower Colorado. About a half dozen wide-ranging species in this category reach southeastern California, e.g., Achryson surinamum (Linnaeus), Dendrobias mandibularis Audinet-Serville, Lissonotus flavocinctus Dupont.

Representatives of the recent Neotropical elements of the Nearctic region include the following genera: Archodontes and Stenodontes (Prioninae); Strangalia, Euryptera, and Ophistomis (Lepturinae); Smodicum, Eburia, Elaphidion, Chion, Psyrassa, IIeterachthes, Ibidion, Plinthocoelium, Megacyllene, Euderces, Rhopalophora, Ancylocera, Agallisus (Cerambycinae); and Lagocheirus, Leptostylus, Leiopus, Lepturges, Eupogonius, Oncideres, Ecyrus, Hippopsis, and Spalacopsis (Lamiinae). Some of these groups apparently came into North America by way of the Antilles and are poorly represented on the coastal plain of Mexico, e.g., Spalacopsis. The majority of the species of West Indian origin are not found north of the southern tip of Florida, most appear to be recent arrivals, and none has reached western North America. However, the largest representation of subtropical Cerambycidae in the United States is found in the lower Rio Grande Valley of Texas. More than eighty species have been collected in this area, and all have southern affinities. Twenty-two occur also in the Austro-Riparian or Carolinian life zones of southeastern United States, ten in the Sonoran subfauna, and the remainder are strictly Neotropical. Thus these faunal elements bear little relationship to those of western North America. Only one austral genus, Neoclytus, has successfully invaded all the northern forests, and it is extremely doubtful if this is a recent arrival. The genus is most highly developed in South America and is entirely absent from the Old World, thus suggesting southern affinities, yet its wide distribution in North America indicates that it must have been established very early in the Tertiary. The majority of the species feed upon broad-leaved and hardwood trees, but $N$. mubilus Linsley and $N$. muricatulus Kirby are restricted to conifers.

The term "Alleghenian" was proposed by Wallace (1876) to designate a large area covering much of eastern North America 
More recently it has been used in reference to the subfauna that centers in the Appalachian and Ozark plateaus. It includes a large number of endemic cerambycid genera and species. The affinities of these beetles are predominantly and clearly northern, but in many respects their relationships appear to be nearer to those now found in the Japano-Manchurian region than with those in the present day Vancouveran of western North America. Unlike the recent Holarctic elements, which are associated mainly with conifers and northern type hardwoods, the Alleghenian species are mostly found on lowland hardwoods, where they exhibit a preference for areas with warm, humid summers, and apparently have little tolerance for cold and for high altitudes. Few of the Alleghanian species have successfully penetrated the Canadian and Hudsonian life zones.

One of the most interesting of the old, relict endemics in the Alleghenian subfauna is the primitive monotypic genus Scaphinus, which represents one of the two living genera of its subfamily. Its only relative is Spondylis, with a single species in the Palaearctic regions, another in the Vancouveran, and a third in the high mountains of the Mexican plateau. Other endemic genera with relatives in eastern Asia or southern Europe are: Cytrophorus and Microclytus (the only New World Anaglyptini), Zammodes, Tylonotus, Physocnemum, Cyrtinus, Psenocerus, Hetoemis, and Dorcaschema. At least one genus, Michythisoma, is now phylogenetically isolated, but all its living relatives, although distant, are associated with northern coniferous forests.

Some endemic Alleghenian species fall in Old World genera not found elsewhere on this continent (Table IV). Genera like Ropalopus, Hesperophanes, and Clytanthus, highly developed in the Palearctic region, have one species each in the Alleghenian subfauna. Other species, numerous in the Alleghenian, represent Holarctic genera absent, or nearly so, from the Vancouveran subfauna. The genus Saperda, with two postglacially dispersed, poplar-feeding species occurring from coast to coast, includes fifteen endemic species associated with various deciduous elements of the Alleghenian forest, and one in the Vancouveran subfauna, S. hormi Joutel, attached to Salix. Similarly, Oberea has eighteen Alleghenian endemics with various deciduous hosts, and one (O. quadricallosa LeConte, also attached to Salix) in the Vancouveran. The Old World-Alleghenian genera Tetrops and Typocerus are both absent 
from the Vancouveran, and Gaurotes is represented by only a single species in that subfauna.

The present Alleghenian subfauna is not, however, entirely composed of northern elements. A few southern derivatives became established at a date early enough for them to persist as endemics, e.g., the clytine genera Glycobius and Sarosesthes, and the lepturine genera Bellamira, Charisalia, and Strangalia. Several Neotropical

Table IV. Discontinuous Distribution of Some Holarctic Genera of Cerambycidae Differentially Represented in the Vancouveran and Alleghenian Faunas of North America ${ }^{a}$

$$
\begin{gathered}
\text { Western } \\
\text { North } \\
\text { America }
\end{gathered}
$$

(Van-

Genus

Hesperophanes

Rhopalopus

Clytoleptus

Saperda

Oberea

Spondylis

Rosalia s. str.

Cortodera

$X y$ losteus

Ergates

Callimellum

Plectrura

$$
\text { couveran) }
$$

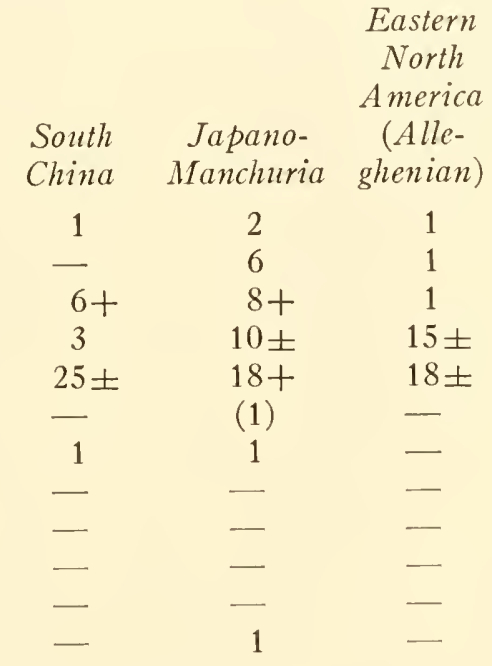

Eastern America

(Alle-

Europe

\begin{tabular}{c}
$7 \pm$ \\
$10+$ \\
$8+$ \\
$9+$ \\
$8+$ \\
$(1)$ \\
1 \\
$25+$ \\
1 \\
1 \\
9 \\
\hline
\end{tabular}

a Numerals indicate approximate numbers of known endemic species.

genera e.g., Neoclytus, Leptostylus, Lepturges, and Leiopus, also give evidence of having come in to the fauna at an early date, and indeed, some of these are represented in the fossil beds at Florissant. The early southern elements may be eastern counterparts of the "Californian" discussed below, but in the absence of climatic barriers that have maintained the integrity of the "Californian" they have apparently blended with the northern Alleghenian elements and shared their late Tertiary geological history.

The Vancouveran subfauna (Van Dyke, 1919, et seq.), in its purest form, occurs along the coast of western North America from the Aleutian Islands to central California, more broadly in the 
Bitter Root and northern Rocky Mountains, the Cascades, Sierra Nevada, and the detached mountain systems of southern California and northern Baja California (San Bernardino, San Jacinto, and San Pedro Mártir Mountains). In more dilute form, clements are recognizable in the southern Rocky Mountains as well as in the high coniferous forests of southern Arizona and northern Mexico

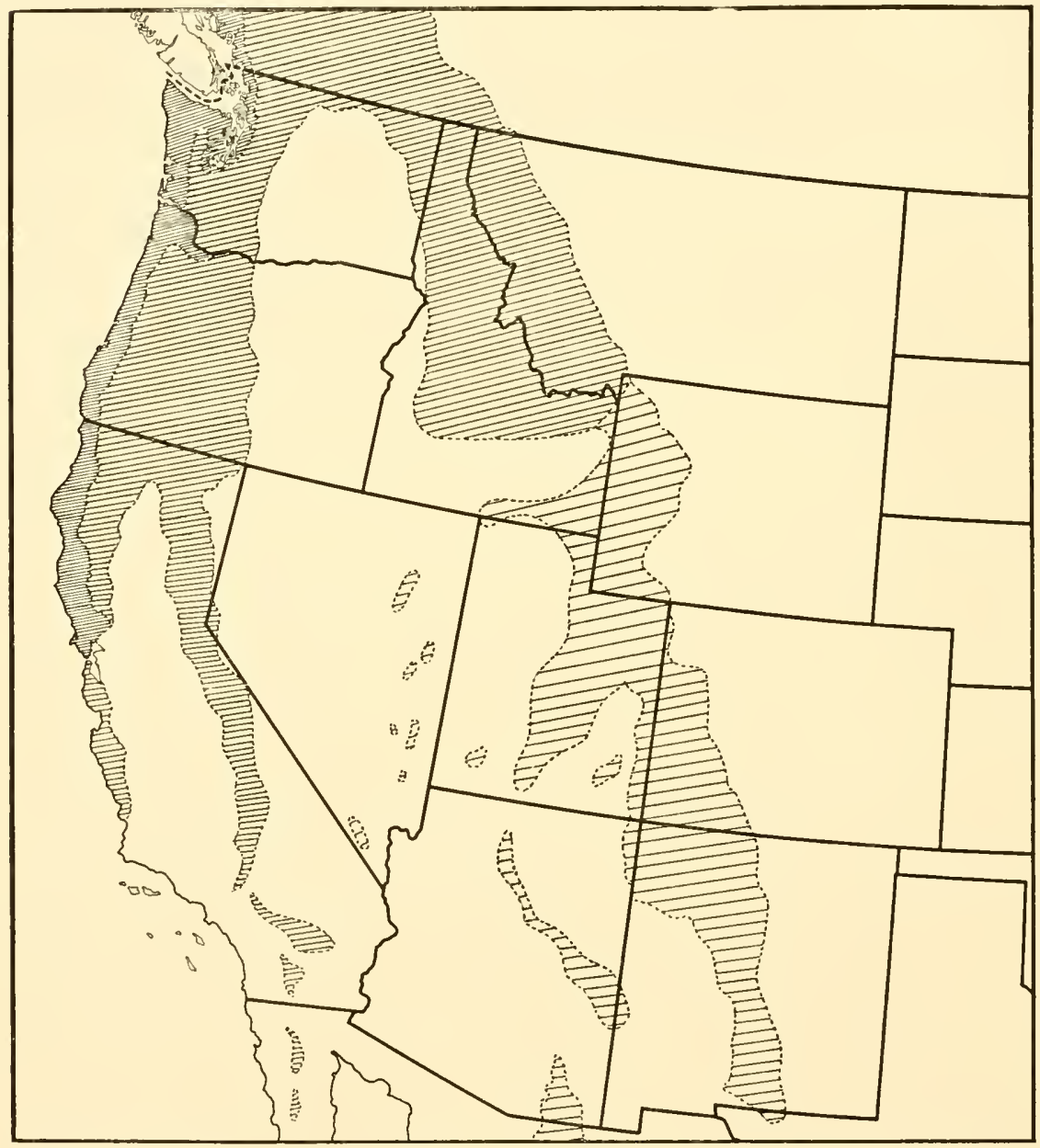

Fig. 1. Primary geographical ranges of some Cerambycidae classed as Vancouveran in the narrowest sense (dark shading), broader sense (with addition of intermediate shading), and widest sense (with addition of lightest shading). 
(Fig. 1). These are the dominant Cerambycidae of the Transition Life Zone of Merriam (1898) and show closer affinities with those of Europe and eastern Asia than with their Alleghenian counterparts in eastern North America. Thus, in the Vancouveran subfauna, we find the endemic Opsimus and Dicentrus (only New World Saphanini), Synaphaeta (only New World genus of Mesosini), and Brothylus, Leptalia, Ulochaetes, Hybodera, and Lophopogonius, all with related genera in the Old World. Several other genera share species with both the Vancouveran subfauna and those of the Palearctic Region, but not the Alleghenian (Table IV). These include Plectrura (one species in Japano-Manchurian region, one in Vancouveran); Spondylis (one species Palearctic, one Vancouveran); Megasemum (one species in Japano-Manchurian, one in Vancouveran); Callimellum (eight species in southern Europe and Asia Minor, two in Vancouveran); Cortodera (numerous species in both Europe and Vancouveran); Xylosteus (one species in southern Europe, one in Vancouveran); and Rosalia (one species in Japano-Manchurian, two in south China, one in Europe, one in Vancouveran). Other genera endemic in the Vancouveran fauna are Xylocrius (two species), Poecilobrium (one species), Eumichthus (one species), Holopleura (one species), Ortholeptura (three species), Piodes (one species), and Pyrotrichus (one species). Presumably all these have ancient northern affinities.

The relict trees of the genus Sequoia, growing within the area occupied by the Vancouveran subfauna, are hosts of several endemic cerambycid species or subspecies (all members of the tribe Callidini). These include Callidium vandykei Linsley, C. sempervirens Linsley, and Semanotus ligneus sequoiae Van Dyke, which are limited to the coast redwood (Sequoia sempervirens), and Callidium sequoiae Fisher, on the big tree ( $S$. gigantea). A more striking group of Cerambycidae is found on the Sargent Cypress (Cupressus sargentii) which grows only in a few restricted areas of serpentine rock in the foothills of northern California. Confined to this host are Vandykea tuberculata Linsley, Atimia helenae Linsley, and Callidiellum cupressi (Van Dyke). The last species has a close relative, C. rufipenne (Motschulsky, in Japan, associated with Crytomeria japonica and Chamaecyparis obtusa, another, C. villosulum (Fairmaire), in China, on Cunninghamia lanceolata, all members of the Cupressaceae or 
Taxodiaceae. However, Vandykea is isolated taxonomically and apparently has southern rather than northern affinities, and I have classed it as "Californian" (see below).

In Oregon and California, the Sierra-Cascades (arid) phase of the Vancouveran subfauna is quite distinct from the coastal (humid) phase, although the two approach each other more closely in Washington and merge in British Columbia. In general, most Cerambycidae that occur in the Sierra-Cascade Vancouveran are found also in the coastal phase. Apparent exceptions include: Desmocerus auripennis Chevrolat, Tetropium abietis Fall, Oeme californica Linsley, Pachyta armata LeConte, Leptura obliterata soror LeConte, Semanotus amethystinus LeConte, Clytus planifrons LeConte, C. clitellarius Van Dyke, Neoclytus nubilus Linsley, and Leptostylus nebulosus Horn. Species of the coastal Vancouveran not known to occur in the Sierra-Cascade phase include: Evodinus vancouveri Casey, Leptura obliterata obliterata LeConte, Desmocerus cribripennis Horn, Callidium vandyke, C. sempervirens Linsley, Clytus blaisdelli Van Dyke, and Plectrura spinicauda Mannerheim. Melanism is a marked characteristic of the humid Vancouveran and is particularly pronounced in Purpuricenus dimidiatus Horn, Necydalis laevicollis LeConte, and Judolia quadrillum LeConte.

The Rocky Mountain area, lying between the Vancouveran and Alleghenian endemic reservoirs, has few endemic cerambycid genera of its own (e.g., Elatrotrypes, with ancient northern affinities), and the intermountain or Great Basin area contains only one, the monotypic Megascheuma, obviously derived from the austral Megacyllene and adapted for life in the roots of shrubby compositae. The present cerambycid fauna is made up primarily of Holarctic elements of recent origin, with an intrusion of Vancouveran forms, especially in the north and, to a lesser extent, of Sonoran elements in the south. A few Alleghenian representatives are to be found on the eastern slopes of the mountains, emphasizing a long separation of Vancouveran and Alleghenian elements, and these are mostly recent arrivals, many of which have followed up the river courses from the Mississippi Valley, e.g., Neoclytus caprea Say. The Great Plains area to the east, which apparently began to develop some of its present characteristics in the Miocene, has produced the prionine subgenus Homaesthesis, and this, like Megascheuma, exhibits 
specialization for life associated with plant roots (in this case, of prairie grasses).

The endemic Sonoran elements among the Cerambycidae are almost entirely of early Neotropical derivation (in the geographic sense) and exhibit various modifications of structure and habit associated with the arid conditions under which they now exist. They are characteristic of the Lower Sonoran Life Zone of Merriam and occupy most of the central and northwestern plateaus of Mexico, western Texas, much of New Mexico and Arizona, southeastern California and eastern Baja California, and they are associated with desert trees, shrubs, and Cactaceae, e.g., Aneflus, Osmidus, Anepsyra, Rhodoleptus, Metaleptus, Schizax, Tylosis, Plionoma, Taranomis, Sphaenothecus, Batyle, Moneilema, Peritapnia, Coenopus, and Glaucotes. Other genera, dominantly Neotropical, but well represented in the Sonoran (and also in the Austro-Riparian) are: Derobrachus, Methia, Elaphidion, Ophistomis, Euryptera, Stenosphenus, Elytroleptus, Stenaspis, Dendrobias, Acanthoderes, Oncideres, and Ataxia. A major derivative of the Sonoran fauna occupies the intermountain area of the Great Basin. It is represented by genera (e.g., Crossidius, Tetraopes, Mecas) associated with the roots of shrubby Compositae ( as Artemisia and Chrysothammus) and asclepiads. However, in the mountains, Eucrossus and Haplidus are present. These are endemic genera with southern affinities, primarily associated with pinyon pine, which I have classed as "Californian" in the broad sense. The small endemic subfauna, designated by Van Dyke (1919) as the "Californian"' is also deserving of brief discussion. In its restricted form it occurs from the middle of the west coast of Baja California to Santa Barbara County and in the interior from the San Pedro Mártir Mountains to the Tehachapi region of southern California (Fig. 2). This area is characterized by many endemic groups of insects, particularly in the Tenebrionidae, and corresponds generally to the center of distribution attributed to the broad-sclerophyll vegetation of the Pacific Coast by Cooper (1922), although many of the forest elements included in his classification could be called "Vancouveran" on the basis of the Cerambycidae associated with them. In a broader

${ }_{1}$ This term is applied in various senses by students of biogeography and ecology. I have not attempted to determine priority of usage. 
sense the "Californian" includes some elements now occurring in the foothill region of the western Sierra Nevada and in the eastern Coast Range, surrounding the great valley of California, and in the Chiricahua and certain other mountain ranges of southern Arizona

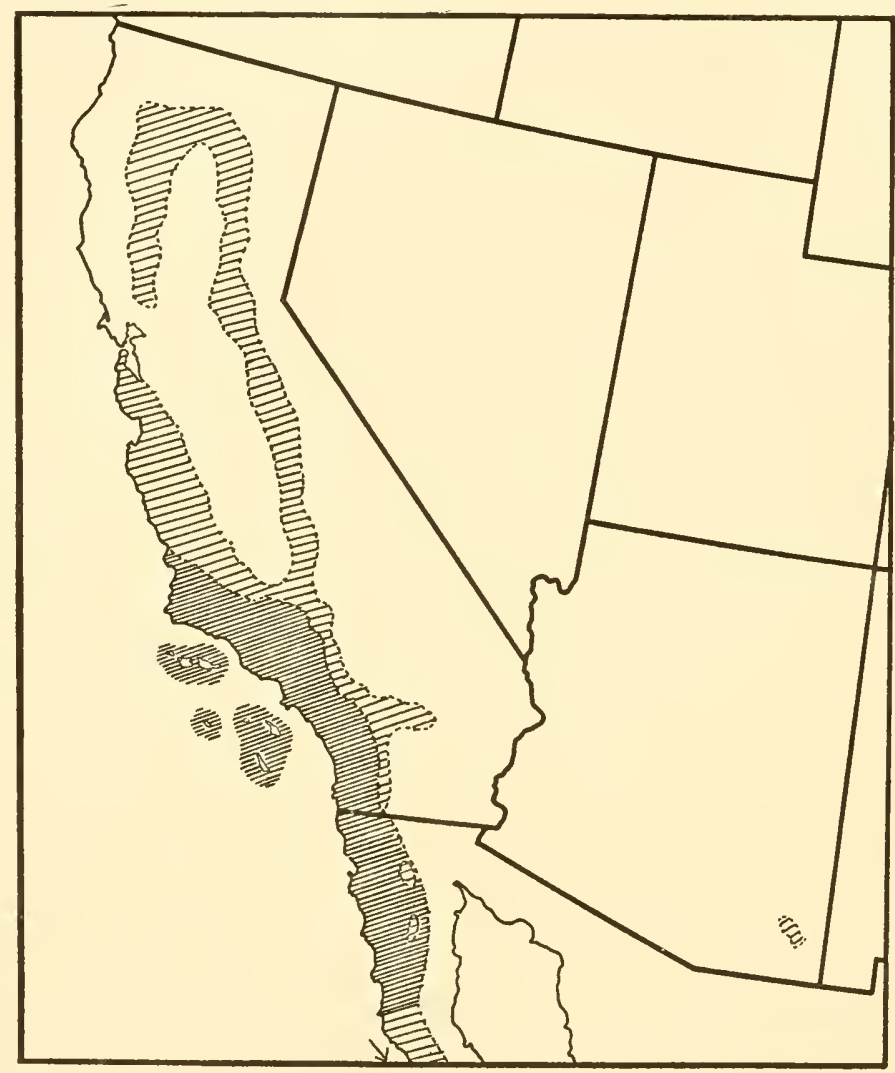

Fig. 2. Primary geographical ranges of some Cerambycidae classed as Californian in the narrowest sense (dark shading), and intermediate sense (with addition of the lighter shading). Note that some of these overlap the ranges of forms classed as Vancouveran (Fig. 1).

(Fig. 2), and is sparsely represented in the Great Basin montane (not shown in Fig. 2). Generally speaking, this is the cerambycid fauna of the Upper Sonoran Life Zone of Merriam, but it is often mixed with elements derived from the Sonoran and Vancouveran subfaunas, especially the latter in so far as the Cerambycidae are concerned. 
Like the Sonoran, the "Californian" subfauna has southern affinities but it is older, perhaps comparable in age with the Vancouveran. It exhibits relationship with elements now found in the montane phases of the Mexican Plateau, but, judging from the beetles, at least some of its affinities suggest a closer relationship to the contemporary faunas of the arid and semi-arid west coast of South America (Peru, Galápagos, Chile, etc.) than to those of humid tropical America. As has been emphasized previously (Linsley, 1939), it appears probable that some time during the later Tertiary a series of arid or semi-arid environments permitted the dispersal of elements between the west coasts of North and South America. It is possible that these environments were associated with mountain ranges or chains of islands. At present, portions of the peninsula of Baja California and the islands off the coast of southern California exhibit arid (landward) phases and humid (seaward) phases, the former usually characterized by desert or semi-desert conditions, and Michener (1954) has emphasized that xeric communities now exist in the vicinity of the Canal Zone in Panama. Such arid phases might well have offered north-south dispersal routes for plants and animals.

Among the Cerambycidae, a typical Californian genus is Ipochus, a wingless group of closely related species or subspecies which occupies an area from the middle of Baja California north to Santa Cruz, California, including Guadalupe and Catalina islands, and is also represented in the Huachuca Mountains. Other groups with southern (but not Sonoran) affinities, apparently assignable as endemics of the Californian in the broad sense, include the monotypic genera Megobrium, Eudistenia, Meganoplium, Paranoplium, Hesperanoplium, Neobellamira, Triodoclytus, and Sternidocinus (associated primarily with oaks and chaparral shrubs); Vandykea, which is attached to Sargent Cypress; Eucrossus and Haplidus, occurring primarily with pinyon pine; and the polytypic genus Poliaenus, with one species limited to Fremontia (a chaparral type), others to pinyon and digger pines (woodland types).

The California insular fauna has been treated as a subdivision of the Californian, but among the Cerambycidae, except as noted for Ipochus (above), no endemic elements are known and typical Californian elements are present (Fig. 2). Mason (1934) has shown that the modern closed-cone pine forest now occupies areas that 
can be demonstated to have been islands in the late Tertiary or which are insular today (islands off the coasts of southern California and Baja California). Insect distributional patterns reveal a similar discontinuity, not only among phytophagous wood-boring forms but in such flightless groups as Pleocoma (Scarabaeidae) and Omus (Cicindelidae). Among the Cerambycidae, this distribution is evident in Megobrium edwardsi (LeConte), Ortholeptura insignis (Fall) (hosts: Pinus muricata, P. radiata), and Paratimia conicola Fisher (in cones of Pinus attenuata and P. bolandari). Other species of the old California insular fauna apparently include Sternidocinus barbarus (Van Dyke) and Necydalis barbarae Van Dyke. The distribution of the former centers in the Santa Inez Mountains, the latter in the region from Santa Barbara north to the Santa Cruz Mountains. The Californian species Ipochus fasciatus LeConte and Atimia maritima Linsley, the Vancouveran Xylotrechus insginis LeConte, and the widespread but austral Romaleum hispicorne (Linnaeus) all occur today on one or more of the southern California islands but, with the exception of the first two, give evidence of being recent immigrants.

\section{SUMMARY}

Judging from an analysis of present day distribution and the limited fossil record, the North American cerambycid fauna is a complex of diverse elements of which five are rather readily identified: the Holarctic, Neotropical, Alleghenian, Vancouveran, and Sonoran. The modern Holarctic and Neotropical constituents are of relatively recent derivation, and endemism is expressed largely at the species level. The Alleghenian, Vancouveran, and Sonoran elements are of more ancient origin, although the first two were apparently derived largely from an early Holarctic fauna associated with the Arcto-Tertiary flora, the last almost entirely from the early Neotropical. Much of the endemism in these subfaunas is at the generic level.

The modern Holarctic elements are more or less equally represented in the northern forests and mountainous regions of Europe, Asia, and eastern and western North America. Their distribution reflects Postglacial dispersal. Their hosts are largely conifers and northern-type deciduous trees as Salix and Populus. In western North America these are the dominant Cerambycidae of the 
Canadian and Hudsonian life zones, but they are also represented in the coniferous phases of the Transition and Upper Sonoran.

The recent Neotropical elements, derived from areas of high temperatures and humidity and attached largely to southern-type hardwoods and Leguminosae, have penetrated northward very unequally. They are largely restricted to the Austro-Riparian belt bordering the Gulf of Mexico, the Atlantic coastal plain, and a few warm river valleys like those of the Mississippi, the lower Rio Grande, and the lower Colorado. About a half-dozen wide-ranging species in this category reach southeastern California.

The Vancouveran elements, in their purest form, occur along the coast of western North America from the Aleutian Islands to Central California, in more dilute form in the Bitter Root and northern Rocky Mountains, the Cascades, Sierra Nevada, San Bernardino, San Jacinto, and San Pedro Mártir Mountains. These are the dominant Cerambycidae of the Transition Life Zone and they show closer affinities with those of Europe and eastern Asia than with their Alleghenian counterpart in eastern North America.

The endemic Sonoran elements are almost entirely of early Neotropical derivation and exhibit various modifications of structure and habit associated with the arid conditions under which they now exist. They are characteristic of the Lower Sonoran Life Zone and occupy most of the central and northwestern plateaus of Mexico, western Texas, much of New Mexico and Arizona, southeastern California and eastern Baja California and are associated with desert trees, shrubs, and Cactaceae. A major derivative of the Sonoran fauna occupies the intermountain area of the Great Basin. It is dominated by genera associated with the roots of shrubby Compositae (as Artemisia and Chrysothammus) and asclepiads.

A small endemic cerambycid subfauna with southern affinities occurs from Monterey County, California, to the middle of the west coast of Baja California and in the interior from the Techachapi area to the San Pedro Mártir; its influence is also seen in the foothill areas surrounding the central valley of California and in some of the mountain ranges of southern Arizona. This subfauna, sometimes called the "Californian," also has an insular phase. Some affinities with the subfauna now occurring along the arid west coast of South America but the Californian also has characteristics of its own, and about a dozen endemic cerambycid genera, mostly mono- 
typic, have been assigned to it. It appears to have been associated with the Madro-Tertiary Flora.

\section{REFERENCES}

Axelrod, D. I. 1948. Climate and evolution in western North America during middle Pliocene time. Evolution, 2: 127-144.

- 1956. Mio-Pliocene floras from west-central Nevada. Univ. Calif. Publs. Entomol. 33: 1-322.

Blackwelder, R. E. 1946. Checklist of the coleopterous insects of Mexico, Central America, the West Indies and South America, Pt. 4. U. S. Natl. Museum, Bull., 185: 551-763.

Bradley, J. C. 1956. The distribution of northeastern insects. Entomol. News, 57: 257-261.

Cockerell, T. D. A. 1908. Fossil insects from Florissant, Colorado. Bull. Am. Museum Nat. Hist., 24: 59-69.

. 1916. Some American fossil insects. Proc. U. S. Natl. Museum, 51: 89-106.

Cooper, W. S. 1922. The broad-schlerophyll vegetation of California, an ecological study of the chaparral and its related communities. Carnegie Inst. Washington Publ. 319: 1-124.

Darlington, P. J. 1938. The origin of the fauna of the Greater Antilles, with a discussion of the dispersal of animals over water and through the air. Quart. Rev. Biol., 13: 274-300.

Davis, A. C. 1932. A list of the Coleoptera of Ft. Tejon, California. Bull. Southern Calif. Acad. Sci., 31: 75-87.

Dorf, E. 1933. Pliocene Floras of California. Carnegie Inst. Washington Publ. 412: 1-112.

Fall, H. C. 1897. List of the Coleoptera of the southern California Islands. Can. Entomologist, 29: 233-244.

1901. List of the Coleoptera of southern California. Occ. Paper Calif. Acad. Sci., 8: 1-282.

Fall, H. C., and A. C. Davis. 1934. The Coleoptera of Santa Cruz Island, California. Can. Entomologist 66: 143-144.

Garnett, R. T. 1918. An annotated list of the Cerambycidae of California. Can. Entomologist, 50: 172-177, 205-213, 248-252, 281-284.

Gressitt, J. L. 1951. Longicorn beetles of China. Longicornia, 2: 1-667. Hamilton, J. 1889. Catalogue of the Coleoptera common to North America, Asia, and Europe. Trans. Am. Entomol. Soc., 16: 88-162.

Handlirsch, A. 1908. Die fossilen Insekten und die Phylogenie der rezenten Formen. Leipzig. pp. 1121-1430.

Hardy, G. H. 1926. Cerambycidae of Vancouver Island. Rept. Prov. Museum Brit. Columbia, 1926: 1-10.

Horn, G. H. 1876. Notes on the Coleoptera of Guadalupe Island. Trans. Am. Entomol. Soc., 5: 198-201. 
Horn, G. H. 1894. The Coleoptera of Baja California. Proc. Calif. Acad. Sci., 4: 302-449.

Hulten, E. 1937. Outline of the History of the Arctic and Boreal Biota during the Quaternary Period. Stockholm.

Klebs, R. 1910. Über Bernsteineinschlüsse im allegemeinen und die Coleopteren meiner Bernsteinsammlung. Schrift. Physik.ökonom. Ges. Königsberg, 51: 217-242.

LeConte, J. L. 1859a. The Coleoptera of Kansas and eastern New Mexico. Smithsonian Contribs. to Knowledge, 11: 1-58.

- 1859b. Catalogue of the Coleoptera of Ft. Tejon, Calif. Proc. Acad. Nat. Sci. Phil., 1859: 69-90.

Linsley, E. G. 1939. The origin and distribution of the Cerambycidae of North America with special reference to the fauna of the Pacific slope. Proc. Sixth Pacific Sci. Congr., 4: 269-282.

- 1942. A review of the fossil Cerambycidae of North America. Proc. New Eng. Zoöl. Club, 21: 17-42.

Linsley, E. G., and J. O. Martin. 1933. Notes on some longicorns from subtropical Texas. Entomol. News, 44: 178-183.

MacGinitie, H. D. 1953. Fossil plants from the Florissant beds, Colorado. Carnegie Inst. Washington, Publ. 599: 1-198.

Mannerheim, G. C. G. 1843. Beitrag zur Kaefer-Faana der Aleutischen Inseln, der Insel Sitkha und New-Californiens. Bull. Soc. Naturalistes Moscow, 16: 175-314.

. 1846. Nachtrag zur Kaefer-Fauna der Aleutischen Inseln und der Insel Sitkha. Bull. Soc. Naturalistes Moscow, 19: 501-516.

- 1852. Zweiter Nachtrag zur Kaefer-Fauna der Nord-Amerikenischen leander des Russischen Reiches. Bull. Soc. Naturalistes Moscow, 25: 283-387.

-_ 1853. Dritter Nachtrag zur Kaefer-Fauna der Nord-Amerikenischen leander des Russischen Reiches. Bull. Soc. Naturalistes Moscow, 26: 95-273.

Mason, H. L. 1934. A Pleistocene Flora of the Tomales Formation. Carnegie Inst. Washington, Publ. 415: 81-179.

- 1936. The principles of geographic distribution as applied to floral analysis. Madroño, 3: 181-190.

- 1947. Evolution of certain floristic associations in Western North America. Ecol. Monographs, 17: 201-210.

Merriam, C. H. 1898. Life zones add crop zones of the United States. U. S. Dept. Agr., Bur. Biol. Survey, Bull. 10: 7-79.

Michener, C. D. 1954. Bees of Panamá. Bull. Am. Museum Nat. Hist., 104: 5-175.

Mitono, T. 1940. Cerambycidae. Catalogus coleopterorum japonicorum, pars $8: 1-283$.

Pongrácz, A. 1935. Die eozäne Insektenfauna des Geiseltales. Nova Acta Leopoldina Carol., 2: 483-572. 
Schaeffer, C. 1908. List of longicorn Coleoptera of Brownsville, Texas, and Huachuca Mts. Bull. Brooklyn Inst. Arts Sci., 1: 325-352.

Scudder, S. H. 1878. An account of some insects of unusual interest from the Tertiary Rocks of Colorado and Wyoming. Bull. U. S. Geol. Geog. Surv. Terr., 4: 519-543.

- 1890. The Fossil Insects of North America, with Notes on Some European Species. New York. 2 vols.

Statz, G. 1938. Fünf neue fossile Cerambyciden-Arten aus den mitteloligocänen Ablagerungen von Rott am Siebenbirge. Entomol. Blätter, 34: 173-179.

Van Dyke, E. C. 1919. The distribution of insects in western North America. Ann. Entomol. Soc. Am., 12:1-12, map.

- 1924. The Coleoptera collected by the Katmai Expeditions. Natl. Geogr. Soc. Contribs., Tech. Paper 2: 1-26.

- 1926. Certain peculiarities of the Coleopterous fauna of the Pacific Northwest. Ann. Entomol. Soc. Am., 19:1-12.

. 1929. The influence which geographical distribution has had in the production of the insect fauna of North America. Trans. IV Intern. Congr. Entomol., 2: 555-566.

Vogt, G. B. 1949. Notes on Cerambycidae from the Lower Rio Grande Valley, Texas. Pan-Pacific Entomol., 25: 137-144, 175-184.

Wallace, A. R. 1876. The Geographical Distribution of Animals. London. 2 vols.

Wickham, H. F. 1911. Fossil Coleoptera from Florissant, with descriptions of several new species. Bull. Am. Musem Nat. Hist., 30: 53-69. - 1912. A report on some recent collections of fossil Coleoptera from the Miocene shales of Florissant. Univ. Iowa Lab. Nat. Hist., 6: 49-67.

1913a. Fossil Coleoptera from the Wilson Ranch near Florissant, Colorado. Univ. Iowa Lab. Nat. Hist., 6: 3-29.

. 1913b. The Princeton collection of fossil beetles from Florissant. Ann. Entomol. Soc. Am., 6: 359-366.

-. 1913c. Fossil Coleoptera from Florissant in the United States National Museum. Proc. U. S. Natl. Museum, 45:283-303, 5 pls.

1914a. Twenty new Coleoptera from the Florissant Shales. Trans. Am. Entomol. Soc., 40: 257-270, pls. 5-8.

- 1914b. New Miocene Coleoptera from Florissant. Bull. Museum Comp. Zool. 58: 423-492.

- 1916. New fossil Coleoptera from Florissant. Bull. Nat. Hist. Soc. Univ. Ioria, 7: 10.

- 1917. New species of fossil beetles from Florissant, Colorado. Pror. IT. S. Natl. Museum, 52: 463-472. 


\section{Distribution of Butterflies in the New World}

William Hovanit?.

Department of Biology, California Institute

of Technology, Pasadena

The butterfly fauna of North America is probably better known than that of any other large group of insects. The reason for this is clear: butterflies are day fliers and thus are apparent to everyone. They are brightly colored and therefore have been collected for non-scientific purposes, for collection hobbyist etc. The result of this activity has been both advantageous and disadvantageous to the knowledge of the group from a scientific standpoint. On the advantageous side is the tremendous job done by the non-scientific or semi-scientific workers on ferreting out butterfly haunts over the entire world and making this information available in collections and the literature, so that the geographic distributions of this group of insects is better known than that of any other. On the disadvantageous side is the lack of organized study on the butterflies due to lack of biological education by the hobbyists on the one hand, and lack of much work by scientific workers created by fear that work in this field will place them in the light of immature or peculiar "butterfly collectors."

Butterflies are a major evolutionary branch of Lepidoptera, adapted to day-flying habits. It is not certain that the group as a whole has had a common origin, or is therefore a natural group. It is almost certain that the skippers (Hesperiidae) originated independently. No data are given for the Hesperiidae because they are not regarded as naturally related to the other families, even though they have commonly been considered to be a part of the butterflies, and because the taxonony of the group involves special problems that do not lend themselves well to this analysis.

The families of butterflies other than the Hesperiidae are fairly distinct, but appear to be closely related. All groups seem to have had a past history of tropical origin. Since their body temperature 
approximates that of the environment, their activity depends on warmer temperatures. The Papilionidae, Pieridae, Danaidae, Morphidae, Satyridae, Brassolidae, Nymphalidae, Erycinidae, and

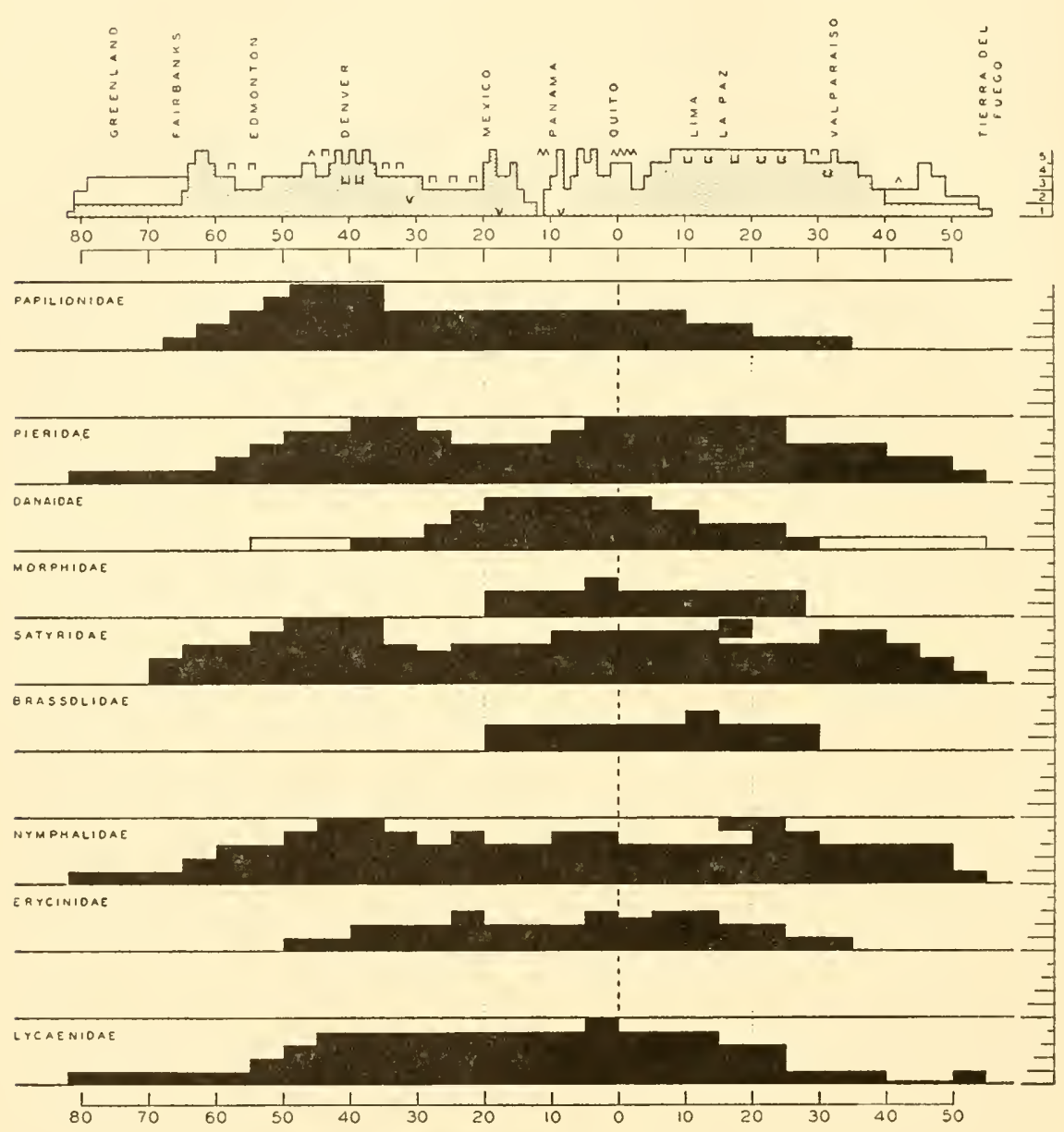

Fig. 1. New World distribution of butterfly families.

Lycaenidae are all represented by far more genera or species in the tropical parts of the world than in the temperate or boreal parts. Independently, certain genera or species of some of these families appear to have become adapted to life in colder regions, so that some of these would be considered as arctic types or temperate types, despite the fact that the family as a whole is tropical. 


\section{DISTRIBUTION OF MAJOR GROUPS (EXCLUSIVE OF THE HESPERIIDAE)}

The distribution of the major taxonomic groups in North and South America is shown by a series of histograms (Figs. 1-19). The histograms are constructed in the following manner. Blocks indicating distributional range are drawn on a scale from left $=$ north to right $=$ south, reading from $82^{\circ} \mathrm{N}$. Lat. to $55^{\circ} \mathrm{S}$. Lat. Each block covers $5^{\circ}$ of latitude and 1,000 meters of elevation above sea level. For example, in the charts on distribution of the Papilionidae (Figs. $2-3$ ), if a species exists at an elevation of 1,500 meters at $46^{\circ} \mathrm{S}$. Lat., this fact is indicated by a block extending from right to left at $45^{\circ}-50^{\circ} \mathrm{S}$. Lat. and up and down from 1,000 to 2,000 meters. On some histograms, where the data warrant and the distributional relations are thereby clarified, the bars are terminated between the arbitrary $5^{\circ}$ class limits, and, occasionally, the altitudinal limits are set at 500-meter intervals. Where the ranges are disjunct, a line has been drawn to connect the base of the separated parts. Where the altitudinal information on a genus is inadequate, the latitudinal distribution is indicated by a thin line.

For comparison with these ranges, a histogram is shown at the top of each figure to indicate the extent of land and habitat available in North and South America, for the absence of a butterfly group in any area may be caused by the absence of a particular elevation at a certain latitude so that no habitat is available there.

This comparative chart is drawn in the same way as those for the butterflies, with the exception that blocks of $1^{\circ}$ latitude are used instead of $5^{\circ}$. Also, since in some areas high elevations are represented solely by a few mountain peaks, these are indicated by the sign $\wedge$, while short ranges are indicated by $\Pi$, mountain passes (breaks in distributional ranges) are indicated by $\sqcup$, and three areas of nearly complete break in the cordillera are indicated by $\vee$.

All areas potentially inhabitable by butterflies are shaded; areas of perpetual frost or cold, in Greenland and southern Chile, are unshaded.

Generic names of the butterflies are taken from Seitz's Macrolepidoptera of the World, even though it is now known that many of these are not correctly used. The reason for this usage is to avoid difficulty in identification due to conflicting opinions.

From the chart of the families (Fig. 1) it can be seen that the 
Papilionidae inhabit America from $68^{\circ} \mathrm{N}$. Lat. to $35^{\circ} \mathrm{S}$. Lat., and range to their highest elevations $(4,000-5,000$ meters) in the latitudes $35^{\circ} \mathrm{N}$. to $49^{\circ} \mathrm{N}$. only. South of $35^{\circ} \mathrm{N}$. Lat., the elevation drops off to less than 3,000 meters, south of $10^{\circ} \mathrm{S}$. Lat. to 2,000 meters, and south of $20^{\circ} \mathrm{S}$. Lat. to 1,000 meters. This distribution indicates a large tropical group of Papilionidae that does not exist in the higher, colder parts of the Andes, and also indicates a northern group that exists in the far north and in the mountains of the temperate zone. This northern group apparently has not been able to extend southward in to the mountains of the tropical regions.

The Pieridae on the other hand have a wider range, extending from $82^{\circ} \mathrm{N}$. Lat. to $55^{\circ} \mathrm{S}$. Lat.- the entire possible range of land. They also inhabit the largest part of available elevations at all points, and are absent primarily only from the higher elevations in the extreme north and south. For further understanding of this group one must study its constituents in the following charts.

The Danaidae occupy primarily a centralized tropical position, from $40^{\circ} \mathrm{N}$. Lat. to $30^{\circ} \mathrm{S}$. Lat., and occur at high elevations only in the equatorial regions. Summer extensions of range are shown by white bars to $55^{\circ} \mathrm{N}$. Lat. and to $55^{\circ} \mathrm{S}$. Lat.

The Morphidae are indicated to be even more tropical, as they probably do not reach the Tropic of Cancer and extend little beyond the Tropic of Capricorn. Within these limits, however, they range locally up to 3,000 meters. The range in the south (to $28^{\circ} \mathrm{S}$.) is greater than in the north (to $20^{\circ} \mathrm{N}$.).

The Satyridae are indicated to have a very complex distribution, covering most available habitats from north to south and at all elevations. In distribution they resemble the Pieridae, but they do not extend quite so far north.

The distribution of the Brassolidae is shown to be almost equivalent to that of the Morphidae, as each is wholly tropical. As for certain other tropical groups, the distribution of this family ranges upward to 3,000 meters and farther southward than northward.

The Nymphalidae are a large group, with a range equivalent to that of the Pieridae in both elevation and latitude, but they usually do not extend so high in the equatorial regions.

The Erycinidae are largely tropical, but extend northward to $50^{\circ} \mathrm{N}$. Lat. and southward to $35^{\circ} \mathrm{S}$. Lat., and upward to 3,000 meters in the broad center of the range. This family thus has a range similar 
to that of the Danaidae, Morphidae, and Brassolidae, except for the greater north-south distribution.

The Lycaenidae occupy a strangely tropical-appearing range, but extend to $82^{\circ} \mathrm{N}$. and to $40^{\circ} \mathrm{S}$. Lat. In the equatorial regions they range up to 5,000 meters, and from $45^{\circ} \mathrm{N}$. to $15^{\circ} \mathrm{S}$. they continuously extend up to 4,000 meters. These ranges must be studied individually by analyzing their constituents, since some forms in the group are clearly cold-adapted.

Observation of the charts as a whole shows that members of the Pieridae, Nymphalidae, and Lycaenidae extend farther to the north than do any other families. The first two are joined by the Satyridae in extending to the southern tip of South America. There are, by the way, no butterflies in Antarctica.

The Lycaenidae equal the Pieridae and the Nymphalidae in northernmost range, and in southernmost range nearly equal those families, as well as the Satyridae and the summer migrants of the Danaiidae. Next in order of northernmost occurrence are the Satyridae and the Papilionidae, each of which nearly reaches to $70^{\circ} \mathrm{N}$. Lat. The Satyridae extend all the way to the tip of South America, along with the Nymphalidae and the Pieridae, but do not extend so far north. All the other families have much more restricted northsouth distributional ranges, and should be considered tropical in their entirety.

The same families that extend far into the north and south latitudes are also found at high elevations in the mountains of the middle latitudes of North America: the Papilionidae, the Pieridae, the Satyridae, the Nymphalidae, and the Lycaenidae. Contrary to expectation, these families are not necessarily the same ones that are found at the highest elevations in the mountains of the equatorial belt, here treated and charted as from $20^{\circ} \mathrm{N}$. Lat. to $20^{\circ} \mathrm{S}$. Lat. Instead, some of the purely tropical families exceed the northern ones in elevation in this belt, where they occupy cold zones high in the mountains. For example, the tropical Danaidae exist up to 4,000 meters in a broad equatorial belt, where the Papilioniclac do not exceed 3,000 meters. Elevations reached by the Papilionidae, the Satyridae, and the Nymphalidae are considerably higher in the middle latitudes of North America than in the central equatorial latitudes.

Of the six families with resident examples in the northern lati- 
tudes north of $40^{\circ} \mathrm{N}$, , only three extend beyond $40^{\circ} \mathrm{S}$. South of the equatorial belt the butterfly fauna is quite depauperate, because of the relative lack of typically cold-adapted forms of northern origin. On the other hand, many typically tropical forms are seen to extend farther southward than northward for reasons that can only be conjectured but are probably a combination of (1) lack of competitive forms in the far south and (2) warmer winters at the same latitudes south of the equator than to the north.

\section{DISTRIBUTION OF GENERA AND SOME SMALLER GROUPS}

Following the chart (Fig. 1) that compares the distributions of the families of American butterflies, block histograms (Figs. 2-19) are presented to show the latitudinal and altitudinal distributions of the genera and of certain lesser groups, when this is deemed desirable. The histogram for each family is repeated, in finely crosshatched form, at the head of the series of black histograms for the contained genera. Within the family divisions coarsely hatched histograms for the recognized subfamilies head the appropriate series of black histograms. As a variation in the scheme, below the black histogram (on Fig. 2) showing the distribution of the first-entered genus, Papilio, there are given three coarsely hatched histograms, each of which gives the range of one of the main "groups" into which this large genus is first divided. Each of the hatched histograms is in turn followed by black histograms for the contained natural species groups; and the first of the three main divisions, the Aristolochia Papilios, is first divided into sections A and B (also shown in black). Under the papilionid genus Parnassius black histograms portray the distribution of the three American species. In the Satyriidae, under the genus Euptychia, black histograms show the ranges of the 27 species groups. Otherwise, the black histograms portray the distribution of genera.

\section{Papilionidae (Figs. 2-3)}

This family is represented by only four genera, of which one (Papilio) is very large and is subdivided many times. It probably should be divided into many genera or subgenera, but so far no other really good natural division has gained acceptance. The groups as organized by Jordan are satisfactory for our purpose.

The genus Papilio has almost the same distributional range as the 

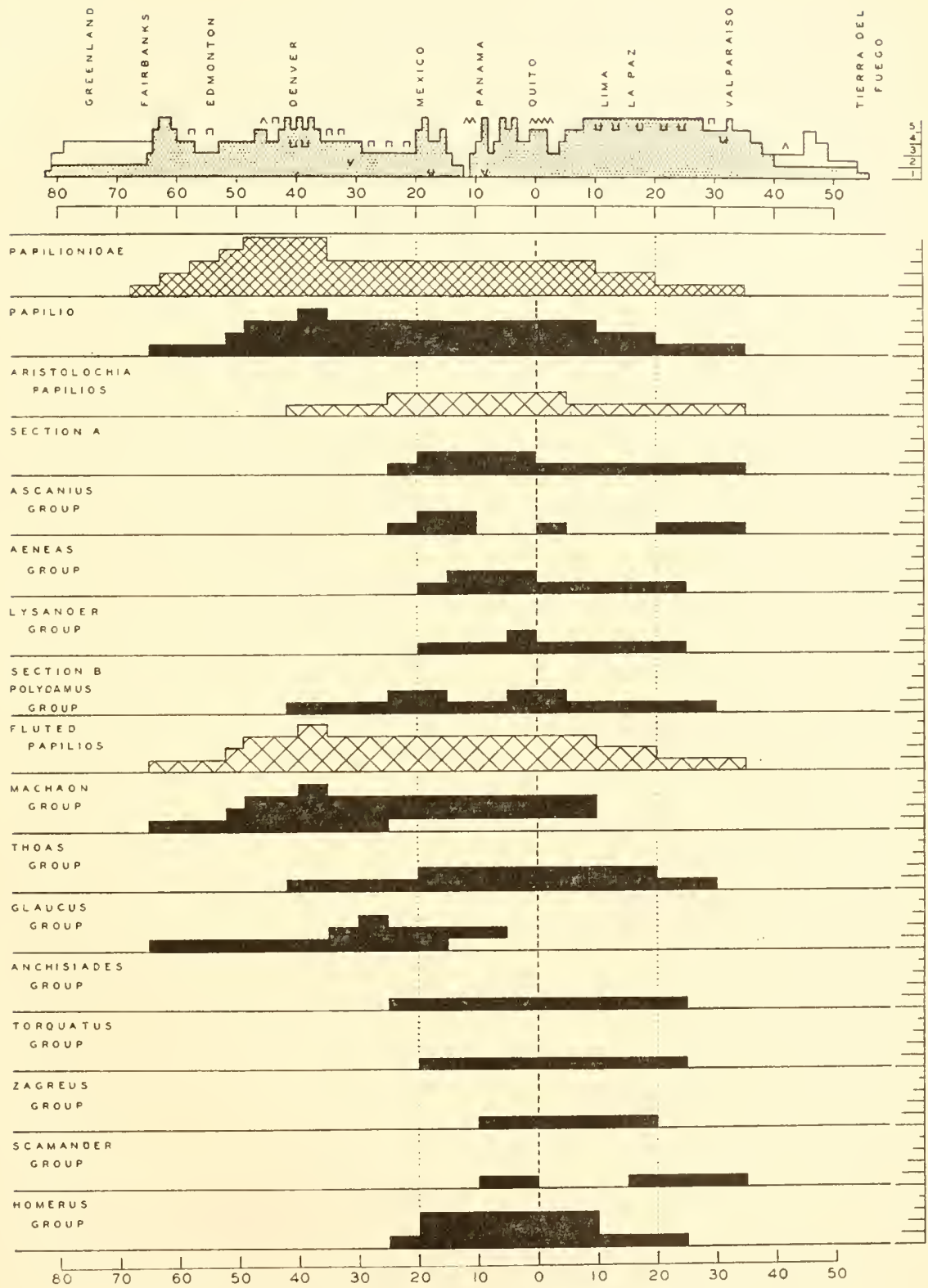

Fig. 2. New World distribution of Papilionidae (1). 


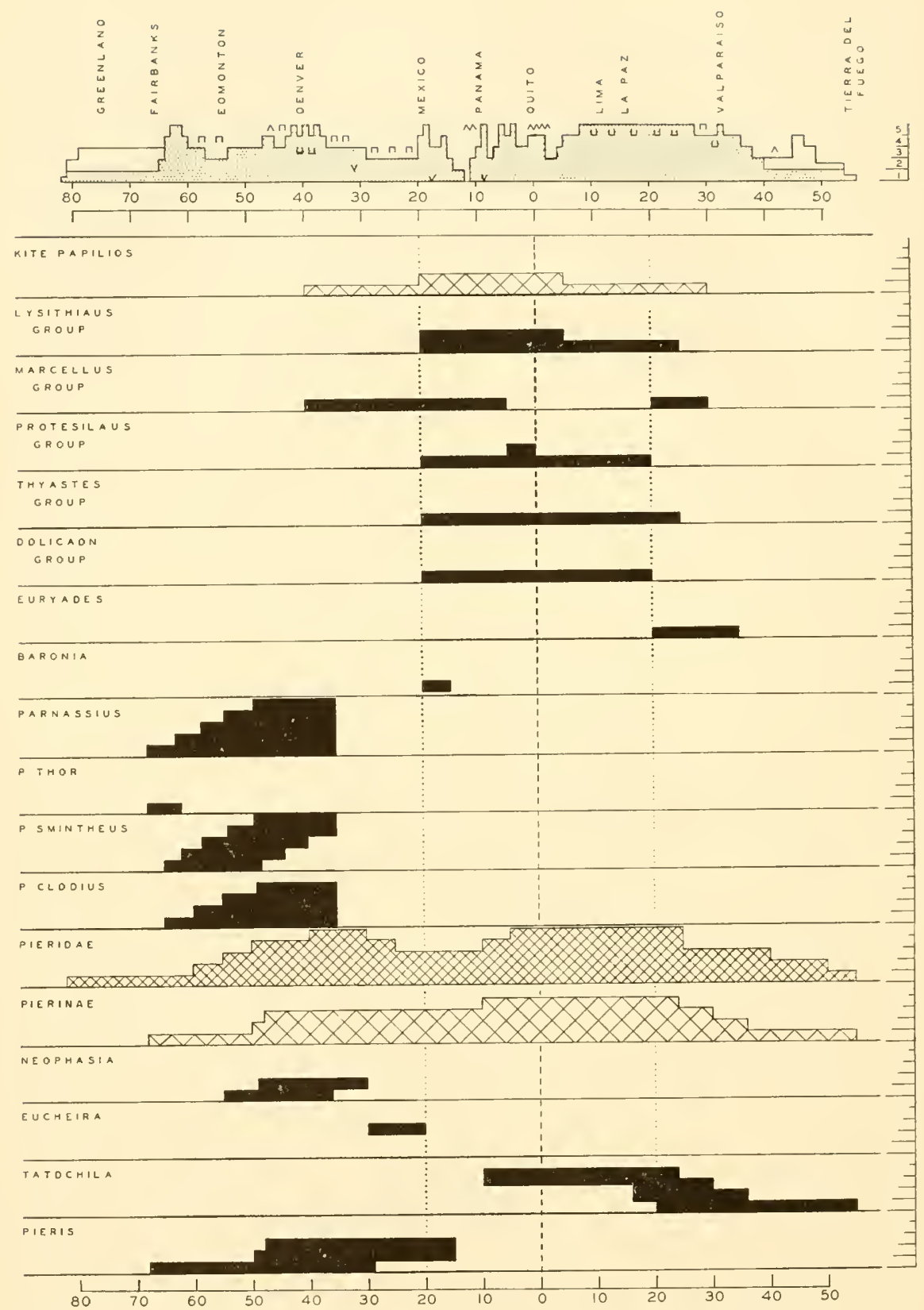

Fig. 3. New World distribution of Papilionidae (2) and Pieridae (1). 
family, being exceeded by the family only in the northern parts of the range and only by the genus Parnassius. The latitudinal range is greater in the north than the south, going to $65^{\circ} \mathrm{N}$. and to only $35^{\circ} \mathrm{S}$. Also, the elevations attained are higher in the north than in the south: to 4,000 meters at about $35^{\circ} \mathrm{N}$. Lat. and to only 1,000 meters at $35^{\circ} \mathrm{S}$. Lat.; to 3,000 meters at $10^{\circ}$ to $20^{\circ} \mathrm{N}$. Lat. but to only 2,000 meters at $10^{\circ}$ to $20^{\circ} \mathrm{S}$. Lat. The distribution of the genus has a northern skew, because, as shall be seen below, some groups of northern origin are superimposed in the north on groups of tropical or equatorial origin.

The genus is subdivided into three natural groups, the Aristolochia, the Fluted, and the Kite Papilios. The Aristolochia group, extending from $42^{\circ} \mathrm{N}$. Lat. to $35^{\circ} \mathrm{S}$. Lat. has a tropical range, extending into the non-equatorial regions only where winter temperatures are not too cold and long. Elevations to 2,000 meters are attained in the equatorial range. Of two sections of the Aristolochia Papilios, only one, comprising the Polydamus group, extends north of the equatorial area more than $5^{\circ}$. The other section $(A)$ is tropical, but extends farther south $\left(35^{\circ} \mathrm{S}\right.$.) than north $\left(25^{\circ} \mathrm{N}\right.$.). This section consists of three natural groups (Ascamius, Aeneas, and Lysander), which have about the same range in the equatorial region.

The Fluted Papilios have nearly the same range as the genus itself, and comprise both northern and tropical members. The species groups considered here are clearly seen on the chart to be divisible into two parts, a northern part consisting of the Machaon and Glaucus groups and an equatorial part consisting of the remaining six groups. The Machaon and Glaucus groups extend to $65^{\circ} \mathrm{N}$. Lat. and the Machaon group reaches 3,000-4,000 meters in elevation in the region of $35-40^{\circ} \mathrm{N}$. Lat. Both groups extend in to the equatorial regions at middle elevations (2,000-4,000 meters) and the Machaon group extends as far as $10^{\circ} \mathrm{S}$. Lat. in the Andes. The Glaucus group does not reach across the barrier presented by the Panamanian isthmus. Of the tropical groups, only Thoas extends much north of the Tropic of Cancer and then only to $42^{\circ} \mathrm{N}$. Lat. Except for the Homerus group, the others are strictly equatorial and tropical, not exceeding 1,000 meters in elevation. The Homerus group ranges up to 3,000 meters in the equatorial belt.

The equatorial Kite Papilios are represented north of the Tropic of Cancer only by the Marcellus group. The Lysithiaus and Thyastes 
groups extend slightly farther south than north. The Marcellus group extends to $40^{\circ} \mathrm{N}$. and to $30^{\circ} \mathrm{S}$., with an apparent gap of some $25^{\circ}$.

The genera Euryades and Baronia are considered as primitive members of the Papilionidae. Their distributional ranges are typical of relict species at the far corners of a once wider range. Euryades exists in the southeastern part of South America where it has a latitudinal range of $15^{\circ}$ on the plains. It extends to $35^{\circ} \mathrm{S}$. Lat., which is as far south as is reached by only one group in Papilio. Baronia is isolated in southern Mexico, where it exists with a range of less than $5^{\circ}$ latitude and of less than 1,000 meters elevation.

Parnassius, the remaining genus in the Papilionidae, is northern in origin and distribution. It has a range from nearly $70^{\circ}$ to $35^{\circ} \mathrm{N}$. Lat. and occurs at elevations from sea level to 5,000 meters. The three species that comprise the genus in America are indicated separately: $P$. thor is restricted to a range of less than $10^{\circ}$ latitude at near sea level in Alaska; $P$. smintheus occurs from sea level in the north $\left(65^{\circ} \mathrm{N}\right.$.) to 5,000 meters in the south $\left(35^{\circ} \mathrm{N}\right.$. $) ; P$. clodius is found from sea level in the north $\left(65^{\circ} \mathrm{N}\right.$.) to both sea level and 5,000 meters in the south $\left(35^{\circ} \mathrm{N}\right.$.) (it accomplishes this dual range in the south by existing along the cool-summer Pacific Coast as well as in the cool-summer mountains of the interior).

Pieridae (Figs. 3-5)

This large family covers the entire range of land from north to south and at nearly all elevations. It is subdivisible into four natural groups, the Pierinae, the Rhodocerinae, the Euchloinae, and the Dismorphiinae. Except for the last, each of these is large in itself and covers almost the same range as the family. The range of the Pierinae is less than that of the Pieridae only in that it extends in the far north only to $68^{\circ} \mathrm{N}$. Lat. instead of to $82^{\circ}$ and reaches lower elevations in North and South America. The subfamily consists of several genera, most of which are divisible into types with narrow temperature tolerance. Neophasia is limited to a range of $30^{\circ}$ to $55^{\circ} \mathrm{N}$. Lat., and should be considered one of the rare types of temperate origin. Eucheira is a relict type found only from $20^{\circ}$ to $30^{\circ} \mathrm{N}$. Lat. at elevations of from 2,000 to 3,000 meters.

Tatochila has an unusual distributional range in that it exists from $55^{\circ} \mathrm{S}$. Lat. to $10^{\circ} \mathrm{N}$. Lat., wholly within the continent of South 

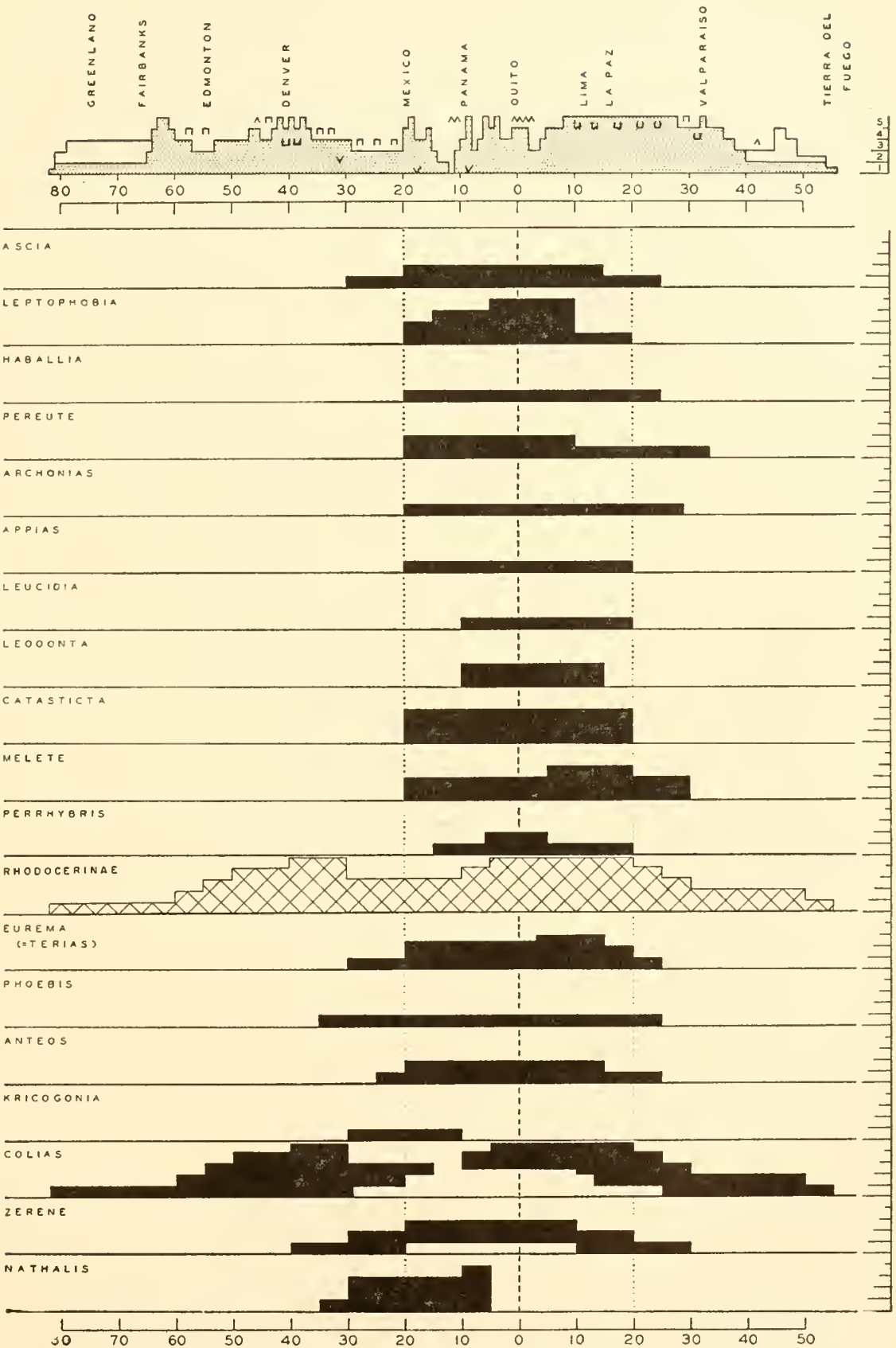

Fig. 4. New World distribution of Pieridae (2). 


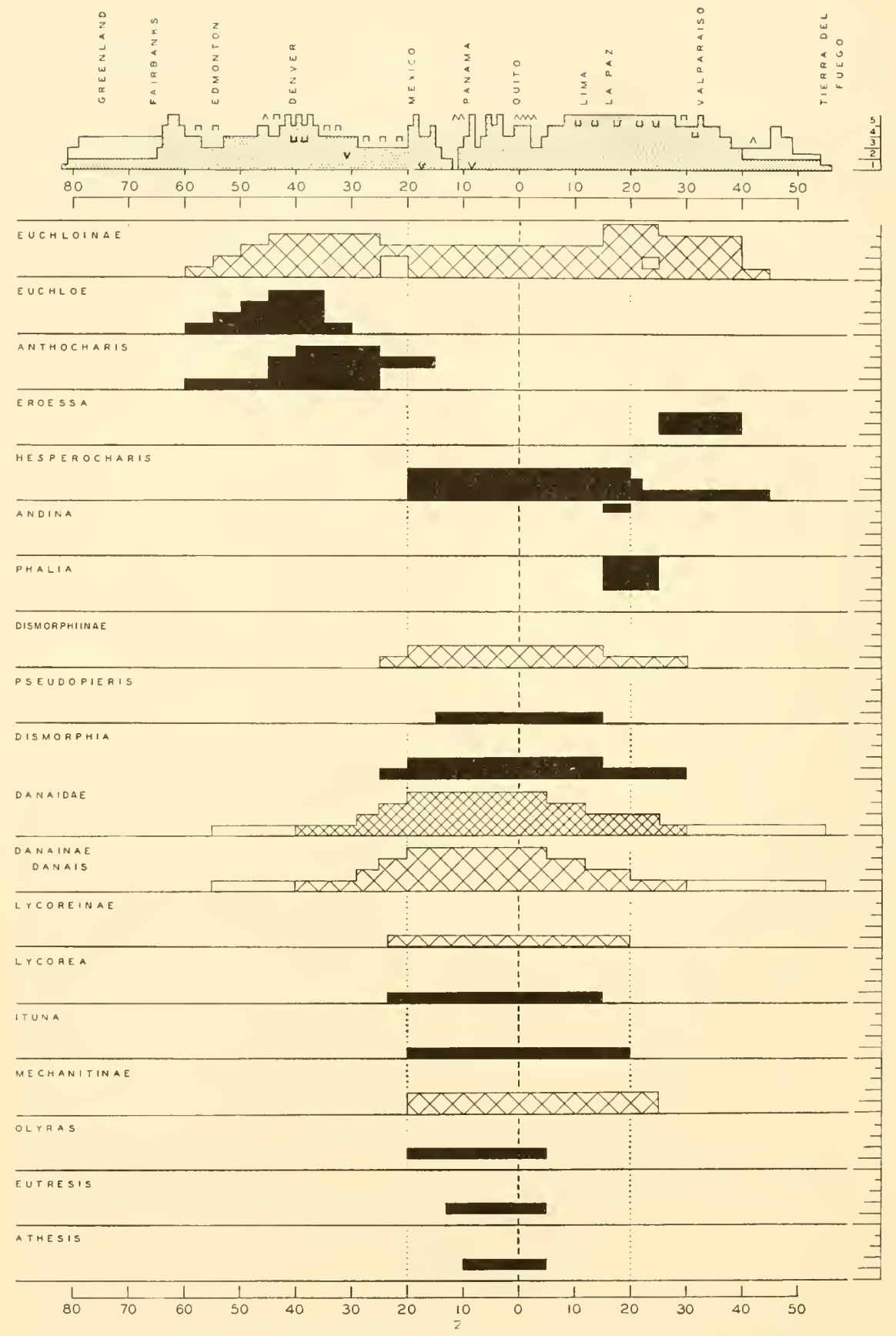

Fig. 5. New World distribution of Pieridae (3) and Danaidae (1). 
America, from sea level in the south to 3,000-4,000 meters in the north. It has a counterpart in the north, Pieris, which extends from $68^{\circ} \mathrm{N}$. Lat. (at sea level) to $15^{\circ} \mathrm{N}$. Lat. (at 2,000-4,000 meters). The ranges of these two nominal genera are separated by lowelevation barriers in Central America. There is good reason for considering them to be congeneric, since the differences between them are not greater than those between species within each group.

The remaining genera of the Pierinae are all equatorial; only one, Ascia, ranges north of the Tropic of Cancer. The altitudinal range of some of the genera is narrow (less than 1,000 meters), of others wide (up to 4,000 meters). Catasticta ranges from $20^{\circ} \mathrm{N}$. Lat. to $20^{\circ} \mathrm{S}$. Lat., and at all elevations from sea level to 3,000 meters.

The range of the Rhodocerinae is wider than that of the Pierinae and is equivalent to that of the Pieridae as a whole. The genera are divisible again into temperature-tolerance groups as is shown by the histograms.

Eurema is equatorial; it ranges to $30^{\circ} \mathrm{N}$. Lat. and to $25^{\circ} \mathrm{S}$. Lat., and up to 3,000 meters in the central Andes. Phoebis is equatorial but extends farther north than Eurema (to $35^{\circ} \mathrm{N}$. Lat.,) although it has a more limited altitudinal distribution. Anteos is also equatorial; it extends north and south only to $25^{\circ}$ and has a limited elevational distribution (to 2,000 meters). Kricogonia is subtropical with a range extending only from $10^{\circ}$ to $30^{\circ} \mathrm{N}$. Lat., at near sea level. This is unusual in that most species or genera that inhabit the tropics cover the entire tropical area from the Tropic of Cancer to the Tropic of Capricorn with little in the way of further limitations.

Colias is low-temperature dependent, as is shown by the histogram. It ranges from $82^{\circ} \mathrm{N}$. Lat. to $55^{\circ} \mathrm{S}$. Lat., is present across the equator at high elevations, but is absent in the low elevations in the tropical regions and exists farther north and at higher elevations than any other butterfly genus. The altitudinal range in North America (to 5,000 meters) and in the Andes is as high as any organism can live. The range is broken by a gap of $5^{\circ}$ latitude from Guatemala to Venezuela and Colombia.

Zerene resembles Colias in pattern of distribution, but usually lives in warmer regions and at lower elevations. It exists only to $40^{\circ}$ N. Lat. and $30^{\circ} \mathrm{S}$. Lat., is absent from lower elevations across the equatorial regions and inhabits the middle-equatorial altitudes (1,000-3,000 meters), in a zone intermediate between the hotter 
tropics at lower elevations and the cooler regions higher in the mountains.

Nathalis resembles Kricogonia in having a limited distributional range from $5^{\circ}$ to $35^{\circ} \mathrm{N}$. Lat.; within this range, however, it occupies a wide altitudinal belt up to 4,000 meters (but typically only to 3,000 meters). It has failed to pass from the North American tropics into the South American tropics despite the apparent absence of a barrier.

The Euchloinae comprise six genera the distribution of which, for such a small group, is especially diverse: two are wholly northern, three are wholly southern, and one is equatorial with a southern expansion. Euchloe, a typical northern type, is found as far north as $60^{\circ} \mathrm{N}$. Lat. with a sea level extension along the Pacific Coast to $30^{\circ} \mathrm{N}$. This pattern is nearly duplicated by that of Anthocharis, with the exception that the latter extends farther south, to $25^{\circ} \mathrm{N}$. Lat. at elevations of 3,000-4,000 meters, and thence to $15^{\circ}$ at 2,000 to 3,000 meters.

Eroessa duplicates, to a certain extent, these distributions south of the equator, covering elevations of from 1,000 to 3,000 meters with a latitudinal range from $25^{\circ}$ to $40^{\circ} \mathrm{S}$. Lat. Hesperocharis is the connecting link between the genera of the southern hemisphere and those of the northern hemisphere. It covers all elevations from sea level to 3,000 meters, from $20^{\circ} \mathrm{N}$. Lat. to $20^{\circ} \mathrm{S}$. Lat., and, in addition, extends southward up to 1,000 meters to $45^{\circ} \mathrm{S}$. Lat. It thus overlaps in distributional range all other genera except Euchloe.

Andina is represented by a very limited distributional range at 4,000-5,000 meters elevation in the Andes, from $15^{\circ}$ to $20^{\circ} \mathrm{S}$. Lat. Phalia extends this range downward to 2,000 meters, over a latitudinal range from $15^{\circ}$ to $25^{\circ} \mathrm{S}$. Lat. These distributions appear to indicate that the Euchloinae are a closely knit group with specific temperature tolerances, with the possibility that the basic origin of the group was tropical and that its northern (Euchloe, Anthocharis) and southern (Eroessa, Andina, Phalia) representatives were independently derived from the tropical Hesperocharis, or from its ancestors. Of course it is always possible that the entire American group was derived from Asiatic representatives, via Euchloe and Anthocharis, that IIesperocharis was derived from these, and the southern types from Hesperocharis. The direction of derivation cannot be deduced from present day distributions alone. 
The Dismorphiinae comprise a small group that may not be derived from the Pieridae. Its range is wholly tropical, with a slightly greater extension to the south than to the north of the tropics. Of the two genera, Dismorphia has the same distribution as the subfamily and Pseudopieris is restricted to a range from $15^{\circ} \mathrm{N}$. Lat. to $15^{\circ} \mathrm{S}$. Lat.

\section{Danaidae (Figs. 5-7)}

The Danaidae comprise thirty-five genera, all but one of which are restricted, or almost confined, to ranges between the Tropics of Cancer and Capricorn. The only genus not so restricted is Danais, one species of which extends its range annually to latitudes of $55^{\circ} \mathrm{N}$. and $55^{\circ} \mathrm{S}$. by seasonal migration. In addition, this species manages to remain at home at latitudes up to $40^{\circ} \mathrm{N}$. and $30^{\circ} \mathrm{S}$. The distributional range of the family as a whole forms a pyramidal histogram with the median point centered at about $10^{\circ} \mathrm{N}$. of the equator, rather than being centrally placed across the tropics. Higher elevations are inhabited north of the equator than southward, but it is possible that this apparent phenomenon is due to the lack of sufficient information for the humid region on the east side of the Andes south of the equator.

The Lycoreinae with two genera are equatorial at low elevations. The Mechanitinae are also equatorial but extend to $25^{\circ} \mathrm{S}$. Lat. This is a very large subfamily ranging from sea level to 2,000 meters. All thirty genera are found within this range; some occupy the whole range, others only a narrow segment. For example, Athesis occupies a range from $10^{\circ} \mathrm{N}$. Lat. to $5^{\circ} \mathrm{S}$. Lat. at elevations of only 1,000 to 2,000 meters. Sais is found only from $5^{\circ} \mathrm{N}$. Lat. to $0^{\circ}$. No reasons for the restricted ranges of some of these genera are apparent from the histograms. A great proportion of genera occupy the area from $10^{\circ}$ or $15^{\circ} \mathrm{N}$. Lat. to $10^{\circ}$ or $15^{\circ} \mathrm{S}$. Lat., although there are no geographic barriers in these regions to hinder their expansion to $20^{\circ}$ in either direction. The family as a whole should be considered as one of entirely tropical origin, for no representative lives permanently in cold regions.

\section{Morphidae (Fig. 7)}

The Morphidae are represented by one genus (Morpho), which is entirely equatorial though extending to considerable elevations (up 


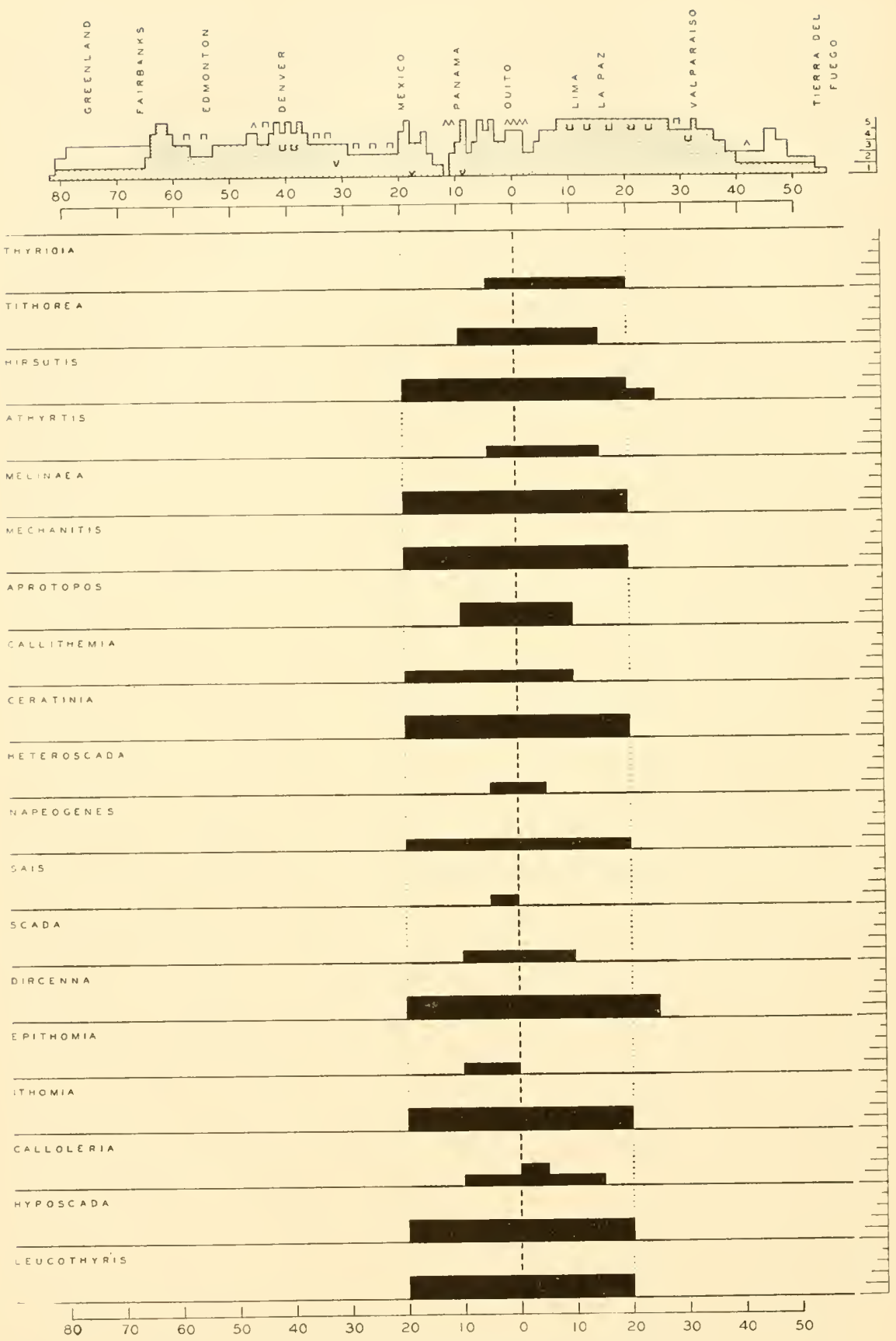

Fig. 6. New World distribution of Danaidae (2). 

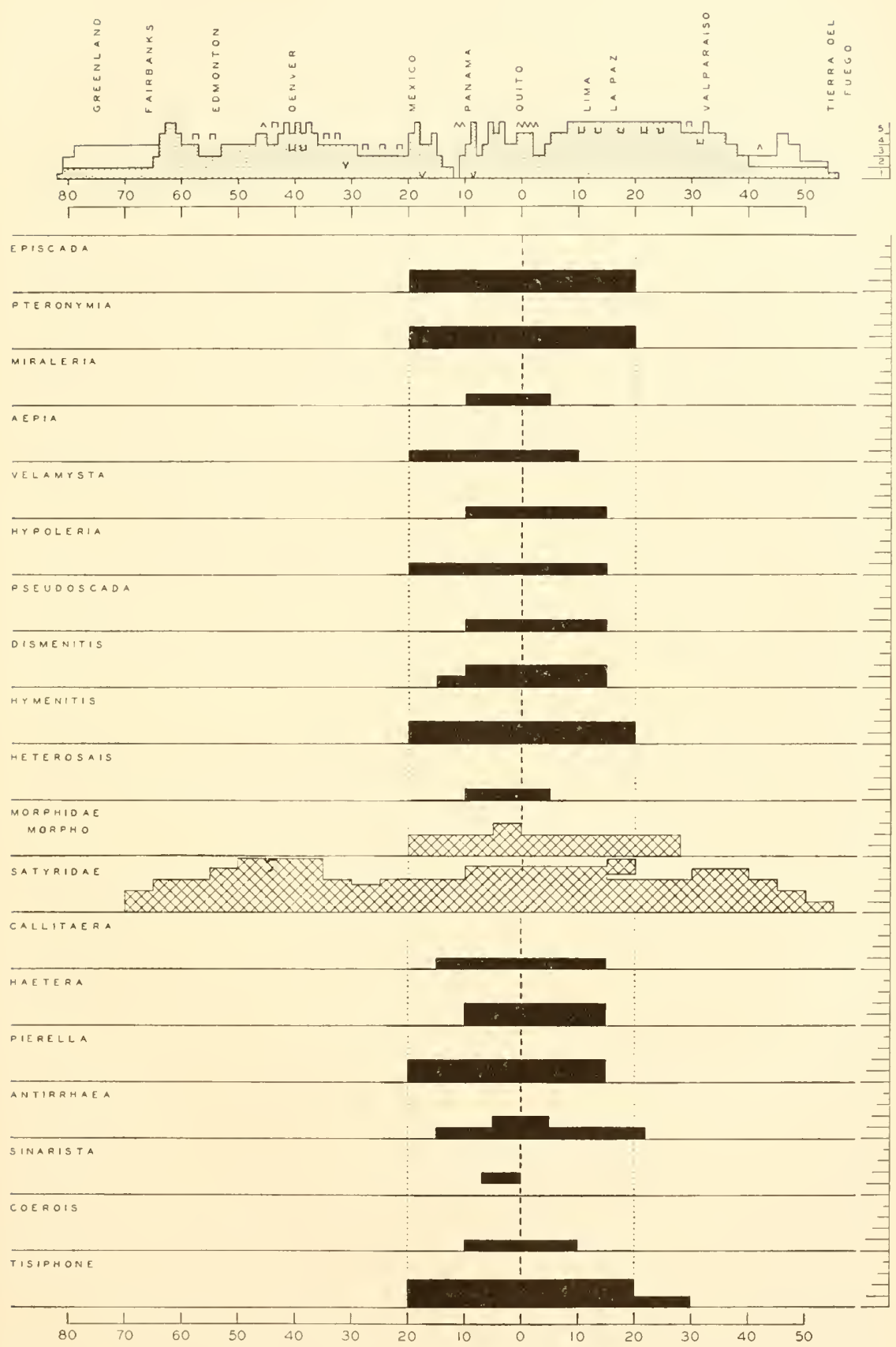

Fig. 7. New World distribution of Danaidae (3), Morphidae, and Satyridae (1). 
to 3,000 meters). As is usual for a number of tropical or equatorial groups, the range southward (to $28^{\circ} \mathrm{S}$. Lat.) is greater than northward. There is no indication of any but a tropical origin for this group.

\section{Satyridae (Figs. 7-12)}

The Satyridae comprise a huge family that extends from the arctic regions at $70^{\circ} \mathrm{N}$. Lat. to $55^{\circ} \mathrm{S}$. Lat. They occur at nearly all elevations throughout this range. Tropical genera, however, are far more abundant than northern genera. The family is an interesting one since many genera have highly restricted habitats both within and outside the tropics.

Callitaera, Haetera, Pierella, and Antirrhaea are confined almost wholly within the tropical regions; except for Callitaera they range up to 2,000 meters. Sinarista has a restricted range from $7^{\circ} \mathrm{N}$. Lat. to the equator and from 1,000 to 2,000 meters in elevation (it exists only in the northern Andes of Colombia and Ecuador). Coerois and Tisiphone are equatorial; the former is the more restricted. Tisiphone extends southward to $30^{\circ} \mathrm{S}$. Lat. and up to 2,500 meters between the tropics.

Enodia, on the other hand, occupies a north temperate habitat ranging from $25^{\circ}$ to $45^{\circ} \mathrm{N}$. Lat. in the eastern part of North America. Since it has no northern affinities but only tropical ones, it may be assumed to be of tropical origin.

Taygetis has a full range between the tropics up to 2,000 meters an $\downarrow$ extends south to $30^{\circ} \mathrm{S}$. Lat. Amphidecta, on the other hand, is restricted to lower elevations south of Panama.

Euptychia is a large genus of certainly tropical origin, but includes at least four groups that extend northward to $45^{\circ} \mathrm{N}$. Lat. and several that extend southward to $35^{\circ} \mathrm{S}$. Lat. The genus is subdivided into groups in the histograms, to show how some groups are restricted tropical, some are extensive tropical, and a few are restricted temperate types. In the first classification (restricted tropical) are the Nossis, Pronophila, Liturata, Gera, Lea, Tolumnia, and Agaga groups. In the second classification (extended tropical) are the Hesione, Mollina, Saturnus, Harmonia, Necys, Pacarars, Batesii, Cephus, and Arnaea groups. In the third category (restricted temperate either north or south) are the Paeon, Cluena, Phocion, and Pyracmon groups. A fourth set might be recognized, namely, those 

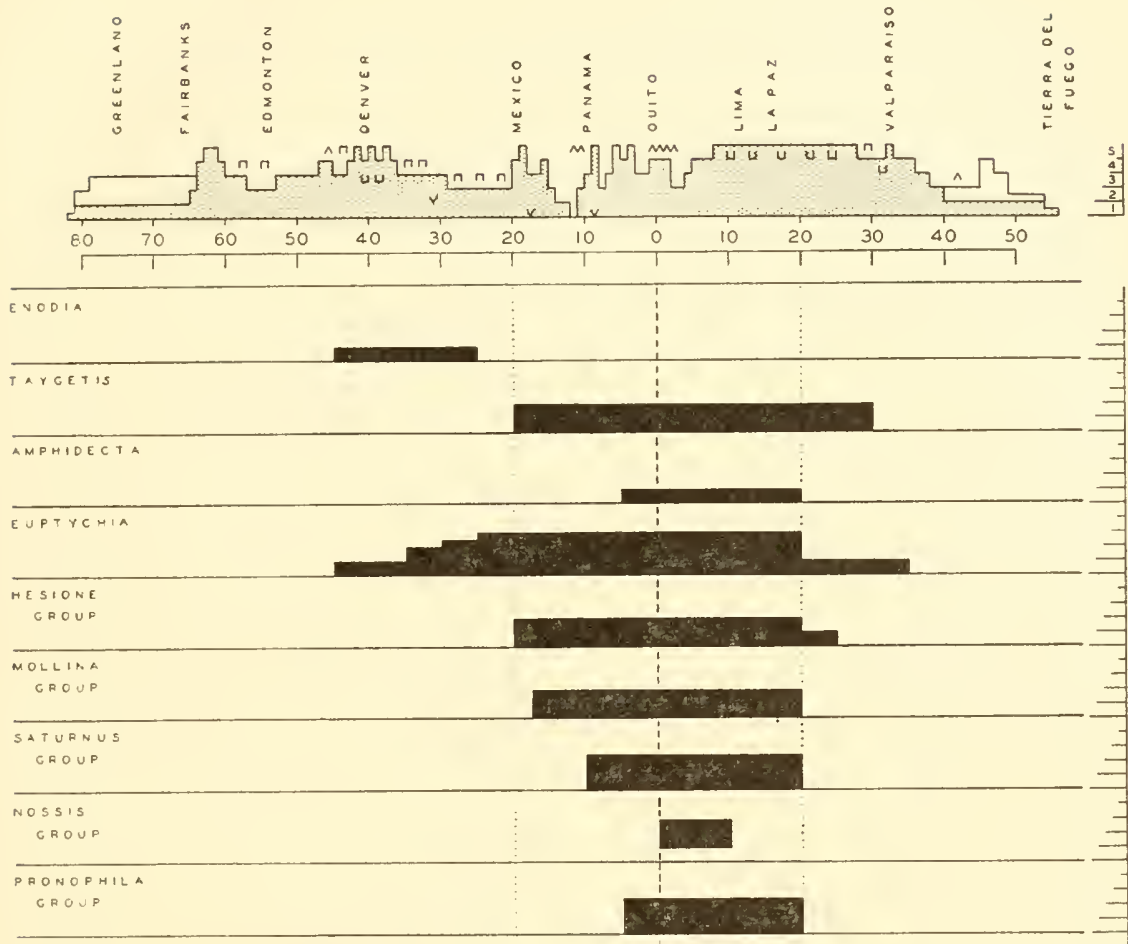

LITUEATA

CAOUP

OCYPETE

GROUF

RENATA

GROUA

PAEON

CROUP

HERMES

GROUP

PHARES

CAOU一

MARMONIA

GROUP

NECYS

GRONP

PACARAAS

PACARAA

BATESI

GROUP

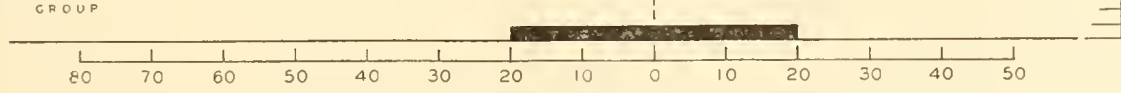

Fig. 8. New World distribution of Satyridae (2). 


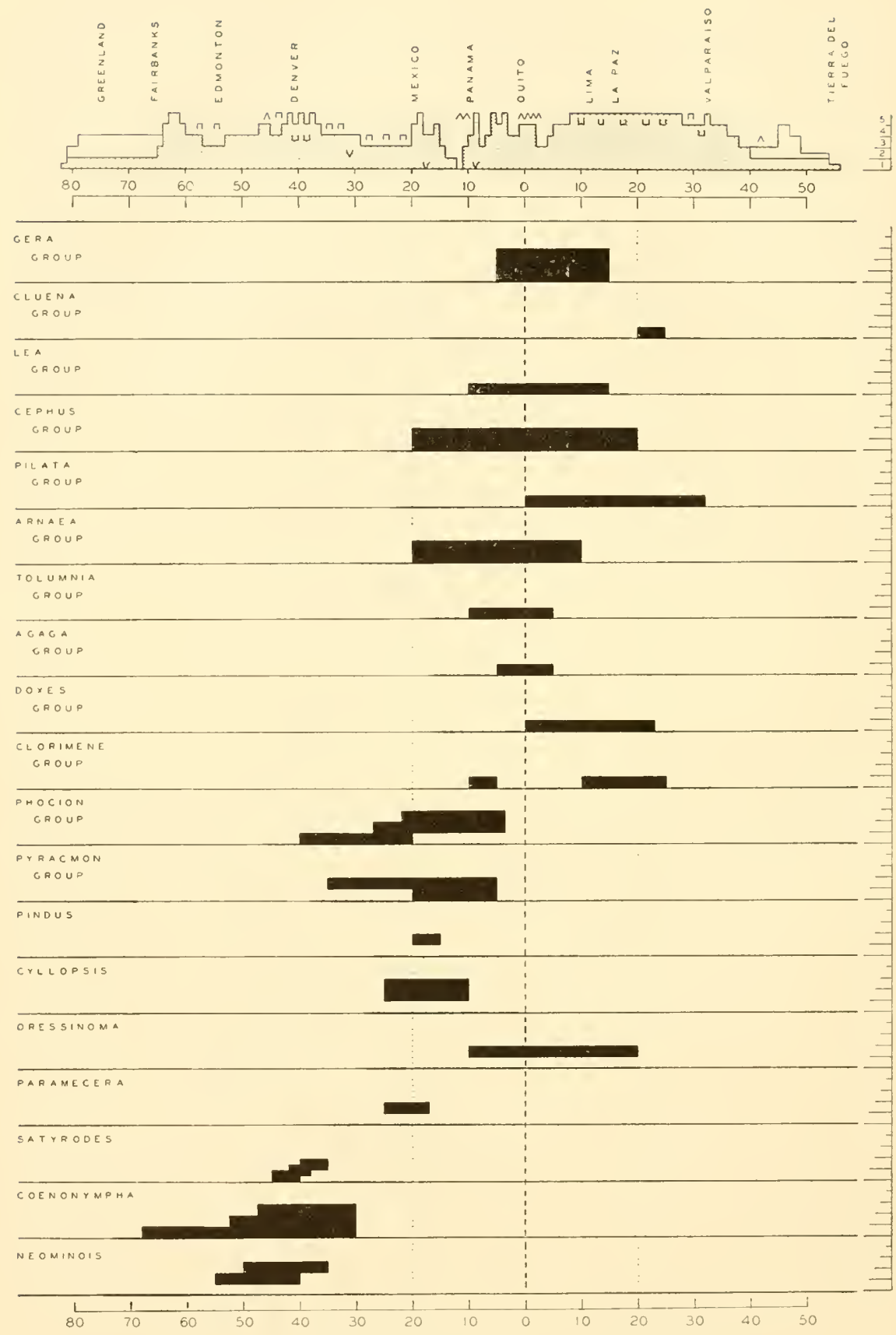

Fig. 9. New World distribution of Satyridae (3). 

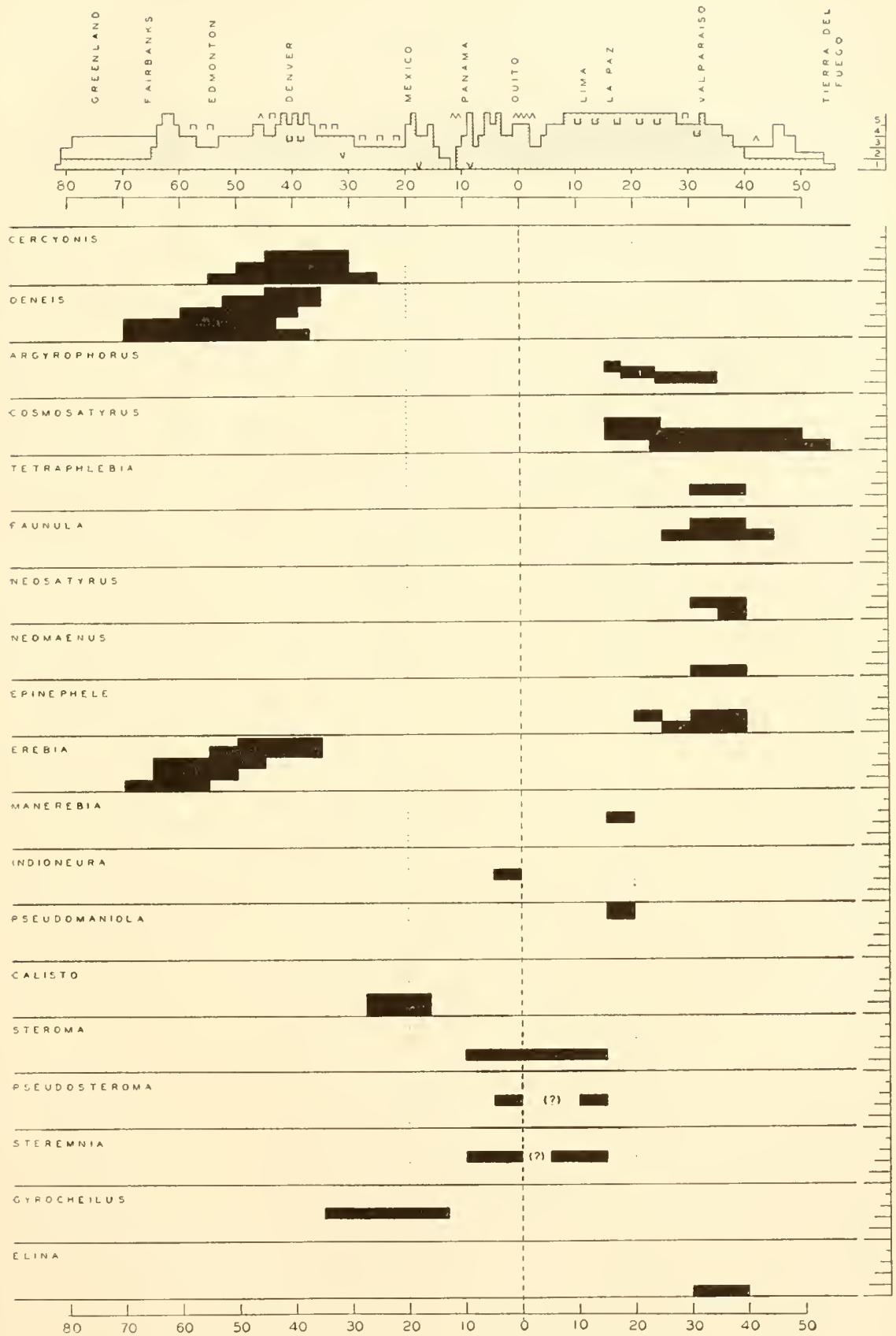

Fig. 10. New World distribution of Satyridae (4). 


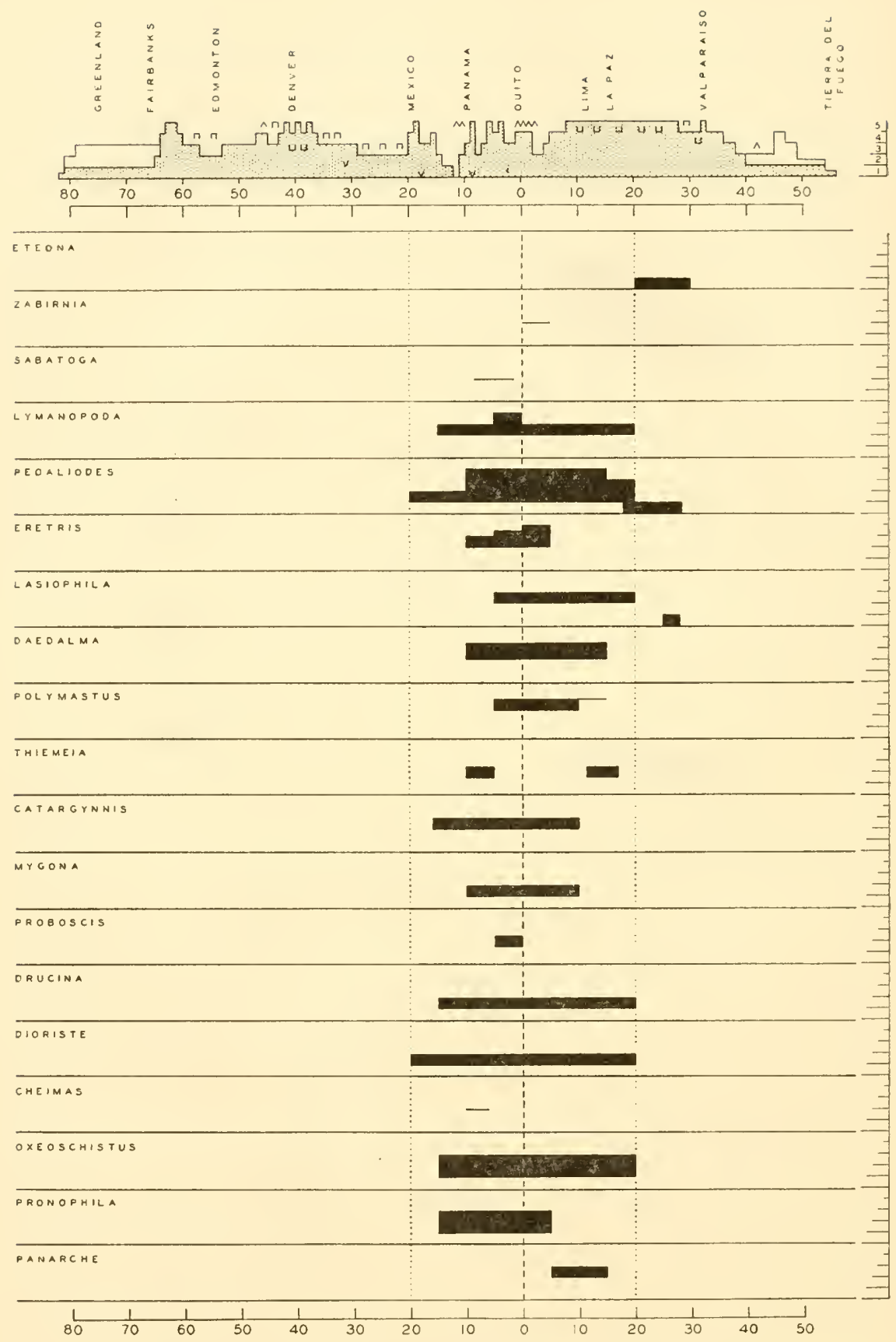

Fig. 11. New World distribution of Satyridae (5). 
with panequatorial distributions that extend far into the temperate zones. These are the Ocypete, Renata, and IIermes groups.

The restricted range $\left(15^{\circ}-20^{\circ} \mathrm{N}\right.$. Lat. at 1,000$)-2,000$ meters suggests that the genus Pindus is a relict group similar to Baronia. Cyllopsis has a similar distribution but extends from $10^{\circ}$ to $25^{\circ} \mathrm{N}$ Lat. and from 1,000 to 3,000 meters in elevation. Oressinoma extends from $10^{\circ} \mathrm{N}$. Lat. to $20^{\circ} \mathrm{S}$. Lat. Paramecera is restricted to the same general area as Pindus $\left(17^{\circ}\right.$ to $25^{\circ} \mathrm{N}$. Lat. and $1,000-2,000$ meters elevation). It too suggests a relict group.

Satyrodes, Coenonympha, Neominois, Cercyonis, Oeneis, and Erebia are all northern genera that have no contact with the tropics. The charts show typical histograms of forms with cold-temperature tolerances, by increasing in elevation in the south. In distribution these northern forms are somewhat duplicated south of the equator by Argyrophorus, Cosmosatyrus, Tetraphlebia, Faumula, Neosatyrus, Neomaenus, Epinephele, Elina, and Eteona. No other family has developed so many genera south of the equator. It may be assumed that they developed from tropical relatives independently of northern genera.

Many of the genera (perhaps not good ones) have very restricted distributions in equatorial habitats. Many have very restricted altitudinal ranges as well; for example:

Manerebia, $15^{\circ}-20^{\circ} \mathrm{S}$. Lat., 2,000-3,000 meters

Indioneura, $5^{\circ} \mathrm{N}$. Lat., $-0^{\circ} 2,000-3,000$ meters

Pseudomaniola, $15^{\circ}-20^{\circ} \mathrm{S}$. Lat., 3,500-5,000 meters

Calisto, $16^{\circ}-27.5^{\circ}$ N. Lat., 0-2,000 meters

Pseudosteroma, $5^{\circ}$ N. Lat. $-15^{\circ}$ S. Lat., (discontinuously?) 2,0003,000 meters

Steremnia, $10^{\circ}$ N. Lat. $-15^{\circ}$ S. Lat., (discontinuously?) 2,000-3,000 meters

Gyrocheilus, $13^{\circ}-35^{\circ}$ N. Lat., 2,000-3,000 meters

Eretris, $10^{\circ}$ N. Lat., $-5^{\circ}$ S. Lat. $2,000-4,000$ meters

Daedalma, $10^{\circ} \mathrm{N}$. Lat., $-15^{\circ} \mathrm{S}$. Lat. 2,000-3,500 meters

Polymastus, $5^{\circ} \mathrm{N}$. Lat., $-10^{\circ} \mathrm{S}$. Lat. $2,500-3,500$ meters

The great prevalence of restricted, narrowly ranging genera in the Andes suggests a center of rapid divergence of these forms in the area. This may not have been the center of origin of the family, but almost certainly has been a secondary center of origin for many genera.

The northern genera of the family have affinities with Asia, and 
it is possible that these have had their origin there, and that the tropical forms of the family have been derived secondarily from these (or from their ancestors). From existing distributions, it is not possible to decide in which direction the migrations went. The systematics of the remaining groups (Figs. 8-12) are too uncertain to warrant extended discussion.

Brassolidae (Fig. 12)

All nine genera of the Brassolidae are equatorial, although as usual for distributions of this type the ranges extend farther south (to $30^{\circ}$ S. Lat.) than north (to $20^{\circ} \mathrm{N}$. Lat.). The altitudinal range is only to 2,000 meters, except in a restricted part of the range of Caligo. The origin of the group is to be regarded as tropical since there are no indications of affinities elsewhere.

Nymphalidae (Figs. 12-16)

This huge family is not exceeded in its diversity by any other, and it is equaled in its distributional range only by the Pieridae. Many of the subfamilies are wholly tropical, but others are northern. Some of the most interesting distributions are found in this family. The distributional range, as in the Pieridae, is from $82^{\circ} \mathrm{N}$. Lat. to $55^{\circ} \mathrm{S}$. Lat. and from sea level to 5,000 meters in elevation.

The four subfamilies are not of equal size or character. The three smaller ones are tropical, or nearly so, and the larger one has the same distributional range as the family itself. The Acreinae are represented by only one genus, which has an equatorial range from $20^{\circ} \mathrm{N}$. Lat. to $30^{\circ} \mathrm{S}$. Lat. and an altitudinal range to 3,000 meters.

Actinote provides no exception to the rule already indicated for other groups that the ranges of equatorial species often extend farther south than north.

The Heliconiinae are another equatorial subfamily, larger than the preceding, with five genera. Three of these extend slightly beyond the confines of the equatorial belt, one as far as $35^{\circ} \mathrm{N}$. Lat. and $35^{\circ} \mathrm{S}$. Lat. Except for Metamorpha these exist as high as 2,000-3,000 meters in elevation. Heliconius, Eulides, Colaenis, and Dione have the full range from north to south; the range of Metamorpha ceases at Panama $\left(10^{\circ} \mathrm{N}\right.$. Lat.) as is typical of the range of many southern genera.

The Clothildinae are represented by one genus, Clothilda, having a 


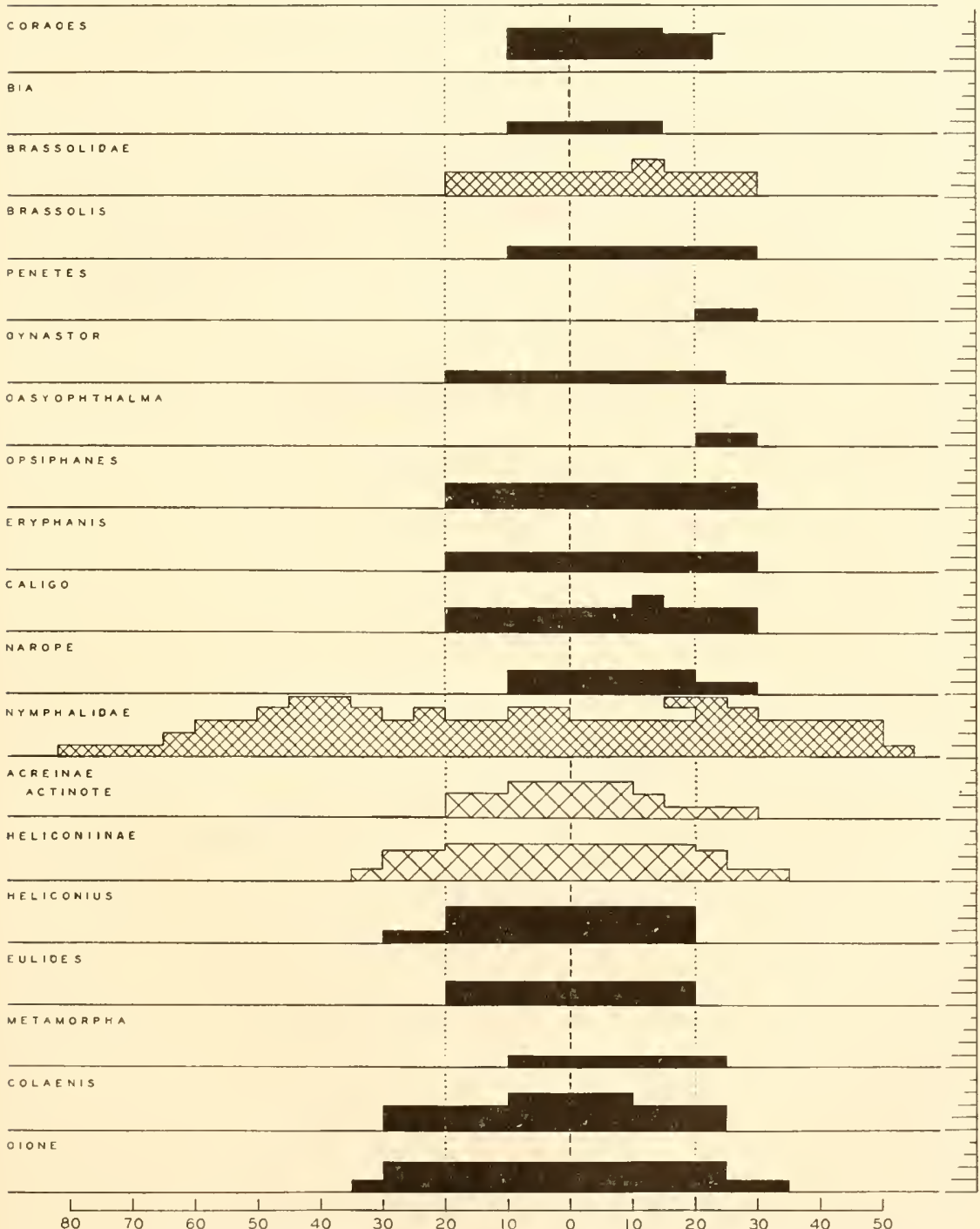

Fig. 12. New World distribution of Satyridae (6), Brassolidae, and Nymphalidae (1). 


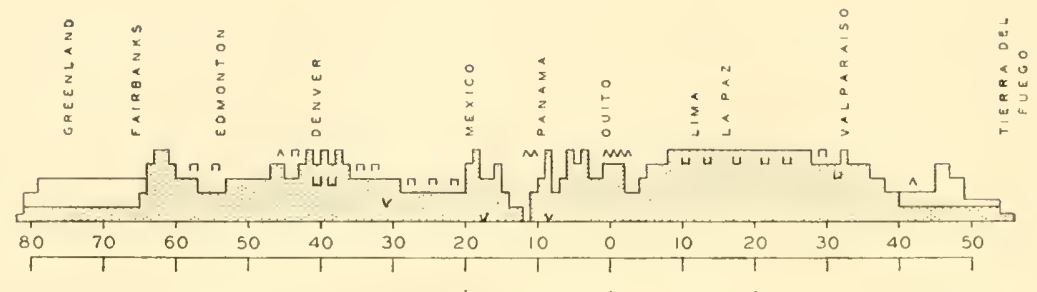

CLOTHILOINAE

CLOTHILOA

NYMPHALINAE

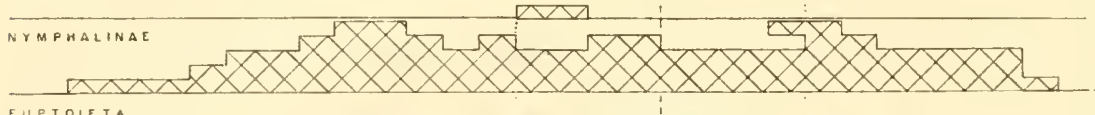
EUPTOIETA
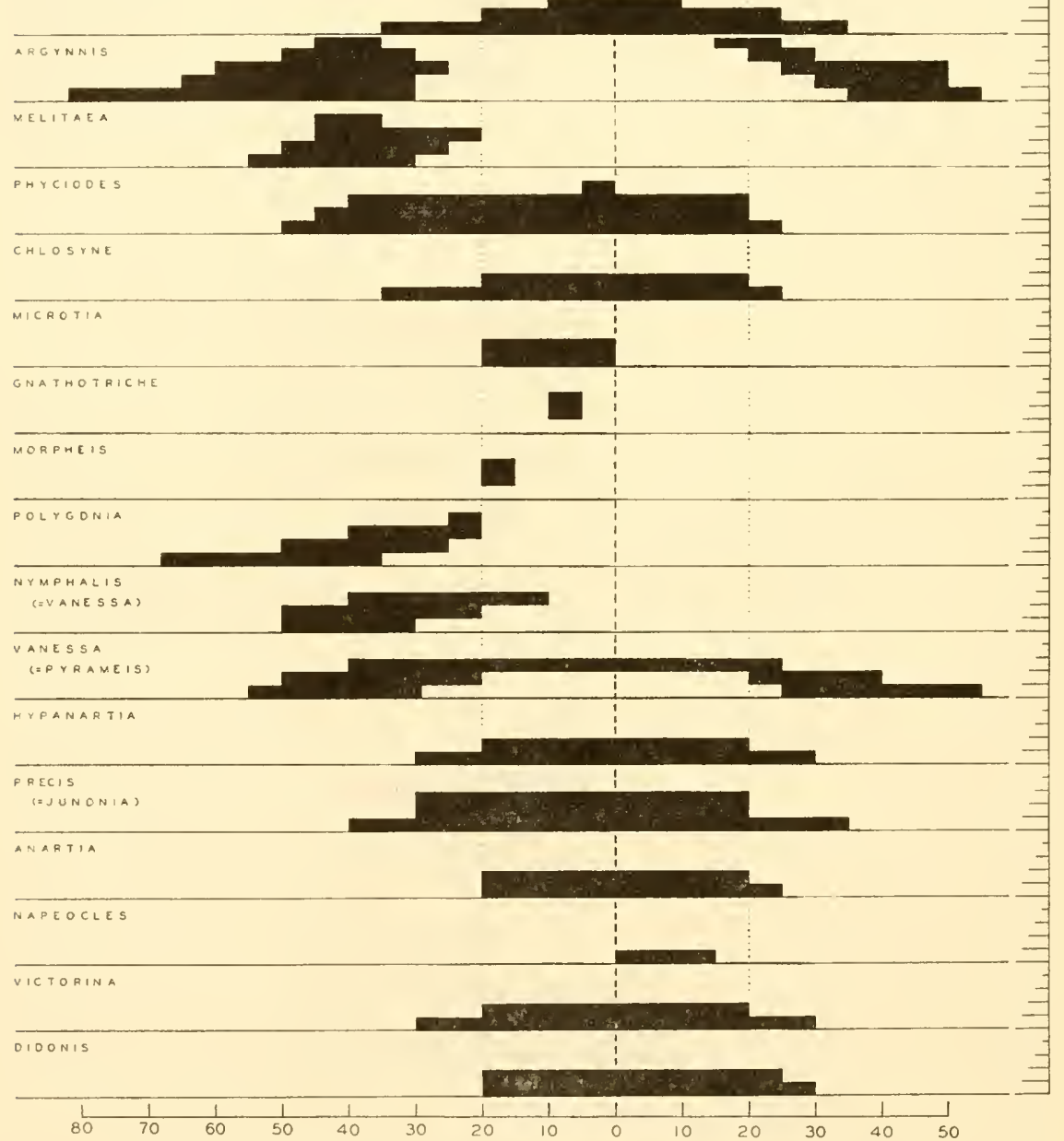

Fig. 13. New Morld distribution of Nymphalidae (2). 

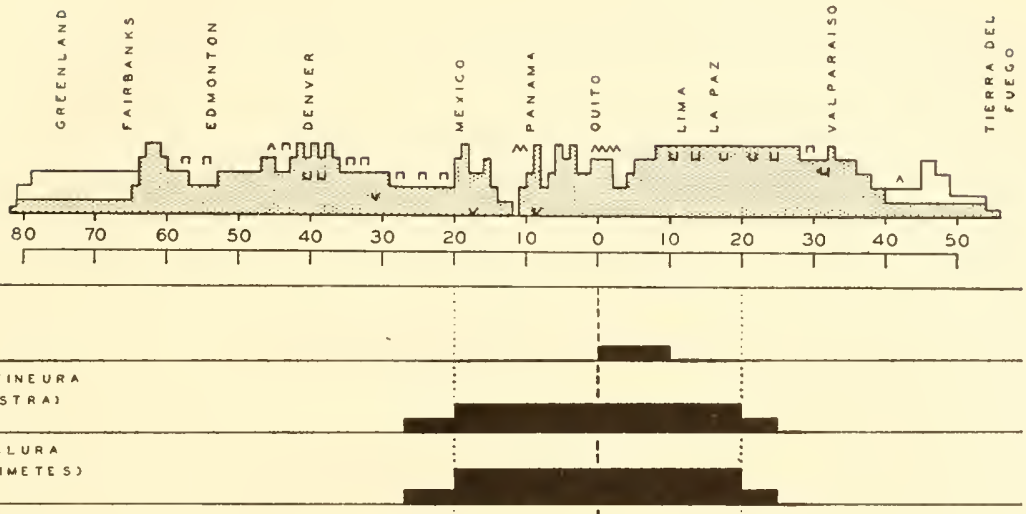

(1)

\section{CALLITONA}

PYRRHOGYAA

LUCINIA

PERIA

TEMENIS

BALBONEURA

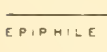

CATONEPHELE

NESSAEA

A.

(
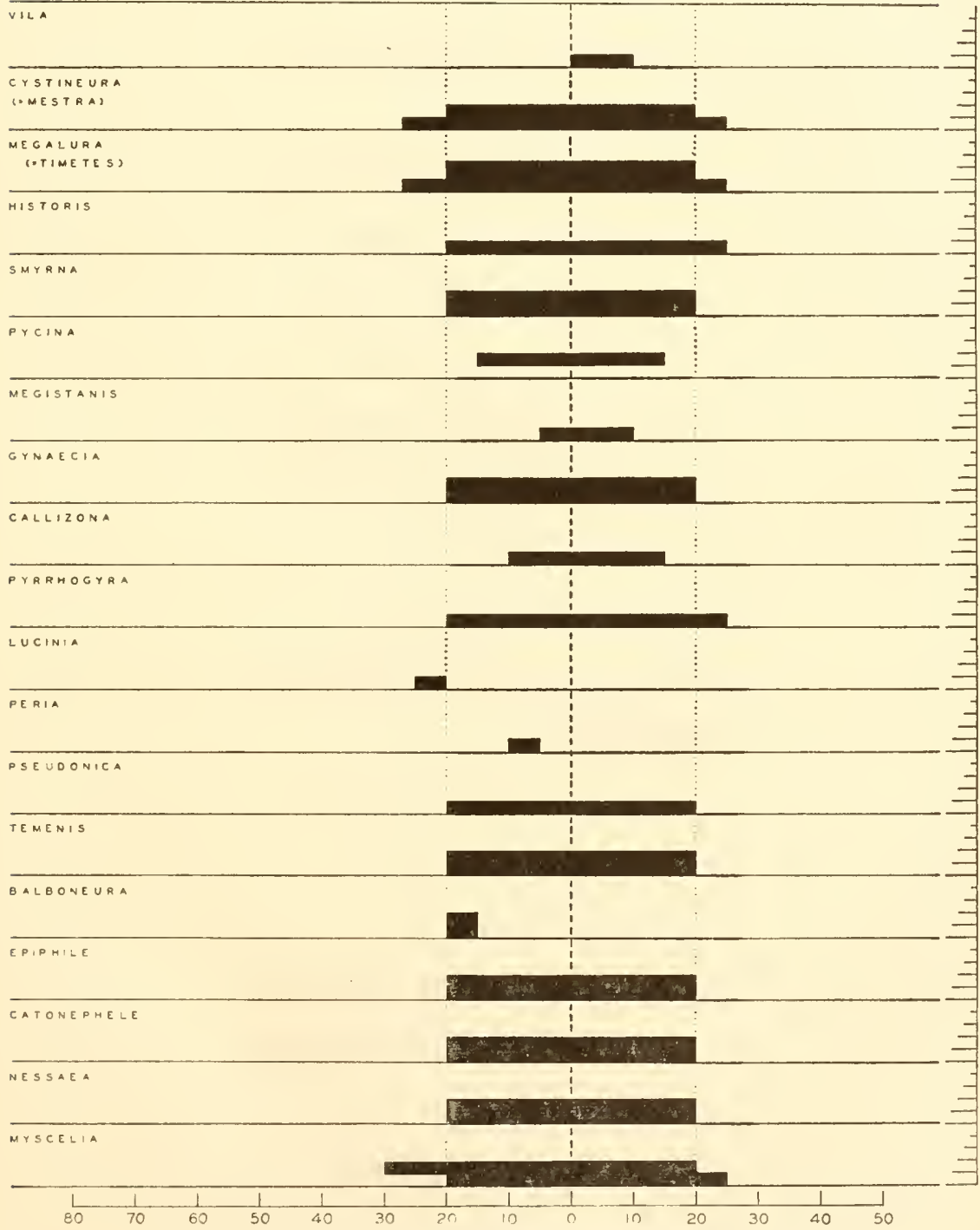

Fig. 14. New World distribution of Nymphalidae (3). 


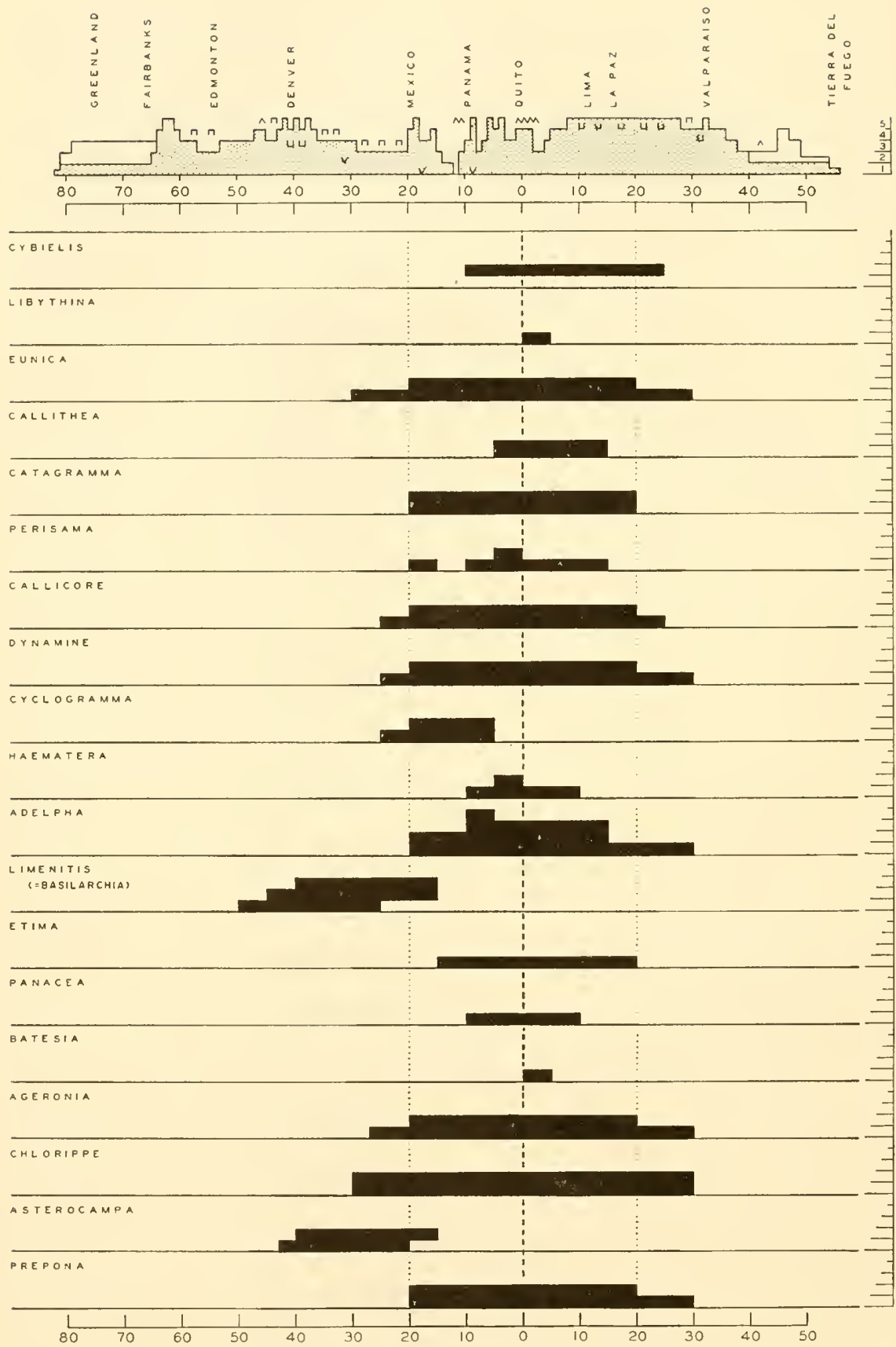

Fig. 15. New World distribution of Nymphalidae (4). 

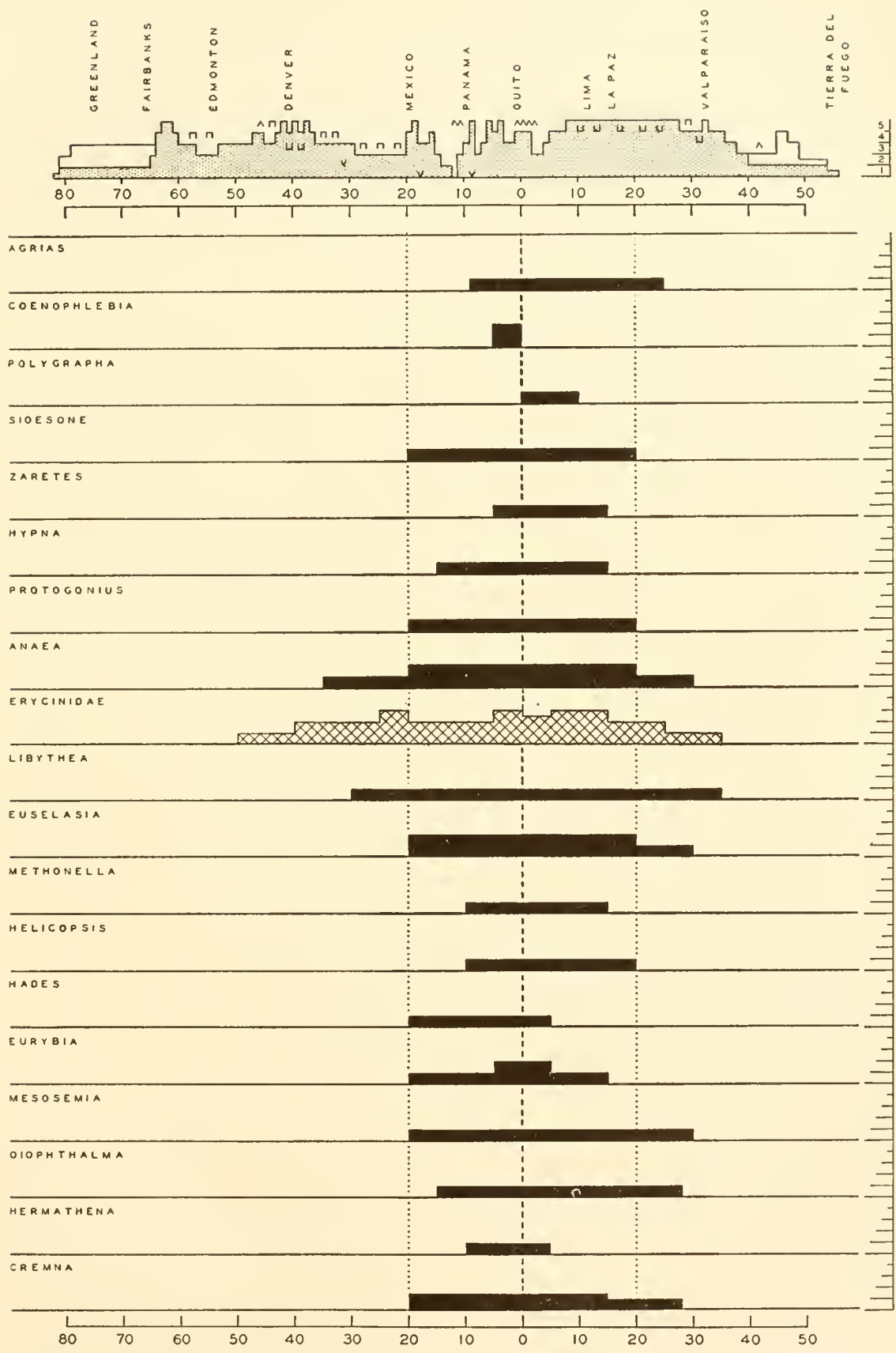

Fig. 16. New World distribution of Nymphalidae (5) and Erycinidae (1). 
narrow range from only $10^{\circ}$ to $20^{\circ} \mathrm{N}$. Lat. It is absent from South America.

The Nymphalinae comprise the major part of the family Nymphalidae, and are not easily subdivided into further parts. The family Pieridae can be divided into several large natural subfamilies. On the other hand, the Nymphalidae can be subdivided only by removing a few odd forms since no large natural cleavage lines are apparent. In fact, even the line between the Nymphalinae and the Heliconiinae is poorly defined.

The genera of the Nymphalinae do not fall into definite classes such as tropical and northern. Instead, each seems to have its specific range of temperature tolerance. One may be wholly tropical, another subtropical, and another cold adapted.

Euptoieta is tropically adapted but exists north and south to $35^{\circ}$, and to 3,000 meters in the central equatorial region. Probably all temperatures short of freezing are satisfactory, as colonies are quite common at 3,000 meters in the Tierra Fria of the equatorial belt.

Argynnis, on the other hand, is a cold-adapted genus. It exists to $82^{\circ} \mathrm{N}$. Lat. and to $55^{\circ} \mathrm{S}$. Lat., but it is absent in the equatorial regions between $25^{\circ} \mathrm{N}$. Lat. and $15^{\circ} \mathrm{S}$. Lat., even at the higher elevations. As is typical of northern types, the elevations at which it survives are higher southward in the northern hemisphere and higher northward in the southern hemisphere. Argynnis is a large genus that exists around the world. It is best considered subdivided in to various subgenera. If this were done for the American forms, at least four subgenera would be recognized for North America and a fifth for South America. Two of the groups that would be treated as subgenera in North America extend nearly to the Bering Straits and are represented in Asia. Thus, there is recent gene continuity between America and Asia. The third subgenus is separated by a considerably greater distance and, at least during the quaternary, has been completely severed from the nearest relatives in Asia. There has developed in the North American temperate zone a particular type not represented elsewhere. Likewise, the South American subgenus has been isolated so long that its type is not represented elsewhere in the world.

The genus Melitaea occupies the temperate part of North America (also Eurasia) and is not represented south of $20^{\circ} \mathrm{N}$. Lat. Phyciodes, on the other hand, covers somewhat the same territory in the north, 
but it occupies in addition the equatorial zone at 3,000 or 4,000 meters altitude to $20^{\circ} \mathrm{S}$. Lat. and extends to $25^{\circ}$.

The genus Chlosyne is equatorial and occupies the lower elevations (less than 2,000 meters), with extensions to $35^{\circ} \mathrm{N}$. Lat. and $25^{\circ}$ S. Lat.

Microtia, Gnathotriche, and Morpheis occupy narrow zones in the northern part of the equatorial region. Undoubtedly, revision of these genera would prove desirable and would indicate relationships better.

Polygonia is a northern type that extends from $68^{\circ}$ to $20^{\circ} \mathrm{N}$. Lat. and occurs at higher elevations in the south. Nymphalis (Vanessa) is slightly less a northern type, extends less far to the north (to $50^{\circ} \mathrm{N}$. Lat.), but farther to the south (to $10^{\circ} \mathrm{N}$. Lat.). Vanessa (Pyrameis) is also not such a northern type, having about the same northern distribution as Nymphalis but extending over the tropics at 2,000-3,000 meters elevation and existing south of the equatorial regions as well. Representatives of this genus exist throughout the world in cold or temperate regions. Contact with Eurasia is broken by a considerable distance across the Bering Straits, but probably only a little increase of ocean temperatures would be sufficient to connect them again.

All the remaining genera of this subfamily are equatorial and seem to owe their origin to America. A few, however, have been able to survive colder temperatures and are found north or south of the equatorial zones. Victorina extends to $30^{\circ} \mathrm{N}$. Lat. and to $30^{\circ} \mathrm{S}$. Lat. Didonis extends to $30^{\circ} \mathrm{S}$. Lat. Cystineura and Megalura (=Timetes) extend to $27^{\circ} \mathrm{N}$. Lat. and to $25^{\circ} \mathrm{S}$. Lat. Myscelia extends to $30 \mathrm{~N}$. Lat. and to $25^{\circ} \mathrm{S}$. Lat. Historis and Pyrrhogyra extend to $25^{\circ} \mathrm{S}$. Lat. A few genera, for example Lucinia, Balboneura, and Peria, have very restricted ranges. These suggest relict genera. Several genera extend northward only to Panama (for example, Cybielis, Callithea, Haematera, Panacea, Agris, and Zaretes). Others that extend north or south of the equatorial zone by $5^{\circ}-10^{\circ}$ are Cybielis, Eunica, Callicore, Dynamine, Cyclogramma, Adelpha, Ageronia, Chlorippe, Prepona, and Anaea. Some of these extend only to the north; others only to the south.

Two of the genera having equatorial affinities, Limenitis (=Basilarchia) and Asterocampa, are found only in the northern temperate latitudes. Limenitis extends from $15^{\circ}$ to $50^{\circ}$ N. Lat. and A sterocampa 
from $15^{\circ}$ to $43^{\circ} \mathrm{N}$. Lat. A reconsideration of these genera may indicate that they are not of generic stature; for example, Leminitis is possibly congeneric with Adelpha.

A number of genera of very restricted ranges in the tropics are insufficiently known to be able to offer reasons for their restriction. Judging from distributions alone, some of these, for example Gnathotriche, Morpheis, Lucinia, Peria, Balboneura, Libythina, Batesia, and Coenophlebia, appear to be relict types. However, study of other relationships is required before differentiations can be made between those that are newly adapted to a localized habitat and those that are relicts.

Contrary to the distributional patterns in the Satyridae, few genera of the Nymphalidae are restricted to intermediate or high elevations in the equatorial regions, or, on the other hand, to a wholly Southern Hemisphere distribution.

\section{Erycinidae (Figs. 16-19)}

Few genera of the Erycinidae occur outside the equatorial regions, or nearby. Only two of the genera range far into northern latitudes. The histogram shows, however, a range from $50^{\circ} \mathrm{N}$. Lat. to $35^{\circ} \mathrm{S}$. Lat. and to 3,000 meters in the equatorial and desert mountains.

Most of the equatorial genera extend farther south of the Tropic of Capricorn than they do north of the Tropic of Cancer. In fact, in this family 23 of the 28 equatorial genera whose ranges reach the Tropic of Capricorn extend beyond at least to $30^{\circ} \mathrm{S}$. Lat. The equatorial genera are nearly all adapted to the lowest elevations $(0-1,000$ meters $)$, though a few extend upward in the Cordillera to $2,000-3,000$ meters. Only one genus is restricted to higher elevations, namely, Imelda at 1,000-2,500 meters.

The genus Charis has an equatorial range but extends also to $42^{\circ}$ N. Lat. and to $33^{\circ} \mathrm{S}$. Lat. A podemia, on the other hand, is restricted to the North Temperate zone, from $50^{\circ}$ to $20^{\circ}$ N. Lat. A Southern Hemisphere range from $20^{\circ}$ to $30^{\circ} \mathrm{S}$. Lat. is also indicated, but is a basis that requires further generic study for certainty.

Lyeaenidae (Fig. 19)

The Lycaenidae is a very large family extending from $82^{\circ} \mathrm{N}$. Lat. to $55^{\circ} \mathrm{S}$. Lat., and from sea level to 5,000 meters in elevation. Over much of its range it exists together with the Nymphalidae and 

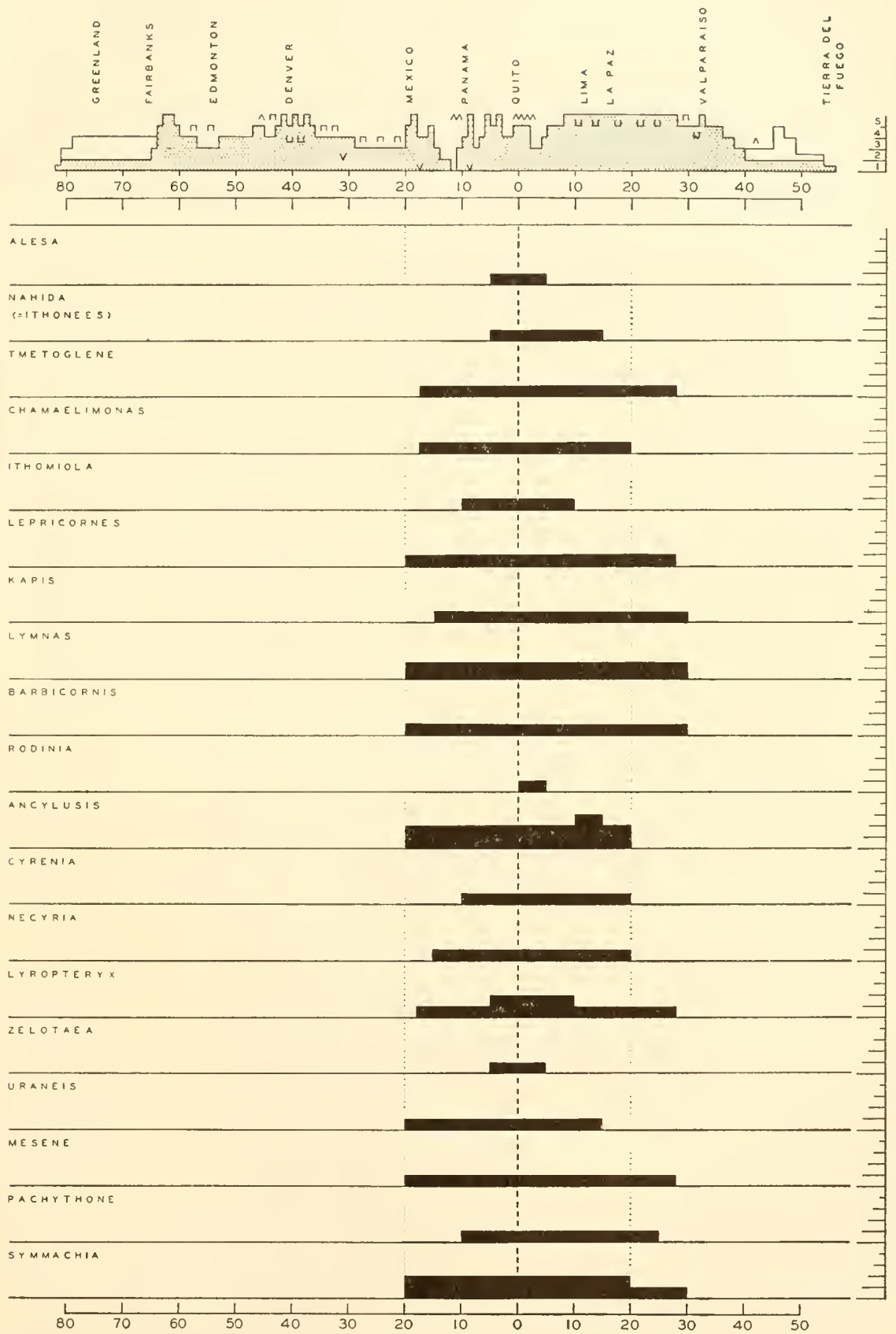

Fig. 17. New World distribution of Erycinidae (2). 

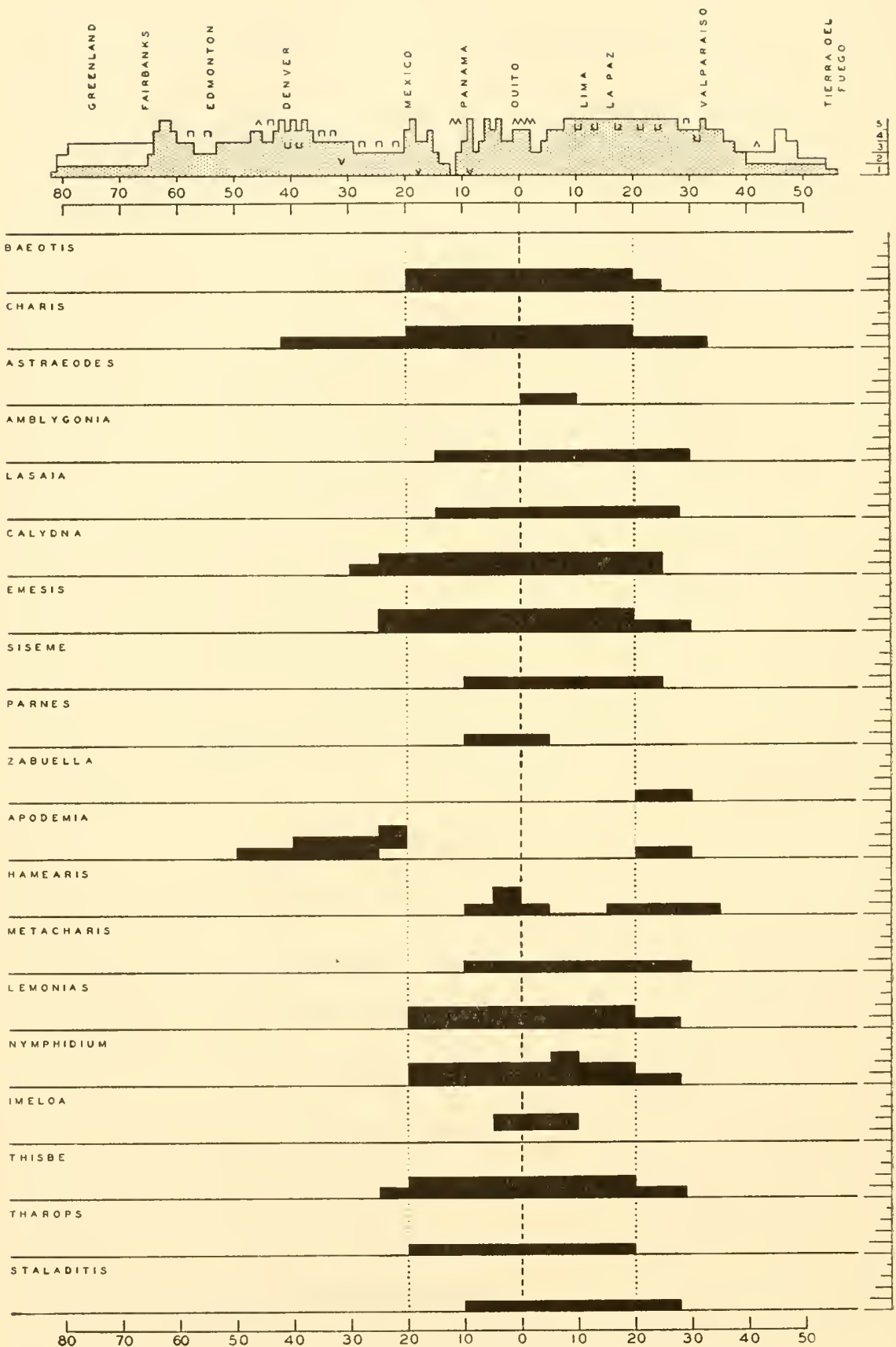

Fig. 18. New World distribution of Erycinidae (3). 


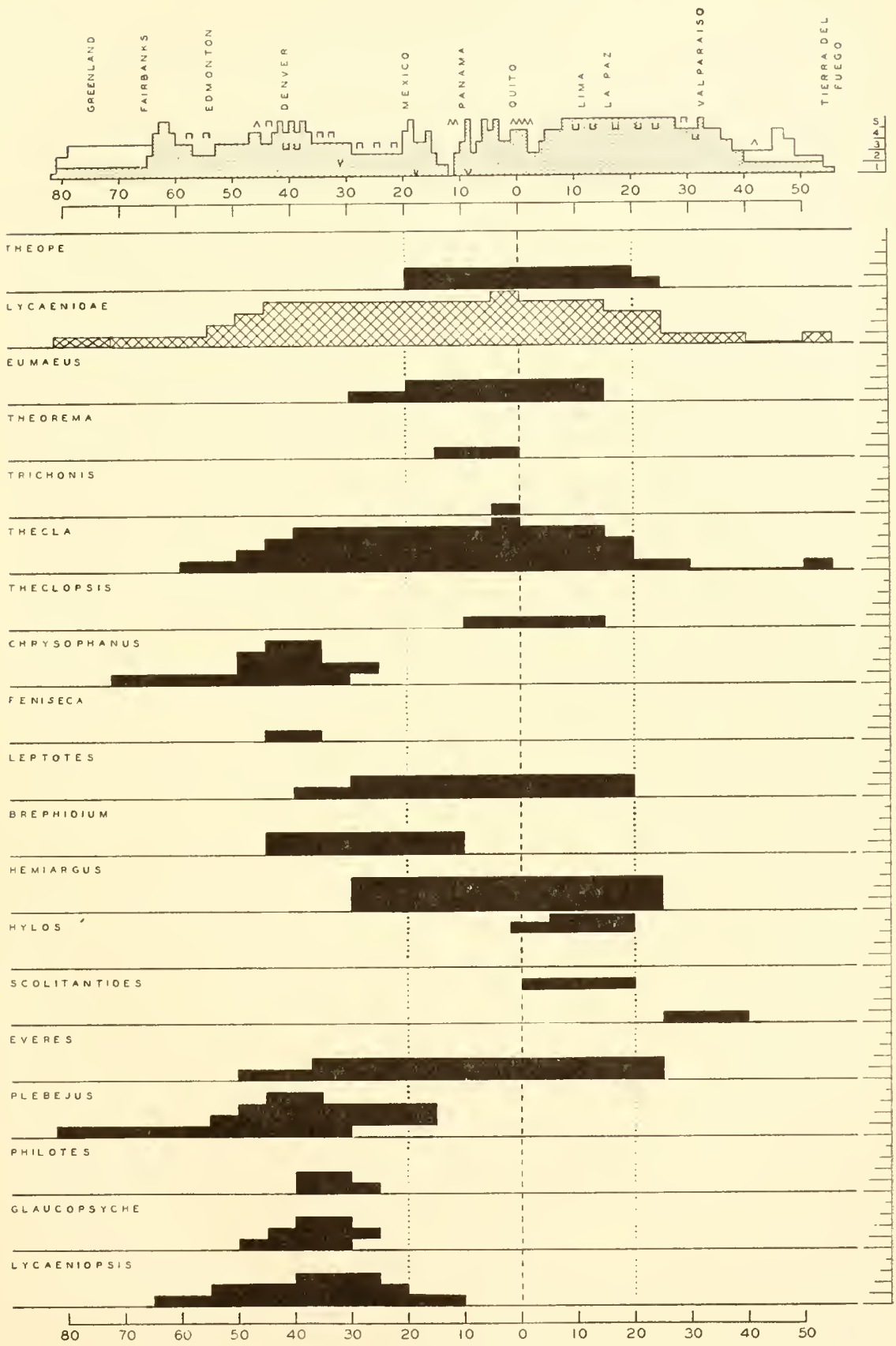

Fig. 19. New World distribution of Erycinidae (4) and Lycaenidae. 
Pieridae. The family contains some huge and diverse genera, which are badly in need of comprehensive study. On the whole, the genera are northern rather than tropical, such as the genera of the Erycinidae. However, since the largest genera are tropical, it is likely that the bulk of species exists in the equatorial range.

Eumaeus has a tropical range extending northward to $30^{\circ} \mathrm{N}$. Lat. and up to 2,000 meters in elevation, but southward only to $15^{\circ}$ S. Lat.

Theorema has a very limited range near sea level from $15^{\circ} \mathrm{N}$. Lat. to $0^{\circ}$. Trichonis is even more restricted, to from $0^{\circ}$ to $5^{\circ} \mathrm{N}$. Lat.

The largest genus from the standpoint of species, but also the most difficult to subdivide naturally, is Thecla. This genus has a tropical core that ranges from tropic to tropic at elevations from 0 to 4,000 meters (some species even to 5,000 meters). But it also exists northward in cold areas as far as $60^{\circ} \mathrm{N}$. Lat., and at elevations up to 4,000 meters as far north as $40^{\circ} \mathrm{N}$. Lat. In addition, it extends southward to $55^{\circ} \mathrm{S}$. This genus is virtually a family in itself and probably ought to be considered at least a subfamily.

Theclopsis has a limited equatorial range from $10^{\circ} \mathrm{N}$. Lat. to $15^{\circ}$ S. Lat. at elevations not over 1,000 meters. Scolitantides has a limited distribution south of the tropics; it ranges from $0^{\circ}$ to $40^{\circ} \mathrm{S}$. Lat., at elevations from 3,000 to 4,000 meters in the equatorial region and at sea level southward.

Chrysophanus has a strictly northern distribution; it ranges from $72^{\circ}$ to $25^{\circ} \mathrm{N}$. Lat., and at high elevations toward the south. This genus is also Eurasiatic, as might be expected.

Feniseca is restricted to a narrow latitudinal range from $35^{\circ}$ to $45^{\circ} \mathrm{N}$. Lat. at lower elevations. Few genera of any family are so restricted to the North American temperate zone.

Leptotes is equatorial, extending from tropic to tropic at 0-2,000 meters, but extending also northward to $40^{\circ} \mathrm{N}$. Lat.

Brephidium is North American tropical and temperate, extending from $10^{\circ}$ to $45^{\circ} \mathrm{N}$. Lat. at all elevations from 0 to 2,000 meters. Few butterfly genera have such a restricted North and Central American range.

Hemiargus lives at elevations from 0 to 3,000 meters and extends slightly farther north (to $30^{\circ}$ ) than south (to $25^{\circ}$ ).

Hylos is found only in the cold temperatures of the Andes from $2^{\circ} \mathrm{N}$. Lat. to $20^{\circ} \mathrm{S}$. Lat. and occurs at elevations between 3,000 
and 5,000 meters. In this zone of endemism it is accompanied by some Pieridae, Nymphalidae, and Satyridae.

Everes along with Leptotes has a tropical core but exists also northward to $50^{\circ} \mathrm{N}$. Lat. and southward to $25^{\circ} \mathrm{S}$. Lat.

Plebejus, Philotes, and Glaucopsyche are North Temperate genera. Plebejus ranges from $82^{\circ}$ to $15^{\circ} \mathrm{N}$. Lat., at higher elevations southward, especially at about $40^{\circ} \mathrm{N}$. Lat. Philotes is restricted to the range $25^{\circ}$ to $40^{\circ} \mathrm{N}$. Lat. Glaucopsyche has a similar range but goes to $50^{\circ}$ N. Lat. Plebejus and Glaucopsyche are also Eurasiatic.

Lycaeniopsis exists at low elevations from $10^{\circ}$ to $65^{\circ} \mathrm{N}$. Lat., but at the higher elevations of 2,000-3,000 meters only in the central part of its range.

\section{CHARACTERISTIC DISTRIBUTIONAL PATTERNS}

The generic and family distributional charts have indicated a number of recurring and characteristic distributional patterns.

The distribution of the families of butterflies (Fig. 1) can be divided into two kinds: (1) the tropical distribution (or nearly so) and (2) the non-specific or general distribution. These are as follows:

Tropical

Danaidae

Morphidae

Brassolidae

Erycinidae
General

Papilionidae

Pieridae

Satyridae

Nymphalidae

Lycaenidae

The genera of the second grouping can be classified according to the nature of their distribution. Two major classifications are readily apparent. These are the strictly equatorial genera ranging generally between the Tropics of Cancer and Capricorn, or at most only a little north or south. Examples of this type of distribution are those of Catasticta and Appias (Fig. 4). Few genera of this classification are found in Eurasia or Africa.

The second major distributional pattern is that of the northern types, which extend to far northern latitudes and typically occur at increasing elevation to the south. Most of these genera live also in Eurasia or Africa. Included in this group are a few genera that occur also across the equator at high levels and in southern latitudes. 
An enumeration of the genera (including "groups") of these two types for each family shows:

Panequatorial

Papilionidae

Pieridae

Danaidae

Morphidae

Satyridae

Brassolidae

Nymphalidae

Erycinidae

Lycaenidae

Total

14

18

15

1

18

4

38

29

5

142

\section{Northern}

3

5

0

0

7

0

7

1

5

28
Other

$\begin{array}{rr}2 & 19 \\ 7 & 30 \\ 19 & 34 \\ 0 & 1 \\ 60 & 85 \\ 4 & 8 \\ 25 & 70 \\ 19 & 49 \\ 5 & 15 \\ 141 & 311\end{array}$

Many genera of the northern distributional pattern have close relatives, or even continuity of species, in Eurasia, or, if they do not at present, did in the immediate past when the northern latitudes were warmer. Except when particular circumstantial evidence provides a measure of plausibility, there seems to be no sound basis for inferring that any given form of this type originated in the Old World or the New.

It can be seen from the figures above that no family has more genera of northern distributional pattern than of panequatorial pattern. If numbers alone were important, this would seem to indicate that all families were, or could be, tropical in origin. Only three families completely lack genera classed as of the northern type.

Except for the Morphidae, containing the one well-known Neotropical genus Morpho, all the families contain genera that do not appear referable to either the panequatorial or the northern category. In four families, more than half the genera are regarded as of other types. The Papilionidae, however, have but 2 such genera out of 19 genera or groups (Figs. 2-3). These are Euryades and Baronia (Fig. 3), both of which are clearly relict types of restricted distribution.

The Pieridae (Figs. 3-5) have 7 such types out of a total of 30 genera. One of these, Eucheira, is similar to Baronia in range, for it is restricted to a narrow elevated range near the Tropic of Cancer Tatochila complements Pieris in the southern hemisphere and probably should be considered at most a subgenus. Two of these 
seven genera display a common equatorial distributional pattern in which the distribution would be panequatorial were it not that the northern range stops at $10^{\circ} \mathrm{N}$. Lat., that is, at the Isthmus of Panama. Since these are usually well-adapted tropical types existing at low elevation, there is no discernible reason for this abrupt termination except for the few that cannot cross the Andes from the eastern to the western tropical regions in Colombia or Venezuela. The two pierid genera of this category are Leucidia and Leodonta (Fig. 4). Complementary distributions from $10^{\circ} \mathrm{N}$. Lat. northward are less common. These are in effect circum-Caribbean types, which are represented in the Pieridae by Kricogonia and Nathalis (Fig. 4), the latter of which reaches as far south as $5^{\circ} \mathrm{N}$. Lat. In the Euchloinae three genera, Eroessa, Andina, and Phalia (Fig. 5), are restricted to southern latitudes at high elevations.

In the Danaidae (Figs. 5-7), 19 out of a total of 34 genera fit into neither the northern nor the panequatorial pattern. Since all these are tropical, the reason for their restricted range is not immediately apparent. Ten of the 19 reach their northern limit at $10^{\circ} \mathrm{N}$. Lat., but most of these also do not extend far southward. The other 9 are limited to belts of varying degrees of latitude in the vicinity of the equator. This would seem to indicate that temperature is not the limiting factor in their distribution.

In the Satyridae (Figs. 7-12), fully 60) of the 85 genera have ranges that do not fit into the two major categories. The Panamanian limit $\left(10^{\circ} \mathrm{N}\right.$. Lat.) characterizes only 18 of the genera. The others are limited in various ways. The most common limitation in this family is restricted altitudinal range for a short latitudinal distance in the equatorial Andes. This family is rich in genera of limited distribution in the Andes and in the Central American Cordillera. Included are genera of very small range at almost every latitudinal belt from $30^{\circ}$ to $40^{\circ} \mathrm{N}$. Lat. to $30^{\circ}$ to $40^{\circ} \mathrm{S}$. Lat. In fact, this family has more genera than any other, and most of them are limited in range. No other family has so many genera (fully 14) restricted to a south latitudinal distributional range or so many (22) restricted to a range of less than $10^{\circ}$ of latitude.

In the Brassolidae (Fig. 12), of the four genera not included in the panequatorial distributional pattern, two cease their northern range at the Panamanian $10^{\circ} \mathrm{N}$. Lat. limit, and two are restricted to a narrow $\left(10^{\circ}\right)$ range south of the Tropic of Capricorn. 
In the Nymphalidae (Fig. 12-16), 25 of the 70 included genera are neither fully panequatorial (38) nor northern (7). The Panamanian $10^{\circ}$ N. Lat. limit disqualifies only 3 genera, Metamorpha, Cybielus, and $A$ grias, from the panequatorial category. Others having narrow distribution are Gnathotriche, Lucinia, Peria, Balboneura, Libythinia, Batesia, Morpheis, and Caenophlebia with $5^{\circ}$ limits; Vila and Polygrapha with $10^{\circ}$ limits; Napeocles and Megistanis with $15^{\circ}$ limits; Haematera, Panacea, Callithea, and Zaretes with $20^{\circ}$ limits. Clothilda like Kricogonia, has a pan-Caribbean distribution $\left(10^{\circ}-20^{\circ} \mathrm{N}\right.$. Lat.).

In the Erycinidae (Figs. 16-19), 19 of the included 49 genera are neither panequatorial (29) nor northern (1). Ten of the 19 are limited in the north by the Panamanian $10^{\circ} \mathrm{N}$. Lat. barrier, even though all exist at the lowest altitudinal ranges. The others are tropical but limited in latitudinal distribution, usually at the lowest altitudinal levels.

The 15 lycaenid genera (Fig. 19) are equally divided into the three major groups. None seems to be affected particularly by the Panamanian $10^{\circ} \mathrm{N}$. Lat. barrier. One of the 5 has a $25^{\circ}$ equatorial range, another $15^{\circ}$, one $10^{\circ}$ in the temperate zone of the north, one at the higher levels of the southern Andes, and one (Brephidium) in the tropics and temperate zones north of $10^{\circ} \mathrm{N}$. Lat.

Altogether 45 genera out of the total of 311 have a distributional range that is equatorial save for the $10^{\circ} \mathrm{N}$. Lat. limits. This number exceeds the combined total (28) of northern genera. Nearly onethird (96) of the total genera have ranges that do not fit into the normal patterns, largely because the ranges are too limited. Only 4 genera, Kricogonia, Nathalis, Clothilda, and Brephidium, are both tropical and restricted latitudinally north of South America (panCaribbean). Some genera are restricted to less than $5^{\circ}$ latitude, mostly in the mountain belt between $30^{\circ} \mathrm{N}$. Lat. and $30^{\circ} \mathrm{S}$. Lat. Exceptional areas of endemism of this sort are: (1) the Mexican mountains, especially in the south, (2) the higher parts of the Andes, especially in Peru and Bolivia, and (3) the plains of South America from $20^{\circ}$ to $35^{\circ} \mathrm{S}$. Lat.

\section{SIGNIFICANT FACTORS}

Butterflies are directly temperature-controlled (i.e., cold-blooded). The larvae are plant feeders. The adults are day fliers, mostly dependent on direct solar radiation for flight. These three factors 
appear to be the most significant in controlling the distribution of butterflies.

Because they are dependent on the heat of the environment for their activity, butterflies become inactive at temperatures below freezing. The tropical environment therefore appears to be ideal. This is reflected by the facts that 262 of the 311 genera (and species groups) are equatorial and that 142 of these occupy the whole, or almost the whole, distance from the Tropic of Cancer to the Tropic of Capricorn. Adaptation to existence in northern or southern latitudes with seasonal cold weather has been attained by members of 7 out of 9 of the families in one of two ways: (1) by remaining during the cold time of the year in an inactive state (diapause), or (2) by migrating out of the area. The former method has been employed most successfully by members of 6 families, which thereby are enabled to exist in areas of freezing winters. The members of the seventh family (Danaidae), without diapause, avoid the hazard of cold by migrating into warmer regions each winter. In fact, it is not unusual for many species of several families to migrate southward in winter and northward in summer, especially in areas on the fringes of their ranges.

Most species appear to have a limited range of temperature tolerance. This is obviously narrower for species than for genera, but even for most genera it appears from the charted distribution to be narrower. Genera adapted for cold climates seem to be unable to exist in areas of continuous high temperatures. Their ranges typically rise in altitude as they progress southward in the northern latitudes, or northward in the southern latitudes. Even the distribution of genera appears to be partly controlled by temperature tolerances. For example, Colias is cold-adapted and skips over the tropics and subtropics, whereas Zerene is adapted to subtropical conditions and remains below the cold regions (altitudinally and latitudinally) and above the hot temperatures (Fig. 4). Other genera occupy the hot areas. The species within a genus occupy belts of latitudinal diversification. The species of Colias can be arranged in consecutive order from those most cold-adapted to those most warm-adapted. The most warm-adapted species (Colias eurytheme) lacks a diapause and depends for its survival in the winter either on migration or on resistance to the relatively short winters in the temperate zone. It cannot survive in the far north. It migrates northward in the Mis- 
sissippi Valley in summer and southward in winter. The species Danais plexippus does so also throughout the whole of its temperate zone range.

Nearly all plant-eating insects develop a high degree of specificity in their food habits. One species or race of insect is commonly restricted to one species or group of plants. Such restrictions naturally limit the geographical ranges of the insects to the range of the necessary plants. These restrictions of temperature or habitat further narrow insects to but a portion of that range. The limited ranges of many tropical genera, indicated before, are undoubtedly related to the distribution of food plants.

With few exceptions, all butterflies depend on direct solar radiation for activity. The few exceptions are certain genera of the Brassolidae Danainae, and Ithomiinae, which fly in the partial shade of the tropical forest. A close relationship exists between temperature and solar radiation, with regard to the tolerances of certain butterflies. These tolerances are controlled even to groups as small as the color phases of a single species. For example, the white and orange color phases of Colias eurytheme have been shown to respond differentially to these two environmental factors, which operate in combination (higher temperatures partly compensate for lower solar radiation and vice versa).

Areas with little or no direct solar radiation, especially where the temperatures are low, do not support butterfly populations. This is true in the Aleutian Islands, Iceland, and southwest Chile.

\section{CHANGING DISTRIBUTIONS}

Distributional maps, or the histograms here shown, give an undue impression of permanence. The distributions change in time: over many years (as with climatic changes), over one year (annually), during part of one year (seasonally), or even daily.

There is much circumstantial evidence for distributional changes in past time. Restriction of colonies of northern species in southern mountains with no recent contact suggests a once wider range with continuity during a colder period. For example, the population of Colias philodice in Guatemala is separated now from its nearest relatives by the whole of Mexico; the population of Colias interior in the southern Appalachians is separated now from the nearest northern stock in the White Mountains of New Hampshire; Colias 
behri is located in the southern Sierra Nevada from its presently nearest relative in central Oregon. Many other examples of such disjunction could be cited.

Tropical forms occasionally invade more northern areas, where they may stay for a season or two. Extremes of climates are usually the limiting factors controlling distributions, but they do not always occur annually. Thus colonies can often survive out of their more permanent range for several years until an unusual year wipes them out. Colias eurytheme periodically invades the colder regions of northern Canada where it may survive for a number of generations. Then a cold winter kills all individuals. Phoebis periodically invades northern areas during the summer and may even survive mild winters.

Ice age distributions may or may not have been very different from what they are now, but great areas were undoubtedly denuded of all populations by the glaciers. Such areas are still being repopulated. Some of the reinvasions from opposite sides of the former continental glacier of North America have led to interesting readjustments of species relationships. Colias hecla and Colias nastes, for example, hybridize in that area to form a third species, not found elsewhere. There is often a narrow line of demarcation between two species, one that existed south and east of the glacier, and one that held out in the unglaciated area to the northwest. For example, in Limenitis, the two species astyanax (south) and arthemis (north) now narrowly overlap in the Great Lakes area. Similarly, Colias interior (south) and Colias palaeno (north) narrowly overlap across central Canada.

Colias eurytheme is absent from the Gulf Coast of the eastern United States in summer, since the temperatures there are unsatisfactory for its existence. However, it is reestablished by migrants from the north in autumn, and passes through two or three generations before the hot summers arrive again. In the meantime, cold winter weather forces the adults to disappear for a month or two.

Daily differences in activity and distribution have been indicated for the genetically determined color phases of Colias. It is of course the selective effect of climate on individuals that determines in a broader sense the distribution of species, of genera, and of families. The groups are no more important than the individuals of which they are composed. 


\section{ORIGINS}

Genetically speaking, the point of origin of any species, genus, or family can be any location inhabited by the genetically aberrant individual ancestor. Origins can ordinarily be determined only by circumstantial evidence and thus are no more certain than the evidence used. Inferences on the origin of any group depend on the distributional pattern of the group, particularly on its isolation, and on the number of forms that have remained isolated in a particular area.

It has been seen that for the American butterflies an Old World origin can plausibly be postulated for all those types having a northern range, as they all have affinities in Eurasia. However, it could be proposed with similar plausibility that these forms originated in North America and dispersed into Eurasia. Moreover, since all these northern types also have affinities in the American tropics, it is possible that they originated in the tropics or at least from the tropical forms. It seems probable that the tropical forms as we know them have originated in the American tropics. The degree of differentiation of the New Morld butterfly fauna from the faunas of Eurasia and the African-Australian region increases progressively in proportion to the distance from Bering Straits. This suggests long and great isolation of the American tropical fauna from the faunas of the Old World tropics. Such continuity as exists is only through the few northern types.

Primary origins, whether of the northern or the tropical groups of butterflies, can seldom be securely determined, or even plausibly suggested. Secondary origins or centers for butterfly types, however, are indicated for various regions, including the zones of endemism already discussed. In the North American temperate region there has been an extensive development of characteristic subgenera in such genera as Colias, Argynnis, Melitaea, Oeneis, Satyrus, Pieris, Limenitis, Plebejus, and Glaucopsyche. Colias and Argynnis give evidence of other secondary origins in the temperate zones of South America. The tremendous development of satyrid genera in the Andes is unique, as is the development of a number of genera in several families on the Altiplano of Peru and Bolivia. The Caribbean region shows relatively little endemism, but four genera are restricted thereto.

By analogy and by theory it seems plausible to postulate that 
centers of origin for many species and genera of butterflies have often been places where invading species have encountered many new, unoccupied habitats, for, it is generally assumed, adaptive speciation is rapid and extensive in such places. Such a process has probably led to the evolution of the endemic genera of Satyridae in the Andes, during the relatively recent grand uplift of the Cordillera. A similar basis may be inferred for the development in northern regions of new species of Colias, Argynnis, and other genera that probably invaded the disturbed lands of North America, some in relatively recent time. Such centers of origin are areas where diverse genetic types on new arrival have found readily available habitats for their occupancy. The trial and error system of natural selection probably succeeds best under such conditions.

\section{BIBLIOGRAPIIY}

Below is a partial compilation of the literature that has provided a large part of the data for the present digest. Nearly every paper published on American butterflies is important in providing geographical or ecological information. A bibliography such as this cannot, however, list every paper seen or read. The author's observations have also been essential in providing accuracy on the altitudinal and geographical distributions in Alaska, the Northwest Territories, the Yukon Territory, Alberta, and British Columbia, the Sierra Nevada, the Rocky Mountains, Mexico, Central America, Colombia, and Ecuador. Without these observations, it would probable have been impossible to have constructed the histograms. Accuracy in the Mexican region is due in large part to the data of Hoffmann. The region poorest known is that of the central to southern Andes, in Peru, Bolivia, Argentina, and Chile. Data obtained from collections should also be mentioned, even though many of these do not give altitudinal details.

Barnes, William, and J. J. McDunnough. 1911-1922. Contributions to the Natural History of the Lepidoptera of North America, Vols. 1-5. Decatur, Ill.

Bates, Marston. 1935. The butterflies of Cuba. Bull. Museum Comp. Zool. Harvard. 78: 61-258.

Bowman, Kenneth. 1919. Annotated Check List of the Macrolepidoptera of Alberta. Alberta Natural History Society, Red Deer, Alberta. With revisions 1919, 1920, 1921, 1924, 1928, 1934, 1938, 1944.

Breyer, Alberto. 1936. Lepidopteros de la Zona del Lago Nahuel Huapi Territorio del Río Negro. Rev. soc. entom. arg., 8: 61-63.

1939. Über die Argentinischen Pieriden. VII Intern. Kongr. Entom., Berlin, 1938: 26-55. 
Brooks, G. Shirley. 1942. A check list of the butterflies of Manitoba. Can. Entomologist, 74: 31-36.

Brown, F. Martin. 1941-43 (continued series). Notes on Ecuadorian butterflies. Various journals.

—. 1943-45 (continued). Notes on Mexican butterflies. I-V. 1950. The American Papilios. Lep. News, 4: 39-42; 63-67.

1953. The Papilios of Ecuador. Rev. Ecuatoriana Entomol. $y$ Parasitol., 1: 41-60.

Carpenter, G. D. Hale, and C. B. Lewis. 1943. A collection of Lepidoptera from the Cayman Islands. Ann. Carnegie Museum, 29: 371-396.

Clark, Austin H. 1932. The butterflies of the District of Columbia and vicinity. Smithsonian Institution, U. S. Natl. Museum Bull. 157.

Comstock, John A 1928. Butterflies of California. Los Angeles.

Comstock, Wm. P. 1944. Insects of Puerto Rico and the Virgin Islands: Rhopalocera or butterflies. N. Y. Acad. Sci., 12, Pt. 4: 419-622.

Davenport, Demorest. 1941. The butterflies of the satyrid genus Coenonympha. Bull. Museum Comp. Zool. Harvard, 87: 215-349.

Dillon, Lawrence S. 1948. The tribe Catogrammini. Part 1. The genus Catogramma and allies. Reading Museum Sci. Publs. No. 8.

Dyar, Harrison G. 1904. The Lepidoptera of the Kootenai District of British Columbia. Proc. U. S. Natl. Museum, 27: 779-938.

- 1914. Report on the Lepidoptera of the Smithsonian Biological Survey of the Panama Canal Zone. Proc. U. S. Natl. Mus., 47: 139350.

Edwards, William H. 1868-1897. The Butterflies of North America. Boston and New York.

Elrod, Morton J. 1906. The butterflies of Montana. Univ. Montana Bull. 30, Biol. Ser. 10.

Elwes, H. J. 1898. A revision of the genus Erebia. Trans. Entomol. Soc. London, 1898: 169-207.

Field, William D. 1938. A manual of the butterflies and skippers of Kansas. Bull. Univ. Kansas, 39 (12): 1-328.

Fiske, W. F. 1901. Butterflies of New Hampshire. New Hampshire College Agr. Expt. Sta. Tech. Bull. No. 1.

Forbes, William T. M. 1945. The genus Phyciodes. Entomol. Americana, 24: 139-207.

Fox, Richard M. 1940. A generic review of the Ithomiinae. Trans. Am. Entomol. Soc., 66: 161-207.

- 1947. Ithomiinae of Rancho Grande, Venezuela. Zool., 32: 173178.

Garth, John S. 1935. Butterflies of Yosemite National Park. Bull. Southern Calif. Acad. Sci., 34: 1-39.

. 1950. Butterflies of Grand Canyon National Park. Grand Canyon, Ariz. Nat. Hist. Assoc., Bull. 11.

Gay, H. 1849. Fauna Chilena. Santiago de Chile. 
Gibson, Arthur. 1920. Report of the Canadian Arctic Expedition 1913-18, Vol. 3, Insects: Pt. 1, Lepidoptera. Ottawa, Canada.

Godman, Frederick D., and Osbert Salvin. 1879-1901. Biologia CentraliAmericana. Insecta-Lepidoptera-Rhopalocera. Vols. 1, 2, 3.

- 1891. in Whymper's Travels among the Great Andes of the Equator, Appendix, Lepidoptera, Rhopalocera.

Grinnell, Joseph, and F. Grinnell, Jr. 1907. Butterflies of the San Bernardino Mountains, California. J. N. Y. Entolol. Soc., 15: 37-50

Grossbeck, John A. 1917. Insects of Florida. IV. Lepidoptera. Bull. Am. Museum Nat. Hist., 37: 1-147.

Hayward, Kenneth J. 1931. Los Nymphalidoes Argentinos. Rev. Soc. entomol. arg, 4 (1-3): 1-199.

Hoffmann, Carlos C. 1940. Catalogo Sistematico Zoogeografico de los Lepidopteros Mexicanos. Primera Parte. Papilionidea. Anales inst. biol. (Uniz. nac. Méx.), 11 (2): 639-739.

Hovanitz, William. 1945. Comparisons of some Andean butterfly faunas. Caldasia, 3: 301-36.

. 1941. Parallel ecogenotypical color variations in butterflies. Ecology, 22: 259-284.

- 1943. Geographical variation and racial structure of Argynnis callippe in California. Am. Naturalist, 77: 400-425.

- 1945. Distribution of Colias in the Equatorial Andes. Caldasia, 3: 283-300.

$49-75$.

Jorgensen, Pedro. 1916. Las Mariposas Argentinos familia Pieridae. Ann. Mus. Hist. Nat., Buenos Aires, 28: 427-520.

Kaye, William J. 1904. Catalogue of the Lepidoptera Rhopalocera of Trinidad. Trans. Entomol. Soc. London, 1904: 159-228.

. 1914. Butterfies of Trinidad, Pt. 1. Agricultural Society, Trinidad and Tobago, Port-of-Spain, Trinidad.

- 1921. A catalogue of the Trinidad Lepidoptera Rhopalocera. Mem. Dept. Agr., Trinidad and Tobago.

Leighton, Ben. V. 1946. The butterflies of Washington. Unir. Wash. Publs. Biol., 9: 47-63.

Longstaff, C. B. 1914. Butterflies of Tobago: On some butterfies of Tobago. Reprinted from Trans. Entomol. Soc. London, 1908.

McAlpine, W. S. 1918. A collection of Lepidoptera from Whitefish Point, Michigan. Occ. Papers Museum Zool. Univ. Mich. No. 54.

Macy, Ralph W., and Harold H. Shepard. 1941. Butterflies (esp. Minnesota). University Minnesota Press, Minneapolis, Minn.

Reed, Edwyn C. 1877. Monografia de las Mariposas Chilenos. Anales Univ. Santiago, 1766: 647-736.

Rothschild, Walter, and Karl Jordan. 1906. A revision of the American Papilios. Novitates Zoologicae, 13: 411-745. 
Ureta, Emilio. 1936-37. Lepidopteros de Chile. Rev. Chilena Hist. Nat. Schudder, Samuel H. 1889. The Butterflies of the Eastern United States and Canada. Cambridge.

Seitz, Adalbert. 1924. Macrolepidoptera of the World. Various authors. The American Phopalocera, Vol. 5, Stuttgart.

Warren, B. C. S. 1936. Monograph of the genus Erebia. British Museum, London.

1944. Review of the classification of the Argynnidi, etc. Trans. Roy. Entomol. Soc. London, 94: 1-53.

Wright, William G. 1906. Butterflies of the West Coast of the United States. San Bernardino, Calif. 


\section{$\mathbb{P} \mathbb{A} \mathbb{R}^{T} \mathbb{I I}$}

Geographic Distribution of Contemporary Organisms 



\section{Introduction}

E. Raymond Hall

The University of Kansas, Lawrence

When a biologist accurately depicts the geographic distribution of species of contemporary organisms, he does, in a sense, about what the merchant does when he completes an inventory of his stock of goods. When the biologist maps also the geographic distribution of these same kinds, and also other kinds, of organisms of the immediately preceding geological epoch, he does, in a sense, what the merchant does when he examines his inventory list of a year ago. Paleontology for the biologist and history of stocks of goods for the merchant better than almost any other information permit the biologist and merchant, respectively, to forecast what lies ahead.

For the biologist who studies evolution and its modus operandi, speciation is of major importance because "species" means "kinds," and the biologist has to distinguish one kind of organism from all others before he can plot the distribution of any one kind. Furthermore, the biologist must, on the one hand, decide on a subjective basis whether a particular morphological ensemble is a species or a genus and, on the other hand, on an objective basis whether that ensemble is a species or a subspecies. In order to decide on species versus subspecies much field work, especially collecting at the right places and times, is required. If the two kinds intergrade in nature, they are subspecies of a single species. If the two kinds do not anywhere in nature intergrade, they are two species.

Therefore, the nontaxonomist should remember when he views a reasonably accurate map of the geographic distribution of an organism that the map represents several steps along the road to an understanding of how evolution occurred in nature.

From what the speakers showed and told and from what was said in the ensuing discussion, I judge that (1) several problems have been solved, but that the solution of a particular problem ordinarily 
poses new unsolved problems; (2) the geographic distributions of many kinds of organisms in the temperate region of North America are explained by Quaternary climates-climates of the immediate past geologically speaking; and (3) shifts of geographic range now in progress are primarily northward.

On the second point, it seems that the alternation of dry and moist periods in the central part of what is now the United States left their marks on contemporary organisms. These alternations of climate are thought to have been associated with recessions and extensions of glaciers in the northern part of North America. There is reason to suppose that each of several mammalian stocks now separated in to two species (eastern and western) formerly ranged as one species across the United States from the Atlantic to the Pacific. For example, the Eastern Cottontail of the eastern region that supports shrubs and trees and Nuttall's Cottontail of the western region that supports shrubs and trees probably owe their existence as separate species to a period of aridity, south of the glacial front, so marked that the common stock withdrew from most of the region that we now designate as the Great Plains. In the now still arid Great Plains, albeit less arid than at some times in the past, the two stocks have reinvaded the region but only by following the few ribbonlike riparian plant associations that extend from west to east across the grassy plains. Where the two stocks of cottontails now meet, they do not intergrade (crossbreed), having evolved, while separated from each other, along different physiological and physical lines, The Shrews of the Sorex vagrans group recently reported on by Dr. James S. Findley (Univ. Kansas Publ., Mus. Nat. Hist., 9: 1-68, 18 figures, December 10, 1955) provide a second example of the effect of a period of aridity, in this instance in the Great Basin of the western part of the United States. While the two stocks of Sorex vagranseast and west-were separated, evolution did not proceed quite so far as in the Cottontails and so the two stocks of shrews crossbreed at a few of the places where their geographic ranges ultimately met again. At other places they do not crossbreed. Indeed the geographic ranges broadly overlap and provide one of the few examples in mammals of two subspecies of the same species occurring together over a considerable geographic region.

Incidentally, it seems to me, that the effectiveness of the grasslands of the Great Plains, extending from Mexico to Canada, in 
isolating closely related stocks of land vertebrates from each other has seldom been recognized by zoogeographers and certainly has not been carefully assessed.

In illustration of the third point I again draw on the Mammalia. Shifts of geographic range now in progress are evident in the Ninebanded Armadillo, in the Hispid Cotton Rat, and seemingly in the Southern Bog Lemming. The northern margin of the geographic range of the Bog Lemming seems to have shifted northward in the past 30 years in the eastern part of the Great Plains. In the same region in the past 40 years the Armadillo has extended the northern margin of its range 75 miles and in the same region and period of time the Cotton Rat has done the same thing by moving approximately 200 miles. 



\section{Pleistocene Ecology and Biogeography of}

\section{North America ${ }^{1}$}

Paul S. Martin

Geochronology Laboratories,

University of Arizona, Tuscon

During the past ten years, the related fields of Pleistocene chronology, biogeography, palynology, and prehistory have experienced vigorous growth. This growth may be attributed in part to methods of isotope dating, fresh interest in periglacial geomorphology, the application of pollen stratigraphy to archaeological and chronological problems, and increased appreciation of "vertebrate microfossils." Students of animal and plant distribution find themselves increasingly committed to archaeological and geological data. The information exchange is mutual and poses a challenge in interdisciplinary communication. For attempting to unify Pleistocene concepts within archaeological, biological, geological, and climatological specialities we are especially indebted to Braun (1955), Clark (1952), Deevey (1949, 1953), Flint (1957), Frenzel and Troll (1952), and Moreau (1955). In North America Dillon's mapping of Pleistocene life zones (1956) has filled something of a vacuum in the area of biogeographic reconstruction.

My present purpose is to identify some of the problems that appear important in the terrestrial ecology and biogeography of North America during the late Pleistocene. This project follows the logical principle advocated by Deevey (1949) that students of plant and animal distributions are obligated to consider the Pleistocene before working backward. To do so does not mean ignoring or neglecting the instructive record of Tertiary environment and life. The adopted course, however, is based on the belief that Pleistocene climatic change was not confined to the glacial border. Until proved otherwise, the more useful working hypothesis is that

\footnotetext{
${ }^{1}$ Contribution No. 9 of the Program in Geochronology, University of Arizona.
} 
existing range gaps and relict populations date from the Glacial period. From the viewpoint of the biologist the foremost events in terrestrial ecology of North America during the Pleistocene appear to include the following: (1) the climatic sequence proper with its attendant displacement of biotic zones; (2) the arrival of prehistoric man; (3) the extinction of late Pleistocene vertebrates. To an ununknown degree these events appear interrelated. The first part of my analysis is devoted to problems of climatic and environmental change, the second to extinction and the effect of man.

\section{LATE PLEISTOCENE ENVIRONMENT}

In view of the relatively poor pre-Wisconsin fossil and sedimentary record, it is expedient to concentrate on the last (Wisconsin) glacial sequence. Environmental change during the Wisconsin glaciation can be considered subequal to that which accompanied the earlier (Nebraskan, Kansan, Illinoian) glaciations. This assumption is based on the coincidence of the four glacial drift borders in eastern North America, the four equivalent periods of glacial temperature drop as recorded in oxygen-isotope analyses of marine foraminifera from the equatorial Atlantic (Emiliani, 1955), and the apparent sequence of cool and warm mammalian faunas found in unglaciated North America (Hibbard, 1958).

Generally, biogeographers keep abreast of modern findings in glacial geology and are not deterred by such views as that of Scharff (1912, p. 156) that glacial drift was formed by marine deposition and that the climate of the Pleistocene was never colder than at present. Admittedly, there is lack of agreement concerning Pleistocene environment and life in the region where glacial geology provides least information, namely in the temperate and tropical zones south of the drift border. Braun (1951, p. 145) felt that "... the deciduous forest zone, although narrowed, maintained itself on the Appalachian Plateaus in southern Ohio and Kentucky while glaciers extended southward in Ohio." Thomas $(1951$, p. 166) followed suit: "The distribution and the ecology of many Ohio animals, I believe, raises strong presumption that they survived the Wisconsin, or perhaps the entire Pleistocene, close to the glacial border; some species in refugia within the limits of glaciated territory." Plants in question include buckeye (A esculus octandra), sweet gum (Liquidambar), Agave, and Magnolia. Animals with distributions that also 
parallel the Wisconsin drift border in Ohio include the fence lizard (Sceloporus undulatus), copperhead (Agkistrodon contoririx), and upland chorus frog (Pseudacris brachyphona). To date there is no sound paleontological support for the postulated ice margin populations of temperate biotas.

On the contrary, evidence of Pleistocene spruce in southern Louisiana and spruce and fir pollen in northern Floricla and eastern Texas seems impeccable (cf. Deevey, 1949; Braun, 1955). The interpretation of the evidence, however, is not immediately shown. Does it prove the existence of boreal forest at this latitude? Or does it reflect an azonal mixture of temperate and boreal floras throughout the unglaciated east as Braun (1955) and Drury (1956) maintained? Presently spruce grows near sea level in Connecticut and southern Michigan, 400 to 500 miles beyond the southern limit of spruce-fir-jack pine boreal forest. The Florida and Texas records of boreal elements may also represent marginal populations of species whose position of dominance lay farther north. We need not insist that fossil spruce meant boreal forest in Texas and Louisiana, but it may well represent population outliers of boreal forest occupying Kentucky and the Carolinas.

An area of intense frost action extending 50 to 100 miles south of the ice sheet is generally accepted by geologists (Flint, 1957), at least for eastern North America. Denny's studies $(1951,1956)$ of periglacial land forms in unglaciated Pennsylvania are relatively conservative, Peltier's (1949) more sweeping in their paleoclimatic conclusions. Quite recently a series of herb-dominated pollen zones have been reported from inorganic sediments in eastern North America (Andersen, 1954; Davis, 1957; Deevey, 1951; Leopold, 1956; Livingstone and Livingstone, 1958; Martin 1958a). I consider these findings as palynological confirmation of Full- and Late-glacial tundra zones.

At this point it may be helpful to insert a definition. Within the scope of the term tundra I would include the following: (1) treeless vegetation in the Arctic; (2) treeless Alpine zones on temperate and tropical mountains; (3) pollen zones in Pleistocene sediments featuring high percentages of herb pollen plus a small amount of spruce and other boreal tree pollen.

There is no question of floristic identity between these communities. As an example, Ambrosia, an element in the Late-glacial pollen 
zones of New England and Michigan, is not found in the Arctic. Both Ambrosia and Ephedra, another steppe species in the Lateglacial of Europe and America, present the problem of how we might distinguish cool prairie from tundra in a pollen diagram. Today these vegetation types are separated by a belt of woodland and forest. Is it possible that they were in contact during the glacial periods?

Perhaps the periglacial landscape was not entirely treeless. If scattered spruce, larch, or jack pine grew near the ice margin, they would have formed a taiga or boreal savanna. Presently the taiga lies between boreal forest and treeless tundra (Rousseau, 1952; Hare, 1954). Occasionally pieces of coniferous wood are found in glacial drift (Flint, 1957, p. 323). Rather than indicating that forest was overridden by ice, they may mean that the glacier swept through a taiga type woodland, a more plausible ice-margin environment. The relatively well-known and widely discussed Two Creeks "forest" bed, silted and covered by Valders ice (Wilson, 1932, 1936) is not an exception. In stump diameter, taper, and growth rate the Two Creeks trees resemble spruce woodland in central Ungava (see Hustich, 1954, for comparative data). In brief, fossil wood is not proof of forest!

We may expect that Full-glacial tundra, boreal forest, and deciduous forest formations were not identical in species composition or even in vegetational structure with their present bioclimatic analogues. Nevertheless, if there is an adaptive relationship between vegetation and climatic zones, it seems unreasonable to postulate an azonal system during the glacial period, as Drury has done (1956, pp. 80-90). The model proposed by Dansereau (1957), with narrowed tundra bordering the ice at one point and maple or oak forest at others, also does not agree with either the concept of bioclimatic gradients or with Late-glacial pollen diagrams. In general the succession of pollen zones, tundra $\rightarrow$ boreal forest $\rightarrow$ deciduous forest in New England and boreal forest $\rightarrow$ mixed deciduous forest $\rightarrow$ oakpine forest in North Carolina (Frey, 1953)² shows, I believe, the

${ }^{3}$ My interpretation of boreal forest in North Carolina is based on Frey's pollen zone M2 in Singletary Lake and Jones Lake J-1. This reveals dominance of pine, including many small grains, with up to $9 \%$ spruce, $7 \%$ oak, $1 \%$ birch, and $1 \%$ hickory. In fairness to Frey $(1953,1955)$ it should be noted that, although he regarded his results as evidence of climatic change, he does not advance the hypothesis of Boreal Forest in the Carolinas. The case I would make for Boreal Forest rests chiefly on the small but crucial percentage of spruce and the scarcity or absence of broad-leaved species.

Another authority on this region, D. R. Whitehead (personal correspondence) takes strong exception to such an interpretation of Frey's work, noting: (1) Size-frequency 
historical integrity of generalized vegetation zones. On this conviction I have attempted to map late Pleistocene vegetation zones in two periods (Figs. 2 and 3). They are based on pollen stratigraphy, periglacial geomorphology and scattered plant and animal fossil records. Presumably, such a map will be of more value to the biogeographer than one based largely on biogeographic evidence that leads to a circular argument. If boreal forest replaced temperate deciduous forest in the Cumberland Plateau and southern Appalachians, it seems preferable to attempt to establish this fact in terms of pollen analysis, buried soils, and other fossil evidence.

\section{Modern Vegetation Zones (Fig. 1)}

Dansereau (1951) has stressed the importance of structure to the geographer and general ecologist, a viewpoint that I believe to be profitable also in paleoecology. Reconstruction of forest community composition from pollen data is beset with difficulties, for example in evaluating relative pollen rain among different wind-pollinated species and correcting for underrepresentation of insect-pollinated plants. However, it seems possible to determine structure of the simplest type, to distinguish forest, savanna, and grassland biochores and, within the first, coniferous and deciduous formations (for definitions of these and other vegetational concepts, see Dansereau, 1957). The six major vegetation zones or formations in eastern North America include: (1) treeless tundra; (2) boreal woodland or taiga, a savanna formation of needle-leaved trees scattered in a shrub and lichen mat; (3) boreal forest with a continuous canopy dominated by needle-leaved evergreens; (4) temperate forest dominated by broad-leaved deciduous trees and shrubs; (5) temperate prairie and savanna; (6) subtropical savanna of evergreen sclerophylls and tall grasses. These six zones represent arbitrary divisions of an adaptive gradient controlled in general, if not always in detail, by climate. Is it unreasonable to assume that this gradient maintained its structural features and sequence during the glacial periods?

features have not been worked out carefully for all the species of pine which are, or might be, expected in this area. Thus the allocation of small grains to the boreal species $P$. bankesiana is premature. (2) Zone M2 from Frey's core LS-2 contains fairly high percentages of oak (about 15\%) and hickory (about 10\%) as well as some pollen of Taxadium, Nyssa, and other temperate elements. (3) The predominance of pine might be the result of "over-representation" of a species such as $P$. serotina, which surrounds boggy sites in the southeast today. In other words, oak, hickory, and associated temperate plants occurred at sites some distance from the bay lakes but were "swampedout" by the well-known heavy rain of pine pollen. 


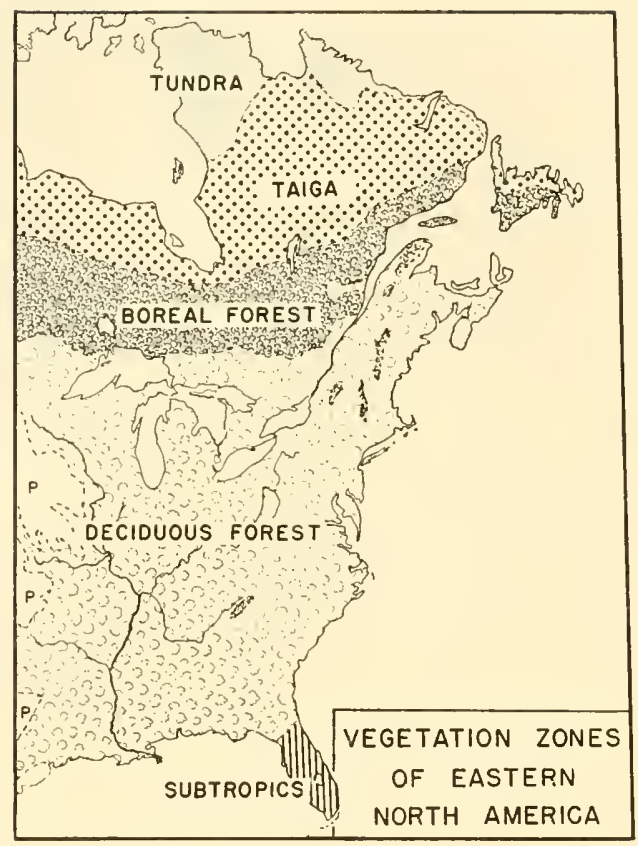

Fig. 1. Vegetation zones of eastern North America. Small, isolated mountain-top populations of boreal forest in parts of the Appalachians are not shown. The southeastern pine forests are considered part of the deciduous forest formation in a broad sense. Taiga is mapped on the basis of its savanna-like structure; floristically it is not very different from boreal forest. $\mathrm{P}=$ prairie.

Full-Glacial (Fig. 2)

Of utmost importance to the student of animal and plant distributions is the extent of Full-glacial biotic displacement. Following Flint we may date this period as ending roughly 17,000 years ago. In New Mexico the San Augustin Plains, 7,000 feet in elevation, were occupied by forest with a spruce pollen frequency of $20 \%$ (Clisby and Sears, 1956). In Postglacial time the spruce has disappeared and non-arboreal species have become more important.

In eastern North America there are only two radiocarbon-dated pollen diagrams that may represent pollen sedimentation of the Full-glacial period. From a piedmont marsh in unglaciated Pennsylvania the peak in non-arboreal pollen lies $80 \mathrm{~cm}$ below a radiocarbon date of 13,500 B. P. (Martin, 1958a). Apparently the formation of 
Pennsylvania piedmont swale marshes 50 miles beyond the ice margin dates from the Full-glacial period and coincides with a tundra-taiga vegetation of grasses, sedges, other non-arboreal species, and scattered spruce and jack pine.

A longer late Pleistocene pollen sequence, perhaps extending back into the middle Pleistocene, has been found in the Carolina Bay lakes (Frey, 1951, 1953, 1955). Possibly rebedding and truncation have occurred (Wells and Boyce, 1953; Frey, 1955). If the upper 10 feet of Frey's sequence is continuous, his zones M1, MI2, and MI3 should correspond to the Full-glacial period. In these pollen zones oak and other deciduous trees are scarce or absent; pine predominates with a high frequency of small-sized grains suggesting Pinus banksiana. There is a low but constant frequency of spruce. In terms of structure, the M zones indicate boreal, needle-leaved forest, with dominance of jack pine attributable to its well-known preference for sandy situations.

The local records of spruce pollen in Texas, Florida, and Louisiana are undated and, except for Potzger and Tharp's work $(1947,1954)$, unaccompanied by detailed stratigraphic study. If maximum displacement is represented, the difference between Full-glacial and present southern limits of marginal spruce populations would seem to be the same as the corresponding past and present southern limits of the boreal forest formation, that is, 800 miles.

Some type of mixed deciduous forest occupied the extreme south, with subtropical vegetation largely driven from Florida. Further discussion of Florida awaits expansion of the pollen studies begun by Wilson (Davis, 1946).

Certain periglacial land forms including boulder fields, colluvial soil mantles, and various types of patterned ground constitute reasonably secure evidence of climatic change. Others, such as loess, are apparently less reliable indicators of ice-margin conditions (Hack, 1953; Dylik, 1954). Uncritical identification of all "periglacial" features with a Full- or Late-glacial tundra climate is to be avoided. A few of these features can form at midlatitudes today. Yehle (1954) described soil tongues similar to periglacial frost cracks appearing in calcareous soils under the present climate. Goodlett (1954) reported patterned ground in miniature appearing on bare earth in central Pennsylvania. Recent colluvial creep and earthflows 
in the unglaciated Appalachian Plateaus "... appear to be most common in pastures, but field and woodland areas are not entirely free from such movements" (Sharpe and Dosch, 1942).

Wolfe's description (1953) of frost-thaw basins and related periglacial features in unglaciated New Jersey has been subjected to certain criticism. Yehle (1954) questioned the authenticity of the alleged frost cracks. Rasmussen (1953) and Deevey (1957) noted that basins of rather similar appearance occur in the Carolinas and coastal Texas, beyond the limit of possible periglacial frost action. However, the involutions and ventifacts which Wolfe described would appear to remain sound evidence of a periglacial tundra climate.

Farther south, in the latitude of Washington, D.C., Hack (1955) and Nikiforoff (1955) found little geomorphological indication of a "periglacial climate," beyond stabilized dunes and a soil hardpan of uncertain origin. For this reason, I have included this area within the Boreal Forest (Fig. 3).

In the Appalachians the block fields or stone streams (Flint, 1957) and glades including "bear wallows" may mark the lower limit of Full-glacial alpine tundra (Braun, 1955; Martin, 1958a). Cranberry Glades in West Virginia at 3,350 feet (Darlington, 1943) is perhaps the best known of the anomalous glade bogs; Core (1949) discussed others. In the Smoky Mountains inactive block fields covered with mosses and ferns and occasional yellow birch trees extend down to at least 4,500 feet. Braun $(1955$, p. 361) believed that they indicate a vertical tree line depression of 2,000 feet. It seems the present regional tree line does not lie at the top of the peaks as Braun implies. Spruce and fir grow as forest at 6,500 feet, the top of the Smokies (Whittaker, 1956). I would allow an additional 2,000 feet for subalpine taiga and "krumholtz" and locate the theoretical present alpine zone at 8,500 feet. This would bring the relative depression of the Alpine Zone in eastern North America into line with that observed at the same latitude in the west, 4,000 to 4,500 feet (Antevs, 1954). In either case the distribution of glade bogs and inactive block fields reveals that a Full-glacial treeless zone extended down into the Great Smokies.

To the south of the region of a periglacial treeless zone we might expect buried organic soils, fossilized "string bogs," or organic terrain of the type that typifies subarctic taiga and boreal forest (Drury, 
1956). Drury (pp. 86-87) believed that fossil peat and muck (leposits resembling those of Alaska are absent from the unglaciated east. It would appear, however, that serious search for ancient boreal forest landforms has not been made in the latitude formerly occupied by this vegetation type (Fig. 2). The famous buried soil of Spartansburg, South Carolina (Cain, 1944), might possibly represent such a

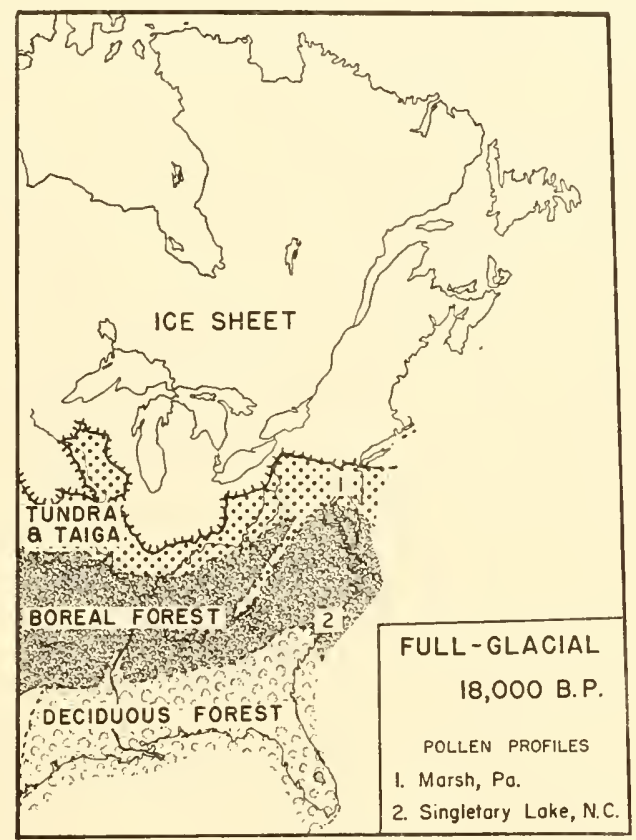

Fig. 2. Vegetation zones during the Full-glacial of the late Wisconsin. Tundra and taiga are mapped as a single zone with no attempt to distinguish them. Shelf exposure following sea level depression permitted some extension of vegetation beyond the present coast line.

feature, lying at the southern margin of the Full-glacial boreal forest. In addition to some hickory and oak these soils contain high percentages of spruce, jack pine, and fir pollen. ${ }^{3}$

Vertebrate fossils may provide some independent support to the existence of a narrow Full-glacial tundra zone. While uncritical acceptance of large mammals as climatic indicators is to be avoided,

${ }^{3} \mathrm{D}$. R. Whitehead (personal correspondence) is presently analyzing pollen from these soils and thinks that they are more likely Interglacial than Full-glacial. He reports finding less spruce and fir than Cain (1944) encountered. 
the fossil distribution of Ovibos (see map of Kitts, 1953) fits the Fullglacial tundra zone fairly well. The barren ground caribou, Rangifer arcticus, is reported from late Pleistocene deposits and its Fullglacial range should be roughly similar to that of Ovibos. Apparently the Postglacial distribution of these species has been so modified by both prehistoric and modern man that their value as tundra indicators is uncertain.

Rather than in eastern North America, the main Full-glacial refugia for tundra mammals and birds (Rand, 1948) lay in unglaciated Alaska. The tundra lemmings, Dicrostony.x and Lemmus, have not been found as fossils south of the ice sheet. The present range of the Peary Caribou, Rangifer arciicus pearyi, in northern Greenland and Ellesmere Land dramatizes the ability of caribou to survive at high latitudes under existing glacial conditions. It is barely possible that cyclonic nourishment of the Laurentian ice sheet in central Canada was accompanied by very low precipitation and sufficient ablation to expose the northern part of Greenland and the Arctic Islan 1s. Mercer (1956) indicates ice of uncertain depth, but evidently not very thick, on Baffin Island in the glacial period. The evidence that Banks Island was largely unglaciated (Manning, 1956) adds support to the concept of local, restricted glacial activity in the Arctic during the Full-glacial of the Wisconsin, and of earlier periods.

The poverty of mammalian biotypes in the tundra of northeastern Canada compared with northwestern Canada and Alaska is noteworthy. Tundra species of the northwest include Sorex tundrensis, Citellus undulatus parryi, Clethrionomys rutilus, Microtus oeconomicus, and $M$. micrus. These lack vicariants in eastern Canada. A faunal parallel to Hulten's Beringia refugium for the Arctic flora seems obvious.

\section{Late-Glacial (Fig. 3)}

It is sobering to recall that pollen evidence of a North American tundra dates back no farther than Deevey's study of Aroostook County in northern Maine (1951). Since then, Livingstone and Livingstone (1958) have confirmed Deevey's tentative recognition of an Allerod type sequence and, by a radiocarbon date of basal organic material, have shown that it was indeed contemporaneous with the Lower Dryas-Allerod-Upper Dryas period in Europe. The subsequent history of Late-glacial tundra, presumably moving 
rapidly into central Canada during the Post-glacial period, remains a mystery.

Although they document changes in forest composition, Potzger and Courtemanche's Quebec profiles (1956) fail to throw much light on this problem. How was the glaciated portion of the Arctic re-

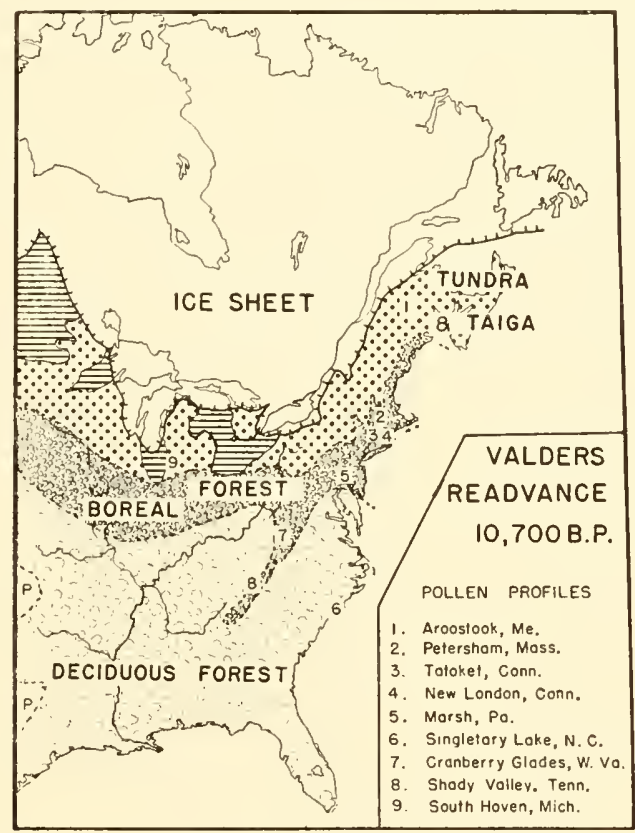

Fig. 3. Vegetation zones during the Valders readvance. Tundra and taiga are not distinguished; the tundra may have been absent west of the Appalachians. Gillis Lake, Nova Scotia, within the tundra-taiga zone at this time (Livingstone and Livingstone, 1958), is not shown. Horizontal ruling marks Lake Agassiz and the proglacial Great Lakes. East of Michigan the position of the Valders drift border is uncertain. $\mathrm{P}=$ prairie.

populated? For the present it may be wise to avoid the issue, noting simply that it is unnecessary to assume a direct continuity of tundra from mid-latitudes to high latitudes. If the last ice to stagnate and melt was the Laurentian sheet, it may have "trapped" the retreating Late-glacial tundra in southern Quebec during deglaciation of northern Quebec, and permitted tundra plants to invade northeastern Canada from the partly unglaciated Arctic Archipelago.

In eastern United States the Late-glacial, from 17,000 to 10,200 
B.P., represented a period of stagnation and retreat, with several climatic reversals and readvances of ice. Pollen records are still scattered, and dated diagrams are not as abundant as we might wish. However, they begin to approach in detail those available for Postglacial time. The stratigraphic break between the Postglacial and Late-glacial, which generally marks a rise in organic sedimentation, is a convenient level for a radiocarbon date. Partly for this reason, I have found it possible to assemble sufficient dated pollen horizons to attempt a vegetation map for the end of the Late-glacial during the Valders readvance. Even though ice returned to central Michigan, considerable climatic improvement is indicated over the Full-glacial conditions. In northern New England Deevey's discovery of Valders tundra is confirmed by Livingstone (see Table I). $\mathrm{C}^{14}$ dating of pollen zone $\mathrm{A}-4$ in Connecticut indicates the presence of boreal forest rather than taiga or tundra. The Valders readvance did not affect radically the forests of southern New England.

Mixed hardwoods and conifers, including spruce, occupied Glade Bog (2,700 feet) in Tennessee (Johnson, personal correspondence). Pine-spruce-birch-hemlock dominated the Cranberry Glades of West Virginia (3,400 feet). Alpine tundra had retreated or perhaps entirely disappeared from the southern Appalachians. Small ice fields, almost certainly surrounded by tundra, excavated circs in the Catskills, Adirondacks, and other high mountains of New England (Manley, 1955). Perhaps of greatest interest is the evidence from pollen studies that mixed deciduous forest had replaced the pinespruce forest of the Carolina Coastal Plain (Frey, 1953). The Valders forests of that area supported mesophytes such as beech and hemlock, temperate species no longer part of the regional pollen rain.

West of the Appalachians the situation is less clear. Andersen (1954) considered a typical Late-glacial profile from the George Reserve in southern Michigan to be of Younger Dryas age (Valders as currently understood in North America). However, if the $\mathrm{C}^{14}$ dates from the George Reserve (M-223, M-224, each 11,450 \pm 600 B.P.) are from the same core as was used in Andersen's study, his NAP zone is older. Possibly it represents the Older Dryas (Port Huron) period. Andersen presented a thoughtful and skilled analysis of the problem of "rebedded" and "redeposited" pollen in Late-glacial sediments and made a strong case for allochthonous origin of such temperate genera as oak, sweet gum, and ash. The regional pollen 


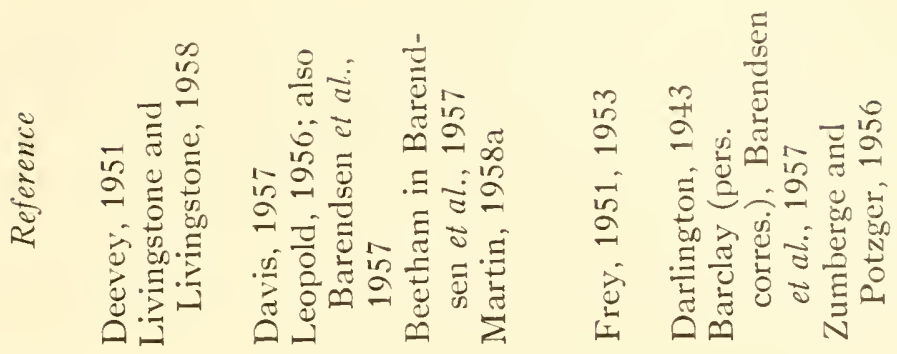

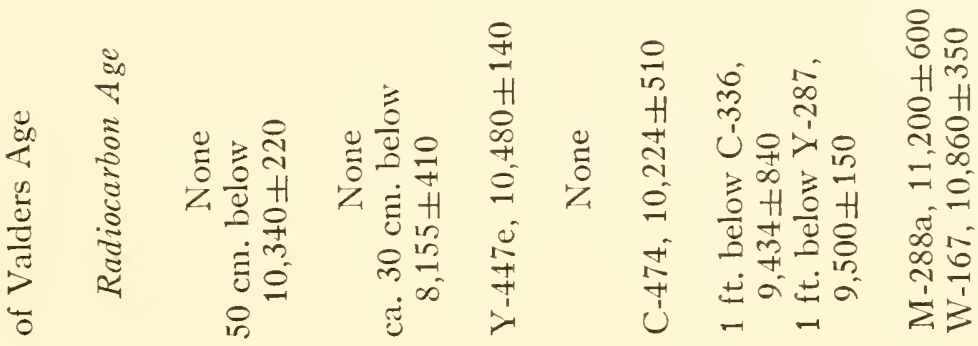

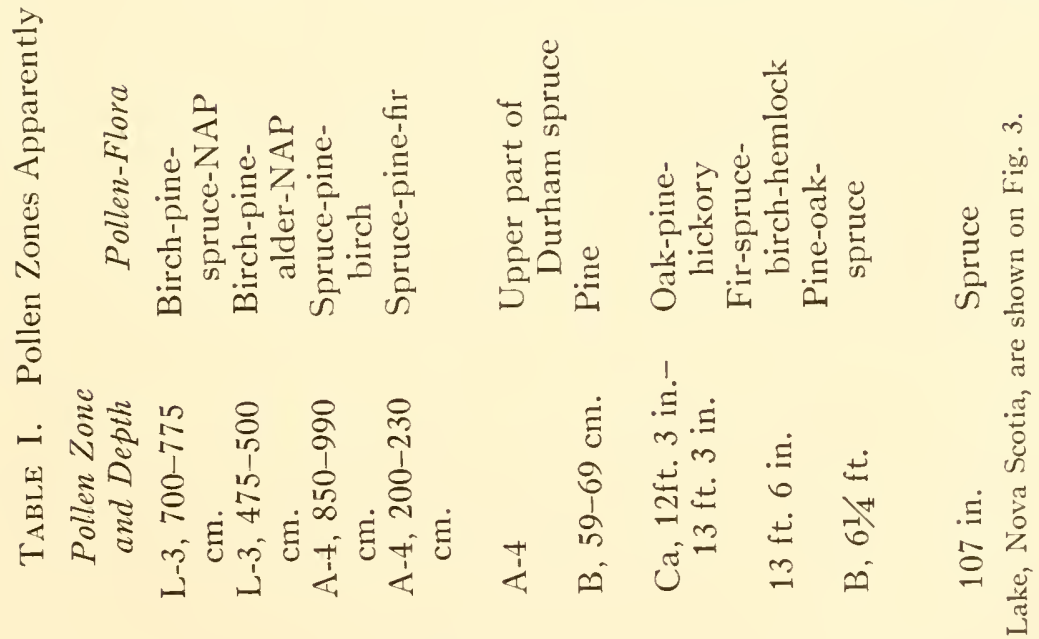

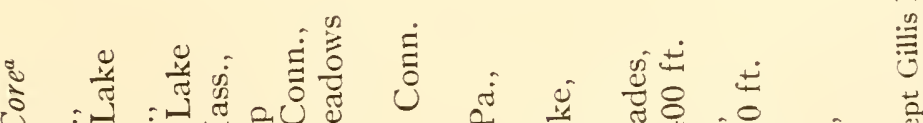

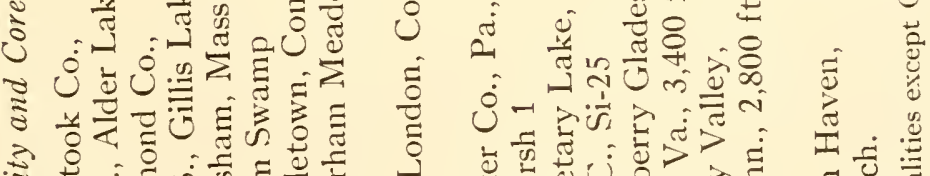

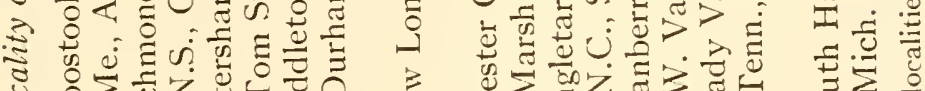

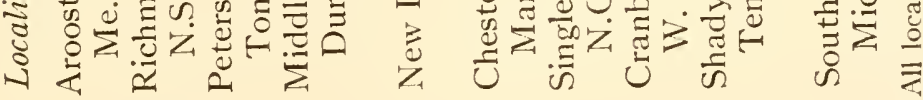

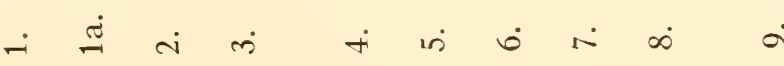


rain represented in the George Reserve clay is predominantly of spruce, various sedges, and grasses. With an NAP pollen sum not exceeding $40 \%$, it appears that the vegetation may have been a taiga rather than a treeless tundra. For my immediate purpose, which is to map vegetation zones during the Valders maximum, it seems best to withold judgment on the age equivalent of Andersen's profile. It does tell us that there was a taiga-tundra period during deglaciation of Michigan.

Pollen studies of Potzger (Zumberge and Potzger, 1956) reveal Postglacial events in the Michigan basin and interrelate shifts in vegetation with changes in lake levels. Potzger failed to encounter any indication of tundra or taiga conditions during the period that he felt should have represented the Valders readvance. In this regard his results agree with those of Davis, Leopold, and others in southern New England. Unfortunately, confidence in Potzger's sequence is considerably undermined by his consistent failure to recognize such pollen zones in any of his numerous studies throughout eastern North America. His rock-flour samples from the inorganic sediments underlying lake gyttja from Hartford Bog indicated no appreciable NAP pollen sum. Elsewhere in both Europe and America inorganic sediments of Late-glacial age generally mark zones of abundant herb pollen, such as Andersen encountered at the George Reserve. Unless Potzger's results are confirmed, I assume that the rock-flour levels in Hartford Bog record a tundra ortaiga phase in the vegetational history of southern Michigan.

The inconclusive results of both Andersen and Potzger provide poor material for attempting to locate formation boundaries during the Valders readvance. In extending the zone of taiga-tundra on Fig. 3 south through southern Michigan I have assumed that the proglacial Great Lakes reenforced the periglacial climatic influence of the Valder's ice sheet producing a poor environment for growth of forest. This judgment may be only slightly less arbitrary than my location of the boundaries of boreal forest and temperate deciduous forest in this region. West of the Appalachians there is no paleoecological record definitely of Valders age to assist in locating these zones.

\section{Postglacial}

Beyond refinements in chronology and mounting evidence of a very close correspondence between climatic events in the New and 
Old World (Deevey and Flint, 1957), little has been added to the Postglacial pollen sequence summarized by Deevey in 1949. The Hypsithermal, also known as Thermal Maximum, Xerothermic, Altithermal, etc., extended with intermittent pulsations from 9,500 to 2,000 years ago (Deevey and Flint, 1957). It is the most important climatic event of the period. Documentation of the classic Midwest Prairie Peninsula extension continues with Smith's recent valuable analysis of terrestrial vertebrates (1957). In addition to mapping relict outposts of prairie animals, Smith showed that it is possible to interpret anomalous and otherwise confusing splits in subspecific populations in terms of post-Xerothermic isolation. Instructive examples are found in Agkistrodon contortrix (copperhead), Natrix erythrogaster (copper-bellied water snake), Diadophis punctatus, and Opheodrys vernalis. In a bold and original interpretation Smith explained the history of the Pseudacris nigrita (chorus frog) complex in terms of invasion of $P . n$. feriarum, the eastern, forest-inhabiting race, by $P$. n. triseriata, a grasslands form from the west. PostXerothermic isolation left a segment of $P . n$. triseriata, recently described as P. n. kalmi, in New Jersey and the Delmarva Peninsula. Thus on both sides of the Appalachians separate, isolated, populations of triseriata type chorus frogs integrate with feriarum.

Postglacial pollen diagrams indicate Thermal Maximum (C-2 pollen zone) shifts in species composition, with an increase in oak and hickory in southern New England and, locally, of hemlock in northern New England. In many diagrams a recovery of spruce follows in C-3. During the Thermal Maximum Whittaker (1956, p. $60)$ believed that spruce and fir were pinched off the tops of certain mountains in the Smokies. Displacement upward of 1,000 feet or more is indicated by absence of these trees in presumably suitable sites on peaks of less than 5,500 feet elevation.

Thermal Maximum changes, which command attention of the student of community composition, the evolutionist, and the biogeographer, were inappreciable in terms of the plant formations mapped in Fig. 1. They do not justify an attempt at a separate vegetation map.

\section{Western United States, Mexieo, and the Tropies}

Exclusion from Figs. 1-3 does not imply that these areas escaped considerable late Pleistocene climatic and environmental change. For the present, however, it seems impossible to express this effec- 
tively on a Pleistocene vegetation map, unless one relies largely on biogeographic data as Dillon (1956) has done. Topographic complexity inevitably leads to considerable difficulties in large-scale mapping of vegetation. Twelve major units on Leopold's very useful vegetation map of Mexico (1950) suggest something of the problem.

Paleobotanical study of the Willow Creek flora of Santa Cruz Island, California, revealed a latitudinal shift in Pseudotsuga, Cupressus, and Pinus of perhaps 440 miles, less than the 800 miles of zonal displacement in eastern North America (Chaney and Mason, 1934). Studies of late Pleistocene fossil birds indicate an even less drastic shift. "The avifaunas of the Carpinteria asphalt and of some of the Pleistocene caves of northern and central California (Miller, 1937, 1939) indicate that the boreal avifauna extended 200 miles farther south along the coast, at least, and 1,000 feet lower on the interior mountains. Possibly even more extreme extensions occurred in other parts of the Pleistocene" (Miller, 1951, p. 610). The latter comment is crucial; either the Carpinteria and other Pleistocene cave faunas are not of Full-glacial age or the avifaunal displacement is discordant with that represented by the Willow-Creek flora. Actually, neither deposit may represent maximum displacement of the coldest period.

The same logic can be directed toward the Rancholabrean biota of the famous tar pits. While the living representatives of this assemblage typify environments subequal to those found today in the Los Angeles basin (summary in Schultz, 1938), the spectacular finds of extinct animals stamp the assemblage as late Pleistocene. In the absence of $\mathrm{C}^{14}$ dating or other absolute age estimate, it is futile to urge any bioclimatic theory relating the Rancholabrean biota to Pleistocene chronology. However, one suspects that certain biogeographers have assumed that the fauna is of Full-glacial age and that it proves lack of climatic change at this latitude. Assumptions about the cause of large-mammal extinction in this biota, as in others, may be intertwined with climatic inference. In view of the results of isotope dating of similar late Pleistocene faunas, it seems we may anticipate an age postdating the Wisconsin maximum for the Rancholabrean fauna.

Except for Clisby and Sears' work in New Mexico, late Pleistocene pollen studies have been confined to the Pacific Northwest and 
Alaska (Hansen, 1947, 1953; Heusser, 1953, 1955). They have developed a sequence that parallels the Postglacial pollen zones of eastern North America. Hansen (1947) found a rise in grasschenopod-composite pollen in south central Oregon in the Thermal Maximum. Apparently, grassland habitats replaced forest along the prairie-woodland border. Elsewhere in the west, archaeological cave sites and pluvial lake beds of the Great Basin promise much to the pollen analyst. Radiocarbon dating of lake sediments may be the most profitable means of correlating pluvial and glacial events, and radiocarbon dates of Searles Lake in southern California confirm a direct relationship between Great Basin pluvial lakes and the classic Wisconsin sequence (Flint, 1957, p. 232). To the ornithologist this should signify abundant and highly productive aquatic environments at a time when glacial ice covered most of the present breeding grounds of waterfowl and scolopacid shore birds.

An original analysis was made by Antevs (1954) of zonal displacement in New Mexico during the Wisconsin. Snowline depression, the hydrography of pluvial Lake Estancia, and the former distribution of Marmota indicate a lowering of life zones in New Mexico on the order of 4,000 to 4,500 feet. The yellow-bellied marmot is reported from Basket-maker burials at 7,000 feet in northeastern Arizona (Lange, 1956). This, and its distribution in grassland of Utah at 4,500 feet, make it a less reliable Pleistocene thermometer than Antevs (1954), Stearns (1942), and Murray (1957) have assumed. Nevertheless, the vertical displacement of snowline and, apparently, of treeline (Martin, 1958b) seems to require a major shift in montane vegetation gradients.

Spruce (Picea) should be an ideal indicator of temperature change in the Southwest and should afford some biological control on the geological evidence of climatic change. Clisby and Sears' pollen study of the San Augustin plains (1956) indicated Full-glacial spread of spruce through central New Mexico at 7,000 feet, with a maximum frequency of $40 \%$, sometime before 27,000 B.P. During the Pleistocene, almost certainly in the Wisconsin, spruce reached the Valley of Mexico (Sears et al., 1955). To enter the Mexican Plateau, spruce, and any associated boreal animals and plants, had to descend to lower elevation. The lowest point on the Continental Divide between the Rockies and the Sierra Madre lies at about 4,500 feet in southern New Mexico. In the adjacent Chiricahua Mountains spruce 
is found today in narrow, northerly ravines at 8,500 feet. These outposts are in extremely favorable microhabitats, and vertical displacement from a sheltered north slope at 8,500 feet to a level site at 4,500 feet would require climatic change of greater magnitude than the temperature depression encountered between these points (average lapse rate of $0.6^{\circ} \mathrm{C}$ per 100 meters or a total drop of $7.2^{\circ} \mathrm{C}$.)

Mysteriously, spruce disappeared south of Chihuahua, Mexico, in Postglacial time. Subalpine conifers immediately below treeline at 10,000 to 12,000 feet in the transverse volcanic belt of the Mexican Plateau include Pinus hartwegii, Abies, and Cupressus. Superficially, these boreal montane forests appear quite suitable for Picea, and more than one biologist has referred to them casually as "sprucefir."

The best record on climatic change in Mexico comes from the sedimentary studies of Sears et al. (1955) and Hutchinson et al. (1956). They demonstrate important climatic fluctuations. However, the correlation of moist climatic intervals in Mexico with Cordilleran glacial advances (i.e., Flint, 1957, p. 233) is considerably less secure than Glacio-pluvial correlations in western North America. Biogeographical evidence and climatological theory raise the possibility that Postglacial pluvial periods in the Mexican Plateau are negatively correlated with minor glacial advances at high latitudes (Martin and Harrell, 1957). In the Thermal Maximum there is no sound evidence of drought in the Plateau.

The presence of Pleistocene spruce in the Valley of Mexico, the biogeography of relict montane plant formations such as Cloud Forest (see below), glacial circ depression on Mexican volcanoes (White, 1956), Chirripo in Costa Rica (Weyl, 1955), and other tropical mountains above 13,000 feet makes it convenient to infer climatic cooling at low latitudes during the glacial period. The presence of an extensive North American ice sheet would, however, eliminate the present high-pressure system which brings summer cyclones to Mexico and the Southwest (J. E. McDonald, personal communication) and one wonders if winter Pacific storms would be shifted sufficiently to produce truly pluvial conditions in the Valley of Mexico in the Full-glacial period. Sears et al. (1955, p. 525) interpreted their Mexican diagrams as climatic oscillations of moist-warm and dry-uncertain, the latter representing the Wisconsin glaciation.

Within Mexico and Central America some of the strongest indi- 
cations of climatic change are found in plant-animal distribution in fragmented and isolated habitats such as the Cloud Forest. Griscom (1932, 1950) noted rather remarkable uniformity from northern South America to Mexico in bird life of the Subtropical Life Zone, which includes Cloud Forest. This habitat generally appears on windward slopes between 3,000 and 7,000 feet elevation. To account for the faunal uniformity Griscom (1932) postulated Pleistocene continuity of the Subtropical Zone, the result of its depression to sea level. It displaced the lowland tropical fauna which withdrew southward.

Stuart (1951, p. 32) noted that the present range of montane lizards and other temperate animals on either side of the Isthmus of Tehuantepec (e.g., Barisia and Sceloporus malachiticus) indicated a past cool corridor across the arid lowlands. But Stuart questioned the displacement of lowland Tropical Rainforest, which Griscom (1950, p. 358) located far south of its present limit in the period of extreme Pleistocene glaciation. ". . . a descent to sea level of a subtropical zone would have brought about either widespread extermination of the tropical fauna or acclimatization of that fauna to subtropical conditions.... The evidence, therefore, points to the presence of a [lowland] tropical environment in northern Central America even at the height of Pleistocene glaciation" (Stuart, 1951, p. 29). It seems we must have the argument both ways, altitudinal depression of subtropical conditions to achieve some continuity of Cloud Forest through Middle America from Mexico to Colombia, but with persistence as far north as Mexico of Arid-Tropical scrub and Tropical Rainforest. Actually, 3,000 feet may be too rigid a lower altitudinal limit for marginal populations of Cloud Forest species. Under extremely humid conditions subtropical animals may descend to 2,000 or 1,000 feet (Wetmore, 1943, p. 223).

The nature of Cloud Forest vegetation, avifauna, and biogeography in tropical America is under study by B. E. Harrell (1951). Marshall's exemplary analysis (1957) of Mexican oak-pine wood land also illustrates the biogeographic advantage of studying environmental rather than political units.

A brief summary of environmental changes in western North America and Central America during the late Pleistocene would include the following points: (1) direct correlation between glacial conditions in the Cordilleras and the growth of pluvial lakes in the 
Great Basin; (2) coincidence of the Thermal Maximum in eastern and western North America; (3) very doubtful correlation of Glaciopluvial conditions in the subtropical latitudes and a negative correlation, controlled by summer cyclones, in Post-glacial time; (4) 4,000 to 4,500 feet displacement of biotic zones in the Southwest during the Full-glacial period; (5) displacement of tropical zones by perhaps 3,000 feet in the Pleistocene, exact time unknown, but possibly during the Glacial maximum.

\section{EARLY MAN IN THE NEW WORLD}

The foregoing cursory analysis of late Pleistocene environments is intended to clear the ground for a brief review of two events that stand foremost in Pleistocene ecology and paleontology. The importance of these events to students of modern biogeography is not immediately obvious and is often ignored. However, both the arrival of prehistoric man and the extinction of late Pleistocene animals pose major biogeographic, as well as paleontological, problems.

Man's arrival in the New World is a matter of continuing controversy. Fluted points, once associated mainly with early man in western North America, are appearing in many parts of the east. They confirm much older evidence of early man, evidence discounted during the Hrdlicka period of skepticism regarding Pleistocene man in the New World. The Schoop site in Pennsylvania (Witthoft, 1952), the Quad site in Alabama (Soday, 1954), fluted points in Michigan (Quimby, 1958), in North Carolina, and an apparent Late-glacial flint industry in the Manitoulin Islands (Lee, 1957) point to the presence of early man in Late-glacial as well as early Postglacial time in the eastern United States. Quimby (1958) related the geochronology of the Lake Michigan basin to archaeological discoveries and infers an association of spruce-fir forest, mastodons, and fluted points from about 10,000 to 7,500 B.C. Williams (1957) extended the latter to a more recent date, indicating no obligate relationship between mastodons and spruce-fir.

The biologist who may wish to review the impressive archaeological record of early man will profit by consulting Wormington's excellent book (1957) and Sellards' equally readable account (1952). Early man is not invariably associated with fluted points; the old desert cultures such as those at Danger Cave in Utah (Jennings, 1957) and at Frightful Cave in Coahuila (Taylor, 1956) represent 
hunting-gathering people who did not prey on large animals. Fluted points may be an independent New World invention; they have not been found with paleolithic sites in Siberia (Wormington, 1957).

In South America early man had arrived at least by early Postglacial time as is demonstrated by the well-known association of man and sloth at Palli Aiki Cave, Chile. Cruxent and Rouse (1956) and Rouse and Cruxent (1957) report Paleo-Indian sites in northern Venezuela.

From the biological viewpoint it does not seem necessary to enter the Interglacial man controversy. If the Tule Spring site, Nevada, is correctly dated at older than 23,800 years, it clearly indicates that prehistoric man arrived before the Wisconsin maximum of 17,000 years ago. Presumably this would require arrival in Alaska, at least by early post-Sangamon time, of a people whose economy was specialized for hunting large animals in treeless tundra. It seems easier to establish a trans-Bering population in southern Alaska than to understand how, during the Wisconsin glacial period, such a population spread south through what is mapped as glaciated terrain.

For the ecologist and biogeographer one point remains clear. From the time of man's arrival we may assume a radical change in fire frequency. In the strict sense, theoretical climatic climax vegetation in savanna and grassland areas (Stewart, 1951, p. 319), and even in parts of the Eastern Deciduous Forest, cannot postdate man's arrival. In addition to savannas many areas of temperate forest may have been greatly modified and subclimax, consolidation, or even pioneer species favored at the expense of those typical only of climax positions in plant succession. The paleoecological dilemma posed by the B zone pine pollen period (Dansereau, 1953) may be resolved in terms of an archaeological disclimax controlled by early man. There is no longer much doubt about his presence in the East at that time.

\section{LATE PLEISTOCENE EXTINCTION}

In the words of Darwin: "It is impossible to reflect on the changed state of the American continent without the deepest astonishment. Formerly it must have swarmed with great monsters; now we find mere pigmies, compared with the antecedent allied races." (Voyage of the Beagle, 1855, p. 222). In the hundred years since Darwin wrote, 
discoveries in both prehistory and paleontology have enriched considerably our knowledge of late Pleistocene fauna. Radiocarbon dates (Fig. 4, Table II) confirm the fact, evident to Darwin and Lyell, that extinction was mainly a Postglacial event. South of Alaska there is abundant proof that the time of maximum glaciation preceded most New World extinction.

Despite these refinements, the extinction of large mammals in continental North and South America and of small mammals in the West Indies has been a major unsolved problem, one certainly not inappropriate in a symposium dedicated to such matters. Until the cause or causes of extinction are understood, biogeographic and ecological interpretations based on the assumption that all fossil mammalian records are of paleoclimatic significance may be overly bold, if not entirely erroneous. Specifically, I would question paleoclimatic deductions based on fossil records of Marmota and Cervus in northeastern Mexico, Erethizon (porcupine) and Hydrochoerus (capybara) in the Melbourne beds of Florida, "musk-ox-like" genera in New Mexico and Mexico, and Tapirus in Arizona (Haury et al., 1950) and Pennsylvania. Strict application of the uniformitarian doctrine is to be avoided in each case; no responsible ecologist would insist that modern tapir habitat, Tropical Rainforest and Cloud Forest, extended into southern Arizona or eastern Pennsylvania in the late Pleistocene.

As Darwin stressed in The Origin of Species, extinction is the inevitable consequence of evolution and in itself will occasion no surprise. Through the Cenozoic equid genera disappear; Hyracotherium and others in the Eocene; Mesohippus in the Oligocene; Miohippus, Parahippus, and others in the Miocene; Calippus, Hipparion, etc., in the Pliocene; and Nammippus and Plesippus in the early Pleistocene. They represent a record of replacement by morphologically modified and adaptively improved types of horses. In the late Pleistocene the extinction of North American Equus and South American Equus and Hippidium is not an equivalent event for it constitutes extinction without replacement. For perhaps 3,000 to 6,000 years in the Americas the horse was absent. Following post-Columbian reintroduction, feral horses reoccupied grassland habitats with unseeming haste. Darwin (1855, p. 299) reported that they spread from Buenos Aires to the Straits of Magellan, 1,300 miles, in 43 years. 


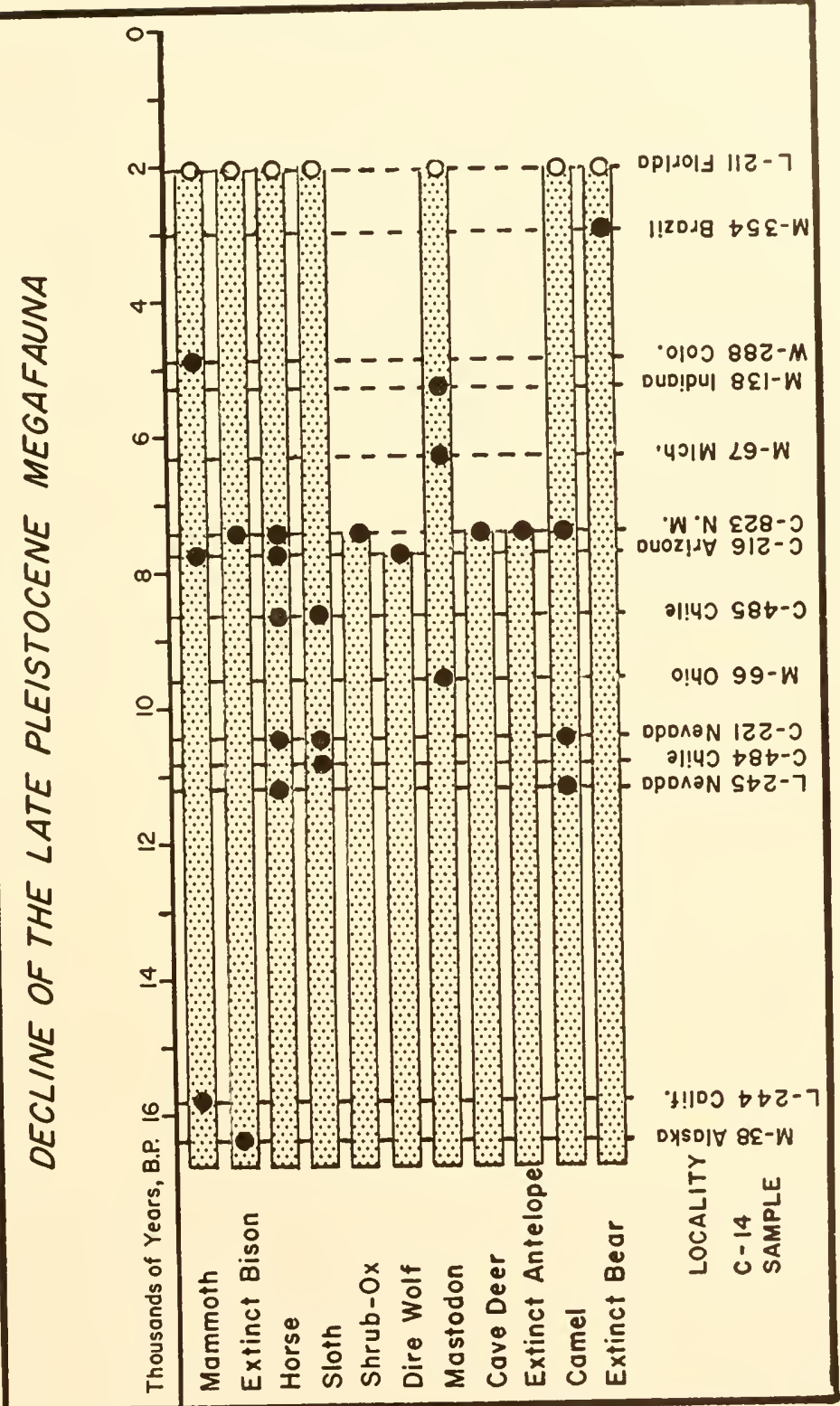

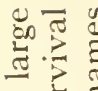

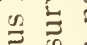

党 $\frac{\text { v. }}{2}$

๖ัญ

0.

$\Xi+$.

$\stackrel{4}{\circ}$

○

ส. $=\frac{0}{2}$

$\overrightarrow{0} \rightleftharpoons \overrightarrow{0}$

デュ.

เ

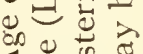

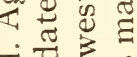

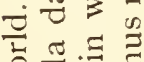

늘

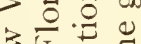

总后异导

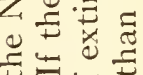

$\pm-\mp$

$\Xi \dot{\Xi} 00$

ฮี

灵 $\frac{0}{0}$

ชิ

E

\&

U.

步

으원

ข

$\because .0$

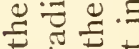

능ㄹㅇㅇ

Uृ $\frac{\omega}{\sigma}$

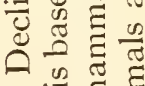

$+\frac{\infty}{\approx} \geq$.

江离吾志 
TABLE II. Radiocarbon Dates Associated with the Extinct Late Pleistocene Fauna in America ${ }^{a}$

Sample

Location

Fauna

1. L-290 R. Santa Rosa Is., Calif.

2. C-914

Tule Springs, Nev.

3. $\mathrm{M}-38$

4. $\mathrm{L}-244$

5. C-301

Fairbanks

Creek,

Alaska

6. L-245

Winnemucca Lake, Nev.

7. $\mathrm{C}-484$

Mylodon Cave, Chile

8. C-221

9. L-231

Gypsum Cave, Nev.

Sussex Co., N. J.

10. L-137 G Seward PeninL-137 N sula, Alaska

11. L-303 Plainview, Texas

12. W-223

$$
\begin{aligned}
& \text { Pictograph } \\
& \text { claim, S.D. }
\end{aligned}
$$

Musk-ox (?Ovibos)

13. M-282

14. A-9 A-10

Lenawee Co., Mich.

Naco, Cochise Co., Ariz.

Mammuthus columbı

15. $\mathrm{M}-66$

Orleton Farms, Ohio

Dwarf mammoth

Bison alleni, mammoth, camel

Bison crassicornis

Dwarf mammoth

"Extinct mammal bones"

Horse, camel

Mylodon

Nothrotherium shastense

Mastodon

Bison ?antiquus

Mastodon

astodon

Mastodon
16. $\mathrm{C}-485$
Palli Aike Cave, Chile

Sloth, horse, guanaco

\section{Comment}

Years, B.P.

Charred bone

$29,700 \pm 3000$
Ancient occupa- tion site, later flooded

Horn sheaths from $16,400 \pm 2000$ gold-bearing gravels

Wood from base $15,820 \pm 280$ of mammothbearing alluvium

IVood from 30 - to 60 -ft. depth

$12,622 \pm 750$

Lowest occupation in Fishbone Cave

Dated sloth dung, $10,800 \pm 570$ no artifacts $\quad 10,864 \pm 720$

Dated sloth dung $10,902 \pm 440$ $10,075 \pm 550$

Peat associated $\quad 10,890 \pm 200$ with remains

Organic material $^{b} \quad 10,200 \pm 800$ $9,400 \pm 750$

Snail shells from $9,800 \pm 500$ bone bed with Plainview material

Bones partly impregnated with caronite

Wood immediately $\quad 9,568 \pm 1000$ above a tusk

Charcoal in clay $\quad 9,250 \pm 300$ matrix around bones

IVood from im-

$$
8,420 \pm 400
$$

mediately under skeleton; first

$8,460 \pm 400$ two dates are of black carbon
Burned bones, with artifacts 
Table II. Radiocarbon Dates Associated with the Extinct Late Pleistocene Fauna in America ${ }^{a}$ - Continued

Sample Location Comment Years, B.P.

17. A-30 to

A-34,

A-40a

$\mathrm{A}-40 \mathrm{~b}$

18. A-69

19. A-67

Lehner site,
Cochise Co.,
Ariz.

Cochise Co.,

Ariz.
Mammuthus
columbi

Murray Springs, Mammoth

Double Adobe, Equus, Canus

Cochise Co., dirus, mam-

Ariz.

moth, Bison

\section{C -216}

Double Adobe,

Cochise Co., Ariz.

21. $\mathrm{Y}-341$

Five-mile Rapids, Ore.
Equus, Canis dirus, mam- moth, Bison
Condor, extinct vulture

(Coragyps occidentalis)
22. C-823 Burnet Cave, N. M.
Extinct mam- mals $^{c}$

23. $M-67$

24. $\mathrm{M}-138$

25. $\mathrm{W}-288$

\section{Washtenaw Co., Mastodon} Mich.

$\begin{array}{cc}\text { Cromwell, Ind. } & \text { Mastodon } \\ \text { Kassler Quad., } & \text { Woolly mam- } \\ \text { Colorado } & \text { moth }\end{array}$

26. M-354
Lagoa Funda, Minas Gerais, Brazil

27. L-211
St. Petersburg,

Fla.
"Giant bear"d

Extinct mam-

mals
Dates between $6,356 \pm 450$ and $12,000 \pm 450$; mammoth kill should be older than overlying organic material dated at about 7,000 B.P.
Sample overlies
$8,250 \pm 200$
clay containing

bones

Charred wood, Sulphur Springs artifacts; same site as C-216

Mammoth lies

$7,756 \pm 370$ above the sample

Extinct scavangers with atlatls, burins, flaked stone tools

Sample from the 8- to 9-ft. level in the fill

Acid-soluble car-

$6,100 \pm 400$

bonates from

$6,300 \pm 500$ tusk

Associated wood $^{f}$

$5,300 \pm 400$

Date on twigs

under a bone, possibly in-

trusive

$4,885 \pm 160$

$7,432 \pm 300$

$8,200 \pm 260$

$7,675 \pm 100$

$$
4,885 \pm 160
$$

Charcoale

$2,040 \pm 90$

a All dates have been published in Science. Initials indicate the laboratory: L, Lamont; C, Chicago; M, Michigan; W, Washington; Y, Yale; A, Arizona.

'b Organic material from muck of deposits that fill valleys of minor streams, "... underlain by blue-gray silt or by an older muck that contains fossil remains such as elephant, horse, and bison, which are conspicuously absent in the dated muck.

cEquus excelsus, Camelops sp., Sangamona sp., Asinus conversidens, Euceratherium collinum, Preptoceras sinclairi, Stockoceros onusrosagris, Bison antiquus, and Rangifer? fricki.

d "Material from this site should date the age of the extinct Giant Bear."

- Charcoal from newly exposed canal. "Associated with extinct Seminole Field mammals, an archaic spear point, flint chips and burned bone."

$f$ Tusk fragments of this mastodon yielded a much older date, M-139, 12, $630 \pm 1000$ years (Science, 127: 1099). 

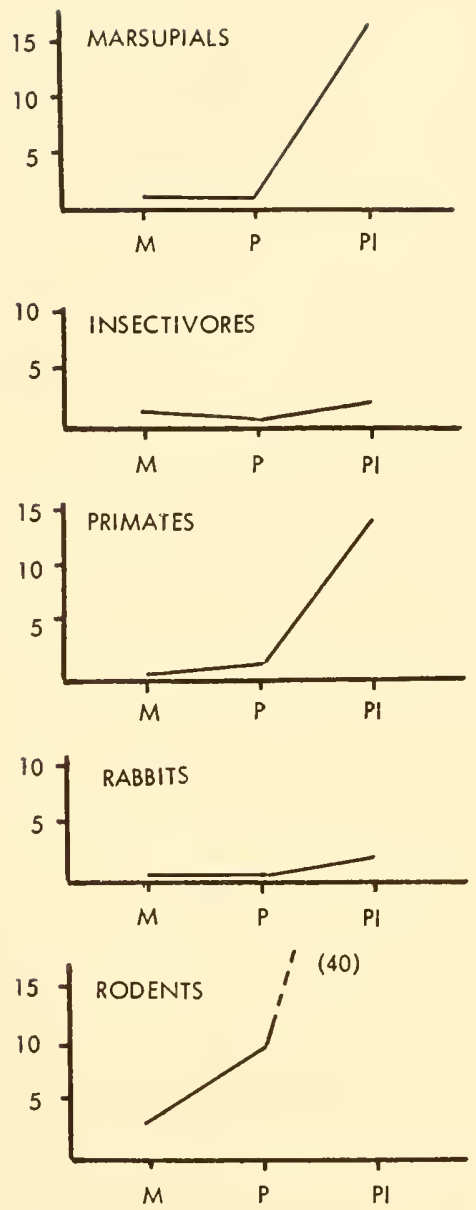

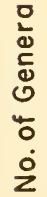

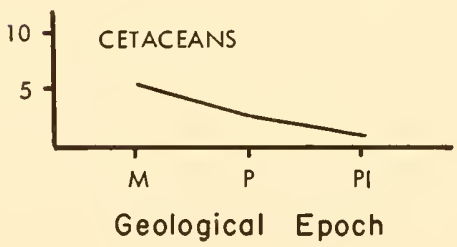

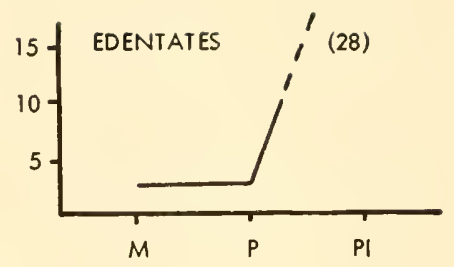

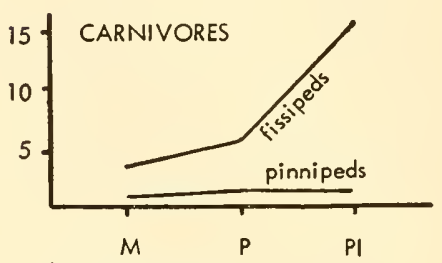

101 NOTOUNGULATES AND LIPTOTERNS
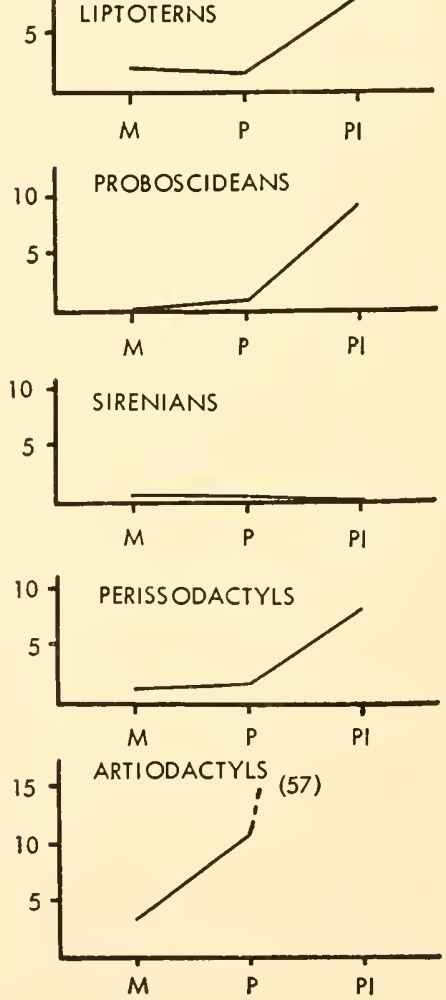

Fig. 5. Caption on facing page. 
Before proceeding directly into a consideration of possible causes, it appears essential to examine the nature of late Pleistocene extinction more closely [cf. Simpson (1953) for a general treatment of phyletic extinction]. If it is no different from that of the early Pleistocene or Tertiary there is little point in proceeding farther.

\section{Extinction without Replacement}

In addition to Equus, cited above, the following North American genera, representing specific ecological life forms with respectable Tertiary lineages, disappeared in the late Pleistocene or sub-Recent time: the elephants and mastodons Mammuthus and Mammut, the camels Tanupolama and Camelops, the Old World antelope Saiga, the cervid deer Sangamona, and Cervalces, the shrub-oxen Symbos, Euceratherium, and Preptoceras, the pronghorns Breameryx and Stockoceros, the giant beaver Castoroides, and others. They reflect abandonment of grazing and browsing habitats by roughly threequarters of the mammalian herbivore fauna. In the IVest Indies four genera of ground sloths and sixteen of hystricomorph rodents, also herbivores, disappeared in sub-Recent time.

The general rule that abandonment of life forms and the disappearance of genera or subfamilies without replacement occurred only in the late Pleistocene may have a single minor exception. Borophagus, a New World equivalent of the hyaenid life form, is unknown beyond the First Interglacial (Hibbard in Flint, 1957, p. 462). However, at no time since the extermination of the Upper Cretaceous duck-bills and other herbivorous dinosaurs has there been unbalanced extinction of equal magnitude.

Fig. 5. Generic extinction rate curves for various mammalian orders. The number of genera last recorded divided by estimated age for each epoch is shown for three Late Cenozoic epochs: $M=$ Miocene, 17 million years; $\mathrm{P}=$ Pliocene, 11 million years $\mathrm{Pl}=$ Pleistocene, one million years. Pleistocene extinction rates rose sharply in the primates, rodents, edentates, fissipeds, notoungulates, liptoterns, proboscideans, perissodactyls, and artiodactyls. There was no comparable rise in extinction rates among the insectivores, rabbits, cetaceans, pinnipeds, and sirenians. Data on extinct genera were obtained from Simpson (1945); orders with poor late Cenozoic fossil records, as the bats, pangolins, and hyraxes, are not included. 


\section{Cenozoic Extinction Rates Rise in the Plcistocene}

Extinction rates in number of genera per million years for several mammalian orders increased greatly at the end of the Cenozoic during the Pleistocene (Fig. 5). The data from Simpson (1945) represent last appearances of genera in each of twenty mammalian orders. To obtain extinction rates, one divides the number of genera last recorded in each period by the geological estimate of elapsed time, 17 million years for the Miocene, 11 for the Pliocene, and 1 for the Pleistocene.

It is obvious that only certain orders exhibit a strong Pleistocene effect. Those include the artiodactyls, proboscideans, marsupials, edentates, rodents, perissodactyls, fissipeds, and primates. Certain groups with moderately good late Cenozoic fossil records, as the cetaceans and pinnipeds, appear unaffected. The extinct Pleistocene genera of marsupials are all Australian and include large kangaroo and phalangeroid herbivores. Within the primates, 8 of 14 extinct Pleistocene genera were lemur-like forms from Madagascar. Among the rodents, a rise in Pleistocene extinction rate can be attributed in part to the extinction of insular genera, 15 of them West Indian. Regarding the entire late Cenozoic record of mammals, extinction rates rise from 25 per million years in the Miocene, 40 in the Pliocene, to 203 in the Pleistocene. From this we may believe that Pleistocene extinction transcends that of the rest of the Cenozoic. Was it caused by climatic change of the Glacial periods?

\section{Pleistocene Extinction Rates Rise in the Last Glacial Period}

Hibbard's valuable list (1958; also in Flint, 1957) of Pleistocene mammals shows a considerable measure of extinction in the First Interglacial, the Aftonian. However, with the single exception of Borophagus, there is continual replacement of generic types until the Wisconsin.

Estimating the Glacial periods arbitrarily at 100,000 years each and the interglacials at 250,000 years we obtain for North America the following extinction rates, expressed as number of genera per 100,000 years: Nebraskan, 1.0; Aftonian, 6.0; Kansan, 5.0; Yarmouth, 1.2; Illinoian, 1.0; Sangamon, 0.0; Wisconsin, 31.0 (terminal records from Hibbard in Flint, 1957, with addition of Floridian Melbourne mammals). On this basis it is possible to conclude (1) that the extinction rate in the Wisconsin was considerably higher 
than earlier in the Pleistocene and (2) that extinction is not related to the Glacial period or to the climatic change brought on by glaciation.

In part such figures may be an artifact of paleontological sampling. Late Pleistocene sediments, bogs, caves, and alluvium, are better preserved than older deposits exposed to a longer history of geological wear and tear. The late Pleistocene should be better known than a preceding fauna. Nevertheless, accepting the fossil record at face value, it seems that extinction was predominantly a $\mathrm{IT}$ isconsin phenomenon. The facts do not agree with the proposal that the rise in Pleistocene extinction rates is the result of climatic change.

\section{Late Pleistocene Extinetion Affected Only Large Animals}

Obviously, this is not strictly true, as Eisley (1946) and Gill (1955) pointed out. On the one hand, cetaceans and pinnipeds were unaffected; on the other, small to medium-sized West Indian mammals, lizards, and birds disappeared. In tropical forests and savannas certain edentates survive, such as the anteaters and tree sloths. Their plains-dwelling relatives of subequal size, such as Nothrotherium and Chalmytherium, disappeared. Moose, elk, white-tailed deer, and probably bison survived in temperate forests while, except for one species of pronghorn and the mule deer, the grasslands were stripped of large herbivores.

Nevertheless, the size relationship is crucially important. The vulnerability on most islands of relatively small animals (from the size of a Norway rat to that of a beaver) can be contrasted with that on continental areas where, aside from possible trimming of marginal populations, the extinction of such small animals did not occur at the end of the Pleistocene. I am indebted to K. C. Parkes for pointing out that, of the reasonably rich late Pleistocene passerine avifauna, there are recognized only two extinct genera, both in the family Icteridae and both cowbirds, Pandanaris and Pyelorhamphus (Wetmore, 1956). It requires no great imagination to suggest that they shared a commensal table with the modern cowbird genera, Molothrus and Tangavius, and that extinction of the large herbivores reduced the variety of ecological niches for both scavenger and cowbird life forms. The extinct scavengers are more numerous and include the genera Breagyps, Teratornis, Cathartornis, Neogyps, and Neophrontops. 


\section{Extinction Marks the Boundary between the Pleistocene and Recent}

In the Rocky Mountain region Hunt (1953) reported that the disappearance of such large mammals as elephants, camels, and horses coincides with a widespread unconformity in the late Quaternary deposits. He correlated this break with the drought of the Altithermal and finds that extinction immediately predates it. While this relationship may be of geological utility in western North America, chronological detail does not bear out such a distinction between "Pleistocene" and "Recent" elsewhere on the continent. In Alaska thin gravels and clays containing remains of extinct mammals are at least of Late-glacial age or older. Organic material overlying the remains of elephant, horse, and extinct bison has been dated at 10,200 $\pm 800(\mathrm{~L}-137 \mathrm{G})$ and $9,400 \pm 750(\mathrm{~L}-137 \mathrm{~N})$ years B.P., (see discussion by Sigafoos and Hopkins in Broecker et al., 1956, pp. 156-157). Horn sheaths of Bison crassicornis were dated at $16,400 \pm 2000(\mathrm{M}-38)$.

In Mexico the Upper Becerra Peat, containing remains of the mammoth $M$. imperator is also considered as older than 10,000 B.P. (Wormington, 1957, pp. 91-99). Hibbard (1955) considered it early Wisconsin. MacNeish's important and, in large part, unpublished studies in southern Tamaulipas $(1950,1955)$ have revealed leaflike points associated elsewhere with the Becerra mammoths, but there is no evidence of extinct animals in his radiocarbon-dated middens, which cover the entire Post-glacial period (personal communication). Apparently extinction in both Mexico and Alaska preceded that in the Rocky Mountains.

In Florida and South America extinction postdated the Altithermal. Unquestionably this is the most controversial aspect of the extinction chronology, partly because it all but eliminates climatic change as an extinction cause. The vastly rich fauna of the Melbourne and Seminole beds of Florida was dated on archaeological and geochronological grounds by Rouse (1952) at 4,000 to 2,000 years ago. A radiocarbon date, $\mathrm{L}-2 \mathrm{~N}, 2,040 \pm 90$, of charcoal from a newly exposed canal is "associated with extinct Seminole Field mammals, an 'archaic' spear point, flint chips, and burned bone ... the date seems anomalously low in view of the extinct fauna" (field description from unidentified collector in Broecker et al., 1956, p. 161). The fauna of the Seminole field includes the porcupine, capy- 
bara, dire wolf, short-faced bear, smilodon, ground sloths, glyptodonts, horses, a tapir, extinct peccaries, camels, mastodons, mammoths, and various small mammals conspecific with living species (Cooke, 1945, pp. 308-309). Forty years of scrutiny have not resolved the apparent contradiction that a rich and varied extinct savanna fauna survived here until a very late date, perhaps 4,000 to 2,000 years ago, contemporaneous with archaic man (Rouse, 1952; Heizer and Cook, 1952).

In South America an extinct mastodon, Cuvieronius, was found associated with pottery (Spillmann in Osborn, 1936, pp. 571-574). More recently a radiocarbon sample from Minas Gerais, 3,000 \pm 300 B.P. (M-354), “. . should date the age of the extinct Giant Bear" (genus unspecified, collected by Evans and reported in Crane, 1956, p. 672). The recent review of mastodon remains and radiocarbon dates by Williams (1957) indicates that outside Florida the genus endured in eastern North America until at least 6,000 years ago and is associated with archaic artifacts.

One waits with keen anticipation additional study of these and other problem areas such as the West Indies. Tentative conclusions, based on the harvest of eight years of radiocarbon dates associated with extinct animals, follow: (1) Mexican and Alaskan large mammals were the first to be eliminated, this in Late-glacial time; (2) the Plains Megafauna disappeared in the early part of the Postglacial period; (3) eastern temperate forest and tropical rainforests were the last continental refugia for large mammals; (4) the Floridian savanna, surrounded by forest, served as a refuge for plains herbivores after they had disappeared elsewhere in western North America.

\section{A LATE Pleistocene EXTINCTION MODEL}

An idealized descriptive model designed to illustrate probability of extinction within the late Pleistocene terrestrial fauna would include many factors. Without doing violence to such a model we may be able to limit it to three: (1) body size, (2) habitat, and (3) total range of the species. Reasons for this choice and certain apparent exceptions to the model will become evident subsequently.

The probability of extinction in the late Pleistocene appears to have been maximized by large body size, usually accompanied by low values of $r$ (intrinsic rate of increase), and T (mean generation 
period); by open habitat, i.e., savanna, grassland, tundra, and desert, and by limited range, either insular or on such ecological islands as Alpine meadows surrounded by forest. Conversely, survival was enhanced by small size, forest habitat, and a large range for the species in question.

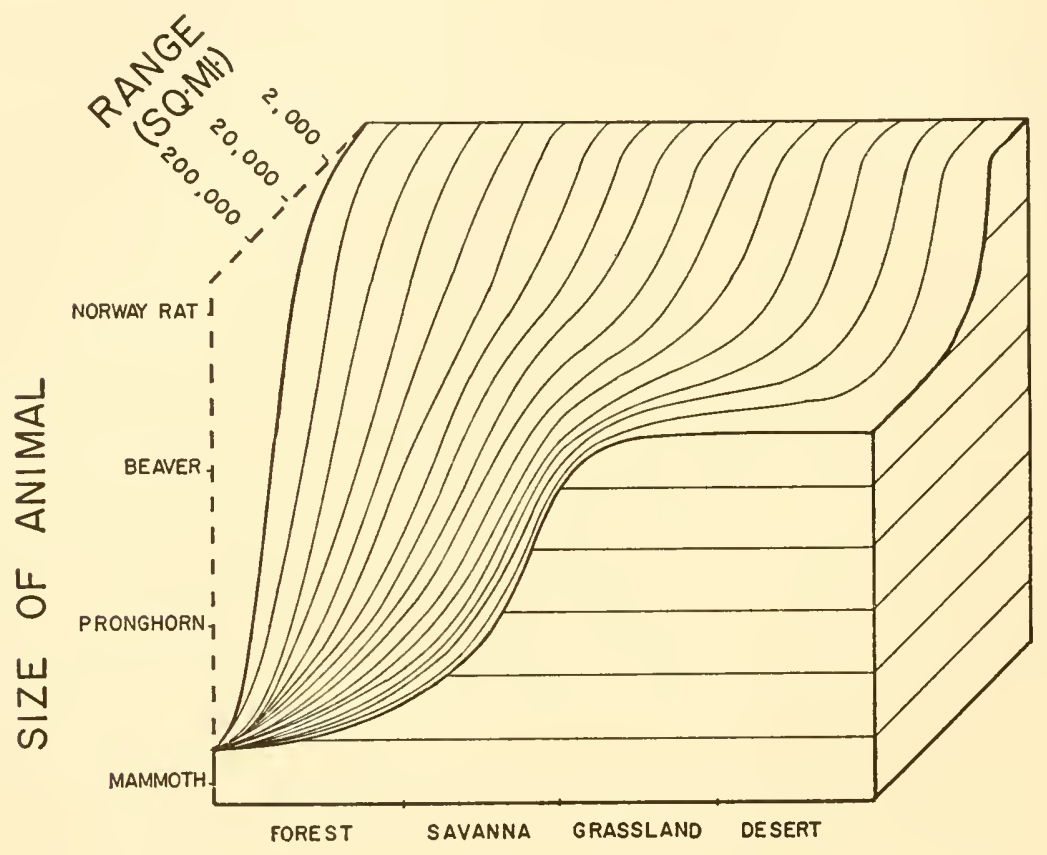

\section{BIOCHORE}

Fig. 6. A Late Pleistocene extinction model for New World mammals. This generalized model is intended to indicate the interaction of variables that appear to have been important in determining probability of extinction for any particular species or population. Points beneath the surface of the solid lie within the region of high extinction probability; those above the surface lie in the region of high probability of survival.

The primary question in late Pleistocene extinction revolves around the herbivores (trophic level $\Lambda_{2}$ in Lindeman's system). According to ecological and evolutionary theory it is axiomatic that a reduction in the number of species operating at one level will require reduction at higher trophic levels. Our present task is to 
describe the pattern of herbivore extinctions, with the assumption that extinction of certain wolf, cat, cowbird, vulture, and vampire life forms followed inevitably.

Figure 6 is a diagrammatic attempt at such a descriptive model, showing high and low regions of extinction probability. The high regions lie within the shaded portion of the solid; the low regions lie above in the unshaded portion. Following Dansereau (1957), habitat can be divided conveniently into the four biochores: forest, savanna, grassland, and desert. All terrestrial communities from the equator to the Arctic fall within one of these units. Animal body size is divided into four classes, represented respectively by (1) Norway rat, (2) Norway rat to beaver, (3) beaver to pronghorn, (4) pronghorn to mammoth. Total range of the species in square miles is arbitrarily listed as very small (less than 2,000), small $(2,000-$ $20,000)$, medium (20,000-200,000), and large (200,000 and more). Three specific examples, which were used in constructing the model, illustrate its predictive function :

Case A. Upper-left-rear corner of the diagram. Small animals in a small area of forest, Puerto Rico.

Extinct. Nesophontes, an insectivore; Acratocnus, a small ground sloth; and six genera of hystricomorph rodents: Heptaxodon, Elasmodontomys, Isolobodon, and Proechimys (surviving on mainland South America), Heteropsomys, and Homopsomys.

Surviving. Eleven genera of native bats; introduced Rattus and Mus.

Extinction intensity. Heavy.

Case B. Upper-left-front corner. Small animals in extensive forest, eastern North America.

Extinct. None known.

Range possibly reduced: Neofiber, round-tailed muskrat; Erethizon, porcupine; Didelphis, opossum.

Surviving. Twenty-one genera of native rodents, various other small terrestrial mammals and bats.

Extinction intensity. Very light.

Case $C$. Lower-center and right-front corner. Large animals in extensive desert, grassland, and savanna habitats, the Basin and Range province and western North America generally.

Extinct. Mammuthus, mammoths of two or three species; Mam- 
mut, mastodon; Paramylodon, Nothrotherium, and Megalonyx, ground sloths; Glyptotherium, glyptodont; Platygonus, peccary; Tanupolama, long-legged llama; Camelops, camel; Sangamona, extinct deer; Breameryx, tar-pit pronghorn; Stockoceros, pronghorn; Euceratherium and Preptoceras, shrub-oxen; Bootherium, musk-ox; Equus, horse and ass, various species.

Surviving. Antilocapra, pronghorn; Odocoileus, mule deer; Bison, buffalo, one species only.

Extinction intensity. Heavy.

In addition to these three cases it is obvious that other regional faunas fulfill the requirements. For example, the Greater Antilles experienced complete extinction of all beaver-sized and larger animals and partial survival only among the small mammals and reptiles. In Alaskan tundra and Mexican steppe there was a high extinction rate for large herbivores (pronghorn size and over), but not for small or medium-sized mammals. Applying the model to South America we would expect heavier extinction on the pampas and campo cerrado savannas than in the Amazonian rainforest.

Paleontology of the Pampean formation (Simpson, 1940) showed that a variety of ground sloths, glyptodonts, and other edentates, horses, certain camels, and the native ungulates, as the macraucheniids, toxodonts, mesotheres, and hegetotheres, disappeared from the plains areas. Some extinction of forest forms must have occurred, probably more than the scanty fossil record of mastodonts and bears would indicate (tropical forest Pleistocene sediments are all but unknown). However, survival in the forest exceeds that on the plains. Peccaries, large edentates, monkeys, tapirs, capybaras, and various deer in the forest and forest margin contrast with the presence of only two large native herbivores in the pampas and in Patagonia, the guanaco or wild llama and the pampas deer.

If the model is adequate in these cases, it by no means explains lack of extinction under certain circumstances that call for it. The survival of four species of native camamelids in South America, at least two of them with relatively narrow ranges in the Andean Puna is mystifying, both in terms of the model and the extermination of the camamelids in North America. The survival of Capromys ingrahami on one of the smaller Bahaman Keys and of Testudo, the giant tortoises of the Galápagos, introduce an additional problem that appears worthy of special treatment. 


\section{WEST INDIAN VERTEBRATES AND GALÁPAGOS TORTOISES}

Late Pleistocene and sub-Recent insular extinction throughout most of the world appears to have been intense. Certain oceanic islands exhibit the phenomenon of extermination without replacement noted in North and South America. Giant marsupials inhabited Australia (Gill, 1955), large flightless birds survived in New Zealand at least until 1300 A.D. (Deevey, 1955), and giant lemurs, tortoises, and large birds lived in Madagascar (Sibree, 1915). West Indian mammals, reptiles, and birds experienced extermination both of relatively medium-sized genera (tortoises and ground sloths) and of many smaller rodents. In this respect West Indian extinction differs from the continental record. Summary articles by Allen (1911) and Matthew (1919) have been superseded by Simpson's valuable zoogeographic synthesis (1956). Allen (1942) discussed most of the extinct mammals. Except for Cuban ground sloths (Allen, 1918; Aguayo, 1950) and Jamaican bats and rodents (Anthony, 1920; Koopman and Williams 1951; Williams, 1952b), the distribution of most of the extinct mammals is covered in Miller and Kellogg's Checklist (1955).

The extinction chronology is rather baffling and is not simplified by the possibility that certain forms such as Nesophontes may yet be found to survive in remote mountainous districts. I am indebted to K. F. Koopman for pointing out that more than 300 years elapsed between discovery of the islands by western man and the first serious scientific description of their fauna. Extermination in this interval, perhaps at the hands of superior competitors as Rattus, or as the result of clearing and cultivation, will be difficult to distinguish from prehistoric extermination. Nesophontes, for example, appears to have been contemporaneous with Rattus. In contrast Testudo and various ground sloths almost surely were not present at the time of the conquest. Ground sloths may have existed into the ceramic period (Aguayo, 1950), and the giant rodent Quemisia was apparently known to Oviedo (Allen, 1942), but there is no certain evidence of other large hystricomorphs (Elasmodontomys, Clidomys, and $A m b l y r h i z a)$ in post-Columbian middens and it is most unlikely that their presence would have gone unrecorded by early observers.

Simpson listed twenty-two extinct genera of terrestrial mammals in the Greater Antilles. Even assuming some unnecessary splitting, the fossil fauna is quite impressive. By comparison, the present sur- 
viving fauna of four genera is depauperate: Solenodon on Hispaniola and Cuba, Oryzomys (recently extinct?) on Jamaica, Capromys (here to include Geocapromys) on Cuba, the Plana Keys, Jamaica, and the Swan Islands, and the closely related Plagiodontia on Hispaniola.

Considering the poverty of chiropteran remains elsewhere, the fossil record of the WVest Indian bats is remarkably good. It has been used to identify relative faunal ages in Jamaica (Koopman and Williams, 1951; Williams 1952b). At first glance the presence of two genera of fossil bats now extinct in Jamaica seems to contradict the principle I have noted earlier that late Pleistocene extinction did not affect such animals. Other than commensals and parasites of large herbivores, such as the cowbirds and vampires, we would predict no elimination of life forms among the bats and birds. In theory climatic change during the Wisconsin and earlier Glacial advances altered the ecological opportunities for various genera and changed faunal composition at low latitudes. However, it is my present thesis that generic extinction did not accompany such events. Koopman and Williams' studies make it clear that the local extirpation of bats (Tonatia and Brachyphylla) in Jamaica was accompanied by replacement by related genera in the same subfamily. Tonatia and Brachyphylla survive in Central America and Hispaniola respectively. The Jamaican bat fauna remained rich and bears no resemblance to the annihilation experienced by the terrestrial herbivores. The shift in the species composition of bats may be attributed to climatic change.

On the other hand, the survival of a rodent, Capromys (Geocapromys) ingrahami, on the tiny Plana Keys and of $C$. thoracatus on the Swan Islands, seems a serious violation of the general rule that the smaller the surface the greater the vulnerability to extinction (Fig. 6). The record of Capromys is instructive. C. ingrahami was described in 1891. Closely related fossil populations were subsequently found on the larger Bahaman Islands, Crooked, Eleuthera, Long, Great Exuma, Great and Little Abaco. In 1955 Rabb and Hayden (1957) revisited the Plana Keys, collected three specimens of the "cootie" and noted that the island had undergone little change since Ingraham's visit. East Plana Key is a small, rocky islet not more than 50 feet above the ocean, one-half mile wide, four to five miles long and ". . . entirely without fresh water except in the rainy season, when pools of fresh water may be found in holes in the rocks" (Allen, 1891). In the absence of fresh water it is doubtful that the 
Carib Indians ever maintained permanent settlement on the island; Rabb and Hayden note that it is uninhabited at present. This feature may be crucial. We can attribute the remarkable survival of Capromys both on the Plana Keys and on the Little Swan Islands to lack of permanent prehistoric habitation. For the archacologist this carries the corollary that the other Bahaman Islands were more intensively occupied.

The foregoing account emphasizes the mammalian fossil record. In addition, there were "giant" late Pleistocene lizards (Hecht, 1951, 1952) turtles (Williams, 1950, 1952a), and birds (Wetmore, 1937). The record of the tortoises, Testudo, is an important adjunct to the extinction of the large mammals. An interesting sidelight is their apparent extinction in the Greater Antilles before the main period of mammalian extinction (IVilliams, 1952a, p. 554). Elsewhere they evolved through the Tertiary and in to the late Pleistocene. Species of relatively small size survive in northern South America. The New World giant tortoises remain only on the Galápagos. As in the case of Geocapromys on the Plana Keys, there is reason to believe that these islands escaped permanent occupation in prehistoric times. Heyerdahl and Skjölsvold (1956) reported no archaeological evidence of prehistoric occupancy of the Galápagos other than temporary or seasonal visits, and no preceramic contact. With a long reproductive time lag and no special defense against man, the giant tortoises must have been especially vulnerable to human predation. This may explain their early demise compared to the rest of the fauna in Cuba (IVilliams, 1952a). The Galápagos and Plana Key exceptions to the generalized extinction model (Fig. 6) indicate that it will apply only to regions permanently inhabited by prehistoric man.

\section{CLIMATIC INDICATORS, EXTINCTION, AND MAN}

"A hypothesis which implies that practically all the important fossil forms had existed until a comparatively Recent date and then become extinct in a geologically short period of time had seemed equally improbable to the writer; and yet it is to such a conclusion that a study of the evidence leads" (Romer, 1933). Flint (1957), Osborn (1936, pp. 1512-1513), and Sauer (1944) are also among those who indicate that prehistoric man was the principal agent of late Pleistocene extinction. If circumstantial evidence points to man, it does not reveal his methods. Sauer's fire-drive hypothesis (1944) 
may be important in understanding the possible hunting techniques of use against the large, gregarious plains herbivores. However, as Eisley (1946) noted, even the most ardent proponent of fire as an ecological force may hesitate to attribute the extinction of forest mastodons, the giant beaver (Castoroides), and the West Indian hystricomorphs to this technique. The mysterious survival of large African herbivores frustrates sweeping conclusions.

For paleoecological purposes it seems necessary to consider the significance of large vertebrates as climatic indicators. If prehistoric man is an extinction agent, how are we to interpret shifts in range in terms of paleoecological uniformitarianism? Tapirs and capybaras, today denizens of tropical forest, formerly ranged far to the north, respectively to Oregon and Pennsylvania and to Florida and Arizona. Are there compelling reasons to believe that, in the absence of man, these animals would not occupy the same range under the present climate?

The porcupine, opossum, and armadillo have notably extended their ranges within historic time. The opossum and armadillo moved northward (Guilday, 1958; Fitch et al., 1952), the porcupine southward, into Sonora (Benson, 1953). These extensions can be attributed to climatic change. They can also reflect the reoccupation by these species of marginal positions in their former range, from which they had been eliminated in prehistoric time by human predation. The mountain top populations of Marmota flaviventris in southern Arizona, New Mexico, and northeastern Mexico were trimmed. Subalpine and boreal habitats, apparently suitable for marmots, persist in these areas today.

The giant tortoises, like the tapir and capybara, are another group in which a complacent assumption of tropicality is read into their ranges, for example, by Crook and Harris (1958, p. 241). Survival of tortoises only on remote oceanic islands seems to be attributable to the circumstance that they here escaped pre-Columbian extermination by man rather than to climatic change. Assumptions of climatic change based on the present distributions of relatives of the late Pleistocene fossil vertebrates are gratuitous as long as an alternate cause of extirpation is possible. In brief we may inquire whether tropical forests and remote islands constitute refugia from climatic change or from the hunting practices of prehistoric man.

For sensitive indicators of climate and past environments it may 
be necessary to consider only plant distributions plus those small animals whose population density and reproductive capacity could keep pace with human predation.

Within our present knowledge there seems little agreement on the problem of extinction and man's role in it. Most authors who have reviewed the problem reduce it to the outcome of an interaction of all factors that can limit animal populations-predation, competition, parasitism, climatic change, evolutionary lag during environmental stress, and also the effect of man (Colbert, 1938; Gill, 1955; Hamilton, 1939; Osborn, 1906; Romer, 1945; Simpson, 1931, 1953). I believe this multiple hypothesis does injustice to the temporal and ecological record, i.e., (1) differential loss of large animals, (2) lack of evidence of major climatic change during the extinction period, (3) the narrow chronological range in which extinction occurred, and (4) the phenomenon of removal without replacement. It would appear that within the Cenozoic the late Pleistocene environment had some unique features. Man is the only one clearly identified.

\section{Acknowledgments}

In part the viewpoints expressed grew out of serninars and less formal discussions on Pleistocene matters at the universities of Michigan, Yale, Montreal, and Arizona. In particular I would thank the following for their help: P. Dansereau, M. B. Davis, E. S. Deevey, J. A. Elson, R. F. Flint, F. K. Hare, B. E. Harrell, E. W. Haury, J. J. Hester, C. W. Hibbard, K. F. Koopman, J. F. Lance, A. and D. Löve, C. H. Lowe, G. Lowther, M. Martin, J. E. McDonald, J. E. Mosimann, J. G. Ogden, G. B. Rabb, J. Schoenwetter, T. L. Smiley, and D. R. Whitehead. Mrs. Helen Griffin provided valuable clerical aid. I am indebted especially to palynologists F. H. Barclay, M. B. Davis, E. B. Leopold, and D. A. Livingstone, who forwarded advance copies of their unpublished pollen diagrams.

\section{REFERENCES}

Aguayo, C. G. 1950. Observaciones sobre mamíferos cubanos extinguidos. Bol. hist. natural soc. Felipe Poey, 1: 121-134.

Allen, G. M. 1911. Mammals of the West Indies. Bull. Museum Comp. Zool., 54: 175-263.

. 1918. Fossil mammals from Cuba. Bull. Museum Comp. Zool., 62: 133-148.

-1942. Extinct and Vanishing Mammals of the Western Hemisphere. American Committee for International Wild Life Protection, Lancaster, Pa. 
Allen, J. A. 1891. Description of a new species of Capromys from the Plana Keys, Bahamas. Bull. Am. Museum Nat. Hist., 3: 329-336.

Andersen, S. T. 1954. A late-glacial pollen diagram from southern Michigan, U. S. A. Danmarks Geol. Undersogelse, 80: 140-155.

Antevs, E. 1954. Climate of New Mexico during the last Glacio-Pluvial. J. Geol., 62: 182-191.

Anthony, H. E. 1920. New mammals from Jamaica. Bull. Am. Museum Nat. Hist., 42: 469-476.

Barendsen, G. IV., E. S. Deevey, and L. J. Gralenski. 1957. Yale natural radiocarbon measurements III. Science, 126: 908-919.

Benson, S. B. 1953. A record of the porcupine (Erethizon dorsatum) from Sonora, Mexico. J. Mammal., 34: 511-512.

Braun, E. L. 1951. Plant distribution in relation to the glacial boundary. Ohio J. Sci., 51: 139-146.

- 1955. The phytogeography of unglaciated Eastern United States and its interpretation. Botan. Rev., 21: 297-375.

Broecker, W. S., J. L. Kulp, and C. S. Tucek. 1956. Lamont natural radiocarbon measurements III. Science, 124: 154-165.

Cain, S. A. 1944. Pollen analysis of some buried soils, Spartanburg County, South Carolina. Bull. Torrey Botan. Club, 71: 11-22.

Chaney, R. W., and H. L. Mason, 1934. A Pleistocene flora from Santa Cruz Island, California. Carnegie Inst. Wash. Publ., 415: 1-24.

Clark, J. G. D. 1952. Prehistoric Europe. Methuen, London.

Clisby, K. H., and P. B. Sears. 1956. San Augustin Plains-Pleistocene climatic changes. Science, 124: 537-539.

Colbert, E. H. 1938. The Pleistocene mammals of North America and their relations to Eurasian forms. In Early Man, G. G. MacCurdy, Editor. Lippincott, London. Pp. 173-184.

Cooke, C. W. 1945. Geology of Florida. Florida Geol. Survey, Geol. Bull., 29: $1-339$.

Core, E. L. 1949. Original treeless areas in West Virginia. J. Elisha Mitchell Sci. Soc., 65: 306-310.

Crane, H. R. 1956. University of Michigan radiocarbon dates. Science, 124: $664-672$.

Crook, W. W., and R. K. Harris. 1958. A Pleistocene campsite near Lewisville, Texas. Am. Antiquity, 23: 233-246.

Cruxent, J. M., and I. Rouse. 1956. A lithic industry of Paleo-Indian type in Venezuela. Am. Antiquity, 22: 172-179.

Dansereau, P. 1951. Description and recording of vegetation upon a structural basis. Ecology, 32: 172-229.

. 1953. The postglacial pine period. Trans. Royal Soc. Can., 47: 23-38.

- 1957. Biogeography, an Ecological Perspective. Ronald, New York.

Darlington, H. C. 1943. Vegetation and substrate of Cranberry Glades, West Virginia. Bot. Gazette 104: 371-393.

Darwin, C. 1855. Journal of Researches. Harper, New York. 
Davis, J. H. 1946. The peat deposits of Florida. Florida Geol. Survey, Geol. Bull., 30: 1-247.

Davis, M. B. 1957. Late-glacial Pollen Diagrams from Central Massachusetts. Ph.D. Thesis, Harvard University (unpublished).

Deevey, E. S. 1949. Biogeography of the Pleistocene. Bull. Geol. Soc. Am., 60: $1315-1416$.

1951. Late-glacial and postglacial pollen diagrams from Maine. Am. J. Sci., 249: 177-207.

- 1953. Paleolimnology and climate. In Climatic Change, H. Shapley, Editor. Harvard University Press, Cambridge, Mass.

. 1955. Paleolimnology of the upper swamp deposit, Pyramid Valley. Records Canterbury Museum (New Zealand), 6: 291-344.

. 1957. Limnologic studies in Middle America. Trans. Conn. Acad. Arts Sci., 39: 213-328.

Deevey, E. S., and R. F. Flint. 1957. Postglacial hypsithermal interval. Science, 125: 182-184.

Denny, C. S. 1951. Pleistocene frost action near the border of the Wisconsin Drift in Pennsylvania. Ohio J. Sci., 51: 116-125.

- 1956. Surficial geology and geomorphology of Potter County, Pennsylvania. U. S. Geol. Survey Prof. Paper, 288: 1-72.

Dillon, L. S. 1956. Wisconsin climate and life zones in North America. Science, 123: 167-176.

Drury, W. H. 1956. Bog flats and physiographic processes in the upper Kuskokwim River region, Alaska. Contribs. Gray Herbarium Harvard Univ. 178: 1-127.

Dylik, J. 1954. (The problem of the origin of loess in Poland.) Biul. Peryglacjalny (Lodz), 1: 19-30, 125-131. (In Polish, English summary.)

Eisley, L. C. 1946. The fire-drive and the extinction of the terminal Pleistocene fauna. Am. Anthropogist, 48: 54-59.

Emiliani, C. 1955. Pleistocene temperatures. J. Geol., 63: 538-578.

Fitch, H. S., P. Goodrum, and C. Newman. 1952. The armadillo in the southeastern United States. J. Mammal., 33: 21-37.

Flint, R. F. 1957. Glacial and Pleistocene Geology. Wiley, New York.

Frenzel, B., and C. Troll. 1952. Die Vegetationszonen des nordlichen Eurasiens wahrend der letzten Eiszeit. Eiszeitalter u. Gegenwart, 2: 154-167.

Frey, D. G. 1951. Pollen succession in the sediments of Singletary Lake, North Carolina. Ecology, 32: 518-533.

- 1953. Regional aspects of the Late-glacial and Post-glacial pollen succession of southeastern North Carolina. Ecol. Monographs, 23: 289-313.

- 1955. A time revision of the Pleistocene pollen chronology of southeastern North Carolina. Ecology, 36: 762-763.

Gill, E. D. 1955. The problem of extinction with special references to Australian marsupials. Evolution, 9: 87-92. 
Guodlett, J. C. 1954. Vegetation adjacent to the border of the Wisconsin Drift in Potter County, Pennsylvania. Harvard Forest Bull., 25: 1-93. Griscom, L. 1932. The Distribution of Bird-Life in Guatemala. Bull. Am. Museum Nat. Hist., 64: 1-439.

- 1950. Distribution and origin of the birds of Mexico. Bull. Museum Comp. Zool., 103: 341-382.

Guilday, J. E. 1958. The prehistoric distribution of the opossum. J. Mammal., 39: 39-43.

Hack, J. T. 1953. Geologic evidence of late Pleistocene climates. In Climatic Change, H. Shapley, Editor. Harvard University Press, Cambridge, Mass.

. 1955. Geology of the Brandywine area and origin of the upland of southern Maryland. Geol. Surv. Prof. Paper, 267 A: 1-41.

Hamilton, W. J. 1939. American Mammals. McGraw-Hill, New York.

Hansen, H. P. 1947. Postglacial forest succession, climate, and chronology in the Pacific Northwest. Trans. Am. Phil. Soc., 37: 1-130.

1953. Postglacial forests in the Yukon Territory and Alaska. Am.

J. Sci., 251: 505-542.

Hare, F. K. 1954. The boreal conifer zone. Geograph. Studies, 1: 4-18.

Harrell, B. E. 1951. The Birds of Rancho del Cielo, an Ecological Invesigation in the Oak-Sweet Gum Forests of Tamaulipas, Mexico. M. A. Thesis, University of Minnesota (unpublished).

Haury, E. IV., et al. 1950. The Stratigraphy and Archaeology of Ventana Cave. University Arizona Press, Tucson.

Hecht, M. K. 1951. Fossil lizards of the West Indian genus Aristelliger (Gekkonidae). Am. Museum Novitates, 1538: 1-33.

- 1952. Natural selection in the lizard genus Aristelliger. Evolution, 6: 112-124.

Heizer, R. F., and S. F. Cook. 1952. Fluorine and other chemical tests of some North American human and fossil bone. Am. J. Phys. Anthropol., 10: 289-303.

Heusser, C. J. 1953. Pollen profiles from southeastern Alaska. Ecol. Monographs, 22: 331-352.

. 1955. Pollen profiles from Prince William Sound and southeastern Kenai Peninsula, Alaska. Ecology, 36: 185-202.

Heyerdahl, T., and A. Skjölsvold. 1956. Archaeological evidence of preSpanish visits to the Galápagos Islands. Am. Antiquity, 22: 1-69.

Hibbard, C. W. 1955. Pleistocene vertebrates from the Upper Becerra. Contrib. Museum Paleontol., Univ. Michigan, 12: 47-96.

- 1958. Summary of North American Pleistocene mammalian local faunas. Papers Mich. Acad. Sci., 43: 3-32.

Hunt, C. B. 1953. Pleistocene-Recent boundary in the Rocky Mountain Region. U. S. Geol. Surv. Bull., 996 A: 1-25.

Hustich, I. 1954. On forests and tree growth in the Knob Lake area, Quebec-Labrador Peninsula. Acta Geografica, 13: 1-60. 
Hutchinson, G. E., R. Patrick, and E. S. Deevey. 1956. Sediments of Lake Patzcuaro, Michoacan, Mexico. Bull. Geol. Soc. Am., 67: 1491-1504. Iversen, J. 1954. The late-glacial flora of Denmark and its relation to climate and soil. Danmarks Geol. Underspgelse, 80: 87-119.

Jennings, J. D. 1957. Danger Cave. Mem. Soc. Am. Archaeology, 14: $1-328$.

Kitts, D. B. 1953. A Pleistocene musk ox from New York and the distribution of the musk-oxen. Am. Museum Novitates, 1607: 1-8.

Koopman, K. F., and E. E. Williams. 1951. Fossil Chiroptera collected by H. E. Anthony in Jamaica, 1919-1920. Am. Museum Novitates, 1519: 1-29.

Lange, A. L. 1956. Woodchuck remains in northern Arizona caves. $J$. Mammal. 37: 289-291.

Lee, T. E. 1957. The antiquity of the Sheguiandah Site. Canadian FieldNaturalist, 71: 117-137.

Leopold, A. S. 1950. Vegetation zones of Mexico. Ecology, 31: 507-518.

Leopold, S. B. 1956. Two late-glacial deposits in southern Connecticut. Proc. Natl. Acad. Sci. U.S., 52: 863-867.

Livingstone, D. A., and B. G. R. Livingstone. 1958. Late-glacial and postglacial vegetation from Gillis Lake in Richmond County, Cape Breton Island, Nova Scotia. Am. J. Sci., 256:341-359.

MacNeish, R. S. 1950. A synopsis of the archaeological sequence in the Sierra de Tamaulipas. Rev. mex. estudios antropol., 11: 79-96.

- 1955. Ancient maize in Mexico. Archaeology, 8: 108-115.

Manley, G. 1955. A climatological survey of the retreat of the Laurentide Ice Sheet. Am. J. Sci., 253: 256-273.

Manning, T. H. 1956. Narrative of a second Defence Research Board expedition to Banks Island. Arctic, 9: 3-77.

Marshall, J. T. 1957. Birds of Pine-Oak Woodland in Southern Arizona and Adjacent Mexico. Pacific Coast Avifauna, 32: 1-125.

Martin, P. S. 1958a. Taiga-tundra and the Full-glacial period in Chester County, Pennsylvania. Am. J. Sci., 256: 470-502.

- 1958b. Pleistocene biogeography of a desert mountain. Am. Phil. Soc. Yearbook, American Philosophical Society, Philadelphia, Pa. Pp. 240-242.

Martin, P. S., and B. E. Harrell. 1957. The Pleistocene history of temperate biotas in Mexico and Eastern United States. Ecology, 38: $468-480$.

Matthew, W. D. 1919. Recent discoveries of fossil vertebrates in the West Indies and their bearing on the origin of the Antillean fauna. Proc. Am. Phil. Soc., 58: 161-181.

Mercer, J. H. 1956. Geomorphology and glacial history of southernmost Baffin Island. Geol. Soc. Am. Bull., 67: 553-570.

Miller, A. H. 1951. An analysis of the distribution of birds of California. Univ. Calif. Publs. Zool., 50: 531-644. 
Miller, G. S., and R. Kellogg. 1955. List of North American Recent mammals. U. S. Natl. Museum Bull., 205: 1-954.

Moreau, R. E. 1955. Ecological changes in the Palearctic region since the Pliocene. Proc. Zool. Soc. London, 125: 253-295.

Murray, K. F. 1957. Pleistocene climate and the fauna of Burnet Cave, New Mexico. Ecology, 38: 129-132.

Nikiforoff, C. C. 1955. Hardpan soils of the coastal plain of southern Maryland. Geol. Surv. Prof. Paper, 267 B: 45-62.

Osborn, H. F. 1906. The causes of extinction of mammalia. Am. Naturalist, 40: 769-795, 829-859.

- 1936. Proboscidea. American Museum of Natural History, New York.

Peltier, L. C. 1949. Pleistocene terraces of the Susquehanna River, Pennsylvania. Penn. Topol. Geol. Survey, ser. 4, Bull., G23: 1-158.

Potzger, J. E., and A. Courtemanche. 1956. A series of bogs across Quebec from the St. Lawrence Valley to James Bay. Can. J. Botan., 34: $473-500$.

Potzger, J. E., and B. C. Tharp. 1947. Pollen profile from a Texas bog. Ecology, 28: 274-280.

- 1954. Pollen study of two bogs in Texas. Ecology, 35: 462-466.

Quimby, G. I. 1958. Fluted points and geochronology of the Lake Michigan basin. Am. Antiquity, 23: 247-254.

Rabb, G. B., and E. B. Hayden. 1957. The Van Voast-American Museum of Natural History Bahama Islands Expedition. Am. Museum Novitates, 1836: 1-53.

Rand, A. L. 1948. Glaciation, an isolating factor in speciation. Evolution, 2: 314-321.

Rasmussen, W. C. 1953. Periglacial frost-thaw basins in New Jersey: a discussion. J. Geol., 61: 473-474.

Romer, A. S. 1933. Pleistocene vertebrates and their bearing on the problem of human antiquity in North America. In The American Aborigines, Their Origin and Antiquity, D. Jenness, Editor. University Toronto Press, Toronto, Canada.

-1945. Vertebrate Paleontology. University Chicago Press, Chicago, Ill.

Rouse, I. 1952. The age of the Melbourne Interval. Texas Archeol. Paleontol. Soc., 23: 293-299.

Rouse, I., and J. M. Cruxent. 1957. Further comment on the finds at El Jobo, Venezuela. Am. Antiquity, 22: 412.

Rousseau, J. 1952. Les zones biologiques de la Péninsule Québec-Labrador et l'hémiarctique. Can. J. Botan., 30, 436-474.

Sauer, C. O. 1944. A geographical sketch of Early Man in America. Geog. Rev., 34: 529-573.

Scharff, R. F. 1912. Distribution and Origin of Life in America. Macmillan, New York. 
Schultz, J. R. 1938. A late quaternary mammal fauna from the tar seeps of McKittrick, California, Carnegie Inst. Wash. Publ., 487: 115215.

Sears, P. B., F. Foreman, and K. H. Clisby. 195.5. Palynology in southern North America. Bull. Geol. Soc. Am., 66: 471-530.

Sellards, E. H. 1952. Early Man in America. University Texas Press, Austin.

Sharpe, C. F. S. and E. F. Dosch. 1942. Relation of soil-creep to earthflow in the Appalachian Plateaus. J. Geomorphol., 5: 312-324.

Sibree, J. 1915. A Naturalist in Madagascar. Seeley, Service \& Co.

Simpson, G. G. 1931. Origin of mammalian faunas as illustrated by that of Florida. Am. Naturalist, 65: 258-276.

1940. Review of the mammal-bearing Tertiary of South America. Proc. Am. Phil. Soc., 83: 649-709.

- 1945. The Principles of Classification and a Classification of Mammals. Bull. Am. Museum Nat. Hist., 85: 1-350.

. 1953. The Major Features of Evolution. Columbia University Press, New York.

. 1956. Zoogeography of West Indian land mammals. Am. Museum Novitates, 1759: 1-28.

Smith. P. W. 1957. An analysis of post-Wisconsin biogeography of the Prairie Peninsula region based on distributional phenomena among terrestrial vertebrate populations. Ecology, 38: 205-218.

Soday, F. J. 1954. The Quad Site, a Paleo-Indian village in northern Alabama. Tenn. A rchaeologist, 10: 1-20.

Stearns, C. E. 1942. A fossil marmot from New Mexico and its climatic significance. Am. J. Sci., 240: 867-878.

Stewart, O. C. 1951. Burning and natural vegetation in the United States. Geog. Rev., 41: 317-320.

Stuart, L. C. 1951. The herpetofauna of the Guatemalan Plateau. Contribs. Lab. Vert. Biol., Univ. Mich., 49: 1-71.

Taylor, W. W. 1956. Some implications of the carbon-14 dates from a cave in Coahuila, Mexico. Texas Archeological Soc. Bull., 27: 215-234.

Thomas, E. S. 1951. Distribution of Ohio animals. Ohio J. Sci., 51: $153-167$.

Wells, B. W., and S. G. Boyce. 1953. Carolina bays: additional data on their origin, age and history. J. Elisha Mitchell Sci. Soc., 69: 119-141.

Wetmore, A. 1937. Bird remains from cave deposits on Great Exuma Island in the Bahamas. Bull. Museum Comp. Zool., 60: 427-441.

-1943. The birds of southern Veracruz, Mexico. Proc. U. S. Natl. Museum, 93: 215-340.

. 1956. A Check-list of the Fossil and Prehistoric Birds of North America and the West Indies. Smithsonian Inst. Publs., Misc. Collections, 131: 1-105.

Weyl, R. 1955. Vestigios de una glaciacion del Pleistoceno en la Cordillera 
de Talamanca, Costa Rica, A. C. Informe Trimestral, Inst. Geog. de Costa Rica, pp. 9-32.

White, S. E. 1956. Probable substages of glaciation on Iztaccihuatl, Mexico. J. Geol., 64: 289-295.

Whittaker, R. H. 1956. Vegetation of the Great Smoky Mountains. Ecol. Monographs, 26: 1-80.

Williams, E. E. 1950. Testudo cubensis and the evolution of western hemisphere tortoises. Bull. Am. Museum Nat. Hist., 95: 1-36.

- 1952a. A new fossil tortoise from Mono Island, West Indies, and a tentative arrangement of the tortoises of the world. Bull. Am. Museum Nat. Hist., 99: 541-560.

- 1952b. Additional notes on fossil and subfossil bats from Jamaica. J. Mammal., 33: 171-179.

Williams, E. E., and K. F. Koopman. 1951. A new fossil rodent from Puerto Rico. Am. Museum Novitates, 1515: 1-9.

Williams, S. 1957. The Island 35 Mastodon. Am. Antiquity, 22: 359-372.

Wilson, L. R. 1932. The Two Creeks forest bed, Manitowoc County, Wisconsin. Trans. Wisconsin Acad. Sci., 27: 31-46.

- 1936. Further fossil studies on the Two Creeks forest bed, Manitowoc County, Wisconsin. Bull. Torrey Botan. Club, 63: 317325.

Witthoft, J. 1952. A Paleo-Indian site in Eastern Pennsylvania: an early hunting culture. Proc. Am. Phil. Soc., 96: 464-495.

Wolfe, P. E. 1953. Periglacial frost-thaw basins in New Jersey. J. Geol., 61: $133-141$.

Wormington, H. M. 1957. Ancient Man in North America, fourth edition, Denver Museum of Natural History, Denver, Colo.

Yehle, L. A. 1954. Soil tongues and their confusion with certain indicators of periglacial climate. Am. J. Sci., 252: 532-546.

Zumberge, J. H., and J. E. Potzger. 1956. Late Wisconsin chronology of the Lake Michigan Basin correlated with pollen studies. Bull. Geol. Soc. Am., 67: 271-288. 


\section{The Palaearctic Element in the New World Avifauna}

Kenneth C. Parkes

Carnegie Museum, Pittsburgh, Pennsylvania

In the March 1946 issue of The Wilson Bulletin, Ernst Nayr published an important paper entitled "History of the North American bird fauna," a review that represents a muchquoted landmark in the study of the zoogeography of North America. Mayr summarized the recent advances in zoogeography in general, with particular reference, of course, to birds, and pointed out especially the contributions of the palaeontologist and the taxonomist. After a brief review of the geological history of North America, he proceeded to classify the avifaunal elements of the Americas on the basis of probable geographic origin. He pointed out that it is impossible to place many of the bird families as to probable major land mass of origin. In the first place, many families, mostly oceanic or freshwater, are now so widely distributed as to make speculation as to their genesis fruitless. Mayr calls these the "unanalyzed element." This group includes such sea birds as the petrels and gulls, such freshwater birds as ducks, herons, rails, the shore birds, and a few families of land birds, including the diurnal birds of prey, the woodpeckers, and the swifts.

Another group of uncertain origin is also widespread but only, at present, in the tropics. Mayr calls this the "pantropical element" (this adjective strikes me as less awkward than "tropicopolitan," used by Darlington (1957) and others). This group includes aquatic birds like the anhingas and skimmers, and a few land birds, the trogons, barbets, and parrots. In the arctic and north temperate zones the loons, auks, and some other birds constitute still another group of families that is now so widely dispersed that no continent can be named as their original source.

The strictly New World families, or rather the families of New World origin, since some of these have found their way to the Old World, were divided by Mayr into (1) those of probable North 
American origin, (2) those of probable South American origin, and (3) a Pan-American element now so widespread in both continents as to be of uncertain continental origin (see Darlington, 1957, pp. 280-286, for a critique of Mayr's theories concerning these New World groups).

Finally, there are the families that are generally acknowledged to be of Old World origin, but that now form a component of the avifauna of the Americas. This is the group which will be reviewed here.

As Mayr pointed out, birds apparently crossed the Bering Strait connection between Asia and North America more or less continuously through most of the Tertiary. This continuity of origin is reflected in the complete spectrum of zoogeographic and taxonomic status of the Old World groups in the Americas. At one end of the spectrum are families the representatives of which arrived so early that there has been time for a major secondary radiation in the Americas. Such a history is exemplified by the quails, derived from the Old World pheasant and partridge family, and by the jays, which are much more diversified in the New World than in the Old. It should be acknowledged that factors other than the mere time element are involved in the extent to which these secondary radiations have developed; evolutionary opportunity in the form of available ecological niches and comparative rates of evolution must also be considered. But it seems safe to assume that a group that has reached approximately the subfamily level of differentiation must have derived from a rather early invasion.

At the opposite end of the spectrum Mayr mentions species which have only a slight foothold on this continent and are inseparable even subspecifically from their Old World progenitors. These include two Alaskan birds, the Yellow Wagtail (Motacilla flava tschutschensis) and the Red-spotted Blue-throat (Luscinia svecica svecica), and one species, the Wheatear, which has entered Alaska from the west (as Oenanthe oenanthe oenanthe) and the eastern Canadian Arctic from Greenland (as O. o. leucorhoa). All these species are obviously recent immigrants but belong to two families (Motacillidae and Turdidae) with wide distribution in the New World from earlier invasions. A category even beyond this can be established for those Old World species that do not have a foothold 
on this continent in the sense that there is no known breeding population, but which occur here from time to time as so-called accidentals or casuals. It is here we encounter some of the "unsolved problems" appropriate to mention in a symposium with the general title, "Some Unsolved Problems in Biology, 1957."

In discussing the so-called accidentals, particular attention will be paid to the Transatlantic species. Fewer Transpacific crossings can be expected for obvious geographic reasons, and a stray Asiatic bird might easily be overlooked along the Pacific Coast of North America, which is much less closely scrutinized by bird-watchers than is the Atlantic Coast.

It is widely known that American birds occur in western Europe, particularly the British Isles, far more of ten than European birds appear in eastern North America. Peterson, Mountfort, and Hollom (1954) list 41 American species or subspecies of non-pelagic, nonintroduced birds as accidental in western Europe. The American Ornithologists' Union Check-list of North American Birds (1957), hereafter referred to as "A.O.U. Check-list," lists 24 such species or subspecies from Europe as accidental in eastern North America. And even the comparative figure 41 versus 24 is misleading, since the actual number of individual occurrences of accidental birds is much higher in Europe than in North America. Alexander and Fitter (1955) listed 260 authenticated records of North American herons, cranes, rails, and waders alone in western Europe, and an additional 126 records of land birds. The figures for European accidentals in North America would be far fewer, particularly since a substantial number of these are among the ducks, gulls, and other families not included in the figures given by Alexander and Fitter.

There is no great mystery here, as the prevailing winds across the North Atlantic are predominantly from west to east. The unsolved problem in this case lies with the species that do manage to get across to the western side of the Atlantic with some frequency. Six species of palaearctic water birds occur along our Atlantic seaboard with such regularity that a large percentage of the birdwatchers of Long Island and New England are familiar with them, and keep an eye out for them every year. Two are ducks, the European Green-winged Teal (Anas crecca) and the European Widgeon (A. penelope); two are sandpipers, the Curlew Sandpiper 
(Erolia ferruginea) and the Ruff (Philomachus pugnax); and two are gulls, the Black-headed Gull (Larus ridibundus) and the Little Gull (L. minutus). ${ }^{1}$

What particular attribute, if any, do these six species share to give them the propensity for such frequent Transatlantic crossings against the prevailing winds? Three of the species, the two ducks and the Black-headed Gull, are known to nest as far west as Iceland. But why, then, do not other, related, Iceland nesters make the same trip? Among the gulls, for instance, the Lesser Black-backed Gull (Larus fuscus) breeds in Iceland, but the two specimens of this species that have been collected in North America were both of the British rather than the Icelandic breeding race. Of the three remaining species, the Little Gull nests as far west as Denmark and the coast of the North Sea, the Ruff to western France, and the Curlew Sanclpiper only in eastern arctic Siberia. The breeding ranges of all these species are more or less duplicated by those of related species or other birds of similar migration patterns. Why, then, do we see these six so much more often along our East Coast? Several possibilities suggest themselves. One is that other vagrant species are being overlooked. Readers familiar with the zeal of the birdwatching groups on Cape Cod or Long Island will discount that one immediately. It has been said that the publication of Peterson's Field Guide to European birds in 1954 was a real boon to many Massachusetts bird-watchers, who had by then worn out their Field Guides to the birds of western North America!

Another possibility is some sort of innate tendency in these few species to go astray, so to speak; perhaps a high incidence of error in their "direction-finding apparatus," that mysterious organ for which ornithologists still search in vain. This would be exceedingly difficult to demonstrate, and seems rather unlikely from an evolutionary point of view, since getting lost would not appear to be a selectively advantageous trait. A third possibility and perhaps the most reasonable, at least for some of the species, is the existence of undiscovered breeding areas of these species much closer than any we know of now, perhaps even in North America itself. Certainly

1 The list of eight European birds most regularly ohserved on the Atlantic Coast of North America presented by Lindroth $(1957$, p. 251 ), which overlaps the above list by four species, was based on an obsolete and incomplete reference, the 1931 edition of the A.O.U. Check-list. Even the 1957 edition is misleading in this respect; see Eisenmann, 1958, for remarks on the status of certain European birds in the New York City region. 
the unexplored tundra in the New World arctic is vast enough to hide a small local breeding population of the Curlew Sandpiper. It may be less likely for some of the larger species, but certainly cannot be discounted. Every year many thousand Eastern Dowitchers (Limnodromus griseus griseus) pass on migration along our East Coast, but as of 1957 the A.O.U. Check-list can only say of this large shorebird, "Breeding range uncertain, but presumed to be in the interior of the Ungava Peninsula." Thus these so-called accidentals may yet be shown to be an established component of the New World avifauna.

We turn next to those Old World groups known to be established in the Americas. Mayr listed approximately twenty families of New World birds as being of Old World origin-approximately, since family limits are a subject for continuing debate among ornithologists. He divided these roughly into three groups; Early, Fairly Early, and Recent Immigrants. Two principal types of evidence are used to classify these groups. The fossil record, of the relatively few species for which it is at all adequate, is naturally the best evidence, but note the warning of Darlington (1957, p. 238): "Birds are a good example of the fact that, in zoogeography, a poor fossil record interpreted too literally is almost worse than no record at all." The other type of evidence is more inferential, based on the relative numbers of species and genera in the New and Old Vorlds, the degree to which the New World forms have differentiated taxonomically, and the distance into the Americas they have penetrated. Mayr's tripartite chronological division is of necessity arbitrary and, particularly for large families, may be misleading in suggesting a lesser number of invasions than has probably occurred. Mayr circumvented the latter difficulty by subdividing the representatives of some families, as the Corvidae (crows and jays) and the Turdidae (thrushes) in to older and newer invasions. Even so, additional subdivision beyond Mayr's seems desirable. For instance, Mayr pointed out, on the basis of both fossil and Recent taxonomic evidence, that the typical owls, family Strigidae, though almost certainly of Old World origin, must have reached the New World very early. Fragmentary remains assigned to an allied but extinct family, Protostrigidae, are known from the Eocene of Wyoming, and a Lower Miocene species from South Dakota is identified with the living genus Strix (this and other data on fossil birds are chiefly 
from Wetmore, 1956). Six endemic genera of owls are currently recognized from the New World. On the other hand, no fewer than eight species, in six genera, are currently considered to be conspecific with Old World owls; among these is a panarctic species with no races, the Snowy Owl (Nyctea scandiaca). Another species, the Short-eared Owl (Asio flammeus), has a highly unusual distribution. The nominate race is found, without appreciable geographic variation, throughout Europe and northern and central Asia, and in North America through about the northern half of the United States. There is then a distributional gap, beyond which the species reappears (as subspecies bogotensis) in the arid temperate zone of the mountains and plateaus of the northern Andes. Again, beyond a gap, appears the subspecies suinda, which ranges from southern Peru and southern Bolivia to Tierra del Fuego. There are isolated endemic subspecies on the Falkland Islands, the Hawaiian Islands, the Galápagos Islands, Hispaniola, Puerto Rico, and Ponape in the Carolines. Probably few living species of birds have had so complex a distributional history.

A good illustration of the value of the fossil record where it is available to counteract misleading evidence based on modern distribution is furnished by the family Gruidae, the cranes. On the basis of the living forms only, one would probably characterize this family as a rather recent immigrant to the New World, for there are only two American species, one of which also occurs in eastern Siberia and both of which belong to a widespread Old World genus, and cranes have penetrated only as far south in the New World as Cuba. However, the evidence of the living species is misleading. Cranes of as many as three extinct genera are known from the Eocene of Wyoming, and one Eocene fossil is tentatively assigned to the living genus Grus. But lest it be thought that cranes became extinct in North America in, perhaps, the late Tertiary, with the two living species representing a rather recent second invasion, it should be pointed out that fossils indistinguishable from the living species occur as early as the Pliocene: the Whooping Crane in the Upper Pliocene, and the Sandhill Crane in the Lower Pliocene.

Good examples of what were undoubtedly secondary New World radiations from an early invading Old World stock are the cuckoos, the pigeons, and the jays. The large and diverse Old World family 
Cuculidae is represented in the Americas by thirty species, which are arranged in ten genera, not a single one of which occurs in the Old World. In the pigeon family, Columbidae, there are nineteen endemic New World genera, some highly distinctive. The twentieth genus, which is shared with the Old World, is the eminently successful genus Columba, to which the domestic pigeon belongs. There are no fewer than eighteen New World species of Columba, of which seventeen are confined to the warm latitudes between the Rio Grande and south Florida to the north and approximately Buenos Aires to the south. Darlington (1957, p. 273) argued for a tropical New World origin of the genus Columba, with dispersal to the Old World through the north. To me, the facts suggest, rather, (1) an origin in the Old World, (2) a secondary radiation in the New World tropics, and (3) a quite recent northward movement by a single species, the Band-tailed Pigeon ( $C$. fasciata), which now ranges from Central America to southwestern British Columbia. That Columba was originally a tropical genus is suggested not only by the somewhat greater number of tropical than of temperate species in the Old World, but by the fact that the genera currently placed closest to Columba (Peters, 1937) are also confined to the Old World topics. This would give strength to the idea that Columba is older in the Old World than in the New, as would the fact that a larger number of species has been able to become adapted to temperate conditions in the former area than in the latter.

Turning now to the family Corvidae, we may note that the greater diversity of the jays in the New World is evidence for an early secondary radiation from corvid stock. It is, in fact, quite conceivable that the few jays of the Old World may represent a reinvasion of the Old World. One genus of jays, Perisoreus, now inhabits northern coniferous forests of both hemispheres, with a distinct but related species ("Boanerges" internigrans) in the mountains of western China. Amadon (1944, p. 5) believed that the distribution of Perisoreus leaves "little doubt that it is an Old World genus which reached America recently, later than the other American jays." If the jays, as postulated above, represent a reinvasion of the Old World by corvid stock which had differentiated in the New World, then Amadon's interpretation would require Perisoreus to have returned, so to speak, to the New World. This is possible, but a New World origin for Perisoreus itself must be considered. 
At any rate, members of the family Corvidae other than the jays have continued to enter the New World, some so recently that the American populations are barely separable subspecifically from their Old World relatives (the family thus paralleling the owls in this respect). The Magpie (Pica pica) now exists in North America in two well-marked forms: the Black-billed ( $P$. p. hudsonia), very similar to Old World races, and the Yellow-billed, usually considered a full species ( $P$. muttalli). Only the latter is known from fossil (late Pleistocene) remains in North America, from within or close to its present range in California. The magpies of North America may well represent a double invasion by the same Old World species (see Lanius, beyond). Again, within this family, the genus Corvus has entered the New World at least twice, and probably more often. A cluster of closely related species of this genus in the southern United States, West Indies, and Mexico probably represents a rather early invasion, since these species at present have no clear affinities with any Old World crows. On the other hand, the southernmost penetration of this genus in the Americas is that of the Raven (C. $\operatorname{corax}$ ), which has reached Nicaragua. Pleistocene fossils of the Raven are known from as far south as Nuevo Leon, Mexico, yet all New World Ravens are only subspecifically different from those of the Old World, and the northernmost populations are barely separable.

The weakness of the fossil record is nowhere better demonstrated than in the large order Passeriformes, the perching birds, to which half our living species belong. Wetmore (1956) listed from North America (including the West Indies) only 51 species of passeriform birds known from fossil (for one species Recent cave) remains. Of these 51 , no fewer than 44 , or $86 \%$, are Pleistocene fossils of living species. A single species, for which the family Palaeospizidae has been erected, is known from the Upper Miocene or Oligocene; one extinct genus of finch is known from the Middle Pliocene; two extinct genera of blackbirds are known from the late Pleistocene, and one of these may prove to be of Recent origin; and two extinct species of living genera are known from the late Pleistocene. All the extinct species of living passeriform families belong to families of New World origin. Thus we have none of the sort of evidence quoted earlier for the cranes to show that deductions on the basis of the living forms only may be highly misleading. 
Evidence from other than fossil sources can, of course, be so overwhelming as to be tantamount to proof of origin of some of these passeriform families. The larks (Alaudidae), for instance, comprise a diverse and widespread Old World family, which extends from the arctic to the tropics. It is represented in the New World by a single species, the Horned Lark (Eremophila alpestris), which, although it has penetrated the Americas as far as the vicinity of Bogota, Colombia, remains no more than subspecifically different from the palaearctic forms.

The distributional history of other passeriform families in the New World is far more obscure. The waxwings (Bombycillidae) are a good example. Mayr, following Lönnberg, listed this family without comment as being of North American origin. The evidence from the three living species is anything but unequivocal. One species (Bombycilla garrulus) is distributed across the northern Palaearctic, from Scandinavia to Siberia, and also in northwestern North America, and breeds about as far southeast in to the continent as Glacier Park, Montana. Another species, the Cedar Maxwing (B. cedrorum), is found virtually throughout North America, from southern Alaska and Newfoundland south to the upper southern states. The third species (B. japonica) breeds only in a relatively small area of eastern Siberia in the Amur River basin. There is little here upon which to base conclusions as to origin, but I would say that the balance might be tipped in favor of the Old World. The next step would be to examine the families considered most closely related to the waxwings. Their nearest allies appear to be two other American groups which are, by some "lumpers," even placed as subfamilies of the Bombycillidae. These are the Ptilogonatidae of the southwestern United States and Central America, and the Dulidae, a monotypic family known only from Hispaniola. This would seem to argue for an American origin for the waxwings. On the other hand, recent investigations indicate that the odd genus Iypocolius from the Persian Gulf region is closely related to the waxwings. Such are the difficulties encountered in trying to work out a distributional history for a small family of birds with no significant fossil record and of uncertain near relationships.

One of the most plausible indications of double invasion of the New World by a palaearctic stock is furnished by the shrikes (Laniidae). It seems clear that the two North American species 
have heen derived from two incursions of the same stock. The details of these invasions may be inferred to have been as follows. The first immigration took place prior to the Pleistocene glaciation by birds belonging to the widespread Old World species that we now call Lanius excubitor. With the advent of glaciation this species moved south. It is highly adaptable, as shown by its Old World range, which extends from northern Scandinavia to India and Arabia. Therefore, with the retreat of the glacier, populations of this shrike were able to remain as far south as southern Mexico, while northern populations reoccupied an area extending to central Canada. At some uncertain time the species again crossed the Bering Strait and quickly spread through the boreal portion of North America. This second wave is currently regarded as conspecific with and closely related to the Old World races through the Siberian population, while the descendants of the first invasion are given specific rank (L. ludovicianus). Certain well-marked differences that have evolved in these earlier and more southern populations are invoked as specific characters. However, members of this so-called species, the Loggerhead Shrike, resemble some of the ecologically parallel populations of the Old World species (Olivier, 1944, p. 43). Judging from published maps and range descriptions, the Northern and Loggerhead shrikes nowhere come into actual contact during the breeding season in North America. There is thus no available natural testing site for the criterion of reproductive isolation. We have here an interesting problem of deciding what to call the two North American shrikes; although they have almost always been listed as full species, there are arguments and precedents for the opposite view. The problem they illustrate is an interesting, although perhaps uncommon one: the question of the taxonomic treatment of obvious derivatives, from two well-separated invasions of the same stock, that are now separated spatially, so that no evidence as to reproductive isolation is forthcoming.

Perhaps the most intriguing problem connected with the palaearctic element in the New World avifauna, and the one least likely to be solved, deals with the related questions "which?" and "why?" - which groups made the trip, and why these and not others? Undoubtedly the most striking aspect of this problem is the apparent one-way traffic between the two continents; Darlington (1957, 
p. 279) reminded us that this pattern is also true of mammals and of cold-blooded vertebrates. Lindroth (1957) listed twenty-four species of passeriform birds as occurring in both Eurasia and North America. After deducting the swallows and the waxwing, of uncertain origin, and two species no longer considered conspecific with their overseas counterparts (Parus atricapillus with P. borealis; Sitta canadensis with $S$. corea, krüperi, villosa, and whiteheadi), we are left with nineteen species in common. Of these, no fewer than sixteen, of nine families, are regarded as of Old World origin and as invaders of the New World, while only three species, of two families, are treated as immigrants from the opposite direction. Two of these species, the Lapland Longspur (Calcarius lapponicus) and the Snow Bunting (Plectrophenax nivalis), are panarctic birds that have developed a few weakly characterized subspecies. The third species, on the contrary, is the highly polytypic wren Troglodytes troglodytes. The A.O.U. Check-list (1957), which probably oversplits them, recognizes no fewer than twelve North American races, while the situation in Eurasia may be judged by Vaurie's recent paper (1955), in which he reduced to eight a total of twenty-one proposed races from eastern Asia alone. The question, of course, is why? Why has this single passeriform species been so obviously successful? Why was it one of the very few that has been able to "swim against the tide," and what caused the "tide" in the first place? Why are the palaearctic-derived siskins, pipits, and thrushes found all through South America in suitable habitats, whereas only a single group of New World passeriform birds, the emberizine finches, has radiated at all in the Old World? Such are the unsolved problems of this corner of zoogeography, and most are likely to remain chiefly intellectual exercises, since the likelihood of securing tangible evidence with which to solve them appears small.

\section{REFERENCES}

Alexander, W. B., and R. S. R. Fitter. 1955. American land birds in western Europe. British Birds, 48: 1-14.

Amadon, Dean. 1944. The genera of Corvidae and their relationships. Am. Museum Novitates, No. 1251: 1-21.

American Ornithologists' Union. 1957. Check-list of North American Birds, 5th edition. Published by the Union.

Darlington, Philip J., Jr. 1957. Zoogeography. John Wiley \& Sons, New York. 
Eisenmann, Eugene. 1958. The new A.O.U. Check-list. Linnaean Newsletter (Linnaean Society of New York), 11, No. 7-8: [1-3].

Lindroth, Carl H. 1957. The Fannal Connections between Europe and North America. John Wiley \& Sons, New York.

Mayr, Ernst. 1946. History of the North American bird fauna. Wilson Bull. 58: 1-41.

Olivier, Georges. 1944. Monographie des Pies-Grièches du genre Lanius. Lecerf, Rouen.

Peters, James L. 1937. Check-List of Birds of the World, Vol. 3. Harvard University Press, Cambridge, Mass.

Peterson, R. T., Guy Mountfort, and P. A. D. Hollom. 1954. A Field Guide to the Birds of Britain and Europe. Houghton, Mifflin, Boston, Mass.

Vaurie, Charles. 1955. Systematic notes on palearctic birds. No. 16. Troglodytinae, Cinclidae, and Prunellidae. Am. Museum Novitates, No. 1751: 1-25.

Wetmore, Alexander. 1956. A check-list of the fossil and prehistoric birds of North America and the West Indies. Smithsonian Misc. Collections, 131, No. 5. 


\title{
Distributional Patterns of Vertebrates in the Southern United States in Relation to \\ Past and Present Environments
}

\begin{abstract}
W. Frank Blair
Department of Zoology, The University of Texas, Austin
\end{abstract}

The thesis of this discussion is that the present distributions of vertebrates in the southern United States, on the Gulf and Atlantic coastal plains in particular, can be explained only on the hypothesis of drastic ecological changes in the deep south in the Pleistocene. The germ of this concept was stated by Adams (1902). More recently, Deevey (1949) expressed the hypothesis clearly and reviewed some of the supporting evidence in his general discussion of Pleistocene biogeography. The argument is essentially that at peaks of glacial advance into the northern United States climatic and ecological changes in the southern United States were so great as to drive warmth-adapted species into separate refuges in Florida and Mexico. Blair (1951) referred to additional evidence from the vertebrates.

Braun (1955 and other papers) has been particularly vigorous in opposition to this hypothesis and has argued that the conditions that produced the Pleistocene glaciations had little effect in the southern United States.

I now reopen the question, reviewing some of the evidence cited by previous workers and introducing additional material. The evidence is concerned primarily with past and present distributions of tetrapod vertebrates, other than birds. One item in the past distribution of fishes is cited, but the present distribution of this group is excluded from consideration. Similarly, no treatment of birds is attempted, because of the author's relative unfamiliarity with this group.

The area to which the discussion will be largely limited is the Gulf 
coastal plain and the bordering grasslands to the west, although the argument applies equally to other species in eastern North America not today limited to the coastal plain. Two major biotic formations are involved. The Austroriparian forest extends with only minor variance in climate, ecological dominants, and general aspect from eastern Texas to the Atlantic coast. The southern grasslands border the forest of the west. These grasslands, with beginnings in the late Miocene and great development in the Pliocene (Clements and Chaney, 1937) stand today as a barrier to the westward distribution of many forest animals.

I consider three major questions:

1. What is the evidence in regard to Pleistocene climates in the southern United States? IVere the climatic changes sufficiently drastic as to force the withdrawal of warmth-adapted coastal plain animals into separate eastern (Floridian) and western (Mexican) refuges?

2. How effective were the grasslands as a Pleistocene barrier to the southwestward withdrawal of warmth-adapted species into Mexico?

3. How do present distributions fit the hypothesized Pleistocene climatic changes?

\section{SOUTHERN CLIMATES IN THE PLEISTOCENE}

Evidence from various sources indicates major ecological changes on the coastal plain in the Pleistocene, including far southward shifting of northern plants and animals during stages of glaciation in the north. Climatic implications from these shifts must rest on the assumption that ecological requirements of living species and genera do not differ significantly from those of their Pleistocene progenitors. When single taxa are involved, this assumption sometimes may be of doubtful validity. When whole faunal or floral assemblages are represented, little or no basis seems to remain for questioning its validity.

\section{Plant Fossils}

Most of the scanty but highly significant evidence from plant fossils has been reviewed by Deevey $(1949,1950)$. On the western coastal plain, spruce (Picea) and fir (Abies) pollens have been found at the base of bog deposits in Lee, Milam, and Robertson counties, 
Texas (Potzger and Tharp, 1947, 1954). The determination that spruce and fir pollens total $11 \%$ of the pollen in the lowermost foot level in the Gause bog in Milam County was interpreted by the authors as "adding to the accumulating evidence of a widespread cool-moist climate, and migration of boreal genera far to the south of the actual borders of the continental ice caps." On the eastern coastal plain, Frey (1951) reported spruce and hemlock (Tsuga) pollens from a profile from Singletary Lake, North Carolina, and found a pine-spruce maximum at a zone of approximately 10,000 years age, determined by radiocarbon dating. Below this zone an amelioration of climate is indicated, and above it successive changes to warm, moist and to warm, dry are indicated. Spruce and fir pollens have been reported from northern Florida, in Pleistocene peats hypothesized as of late Wisconsin age (Davis, 1946).

Pleistocene macrofossils of northern types have been recorded from a few southern localities. Larch (Larix) has been reported from northern Georgia (Berry, 1907). Remains of larch, spruce, and arbor vitae (Thuja) have been found along Little Bayou Sara in southern Louisiana (Brown, 1938). Braun (1955) attempted to rationalize these southern records of northern plants with her argument against general displacement southward of climatic zones in the Pleistocene. The hypothesis that frost pockets existed near the coast and that cold, foggy climates prevailed there was suggested as the explanation of the past occurrence of northern species on the southern Atlantic coastal plain. She further suggested that ecological requirements of the northern indicator species may have been at one extreme of the tolerance range as manifested today. On the contrary, the past occurrence of species that now live in the region of the Little Bayou Sara deposits with the northern invaders can more plausibly be explained by the assumption that they then existed there at the limits of their cold tolerance, rather than that the northern species were there with them because of their own warmth tolerance. It seems quite unreasonable to attribute the appearance of the presently cold-adapted species near the present Gulf shores to any circumstance other than climatic change, and it seems only reasonable on Dr. Braun's own argument to attribute their coexistence with present warmth-adapted species to the ability of the latter to exist under conditions bordering the limits of their cold tolerance. 


\section{Vertebrate Fossils}

Pleistocene fossils from the coastal plain itself are few, except in Florida, which is postulated as a glacial-stage refuge. Records from other areas, however, are strongly indicative of major southward shifts of climatic zones. The evidence comes from individual species with northern distributions today and from relatively large faunal assemblages with similar distributions.

Southernmost records of the Pleistocene muskox Symbos (Hay, 1923 , 1924) lie far south of the present distribution of the living genus Ovibos (Fig. 1). These records show that this muskox ranged at least as far south as LeFlore County, Oklahoma, and Natchez, Mississippi. If it is assumed that Symbos even approached Ovibos in its ecological requirements, and it is plausible to do so, these records indicate much colder conditions than those of the present. The Oklahoma and Mississippi records are far south of the glacial border at the time of maximum advances.

The walrus (Odobenus) is known from several Pleistocene fossils collected in the vicinity of Charleston, South Carolina (Hay, 1923), but in historic times it has occurred only as far south as Maine (Allen, 1930).

The moose (Alces) is known from the Pleistocene as far south as Charleston, South Carolina, and Bigbone Lick, Kentucky (Hay, 1923), but within historic times has occurred only as far south as northern New York (Miller and Kellogg, 1955).

Among small mammals, a shrew (Sorex cinereus) is known from several Pleistocene localities far south of its present range (Fig. 2). The southernmost of these is the San Josecito cave in southern Nuevo León (Findley, 1953). This species is also listed in the Conard Fissure fauna of northwestern Arkansas (Hay, 1924), and Hibbard (1949) reported it from the Cudahy fauna, regarded as Kansan in age, and from the Jones Ranch fauna, regarded as late Wisconsin, of southwestern Kansas.

The marmot (Marmota) likewise lived south of its present southern limits during parts of the Pleistocene. The southernmost record is from San Josecito cave in southern Nuevo León (Cushing, 1945). This rodent has also been recorded from Pleistocene cave deposits in southern Arizona and New Mexico (Skinner, 1942; Stearns, 1942; Murray, 1957). The present southern limit of Marmota flaviventris is in northern New Mexico, at elevations above 11,000 feet. 


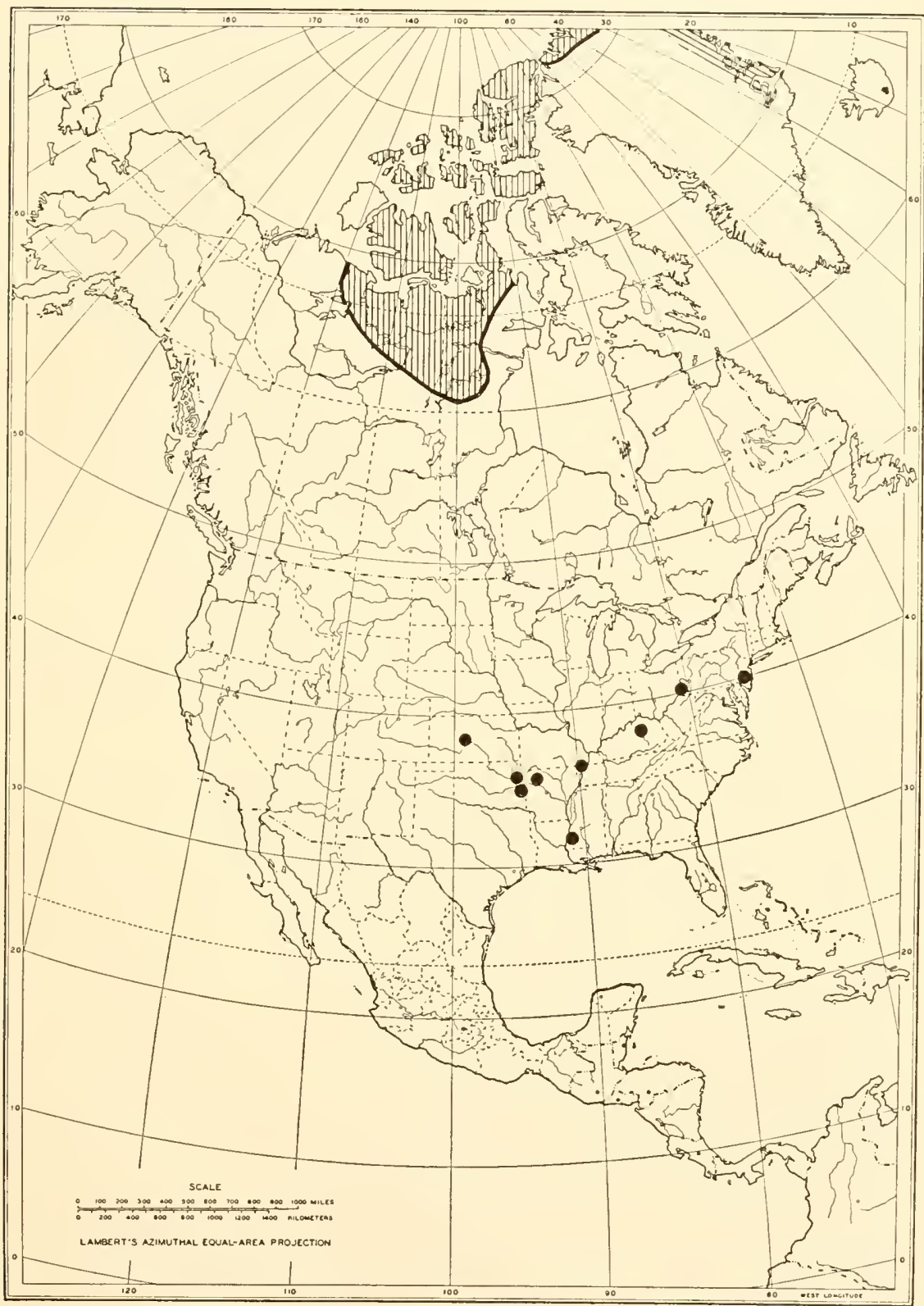

Fig. 1. Present distribution of the muskox, Ovibos (shaded) and southernmost records of the Pleistocene muskox, Symbos. 
The climatic implications of the bog lemming (Synaptomys cooperi) in the San Josecito cave fauna (Cushing, 1945) have been discussed by Hibbard (1955a). The present southern limits of this species are in northeastern Kansas, except for relictual populations in small bogs in southwestern Kansas.

The most complete picture of the southward shift of northern faunas comes from the work of Hibbard in southwestern Kansas and northwestern Oklahoma. Four cool faunas are recognized and tentatively identified with the four major glaciations of the Pleistocene (Hibbard, 1953). Two warm faunas are attributed to the Second and Third Interglacials, and only the First Interglacial is unrepresented. Mammalian components of several of these faunas are listed by Hibbard (1949). The Cudahy fauna, regarded as representing the closing phase of a Glacial age (Kansan), has the following small mammals of northern affinity:

Sorex cinereus, present distribution (Fig. 2).

Sorex cudahyensis, extinct.

Sorex (Neosorex) lacustris, extinct; most closely related species today mostly in Canada, south in Rocky Mountains to northern New Mexico.

Microsorex pratensis, extinct; most closely related species today mostly in Canada and Alaska, south to northern Iowa.

Synaptomys borealis, now north of Canadian border.

Microtus paraoperarius, extinct; related species operarius now in northwestern Canada and Alaska.

Microtus llanensis, extinct.

Pitymys meadensis, extinct.

Phenacomys sp., genus now mostly in Canada, but south in Rocky Mountains to northern New Mexico.

The assemblage contains a few cricetine rodents and a few species of little climatic significance. The great preponderance of microtine rodents and shrews, however, leaves no doubt that there was a shift of a boreal fauna at least as far southward as southwestern Kansas. There is no reason to assume that Hibbard's work in this area was done at the periphery of the range of this northern fauna, but the evidence has yet to be accumulated to show how much farther south it extended.

The Jones fauna (Hibbard, 1949), regarded as late Wisconsin in age, includes the northern species Sorex cinereus, Citellus richardsoni, 


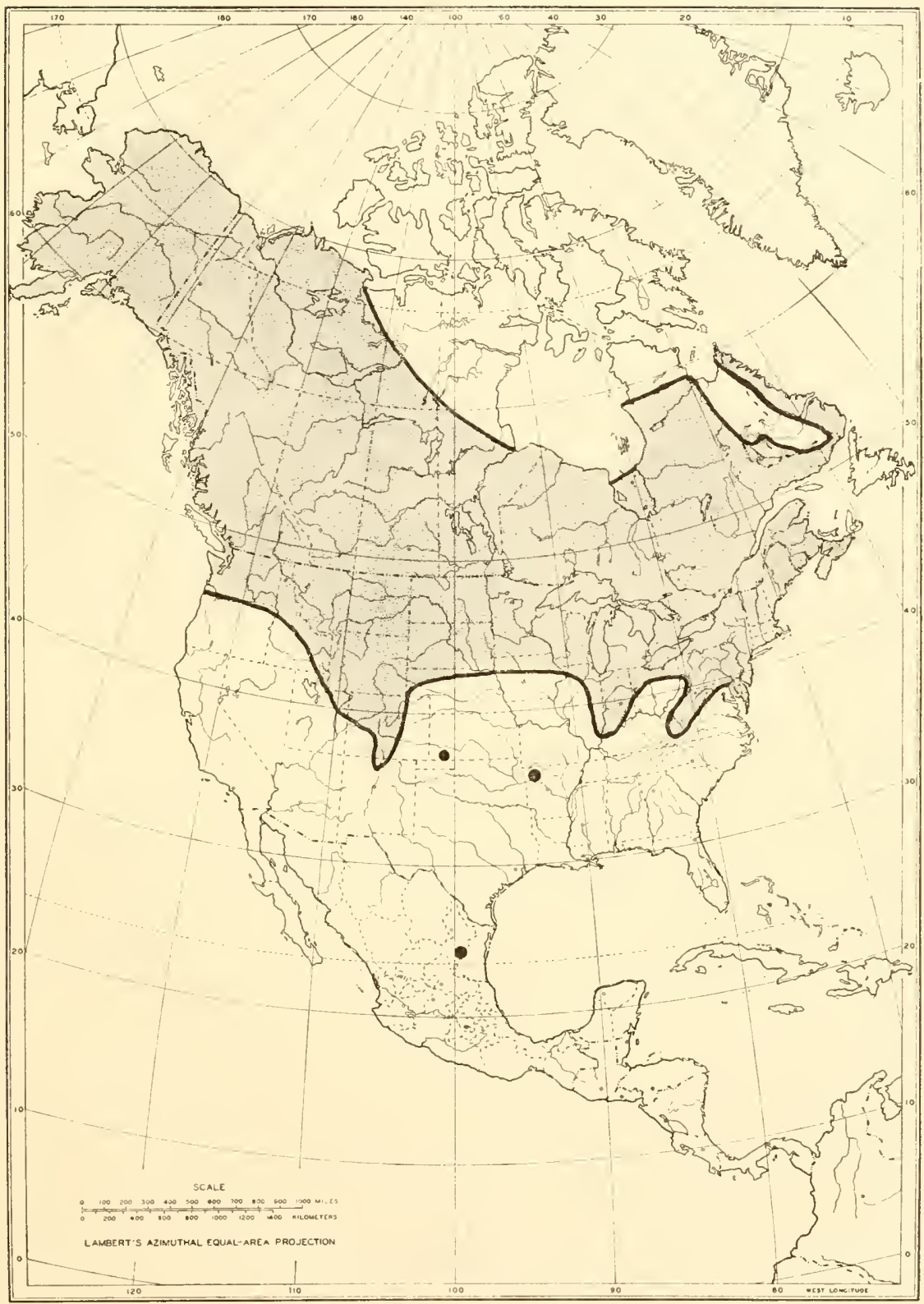

Fig. 2. Present distribution of the masked shrew, Sorex cinereus, (stippled) and Pleistocene records of this species (dots). 
and Microtus pennsylvanicus, along with various species and genera that occur in southwestern Kansas today and some highly eurythermal forms.

Another fauna from the same general area is of extreme interest because it includes a number of fishes (Smith, 1954). This fauna, from Beaver County, Oklahoma, is regarded as Illinoian in age. Along with species of presently wide distribution, it includes such northern species as the muskellunge (Esox musquinongy) and yellow perch (Perca flavescens), both of which have southern limits today several hundred miles to the northeast. Spruce, fir, and pine pollens were found in the deposits from which the fossils were taken. Mammals listed in this fauna include the northern species Sorex cinereus and Microtus pennsylvanicus and a few types that occur in the region today.

Other faunas from this same region are regarded as Interglacial, and are dominated by mammals of generally southern affinities (Hibbard, 1949, 1955b). When considered along with the coolclimate faunas, they indicate recurrent major climatic shifts in the region.

The Conard Fissure fauna of northwestern Arkansas (described by Barnum Brown and listed by Hay (1924), who regarded it as possibly Illinoian in age) includes a number of mammals that occur today considerably farther north, or have their closest relatives there. These are: the red squirrel (Sciurus hudsonicus), which now ranges south to southern lowa; the porcupine (Erethizon dorsatum), which now ranges south to central Wisconsin in the central states, but is widely distributed in mountains of the west; the snowshoe hare (Lepus americanus), which now reaches a present southern limit in the central United States similar to that of the porcupine; the masked shrew (Sorex cinereus) and the pigmy shrew (Microsorex), which now range south to northern Iowa; the fisher (Martes pennanti), which now occurs north of the Great Lakes; and the least weasel (Mustela erminea). which now ranges south to southern Nebraska. The extinct muskox (Symbos) is also represented.

Another cave fauna from much farther south includes a similar representation of cold-adapted mammals. This is the Burnet Cave fauna of the Guadalupe Mountains, New Mexico. As listed by Murray (1957) this assemblage includes various species that occur in the region today and several of presently more northern distribution. 
The latter are: the hoary marmot (Marmota flaviventris), a microtine (Microtus longicaudus), the hoary packrat (Neotoma cinerea), the white-tailed jackrabbit (Lepus townsendi), and the red fox (Vulpes fulva). These species are associated today with yellow pine and spruce-fir forests and with the exception of the microtine reach their southern limits about 250 miles to the north at high elevations in the mountains. An extinct caribou-like species, Rangifer fricki, and an extinct bovid, Euceratherium collinum, of debated ecological significance, are also listed.

As listed by Sherman (1952), the Pleistocene mammalian fauna of Florida, which is commonly regarded as a refuge for warmth-requiring species during the glacial stages, contains virtually no mammals of boreal affinity. Possible exceptions are an elk (Cervus sp.) and a bog lemming (Synaptomys australis). The latter, however, is associated with a presumably Sangamon (Third Interglacial) fauna in Kansas (Hibbard, 1955b).

The evidence from plant fossils on the coastal plain, from pollen profiles that show spruce, fir, and other northern species of plants as far south as southeastern Texas and northern Florida, and from the numerous Pleistocene occurrences of vertebrates and vertebrate faunas far south of their present distributions, leads to the conclusion that there were great ecological changes in the southern United States in the Pleistocene. It is the thesis of the present discussion that these changes, particularly those accompanying the glacial stages, were sufficiently drastic to fragment the ranges of warmthadapted coastal plain species and to force their southeastward and southwestward withdrawal, respectively into Florida and Mexico.

\section{EFFECTIVENESS OF THE GRASSLANDS BARRIER}

It has been argued that the southern grasslands have existed as a barrier to the interchange of forest biota between the eastern United States and Mexico since the development of the grasslands under increasing aridity in the Pliocene. Separation since pre-Pliocene times and slow rates of evolution are explanations given for the strong floral resemblance between the humid forests along the escarpment of the Mexican Plateau and the eastern forests (Braun, 1955). Martin and Harrell (1957) discussed this theory in the light of some vertebrate distributions and suggested that "few temperate-forest animals were able to cross the arid Texas barrier in the Pleistocene. 
They probably did so along a cool savanna or open woodland corridor."

The question of past conditions in the area occupied by the southern grasslands is highly germane to the problem of Pleistocene disjunctions in the southern United States. Most of the evidence pertinent to this problem has never been summarized. It involves Pleistocene fossils and present relictual distributions. The specific question is one of how permanent has been the arid grassland barrier.

\section{Invasion from South America}

Several South American groups of mammals crossed the supposed grassland barrier and the coastal plain in the Pleistocene. Their arrival in North America must have followed the development of the Central American land bridge in the late Pliocene and early Pleistocene, and their dispersal around the Gulf of Mexico and eastward across the coastal plain must have occurred after the development of the presumed grassland barrier. The known Pleistocene faunas of Florida include several representatives of this element, including: the common porcupine (Erethizon dorsatum), capybaras (two genera, Hydrochoerus and Neochoerus), glyptodonts (Boreostracon), armadillos (Daspyus, Holmesina), and ground sloths (Megatherium, Megalonyx, Paramylodon, Thinobadistes), as listed by Sherman (1952). Of these, the porcupine and ground sloths must have required trees for their dispersal, and others, the capybaras, at least, would have required much greater moisture than is available at present in the southern grasslands.

\section{Fossil Evidence of Interglacial Conditions}

Various Pleistocene fossils from the region of the present grasslands represent groups that probably could not exist there under present conditions and that probably required greater moisture or forest. One of the most striking of these is the water rat (Neofiber). At present this rodent is limited to bog situations in peninsular Florida (Fig. 3). In what was probably the Third Interglacial (Sangamon) this water rat occurred in the Texas panhandle and in central Kansas (Meade, 1952; Hibbard, 1943). This rodent is also known from the Pleistocene of Pennsylvania (Hibbard, 1955c), where it presumably lived during an Interglacial interval. Another 


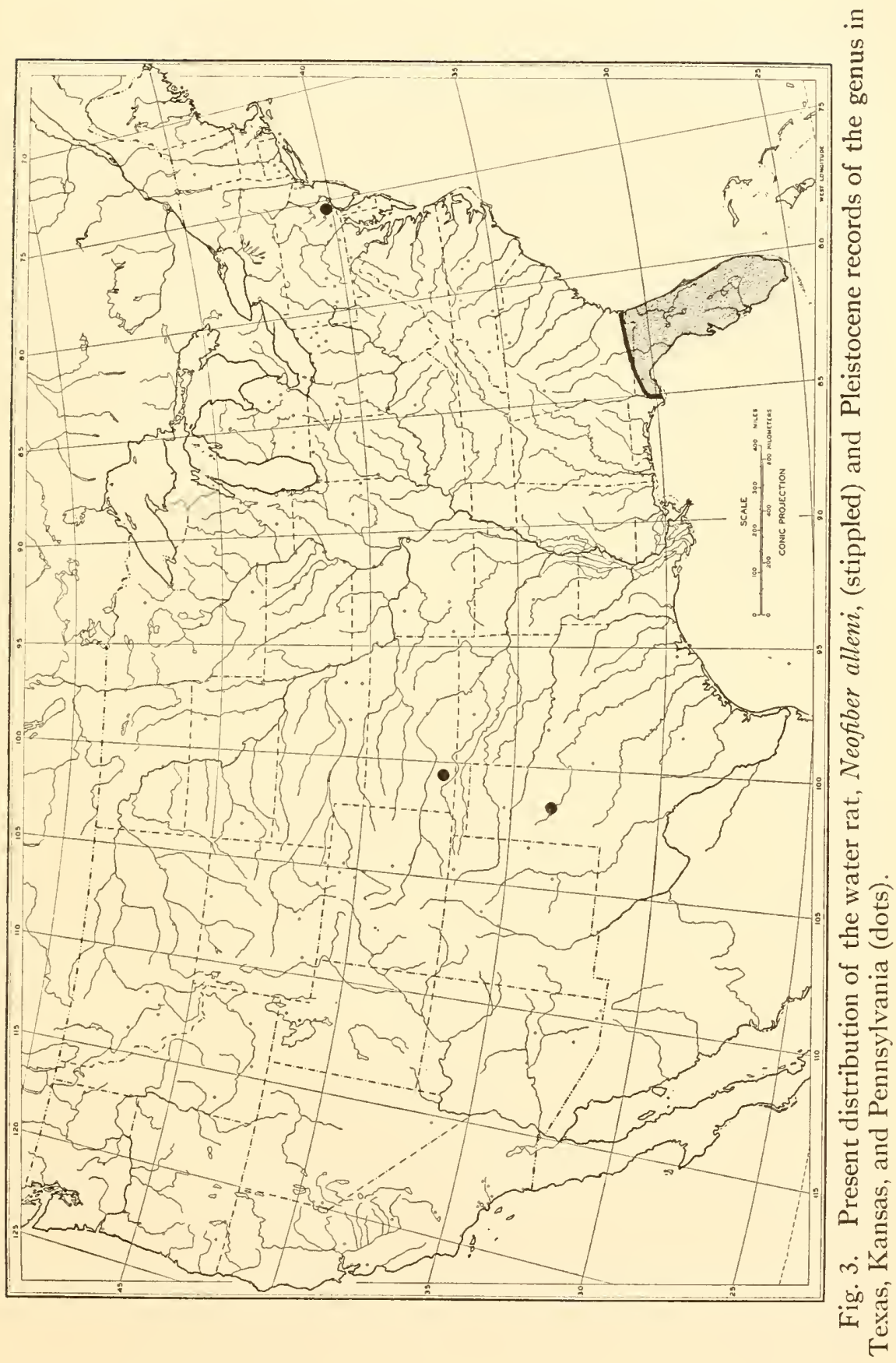


significant distribution is that of an extinct bog lemming (Synaptomys australis), which is known from the Pleistocene of Florida (Sherman, 1952) and from the Jinglebob fauna (Sangamon) of southwestern Kansas (Hibbard, 1955b).

Ground sloths, which presumably depended on trees for browsing, have been recorded from various localities in the present grasslands. Paramylodon is known from the Jinglebob (Sangamon) fauna of southwestern Kansas, where its fossils are associated with pine (Pimus) and Osage orange (Machura) pollens (Hibbard, 1955b). This sloth is also known from various localities in Colorado, Nebraska, and Texas in the area of the present grasslands, and Nothrotherium is known from such presently arid grasslands as the Big Bend region and panhandle of Texas (Hay, 1924).

Tapirs (Tapirus) are even more indicative of forests than ground sloths. These have been recorded from the present grasslands in north central Oklahoma and as far west as El Paso, Texas (Hay, 1924) and southwestern Oklahoma (Hibbard, 1957). A mandible in the Centennial Museum, Texas Western College, from a cave in the Hueco Mountains, Texas, is not permineralized and possibly represents a late occurrence of the tapir in this presently arid and treeless region (W. S. Strain, oral communication).

The preceding evidence implies that vastly different conditions prevailed at times during the Pleistocene, where grasslands exist today. It seems reasonable to hypothesize that under the vast shifts of climatic regimes that characterized the Pleistocene a wide spectrum of conditions from moist to arid might be expected to have existed in the present grasslands in various combinations with temperature conditions.

\section{Relations of the Floridian Vertebrates}

The present Floridian fauna includes various animals that have been there for a long time, including some that have their nearest living relatives in eastern Asia, but this circumstance is not pertinent to the present discussion except as it indicates the long-continued existence in the Southeast of a faunal center of distribution and dispersal. The Floridian fauna also includes a considerable element of species that belong to groups with centers of distribution in the Southwest, where they are generally adapted to more xeric conditions than exist today on the coastal plain. The presence of 
this western element in Florida suggests past climatic fluctuations on the coastal plain that favored eastwarl spread. This element includes: Scaphiopus holbrooki, Bufo woodhousei, Microhyla carolinensis, Sceloporus undulatus, Cnemidophorus sexlineatus, Crotalus adamanteus, Speotyto cunicularia, Aphelocoma coerulescens, Peromyscus polionotus, $P$. gossypinus, Reithrodontomys humulis, $R$. fulvescens, Geomys pinetis, and Neotoma floridana. Some of these (e.g., Microhyla carolinensis and Peromyscus gossypinus) have become adapted to high-moisture situations of the coastal plain. Others have tended to retain their xeric adaptations and exist today in the most xeric situations available. The most extreme examples of the latter group include Scaphiopus, Cnemidophorus, Aphelocoma, and Peromyscus polionotus.

\section{Relictual Distributions in the Southern Grasslands}

Present relictual occurrences of forest plants and animals argue against the past stability of the grasslands. The isolated populations are reasonably assumed to be remnants of the widespread populations of post-Wisconsin time and inclicate greater, or at least more effective, moisture in the not distant past than prevails in the grassland today. The sugar maple group (Acer saccharum and others) is an important example because it is representative of a group with Mexican disjuncts that was regarded by Braun (1955) as having been separated since pre-Pliocene times. Martin and Harrell (1957) showed the occurrences of Acer skutchii in Mexico and Guatemala and the general distribution of the saccharmm group in the eastern United States, but they overlooked a highly significant group of relictual populations in Texas and western Oklahoma. These are shown in Fig. 4 along with an approximation of the western limits of this group in the eastern forest and the approximate eastern limits of the representative of this group (A. grandidentatum) in the southern Rocky Mountain chain. In Oklahoma, these relicts occur in the Vichita Mountains in the southwestern part of the state and in Caddo Canyon, Caddo County. In Texas, there are relict populations along the southern escarpment of the Edwards Plateau (Sargent, 1922). Sugar maples (identified as A. grandidentatum) occur in moist ravines in the higher mountains of trans-Pecos Texas (Sargent, 1922, and author's observations). It does not seem possible that the Oklahoma and Texas populations are relicts of a pre-Pliocene dis- 

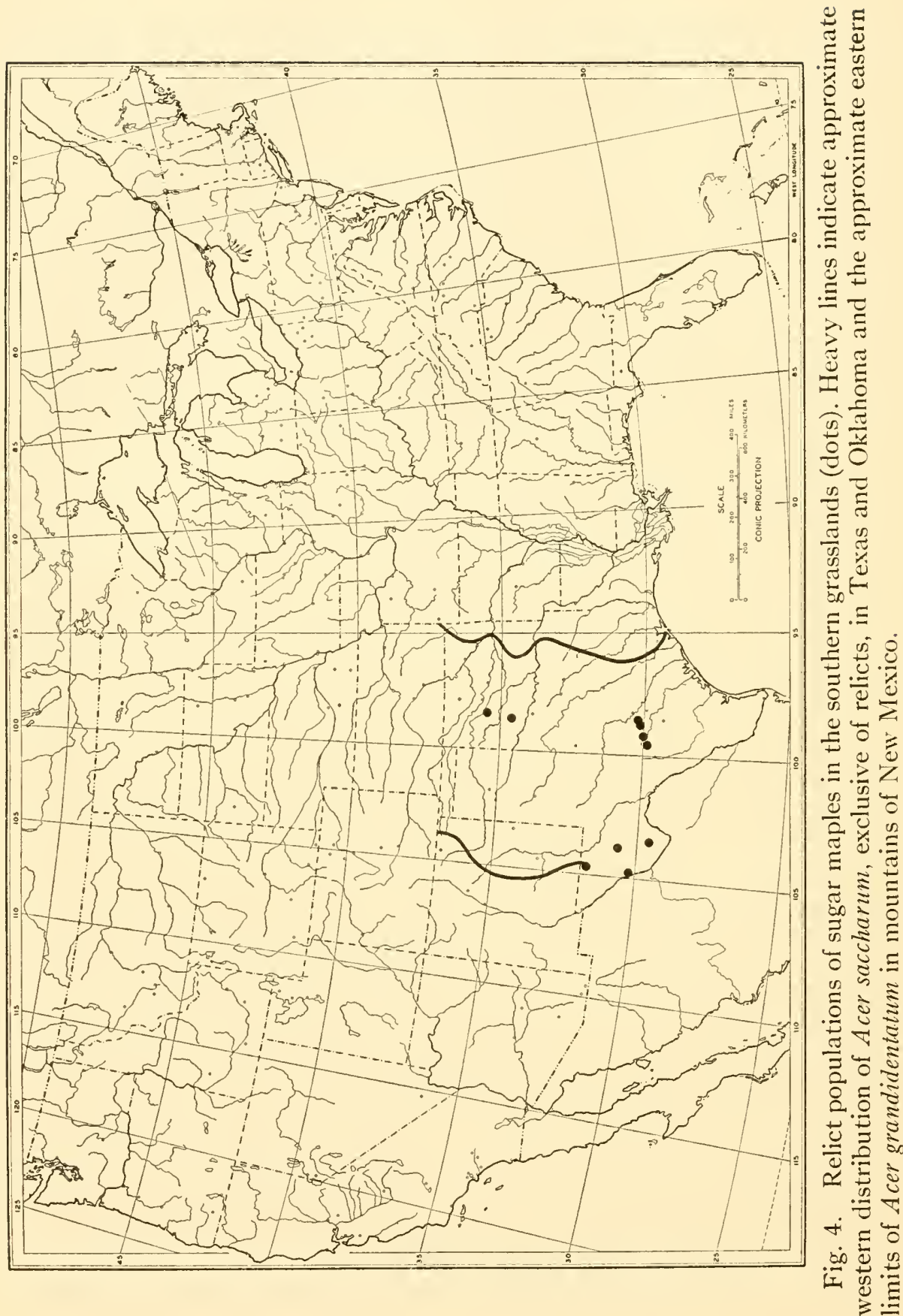
tribution. They are taken, instead, to indicate a Wisconsin or post-Wisconsin distribution that could have connected the Mexican and eastern populations of sugar maples.

The bald cypress (Taxodium distichum) occurs as far west in Texas as the Devil's River (Sargent, 1922). Isolated palmetto (Sabal minor) plants are found on the Edwards Plateau west of Austin, Texas. One of these was found on the floodplain of Bear Creek, Hays County, when we went to investigate the locality at which an isolated specimen of Microhyla carolinensis had been collected far west of the continuous range of this eastern species of frog. The loblolly pine (Pinus taeda) grows on sandy soil over an extensive disjunct area in Bastrop County, Texas. A disjunct population of the greenfrog (Rana clamitans) lives along Alum Creek in this same area. A western montane species, the piñon pine (Pimus edulis) has disjunct growths as far eastward as Kerr County on the Edwards Plateau.

The piñon mouse (Peromyscus nasutus), which is distributed in the piñon belt and above in the southern Rocky Mountain chain, is represented by a disjunct sibling species ( $P$. comanche) in the cedar (Juniperus) forests of the Palo Duro Canyon and other canyons along the escarpment of the High Plains in the Texas panhandle. The two are separated today by more than 100 miles of arid grassland (Blair, 1943). The brush mouse (Peromyscus boylei), which is associated with montane forests in the west, has relictual populations (Fig. 5) much farther east than the preceding species. The most eastern of these is in the Ozarks and Ouachita Mountains of Oklahoma, Arkansas, and Missouri and is so little differentiated that it has been treated as the same subspecies as in western Texas. An eastern forest species that shows relictual populations deep into the present grasslands is the pine vole (Pitymys pinetorum) which has a close relative ( $P$. quasiater) in eastern Mexico. The map of the distribution of these voles drawn by Martin and Harrell (1957) gives an erroneous impression of the relation of the eastern species to the grasslands, because the range of this species is drawn to include these relicts. Actually (Fig. 6), the westward distribution of the main body of the population of this species ends at or inside the border of the eastern forest in eastern Texas and Oklahoma. The relictual populations near Kerrville on the Edwards Plateau of Texas (Bryant, 1941) and in the Wichita Mountains, Oklahoma (Blair, 


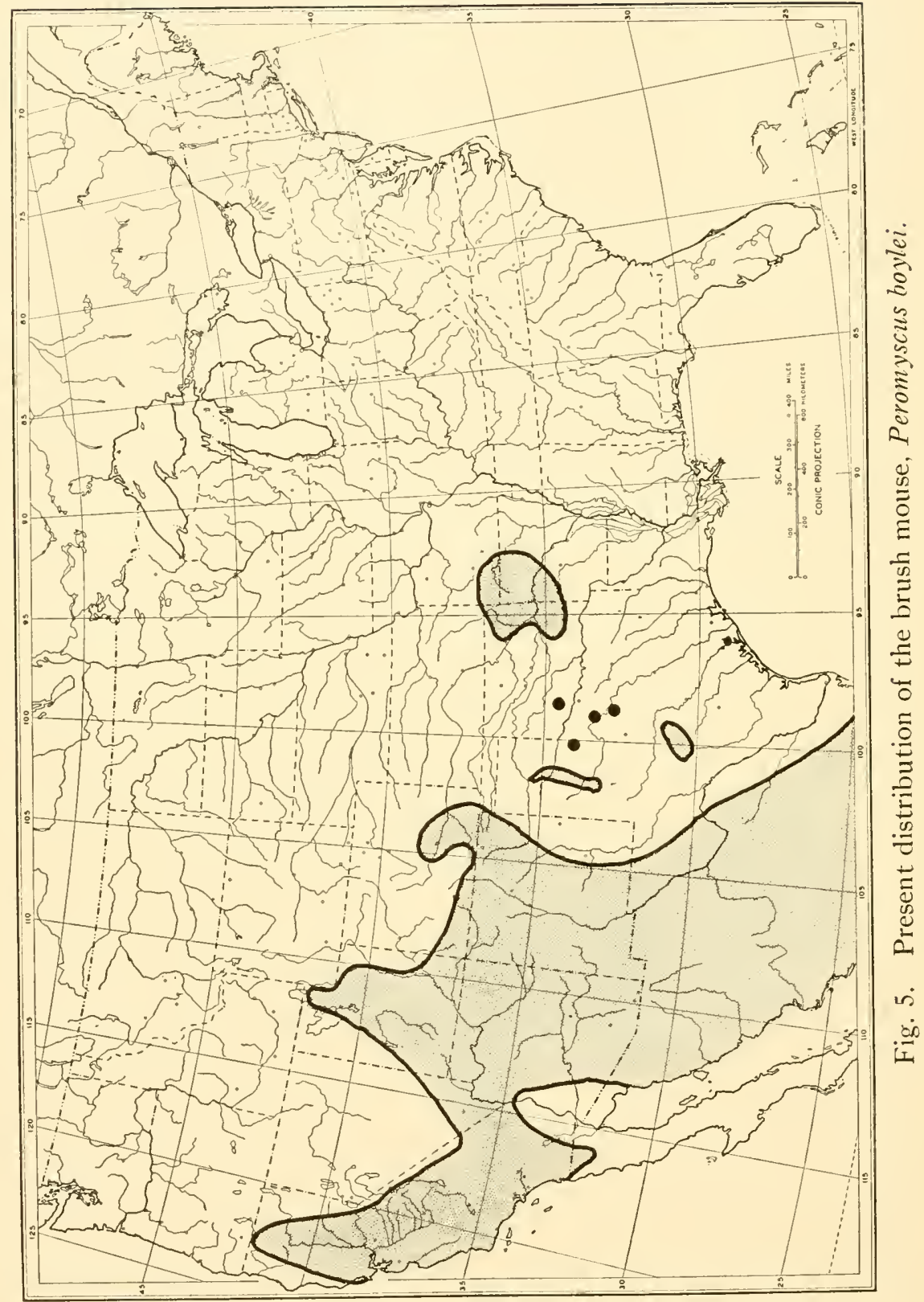




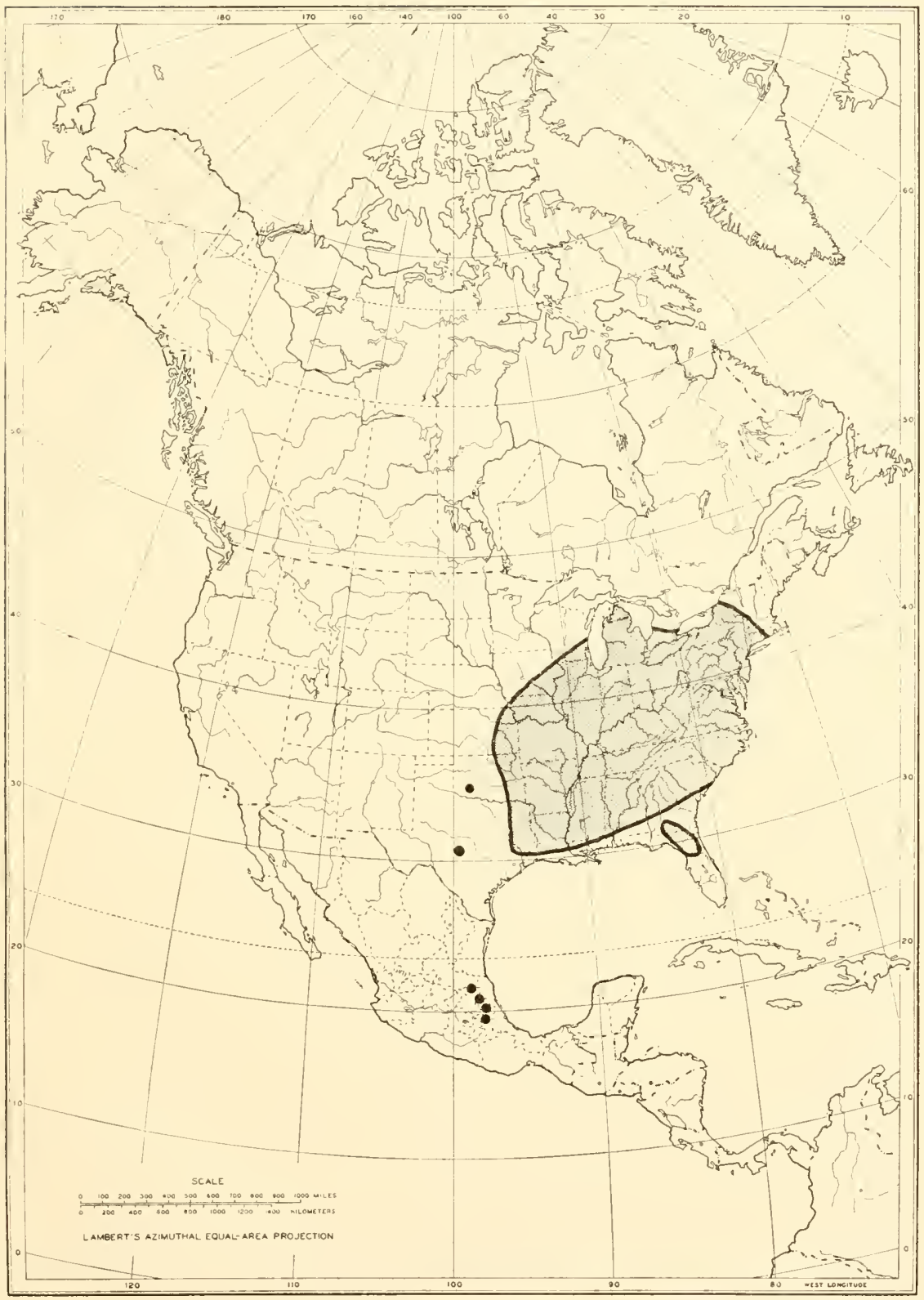

Fig. 6. Present distribution of pine voles, Pitymys: P. parrulus in southeast; $P$. pinetorum in eastern United States, with relicts in Texas and Oklahoma; and relict $P$. quasiater in Mexico. 
1939) live about 200 miles farther west. This species is closely associated with forests throughout its range, and the relicts in Texas and Oklahoma as well as the Mexican relicts must have reached their present locations by way of forests.

The neotenic salamanders of the genus Eurycea on the Edwards Plateau of Texas appear to be closely related to similarly adapted E. tynerensis of the Ozarks and thus indicate a southward as well as westward shift of conditions favorable for this group. The two groups are separated today by a distance of over 400 miles. In both areas, these salamanders are restricted to cool springs in forested regions. Another plethodontid genus (Plethodon) shows an interesting but more complex pattern of relictual distribution (Fig. 7). A population of $P$. glutinosus on the Edwards Plateau is disjunct from the main distribution of this eastern species, which reaches into eastern Texas. On the Edwards Plateau this species is found in relatively moist ravines and around springs or entrances to caves. Plethodon ouachitae of Rich Mountain in southwestern Arkansas appears to be a relict of an Appalachian group (Dunn and Heinze, 1933). Another species of this genus ( $P$. neomexicanus) occurs in spruce-fir forests of the Jemez Mountains of northern New Mexico (Stebbins and Riemer, 1950). This species is described as "close to Plethodon cinereus of eastern United States and Canada." There are disjunct populations of $P$. cinereus in the Ozarks and in eastern Missouri, but the main body of the population is east of the Mississippi River. Stebbins and Riemer surmised that southward dispersal through the Rocky Mountains accounted for the New Mexico population, but dispersal directly across Oklahoma in the Wisconsin seems a more plausible explanation. The genus occurs along the Pacific Coast from northern California to British Columbia, and there is a relict species in northern Idaho. Another plethodontid genus with wide disjunctions is Aneides. One species lives in the Appalachian region of the eastern United States, one in the Sacramento Mountains of southern New Mexico, and three along the Pacific Coast. Lowe (1950) hypothesizes geographical separation of the New Mexico species ( $A$. hardyi) during early Pliocene. We suggest alternatively that a connection between it and the eastern population could have existed as recently as the late Pleistocene.

An area on the floodplain of the San Marcos River in Gonzales County, Texas, has an assemblage of eastern coastal plain plants 


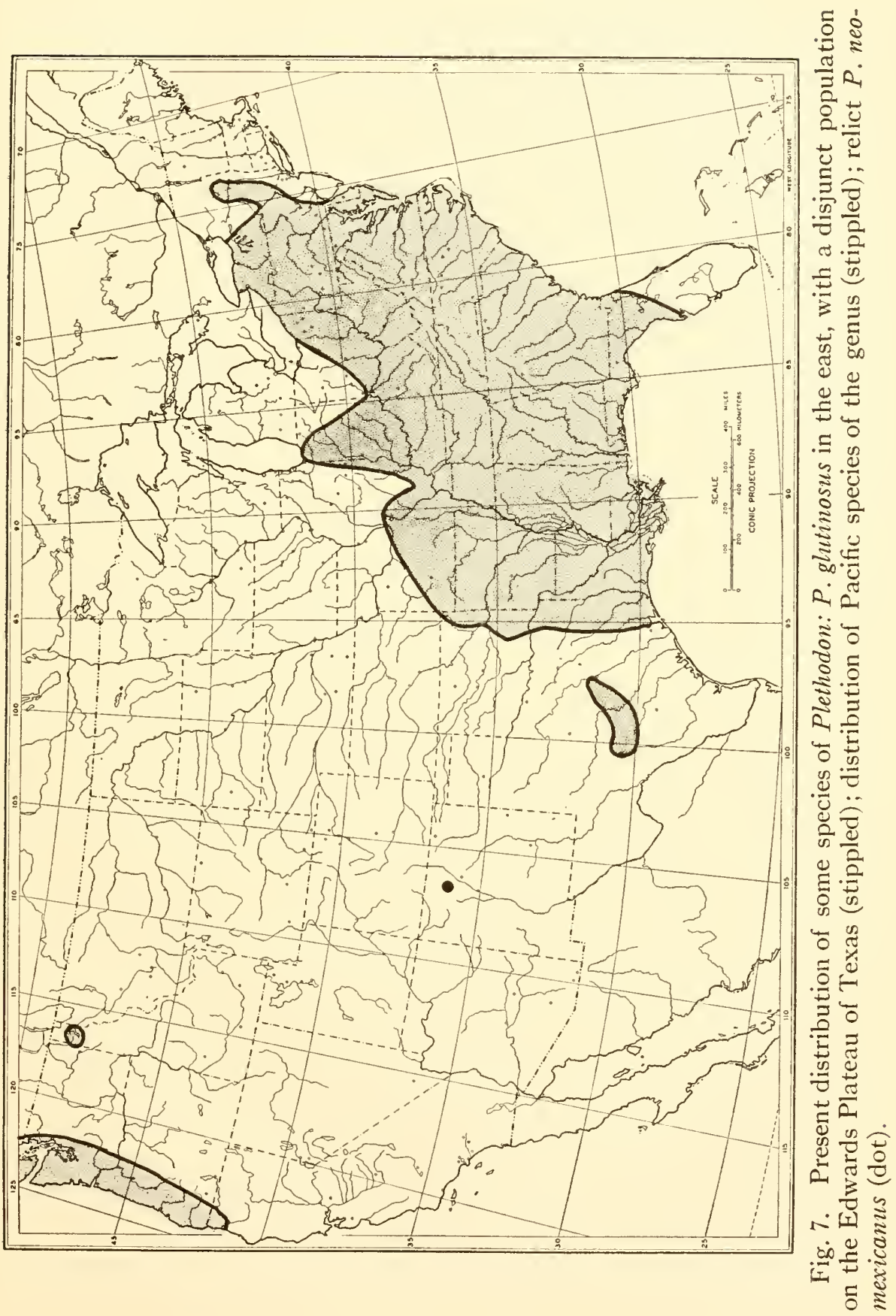


and animals that are disjunct from their main populations. The palmetto (Sabal minor), burr oak (Quercus macrocarpa), wax myrtle (Myrica cerifera) and ash (Fraxinus) are representative of a rather large number of plants in this category. The vertebrates include the canebrake rattlesnake (Crotalus horridus), banded watersnake (Natrix sipedon), and narrow-mouth frog (Microhyla carolinensis).

\section{PRESENT PATTERNS OF DISTRIBUTION}

The vertebrate groups of the coastal plain under consideration are characterized with few exceptions by a relative scarcity of closely related sympatric species and by a rather large number of allopatric species or populations that show evidence of relatively recent disjunction. Among the 40 genera of mammals, only seven include species that are sympatric on the coastal plain. The best represented genus is Peromyscus, with five species that represent three subgenera. The lizard fauna is sparse, with only eight genera, of which three, Sceloperus, Eumeces, and Ophisaurus, include species that are sympatric there. On the coastal plain, there are 25 genera of snakes of which nine there include sympatric species, with the largest representation in the genus Natrix. Four of the 13 genera of turtles include species that are sympatric on the coastal plain. Five of the seven genera of anurans include species that are sympatric on the coastal plain, but only Rana and IIyla, which have their United States center of distribution on the plain, include several species that are broadly sympatric there. Six of the 12 genera of urodeles include species that are sympatric on the coastal plain.

If the urodeles are excluded from the tabulation the some 40 cases of allopatry, secondary interbreeding, or narrow sympatry indicative of past separation into east and west populations outnumber the cases indicative of north-south clisjunction in a ratio of more than seven to one. These east-west disjunctions follow a few general patterns. One pattern involves present limitation of the disjunct populations to forests. One example is that of Pitymys (Fig. 6), which was mentioned earlier. Another example is furnished by the flying squirrel (Glancomys volans), which ranges west to the border of the eastern deciduous forest and has a disjunct subspecies in the mountains from Chihuahua to Honduras (Martin and Harrell, 1957). The opossum (Didelphis marsupialis) shows evidence of secondary interbreeding of previously disjunct populations in 
southern Texas (Blair, 1952). Peromyscus gossypinus of the coastal plain and $P$. leucopus overlap in a generally narrow zone along the border of the coastal plain and along the deciduous forest border in eastern Texas and Oklahoma (Osgood. 1909; McCarley, 1954). The present distribution of this species pair can be explained as a result of the westward and northward spread of the coastal-plain-adapted gossypinus from a refuge in Florida and the northward and eastward spread of leucopus from a Mexican refuge, where it would have been adlapted to less mesic upland forests. The remarkable call "races" of the gray treefrog (IIyla versicolor) described by Blair (1958) imply the splitting of this species into three populations along northsouth axes, with subsequent spread to bring about the present relationships.

Other examples of forest-restricted isolates, discussed by Martin and Harrell (1957), include: (1) the red-bellied snake (Storeria occipitomaculata), which is widely distributed in the eastern forest with relicts in the central grasslands and in Mexico, (2) the yellowlipped snakes, which comprise Rhadinea flavilata to the east on the coastal plain and a closely related species, $R$. laureata, disjunct in Mexico, and (3) the barred owl (Strix varia), which has a MexicanCentral American disjunct.

The largest group providing evidence of past or present disjunction into eastern and western populations is the one in which the eastern population inhabits forests and the western population is adapted to, or tolerant of, grasslands. The members of some of these species pairs meet or approach at or near the forest boundary in eastern Texas and Oklahoma. Two hylid frogs, Pseudacris nigrita and $P$. clarki, which are interfertile in the laboratory, overlap narrowly along this boundary, where they show a complex set of isolation mechanisms (Lindsay, 1958). Two narrow-mouth frogs, Microhyla carolinensis and $M$. olivacea, overlap narrowly in this same area, where they hybridize to a limited extent and where their isolation mechanisms are apparently being reinforced (Blair, 1955). Two populations of toads referred to by some (as by A. P. Blair, 1941) as an eastern species, Bufo fowleri, and a western species, $B$. woodhousei, meet and freely interbreed, secondarily, in this same area (Meacham, 1958). The eastern pine snake (Pituophis melanoleucus) and the western bullsnake ( $P$. catenifer) either approach range or interbreed in southeastern Texas (Smith and Kennedy, 
1951). The pigmy rattlesnakes comprise an eastern, forest species, Sistrurus miliarius, a grasslands species, S. catenatus, and a disjunct species, S. ravus, in eastern Mexico (Smith and Taylor, 1945). The eastern box turtle (Terrapene carolina) and western box turtle ( $T$. ornata) overlap narrowly along the forest border. Two harvest mice, the eastern Reithrodontomys humulis and the western $R$. montanus, approach one another but apparently do not meet along the forest horder. The ranges of two packrats, the eastern Neotoma floridana and the western $N$. micropus, interdigitate in the broad forest-grassland ecotone. Two skinks, the eastern Eumeces anthracimus and the western E. septentionalis, overlap in eastern Oklahoma and Kansas. An eastern newt, Diemictylus viridescens, ranges west to the edge of the forest and is separated by a grassland gap from the related species D. meridionalis of southern Texas and northeastern Mexico.

The group of species pairs discussed above interpret as having reached their present distributional relationships through postWisconsin spread to the margin of their respective environments, where they have attained contact or near contact with their sibling species. Another sizable group of species pairs shows a quite different pattern in that the Mississippi Embayment, deep within the Austroriparian forest, is involved in their separation. The species pairs in this group have mostly remained widely disjunct. Two pairs appear to be limited by soil types. An eastern pocket gopher, Geomys pinetis, occurs on sandy soil of the coastal plain to the east of the embayment, and a western species, G. bursarius, occurs on sands to the west of it. The alluvial soils of the embayment appear to be the ecological factor separating the present ranges of these allopatric species. Two species of spadefoots (Scaphiopus) have essentially similar distributions. The eastern $S$. holbrooki and western S. hurteri have been shown to be interfertile in the laboratory (Wasserman, 1956). A broader hiatus, of forested land, separates two chorus frogs, Pseudacris streckeri and P. ornata (Fig. 8). P. streckeri occurs west of the forest border, which imposes a limit to its eastward distribution. P. ornata ranges west on the coastal plain to the Mississippi Embayment. There is little differentiation between the two in mating call or morphology. Hybrids between them have been produced, but one attempted backcross of a male hybrid to streckeri failed (Mecham, 1957). Two species of Rana have a rather similar distribution: The eastern gopher frog ( $R$. capito) ranges west on the 
coastal plain to the Pearl River; the western crawfish frog $(R$. areolata) is abundant on the coastal prairie in eastern Texas and ranges northeastward in the grasslands but is limited in its eastward distribution by the forest.

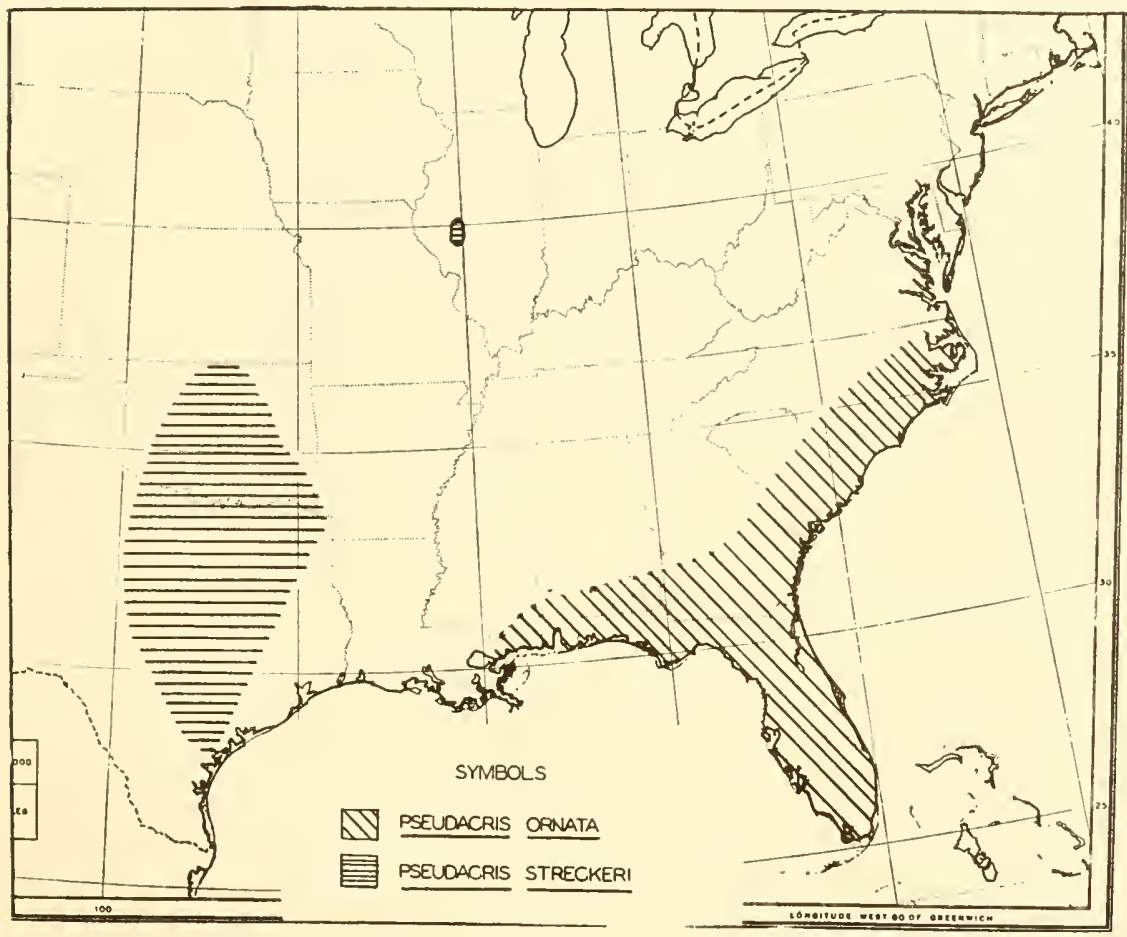

Fig. 8. Present distributions of two closely related, allopatric species of chorus frogs.

Both forest and grassland occur in the hiatus between the eastern and western populations of the indigo snake (Drymarchon corais). The eastern population occurs on the coastal plain east of the Mississippi Embayment; the western population ranges from the area of Corpus Christi in Texas southward into northern South America. The eastern black-headed snake (Tantilla coronata) occurs cast of the embayment, and its western counterpart, T. gracilis, lives west of the forest border. Eastern and western populations of Amphiuma, distinguished by a difference in the number of toes, meet at the Mississippi Embayment where they may act as species 


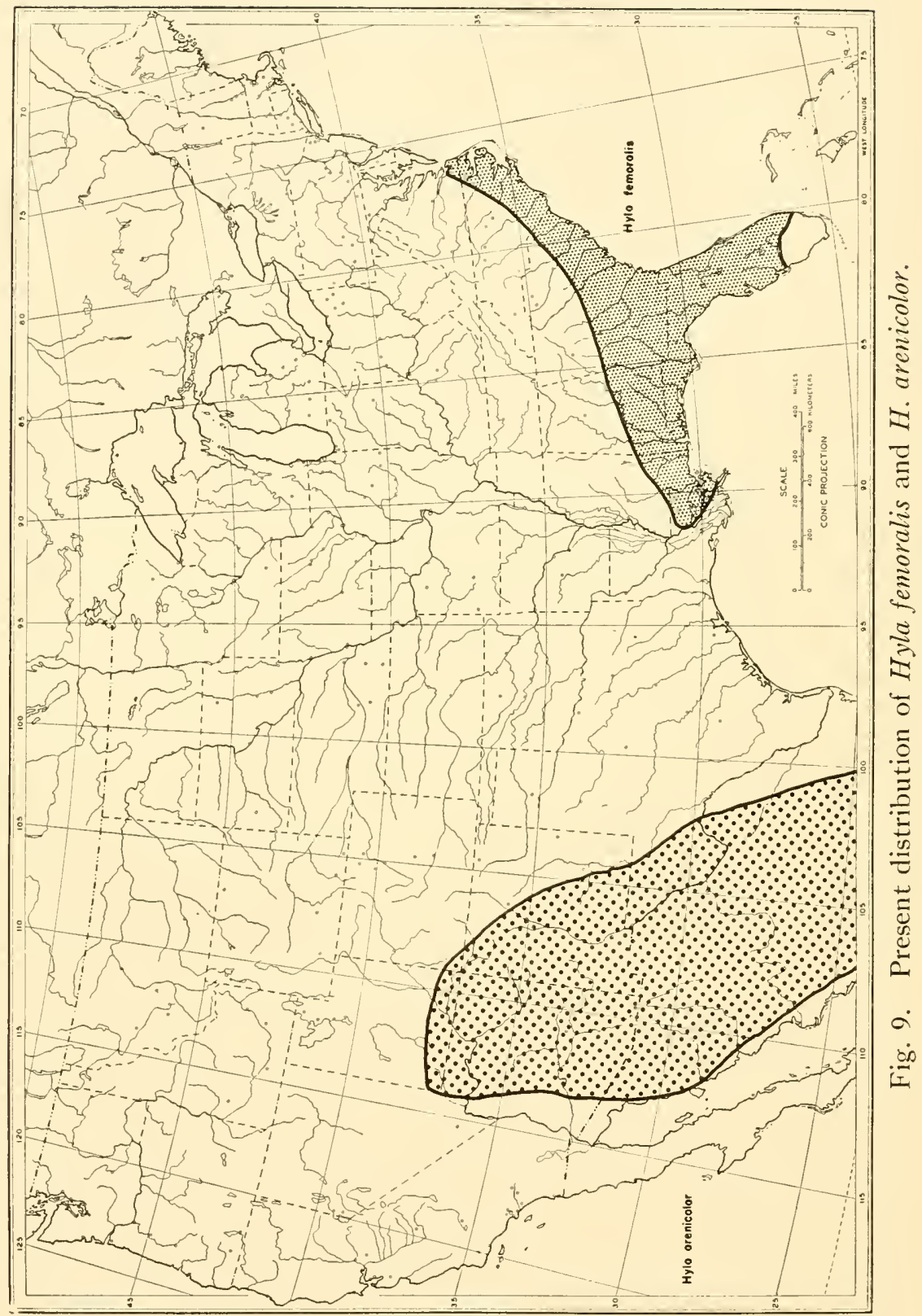


(see Baker, 1947) or at most secondarily interbreed. A very wide disjunction exists between an eastern treefrog, IIyla femoralis, and the apparently related $H$. arenicolor of the west (Fig. 9): $I$. femoralis occurs on the coastal plain west to the embayment and II. arenicolor ranges westward from trans-Pecos Texas, which means there is a gap of some 700 miles between the ranges.

Another disjunction involving the Mississippi Embayment and a forest gap is that of the diamondback rattlesnakes. The eastern diamondback ( $C$. adamanteus) is limited on the west by the embayment; the western diamondback ( $C$. atrov), with a wide range in northern Mexico and the southwestern United States has its eastward distribution limited at the forest border. An apparently isolated (relict) population of this species is known from the vicinity of Tehuantepec, Oaxaca, Mexico (Stebbins, 1954). A third isolate, C. ruber, in southern California and Baja California, possibly stems from a Pleistocene isolate in Baja California (see Gloyd, 1940).

The gopher turtles (Gopherus) also comprise three isolates (Fig. 10). The eastern species, $G$. polyphemus, ranges on the coastal plain west to the vicinity of the Mississippi Embayment. Another, $G$. berlandieri, occurs in northeastern Mexico and southern Texas and is separated from the eastern species by a gap involving both grassland and forest. The third disjunct, $G$. agassizi, ranges from northem Sonora through western Arizona and southeastern California to southern Nevada.

The cricketfrogs (Acris) have overlapping ranges that involve the Mississippi Embayment and the margin of the coastal plain. The eastern coastal plain species, A. gryllus, is limited westward by the embayment. The western species, $A$. crepitans, overlaps the range of the eastern species just east of the embayment and along the Fall Line (see Blair, 1958). The distributional relationships of these frogs are comparable to those of the Peromyscus leucopus group except for the limitation of the eastern population by the embayment, and they are interpreted similarly as the result of post-Pleistocene spread from Floridian and Mexican refuges.

The distributional pattern of the Bufo americanus group of toads is a more complex variation of the same general pattern (Blair, 1958). The eastern coastal plain form, B.terrestris, is limited westward by the Mississippi Embayment. A population to the north of the Fall Line, B. americamus, is interpreted as having spread from a 

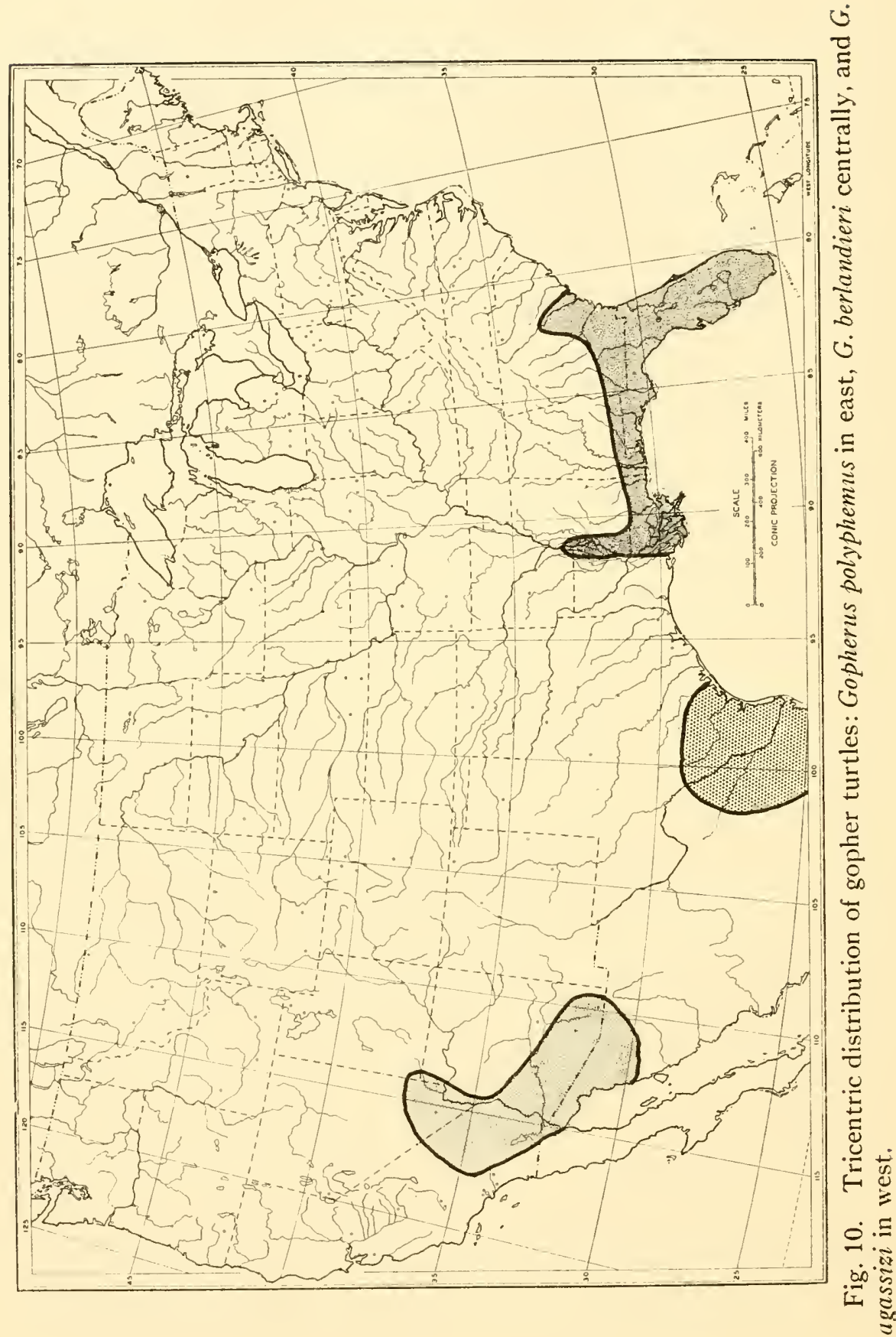
southwestern refuge, leaving a relict, $B$. houstonensis, on the eastern Texas coast.

The Mississippi Embayment also limits the westward distribution of five species of anurans that have no western counterparts. These are the oak toad (Bufo quercicus), bird-voiced treefrog (Hyla phaeocrypta), barking treefrog (H. gratiosa), little grass frog (H.ocularis), and river frog (Rana heckscheri).

The Peromyscus maniculatus group of mice, with one of the most complex distributional patterns of any North American vertebrate (Fig. 11), shows east-west speciation on the coastal plain (Blair, 1950). The beach mouse ( $P$. polionotus), which occurs on the coastal plain east of Mobile Bay, on morphological evidence is derived from the grassland-adapted ecotype of the deer-mouse ( $P$. maniculatus), which today ranges southward into south-central Texas (Fig. 11). The beach mouse presumably originated through an eastward dispersal along Gulf Coast beaches and subsequent isolation in Florida. The forest-adapted ecotype of the deer-mouse living today in the southern Appalachians presumably moved south during glacial stages into the area that is today a gap between the range of the beach mouse and that of its Texas progenitor.

The brown water snake (Natrix taxispilota), which ranges from Florida into Mexico, has a disjunct population in southern Mexico (Smith and Taylor, 1945). The rat snake (Elaphe obsoleta) shows evidence of secondary interbreeding on the Edwards Plateau in Texas. Turtles of the genus Graptemys are of dubious value here because of lack of agreement among specialists on the group. As mapped by Carr (1952) the range of $G$. pseudogeographica is mostly west of the Mississippi River, and that of G. geographica mostly east of it. The mud turtles, Kinosternon, are represented by two species in the eastern forest and three to the west of it (Cagle, 1957).

The bats have been omitted from the preceding discussion, but they too show east-west disjuncts across the coastal plain. Examples are found in the genera Tadarida, Eumops, Corynorhinus, Pipistrellus, Dasypterus, and Lasiurus. In Lasiurus, the pattern of distribution is comparable to that of the Peromyscus leucopus group: the western $L$. borealis overlaps the coastal plain $L$. seminolus along the forest border in the west and along the Fall Line.

Some species of vertebrates, showing no evidence of previous disjunction, range today completely across the Gulf Coast, and conse- 


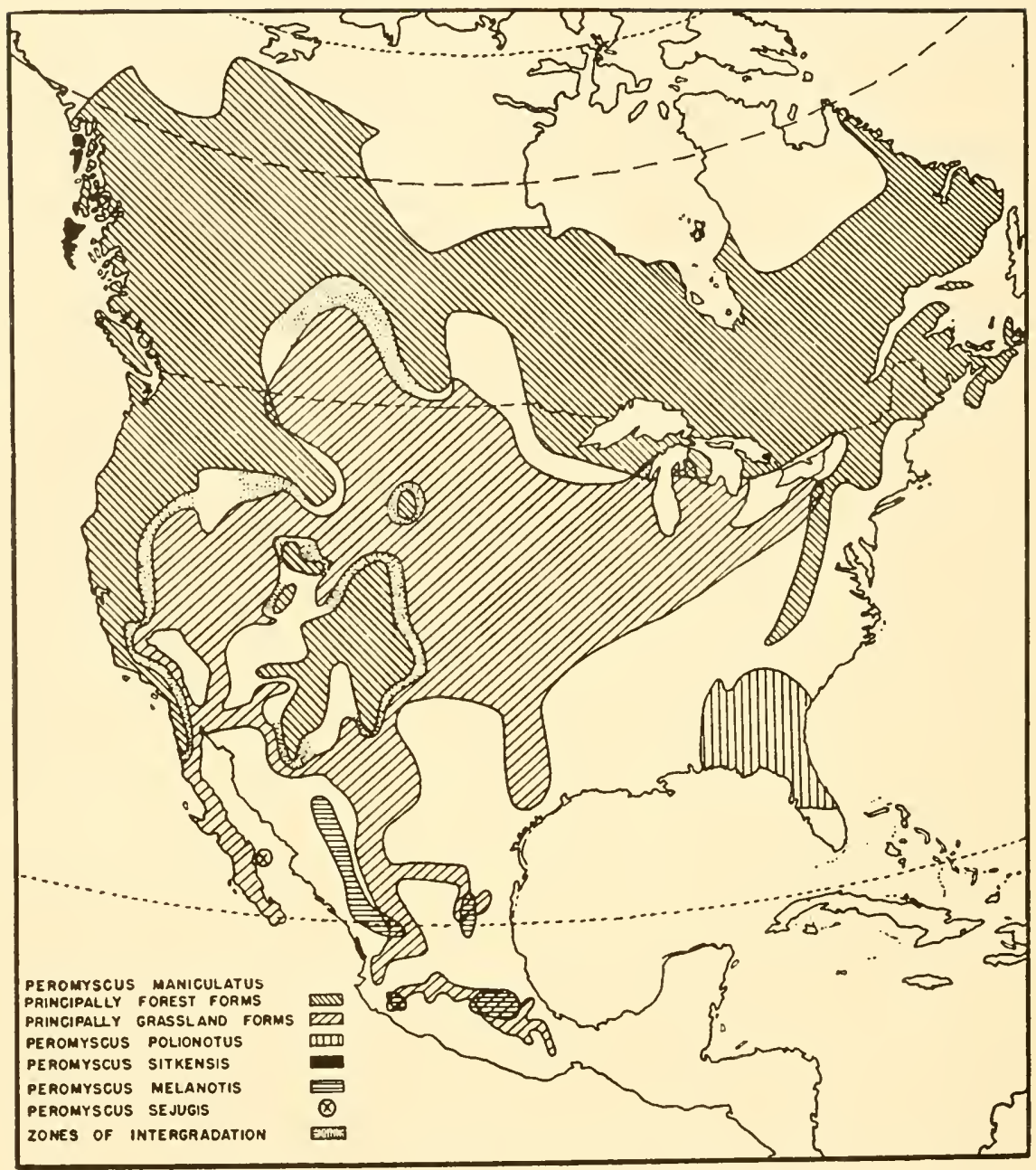

Fig. 11. Distribution of the Peromyscus maniculatus species group of mice (from Blair, 1950).

quently across the central area from which warmth-adapted species are indicated to have been driven. Such species as the cotton rat (Sigmodon hispidus), cottontail (Sylvilagus floridanus), coachwhip (Masticophis flagellum), and green treefrog (Hyla cinerea) are representative. Their wide distribution can be explained as having been attained by spread from an eastern or western refuge or by such a rapid spread from both refuges that contact of populations and interbreeding were reestablished before marked differentiation 
had occurred. Their existence does not controvert the evidence presented above of extensive east-west fragmentation of ranges among warmth-adapted coastal plain vertebrates in the Pleistocene.

Instances of north-south fragmentation of ranges involving coastal plain species, exclusive of the urodeles, are contrastingly scarce. The southern rough green snake (Opheodrys aestivus) and northern smooth green snake $(O$. vernalis) constitute one example. However, relicts of the northern species in central and southeastern Texas (Davis, 1949) indicate a very different past distribution and suggest the possibility that the present distribution is derived from an east-west disjunction comparable to that postulated for the Peromyscus leucopus group. In the common water snake (Natrix sipedon) a freshwater ecotype shows secondary interbreeding with a salt-marsh ecotype around the Gulf Coast. Pettus (1956) hypothesized continuous distribution of the salt-marsh type in the Pleistocene and a southern refuge or refuges for the freshwater type. IIyla andersoni of the New Jersey pine barrens is an apparent relict of a formerly more northern extension of $I I$. cinerea on the Atlantic coastal plain (see Blair, in press).

The Pseudacris nigrita group, with the most complex distribution pattern of any group of North American anurans, does show evidence of north-south speciation in the eastern United States. A small group of relicts of grasslands-adapted mammals in Mexico and on the Texas coast (Blair, 1954) is consistent with the thesis of southward displacement of cold climates and of the Arcto-Tertiary forest. In the east there are a few such relicts of groups that occur today in the northern United States. The spotted turtle (Clemmys guttata) occurs as a relict in northern Florida. A northern species of frog, Rana sylvatica, has left relict populations in northwestern Arkansas and in the Flint Hills of Kansas (Smith, 1950).

The distributional patterns of warmth-adapted vertebrates on the coastal plain as discussed above are overwhelmingly indicative of east-west fragnentation of ranges as the initial agent of geographic speciation in this fauna. The variations in distributional patterns shown by allopatric populations undoubtedly reflect differences in ability to reoccupy territory after the initial disjunction, differences in the time that has elapsed since the initial separation, and other more subtle factors. It might be argued that the east-west speciation simply reflects adaptation to forest and grassland environments. 
However, evidence inconsistent with such an explanation is provided by the numerous hiatuses between eastern and western populations that involve segments of one or the other environments or segments of both.

Sympatric distributions of coastal plain groups may trace back to the same kind of east-west disjunction exhibited by the allopatric populations, but such history is difficult to demonstrate. McConkey (1954) has theorized that the three species of legless lizards (Ophisaurus) of the coastal plain originated through east-west splitting in the Third Glacial (Illinoian) and through subsequent isolation of the third population on Florida islands in the Third Interglacial (Sangamon).

\section{DISTRIBUTIONAL PATTERNS OF ANURANS AND URODELES}

A comparison of the distributional patterns of anuran and urodele amphibians in the eastern United States illustrates as clearly as any possible documentation the postulated Pleistocene history of the coastal plain biota. The anurans are mostly a warmth-adapted group, with more species on the coastal plain than anywhere else in the United States. Ten of the 24 coastal plain species or species groups show evidence of past or present disjunction into eastern and western populations, as discussed in the preceding section. Seven of the 10 have their eastern population limited to the coastal plain. The other three, Bufo woodhousei, Pseudacris nigrita, and IIyla versicolor, range widely in the eastern United States. Six of the remaining 14 species are limited to the coastal plain east of the Mississippi Embayment and are presumed to have spread to their present limits from a Pleistocene refuge in Florida. Of the eight remaining species, only three are limited to the coastal plain. Two of these, Hyla cinerea and $H$. squirella, range across the coastal plain from the Atlantic to Texas, and the range of the third, Rana grylio, stops short of the forest border in eastern Texas. The five remaining species, Hyla crucifer, Rana pipiens, R. palustris, R. clamitans, and $R$. catesbeiana, all range northward into Canada, and on the basis of their present distribution it seems likely that they could have existed continuously across the coastal plain under Pleistocene Glacial-stage conditions. North-south speciation in the anurans is limited to the splitting off of IIyla andersoni and the speciation in the Pseudacris nigrita complex discussed earlier. 
The urodeles, by contrast with anurans, are typically a cool- or cold-adapted group. The center of distribution of the large family Plethodontidae, which includes a majority of the urodeles of the eastern United States, is in the Appalachian highlands in remnants of the Arcto-Tertiary forest, which the evidence shows to have shifted southward in the Glacial stages of the Pleistocene. As might be expected, there is for this group no strong pattern of east-west disjunction comparable to that of the warmth-adapted anurans. Of some 56 species and species groups of urodeles in the eastern United States, only 23 occur on the coastal plain, and only 11 are restricted there. Only two of the coastal plain group. Diemictylus and Amphiuma, show evidence of east-west disjunction, as earlier mentioned. The most obvious disjunctions in the eastern urodeles are ones that are attributable to the southward and westward spread of the ArctoTertiary forest and its urodele fauna under Glacial-stage climates and to the isolation of relictual populations under locally tolerable conditions, as the environment became warmer and dryer. This would explain the relict populations of Plethodon. Hemidactylium. and Eurycea in the Ozarks, of Plethodon and Eurycea on the Edwards Plateau, and of Aneides and Plethodon in the mountains of New Mexico. The absence of plethodontid relicts from the cloud forests of Mexico, discussed by Martin and Harrell (1957), would be expected if these animals stayed with the Arcto-Tertiary forest in the southern United States. The difference in the pattern of distribution of anurans and urodeles results, then, from the fact that the urodeles would have moved with the invading environment that fragmented anuran ranges. Amelioration of the environment that permitted reoccupation of the coastal plain by warmth-adapted anurans would have led to the observed disjunctions in urodele ranges. Unlike the situation in the anurans, there are numerous instances of northsouth or unoriented speciation in the urodeles of the eastern United States.

\section{SUMMARY}

A large body of paleontological and zoogeographical data support the thesis that present distributional patterns of the warmthadapted vertebrates of the Gulf of Mexico and southern Atlantic coastal plains reflect Pleistocene splitting of this faunal group into eastern and western populations. The agency of this splitting, as 
hypothesized by previous workers, is considered to be the southward shifting of climatic belts during the Glacial stages of the Pleistocene and the resultant enforced withdrawal of the warmth-adapterl biota into separate refuges in Florida and Mexico.

The evidence from fossil pollens and from plant macrofossils indicates that at times in the Pleistocene northern species of trees such as spruce, hemlock, fir, larch, and arbor vitae extended onto the Gulf and southern Atlantic coastal plains. Boreal mammals and a few fishes of northern affinity are known from Pleistocene deposits far south of their present distributions and as far south as southern Nuevo León in Mexico. Both the plant and animal fossils are indicative, then, of major ecological changes in the southern United States in the Pleistocene.

Evidence from various sources indicates that the southern grasslands have not acted as a continuous barrier to the exchange of forest biotas between the eastern United States and the Mexican highlands since their origins in the late Miocene and early Pliocene. The Pleistocene mammalian fauna of Florida includes various groups of South American origin, some of them forest types, that must have crossed the area of the present grasslands barrier, as their entry into North America would necessarily have followed the emergence of the Central American land bridge in the late Pliocene. Various Pleistocene fossils from the area of the present grasslands are indicative of greater moisture and of forests at times in this area in the Pleistocene. These include such indicators of extreme departure from present ecological conditions in the area as Neofiber in the Texas panhandle and Tapirus in trans-Pecos Texas. An impressive number of present day relicts of forest-adapted species in the grasslands also argues against past continuity of grassland in the area.

Present distributional patterns of coastal plain vertebrates indicate many east-west and very few north-south disjunctions. Some of these involve eastern, forest-adapted and western, grasslandsadapted populations, with the forest-grasslands boundary important in their present distributional relationships. Other patterns involve the Mississippi Embayment as a distributional boundary, and in this group the hiatus between eastern and western populations may include either forest or grassland, or both. Still other patterns involve eastern and western forest-adapted types, some of which have their western populations as relicts in the Mexican highlands. 
The fossil evidence of ecological change in the southern Initerl States during the Pleistocene and the evidence derived from the existing distributional patterns of vertebrates are consistent in indicating that the east-west splitting of the warm-adapted biota by the southward shift of colder climates and of the cold-adapted biotas has been the chief agency initiating speciation in this area. The urodeles of the eastern United States show very different distributional patterns from the anurans, because the conditions that fragmented the ranges of the warmth-adapted anurans promoted the southward and westward spread of the urodeles. Then, the conditions that permitted reoccupation of the coastal plain by the anurans would have forced northward and eastward the retreat of the urodeles.

\section{ACKNowledgment}

Base map for figures used with permission of University of Chicago. Base map for Figs. 1, 2, and 6, copyright 1937 by the University of Chicago. Base map used for Figs. 3, 4, 5, 7, 9, and 10, copyright 1938 by the University of Chicago.

\section{REFERENCES}

Adams, Charles C. 1902. Southeastern United States as a center of geographical distribution of flora and fauna. Biol. Bull., 3: 115-131.

Allen, Glover M. 1930. The walrus in New England. J. Mammal., 11: 139-145.

Baker, C. L. 1947. The species of amphiumae. J. Tenn. Acad. Sci., 22: $9-21$.

Berry, E. IV. 1907. Pleistocene plants from Alabama. Am. Naturalist, 41: 689-690.

Blair, Albert P. 1941. Variation, isolation mechanisms and hybridization in certain roads. Genetics, 26: 398-417.

Blair, W. Frank. 1939. Faunal relationships and geographic distribution of mammals in Oklahoma. Am. Midland Naturalist, 22: 85-133.

. 1943. Biological and morphological distinctness of a previously undescribed species of the Peromyscus truei group from Texas. Contribs. Lab. Vert. Biol., Univ. Mich. 24: 1-8.

1950. Ecological factors in speciation of Peromyscus. Evolution, 4: $253-275$.

1951. Interbreeding of natural populations of vertebrates. Am. Naturalist, 85: 9-30.

- 1952. Mammais of the Tamaulipan biotic province in Texas. Texas J. Sci., 4: 230-250.

. 1954. Mammals of the mesquite plains biotic district in Texas 
and Oklahoma, and speciation in the central grasslands. Texas $J$. Sci., 6: 235-264.

- 1955. Mating call and stage of speciation in the Microhyla olivacea-M. carolinensis complex. Evolution, 9: 469-480.

. 1958. Mating call in the speciation of anuran amphibians. $A m$. Naturalist, 92: 27-51.

- In press. Call structure and species groups in U. S. treefrogs (Hyla). Southwestern Naturalist.

Braun, E. Lucy. 1955. Phytogeography of unglaciated eastern United

States and its interpretation. Botan. Rev., 21: 297-375.

Brown, Clair A. 1938. The flora of Pleistocene deposits in the western

Florida parishes, West Feliciana Parish, and East Baton Rouge

Parish, Louisiana. State of Louisiana, Dept. Conservation, Geol. Bull., 12: 59-96.

Bryant, M. D. 1941. A far southwestern occurrence of Pitymys in Texas.

J. Mammal., 22: 202.

Cagle, F. R. 1957. Reptiles. In Blair, Blair, Brodkorb, Cagle, and Moore,

Vertebrates of the United States. McGraw-Hill, New York.

Carr, Archie. 1952. Handbook of Turtles. Comstock Publ. Assoc., Ithaca, New York.

Clements, Frederic E., and Ralph W. Chaney. 1937. Environment and life in the Great Plains. Carnegie Inst. Wash., Suppl. Publ. 24: 1-54.

Cushing, J. E., Jr. 1945. Quaternary rodents and lagomorphs of San Josecito Cave, Nuevo León, Mexico. J. Mammalogy, 26: 182-185.

Davis, J. H. 1946. The peat deposits of Florida. Their occurrence, development and uses. Florida Geol. Survey, Geol. Bull., 30.

Davis, W. B. 1949. The smooth green snake in Texas. Copeia, 1949: 233. Deevey, Edward S., Jr. 1949. Biogeography of the Pleistocene. Bull. Geol. Soc. Am., 60: 1315-1416.

-1950. Hydroids from Louisiana and Texas, with remarks on the Pleistocene biogeography of the western Gulf of Mexico. Ecology, 31: 334-367.

Dunn, E. R., and Albert A. Heinze. 1933. A new salamander from the Ouachita Mountains. Copeia, 1933: 121-122.

Findley, James S. 1953. Pleistocene Soricidae from San Josecito Cave,

Nuevo León, Mexico. Univ. Kan. Publ. Mus. Nat. Hist., 5: 633-639.

Frey, David G. 1951. Pollen succession in the sediments of Singletary Lake, North Carolina. Ecology, 32: 518-533.

Gloyd, Howard K. 1940. The rattlesnakes, genera Sistrurus and Crotalus. Special Publ. Chicago Acad. Sci., 4: 1-266.

Hay, Oliver P. 1923. The Pleistocene of North America and its vertebrated animals from the states east of the Mississippi River and from the Canadian provinces east of longitude $95^{\circ}$. Carnegie Inst. Wash. Publ. 322.

- 1924. The Pleistocene of the middle region of North America and its vertebrated animals. Carnegie Inst. Wash. Publ. 322 A. 
Hibbard, Claude W. 1943. The Rezabek fauna, a new Pleistocene fauna from Lincoln County, Kansas. Univ. Kan. Sci. Bull., 29, Pt. 2, No. 2: $235-247$.

- 1949. Pleistocene vertebrate paleontology in North America. Bull. Geol. Soc. Am., 60: 1417-1428.

- 1953. The Saw Rock Canyon fauna and its stratigraphic significance. Papers Mich. Acad. Sci., 38: 387-411.

- 1955a. Pleistocene vertebrates from the Upper Becerra (Becerra Superior) formation, Valley of Tequixquiac, Mexico, with notes on other Pleistocene forms. Contribs. Museum Paleontol., Univ. Mich., 12: $47-96$.

- 1955b. The Jinglebob interglacial (Sangamon?) fauna from Kansas and its climatic significance. Contribs. Museum Paleontol., Univ. Mich., 12: 179-228.

1955c. Notes on the microtine rodents from the Port Kennedy Cave deposit. Proc. Acad. Nat. Sci. Phila., 107: 87-97.

- 1957. Tentative list of Pleistocene fossil mammals in North America, with their stratigraphic occurrence. In Flint, Glacial and Pleistocene Geology. Wiley, New York.

Lindsay, Hague L. 1958. An analysis of variation and factors affecting gene exchange in Pseudacris clarki and Pseudacris nigrita in Texas. Unpublished doctoral dissertation, The University of Texas.

Lowe, Charles H., Jr. 1950. The systematic status of the salamander Plethodon hardii, with a discussion of biogeographical problems in Aneides. Copeia, 1950: 92-99.

McCarley, W. H. 1954. Natural hybridization in the Peromyscus leucopus species group of mice. Evolution, 8: 314-323.

McConkey, Edwin H. 1954. A systematic study of the North American lizards of the genus Ophisaurus. Am. Midland Naturalist, 51:133-171.

Martin, Paul S., and Byron E. Harrell. 1957. The Pleistocene history of temperate biotas in Mexico and eastern United States. Ecology, 38: $468-480$.

Meacham, IV. R. 1958. Factors affecting gene exchange between two allopatric populations in the Bufo woodhousei complex. Unpublished doctoral dissertation, The University of Texas.

Meade, Grayson E. 1952. The water rat in the Pleistocene of Texas. J. Mammal., 33: 87-89.

Mecham, John S. 1957. Some hybrid combinations between Strecker's chorus frog, Pseudacris streckeri, and certain related forms. Texas J. Sci., 9: 337-345.

Miller, Gerrit S., Jr., and Remington Kellogg. 1955. List of North American recent mammals. U. S. Natl. Museum Bull., 205.

Murray, Keith F. 1957. Pleistocene climate and the fauna of Burnet Cave, New Mexico. Ecology, 38: 129-132.

Osgood, Wilfred H. 1909. Revision of the mice of the American genus Peromyscus. North Am., Fauna, 28: 1-285. 
Pettus, David. 1956. Ecological barriers to gene exchange in the common water snake (Natrix sipedon). Unpublished doctoral dissertation, The University of Texas.

Potzger, J. E., and B. C. Tharp. 1947. Pollen profile from a Texas bog. Ecology, 28: 274-280.

- 1954. Pollen study of two bogs in Texas. Ecology, 35: 462-466.

Sargent, C. S. 1922. Manual of the Trees of North America (exclusive of Mexico), second edition. Houghton Mifflin, Boston, Mass.

Sherman, H. B. 1952. A list and bibliography of the mammals of Florida, living and extinct. Quart. J. Florida Acad. Sci., 15: 86-126.

Skinner, Morris F. 1942. The fauna of Papago Springs Cave, Arizona, and a study of Stockoceros; with three new antilocaprines from Nebraska and Arizona. Bull. Am. Museum Nat. IIist., 80: 143-220.

Smith, C. Lavett. 1954. Pleistocene fishes of the Berends fauna of Beaver County, Oklahoma. Copeia, 1954: 282-289.

Smith, Hobart M. 1950. Handbook of amphibians and reptiles of Kansas. Univ. Kan. Mus. Nat. Hist. Misc. Publ. No. 2: 1-336.

Smith, Hobart M., and J. P. Kennedy. 1951. Pituophis melanoleucus ruthveni in eastern Texas and its bearing on the status of $P$. catenifer. Herpetologica, 7: 93-96.

Smith, Hobart M., and Edward H. Taylor. 1945. An annotated checklist and key to the snakes of Mexico. U. S. Natl. Mus. Bull., 187.

Stearns, Charles E. 1942. A fossil marmot from New Mexico and its climatic significance. Am. J. Sci., 240:867-878.

Stebbins, Robert C. 1954. Amphibians and Reptiles of Western North America. McGraw-Hill, New York.

Stebbins, Robert C., and William J. Riemer. 1950. A new species of plethodontid salamander from the Jemez Mountains of New Mexico. Copeia, 1950: 73-80.

Wasserman, A. O. 1956. Factors affecting interbreeding in sympatric and allopatric species of spadefoot toads (genus Scaphiopus). Unpublished doctoral dissertation, The University of Texas. 


\section{General Conclusions}

Carl L. Hubbs

Scripps Institution of Oceanography, University of California, La Jolla

The fourteen papers from the symposium on The Origins and Affinities of the Land and Freshwater Fauna of Western North America, plus the three richly supplementing contributions from the symposium on Geographic Distribution of Contemporary Organisms, constitute a vast storehouse of information on zoogeography, on companion fields, and on various sciences that provide the background that is necessary for a full understanding of zoogeography. The seventeen contributions deal not only with the actual distribution of many but of course not all groups of land and freshwater animals, along with some aspects of phytogeography, but also with various biogeographical topics, and with the background material. Most of the contributors deal largely with western North America, but a few cover all of North America, and one even straddles the whole New World.

The contributions are diverse not only in respect to the groups of organisms, the areas covered, and the topics stressed, but also in the angle of approach, in the length and completeness of review, in the amount of original material, in the thoroughness (or lack) of documentation, and in the abundance, paucity, or lack of illustrations. The separate articles vary from abstracts (two) and mere thoughtful commentaries, on some phase of the general subject, to long, scholarly studies that give us, for the first time, the summary of a distinguished author's long-continued and intensive research.

The whole volume has both the strength and the weakness that goes with diversity. It is strong in the variety of viewpoints and specialties, in the high competence of each invited participant in some aspect of zoogeography or in one of the basically related sciences, and in the potential synthesis that is favored by the close association of the diverse contributions. It is weak in the fragmenta- 
tion of the subject, due to the increasing specialization of scientists, in the lack of attention to some groups and topics (an unavoidable defect in the age of specialization), and in the limited detail and documentation in some of the papers.

The diversity of treatment calls at the outset for an organized indication (Table I) of the coverage of the various papers, in terms of geographic, evolutionary, systematic, and background considerations.

The individual papers are referred to in the table (and in the following text) by number as given in the Contents. In the table, degree of emphasis (in the papers as printed) is roughly approximated by the type: roman for least emphasis, italics, for more thorough treatment, and boldface for most exhaustive coverage.

The emphasis on background considerations and on evolutionary and systematic correlatives, brought to focus in the table, is a strong indication of a healthy rebound from the course of overspecialization. The trend toward interdisciplinary research is exemplified in several of the contributions, and is perhaps best illustrated, as well as stated, in Martin's contribution (15) on Pleistocene ecology. The same happy trend is glowingly evident in several of the other papers, notably, for example, those by MacGinitie (2) and by Blair (17).

The overall treatment further indicates a shift from the classical, purely descriptive biogeography to a kinetic approach, which is more concerned with processes and explanations than with the classification of the earth in to a hierarchy of biogeographical regions. Attention is focused on floral and faunal elements of diverse origin, which may be mixed in any one area, and on the past and present dispersions of these biotic elements. This concept of biotic elements, which was advanced particularly by Ernst Mayr (followed herein by Parkes, 16), penetrates into the limited regional classifications of faunas in these symposia. Linsley (13), for example, maps the same area of the central California coast as a diluted part of both the Vancouveran and Californian faunas, and Rehn (12) apportions the western North American orthopteran fauna according to regions of origin.

Past and continuing shifts in biota receive considerable attention, in line with the more kinetic approach that is fortunately coming into vogue. The background for such biotic dispersals is elucidated in several of the papers, notably by King's (1) sweep through the 
grand history of changes in the face of the earth over western North America, by MacGinitie's (2) analysis of climatic trends and fluctuations in this region since Cretaceous time, and by the excellent reviews by Martin (15) and by Blair (17) on the dramatic events of the Pleistocene and their consequences.

Some new, refined approaches in biogeographical analysis are emphasized. One of these is the quantitative reconstruction of past vertebrate biocoenoses through the study of all identifiable material obtained by soil washing - a truly revolutionary (and long overdue) development, as D. E. Savage (4) indicates. Another major refinement is the more precise and penetrating systematic analysis, such as is indicated in most of the reports, notably those by Peabody and J. M. Savage (S), R. R. Miller (9), and Parkes (16). Another circumstance favoring sound biogeographical conclusions is the life-long devoted specialization on single groups, throughout their range, that is obvious in the contributions by several of the authors, notably A. H. Miller (6), R. R. Miller (9), and the entomologists: Ross (11), Rehn (12), Linsley (13), and Hovanitz (14). Radiocarbon dating becomes a tool of research in biogeography, as in other areas (Martin, 15). Quantitative studies, including pollen analysis, are helping to displace inference with clata. And, most effective of all as a lead toward a fuller understanding of the events and processes in biogeography is the recourse to interdisciplinary and multidisciplinary approaches.

The fabric of this symposium has been woven of threads that vary so much in color, size, and strength as to make it difficult to pick out these threads to reweave a simple review and conclusion. On some basic lines, however, there is sufficient consensus to permit some generalization.

One initial thought that seems justified is that biogeography is still a propitious field of inquiry. Certainly, many of the defects of the past are attributable to excessive inference on the basis of inadequate data. Through more intensive research, sharpened by new techniques and enriched by interdisciplinary approach, sound data are certain to result, and broader and more reliable interpretations are bound to develop. Through the symposium there is to be found much justification for this optimism.

A notable feature of the whole series of papers is that there is hardly a mention of the transoceanic land bridges that biogeog- 
raphers not long ago threw around with abandon. King (1) assures us that geologists hold to the theory of the essential permanence of the ocean basins, and the biologists seem to have proceeded on this assumption. The verified intercontinental connections across the Isthmus of Panama and especially across the Bering Strait region are duly treated. The intimate relationships between the Palearctic and Nearctic faunas are pointed out by Parkes (16) and other authors, and are rightly assumed to indicate a past continuity, but, as Burt (5), Rehn (12), and Hovanitz (14) point out with admirable reserve, there is, as yet, usually little basis for postulating the region of origin and the direction of dispersal. In some groups there may have been a complex interchange.

In general, it is admitted, or apparently assumed, that the reconstruction of the past history of a group, whether of origin or dispersal, cannot ordinarily be postulated with assurance on the sole basis of the present distributional pattern. Considerable variance in reserve or reliance, however, is displayed in such reconstructions. Bartholomew (3) and Burt (5) go so far as to say there are no separate "origins," because there has been a continuum of life, but are they not playing with semantics? In terms of given natural groups or stages of evolution there is an origin, in both time and space.

The criteria of center of origin, or of differentiation, as some would prefer to say, are definitely discussed by only two of the authors, D. E. Savage (4) and Burt (5). Savage's criteria are the more impressive because they emphasize the fossil record. His first criterion of area of origin is the region from which the oldest fossil is known. This is fine for groups with a well-known fossil record, but for groups with few known fossils may, as Parkes (16) notes, be even more treacherous than criteria based on present distributions. Savage's second criterion is an earlier record of progenitors (the sort of evidence that puts man's origin securely in the Old World)-again good, if the data are adequate. His third criterion is the area of greatest taxonomic diversity. This criterion may usually hold, but certainly not always. It seems not to apply, for example, to the origin of the catostomid fishes, which are almost restricted to North America, but which R. R. Miller (9) and I believe, on scanty but pertinent distributional and fossil evidence, to have originated in Asia, though they seem to have undergone most of their differentia- 
tion in North America. Savage argues wisely that phyletic age, relict occurrence, and vagility must be taken into account, but he doesn't indicate just how. Other frequently expounded criteria are just mentioned, along with Mathew's hypothesis that primitive forms are peripheral.

Savage sharply criticizes the location of the major center of origin in the Old Morld tropics, on the basis of the evidence that the present Holarctica is temperate to boreal. As both he and MacGinitie (2) point out, the northern lands were subtropical through much of Cenozoic time. Obviously, much of evolutionary history is still hidden in a fog of ignorance. The task of the historians of life has barely begun. And until we know the past, we cannot fully understand the present nor guess the future.

Several of the authors hold to the view long championed by Chaney and by Axelrod, and here expounded by MacGinitie (2), that world climate became progressively more arid and cooler through Tertiary time, while increased relief and other factors caused greater local diversity. It seems that there was a general northward shift in the climatic zones. All this caused a great translocation of the geo-floras, and, presumably, of the accompanying animal communities. Some zoologists, for example Peabody and J. M. Savage (8), have been bold enough to reconstruct origins and dispersals of certain animals on the basis of the history of the geofloras with which they infer these animals were associated. Are they treading on firm ground or on quicksand?

It seems to be the general consensus that the vast uniformity of life that characterized the early Cenozoic, in both space and time, gradually changed to diversity throughout Tertiary time, in a grand crescendo that reached ecstatic proportions in the Pleistocene. Martin (15) and Blair (17) have compiled impressive evidence favoring the view, which seems to me to be well justified, that the Ice Ages were periods of intense cold, during which climatic belts were displaced far southward (and far downward on the mountains), and during which even the tropics were very considerably cooled. During the Wisconsin period the temperate biota of eastern North America seems to have been forced into refugia in Florida and Mexico (Blair, 17), while in the West (Miller, 9) there was extensive extermination of the freshwater fauna in the north and a vast development of lakes in the Great Basin and southward. 
TABLE I. Index to Subject Coverage in Symposia on Zoogeography

Numbers in parenthesis refer to the separate papers by the stated authors. Degree of emphasis is roughly approximated by type-roman for least emphasis, italics for more thorough treatment, boldface for most exhaustive coverage.

Geographical

Considerations

Criteria (on Centers of Origin or Differentiation): D. E. Savage (4), Burt (5), Rehn (12), Hovanitz (14),

Parkes (16) EFFECTS OF MAN

Of Primitive Man: Martin (15)

Of Modern Man :

Pennak (10) AREAS TREATED

BIOGEOGRAPHICALLY Entire New World:

Hovanitz (14)

Nearctica: D. E. Savage (4), Martin (15), Parkes (16), R. R. Miller (9), Linsley (13)

Southeastern United States: Blair (17)

Western North

America: King (1), MaeGinitie (2), D. E. Savage (4), Burt (5), Peabody and J. M. Savage (8), R. R. Miller, (9), Rehn (12), Pennak (10), Ross (11), Linsley (13)
Background Considerations

PHYSIOLOGICAL BACKGROUND: Bartholomew (3), Hovanitz (14) GEOLOGICAL BACKGROUND General: King (1), MacGinitie (2), Peabody and J. M. Savage (8) Hydrographic History: R. R. Miller (9), King (1) Pleistocene Events:

Martin (15), King (1), MacGinitie (2), Blair (17)

Physiographic Relations: King (1), Peabody and J. M. Savage (8), R. R. Miller (9), MacGinitie (2), Hovanitz (14), Blair (17) PALEONTOLOGICAL

BACKGROUND Plantes: MacGinitie (2), Linsley (13), Martin (15), Blair (17) Insecta: Linsley (13), Ross (11), Rehn (12), Martin (15) Pisces: R. R. Miller (9), Blair (17)
Evolutionary and Systematic Considerations Phylogexies: D. E.

Savage (4), Burt (5), R. R. Miller (9), Ross (11) EVOLUTIONARY RATES: Martin (15), D. E. Savage (4), Ross (11)

speciation: Peabody and J. M. Sarage $(8)$, A. H. Miller (6), Pennak (10), Hovanitz (14), Martin (15), Parkes (16), Blair (17) GROUPS TREATED BIOGEOGRA PHICALI, Y Plantes:MacGinitie (2), Martin (15), Linsley (13), Blair (17)

Invertebrata: Pennak (10)

Insecta

Dermaptera and Orthoptera: Rehn (12)

Northern and Montane Insects: Ross (11)

Cerambycidae: Linsley (I3) 
TABle I. Index to Subject Coverage in Symposia on Zoogeography -Continued

Geographical

Considerations

Relations with Asia:

Burt (5),

Parkes (16),

MacGinitie (2),

D. E. Savage (4),

A. H. Miller (6),

R. R. Miller (9),

Ross (11), Rehn

(12), Linsley (13),

Hovanitz (14)

Relations with

South America:

Hovanitz (14),

D. E. Savage

(4), Burt (5), R. R.

Miller (9), Lins-

ley (13), Blair

(17)

Relations of East-

ern to Western

North America:

Blair (17), Pennak

(10), Burt (5),

A. H. Miller (6),

R. R. Miller (9),

Ross (11), Lins-

ley (13), Hovanitz

(14), Martin (15)
Background

Considerations

Amphibia and

Reptilia: Peabody and J. M. Savage

Aves: Parkes (16)

Mammalia: D. E.

Savage (4),

Martin (15), Blair

(17)

PALEOCLIMATOLOGICAL

BACKGROUND

Cretaceous:

MacGinitie (2)

Tertiary:

MacGinitie (2),

King (1), Peabody and J. M. Savage

(8), Linsley (13),

Blair (17)

Pleistocene: Martin

(15), Blair (17),

MacGinitie (2),

King (1), Stebbins

(7), Hovanitz (14)

PALEOECOLOGICAL

BACKGROUND :

MaeGinitie (2),

Blair (17),

Martin (15), D. E.

Savage (4), Burt (5)

ECOLOGICAL BACK-

GROUND: Martin

(15), Pennak (10),

Linsley (13),

Hovanitz (14),

Blair (17), R. R.

Miller (9), Ross (11)
Evolutionary and

Systematic Considerations

Lepidoptera:

Hovanitz (14)

Pisces: R. R. Miller

(9), Blair (17)

Amphibia and

Reptilia: Peabody

and J. M. Sarage

(8), Stebbins (7),

Martin (15),

Blair (17)

Aves: Parkes (16),

A. H. Miller (6)

Mammalia: D. E.

Savage (4),

Burt (5),

Martin (15),

Blair (17)

Man: Martin (15) 
Despite the evidence of extreme climatic change at the close of Wisconsin time and during the Postpleistocene millenia, Martin (15) holds to the view that the extinction of the large Pleistocene mammals is attributable not to climatic change, but to man. I favor the theory of a combination of factors.

After the recurrent restoration of humidity in the Pleistocene, the trend toward aridity seems to have continued in the West. The deserts seem to have marched northward and to have spread out like a vast desiccating fan toward the Pacific Coast and onto the Great Plains. This trend is just mentioned in the abstract by Stebbins (7), and it is considered, but I believe probably set too far back in Cenozoic time, by Peabody and J. M. Savage (8). Desiccation is plausibly held by R. R. Miller (9) and by Pennak (10) to have been largely responsible for the impoverished freshwater fauna of the West and for the high incidence of local endemism. A. H. Miller (6) attributes the high ratio of endemism among the birds of the Californian fauna to the isolation of this fauna by deserts.

In some groups, as the Orthoptera (Rehn, 12) and Reptilia, in contrast, the intensification and spread of the Sonoran region seems to have been a potent evolutionary stimulus.

Redispersals following the vast displacements of the Pleistocene are held to have induced some very interesting speciational situations. Blair (17) postulates the genetic responses, during Recent sympatry, of cognates that had been isolated in the Floridan and Mexican refugia. Hovanitz (14) similarly treats the consequences of cohabitation of butterflies previously segregated by the Wisconsin ice sheet. One pair, he states, has, by hybridization, thus produced a third species.

Geologically recent topographic changes are held to have conditioned other significant speciational events. Hovanitz (14) attributes the high incidence of endemism of butterflies in the Andes to the new environments suddenly furnished by the rapid uplift of the Cordillera, and he regards this type of response as of general significance. Peabody and Savage (8) explain speciational relations among amphibians and reptiles in California on the basis of the establishment of a Coast Range Corridor. They cite evidence that the Sierra Nevada and Coast Ranges were long separated on the south by a marine barrier, so that the forms on the two ranges became subspecifically differentiated, though intergrading where their ranges 
converged in the north. They postulate that when the corridor became established the cognates met, but, because of the degree of separation, remained distinct in cohabitation, behaving here as full species at the respective ends of an otherwise specific continuum (in other words, forming "open circles").

In a slightly Chauvanistic vein, these authors close their paper with this exultation: "We may confidently reaffirm and echo $\mathrm{A}$. B. Howell's assertion of thirty years ago that the fauna of the Pacific Coast is of unusual interest and presents many fascinating problems. Californians have a land-bridge laboratory in their own back yard!" But, as is suggested by the references just made to Hovanitz and to Blair, similarly fascinating situations exist outside the Golden West. Zoogeographical gold is where you find it! 

Adams, C. C., 433, 465

Aguayo, C. G., 409, 413

Allee, W. C., 85, 94, 97, 127

Alexander, W. B., 423, 431

Allen, G. M., 409, 413, 436, 465

Allen, J. A., 410, 414

Allen, V. T., 40, 57

Amadon, D., 427, 431

Andersen, S. 'T., 377, 386, 414

Anderson, F. M., 19, 57

Andrewartha, H. B., 82, 93

Antevs, E., 72, 77, 382, 391, 414

Anthony, B., 219

Anthony, H. E., 409, 414

Atkinson, IV. S., 209

Atwood, W. W., 28, 31, 33-35, 57

Atwood, W. W., Jr., 28, 31, 33-35, 57

Axelrod, D. I., 34, 41-43, 57, 69, $77,100,114,126,166-168,170$, $185,303-306,318,473$

Bailey, R. M., 198, 219

Baker, A. A., 14, 57

Baker, C. L., 457, 465

Baldwin, A. H., 198

Barclay, F. H., 413

Barendsen, G. W., 387, 414

Barnes, W., 365

Bartholomew, G. A., 85, 86, 8890, 472, 474

Bates, M., 365

Bell, R. Y., 59

Bell, W. A., 112, 127

Benson, R. B., 233, 252

Benson, S. B., 412, 414

Bentley, P. J., 89, 94

Berg, L. S., 197, 205, 219

Berry, E. W., 112, 127, 435, 465

Birch, L. C., 82, 93

Blackwelder, E., 213, 219

Blackwelder, R. E., 318

Blair, A. P., 453, 465
Blair, IV. F., 433, 447, 453, 457, $459,461,465,466,470,471$, 473-477

Blaxter, K. L., 87, 94

Bogert, C. M., 85, 94

Bogolepov, K. V., 66, 77

Bowman, K., 365

Boyce, S. G., 381, 419

Bradley, J. C., 318

Bradley, W. H., 27, 28, 33, 57

Brame, A. H., 179, 186

Brattstrom, B. H., 160, 185

Braun, E. L., 375, 377, 382, 414, $433,435,441,445,466$

Breyer, A., 365

Brock, V. E., 214

Broecker, W. S., 404, 414

Brooks, C. E. P., 64, 71, 77

Brooks, G. S., 366

Brown, A. L., 210

Brown, B., 440

Brown, C. A., 72, 77, 435, 466

Brown, F. M., 366

Bryan, K., 36, 57

Bryant, M. D., 447, 466

Bullock, T. H., 88, 94

Burbank, W. S., 14, 23, 57

Burt, W. H., 153, 472, 474, 475

Cabrera, A., 136, 137, 153

Cade, T. J., 86, 88, 93

Cagle, F. R., 459, 466

Cain, S. A., 134, 153, 383, 414

Camp, C. L., 160, 163, 164, 185

Carpenter, F. M., 233, 252

Carpenter, G. D. H., 366

Carr, A., 459, 466

Chandler, M. E. J., 65, 79

Chaney, R. W., 46, 57, 64, 66, 67, $69,78,100,127,129,168,185$, $390,414,434,466,473$

Chu, Y. T., 220

Clark, A. H., 366 
Clark, J., 129

Clark, J. G. D., 375, 414

Chatfield, P. O., 88, 94

Clements, F. E., 434, 466

Clisby, K. H., 380, 390, 391, 414, 419

Cockerell, T. D. A., 259, 318

Cohen, N. W., 85, 94

Colbert, E. H., 120, 127, 129, 413, 414

Comstock, J. A., 366

Comstock, W. P., 366

Condit, C., 185

Cook, H. J., 104, 127

Cook, S. F., 405, 416

Cooke, C. W., 405, 414

Cooper, IV. S., 313, 318

Cope, E. D., 192, 194, 220

Core, E. L., 382, 414

Courtemanche, A., 385, 418

Cowles, R. B., 85, 94

Craig, R. A., 71, 77, 78

Crampton, G. C., 289

Crane, H. R., 405, 414

Crook, IV. W., 412, 414

Cross, W., 30, 58

Crowell, J. C., 52, 58

Cruxent, J. M., 395, 414, 418

Curtis, G. C., 58

Cushing, J. E., Jr., 436, 438, 466

Dane, C. H., 57

Dansereau, P., 378, 379, 395, $407,413,414$

Darlington, H. C., 382, 387, 414

Darlington, P. J., Jr., 101, 102, $127,134,142,153,190,199$, $220,318,421,422,425,427$, 430,431

Darwin, C., 97, 104, 127, 395, 396, 414

Davenport, D., 366

Davis, A. C., 318

Davis, J. H., Jr., 72, 78, 415, 435,466
Davis, M. B., 377, 381, 387, $388,413,415$

Davis, W. B., 461, 466

Davis, W. M., 38, 58

Dawson, W. R., 85, 86, 90, 93

Deevey, E. S., Jr., 141, 153, 375, $377,382,384,386,387,389$, $409,413,414,417,433,434$, 466

Denny, C. S., 377, 415

Denton, S. F., 202

Dibblee, T. W., Jr., 52, 58, 114, 127

Dietz, R. S., 53, 59

Dillon, L. S., 366, 375, 390, 415

Dorf, E., 62, 63, 78, 318

Dosh, E. F., 382, 419

Drury, W. H., 377, 378, 382, 383, 415

Dumas, P. C., 90, 94

Dunbar, C. O., 57

Dunkle, D. H., 106, 127

Dunn, E. R., 450, 466

Durham, J. W., 63, 65, 68, 78, $114,127,249,252$

Durham, W., 168, 185

Dyar, H. G., 366

Dylik, J., 381, 415

Eager, G., 206

Eardley, A. J., 10, 12, 57, 58, $164,165,185$

Eastman, C. R., 220

Eaton, T. H., Jr., 203, 220

Edwards, R. S., 58

Edwards, W. H., 366

Eisenmann, E., 424, 432

Eisley, L. C., 403, 412, 415

Elias, M. K., 69, 78

Ellerman, J. R., 136, 137, 153

Elrod, M. J., 366

Elson, J. A., 413

Elwes, H. J., 366

Emerson, A. E., 99, 102, 127

Emiliani, C., 63, 72, 78, 141, 153, $249,252,376,415$ 
Epstein, S., 249, 252

Erdbrink, D. P., 137, 145, 153

Estes, R., 161

Evermann, B. W., 198, 200, 202, 205, 207-209, 220

Evernden, J. F., 18, 58

Ewing, M., 8, 16, 58

Fall, H. C., 318

Fenneman, N. M., 57

Ferguson, H. G., 18, 58, 59

Field, W. D., 366

Findley, J. S., 372, 436, 466

Fiske, W. F., 366

Fitch, H. S., 412, 415

Fitter, R. S. R., 423, 431

Flint, R. F., 72, 74, 77, 78, 122, $127,375,377,378,382,389$, $391,392,401,402,411,413$, 415

Forbes, W. T. M., 366

Foreman, F., 419

Fox, R. M., 366

Frenzel, B., 375, 415

Frey, D. G., 378, 379, 381, 386, $387,415,435,466$

Fries, C. C., 106, 127

Frye, J. C., 70, 78

Garnett, R. T., 318

Garth, J. S., 366

Gay, H., 366

Gazin, C. L., 106, 127

Gibson, A., 367

Gilbert, C. H., 210, 220

Gill, E. D., 403, 409, 413, 415

Gilluly, J., 53, 58, 59

Gloyd, H. K., 457, 466

Godman, F. D., 367

Goldsmith, J. W., 59

Goodlett, J. C., 381, 416

Goodrum, P., 415

Gralenski, L. J., 414

Grant, M., 107, 127

Gressitt, J. L., 318

Griffin, H., 413
Grinnell, F., Jr., 367

Grinnell, J., 367

Griscom, L., 393, 416

Grossbeck, J. A., 367

Guilday, J. E., 412, 416

Hack, J. T., 381, 382, 416

Hall, E. R., 135, 153

Hamilton, J., 318

Hamilton, W. J., 89, 94, 413, 416

Handlirsch, A., 303, 318

Hansen, H. P., 391, 416

Hardy, G. H., 318

Hardy, R., 142, 153

Hare, F. K., 378, 413, 416

Harrell, B. E., 392, 393, 413, 416, $417,441,445,447,452,453$, 463,467

Harris, R. K., 412, 414

Harriss, T. F., 18, 60

Haury, E. W., 396, 413, 416

Hay, O. P., 436, 440, 444, 466

Hayden, E. B., 410, 411, 418

Hayward, K. J., 367

Hecht, M. K., 411, 416

Heinze, A. A., 450, 466

Heizer, R. F., 405, 416

Herre, A. W. C. 'T., 214, 220

Hesse, R., 85, 94, 97, 127

Hester, J. J., 413

Heusser, C. J., 391, 416

Heyerdahl, T., 411, 416

Hibbard, C. W., 106, 122, 123, $127,376,401,402,404,413$, $416,436,438,440-442,444$, 467

Hill, M. L., 52, 58

Hock, R. J., 88, 94, 95

Hodge, E. T., 47, 48, 58

Hoffmann, C. C., 367

Hollister, J. S., 51, 53, 59

Hollom, P. A. D., 423, 432

Horn, G. H., 318, 319

Hospers, J., 76, 78

Hotz, P. E., 59

Houpt, T. R., 95 
Hovanitz, W., 367, 471, 472, 474477

Howard, A. D., 36, 58

Howell, A. B., 159, 185, 477

Howell, T. R., 92, 93

Hoy, H. E., 215, 220

Hubbell, T. H., 284

Hubbs, C. L., 37, 42, 43, 58, $193,203,206-210,212-214$, $216,217,219-221$

Hultén, E., 319

Hunt, C. B., 30, 35, 36, 58, 404, 416

Hussakof, L., 193, 220

Hustich, I., 378, 416

Hutchinson, G. E., 91, 94, 392, 417

Irving, L., 86, 94, 95

Irwin, J. H., 19, 31, 58, 59

Iversen, J., 417

Jameson, D. J., 59

Jarnum, S. A., 95

Jenness, D., 418

Jennings, J. D., 417

Jepsen, G. L., 120, 127, 129

Johnson, F., 95

Johnson, H. R., 58

Johnson, W. D., 31, 58

Jordan, D. S., 198, 200, 202, 205. 208, 209, 220

Jordan, K., 367

Jorgensen, P., 367

Kay, M., 9, 58

Kaye, W. J., 367

Kayser, C., 88, 94

Kellogg, R., 136, 137, 153, 409, $418,436,467$

Kennedy, J. P., 453, 468

Ketner, K. B., 59

Khalaf, K., 245, 252

King, P. B., 36, 58, 470, 472, 474, 475

Kitts, D. B., 384, 417
Klebs, R., 303, 319

Knowlton, F. H., 65, 78, 112, 127

Koopman, K. F., 409, 410, 413, 417,420

Krog, H., 94

Kulp, J. L., 414

Lack, D., 83, 94

Lance, J. F., 59, 221, 413

Landry, S. O., Jr., 100, 127

Lange, A. L., 391, 417

Langston, W., Jr., 101, 127

Larsen, E. S., 30, 59

LeConte, J. L., 319

Lee, A. K., 89, 94

Lee, T. E., 394, 417

Lee, W. T., 36, 59

Leighton, B. V., 367

Leonard, A. B., 70, 78

Leopold, A. S., 390, 417

Leopold, E. B., 413

Leopold, L. B., 72, 78

Leopold, S. B., 377, 387, 388, 417

Lewis, C. B., 366

Li, Hui-Lin, 69, 78

Lindroth, C. H., 424, 431, 432

Lindsay, H. L., 453, 467

Lindsey, C. C., 187, 198, 211, $217,218,220$

Linsley, E. G., 104, 128, 302, 315, $319,470,471,474,475$

Lipson, J. I., 58

Livingstone, B. G. R., 377, 384, $385,387,417$

Livingstone, D. A., 377, 384, 385, $387,413,417$

Longstaff, G. B., 367

Longwell, C. R., 10, 36, 39, 56, 59, 221

Lönnberg, E., 429

Lonsdale, J. T., 129

Louderback, G. D., 59

Löve, A., 413

Löve, D., 413

Lovering, T. S., 14, 23, 57 
Lowe, C. H., Jr., 74, 78, 179 , $186,413,450,467$

Lowenstam, H. A., 249, 252

Low ther, G., 413

Lucas, F. A., 194, 221

Lydekker, R., 97

Lyman, C. P., 88, 94

McAlpine, IV. S., 367

McCarley, W. H., 453, 467

McConkey, E. H., 462, 467

MacCurdy, G. G., 414

McDonald, J. E., 413, 492

MacDonald, J. R., 67, 78

McDunnough, J. J., 365

NacGinitie, H. D., 65, 67, 69, $79,301,304,319,470,471$, 473-475

McGrew, P. O., 107, 128

McKee, E. D., 19, 59

McKenna, M., 161

McKenna, M. C., 106, 111, 119, 128

MacLachlan, J. C., 59

MacLachlan, M. E., 59

MacNeish, R. S., 404, 417

Mackin, J. H., 25, 31, 34, 56, 59

Macy, R. W., 367

Main, A. R., 89, 94

Malin, J. C., 74, 79

Manley, G., 71, 79, 386, 417

Mannerheim, G. C. G., 319

Manning, T. H., 384, 417

Marshall, J. T., 393, 417

Martin, J. O., 319

Martin, M., 413

Martin, P. S., 377, 380, 382, 387, $391,392,417,441,445,447$, $452,453,463,467,470,471$, 473-476

Martynov, A. V., 254

Mason, H. L., 61, 79, 304, 325, $319,390,414$

Matthew, W. D., 97, 101, 102, $104,127,134,409,417,475$
Maxwell, R. A., 129

Mayr, E., 100, 102, 104, 128, 421, $422,425,429,432,470$

Meacham, IV. R., 453,467

Meade, G. E., 442, 467

Mecham, J. S., 454, 467

Meek, S. E., 214, 221

Menard, H. W., 53, 59

Mercer, J. H., 384, 417

Merriam, C. H., 137, 141, 153, $311,313,314,319$

Michener, C. D., 315, 319

Miller, A. H., 92, 94, 390, 417, $471,474-476$

Miller, G. S., Jr., 136, 137, 153, $409,418,436,467$

Miller, R. R., 37, 43, 58, 193, 207$210,212-217,220-222,471-476$

Mitono, T., 319

Monson, M., 94

Moore, T. E., 243, 244, 252

Moreau, R. E., 375, 418

Morrison-Scott, T. C. S., 136, 137,153

Mosely, M. E., 232, 252

Mosimann, J. E., 413

Mountford, G., 423, 432

Muller, S. W., 18, 58

Murray, K. F., 73, 79, 391, 418, $436,440,467$

Myers, G. S., 102, 128, 191, 221

Nelson, E. M., 199, 201, 221

Newman, C., 415

Nikiforoff, C. C., 382, 418

Noble, L. F., 52, 59

Nolan, T. B., 12, 38, 59

Norris, K. S., 85, 92, 94

Officer, C. B., 58

Ogden, J. G., 413

Olivier, G., 430, 432

Olson, E. C., 107, 128

Öpik, E. J., 77, 79

Oriel, S. S., 59 
Osborn, H. F., 97, 128, 405, 411, 413,418

Osgood, W. H., 135, 153, 154, 453, 467

Parkes, K. C., 403, 470-472, 474, 475

Patrick, R., 417

Patterson, B., 106, 120, 128

Peabody, F. E., 161, 180, 185, 186, 471, 473-477

Pearson, O. P., 85, 86, 9.5

Peltier, L. C., 377, 418

Pennak, R. IV., 474-476

Peters, J. L., 432

Peterson, R. T., 423, 424, 427, 432

Pettus, D., 461, 468

Plass, G. N., 75, 77, 79

Pongrácz, A., 303, 319

Potzger, J. E., 72, 79, 381, 385, $387,388,418,420,435,468$

Powell, J. W., 59

Press, F., 8, 58

Pruitt, IV. O., Jr., 142, 154

Quimby, G. I., 394, 418

Quinn, J. H., 129

Rabb, G. B., 410, 411, 413, 418

Ramaswami, L. S., 203, 221

Rand, A. L., 384, 418

Rasmussen, W. C., 382, 418

Reed, C. F., 160, 186

Reed, E. C., 367

Reed, R. D., 51, 53, 59

Reeside, J. B., Jr., 57, 129

Regan, C. T., 199, 205, 221

Rehn, J. A. G., 470-472, 474-476

Reid, E. M., 65, 79

Repenning, C. A., 31, 37, 59, 193, 221

Riemer, W. J., 450, 468

Roberts, R. J., 12, 59

Robins, C. R., 210, 222

Robinson, G. D., 56
Romer, A. S., 101, 128, 411, 413, 418

Rosenthal, G. M., 171, 186

Ross, H. H., 234-236, 238, 239, 241-244, 251,252,471,474, 475

Rostlund, E., 197, 198, 222

Rothschild, WV., 367

Rouse, I., 395, 404, 405, 414, 418

Rouse, J. T., 30, 59

Rousseau, J., 378, 418

Russell, L. S., 106, 128

Salvin, O., 367

Sargent, C. S., 445, 447, 468

Sauer, C. O., 411,418

Savage, D. E., 471-475

Savage, J. M., 179, 186, 471, 473-477

Sawyer, W. H., 85, 95

Schaeffer, B., 102, 128

Schaeffer, C., 320

Scharff, R. F., 376, 418

Schmid, F., 235, 252

Schmidt, K. P., 85, 94, 97, 101, 127,128

Schmidt-Nielsen, B., 87, 95

Schmidt-Nielsen, K., 87, 95

Schoenwetter, J., 413

Scholander, P. F., 86, 95

Schultz, J. R., 390, 419

Schultz, L. P., 196, 219, 222

Schwade, I. T., 114, 128

Sclater, P. L., 97

Scott, W. B., 132, 141, 154

Scudder, S. H., 320, 368

Sears, P. B., 380, 390-392, 414, 419

Seitz, A., 323, 368

Sellards, E. H., 394, 419

Seward, A. C., 64, 79

Shapley, H., 415

Sharp, A. J., 74, 79

Sharpe, C. F. S., 382, 419

Shepard, H. H., 367

Sherman, H. B., 441, 442, 444, 468 
Shotwell, J. A., 108, 128

Sibree, J., 409, 419

Simpson, G. G., 97, 104, 106, 109 , $110,112,120,121,123,128$, $136,139-141,143,154,401$, 402, 408, 409, 413, 419

Skinner, M. F., 436, 468

Skjölsvold. A., 411, 416

Smiley, T. L., 413

Smith, C. L., 440, 468

Smith, H. M., 453, 454, 459, 461, 468

Smith, P. W., 74, 79, 389, 419

Snyder, J. O., 210, 211, 222

Soday, F. J., 394, 419

Spieker, E. M., 20, 59

Statz, G., 303, 320

Stearns, C. E., 391, 419, 436, 468

Stebbins, G. L., Jr., 100, 101, 128

Stebbins, R. C., 160, 162, 171, $178,179,186,450,457,468$, 475,476

Stewart, O. C., 395, 419

Stille, H., 54, 59

Stirton, R. A., 194, 222, 301

Stock, C., 129

Stovall, J. W., 106, 129

Strain, W. S., 444

Stuart, L. C., 393, 41 ?

Swanson, V. W., 59

Taliaferro, N. L., 17, 18, 53, 60, 164,186

Taylor, E. H., 454, 459, 468

Taylor, W. W., 394, 419

Tharp, B. C., 72, 79, 381, 418, 435,468

Théobald, N., 259

Thomas, E. W., 376, 419

Thorson, T. B., 86, 89, 95

Tillyard, R. J., 254, 259

Troll, C., 375, 415

Tucek, C. S., 414

Ulmer, G., 232, 252

Underwood, E. J., 88, 95
Ureta, E., 368

Urey, H. C., 72, 79

Usinger, R. L., 104, 128

Uyeno, T., 215, 221

Van Dyke, E. C., 309, 313, 320

Van Frank, R., 160, 162, 186

Van Houten, F. B., 25, 27, 28, 40, $41,43,60,109,112,129$

Vaurie, C., 431, 432

Vogt, G. B., 320

Wadia, D. N., 74, 79

Walker, E. M., 289

Wallace, A. R., 97, 307, 320

Wallace, R. E., 53, 60

Wallgren, H., 86, 95

Walters, V., 95, 198, 203, 222

Warren, B. C. S., 368

Wasserman, A. O., 454, 468

Waters, A. C., 46-48, 60

Wells, B. W., 381, 419

Wetmore, A., 393, 403, 411, 419, $426,428,432$

IVeyl, R., 392, 419

White, S. E., 392, 420

Whitehead, D. R., 378, 383, 413

Whittaker, R. H., 382, 389, 420

Wickham, H. F., 320

Wilimovsky, N. J., 196

Wilke, F., 90, 94

Willett, H. C., 71, 74, 76-79

Williams, E. E., 409-411, 417, 420

Williams, S., 394, 405, 420

Wilson, J. A., 106, 129

Wilson, L. R., 378, 381, 420

Witthoft, J., 394, 420

Wodehouse, R. P., 66-79

Wolfe, P. E., 382, 420

IVood, H. E., 106, 129

Woodford, A. O., 18, 56, 60

Woodring, W. P., 16, 60

Wormington, H. M., 394, 395, 404,420

Wright, W. G., 368 
Wynne-Edwards, V. C., 201, 204, Zeuner, F. E., 62, 79, 259, 282, 222 285, 289

Yehle, L. A., 381, 382, 420

Zumberge, J. H., 387, 388, 420

Yepes, J., 136, 137, 153

Zweifel, R. G., 160, 180, 186 
Abies, 304, 305, 392, 434

Abramidinae, 203

Acacia, 265

Acantherus, 275

Acanthocinus, 306

Acanthoderes, 313

Acer, 67, 304, 305

grandidentatum, 445, 446

saccharum, 445, 446

skutchii, 445

Acheta, 287

assimilis, 287

Achiridae, 189

Achryson surinamum, 307

Achurum, 274, 275

Acipenseridae, 188

Acmaeops pratensis, 306

Acratocnus, 407

Acreinae, 344, 345

Acrididae, 259-277

Acridinae, 273-277

Acridoidea, 256-277

Acris, 457

crepitans, 457

gryllus, 457

Acrodectes, 282

Acrolophitus, 274

Actinote, 344, 345

Adelpha, 348, 351, 352

Adenostoma, 261

Aeoloplides, 268

Aeria, 337

Aerochoreutes, 272

Aeropedellus, 273, 274

Aeropus, 273

Aesculus, 376

octandra, 376

Agallisus, 307

Agapetus, 239

Agave, 376

Ageneotettix, 274, 275

Ageronia, 348, 351

A gkistrodon, 377, 389

contortrix, 377, 389
Aglaothorax, 281, 282

Agosia chrysogaster, 215

klamathensis, 211

nubila, 211

Agrias, 349, 360

Agris, 351

Agroecotettix, 268

Agymnastus, 270

Aidemona, 268

Ailanthus, 67, 305

Alaudidae, 429

Alce, 124

Alces, 137, 149, 436

alces, 137

Alesa, 353

Alnus, 304

Alopex, 124, 137, 148

lagopus, 137

Amauronematus, 243

A mblycorypha, 278

Amblygonia, 354

Amblyrhiza, 409

Amblytropidia, 274

Ambrosia, 377, 378

Ambystomidae, 161

Amelanchier, 304

Amelinae, 292

Amiidae, 218

Ammobaenetes, 284

Amphibia, 85, 475

Amphidecta, 338, 339

Amphipoda, 227, 228

Amphitornus, 274

Amphiuma, 455, 463

Amyzon, 193, 202

Anabrus, 280, 281

Anaea, 349, 351

Anagapetus, 237, 238

bernea, 238

chandleri, 238

debilis, 238

hoodi, 238

Anaglyptini, 308

Anaptomorphidae, 110 
Anartia, 346

A nas crecca, 423

penelope, 423

Anaxipha, 288

Anconia, 272

Ancylocera, 307

Ancylusis, 353

Andina, 332, 334, 359

Andrias scheuchzeri, 101

Anechurella, 255

vara, 255

Anefus, 313

Aneides, 450, 463

hardyi, 450

lugubris, 171, 172, 183

Anepsyra, 313

Anisolabis, 254

Anniella pulchra, 172

Anoplodera, 302, 306

A noplodusa, 281

Anostraca, 227

Anteos, 331, 333

Anthocharis, 332, 334

Antilocapra, 124, 139, 149, 408

Antilocapridae, 121, 122, 133, 152

Antirrhaea, 337, 338

Antrozous, 125

A phelocoma, 445

coerulescens, 445

Aphredoderidae, 193, 197, 198

Aplodontia, 125, 149

Aplodontidae, 121, 122, 146

A podemia, 352, 354

A pote, 281

Appalachia, 266

Appias, 331, 357

Aprotopos, 336

Arbutus, 305

Archiclermaptera, 254

Archodontes, 307

Archonias, 331

Archoplites, 199, 219

interruptus, 200

Arctocyonidae, 110

Arctostaphylos, 261, 306

Arenivaga, 297
Arethaea, 277, 278

Argiacris, 267

Argynnis, 346, 350, 364, 365

Argyrophorus, 341, 343

Argytes, 284

Arhopalus, 306

rusticus, 306

Ariidae, 188

Artemesia, 37, 313

Artiodactyla, 116, 117, 119

Ascia, 331, 333

Aseminae, 306

Asemoplus, 269

A semum, 306

striatum, 306

A sinus, 399

conversidens, 399

A sio flammens, 426

flammens bogotensis, 426

flammeus suinda, 426

Astacinae, 227

A sterocampa, 348, 351

Astraeodes, 354

Astyanax fasciatus, 195

Ataxia, 313

Atelopus, 281, 282

Atherinidae, 189, 195

Athesis, 332, 335

Athripsodes, 245

cancellatus, 225

tarsipunctatus, 245

Athyrtis, 336

Atimia helenae, 311

maritima, 316

Atlanticus, 280, 282, 290, 297

Atta, 296

Attaphila, 296

Attaphilinae, 296

Atyidae, 225

A ulocara, 274

Aves, 472

Aztecacris, 268

Baeotis, 354

Baiomys, 124, 149

Balboneura, 347, 351, 352, 360 
Barbicornis, 353

Barisia, 393

Baronia, 328, 330, 343, 358

Barytettix, 268

Basilarchia, 348, 351

Bassariscidae, 150

Bassariscus, 125, 148

Batesia, 348, 352, 360

Bathynella, 225

Batrachideinae, 259

Batrachoseps, 161, 179, 181, 183, 184

attenuatus, 179, 180, 184

lencopus, 179

major, 179

pacificus, 179, 180, 184

wrighti, 179

Batyle, 313

Bellamira, 309

Betula, 304, 305

Bia, 345

Bison, 124, 149, 398, 399, 404, 408 alleni, 398

antiquus, 398, 399

crassicornis, 398, 404

Blarina, 125, 148

Blasticotoma, 233

Blatta, 294

Blattella, 294

Blattoidea, 294-298

"Boanerges" internigrans, 427

Bombycilla cedrorum, 429 garrulus, 429 japonica, 429

Bombycillidae, 429

Boopedon, 274

Bootettix, 275

Bootherium, 408

Boreostracon, $4+2$

Borophagus, 401, 402

Bothidae, 188

Bovidae, 121, 122, 147

Brachyinsara, 277

Brachyphylla, 410

Brachystola, 262, 263

Bradynotes, 268, 269
Brassolidae, 322, 32t, 325, 344, $345,357-359,362$

Brassolis, 345

Breagyps, 403

Breameryx, 401, 408

Brephidium, 355, 356, 360

Brothylus, 311

Brunneria, 270, 274, 276, 293 borealis, 293

Bryodema, 272

Bryozoa, 226, 228

Buckellacris, 268, 269

Bufo americanus, 457

boreas, 170

fowleri, 453

houstonensis, 459

microscaphus, 170, 173

quercicus, 459

terrestris, 457

woodhousei, 445, 453, 462

Bumelia, 305

Cactaceae, 313

Cadomastax, 261

Caclifera, 256-277

Caenophlebia, 360

Calcarius lapponicus, 431

Caligo, 344, 345

Calippus, 396

Calisto, $3+1,343$

Callicore, 348, 351

Callidiellum cupressi, 311 rufipenne, 311 villosulum, 311

Callidini, 311

Callidium, 306

sempervirens, 311,312

sequoiae, 311

randykei, 311, 312

Callimellum, 309, 311

Callimoxys, 302

Callitaera, 337, 338

Callithea, 348, 351, 360

Callithemia, 336

Callizona, 347

Calloleria, 336 
Callorhinus ursinus, 89

Calydna, 354

Cambarinae, 227

Camelidae, 133

Camelops, 399, 401, 408

Camelus dromedarius, 87

Camnula, 270

Campostoma, 204

ornatum, 214

Camptocercus, 226

Campylacantha, 267

Canidae, 121, 122, 145

Canis, 108, 124, 137, 148, 399

dirus, 399

lupus, 137

Capnobotes, 281, 282

Capromys, 408, 410, 411

ingrahami, 408, 410

thoracatus, 410

Carinifex, 227

Carnivora, 110, 116-118

Carpinus, 305

Carpiodes, 202

Carpodaptes aulacodon, 110

Carpolestidae, 110

Carya, 303, 305

Castanea, 305

Castanopsis, 67, 304

Castor, 120, 124, 049

Castoridae, 120-122, 146

Castoroides, 401, 412

Catagramma, 348

Catargynnis, 342

Catastica, 331, 333, 357

Cathartornis, 403

Catonephele, 347

Catostomidae, 188, 193, 195, 201$203,205,212,219$

Catostominae, 201

Catostomini, 201, 202

Catostomus, 201, 202, 214, 215 ardens, 212

bernardini, 215

catostomus, 199, 203, 212, 218

columbianus, 212

rimiculus, 211 snyderi, 210

warnerensis, 216

wigginsi, 214

Ceanothus, 302, 306

Cedrela, 69, 70

Celastrus, 67

Celtis, 305

Centrarchidae, 188, 193, 195, 199 , 200

Centropomidae, 188

Centropomus, 214

Cerambycidae, 299-320, 474

Cerambycinae, 306, 307

Ceratinia, 336

Cercidiphyllum, 305

Cercyonis, 341, 343

Cerocarpus, 306

Cervalces, 400

Cervidae, 121, 122, 147

Cervus, 149, 396, 441

Ceuthophilini, 284-285

Ceuthophilus, 284-285

Chalmytherium, 403

Chamaecyparis, 304, 311 obtusa, 311 villosulum, 301

Chamaelimonas, 353

Characidae, 195

Charis, 352, 354

Charisalia, 309

Chasmistes, 202, 212, 213

Cheimas, 342

Cheleutoptera, 289, 290

Chelisoches, 254

Chimarocephala, 270

Chimarra, 235

Chion, 307

Chiroptera, 103, 116-118

Chirostoma, 195

Chloealtis, 273

Chlorippe, 348, 351

Chloroplus, 268

Chlosyne, 346, 351

Choeronycteris, 125

Chorisoneurinae, 296

Chorisoneura texensis, 296 
Chorthippns, 273

longicornis, 273

Chortophaga, 270

Chriacus sp., 110

Chrysochraon, 273

Chrysophanus, 355, 356

Chrysothamnus, 313, 317

Cibolacris, 271

Cichlidae, 188, 195, 205

Cichlasoma beani, 205, 214 cyanoguttatum, 195

Cincindelidae, 316

Circotettix, 272

Citellus, 108, 125, 137, 146, 148,384 richardsoni, 438

undulatus, 137

undulatus parryi, 384

Cladocera, 226, 228

Clematodes, 265

Clemmys guttata, 461

Clethra, 305

Clethrionomys, $124,137,149,384$ rutilus, 137, 384

Clidomys, 409

Clinopleura, 282

Clothilda, 344, 346, 360

Clothildinae, 344, 346

Clupeidae, 188

Clytanthus, 308

Clytoleptus, 309

Clytus, 306

blaisdelli, 312

clitellarius, 312

planifrons, 312

Cnemidophorus, 445

sexlineatus, 445

Cnemotettix, 283

Coelenterata, 228

Coenonympha, 340, 343

Coenophlebia, 349, 352

Coenopus, 313

Coerois, 337, 338

Colaenis, 344,345

Colias, 331, 333, 361-365

behri, 363

eurytheme, 361-363 hecla, 363

interior, 362, 363

nastes, 363

palaeno, 363

philodice, 362

Columba, 427

fasciata, 427

Columbia, 197, 219

transmontana, 198, 211

Columbidae, 427

Compositae, 68, 313

Compsodes, 296

Conalcaea, 268

Conchostraca, 227

Condylarthra, 110, 116-118

Condylura, 125, 148

Conepatus, 124, 145, 148

Coniana, 272

Conocephalinae, 279, 280

Conocephalus, 279, 280

Conozoa, 272

Copepoda, 228

Copiphorinae, 279

Corades, 345

Coragyps, 399

occidentalis, 399

Cordillacris, 274

Coregonidae, 187, 188, 212

Coregonus clupeaformis, 211

Cormus, 304

Cortodera, 309, 311

Corvidae, $425,427,428$

Corvus, 428

$\operatorname{corax}, 428$

Corydinae, 296

Corynorhinus, 125, 459

Cosmosatyrus, 341,343

Cottidae, 189, 193, 212

Cottus, 187, 208, 210, 211, 213

annae, 208

bairdi, 208, 212, 213, 218

belding $i, 212$

princeps, 210, 211

tenuis, 211

Covillea, 275, 277

tridentata, 263 
Crataegus, 305

Cratogeomys, 124, 149

Cratypedes, 270

Cremna, 349

Crenichthys, 207, 217 baileyi, 217 nevadae, 206, 217

Cricetidae, 121, 122, 146

Cricetinae, 146

Crossidius, 313

Crotalus adamanteus, 445, 447 atrox, 457 horridus, 452 ruber, 457

Crotaphytus wislizenii, 174 wislizenii silus, 174, 175

Cryptocerous, 258, 267, 281, 297

Cryptomeria japonica, 311

Cryptophyllicus, 282

Cryptotis, 125, 148

Cuculidae, 427

Culicoides, 245 obsoletus, 245 tristriatulus, 245

Cunninghamia lanceolata, 311

Cupressaceae, 302, 311

Cupressus, 305, 390, 392 sargentii, 311

Cuvieronius, 405

Cybielis, 348, 351, 360

Cycleptinae, 199, 202

Cycleptus, 199, 201, 202

Cyclogramma, 348, 351

Cyllopsis, 340, 343

Cycloptilum, 286

Cynomys, 124, 146, 148

Cyphoderris, 283

Cyprinidae, 188, 193, 195, 203205, 212, 219

Cypriniformes, 191

Cyprinodon, 207, 209, 213

Cyprinodontidae, 188, 193, 205, 206, 212, 213

Cyrenia, 353

Cyrtacanthacridinae, 263-269

Cyrtacanthacridini, 263-265
Cyrtinus, 308

Cystineura, 347, 351

Cytrophorus, 308

Dactylotum, 267

Daedalma, 342, 343

Daihinia, 284

Daininiella, 284

Daihiniodes, 284

Dallia, 196, 197

Danaidae, 322, 324, 325, 332, $335-337,357-359,361$

Danainae, 332, 362

Danais, 332, 335 plexippus, 362

Dasyophthalma, 345

Dasypodidae, 121, 122

Dasypterus, 459

Dasypus, 125, 442 novemcinctus, 122

Davisonia, 244

Decapoda, 228

Decticinae, 280-282

Decticita, 282

Dendrobias, 313 mandibularis, 307

Dendromecon, 306

Dendrotettix, 266

Dermaptera, 254-256, 299, 471

Derobrachus, 313

Derotmema, 270, 271 piute, 271

Dermoptera, 103, 116, 117, 126

Desman, 108

Desmocerus auripennis, 312 cribripennis, 312

Diadophis, 389 amabilis, 175 punctatus, 389

Diapheromera, 291, 292

Dicamptodon, 161

Dicentrus, 311

Dichopetala, 278

Dichromorpha, 270, 276

Dicosmoecus, 235

Dicrostonyx, 124, 137, 149, 384 
Dictyoptera, 289, 292

Didelphidae, $110,120-122$

Didelphis, 120, 125, 148, 407 marsupialis, 89, 452

Didelphoidea, 100

Didolodontidae, 119

Didonis, 346, 351

Diemictylus, 463 meridionalis, 454 viridescens, 454

Dinocerata, 116, 117, 119

Dione, 344, 345

Diophthalma, 349

Dioriste, 342

Dipodomys, 124, 139, 149, 151

Dipoides, 108

Dipteronia, 67

Dircenna, 336

Dismenitis, 337

Dismorphia, 332, 335

Dismorphiinae, 330, 332, 335

Dissacus, 110

Dissosteira, 271

Docodonta, 116, 117, 119, 120

Dolerus, 243

Doloclanes, 233, 235

Dolophilodes, 234

Dorcaschema, 308

Dormitator, 214

Dorosoma, 187, 214

Dorı, 254, 255

aculeatum, 255

davisi, 255

lineare, 254, 255

Dracotettix, 262, 263

Drepanopterna, 274

Drucina, 342

Drymarchon carais, 455

Dryobius, 302, 303

Dulidae, 429

Dynamine, 348, 351

Dynastor, 345

Eburia, 307

Ecclisomyia, 234

Ectypodus musculus, 110
Ecyrus, 307

Edentata, 116-118, 126

Elaphe obsoleta, 459

Elaphidion, 307, 313

Elasmodontomys, 407, 409

Elatrotrypes, 312

Eleotridae, 189

Eleotris, 208

Elina, 341, 343

Elopidae, 188

Elops, 208

Elytroleptus, 313

Embiotocidae, 189, 209

Embrithopoda, 120

Emesis, 354

Empetrichthys, 206, 207, 213

Encoptolophus, 270

Enodia, 338, 339

Ensatina, 162, 171, 180, 181

eschscholtzii, 178

eschscholtzii croceator, 178

eschscholtzii eschscholtzii, 178

eschscholtzii klauberi, 178

eschscholtzii oregonensis, 178

eschscholtzii platensis, 171, 178

eschscholtzii xanthoptica, 171 , 178

Ensifera, 277-292

Entosphenus tridentatus, 210

Ephedra, 66, 378

Epinephele, 341, 343

Epiphile, 347

Episcada, 337

Epithomia, 336

Eptesicus, 125

fuscus, 122

Equus, 396, 399, 401, 408

excelsus, 399

Erebia, 341, 343

Eremiacris, 274

Eremoblatta, 297

Eremopedes, 281, 282

Eremophila alpestris, 429

Erethizon, 124, 149, 396, 407

dorsatum, 440, 442

Erethizontidae, 121, 122, 151 
Eretris, 342, 343

Ergates, 309

Erimyzon, 202

Erimyzontini, 202

Eritettix, 276

Eroessa, 332, 334, 359

Erolia ferruginea, 424

Erycinidae, 322, 324, 349, 352,

$$
353-358,360
$$

Eryphanis, 345

Erythroneura, 239

Esocoidei, 196

Esox, 218

lucius, 218

musquinongy, 440

Esselenia, 276

Eteona, 342, 343

Etheostomatinae, 219

Etima, 348

Euarctos, 137

Euborellia, 254

Eubranchiopoda, 228

Euceratherium, 399, 401, 408 collinum, 399, 441

Eucheira, 328, 330, 358

Euchloe, 332, 334

Euchloinae, 330, 332, 334, 359

Eucrossus, 313, 315

Euderces, 307

Euderma, 125

Eudistenia, 315

Eulides, 344, 345

Eumaeus, 355, 356

Eumastacidae, 259-261, 290

Eumeces, 452

anthracinus, 454

gilberti, 181, 182

lagunensis, 182

septentrionalis, 454

skiltonianus, 181

Eumichthus, 311

Eumops, 125, 459

perotis, 122

Eumorsea, 260, 261

Eunica, 348, 351
Eupnigodes, 276

Eupogonius, 307

Euptoieta, 346, 350

Euptychia, 326, 338-340, 343

Eurema, 331, 333

Euryades, 328, 330, 358

Eurybia, 349

Eurycea, 450, 463

tynerensis, 450

Euryptera, 307, 313

Euselasia, 349

Eutamias, 124, 137, 146, 148

Eutheria, 118, 119, 126

Euthlastoblatta, 295

Eutresis, 332

Everes, 355, 357

Evodinus vancouveri, 312

Exbucklandia, 67

Eysenhardtia, 305

Faguıs, 305

Farrila, 234

Faunula, 341, 343

Felidae, 121, 122, 145

Felis, 108, 125, 141, 145, 148 concolor, 145

Feniseca, 355, 356

Flourensia, 275

Fluminicola, 227

Forestiera, 305

Forficula, 254

Fraxinus, 304, 305, 452

Fremontia, 306, 315

Fumonta, 234, 235

Fundulus, 207, 213, 214

lima, 215

nevadensis, 193

parvipinnis, 215

Gadidae, 188

Galbula ruficauda, 92

Galeichthys, 214

Galloisiana, 289

Gammarotettix, 284

Garrya, 306 
Gasterosteidae, 189, 193

Gasterosteus, 214 doryssus, 193

Gastropoda, 228, 229

Gastrotricha, 225, 228, 229

Gaultheria, 304

Gaurotes, 302, 309

Geocapromys, 408, 410, 411

Geomyidae, 121-133, 150

Geomys, 124, 149

bursarius, 454

pinetis, 445, 454

Gerrhonotus coerulus, 175-177

coerulus coerulus, 176

coerulus palmeri, 176

coerulus principis, 176

coerulus shastensis, 176

kingi, 176, 177

multicarinatus, 175, 177

multicarinatus multicarinatus,

176, 077

multicarinatus scincicauda, 177

multicarinatus webbii, 176, 177

Gila, 193, 194, 204, 205, 207, 210,

213,217

atraria, 212

bicolor, 210

ditaenia, 214, 215

minacae, 215

nigrescens, 214

orcutti, 214, 215

purpurea, 214, 215

robusta, 205

Gillichthys, 208

Ginkgo, 305

Glaucomys, 124, 139, 146, 148 volans, 452

Glaucopsyche, 355, 357, 364

Glaucotes, 31.3

Glossosoma, 237, 241, 250, 251

alascense, 250

parvulum, 250

penitum, 241

(Ripaeglossa) spp., 251

traviatum, 250
Glossosomatidae, 237

Glycobius, 309

Glyptostrobus, 67

Glyptotherium, 408

Gnathotriche, 346, 351, 352, 360

Gobiidae, 189

Gomphocerus, 273

Gomphomastacinae, 261

Goniatron, 275

Goodeidae, 195

Gopherus, 457

agassizi, 457,458

berlandieri, 457,458

polyphemus, 457, 458

Grammoptera, 302, 306

Graptemys, 459

geographica, 459

pseudogeographica, 459

Gruidae, 426

Grus, 426

Gryllacrididae, 282-285

Gryllidae, 285-288

Gryllinae, 287

Gryllita, 287

Grylloblatta, 283, 289, 290

campodeiformis, 290

Grylloblattidae, 289-290

Grylloblattina, 289

Grylloblattoidea, 289-290

Grylloidea, 285-288

Gryllotalpa, 285

gryllotalpa, 285

Gryllotalpidae, 285

Gryllulus, 287

Gulo, 124, 137, 148

gulo, 137

Gymnotidae, 195

Gynaecia, 347

Gyrocheilus, 341, 343

Haballia, 331

Hades, 349

Hadrotettix, 271

Haematera, 348, 351, 360

Haetera, 337, 338 
Hamamelis, 305

Hamearis, 354

Haplidus, 313, 315

Haplomi, 196

Hebardacris, 269

Heleioporus, 89

Heliastus, 269, 272

Heliaula, 273

Heliconiinae, 344, 345

Heliconius, 344, 345

Helicopsis, 349

Helicopsyche, 246, 248 borealis, 246, 248

limnella, 248

mexicana, 246, 248

piroa, 248

planata, 248

selanderi, 248

vergelana, 246, 248

Hemiargus, 355, 356

Hemidactylium, 463

Henicinae, 283

Heptaxodon, 407

Hermathena, 349

Hesperanoplizm, 315

Hesperiidae, 321

Hesperocharis, 332, 334

Hesperoleucus, 216

Hesperophanes, 308, 309

Hesperotettix, 268

Heterachthes, 307

Heteromyidae, 87, 121, 122, 133, 150

Heteronemiinae, 291-292

Heteropsomys, 407

Heterosais, 337

Heteroscada, 336

Hetoemis, 308

Himalopsyche, 241, 242

phryganea, 241, 242

spp., 242

Hipparion, 108, 396

Hippidium, 396

Hippiscus, 270

Hippopsis, 307
Hirsutis, 336

Hirudinea, 225, 228

Historis, 347, 351

Holmesina, 442

Holmskioldia, 67

Holopleura, 311

Homaesthesis, 312

Hominidae, 121, 122, 145

Homo, 124, 475

Homopsomys, 407

Hoplosphyrum, 286

Horesidotes, 275

Hybodera, 311

Hybognathus, 204

hankinsoni, 211

Hybopsis, 204

plumbea, 211

Hydracarina, 226, 228

Hydrangea, 305

Hydrobiosella, 235

Hydrochoerus, 396, 442

Hyla, 452

andersoni, 461, 462

arenicolor, 173, 456, 457

cinerea, 460, 461, 462

crucifer, 462

femoralis, 456, 457

gratiosa, 459

ocularis, 459

phaeocrypta, 459

regilla, 183

squirella, 462

versicolor, 453, 462

Hylos, 355, 356

Hymenitis, 337

Hyopsodontidae, 119

Hypanartia, 346

Hypentelium, 202

Hуриа, 349

Hypochlora, 267

Hypocolius, 429

Hypolagus, 108

Hypoleria, 337

Hyposcada, 336

Hyracoidea, 120 
Hyracotherium, 396

Hysterocarpus, 187 traski, 209

Ibidion, 307

Ictaluridae, 188, 193, 195, 197

Ictalurus, 194, 197 meridionalis, 195 pricei, 214, 217

Ictiobinae, 199, 202

Ictiobus, 199, 202 meridionalis, 195

Idionotus, 282

Idionycteris, 125

Idiostatus, 281, 282

Iguanidae, 162

Ilex, 305

Imelda, 352, 354

Indioneura, 341, 343

Insara, 277

Insectivora, 110, 116-119

Insects, 474

Invertebrata, 474

Ipochus, 315 fasciatus, 316

Ischnoptera, 295 deropeltiformis, 295 rufa occidentalis, 295

Isolobodon, 407

Isopoda, 227, 228

I thnonees, 353

Ithomia, 336

I thomiinae, 362

Ithomiola, 353

Ituna, 332

Judolia quadrillum, 312 sexmaculata, 306

Juglans, 305

Juniperus, 447

Junonia, 346

Kapis, 353

Kenkia, 225

Keteleeria, 305
Kinosternon, 459

Kisaura, 235

Koelreuteria, 67

Kricogonia, 331, 333, 334, 359, 360

Labia, 254

Labidolemur soricoides, 110

Labidura, 254

Lactista, 271

Lagocheirus, 307

Lagochila, 201, 202

Lagomorpha, 116, 117, 119

Lagurus, 124, 149

Lamiinae, 306, 307

Lampropeltis zonata, 175

Laniidae, 429

Lanius, 428

excubitor, 430

ludovicianus, 430

Larix, 435

Larus fuscus, 424

minutus, 424

occidentalis, 90

ridibundus, 424

Lasaia, 354

Lasionycteris, 125

Lasiophila, 342

Lasiurus, 125, 459

borealis, 122, 459

seminolus, 459

Latiblattella, 295

Lea, 279

Leguminosae, 307, 317

Leiopus, 307, 309

Lemmus, 124, 137, 149, 384

Lemonias, 354

Leodonta, 331, 359

Lepidomeda, 209

Lepidoptera, 321-368, 474

Lepomis, 194

Leporidae, 121, 122, 147

Lepricornes, 353

Leprus, 270

Leptacodon tener, 110

Leptalia, 311 
Leptictidae, 110

Leptocottus, 210

Leptonycteris, 125

Leptophobia, 331

Leptostylus, 302, 303, 307, 309 nebulosus, 312

Leptotes, 355, 356, 357

Leptura, 302, 306

obliterata obliterata, 312

obliterata soror, 312

Lepturges, 307, 309

Lepturinae, 306, 307

Leptysma, 263, 264

Leptysmini, 263-264

Lepus, 124, 149

americanus, 440

townsendi, 441

Leucidia, 331, 359

Leuciscinae, 203

Lenciscus rosei, 193 turneri, 194

Leucothyris, 336

Libocedrus, 304

Libythea, 349

Libythina, 348, 352, 360

Ligurotettix, 275

Lile, 214

Limenitis, 348, 351, 352, 363, 364 arthemis, 363 astyanax, 363

Limnephilus, 250 sublunatus, 250

Limnodromus griseus griseus, 425

Lindera, 305

Liodontia, 108

Liolaemus multiformis, 85

Liomys, 149

Liotettix, 256

Liquidambar, 305, 376

Lissonotus flavocinctus, 307

Listroscelinae, 280

Litaneutria, 292

Lithocarpus, 304

Litoscirtus, 263

Lophopogonius, 311
Lota, 187

Loxia curvirostra, 92

Lucinia, 347, 351, 352, 360

svecica svecica, 422

Lutra, 125, 137, 141, 148

Lycaenidae, 322, 325, 352, 355358,360

Lycaeniopsis, 355,357

Lycorea, 332

Lycoreinae, 332, 335

Lymanopoda, 342

Lymnas, 353

Lynx, 124, 137, 148

Lyonothamnus, 305

Lype, 232

phaeopa, 232

sericea, 232

Lyropteryx, 353

Machairodus, 108

Maclura, 444

Macneillia, 276

Macrosteles, 243, 244 ssp., 244

Macrotus, 125

Magnolia, 376

Mahonia, 304

Mammalia, 233, 475

Mammur, 400

Mammut, 407

Mammuthus, 398, 399, 401, 407 columbi, 398, 399 imperator, 404

Manerebia, 341, 343

Manomera, 292

Manteinae, 292-293

Mantoidea, 292-293

Margaritifera margaritifera, 227

Marifugia, 225

Marmota, 108, 125, 146, 148, 391, $396,412,436$

flaviventris, 412, 436, 441

Marsupialia, 110, 115-117, 126

Martes, 108, 125, 137, 148

pennanti, 440 
Masticophis flagellum, 460

Mecas, 313

Mechanitinae, 332, 335-337

Mechanitis, 336

Megacyllene, 302, 303, 307, 312

Megalonyx, 408, 442

Megalura, 347, 351

Meganoplium, 315

Megaphasma, 291

Megascheuma, 312

Megasemum, 311

Megatherium, 442

Megistanis, 347, 360

Megobrium, 315

edwardsi, 316

Melanoplini, 263, 265-269

Melanoplus, 267

Melete, 331

Melinaea, 336

Meliosma, 70

Melitaea, 346, 350, 364

Meniscotheriidae, 119

Mephitinae, 145

Mephitis, 124, 145, 148

Mermiria, 274-275 texana, 274-275

Mesene, 353

Mesochloa, 276

Mesohippus, 396

Mesonychidae, 110

Mesosemia, 349

Mesosini, 311

Mestobregma, 271, 272

Mestra, 347

Metacharis, 354

Metaleptus, 313

Metamorpha, 344, 345, 360

Metasequoia, 61, 67, 305

Metator, 271

Methia, 313

Methonella, 349

Metrioptera, 281 ussuriana, 281

Michythisoma, 308

Microcentrum, 277
Microclytus, 308

Microdipodops, 124, 149

Microhyla carolinensis, 445, 447, 452,453 olivacea, 453

Microsorex, 125, 148, 440 pratensis, 438

Microtes, 271

Microtia, 346, 351

Microtinae, 121, 146

Microtus, 124, 137, 149, 384 llanensis, 438

longicaudus, 441

micrus, 384

oeconomicus, 137, 384

operarius, 438

paraoperarius, 438

pennsylvanicus, 440

Minytrema, 201, 202

Miogryllus, 287

Miohippus, 396

Miraleria, 337

Mogoplistinae, 286

Mohavacris, 260

Moina, 226

Molossidae, 121, 122

Molothrus, 403

Moneilema, 313

Monochamus, 306

Monotremata, 120

Mormoops, 125

Morpheis, 346, 351, 352, 360

Morphidae, 322, 324, 325, 335, $337,338,357,358$

Morpho, 335, 337, 338, 358

Morsea, 260, 261

Morseiella, 274

Morseinae, 261, 290

Motacilla flava tschutschensis, 422

Motacillidae, 422

Moxostoma, 199, 201, 202

Moxostomatini, 201, 202

Mugil, 208

Mugilidae, 189

Multituberculatu, 110, 116, 117 
Muridae, 121, 122

Mus, 124, 407

Mustela, 125, 137, 141, 148

erminea, 137, 440

nivalis, 137

Mustelidae, 121, 122, 145

Mygona, 342

Mylocheilus, 205

Mylocyprinus, 205

Mylodon, 398

Mylopharodon, 204, 205

Myotis, 125

Myrica cerifera, 452

Myrmecophila, 286

Myrmecophilinae, 286

Myscelia , 347, 351

Myxocyprinus, 199, 201, 202

Nahida, 353

Nannippus, 396

Napaeozapus, 125, 149

Napaia, 273

Napeocles, 346, 360

Napeogenes, 336

Narope, 345

Nasua, 148, 150

Nathalis, 331, 334, 359, 360

Natrix, 389, 452 erythrogaster, 389 sipedon, 452, 461 taxispilota, 459

Navajovius kohlaasae, 110

Necydalis barbarae, 316 laevicollis, 312

Necyria, 353

Neduba, 281, 282

Nematoda, 225, 228, 229

Nematus, 243

Nemobiinae, 286-287

Nemobius, 286-287 fasciatus, 286

Neobarrettia, 280

Neobatrachus, 89

Neobellamira, 315

Neochoerus, 442
Neoclytus, 307, 309

caprea, 312

muricatulus, 307

nubilus, 307, 312

Neoconocephalus, 279

Neocurtilla, 285

Neodiprion, 239, 240

spp., 240

Neofiber, 125, 149, 407, 442, 464 alleni, 443

Neogyps, 403

Neohipparion, 108

Neomaenus, 341, 343

Neominois, 340,343

Neophasia, 328, 330

Neophrontops, 403

Neosatyrus, 341, 343

Neostylopyga, 294, 295 rhombifolia, 294-295

Neotettix, 256

Neotoma, 124, 149 cinerea, 441 floridana, 445, 454 micropus, 454

Neoxabea, 288

Nesophontes, 409

Nessaea, 347

Neurotrichus, 125, 148

Nisquallia, 268

Notemigonus, 203

Nothrotherium, 398, 403, 408, 444 shastense, 398

Notiosorex, 125, 148

Notoptera, 289

Notostraca, 227

Notoungulata, 116, 117, 119

Notropis, 204 formosus, 215 mearnsi, 214, 215

ornatus, 214

Novumbra, 195, 196, 219 hubbsi, 196, 211

Nyctea scandiaca, 426

Nymphalidae, 322, 324, 325, 344$352,357,358,360$ 
Nymphalinae, 346-349, 350-352

Nymphalis, 346, 351

Nymphidium, 354

Nyssa, 305

Oberea, 308, 309 quadricallosa, 308

Ochetotettix, 256

Ochotona, 108, 125, 149

Ochotonidae, 121, 122, 147

Odobenus, 436

Odocoileus, 125, 139, 149, 408

Oecanthinae, 287-288

Oecanthus, 288 californicus, 288

Oedaleonotus, 268

Oedipodinae, 269-273

Oeme californica, 312

Oenanthe oenanthe leucorhoa, 422 oenanthe oenanthe, 422

Oeneis, 341, 343, 364

Oligochaeta, 225, 228, 229

Oligonicella, 293

Oligonicinae, 293

Olyras, 332

Omus, 316

Oncideres, 307, 313

Oncorhynchus, 216

Ondatra, 124, 149

Onychomys, 124, 149

Oothecaria, 289, 292-298

Opeia, 274

Opheodrys, 389 aestivus, 461 vernalis, 389, 461

Ophiosaurus, 452, 462

Ophistomis, 307, 313

Opshomala, 264

Opsihanes, 345

Opsimus, 311

Opuntia, 255

Orchelimum, 279

Oreamnos, 124, 147, 149

Oreopedes, 282

Oressinoma, 340, 343
Orphulella, 274

Ortholeptura, 311 insignis, 316

Orthoptera, 256-299, 474, 476

Oryzomys, 124, 149, 410

Osmeridae, 188

Osmidus, 313

Ostariophysi, 191

Osteoborus, 108

Ostracoda, 226, 228

Ostrya, 305

Ovibos, 124, 149, 384, 436, 437

Ovis, 124, 149

Oxeoschistus, 342

Pachymorphinae, 291

Pachyta armata, 312 lamed, 306

Pachythone, 353

Palaeoesox, 197

Palaeospizidae, 428

Paleotaricha, 160, 161

Paliurus, 67

Panacea, 348, 351, 360

Panarche, 342

Panchlora, 296

cubensis, 296

Panchlorinae, 296

Pandanaris, 403

Panesthiinae, 297

Pantodonta, 116, 117, 119

Pantosteus, 201, 207, 216, 218 platyrhynchus, 211, 212

plebeinis, 214 santaanae, 215

virescens, 212

Pantotheria, 116, 117, 119

Papatemyidae, 110

Papilio, 326-330

Papilionidae, 322-330, 357, 358

Parabacillus, 291

Paracyrtophyllus, 279

Parahippus, 396

Paraidemona, 268

Paramecera, 340, 343 
Paramylodon, 408, 442, 444

Paranoplium, 315

Parapholyx, 227

Parascalops, 125, 148

Paratettix, 258-259

aztecus, 258-259

cucullatus, 258

Paratima conicola, 316

Parcoblatta, 295

americana, 295

bolliana, 295

desertae, 295

fulvescens, 295

notha, 295

pensylvanica, 295

Pardalophora, 270

Parnassius, 326, 328-330

clodius, 328, 330

smintheus, 328, 330

thor, 328, 330

Parnes, 354

Parolamia, 303

Paropomala, 274, 275

Parus atricapillus, 431 borealis, 431

Passeriformes, 428

Paulianodes, 2.34

Paxilla, 259

Pecari, 149

Pedaliodes, 342

Pediodectes, 281, 282

Pedioscirtetes, 275

Pedomoecus, 235

Pelecanus occidentalis, 90

Pelecypoda, 227, 228, 232

Penetes, 345

Pentacentrinae, 288

Peranabrus, 280, 281

Perca flavescens, 440

Percopsidae, 188, 195, 198

Percopsis, 197

Perente, 331

Peria, 347, 351, 352, 360

Periplaneta, 294

Periptychidae, 110, 119
Periptychus, 110

superstes, 110

Perisama, 348

Perisoreus, 427

Perissodactyla, 116, 119, 126

Peritapnia, 313

Perodectes elegans, 110

Perognathus, 108, 125, 139, 149, 151

Peromyscus, 125, 133, 135, 149, 452 boylei, 447,448

comanche, 447

gossypinus, 445,453

leucopus, 453, 457, 459, 461

maniculatus, 133, 135, 459, 460

melanotis, 460

nasutus, 447

polionotus, 445, 459, 460

sejugis, 460

sitkensis, 460

Perrhybris, 331

Persea, 69

Petromyzontidae, 188

Phaedrotettix, 268

Phalia, 332, 334, 359

Phaneropterinae, 277

Phasmatoidea, 289, 290-292

Phaulotettix, 268

Phenacodontidae, 110, 119

Phenacodus, 110

gidleyi, 110

grangeri, 110

metthervi, 110

Phenacolemur frugivorus, 110

Phenacolemuridae, 110

Phenacomys, 124, 139, 149, 438

Philibostroma, 274

Philomachus pugnax, 424

Philopotamus, 235

Philotes, 355, 357

Phoberopus, 284

Phoebis, 331, 333, 363

Phoetaliotes, 267

Pholidota, 120

Photinia, 306 
Photininae, 293

Phoxinus, 205

Phrynotettix, 262, 263

Phyciodes, 346, 350

Phyllostomatidae, 121, 122

Phyllovates, 293

Phylocentropus, 233

Phymatodes, 302

Physocnemum, 308

Pica muttalli, 428 pica, 428 pica hudsonia, 428

Picea, 305, 391, 392, 434

Picrodontidae, 110

Pidonia, 302, 303, 306

Pierella, 337, 338

Pieridae, 322, 324, 325, 328, 330$335,344,356,357-359$

Pierinae, 328, 330, 331, 333

Pieris, 328, 333, 358, 364

Pimephales, 204 promelas, 214

Pinaceae, 303, 306

Pindus, 340, 343

Pinus, 305, 381, 390, 392, 444

attenuata, 316

banksiana, 379, 381

bolandari, 316

edulis, 447

hartwegii, 392

muricata, 316

radiata, 316

serotina, 379

taeda, 447

Piodes, 311

Pipistrellus, 125, 459

Pisces, 474

Pistacia, 305

Pituophis catenifer, 453

melanoleucus, 453

Pitymys, 124, 149, 449, 452

meadensis, 438

parvulus, 449

pinetorum, 447, 449

quasiater, 447, 449
Plagiodontia, 410

Plagiostira, 281, 282

Plantes, 474

Platanus, 305

Platygonus, 408

Platylactista, 271

Platylyra, 277

Plebejus, 355, 357, 364

Plectrophenax nivalis, 431

Plectrura, 309, 311

spinicauda, 312

Pleocoma, 316

Plesiadapidae, 110

Plesiadapis gidleyi, 110

Plesiogulo, 108

Plesippus, 396

Plethodon, 450, 451, 463

cinereus, 450

glutinosus, 450, 451

neomaxicamus, 450, 451

ouachitae, 450

Plethodontidae, 161

Pleuroceridae, 225

Pleuronectidae, 188

Pleuroxus, 226

Plinthocoelium, 307

Plionoma, 313

Pliosaccomys, 108

Pliozapus, 108

Podisma, 266

hesperus, 266

sapporensis, 266

Poeciliidae, 188, 195, 205

Poeciliopsis, 205, 209

Poecilobrium, 311

Poecilotettix, 268

Pogonocherus, 306

Polaeanodonta, 117

Poliaenus, 315

Polygonia, 346, 351

Polygrapha, 349, 360

Polymastus, 342, 343

Polyodontidae, 218

Polyphaginae, 296-297

Populus, 305, 306, 316 
Porifera, 225, 228

Precis, 346

Prepona, 348, 351

Preptoceras, 399, 401, 408 sinclairi, 399

Primates, 110, 116-118

Prioninae, 307

Priscacara, 199

Pristoceuthophilus, 284

Proboscidea, 99, 116, 117, 119

Proboscis, 342

Procyon, 124, 148

Procyonidae, 121, 122, 147

Procyoninae, 150

Proechymis, 407

Prolabia, 254

Promastax, 259

Pronophila, 342

Prophalangopsidae, 283

Prophalangopsinae, 283

Prophalangopsis, 283

Prorhaphidophora, 284

Prorocorypha, 275

Proscopiidae, 260

Prosopium, 208 williamsoni, 208, 212, 218

Prosthennops, 108

Protarra, 234

Protipochus, 303

Protodiplatys, 254

Protoelytroptera, 254

Protogonius, 349

Protogryllinae, 285

Protorthoptera, 282, 289

Protospondylis, 303

Protostrigidae, 425

Protozoa, 225, 228

Prumnacris, 268, 269

Prunus, 305

Psapharochus, 302, 303

Psenocerus, 308

Pseudacris, 377, 389

brachyphona, 377

clarki, 453

nigrita, 389, 453, 461, 462

n. feriarum, 389 n. kalmi, 389

n. triseriata, 389

ornata, 454,455

streckeri, 454, 455

Pseudomaniola, 341, 343

Pseudomopinae, 295-296

Pseudomops, 295

Pseudonica, 347

Pseudophyllinae, 278-279

Psendopieris, 332, 335

Psendopomala, 275

Pseudoscada, 337

Pseudosermyle, 291

Pseudosteroma, 341, 343

Pseudotsuga, 390

Psoloessa, 276-277

Psychomastax, 260, 261

Psyrassa, 307

Pterocarya, 67, 305

Pteromys, 146

Pteronymia, 337

Pterophylla, 279

Pterophyllini, 278

Ptilodontidae, 110

Ptilogonatidae, 429

Ptychocheilus, 193, 207, 210

Purpuricenus dimidiatus, 312

Pycina, 347

Pycnopsyche, 239

Pycnoscelus, 294, 296

surinamensis, 294

Pyelorhamphus, 403

Pyrameis, 346, 351

Pyrotrichus, 311

Pyrrhogyra, 347, 351

Quercus, 67, 305, 306, 452

macrocarpa, 452

Radinotatum, 275

Rana, 452, 454

areolata, 455

aurora, 170, 171

boylii, 170, 180

capito, 454

catesbeiana, 462 
clamitans, 447, 462

grylio, 462

heckscheri, 459

muscosa, 170, 180

palustris, 462

pipiens, 462

sylvatica, 461

Rangifer, 124, 149, 384, 399

arcticus, 384

arcticus pearyi, 384

fricki, 399, 441

Raphidia, 233

Rattus, 125, 407, 409

rattus, 294

norvegicus, 294

Rehnia, 280

Rehnita, 272

Reithrodontomys, 124, 149

fulvescens, 445

humulis, 445, 454

montanus, 454

Reptilia, 475, 476

Rhabdoceratites, 291

Rhachocnemis, 284

Rhadinea flavilata, 453

laureata, 453

Rhadinoceraea, 243

Rhammatocerus, 274

Rhaphidophorinae, 284

Rhinichthys, 204, 207, 214, 216

cataractae, 211, 212, 218

osculus, 207, 210-213, 215, 216

Rhodocerinae, 330, 331, 333-334

Rhododendron, 304

Rhodoleptus, 313

Rhopalophora, 307

Rhopalopus, 309

Rhus, 305, 306

Rhyacophila, 237, 239, 241-243, 245

acropedes, 241

bifila, 243

carolina, 242, 243

castanea, 243

glareosa, 242, 243

hyalinata, 243 invaria, 242, 243

pepingensis, 242, 243

philopotamoides, 243

profusa, 243

rayneri, 243

scissa, 243

sibirica gp. spp., 241

vagrita, 242

verrula, 242

Rhyacophilidae, 237

Richardsonius, 193, 212, 213

balteatus, 205, 212

Ripaeglossa, 237, 250, 251

Robinia, 303, 305

Rodentia, 116-118, 126

Rodinia, 353

Romalea, 262

Romaleinae, 261-263

Romaleum hispicorne, 316

Romerologus, 124

Ropalopus, 308

Rosa, 304

Rosalia, 309, 311

Rotatoria, 225, 228

Rutilus bicolor, 210

Sabal minor, 447, 452

Sabatoga, 342

Saiga, 401

Sais, 335, 336

Salamandridae, 161

Salicaceae, 306

Salishella, 284

Salix, 304, 306, 308, 316

Salmo, 208, 214 clarki, 208, 210, 212, 216, 218 gairdneri, 210

Salmonidae, 187, 188, 193, 212

Salvelinus malma, 218

Sangamona, 399, 401, 408

Saperda, 302, 303, 308, 309 horni, 308

populnea, 306

Saphanini, 311

Sapindus, 305

Sarosesthes, 309 
Sassafras, 305

Satyridae, 322, 324-326, 337-345, $352,357-359,364,365$

Satyrodes, 340, 343

Satyrus, 364

Scada, 336

Scalopodinae, 121

Scalopus, 125, 148

Scapanus, 108, 125, 139, 148

Scaphinus, 303, 308

Scaphiopus, 445, 454

hammondi, 89, 173

holbrooki, 445, 454

hurteri, 474

intermontanus, 173

Scarabaeidae, 316

Sceloporus, 377, 393, 452

graciosus, 174-176

graciosus gracilis, 175

graciosus graciosus, 174, 175

graciosus vandenburghianus,

175

malachiticus, 393

undulatus, 377, 445

Schistocerca, 264-265

gregaria, 264

mexicana, 265

paranensis, 265

Schizax, 313

Scirtetica, 271

Sciuridae, 121, 122, 146, 150

Sciurus, 125, 146, 148

hudsonicus, 440

Scolitantides, 355, 356

Scudderia, 278

Semanotus, 302, 306 amethystinus, 312

ligneus sequoiae, 311

Semenoviola, 254

Sequoia, 304, 311

gigantea, 311

sempervirens, 311

Sermyle, 291

Serranidae, 199

Shotwellia, 271

Sidesone, 349
Sigmodon, 124, 149 hispidus, 460

Sinarista, 337, 338

Siphateles, 207, 210, 213, 214, 216, 217

bicolor, 210, 211, 216, 217

Siseme, 354

Sisko, 234, 235

Sistrurus catenatus, 454

miliarius, 454

ravus, 454

Sitta canadensis, 431

corea, 431

krüperi, 431

villosa, 431

whiteheadi, 431

Smilax, 305

Smodicum, 307

Smyrna, 347

Snyderichthys copei, 212

Solenodon, 410

Sonronius, 244

Sorbus, 304

Sorex, 125, 137, 144, 148, 384 cinereus, 436, 438-440

cudahyensis, 438

lacustris, 438

pacificus, 137

tundrensis, 384

vagrans, 372

Soricidae, 121, 122, 145

Sortosa, 234, 235, 237

Spalacopsis, 307

Spaniacris, 272

Speotyto cunicularia, 445

Sphaenothecus, 313

Sphaeriidae, 227

Spharagemon, 271

Spilogale, 124, 145, 148

Spondylis, 303, 308, 309, 311

Spongovostox, 254

Stagmomantis, 292

californica, 292

carolina, 292

gracilipes, 292

limbata, 292 
Staladitis, 354

Steiroxys, 282

Stenaspis, 313

Stenocorus inquisitor, 306

Stenodontes, 307

Stenopelmatinae, 283-284

Stenopelmatus, 283

Stenosphenus, 302, 303, 313

Steremnia, 341, 343

Sternidocinus, 315 barbarus, 316

Steroma, 341

Stethophyma, 273

Sticthippus, 270

Stockoceros, 399, 401, 408 onusrosagris, 399

Storeria occipitomaculata, 453

Strangalia, 307, 309

Strigidae, 425

Strix, 425 varia, 453

Stygobromus, 225

Styracosceles, 284

Supella, 294 supellectilium, 294

Sylvilagus, 124, 139, 149 floridanus, 460

Symbos, 400, 436, 437, 440

Symmachia, 353

Symmetrodonta, 116, 117, 119

Synaphaeta, 311

Synaptomys, 124, 149

australis, 441, 444

borealis, 438

cooperi, 438

Syrbula, 274

Tachycines, 284

Tadarida, 125, 459

macrotis, 122

Taeniodonta, 116-118, 126

Taeniopoda, 262, 263

Talpidae, 121, 122, 143

Tamias, 124, 148

Tamiasciurus, 124, 139, 148

Tanaocerinae, 260
Tanaocerus, 260

Tangavius, 403

Tantilla coronata, 455 gracilis, 455

Tanupolama, 401, 408

Taphacris, 259

Tapirus, 396, 444, 464

Taranomis, 313

Tardigrada, 225, 228

Taricha, 161

Tatochila, 328, 330, 333, 358

Taxidea, 124, 139, 148

Taxodiaceae, 302, 312

Taxodium, 305 distichum, 447

Tayassu, 120, 124 angulatus, 122

Tayassuidae, 120-122, 147

Taygetis, 338, 339

Teicophryinae, 261

Teicophrys, 261

Teleoceras, 108

Temenis, 347

Tenebrionidae, 313

Teratornis, 403

Terias, 331

Terrapene carolina, 454 ornata, 454

Testudo, 408, 409, 411

Tetraopes, 313

Tetraphlebia, 341, 343

Tetrigidae, 256-259

Tetrix, 256-258

arenosa, 256

brunneri, 258

ornata, 256, 257

ornata hancocki, 257

ornala insolens, 257

ornata occidua, 257

ornata ornata, 257

sierrana, 256

subulata, 257

Tetropium, 306

abietis, 312

Tetrops, 308 
Tettigidea, 259 lateralis, 259

Tettigoniidae, 277-282

Tettigonioidea, 277-285

Thalarctos, 124

Tharops, 354

Thecla, 355, 356

Theclopsis, 355, 356

Theope, 355

Theorema, 355, 356

Thiemeia, 342

Thinobadistes, 442

Thisbe, 354

Thoburnia, 202

Thomomys, 124, 139, 149

Thryptacodon australis, 110

Thuja, 304, 435

Thylakion, 235

Thymallidae, 187, 188

Thymallus, 218 arcticus, 211

Thyridia, 336

Tillodontia, 116-118, 126

Timema, 290

Timemidae, 290-291

Timetes, 347, 351

Tisiphone, 337, 338

Tithorea, 336

Tmetoglene, 353

Tomonotus, 271

Tonatia, 410

Toxotus, 306

Trachyrhachis, 272

Tragosoma depsarium, 306

Trepidulus, 271

Triaenodes, 245-247

baris, $245-247$

tarda, 245-247

ssp., 246, 247

Tribolodon, 205

Trichonis, 355, 356

Trichophanes, 193, 198

Triconodonta, 116, 117, 119

Tridactylidae, 285-286

Tridactylus, 286

Trigonidiinae, 288
Trigonidomimus, 288

Trimerotropis, 269, 270, 272

Trinectes, 214

Triodoclytus, 315

Troglochaetus, 225

Troglodytes troglodytes, 431

Tropidischia, 284

Tropidolophus, 271

Tsuga, 304, 435

Tubulidentata, 120

Tubulodon, 120

Turbellaria, 225, 228

Turdidae, 422, 425

Tylonotus, 308

Tylosis, 313

Typocerus, 308

Tytthotyle, 262, 263

Udeopsylla, 284

Ulmus, 305

Ulochaetes, 311

Uma, 92

Umbellularia, 305

Umbra, 196 krameri, 196

Umbridae, 188, 195, 219

Ungnadia, 305

Uraneis, 353

Urocyon, 124, 148

Ursidae, 121, 122, 145

Ursus, 122, 137, 148

arctos, 137

Vaccinium, 305

Vandykea, 313, 315

tuberculata, 311

Vanessa, 346, 351

Varanidae, 162

Vates, 293

Vatinae, 293

Velamysta, 337

Vespertilionidae, 121, 122

Victorina, 346, 351

Vila, 347, 360

Vilernini, 263, 265 
Vostox, 254

Vulpes, 125, 137, 148

fulva, 441

Wormaldia, 233, 234, 236, 237 spp., 236

Xanthippus, 270

Xantusia vigilis, 174

Xenacodon multilatus, 110

Xenarthra, 117

Xeracris, 272

$X$ ylocrius, 311

Xylosteus, 309, 311

Xylotrechus, 306 insignis, 316

Xyrauchen, 201

texanus, 202
Yersinia, 292

Yersiniops, 292

Zabirnia, 342

Zabuella, $35+$

Zacycloptera, 281, 282

Zammodes, 308

Zanthoxylum, 305

Zanycteris paleocena, 110

Zapata, 276

Zapodidae, 121, 122, 147

Zapodinae, 121

Zapus, 125, 149

Zaretes, 349, 351, 360

Zelkova, 67

Zelotaea, 353

Zerene, 331, 333, 361

Zubovskya, 258, 266-267, 281, 290, 297 




